NASA Contractor Report 165944

NASA-CR-165944

19820021584

EVALUATION OF HIGH

TEMPERATURE STRUCTURAL

ADHESIVES FOR EXTENDED

SERVICE

S. G. Hill, P. D. Peters, and C. L. Hendricks

Boeing Aerospace Company

Seattle, Washington 98124

Contract NAS1-15605

July 1982

langir gany

4it: 261982

LINGLEY RESEARNH GENTER

LIERARY, WASA

HARPTON, VIRGINIA

\title{
N/Sก
}

National Aeronautics and

Space Administration

Langley Research Center

Hampton, Virginia 23665 
NASA Contractor Report 165944

\section{EVALUATION OF HIGH TEMPERATURE STRUCTURAL ADHESIVES FOR EXTENDED SERVICE}

S. G. Hill, P. D. Peters, and C. L. Hendricks Boeing Aerospace Company Seattle, Washington 98124

Contract NAS1-15605 July 1982

\section{N/SA \\ National Aeronautics and \\ Space Administration \\ Langley Research Center \\ Hampton, Virginia 23665}




\section{TABLE OF CONTENTS}

$\underline{\text { Page }}$

Table of Contents

List of Figures

List of Tables

1.0 Summary and Introduction

2.0 Phase I - Adhesive Screening

2.1 Adhesive System Candidates

2.1.1 Adhesive Candidate Selection 7

2.1.2 Surface Treatment Candidate Selection 13

2.1.3 Primer Candidate Selection

2.2 Initial Adhesive Evaluation

2.3 Adhesive System Screening

2.3.1 Cure Cycle Optimization

2.3.2 Surface Treatment Study

2.4 Surface Characterization and Failure Analysis

2.4.1. Introduction

2.4.2 Analytical Techniques

2.4.2.2 Surface Analysis

2.4 .2 .3 TEM 
TABLE OF CONTENTS (Continued)

Page

2.4.3 Technical Discussion $\quad 61$

2.4.4 Surface Characterization 62

2.4.4.1 Phosphoric Acid Anodize (PAA) 63

2.4.4.2 PASA-JELL $107 \quad 64$

2.4.4.3 Phosphate Fluoride (BAC 5514) . 64

2.4.4.4 Phosphate Fluoride (Picatinny Modified) 65

2.4.4.5 Turco $5578 \quad 66$

2.4.4.6 Chromic Acid Anodize (CAA) 66

2.4.4.7 Discussion 68

$\begin{array}{lll}2.4 .5 & \text { Failure Analysis } & 71\end{array}$

2.4.5.1 Preliminary Analysis 71

2.4.5.2 Failure Trends With Surface Properties 72

2.4.5.3 Baseline Studies for Detailed Failure Analysis 73

2.4.5.4 PPQ/10VCAA Lap Shear: 10,000 Hours: $450^{\circ} \mathrm{F} \quad 75$

2.4.5.5 PPQ/5VCAA Lap Shear: 10,000 Hours: $450^{\circ} \mathrm{F} \quad 78$

2.4.5.6 LARC-13/10VCAA Lap Shear: 79

10,000 Hours: $450^{\circ} \mathrm{F}$

2.4.5.7 LARC-13/PASA-JELL Lap Shear: 81 10,000 Hours : $450^{\circ} \mathrm{F}$

2.4.5.8 Summary of Results 82

$\begin{array}{lll}2.4 .6 & \text { Discussion } & 176\end{array}$

$\begin{array}{lll}2.5 & \text { Large Area Bond Study } & 181\end{array}$ 


\section{TABLE OF CONTENTS (Continued)}

\section{Page}

3.0 Phase II Adhesive Optimization and Characterization 184

$\begin{array}{ll}3.1 \text { Task I Adhesive Optimization } & 185\end{array}$

3.1.1 Chemical Characterization 185

3.1.2 Cure Cycle Optimization 189

3.2 Task II Environmental Exposure Data 192

3.2.1 Unstressed Thermal Aging 192

3.2.2 Stressed Thermal Aging 192

3.2.3 Humidity Exposure 197

3.2.4 Fluid Exposure 199

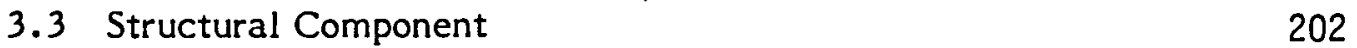

4.0 Conclusions and Recommendations 204

$\begin{array}{lll}5.0 & \text { References } & 206\end{array}$ 


\section{LIST OF FIGURES}

Page

Figure 1-1

Figure 1-2

Figure 2.2-1

Figure 2.2-2

Figure 2.2-3

Figure 2.2-4

Figure 2.2-5

Figure 2.2-6

Figure 2.2-7

Figure 2.2-8

Figure 2.2-9

Figure 2.2-10

Figure 2.2-11

Figure 2.2-12

Figure 2.2-13

Figure 2.2-14

Figure 2.2-15

Figure 2.2-16
Phase I Flow Diagram

Phase II Adhesive Optimization and

Characterization Flow Diagram

Phase I Initial Adhesive Evaluation Tests

Mechanical Test Specimens

Adhesive Evaluation Lap Shear Test Results -

LARC-13

Adhesive Evaluation Lap Shear Test Results -

LARC-13 MOD I

Adhesive Evaluation Lap Shear Test Results -

LARC-13 MOD II

Adhesive Evaluation Lap Shear Test Results - PPQ

Adhesive Evaluation Lap Shear Test Results PPQ MOD I

26

Adhesive Evaluation Lap Shear Test Results -

27

NR150A2

Adhesive Evaluation Lap Shear Test Results -

NR150B2

Adhesive Evaluation Lap Shear Test Results NR056X

Adhesive Evaluation Lap Shear Test Results HR602

Adhesive Evaluation Lap Shear Test Results -

FM-34

Crack Extension Environmental Exposure Results -

LARC-13

Crack Extension Environmental Exposure Results -

NR150B2

Crack Extension Environmental Exposure Results $\mathrm{FM}-34$ 


\section{LIST OF FIGURES (Continued)}

Page

Figure 2.3.1-1 Effect of 505K (450\% F) Upon Adhesive Lap Shear LARC-13

Figure 2.3.1-2 Effect of $505 \mathrm{~K}\left(450^{\circ} \mathrm{F}\right)$ Upon Adhesive Lap Shear PPQ

Figure 2.3.1-3 Effect of 505K (450\% F) Upon Adhesive Lap Shear NR056X

Figure 2.3.2-1 Effect of $322 \mathrm{~K}\left(1200^{\circ} \mathrm{F}\right) / 95 \% \mathrm{RH}$ Upon Adhesive Crack Extension - LACR-13

Figure 2.3.2-2 Effect of 505K (450\% F) Exposure Upon Adhesive Crack Extension - LACR-13

Figure 2.3.2-3 Effect of $322 \mathrm{~K}\left(120^{\circ} \mathrm{F}\right) / 95 \% \mathrm{RH}$ Upon Adhesive Lap Shear - LACR-13

Figure 2.3.2-4 Effect of 505K (450\% F) Upon Adhesive Lap Shear LACR-13

Figure 2.3.2-5 Effect of $322 \mathrm{~K}$ (1220F) Upon Adhesive

Crack Extension - NR056X

Figure 2.3.2-6 Effect of $505 \mathrm{~K}\left(450^{\circ} \mathrm{F}\right)$ Exposure Upon Adhesive

Crack Extension - NR056X

Figure 2.3.2-7 Effect of $322 \mathrm{~K}\left(120^{\circ} \mathrm{F}\right) / 95 \% \mathrm{RH}$ Upon Adhesive Lap Shear - NR056X

Figure 2.3.2-8 Effect of $505 \mathrm{~K}\left(450^{\circ} \mathrm{F}\right)$ Upon Adhesive Lap Shear NR056X

Figure 2.3.2-9 Effect of 322K (120\%F)/99\% RH Upon Adhesive Crack Extension - Polyphnylquinoxaline

Figure 2.3.2-10 Effect of $505 \mathrm{~K}\left(450^{\circ} \mathrm{F}\right)$ Exposure Upon Adhesive Crack Extension - Polyphenylquinoxaline

Figure 2.3.2-11 Effect of 322K (1200F)/95\% RH Upon Adhesive Lap Shear - Polyphnylquinoxaline

Figure 2.3.2-12 Effect of $505 \mathrm{~K}\left(450^{\circ} \mathrm{F}\right)$ Upon Adhesive 
Figure 2.4.2-1 Secondary electron collection for:

a) Scanning electron microscope (SEM)

b) Scanning transmission electron microscope (STEM)

Figure 2.4.2-2 Schematic of Specimen Preparation

Figure 2.4.2-3 10-V CAA Oxide, 588K (600\% F) Heat Treat, Old Bath,

AES Profile

Figure 2.4.4-1

Figure 2.4.4-2

Figure 2.4.4-3

Figure 2.4.4-4

Figure 2.4.4-5

Figure 2.4.4-6

Figure 2.4.4-7

Figure 2.4.4-8

Figure 2.4.4-9

Figure 2.4.4-10

Figure 2.4.4-11

Figure 2.4.4-12

Figure 2.4.4-13

Figure 2.4.4-14

Figure 2.4.4-15

Figure 2.4.4-16

Figure 2.4.4-17

Figure 2.4.4-18

Figure 2.4.4-19

Figure 2.4 4-20
5-V Phosphoric Acid Anodize As-Received Surface

5-V Phosphoric Acid Anodize As Lab-Fractured

5-V PAA Presputter Survey

5-V PAA Oxide Intermediate Survey

Pasa Jell 107 Treated, As Received Surface

Pasa Jell 107 Treated, Lab-Fractured

Pasa Jell 107 Presputter Survey

Pasa Jell 107 Intermediate Survey

Phosphate Fluoride 5514 Treated, As-Received Surface

Phosphate Fluoride (BAC 5514) Presputter Survey

Phosphate Fluoride (BAC 5514) Intermediate Survey

Phosphate Fluoride Picatinny Modified Treatment,

As-Received Surface

Phosphate Fluoride (Picatinny Mod.) Presputter Survey

Phosphate Fluoride (Picatinny Mod.) Intermediate Survey

100

Turco 5578 Treated As-Received Survey

Turco Presputter Survey

101

102

Turco Intermediate Survey

103

Turco Only Mottled Appearance Presputter Survey

104

10-V Chromic Acid Anodize, No Heat Treatment,

105

As-Received Surface, Old Bath

106

Lab-Fractured, Old Bath 


\section{LIST OF FIGURES (Continued)}

Page

Figure 2.4.4-21 10-V Chromic Acid Anodize, Heat Treated to $588 \mathrm{~K} \cdot\left(600^{\circ} \mathrm{F}\right)$ for 1 Hour, Lab-Fractured, Old Bath

Figure 2.4.4-22 10-V Chromic Acid Anodize, Heat Treated to 672K (7500F) for 1 Hour, Lab-Fractured, Old Bath

Figure 2.4.4-23 5-V Chromic Acid Anodize, As-Received Surface,

Figure 2.4.4-24 10-V Chromic Acid Anodize, As-Received Surface,

Figure 2.4.4-25 10-V Chromic Acid Anodize, No Heat Treatment,

Figure 2.4.4-26 10-V CAA Oxide, No Heat Treat, Old Bath, Presputter Survey

Figure 2.4.4-27 10-V CAA Oxide, No Heat Treat, Old Bath, Intermediate Survey

Figure 2.4.4-28 10-V CAA Oxide, 588K (6000 F) Heat Treat, Old Bath, Presputter Survey

Figure 2.4.4-29 10-V CAA Oxide, 672K (750\% F) Heat Treat, Old Bath, Presputter Survey

Figure 2.4.4-30 10-V CAA Oxide, 672K (7500 F) Heat Treat, Old Bath, Intermediate Survey

Figure 2.4.4-31 5-V CAA Oxide, Old Bath, No Heat Treat, Presputter Survey

Figure 2.4.4-32 5-V CAA Oxide, Old Bath, No Heat Treat, Intermediate Survey

Figure 2.4.4-33 Auger Carbon-to-Titanium Ratio Auger Oxygen-to-Titanium Ratio

Figure 2.4.4-35 Auger Aluminum-to-Titanium Ratio Auger Fluoride-to-Titanium Ratio 


\section{LIST OF FIGURES (Continued)}

Figure 2.4.5-2 10-V Chromic Acid Anodize, NASA "Slick" Lap-Shear

Failure, Lap-Fractured Specimen

Figure 2.4.5.3 Fractured Lap Shear, NASA Sample 1530P-3, Side A, $\mathrm{PPQ} / 10-\mathrm{V}$ CAA Oxide, 3 months at 505K (450\% F)

Figure 2.4.5-4 Fractured Lap Shear, NASA Sample 1530P-3, Side B, PPQ/10-V CAA Oxide, 3 Months at 505K (4500F)

Figure 2.4.5-5 Fractured Lap Shear, NASA Sample 1527P-3, Side A, PPQ/10-V CAA Oxide, No Thermal Exposure

Figure 2.4.5-6 Fractured Lap Shear, NASA Sample 1527P-3, Side B, PPQ/10-V CAA Oxide, No Thermal Exposure

Figure 2.4.5-7 Fractured Lap Shear, NASA Sample 1532P-2, Metal Side, PPQ/10-V CAA Oxide, 6 Months at 505K (450\% F)

Figure 2.4.5-8 Fractured Lap Shear, NASA Sample 1532P-3, Adhesive Side, PPQ/10-V CAA Oxide, 6 Months at 505K (450\%F)

Figure 2.4.5-9 10-V CAA/PPQ Lap-Shear Specimen, Disbonded Surface, Metal Side, 672K (750\% F) Heat Exposure for 1 Hour, Presputter Survey

Figure 2.4.5-10 10-V CAA/PPQ Lap-Shear Specimen, Disbonded Surface, Metal Side, $672 \mathrm{~K}\left(750^{\circ} \mathrm{F}\right)$ Heat Exposure for 1 Hour, Intermediate Survey, $50 \mathrm{~A}$ Removed

Figure 2.4.5-11 10-V CAA/PPQ Lap-Shear Specimen, Disbonded Surface, Metal Side, 672K (750\% F) Heat Exposure for 1 Hour, Intermediate Survey, $200 \mathrm{~A}$ Removed

Figure 2.4.5-12 Surface Treatment Oxide Thickness

Figure 2.4.5-13 Surface Treatment Auger Aluminum to Titanium Ratio

Figure 2.4.5-14

Surface Treatment Auger Fluorine to Titanium Ratio

Figure 2.4.5-15

Surface Treatment Remaining Elements to Titanium Ratio

Figure 2.4.5-16 10-V CAA as Anodized - No Additional Processing in Diameter) 


\section{LIST OF FIGURES (Continued)}

Page

Figure 2.4.5-17 10-V CAA as Anodized - No Additional Processing

Profile View. The Oxide has a Columnar Structure

with a Thickness of $\sim 120 \mathrm{~nm}$

Figure 2.4.5-18 10-V CAA Primed with P.P.Q. - No Environmental

Exposure. Stereo Pair Profile View Showing Primer

Penetration to the Base of the Oxide.

Figure 2.4.5-19 10-V CAA Primed with P.P.Q. - No Environmental

Exposure. Stereo Pair Profile View Showing the Primer

Pulling Away from the Oxide.

Figure 2.4.5-20 Thin Section of Titanium with CAA Oxide and LARC-13

Primer

Figure 2.4.5-21 Photomacrograph of Failed PPQ/10V CAA Lap Shear Thermally

Aged at $505^{\circ} \mathrm{K}\left(450^{\circ} \mathrm{F}\right)$ for 10,000 Hours

Figure 2.4.5-22 10V CAA Failed Specimen - Oxide Side of Failure Top View

of Oxide Failed Surface Showing Some Polymer on The

Oxide Surface

Figure 2.4.5-23 10V CAA Failed Specimen - Oxide Side of Failure Stereo

Pair Top View of Oxide Showing Polymer on Oxide

(Pore Size $\sim$ 30nm)

Figure 2.4.5-24 10V CAA Failed Specimen - Oxide Side of Failure Fractured

Oxide of Failed Lap Shear Specimen Showing Some Polymer on Oxide (Oxide Thickness $\sim 140 \mathrm{~nm}$ )

Figure 2.4.5-25 10V CAA Failed Specimen - Oxide Side of Failure Stereo

Pair of Fractured Oxide from Failed Lap Shear Specimen Showing Polymer on Top of Oxide, Polymer Stretching Between Oxide Islands, and Limited Polymer Penetration

Figure 2.4.5-26 10V CAA Failed Specimen - Primer Side of Failure Top View of Polymer Side of Failed Lap Shear. At 50,000X Two

Features are Shown. These Two Features are Depressions $\sim 90 \mathrm{~nm}$ in Diameter and Small Bright Nodules Which are $\sim 30 \mathrm{~nm}$ in Diameter 
LIST OF FIGURES (Continued)

Page

Figure 2.4.5-27 10V CAA Failed Specimen - Polymer Side of Failure Fractured

View of Polymer Side of Failure Also Shows Bright Nodules and Depressions.

Figure 2.4.5-28 ESCA Spectrum of The Failed PPQ/10V CAA Lap Shear, Adhesive Surface

Figure 2.4.5-29 ESCA Spectrum of The Failed PPQ/10V CAA Lap Shear, Adherend Surface

Figure 2.4.5-30 AES Analysis of Regions A and B on The PPQ/10V CAA

Adherend Surface (50X Inverted Absorbed Current Image)

Figure 2.4.5-31 10V CAA Failed Specimen Polymer Side of Failure 150 TEM/Microtomy Section of Failed Polymer Surface Showing Two EDX Analysis Areas with a Typical EDX Spectrum from Those Two Areas

Figure 2.4.5-32 10V CAA Failed Specimen - Polymer Side of Failure Printout of EDX Spectrum

Figure 2.4.5-33 10V CAA Failed Specimen - Polymer Side of Failure EDX Spectrum Expanded

Figure 2.4.5-34 Photomacrograph of Failed PPQ/5V CAA Lap Shear Thermally Aged at $505^{\circ} \mathrm{K}\left(450^{\circ} \mathrm{F}\right)$ for 10,000 Hours

Figure 2.4.5-35 5V CAA Test Failure-Oxide Side Stereo Pair Showing 154

Top View of Oxide with Indications of the Presence of Some Polymer

Figure 2.4.5-36 5V CAA Test Failure-Oxide Side

Figure 2.4.5-37 5V CAA Test Failure-Oxide Side Fractured Oxide with 155 Very Small Amounts of Polymer Present and an Oxide Thickness of $\sim 130 \mathrm{~nm}$

Figure 2.4.5-38 ESCA Spectrum of The Failed PPQ/5V CAA Lap Shear, Adhesive Surface

Figure 2.4.5-39 ESCA Spectrum of The Failed PPQ/5V CAA Lap Shear, 157 Adherend Surface 


\section{LIST OF FIGURES (Continued)}

Figure 2.4 . 5-40

Figure 2.4.5-41

Figure 2.4 .5-42

Figure 2.4.5-43

Figure 2.4.5-44

Figure 2.4.5-45

Figure 2.4.5-46

Figure 2.4 .5-47

Figure 2.4 5-48

Figure 2.4 .5-49

Figure 2.4.5-50

Figure 2.4.5-51

Figure 2.4 -5-52
AES Analysis of Regions A and B on The PPQ/5V CAA Adherend Surface (50X Inverted Absorbed Current Image) Photomacrograph of Failed LARC-13/10V CAA Lap Shear Thermally Aged at $505^{\circ} \mathrm{K}$ (450\% F) for 10,000 Hours of Test Failure Showing Polymer Islands on Top of Oxide Surface IOV CAA 10,000 Hours Test Failure-Oxide Side Top View Showing Some Polymer Atop Essentially Open-Celled Oxide (Pore Size $\leadsto 30 \mathrm{~nm}$ in Diameter) 10V CAA 10,000 Hours Test Failure-Oxide Side Polymer/Oxide Interface Shown in Lab-Fractured Views IOV CAA 10,000 Hours Test Failure-Oxide Side Stereo Pair of Oxide With No Polymer Material in View IOV CAA 10,000 Hours Test Failure-Polymer Side Top View of Polymer Side of Test Failure Showing (A), Aluminum Particles in The Polymer and (B), Areas of Polymer/Aluminum Particle Interfacial Pullout

IOV CAA 10,000 Hours Test Failure-Polymer Side Stereo

Pair of Top View of a Polymer Pullout Area, Showing

Bright Nodules on Top of The Polymer

ESCA Spectrum of The Failed LARC-13/10V CAA Lap Shear Adhesive Surface

ESCA Spectrum of The Failed LARC-13/10V CAA Lap Shear Adherend Surface

AES Analysis of Regions C and D on The LARC-13/10V CAA Adherend Surface (50X Inverted Absorbed Current Image) Photomacrograph of Failed LARC-13/Pasa Jell Lap Shear Thermally Aged at $5050 \mathrm{~K}$ (4500F) for 10,000 Hours ESCA Spectrum of The Failed LARC-13/Pasa Jell 169 Lap Shear, Adhesive Surface 


\section{LIST OF FIGURES (Continued)}

Page

Figure 2.4.5-53 ESCA Spectrum of The Failed LARC-13/Pasa Jell Lap Shear, Adherend Surface

Figure 2.4.5-54 AES Analysis of Regions $C$ and D on The LARC-13/Pasa Jell

Adherend Surface (50X Inverted Absorbed Current Image)

Figure 2.4.6-1 Schematic Diagram of crack propagation influenced

by scrim node porosity

Figure 3.3-1 Large area bond Panels 


\section{LIST OF TABLES}

Table 2.1 . 1-1

Table 2.1.2-1

Table 2.2-1

Table 2.3.1-1

Table 2.4.4-1

Table 2.4.4-2

Table 2.4.4-3

Table 2.4.5-1

Table 2.5-1

Table 3.1.2-1

Table 3.2.1-1

Table 3.2.1-2

Table 3.2.2-1

Table 3.2.2-2

Table 3.2.3-1

Table 3.2.3-2

Table 3.2.4-1

Table 3.2.4-2
Candidate Adhesives - Phase I

Candidate Surface Treatments

14

Adhesive Film Volatile Content

Summary of Cure Cycle Effects On Lap Shear

55

Strength

CAA Surface Composition by ESCA Reported

171 as Atom Percent

Element Ratios

172

Surface Composition of Baseline Oxides

Reported as Atom Percent

PPQ/IOV CAA Bonded Lap-Shear Specimens

174

Large-Area Bond Flatwise Tensile Strength

183

Phase II Cure Cycle Optimization - Lap Shear

191

Strength, MPa (psi) Data Summary

Unstressed Thermal Aging - PPQ, Data Summary

193

Unstressed Thermal Aging - LaRC-TPI, Data

194

Summary

Stressed Thermal Aging, 505K (450\% F) - PPQ

195

Data Summary - Lap Shear

Stressed Thermal Aging, 505K (4500F) - LaRC-TPI

196

Data Summary - Lap Shear

Humidity Exposure - PPQ, Data Summary

198

Humidity Exposure - LaRC-TPI, Data Summary

198

Aircraft Fluid Exposure - PPQ, Data Summary

200

Aircraft Fluid Exposure - LaRC-TPI, Data Summary 


\section{EVALUATION OF HIGH TEMPERATURE STRUCTURAL ADHESIVES FOR EXTENDED SERVICE \\ Sylvester G. Hill, Patricia D. Peters, and Carl L. Hendricks}

THE BOEING COMPANY

\subsection{SUMMARY AND INTRODUCTION}

\section{Summary}

This report documents the work performed by Boeing Aerospace Company for the National Aeronautical and Space Administration, Langley Research Center, under Contract NAS1-15605. The primary objective of this program was to evaluate, select, and demonstrate structural adhesive systems for Supersonic Cruise Research (SCR) applications, and establish environmental durability of selected systems for up to 20,000 hours.

The program was divided into two (2) phases.

Phase I of the program initially evaluated ten (10) candidate adhesives. During screening and evaluation, these candidates were narrowed to three (3) of the most promising for Phase II environmental durability testing. The three adhesives were LARC-13, PPQ, and NR056X. LARC-13 was eliminated because of a lack of stability at 505K. NRO56X was removed from the market by DuPont and also had to be eliminated from Phase II evaluation. LARC-TPI was added to Phase II after preliminary evaluation by Boeing and an abbreviated Phase I screening test. Although extensive Phase II work was conducted on all four (4) systems, only PPQ and LARC-TPI remained as the reasonable candidates late into Phase II. Large area bond panels were fabricated to demonstrate the processibility of the Phase Il selected systems. Specifications were prepared to assure control over critical material and process parameters.

Surface characterization concentrated primarily upon titanium surface treatments of 10 volt chromic acid anodize, 5 volt chromic acid anodize and PASA-JELL. Failure analysis was conducted on lap shear adhesive bond failures which occurred in PPQ and LARC-13 test specimens after 10,000 hours at $505 \mathrm{~K}$. 


\section{Introduction}

This report presents the program performed by the Boeing Aerospace Company for the National Aeronautics and Space Administration, Langley Research Center, under Contract NAS1-15605. The work was conducted during the period November 2, 1978 to July 15, 1982. Use of commercial products or names of manufacturers in this report does not constitute official endorsement of such products or manufacturers, either expressed or implied, by the National Aeronautics and Space Administration.

The increasing demands upon aerospace vehicle performance and design has forced requirements of structural efficiency and environmental durability beyond the limits of available material concepts and material systems. This program was dedicated to support of Supersonic Cruise Research (SCR) in development and evaluation of high temperature stable adhesive systems for designs using bonded titanium structural concepts.

Mr. James B. Nelson was the NASA Technical Monitor. The Materials and Processes Technology organization of The Boeing Aerospace Company was responsible for the work performed in this program. Mr. C. L. Hendricks was Program Manager, and Mr. S. G. Hill was Technical Leader. The following personnel provided critical support to various program activities.

Boeing Aerospace Company

William Dumars - Materials and Processes

Ralph Hodges - Materials and Processes

Bernie Hunter - Quality Control

Julie Vry - Materials and Processes

Rusty Sheppard - Materials and Processes

Gene Carison - Materials and Processes 
Boeing Commercial Airplane Company

Patricia Peters - Failure Analysis

Al Miller - Failure Analysis

Eugene Ludbury - Failure Analysis

Brian Smith - Failure Analysis

Brian MacElroy - Failure Analysis

The basic approach to this study was a two (2) phase program -

Phase I Adhesive Screening

Phase I Adhesive Optimization and Characterization

Phase I and Phase II flow diagrams are illustrated by Figures 1-1 and 1-2.

Phase I - Adhesive Screening was a 12 month effort to screen 11 adhesive resins, 8 surface treatments, and 2 primers for each adhesive - surface treatment combination. Lap shear strength and crack extension using 6A1-4V Titanium alloy adherend were determined for each adhesive system. The adhesives evaluated were polymide and polyphenylquinoxaline based resins. Surface treatments evaluated were processes considered commercially available and feasible for production operations. Subsequent to initial screening, three (3) adhesive systems were selected for additional evaluation. The evaluation tests included bond strengths vs. temperature ( $219 \mathrm{~K}$ to $505 \mathrm{~K})$, thermal aging at $505 \mathrm{~K}$, humidity exposure, and ability to exhibit structural bond strengths in large area bonds ( 30 . $\mathrm{cm} \times 30 \mathrm{~cm}$ ). At the conclusion of Phase I, two (2) adhesive systems were selected and approved by NASA for more extensive test and evaluation planned for Phase II, Adhesive Optimization and Characterization.

Phase II consisted of two (2) tasks - Task I, Optimization and Characterization and Task II, Environmental Exposure Data. Task I concentrated on the chemical characterization of the adhesive resins, optimization of adhesive cure cycles, and generation of baseline mechanical data. Task II was an extensive environmental durability study program which determined the lap shear and crack propagation characteristics of the adhesive systems under, stressed $505 \mathrm{~K}$ aging, unstressed $505 \mathrm{~K}$ aging, thermal cycling, humidity exposure, and aircraft fluids exposure. A large area bond structural component $91 \mathrm{~cm} \times 122 \mathrm{~cm}$ was 
fabricated to demonstrate the capability of the developed materials and processes. Specifications for these adhesive materials processes were prepared.

In addition, a complete surface characterization study was conducted on selected titanium surface preparations with regard to surface morphology and chemical make-up. Failure analysis was also conducted on lap shear and crack extension specimens to determine mode and cause of adhesive bond failures during the course of environmental durability testing.

A complete set of program summary data (test value averages) in tabular and graphic form is contained in this report. The appendix contains a complete set of all individual test values in tabular form, as well as text of the Material and Process Specifications. 
$\rightarrow \rightarrow \rightarrow \rightarrow \rightarrow \rightarrow \rightarrow \rightarrow-) \rightarrow-(\rightarrow)$

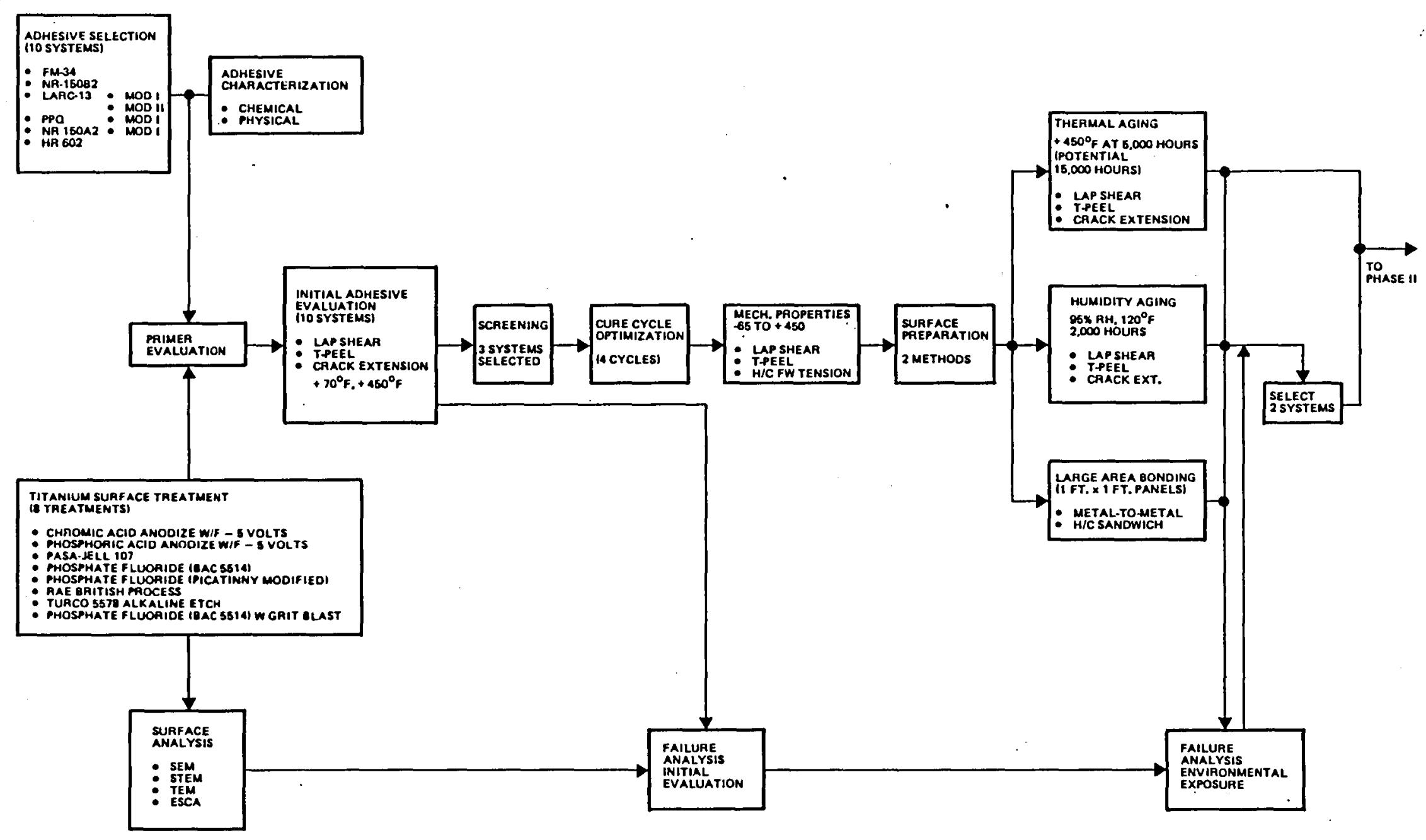

Figure 1-1: Phase 1, Flow Diagram 


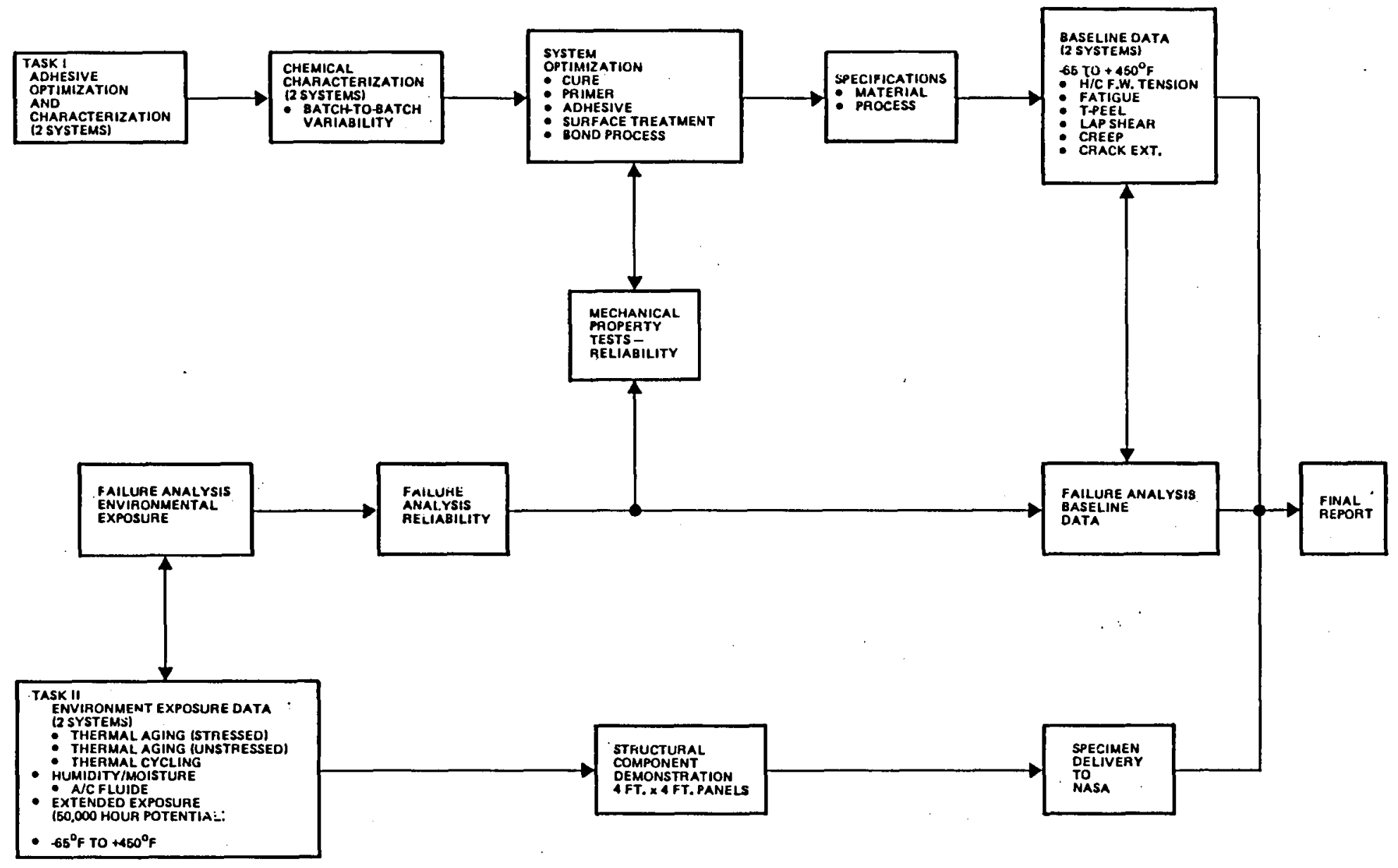

Figure 1-2: Phase II, Adhesive Optimization and Characterization Flow Diagram 


\subsection{PHASE I ADHESIVE SCREENING}

Phase I was a 12 month effort (see Figure 1-1) which screened and evaluated 10 adhesive resin and 8 titanium surface treatment combinations or systems. An "adhesive system" as defined for this program consists of the adhesive resin, primer, and the titanium surface treatment.

A detailed description of each candidate resin and titanium surface preparation orginally selected and evaluated for this program follows:

\subsection{ADHESIVE SYSTEM CANDIDATES}

\subsubsection{Candidate Adhesive Resins}

1) LARC-13 Polyimide Adhesive - This resin was selected as an adhesive candidate based on preliminary data obtained by Boeing which demonstrated good elevated temperature thermal stability and desirable failure modes. The base resin synthesis and cure chemical reactions are illustrated below:

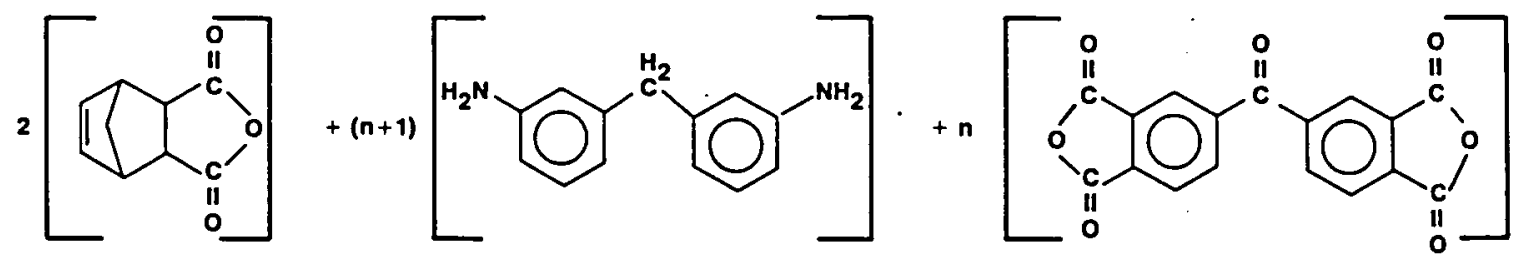

NADIC ANHYDRIDE (NA)

METHYLENE DIANILINE (MDA)

$$
\Delta \mid-\mathrm{H}_{2} \mathrm{O}
$$

BENZOPHENONE TETRACARBOXYLIC DIANHYDRIDE (BTDA)
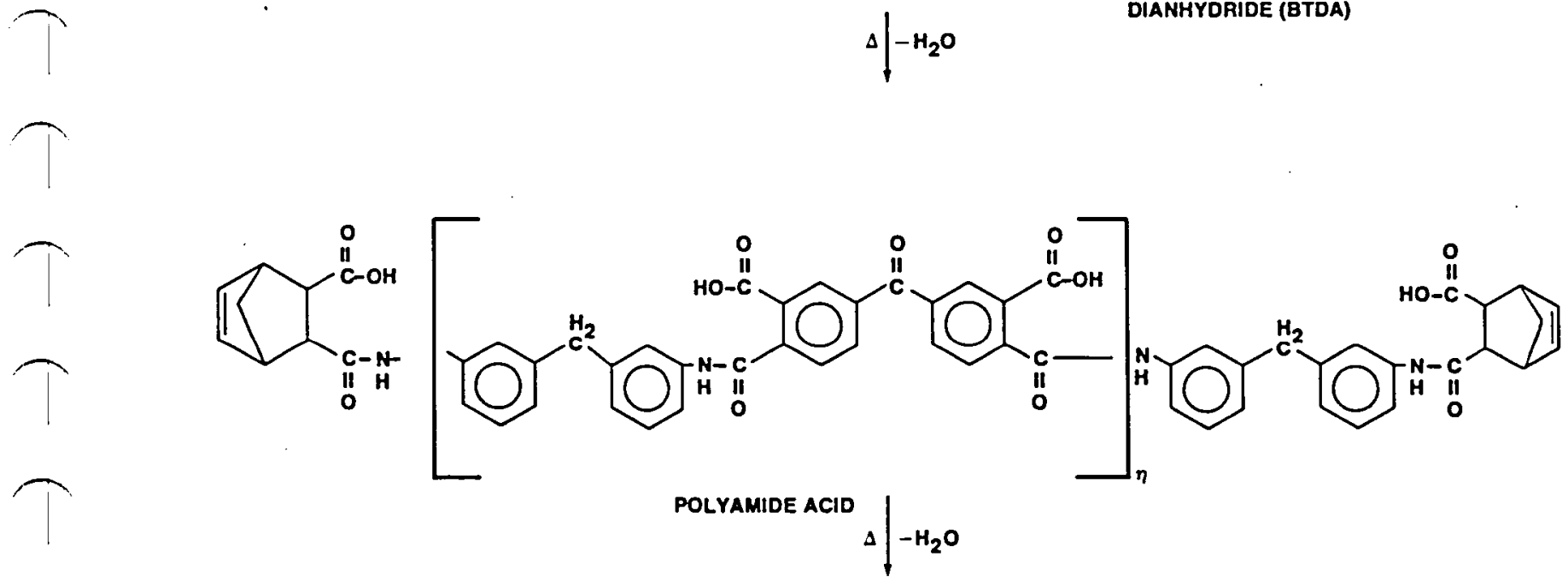


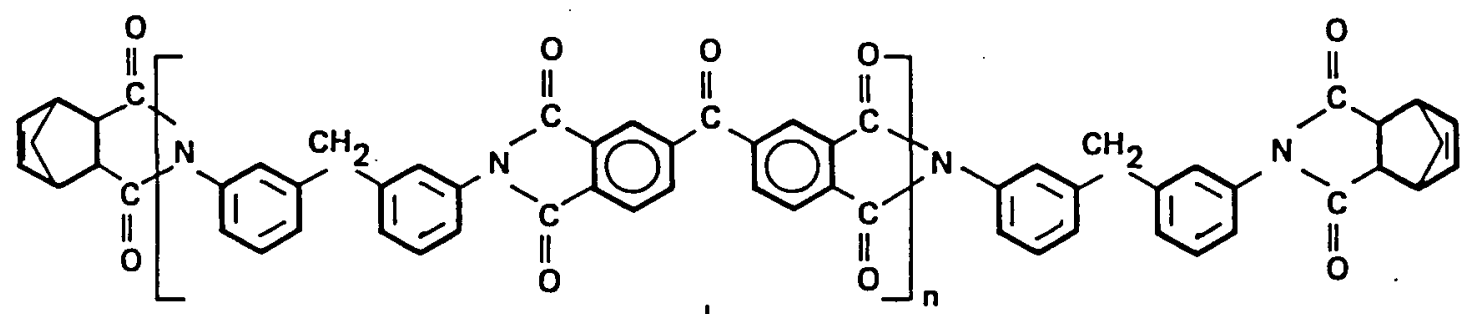
END-CAPPED POLYIMIDE $\Delta \mid$ PRESSURE

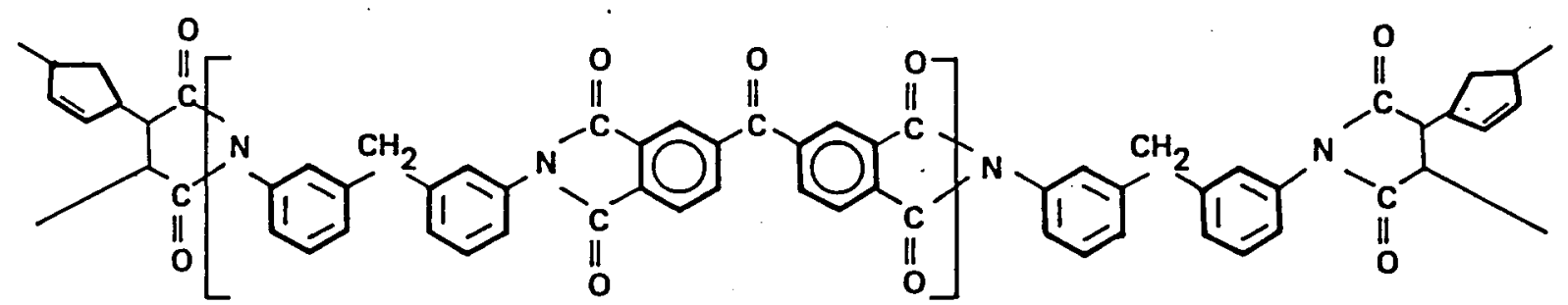

THERMALLY

CROSS-LINKED LARC-13 POLYIMIDE CHEMISTRY

LARC-13 base resin formulated with 30 weight percent aluminum powder (Alcoa 101) was supplied by NASA Langley for this program. The adhesive was subsequently impregnated by Boeing on Style 112, A-1100 finished glass fabric and B-staged to a low flow state. The control of B-staging just prior to crosslinking reaction is critical to low or no volatile release during final cure.

2) LARC-13 Modification I - LARC-13 does demonstrate good adhesive properties, however, it also exhibits undesirable processing characteristics. This modification consisted of Amoco Amide-imide AI-1130 mixed at 50 phr with the base LARC-13 formulation plus addition of Alcoa 101 aluminum powder to $60 \mathrm{phr}$. This adhesive formulation provides controlled flow and honeycomb filleting for structural bonding. Style 112, A-1100 glass fabric films were prepared for bonding operations.

3) LARC-13 Modification II - In addition to copolymer (Amide-imide) studies performed on Modification 1, a second modification was selected/evaluated which involves methyl nadic capped polymer and addition of 20 mole percent of Meta phenylene diamine as codiamines. This results in a nominal polymer 
molecular weight of 1,300 . The modification procedures just described were performed by Boeing personnel using identical synthesis procedures as those used by NASA Langley in making the LARC-13 resin.

4) NR150B2 - This resin supplied by DuPont was selected and evaluated because of excellent strength retention in $588 \mathrm{~K}\left(600^{\circ} \mathrm{F}\right)$ environments. The chemical reaction is shown below:<smiles>CC(c1ccc(C(=O)O)c(C(=O)O)c1)(c1ccc(C(=O)O)c(C(=O)O)c1)C(F)(F)F</smiles>

4,4' - Hexaf luoropropyl idene<smiles>[AlH2][V]</smiles><smiles>Nc1ccc(N)cc1</smiles>

Para diamino Benzene<smiles>Nc1cccc(I)c1</smiles>

$\mathrm{NH}_{2}$ NMP/ETOH<smiles>CC(C)(C)c1ccc(N2Cc3ccc(C(C)(C)C)cc3C(O)N(C(C)(F)F)C2)cc1</smiles>

NR $150 \mathrm{B2}$.

This system uses NMP as its solvent which is a major disadvantage in establishing a tough durable bond on large area bond titanium substrates.

5) NR150A2 - This polymide resin, also supplied by DuPont, is stable at elevated temperatures, exhibits good processing characteristics, and is tougher, but possesses lower Tg than NR150B2. The base resin was evaluated unfilled and with 30 phr aluminum powder (Alcoa 101). Both formulations were applied to 112 A-1100 glass fabric for preparation of adhesive films. Chemicals used for synthesis and cured polymer structure is shown below: 


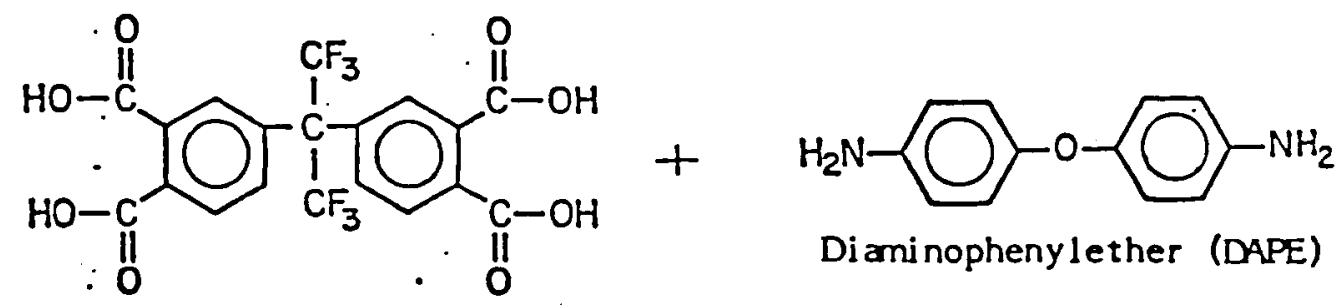

4, 4' - Hexafluoropropylidene bis (phthalic acid)

NMP/ETOH<smiles>CC(C)(C)c1ccc2c(c1)[C@@H](O)N(C(C)(C)C)[C@@H]2O</smiles>

NR 150 A2

6) NR 056X - This resin represents a modification of the NR150 series synthesized from a monomeric solution of $4,4^{\prime}$ - hexafluoropropylidene bis (phthalic acid), diamino benzene, and diamino phenyl ether (mole ratio 1.0/0.75/0.25) in diglyme solvent. This resin formulation in diglyme offers potential for a tough adhesive bond and improvement in processibility by removing the undesirable polar solvent NMP. The chemistry of this system is very similiar to the NR150B2 system.

7) Polyphenylquinoxaline (PPQ) - This resin is supplied by NASA Langley as Mono Ether Polyphenylquinoxaline in a solvent mixture $1: 1$ of practical grade $\mathrm{m}$ cresol and mixed xylenes. Solids content is about $16.6 \%$ based upon final polymer weight. PPQ has demonstrated excellent elevated temperature stability and represents a different family of polymers for evaluation in this program. The chemistry of this polymer is shown below. 
<smiles>Nc1ccc(-c2ccc(N)c(N)c2)cc1N</smiles>

3,3' - DIAMINOBENZIDINE (DAB)

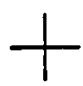

$\phi \circ \mathrm{coc}$<smiles>c1ccccc1</smiles><smiles>CC(=O)Oc1ccc(O)cc1</smiles>

$P, P^{\prime}$ - OXYDIBENZIL (ODB)<smiles></smiles>

MONOETHER PPQ

8) PPQ MOD I - This modification consists of the addition of Boron powder at $30 \mathrm{phr}$ to PPQ resin solution. This modification was an attempt to modify the adhesive's coefficient of thermal expansion to the coefficient of thermal

- of expansion of the metal substrate. This modification was deemed desirable for adapting the system for large area bonding.

9) HR-602 - This system represents a different resin chemistry through use of acetylene terminated polyimide structure. The cure mechanism consists of an addition reaction with no release of volatiles during cure. Intermediate acetylene terminated polyimide structure is shown below. Reaction to the final cured structure is proposed as a trimerization of the acetylene groups to form an aromatic structure.

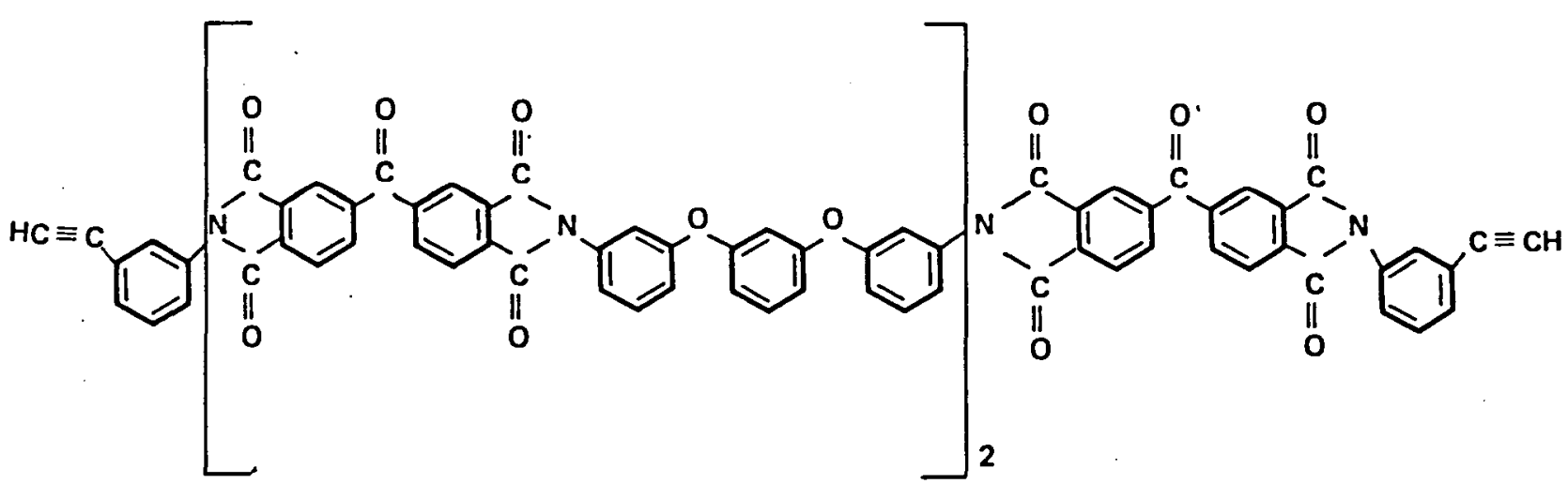


10) FM-34 - This polyimide system was selected as a baseline control. The chemistry and thermal stability are well known. Because it is not suitable for large area bonding this system was limited to the initial evaluation phase only.

11) LARC-2 (LARC-TPI) - Is a thermoplastic polyimide supplied by NASA Langley which was added to Phase II portion of the program. All other adhesive system candidates, except PPQ, were not suitable for full evaluations of Phase II, and to maintain two systems in this study LARC-TPI was screened to Phase I requirements then added to Phase II. This polymer is the reaction product of pyromellitic dianhydride (PMDA) and 3,3', 4,4' - benzophenone tetracarboxylic dianhydride (BTDA) using reagent grade bis (2-methoxyether) ether (diglyme) solvent.

Summary of the candidate resin adhesives is shown in Table 2.1.1-1.

Table 2.1.1-1. Candidate Adhesives - Phase I

Adhesive

1. LARC-13

2. LARC-13 AI Modified

3. LARC-10 Diamine Modified

4. NR150B2

5. NR150A2

6. NR056X

7. $\mathrm{PPQ}$

8. PPQ Modification

9. $\mathrm{HR}-602$

10. FM-34

11. LARC-TPI
Supplier

NASA Langley

Boeing

Boeing

DuPont

DuPont

DuPont

NASA Langley

Boeing

Hughes

American Cyanamide

NASA Langley 


\subsubsection{Candidate Adherend Surface Treatments}

The purpose of this portion of the program was to select an adherend surface treatment for each of the candidate adhesive resins.

Eight candidate adherend surface treatments were selected for study. They include treatments for which reliable processes already exist, potential new processes with limited promising data, and new experimental processes.

Table 2.1.2-1 lists the eight surface treatments. Those processes are:

A. Chromic acid anodize (with fluoride) - This is a relatively new titanium adherend surface treatment process developed by Boeing for optimum bond durability. It is described in Boeing Process Specification BAC 5890 and in U.S. patents 3,959,091 and $3,989,876$. This surface treatment has been used in several Naval Air Systems command contracts and Boeing's internal research programs during the past several years with some promising test results (References 1 and 2 ).

B. Phosphoric acid anodize (with fluoride) - This process will be basically the same as the chromic acid anodize process described above with the exception of the electrolyte utilized. This process was selected in part because of the current wide interest in phosphoric acid anodizing of aluminum for improved bond durability and the oxide stability offered by the phosphate ion.

C. Pasa-Jell 107 - This process has been selected as the baseline process because of Boeing's extensive developmental experience with it on the SST program along with the FM34/BR34 adhesive/primer system for continuous high temperature operation. This is a commercially available titanium adherend surface treatment.

D. Phosphate fluoride - This is a commercially available titanium adherend surface treatment process widely used by many aerospace companies as a base for paints and adhesives. This process is described in Boeing Process Specification BAC 5514. It has been in use for many years for both high temperature and moderate temperature applications. 
E. Phosphate fluoride (Picatinny modified) - This process is a recent modification of the phosphate fluoride process described above and developed by the Picatinny Arsenal, Dover, N.J. The modification consists of a change in chemistry of one of the chemical solutions resulting in a more stable surface on the titanium. This more stable surface has reportedly produced bonds more durable than the standard process (Reference 3).

F. Phosphase Fluoride (with grit blast) - This process is identical to process D, discussed previously, except for addition of a titanium surface grit blast during preparation.

G. Turco 5578 etch - This process is reportedly in-use by a few aerospace companies. It employs a hot alkaline solution manufactured by Turco Products, a Division of the Purex Corp. It has been shown to be a good titanium surface treatment process for moderately high temperature cure adhesive systems (Reference 4 ).

H. RAE Process - This process, developed in Britain, uses a combination of sodium hydroxide and hydrogen peroxide in preparation of the adherend for bonding.

More complete details of process parameters for each of the above adherend surface treatments are found in the attached appendix.

Table 2.1.2-1. Candidate Surface Treatments

Surface Treatment
A
B
C
D
$\mathrm{E}$
$\mathrm{F}$
G
$\mathrm{H}$

Description

Chromic Acid Anodize with Fluoride

Phosphoric Acid Anodize with Fluoride

Pasa-Jell 107

Phosphate Fluoride

Phosphate Fluoride (Picatinny Modified)

Phosphate Fluoride with Grit Blast

Turco 5578 Alkaline Etch

RAE Process 


\subsubsection{Primer Evaluation}

Prior to conducting the adhesive evaluation studies, a primer evaluation effort was conducted for each of the six major adhesive resin formulations. In this separate study, a series of crack extension specimens were tested for the six basic polymers, candidate surface treatments, and two primers. The primers selected were those considered most compatible with each specific adhesive. Each polymer system was evaluated at room temperature, after exposure to $322 \mathrm{~K}(1200 \mathrm{~F}) / 100 \%$ relative humidity for seven days, and after exposure to $505 \mathrm{~K}\left(450^{\circ} \mathrm{F}\right)$ for five days.

Primers selected for evaluation with the candidate adhesive resins were considered to be the most likely to produce good metal-to-metal bonds. Descriptions of the primer selected for evaluation are as follows:

LARC-13-Primer One - LARC-13 with $30 \%$ aluminum filler diluted with DMF. This primer would be most compatible with LARC-13 to promote good bonds because of the common base resin. Primed panels were baked an hour at $408 \mathrm{~K}\left(275^{\circ} \mathrm{F}\right)$ prior to bonding.

LARC-13-Primer Two - BR-34 resin diluted with BR-34 Thinner. BR-34 has an established data base for long term elevated temperature bond stability and was selected for evaluation on that basis. Primed panels were baked one hour at $366 \mathrm{~K}$ $\left(200^{\circ} \mathrm{F}\right)$ followed by one hour at $477 \mathrm{~K}\left(400^{\circ} \mathrm{F}\right)$. See test data in Table 2.1.3-A (Appendix).

LARC-13 Mod I and Mod II Primer evaluations/selections were determined from the data developed on LARC-13 for both Primer One and Primer Two. See test data in Table 2.1.3-A (Appendix).

NR150B2-Primer One - NR150B2 resin diluted with DMF. This primer was selected because of the common base resin between primer and adhesive to promote optimum bond at the primer/adhesive interface. 
NR150B2-Primer Two - NR150B2 with $30 \mathrm{phr}$ aluminum diluted with DMF, Aluminum powder was added to increase thermal stability and toughness and promotes more controlled adhesive flow. Panels with both primer were baked one hour at $477 \mathrm{~K}\left(400^{\circ} \mathrm{F}\right)$ prior to bonding. See test data in Table 2.1.3-B (Appendix).

NR150A2-Primer One - NR150A2 resin diluted with DMF. Again, the primer evaluated is the same as the base resin to take advantage of a common polymer to enhance bond strength.

NR150A2-Primer Two - NR150A2 resin with 50 phr aluminum powder and diluted with DMF. The increased aluminum content lover that used in primer two for NR150B2) was to further study effects of aluminum content on bond strength and toughness. Panels with both primers were baked one hour at $477 \mathrm{~K}\left(400^{\circ} \mathrm{F}\right)$ prior to bonding. See test data in Table 2.1.3-C (Appendix).

NR056X - NR056X resin undiluted. Diglyme solvent was not available to the program to prepare the diluted form. This primer resin was, therefore, more difficult to apply to the metal surface because of its high viscosity. However, good quality primer coatings were possible. At this stage of testing with previous systems, (especially NR150B2 and NR150A2) it was clear that the base unfilled resin demonstrates superior bonding properties. For NR056X, the base unfilled resin based upon data from the two other NR systems and at the recommendation of DuPont. See test data in Table 2.1.3-C (Appendix).

Polyphenylquinoxaline (PPQ)-Primer One - PPQ resin diluted with a 50/50 mixture of cresol and xylene. The base resin compatibility with this primer again was evaluated to promote superior bonds between the adhesive and primer.

Polyphenylquinoxaline (PPQ)-Primer Two - NR150A2 resin diluted with DMF. This primer was evaluated to determine the adhesion of two different polymers to each other as a primer/adhesive combination. NR150A2 was most compatible with PPQ processing for these studies. See test data in Table 2.1.3-D (Appendix). 
Polyphenylquinoxaline (PPQ) Mod I-Primer One - from PPQ evaluations (previously discussed) was selected for this adhesive resin. The similarity of this modification ( $30 \mathrm{phr}$ boron powder added to PPQ solution) to PPQ was used as a basis for the arbritary decision to use dilute PPQ. See test data in Table 2.1.3-D (Appendix).

HR-602-Primer One - Is an adhesive primer resin supplied by Hughes for use with HR-602 titanium metal-to-metal bonding. This adhesive was received late in the primer evaluation testing. To maintain reasonable program scheduling and because of the limited sample available for test, primer one was selected for bonding of mechanical test coupons in adhesive evaluation.

FM-34-Primer One - BR-34 resin diluted with BR-34 thinner. This is the standard primer used with FM-34 adhesive. Primed panels were baked one hour at $366 \mathrm{~K}$ $\left(300^{\circ} \mathrm{F}\right)$ followed by one hour at $477 \mathrm{~K}\left(400^{\circ} \mathrm{F}\right)$.

FM-34-Primer Two - NR150B2 resin diluted with DMF. This primer system was selected to determine the effect of a different primer on FM-34 bond properties. See test data in Table 2.1.3-E (Appendix).

LARC-TPI-Primer One - LARC-TPI resin diluted with diqlyme solvent. Primed panels were baked at $408 \mathrm{~K}\left(275^{\circ} \mathrm{F}\right)$ for one hour. A second primer was not evaluated for this adhesive so that is could be accelerated for Phase II studies.

A complete tabulation of the crack extension test results is found in the appendix Table 2.1.3-A through Table 2.1.3-E.

Based on the crack extension test results, the following primers were chosen to be used for the adhesive evaluation study.

Adhesive

LARC-13

LARC-13 Mod I

LARC-13 Mod II

FM-34

NR150B2 $\underline{\text { Primer }}$

LARC-13

LARC-13 Mod I

LARC- 13 Mod II

BR-34

NR150B2 unfilled 
Adhesive

NR150A2

NR056X

Polyphenlquinoxaline

PPQ Mod I

HR 602

LARC-TPI
Primer

NR150A2 unfilled

NR056X unfilled

PPQ

PPQ

Hughes supplied resin

LARC-TPI 


\subsection{INITIAL ADHESIVE SYSTEM EVALUATION}

The objective of this portion of the program was to evaluate the initial 10 adhesive resin/8 titanium surface treatment combinations and select four (4) superior systems for additional extensive screening. The test matrix is shown in Figure 2.2-1. Mechanical test coupon configurations are illustrated in Figure 2.2-2 for lap shear, T-peel and crack extension respectively.

Successful testing of the various resin/surface treatment combinations required fabrication of good quality adhesive films with controlled volatile contents. Many of the candidate resins had not been fabricated onto 112 style glass fabric films prior to this program. Therefore, a significant effort was devoted to development of suitable adhesive films from the candidate resin formulations. Of prime concern, is film volatile content and resin uniformity to assure void free or very low void adhesive bond lines. Many of the resin candidates required a trial-and-error approach to develop adhesive films which resulted in adequate bond specimens. Table 2.2-1 lists volatile contents for the candidate film adhesives.

\begin{tabular}{|c|c|c|c|c|c|c|c|}
\hline \multirow{3}{*}{ menesive } & \multirow{3}{*}{$\begin{array}{l}\text { SUAFACE } \\
\text { TREATMENT } \\
2\end{array}$} & \multicolumn{6}{|c|}{ TESTS } \\
\hline & & \multicolumn{2}{|c|}{ WO SHEAR } & \multicolumn{2}{|c|}{ T.PEEL } & \multicolumn{2}{|c|}{ CRACX EXTENSION } \\
\hline & & $.70^{\circ} \mathrm{F}$ & $\cos 0^{\circ} \mathrm{F}$ & $+70^{\circ} \mathrm{F}$ & $-4500^{\circ}$ & $.700 \mathrm{~F}$ & ASO ${ }^{\circ} \mathrm{F}$ \\
\hline \multirow[t]{8}{*}{1 THAU 10} & $A$ & s & 3 & 3 & 3 & 3 & 3 \\
\hline & 8 & 5 & 3 & 3 & J & 3 & 3 \\
\hline & c & 5 & 5 & 3 & 3 & 3 & 3 \\
\hline & 0 & 5 & 5 & $\mathbf{3}$ & J & 3 & 3 \\
\hline & E & 5 & $\mathbf{s}$ & 3 & נ & 3 & 3 \\
\hline & $F$ & 5 & $\mathbf{s}$ & $\mathbf{J}$ & J & 3 & 3 \\
\hline & a & 3 & $\mathbf{s}$ & J & 3 & 3 & 3 \\
\hline & H & s & $\mathbf{s}$ & J & $\mathbf{3}$ & 3 & 3 \\
\hline \multicolumn{2}{|r|}{ TOTALSTSTEM } & $\infty$ & $\infty$ & 24 & 24 & 24 & 24 \\
\hline \multicolumn{2}{|r|}{3 TOTAL } & $\infty$ & $\infty$ & 240 & 240 & 240 & 240 \\
\hline
\end{tabular}

Figure 2.2-1 : PHASE I - INITIAL ADHESIVE EVALUATION TESTS 
Figure 2.2-2 Mechanical Test Specimens
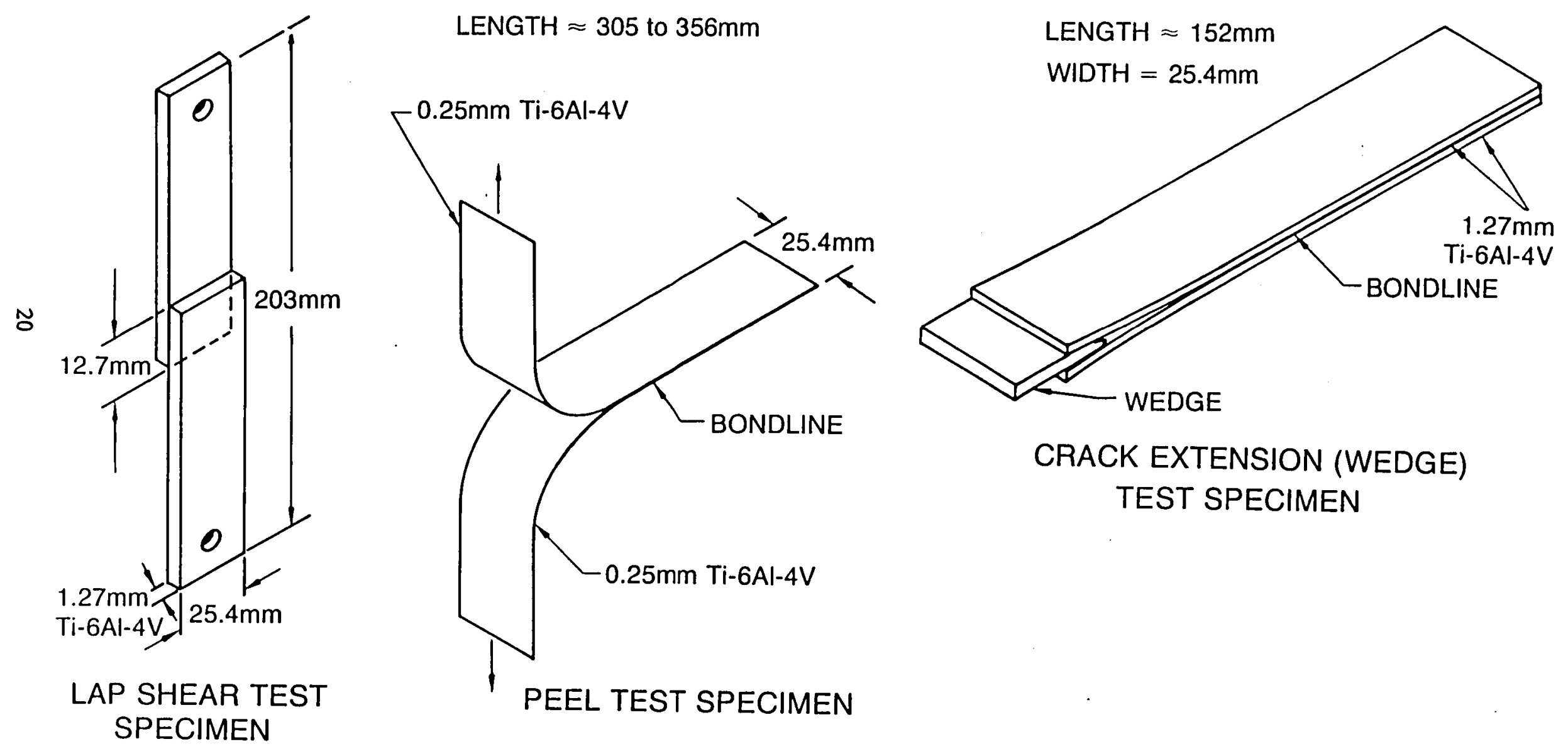
Figures 2.2-3 through 2.2-16 illustrate the lap shear and crack extension average values obtained on the various adhesive systems.

The individual lap shear results obtained on each of the systems evaluated are listed in the appendix (Tables 2.2-A through 2.2-J). Two adherend surface preparations were consistantly superior for all adhesives: chromic acid anodize and phosphoric acid anodize.

T-peel specimens for all candidates systems produced disappointingly low values. These results are not entirely unexpected since polyimide resins are relatively brittle compared to formulated epoxy adhesives. The T-peel data did not contribute significantly to the selection process.

Crack extension data used for selection was generated during the primer evaluation study discussed in Section 2.1.3. Consistantly lower values in crack length were demonstrated by chromic acid anodize and phosphoric acid anodize adherend surface treatments. Cure cycles used to prepare coupons for this part of the program are illustrated in the appendix.

Final adhesive system selection was based upon the data generated during the adhesive evaluation portion of this program and critical factors of relative process difficulty, thermal stability, material availablity, and cost and mechanical properties.

Three (instead of four) systems were selected from the 10 candidates. Because of poor performance in the various systems and similiarity between other candidates, it was decided that it would be redundant and/or unrealistic to consider evaluation of an additional adhesive system at this stage of the program.

The 3 adhesive systems selected for screening are listed below:

\section{SELECTED ADHESIVE SYSTEMS}

$\begin{array}{lll}\text { RESIN } & \text { PRIMER } & \text { SURFACE } \\ \text { 1. PPQ } & \text { Dilute PPQ } & \text { TREATMENT } \\ \text { 2. LARC-13 } & \text { Dilute LARC-13 } & \text { Chromic Acid Anodize } \\ \text { 3. NR056X } & \text { Dilute NR056X } & \text { Chromic Acid Anodize }\end{array}$


Figure 2.2-3

\section{ADHESIVE EVALUATION LAP SHEAR STRENGTH TEST RESUL-TS}

\section{LARC-13}

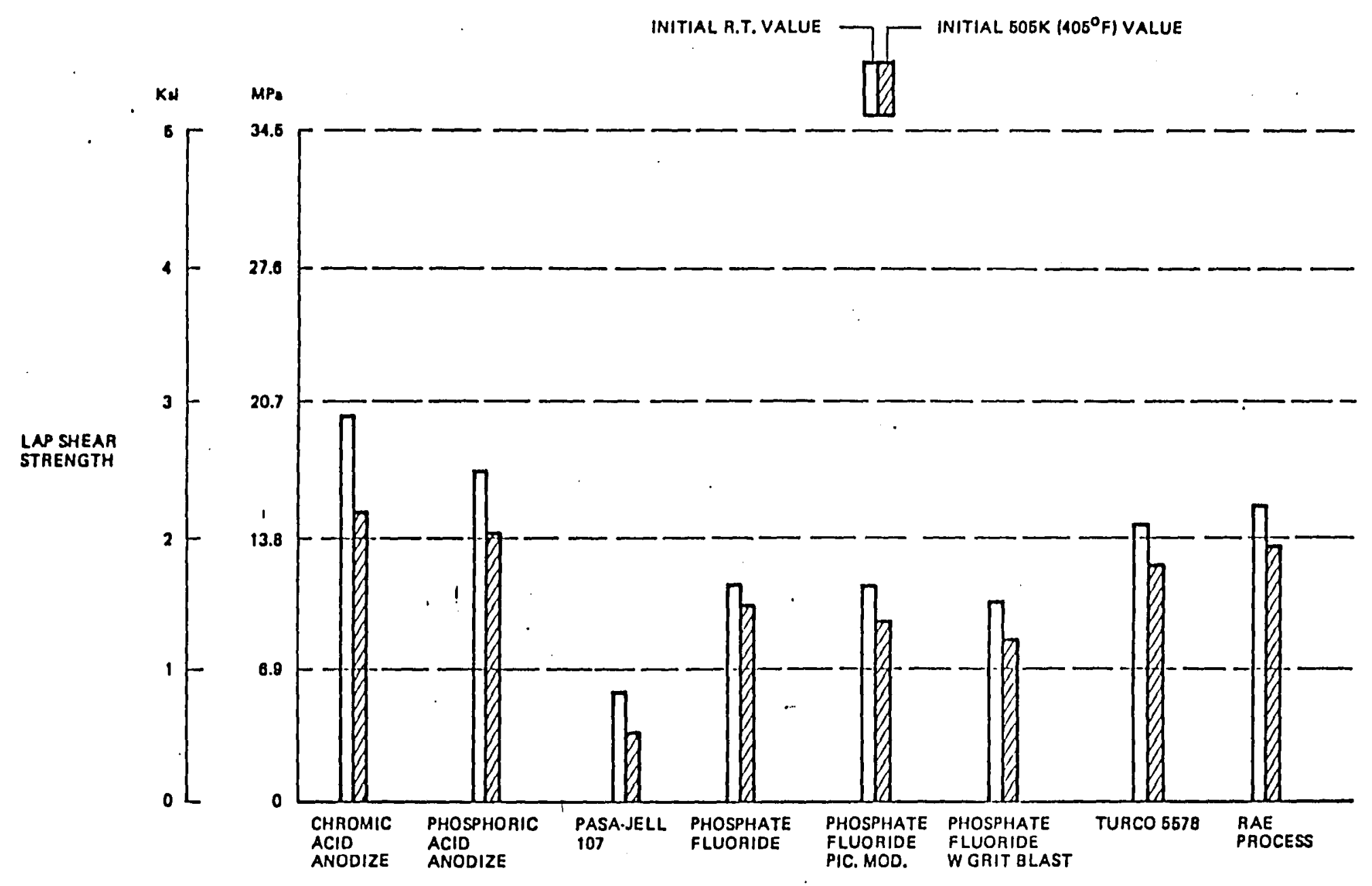


$\rightarrow \rightarrow \rightarrow \rightarrow \rightarrow \rightarrow \rightarrow \rightarrow \rightarrow \rightarrow \rightarrow \rightarrow-) \rightarrow$

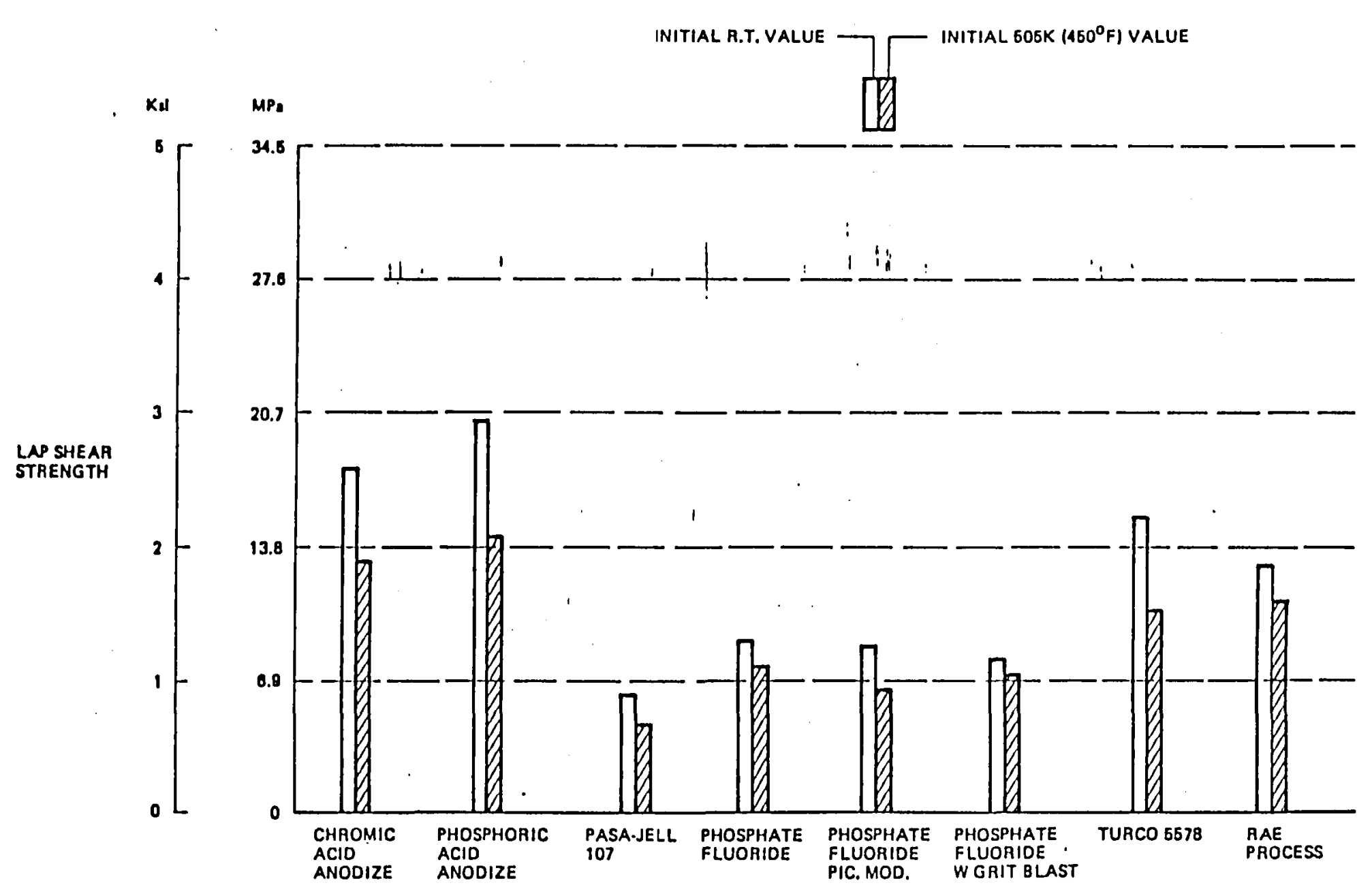

Figure 2.2-4

ADHESIVE EVALUATION LAP SHEAR STRENGTH TEST RESULTS LARC-13 MOD I 


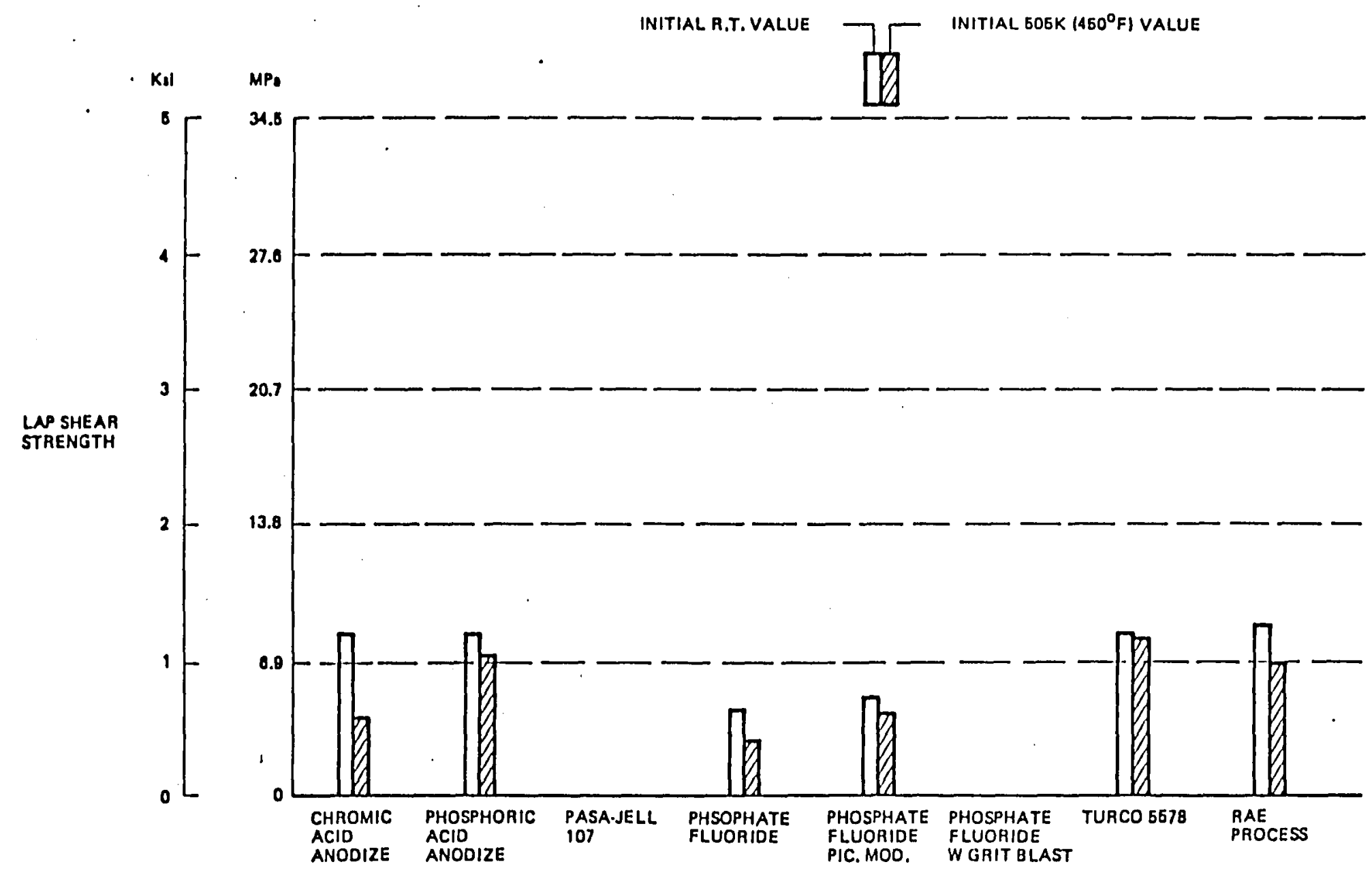

Figure 2.2-5

ADHESIVE EVALUATION LAP SHEAR STRENGTH TEST RESULTS LARC-13 MOD II 


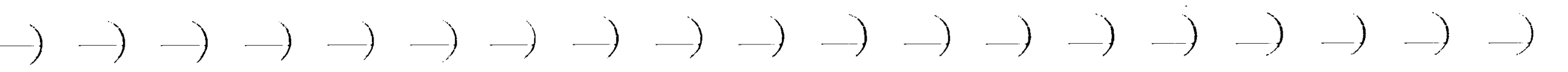

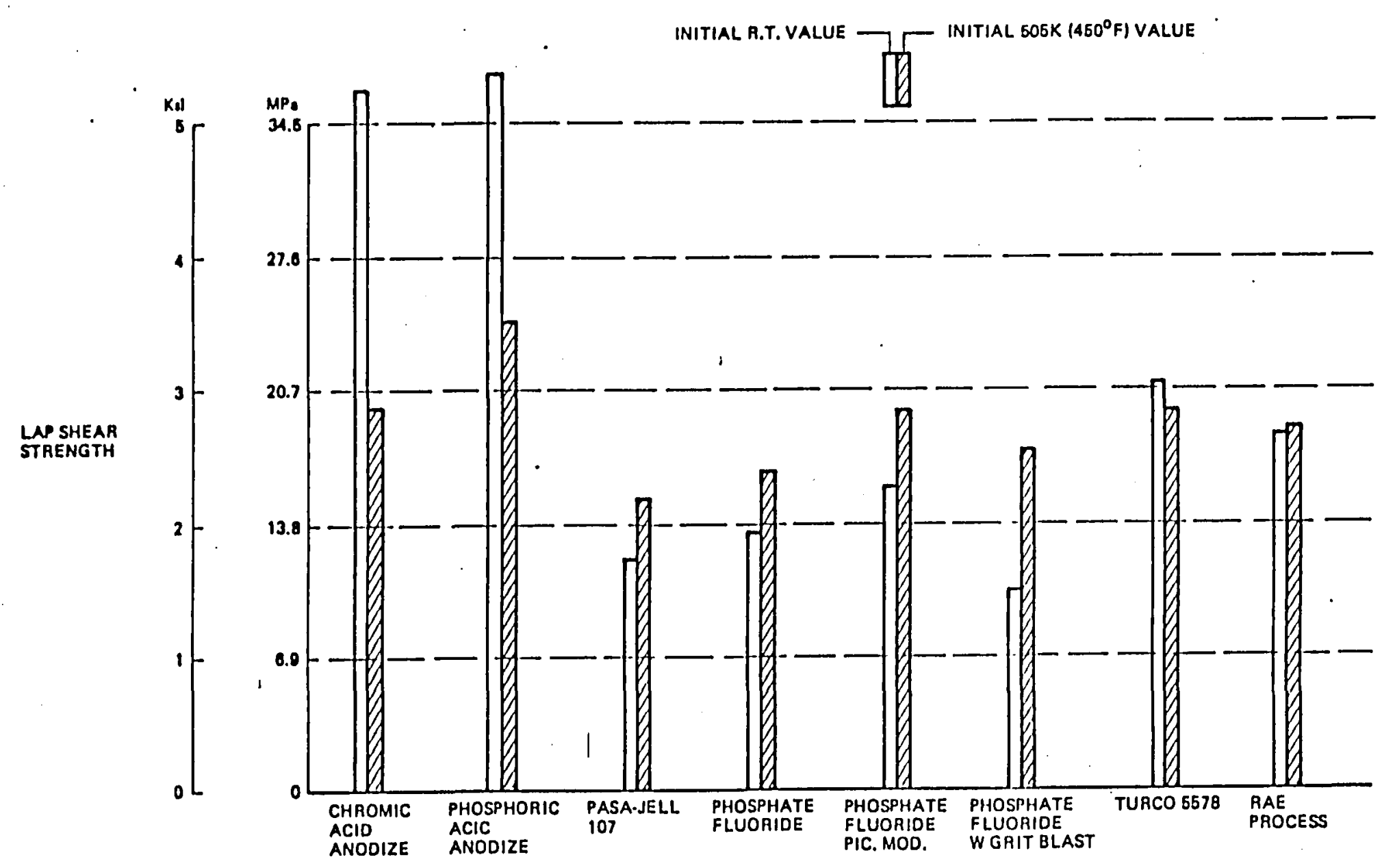

Figure 2.2-6

ADHESIVE EVALUATION LAP SHEAR STRENGTH TEST RESULTS

$P P O$ 


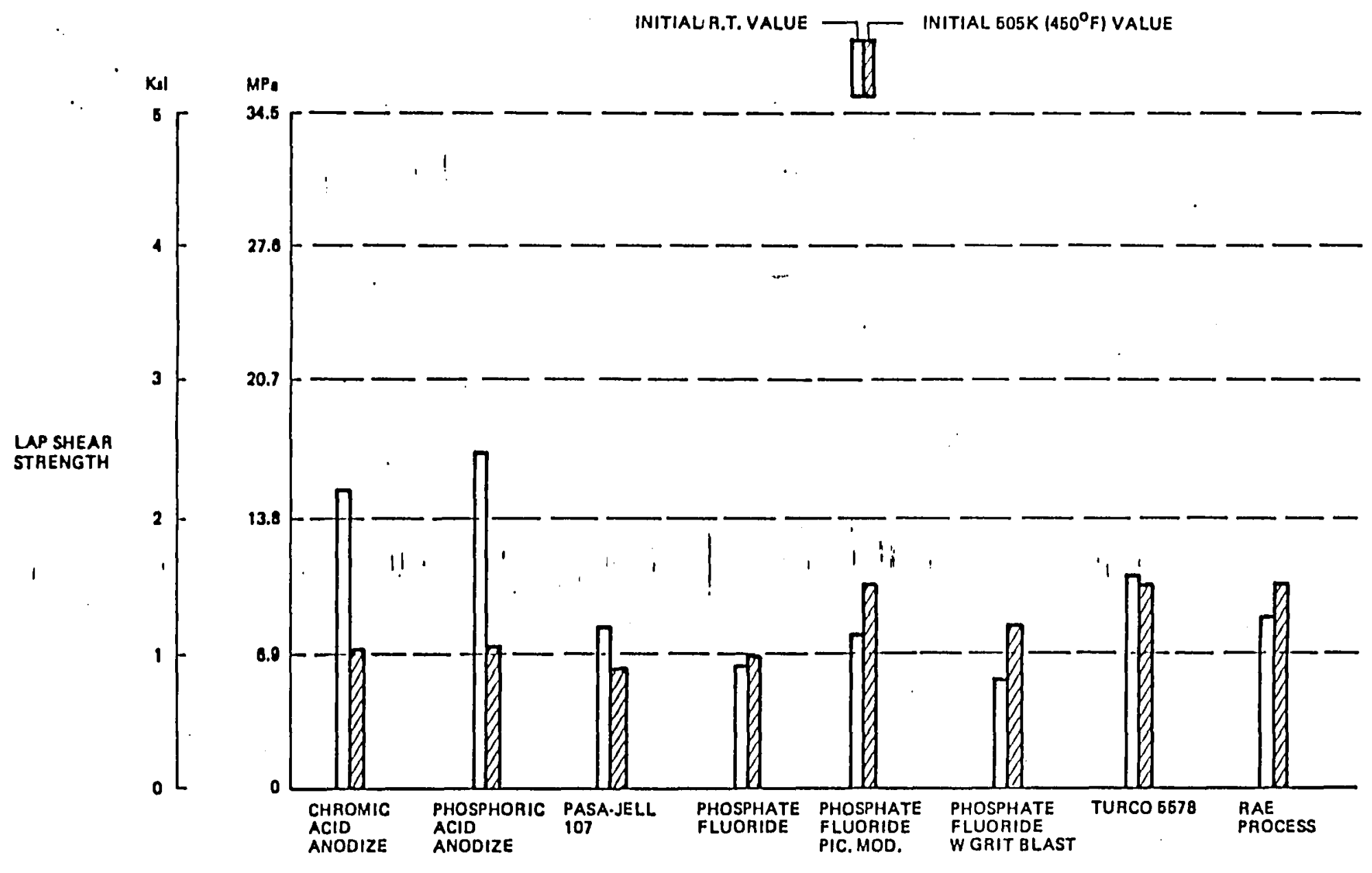

Figure 2.2-7

ADHESIVE EVALUATION LAP SHEAR STRENGTH TEST RESULTS PPQ MOD I 
$\rightarrow \rightarrow \rightarrow \rightarrow \rightarrow \rightarrow \rightarrow \rightarrow \rightarrow \rightarrow \rightarrow-\rightarrow \rightarrow$

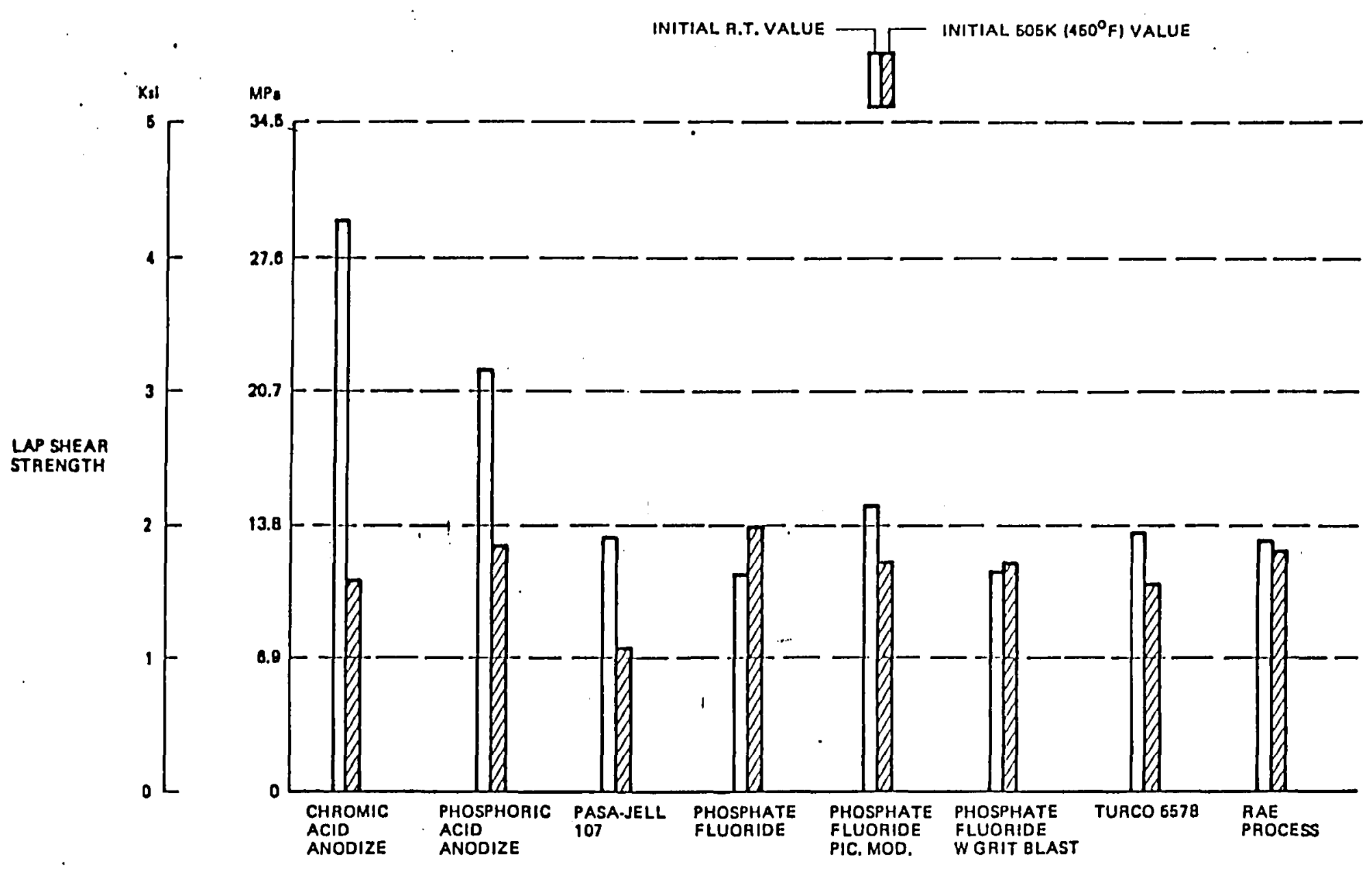

Figure 2.2-8

ADHESIVE EVALUATION LAP SHEAR STRENGTH TEST RESULTS NR150 A2 


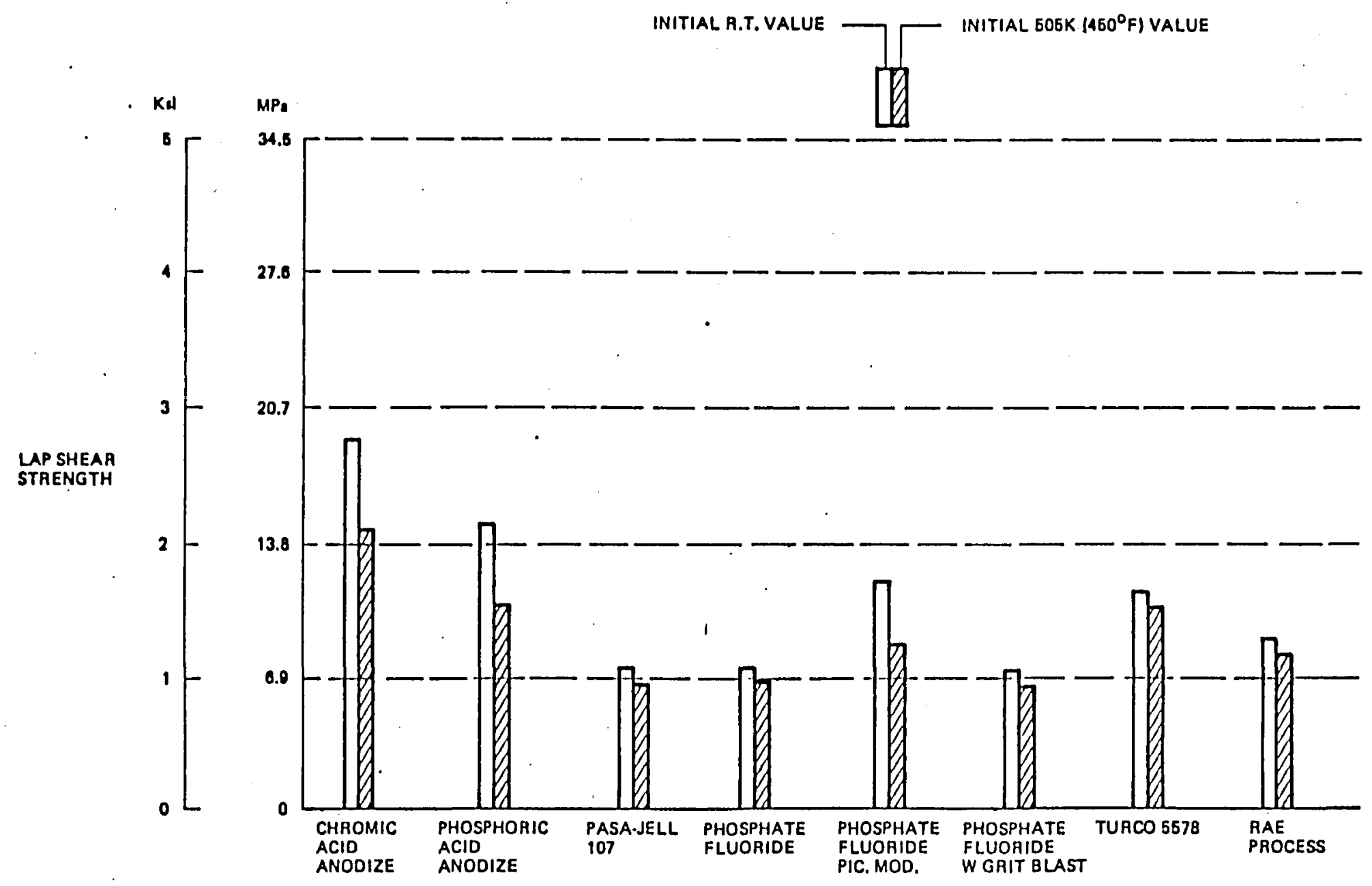

Figure 2.2-9

' ADHESIVE EVALU'ATION LAP SHEAR STREN'GTHH TEST RESULTS NR150 B2 


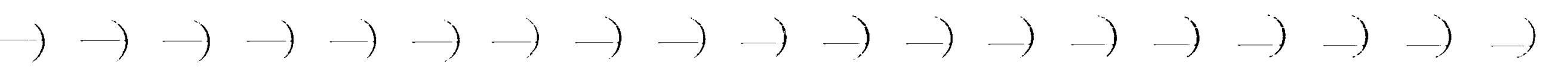

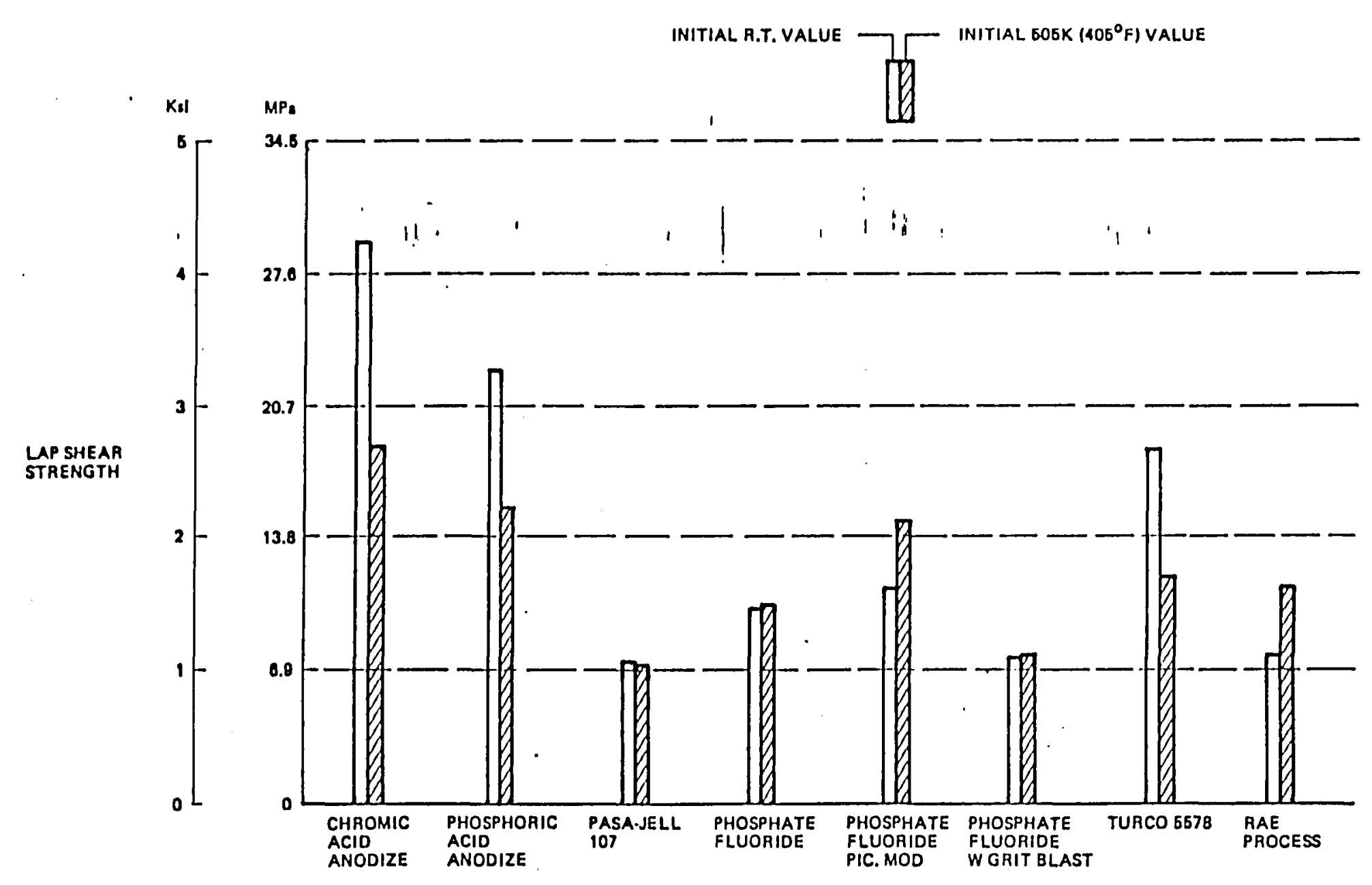

Figure 2.2-10

ADHESIVE EVALUATION LAP SHEAR STRENGTH TEST RESULTS NR056X 


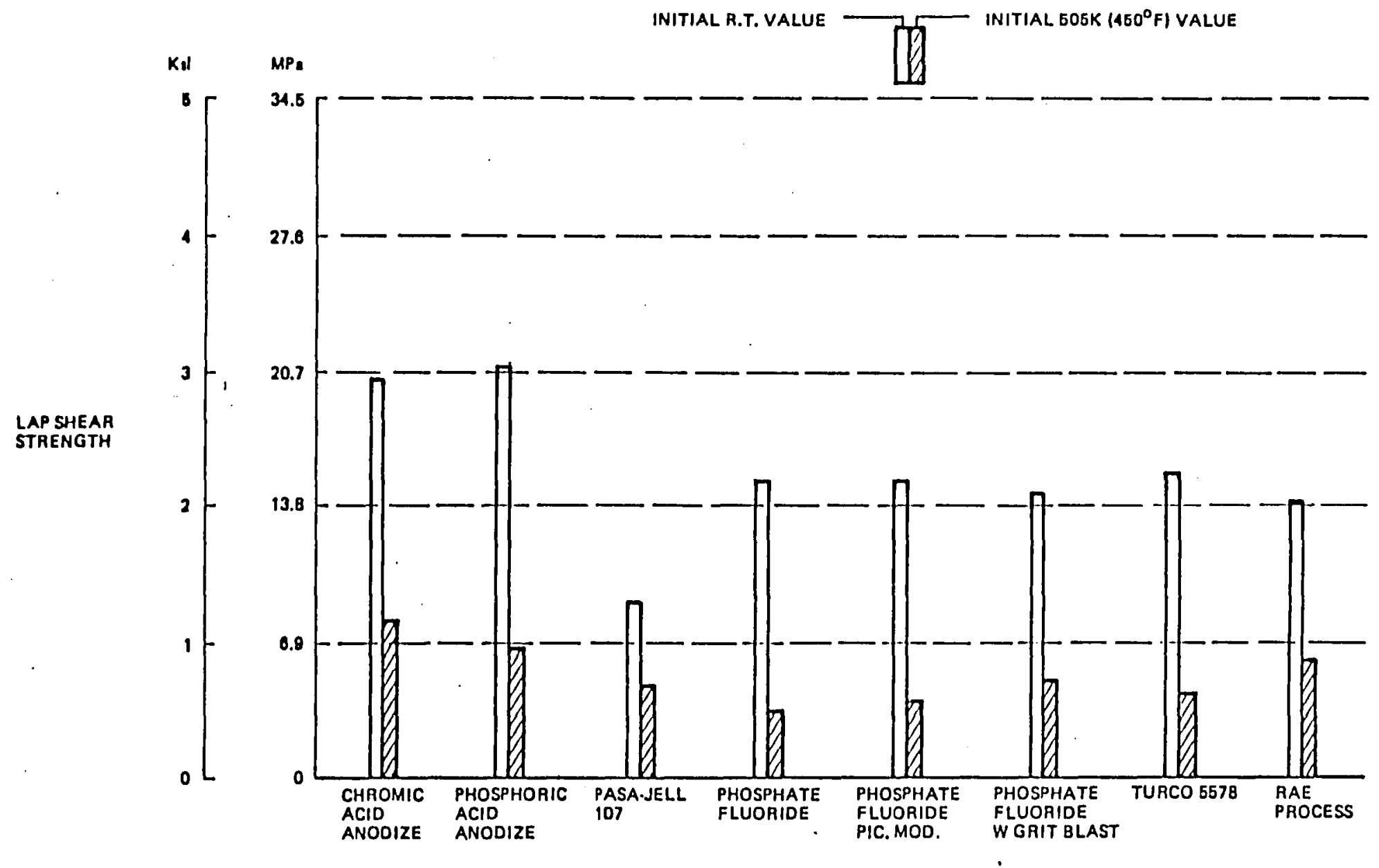

Figure 2.2-11

ADHESIVE EVALUATION LAP SHEAR STRENGTH TEST RESULTS HR 602 
$\rightarrow \rightarrow \rightarrow \rightarrow \rightarrow \rightarrow \rightarrow \rightarrow \rightarrow \rightarrow \rightarrow \rightarrow \rightarrow$

$\omega$

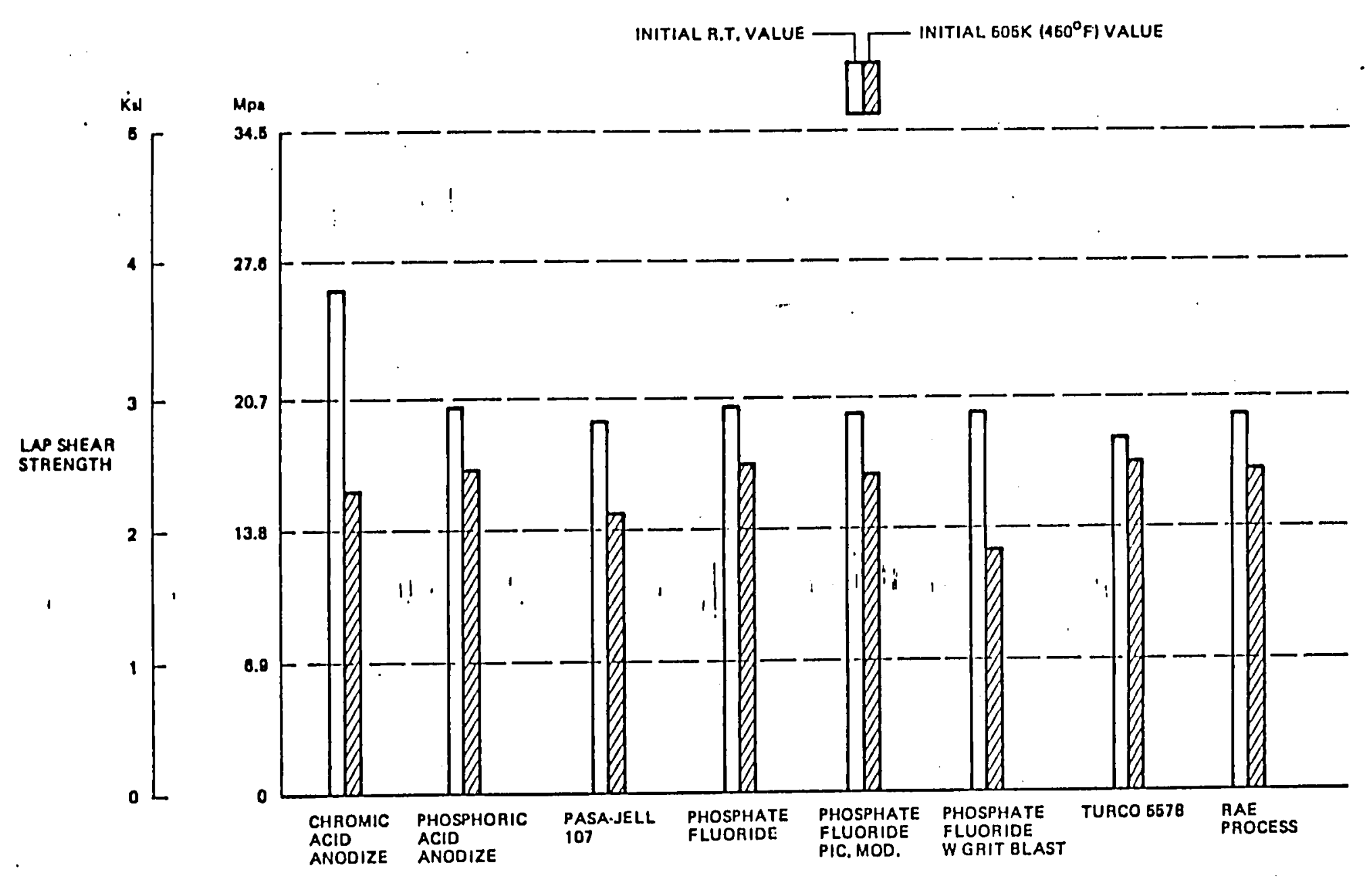

Figure 2.2-12

ADHESIVE EVALUATION LAP SHEAR STRENGTH TEST RESULTS FM-34 


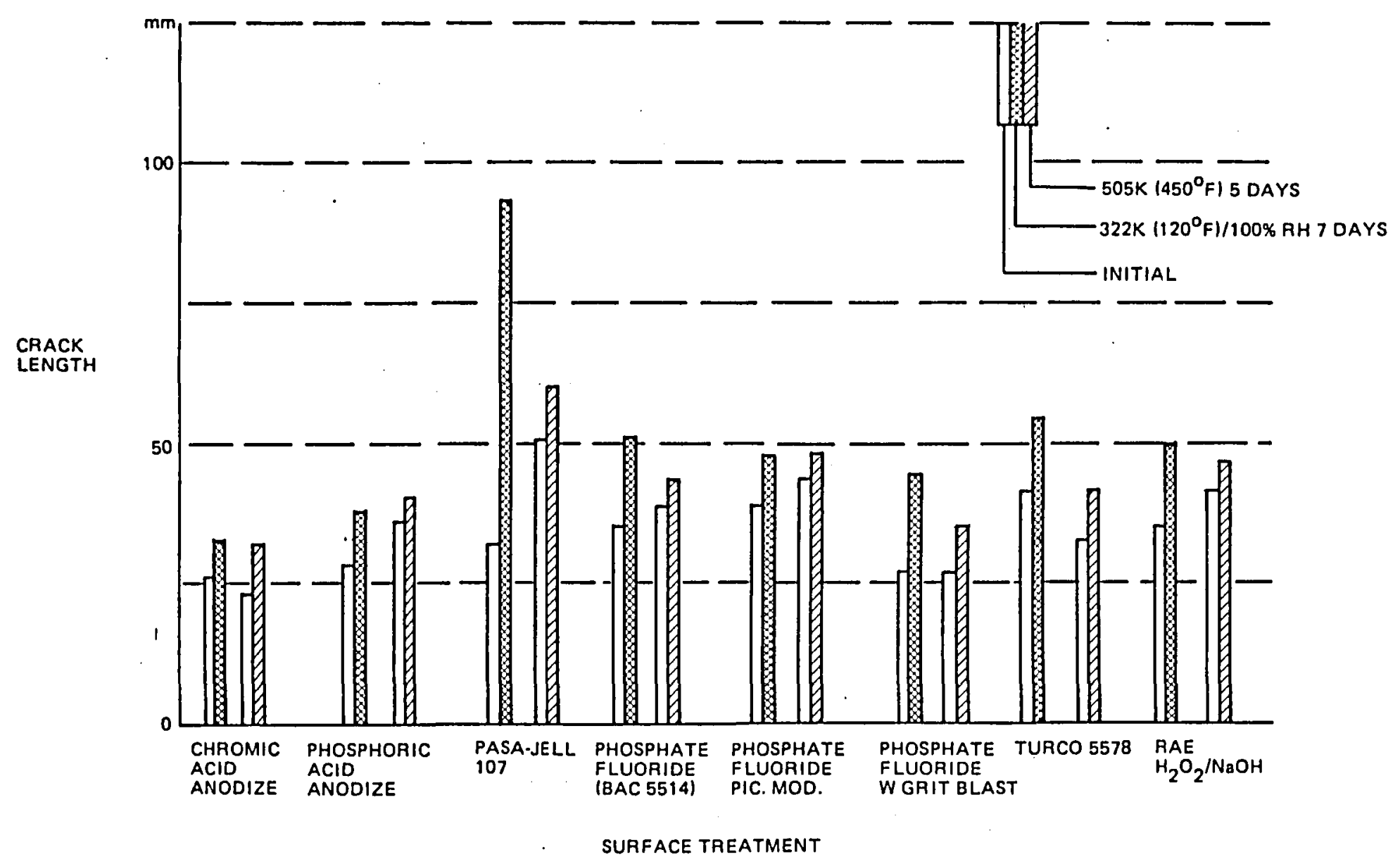

Figure 2.2-13 Crack Extension Environmental Exposure Results - LARC-13 


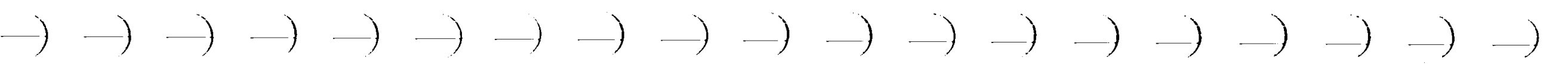

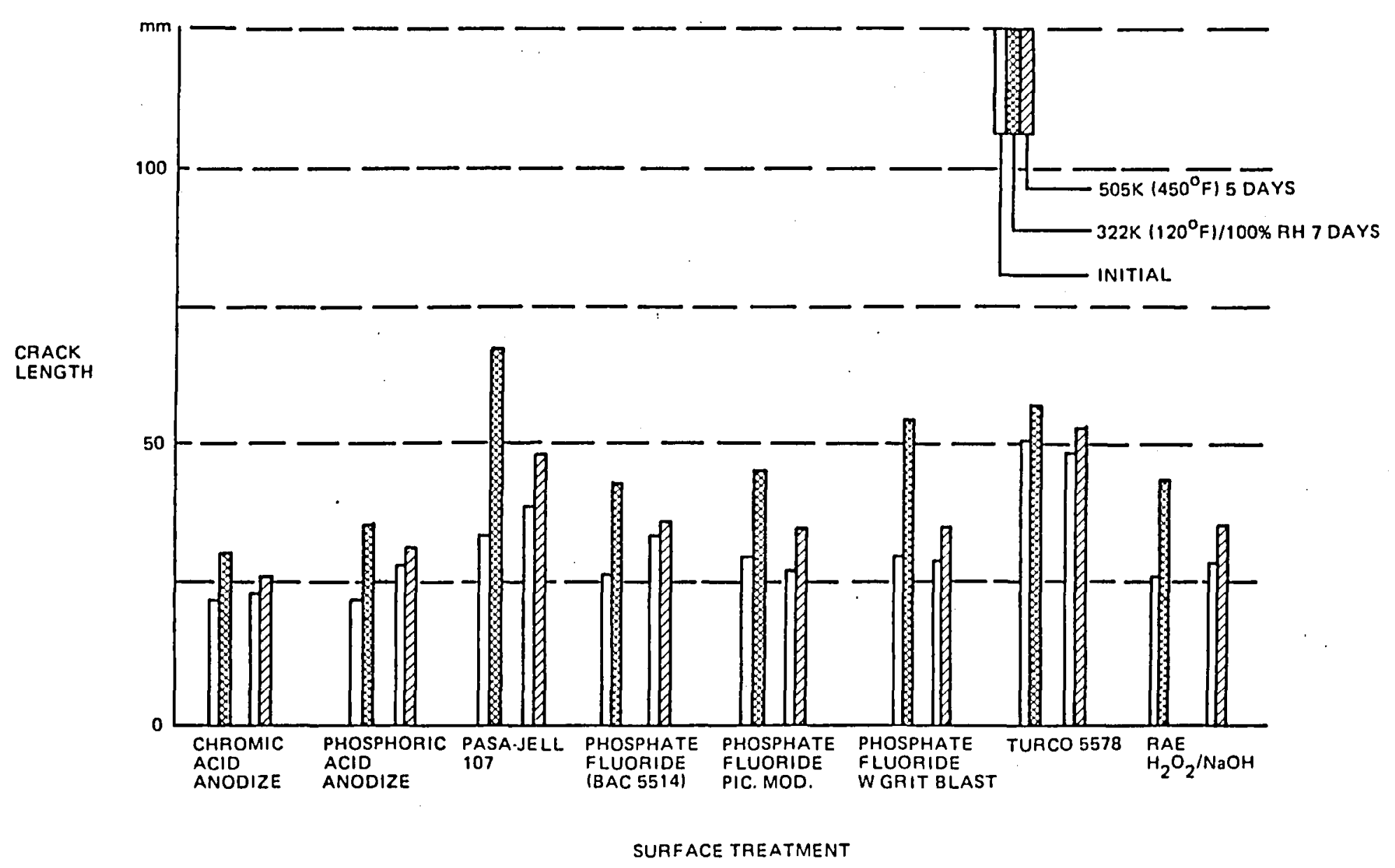

Figure 2.2-14 Crack Extension Environmental Exposure Results - NR150B2 


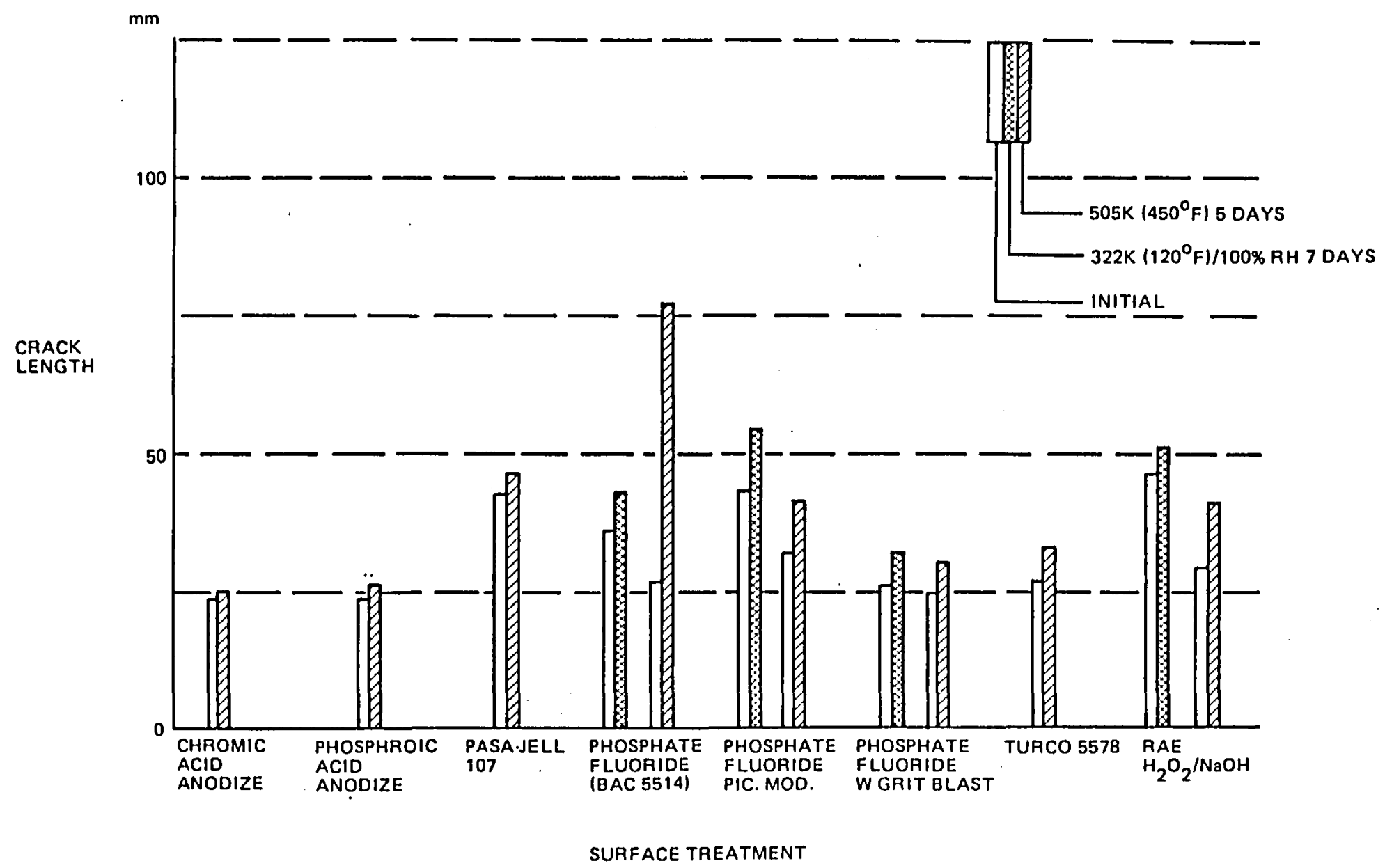

Figure 2.2-15 PPQ Crack Extension Environmental Exposure Results 


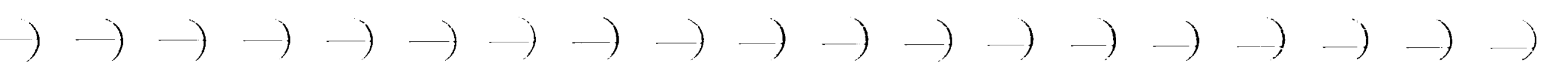

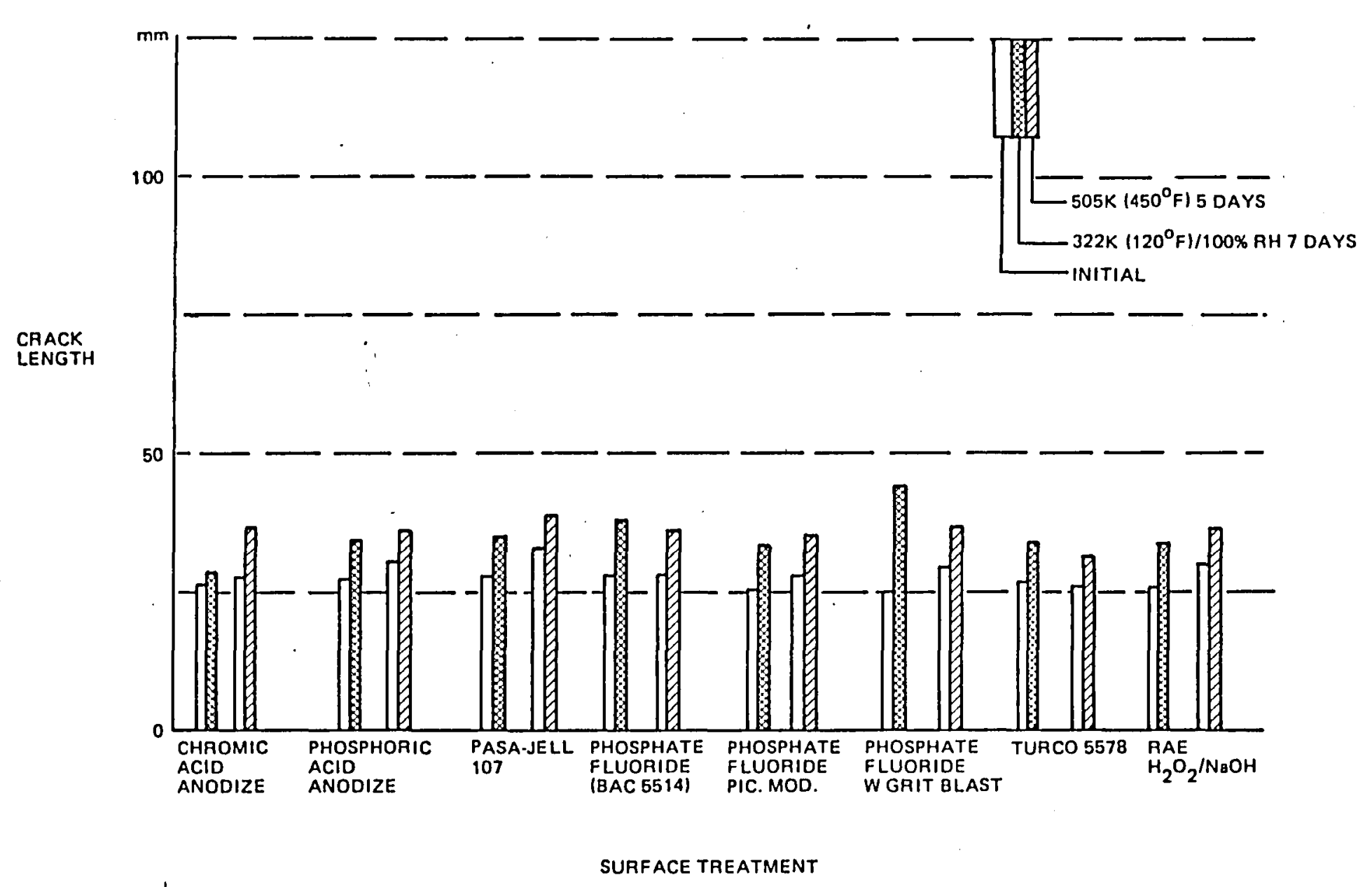

Figure 2.2-16 Crack Extension Environmental Exposure Results - FM.34 
Table 2.2-1

ADHESIVE FILM VOLATILE CONTENT

\begin{tabular}{|l|r|r|r|c|}
\hline ADHESIVE FILM & \multicolumn{4}{|c|}{ VOLATILE CONTENT, \% WT } \\
\hline & 1 st & 2nd & 3rd & AVERAGE \\
\hline LARC-13 & 5.6 & 5.2 & 5.4 & 5.4 \\
LARC-13 MOD I & 11.2 & 10.2 & 10.9 & 10.8 \\
LARC-13 MOD II & $*$ & $*$ & $*$ & $*$ \\
NR150B2 & 11.2 & 11.1 & 10.9 & 11.1 \\
NR150A2 & $*$ & $*$ & $*$ & $*$ \\
NR056X & 5.3 & 5.2 & 4.8 & 5.1 \\
PPQ & 1.4 & 1.5 & 1.4 & 1.4 \\
PPQ M0D I & 1.0 & 1.0 & 0.9 & 1.0 \\
HR602 & 5.9 & 6.1 & --- & 6.0 \\
FM-34 & 13.9 & 13.8 & --- & 13.8 \\
\hline
\end{tabular}


The PPQ adhesive system made up of PPQ adhesive resin, dilute PPQ resin primer, and chromic acid anodize surface treatment was selected based upon data generated from this program, as well as from internal Boeing research programs. Lap shear data in Figure 2.2-6 shows phosphoric acid anodize surface treatment superior to chromic acid anodize. However, Boeing data on both these surface treatments has shown that phosphoric acid anodize is not stable in long term ( $125 \mathrm{hr}$ ) elevated temperature $\left(600^{\circ} \mathrm{F}\right)$ environments. Chromic acid anodize exhibited good thermal stability. Therefore, chromic acid anodize was selected over phosphoric acid anodize for this program. PPQ has demonstrated excellent lap shear values. Film producibility and quality has been excellent. Primary disadvantage with $\mathrm{PPQ}$ is the high $644 \mathrm{~K}\left(700^{\circ} \mathrm{F}\right)$ process temperature. However, the overall process time is shorter than for the other candidate systems (see cure cycles in appendix). The combined advantages of good mechanical properties, ease of film fabrication, and potential thermal stability were the main reasons for its selection for further evaluation.

LARC-13 also demonstrated superior adhesive properties when used in combination with dilute LARC-13 primer and chromic acid anodize titanium surface treatment. The primary disadvantage with LARC-13 is the high flow exhibited during its curing cycle. This would tend to produce sandwich panels with marginal flatwise tensile properties. The data gathered on Boeing and the Phase I studies indicate no significant difference in the properties obtained with BR34 primed substrates when compared to LARC-13 primed substrates. The LARC-13 polyimide system is less thermally stable than the NR056X system. However, its advantage is that it possesses the capability of complete devolatilization prior to the bonding cycle.

NR056X - This polyimide system possesses excellent strength retention at $450^{\circ} \mathrm{F}$ because of its chemical structure. Even though its cured chemical structure is similar to NR150B2 it has the added advantage of using diglyme solvent rather than NMP. This enhances solvent removal in adhesive tape manufacture at lower temperatures than necessary for NR150B2. The major deficiency is that it is a condensation polymer which causes volatile release problems during bonding using large area substrates.

The modifications to PPQ and LARC-13 did not exhibit any significant improvement over the base formulations as seen from the data previously listed. PPQ Mod 1 with boron powder apparently reduced the flow of the system to such an extent that processing conditions used in panel preparation resulted in properties being somewhat lower than expected. 
With respect to the LARC-13 modifications, the following reasoning was used to eliminate them from further evaluation. LARC-13 Mod I simply replaced 50 phr LARC-13 resin with AMOCO A1130 polyamide-imide resin. Based on results of Phase I, the properties were essentially identical with LARC-13. However, utilizing data obtained on other Boeing programs, it was found that the AI 1130 polyamide-imide made it more difficult to bond large areas because of the NMP solvent that it contained. Since the properties required in this program (SCR) are based on solid metallic substrates, it was determined that the basic LARC-13 system would provide data for the addition type polyimides. With respect to the LARC-13 Mod II, the chemistry is essentially the same as LARC-13. The variation of the ingredients would only cause the Mod II to possess a slightly higher Tg. This same type of system was characterized in detail on another NASA program (ref. 5). The data from this program was available before Phase II of this program started, leaving the option open for its inclusion in the program if desired. As previously mentioned, the basic properties of the LARC-13 were similar to those obtainable with LARC-13 Mod II.

FM-34 was eliminated at this stage of the program since it cannot be reliably processed in large area bond structures. This adhesive did function as a baseline control to compare with the newer adhesive resin formulations.

HR602 was not selected because of its low lap shear properties with all metal surface treatments. Data generated on this adhesive for this program is very similar to the test data submitted by Hughes on the test sample material. All process procedures used for HR602 were performed as specified by Hughes. Subsequent evaluation of this adhesive by Boeing (independent of this contract) did produce much improved bond properties. These improvements were primarily the result of changes in the cure cycle. 


\subsection{ADHESIVE SYSTEM SCREENING}

This portion of the program extended the evaluation of the three selected adhesive systems to include (1) Cure Cycle Optimization, (2) determination of bond properties at various temperatures, (3) long term 505K thermal aging, (4) long term humidity aging, and (5) ability of each system to produce good large area structural bonds. The objective of this study was to select two (2) adhesive systems for Phase II comprehensive characterization and test.

\subsubsection{Cure Cycle Optimization}

To establish more optimized processing conditions four (4) different cure cycles were used for each of the three adhesive systems to fabricate lap shear mechanical test coupons. These coupons were then subjected to $505 \mathrm{~K}$ thermal aging to 6000 hours and tested for change in shear strength during this exposure.

The cure cycles used for the three adhesive systems were:

LARC-13 (LARC-13 Adhesive, LARC-13 Primer, Chromic Acid Anodize-10 volts).

\section{CURE 非}

1. Apply vacuum and $0.060 \mathrm{MPa}(10 \mathrm{psi})$.

2. Heat to $575 \mathrm{~K}\left(575^{\circ} \mathrm{F}\right)$ at $1.7-2.8 \mathrm{~K}\left(3-5^{\circ} \mathrm{F}\right) /$ minute.

3. Apply $0.69 \mathrm{MPa}(100 \mathrm{psi})$ autoclave pressure at $575 \mathrm{~K}\left(575^{\circ} \mathrm{F}\right)$.

4. Hold at $575 \mathrm{~K}(575 \circ \mathrm{F})$ for 2 hours.

5. Cool to below $338 \mathrm{~K}\left(150^{\circ} \mathrm{F}\right)$ before releasing pressure.

6. Postcure 16 hours at $575 \mathrm{~K}\left(575^{\circ} \mathrm{F}\right)$.

\section{CURE 非2}

1. Apply vacuum and $0.060 \mathrm{MPa}$ (10 psi).

2. Heat to $588 \mathrm{~K}\left(600^{\circ} \mathrm{F}\right)$ at $1.7-2.8 \mathrm{~K}\left(3-5^{\circ} \mathrm{F}\right) /$ minute.

3. As temperature reaches $575 \mathrm{~K}\left(575^{\circ} \mathrm{F}\right)$ apply $0.69 \mathrm{MPa}(100 \mathrm{psi})$ autoclave pressure.

4. Hold at $588 \mathrm{~K}\left(600^{\circ} \mathrm{F}\right)$ for 2 hours.

5. Cool to below $588 \mathrm{~K}\left(600^{\circ} \mathrm{F}\right)$ before releasing pressure.

6. Postcure 16 hours at $575 \mathrm{~K}(5750 \mathrm{~F})$. 


\section{CURE 非3}

1. Apply vacuum and $0.060 \mathrm{MPa}$ (10 psi).

2. Heat to $575 \mathrm{~K}\left(575^{\circ} \mathrm{F}\right)$ at $1.7-2.8 \mathrm{~K}\left(3-5^{\circ} \mathrm{F}\right) /$ minute.

3 Apply $0.69 \mathrm{MPa}(100 \mathrm{psi})$ autoclave pressure at $575 \mathrm{~K}\left(575^{\circ} \mathrm{F}\right)$.

4. Hold at $575 \mathrm{~K}\left(575^{\circ} \mathrm{F}\right)$ for 2 hours.

5. Cool to below $338 \mathrm{~K}\left(150^{\circ} \mathrm{F}\right)$ before releasing pressure.

6. Postcure 6 hours at $588 \mathrm{~K}\left(600^{\circ} \mathrm{F}\right)$.

\section{CURE \#4}

1. Apply vacuum and $0.060 \mathrm{MPa}(10 \mathrm{psi})$.

2. Heat to $588 \mathrm{~K}\left(600^{\circ} \mathrm{F}\right)$ at $1.7-2.8 \mathrm{~K}\left(3-5^{\circ} \mathrm{F}\right) /$ minute.

3. Apply $0.69 \mathrm{MPa}(100 \mathrm{psi})$ autoclave pressure as temperature reaches $575 \mathrm{~K}$ $\left(575^{\circ} \mathrm{F}\right)$.

4. Hold at $588 \mathrm{~K}\left(600^{\circ} \mathrm{F}\right)$ before releasing pressure.

5. Cool to below $338 \mathrm{~K}\left(150^{\circ} \mathrm{F}\right)$ before releasing pressure.

6. Postcure 6 hours at $588 \mathrm{~K}\left(600^{\circ} \mathrm{F}\right)$.

PPQ (PPQ Resin Adhesive, PPQ Primer, Chromic Acid Anodize--10 volts)

\section{CURE 非 1}

1. Apply vacuum and $1.38 \mathrm{MPa}(200 \mathrm{psi})$ autoclave pressure.

2. Heat to $644 \mathrm{~K}\left(700^{\circ} \mathrm{F}\right)$ at $1.7-2.8 \mathrm{~K}(3-50 \mathrm{~F}) /$ minute.

3. Hold at $644 \mathrm{~K}\left(700^{\circ} \mathrm{F}\right)$ for 30 minutes.

4. Cool to below $338 \mathrm{~K}\left(150^{\circ} \mathrm{F}\right)$ before releasing pressure.

\section{CURE 非2}

1. Apply vacuum and $1.38 \mathrm{MPa}(200 \mathrm{psi})$ autoclave pressure.

2. Heat to $644 \mathrm{~K}\left(700^{\circ} \mathrm{F}\right)$ at $1.7-2.8 \mathrm{~K}\left(3-5_{\mathrm{O}} \mathrm{F}\right) /$ minute.

3. Hold at $644 \mathrm{~K}\left(700^{\circ} \mathrm{F}\right)$ for 60 minutes.

4. Cool to below $338 \mathrm{~K}\left(150^{\circ} \mathrm{F}\right)$ before releasing pressure.

\section{CURE \#3}

1. Apply vacuum and $1.38 \mathrm{MPa}(200 \mathrm{psi})$ autoclave pressure.

2. Heat to $672 \mathrm{~K}\left(750^{\circ} \mathrm{F}\right)$ at $1.7-2.8 \mathrm{~K}\left(3-5^{\circ} \mathrm{F}\right) /$ minute.

3. Hold at $672 \mathrm{~K}\left(750^{\circ} \mathrm{F}\right)$ for 30 minutes.

4. Cool to below $338 \mathrm{~K}\left(150^{\circ} \mathrm{F}\right)$ before releasing pressure. 


\section{CURE 非 4}

1. Apply vacuum and $1.38 \mathrm{MPa}(200 \mathrm{psi})$ autoclave pressure.

2. Heat to $672 \mathrm{~K}\left(750^{\circ} \mathrm{F}\right)$ at $1.7-2.8 \mathrm{~K}\left(3-5_{\mathrm{O}} \mathrm{F}\right) /$ minute.

3. Hold at $672 \mathrm{~K}\left(750^{\circ} \mathrm{F}\right)$ for 60 minutes.

4. Cool to below $338 \mathrm{~K}\left(150^{\circ} \mathrm{F}\right)$ before releasing pressure.

NR056X (NR056X Resin Adhesive, NR056X Primer, Chromic Acid Anodize--10 volts)

\section{CURE 非 1}

1. Apply vacuum and $1.38 \mathrm{MPa}(200 \mathrm{psi})$ autoclave pressure.

2. Heat to $575 \mathrm{~K}\left(575^{\circ} \mathrm{F}\right)$ at $1.7-2.8 \mathrm{~K}\left(3-5^{\circ} \mathrm{F}\right) /$ minute.

3. Hold at $575 \mathrm{~K}(5750 \mathrm{~F})$ for 2 hours.

4. Cool to below $338 \mathrm{~K}\left(150^{\circ} \mathrm{F}\right)$ before releasing pressure.

5. Postcure 16 hours at $575 \mathrm{~K}\left(575^{\circ} \mathrm{F}\right)$.

\section{CURE 非2}

1. Apply vacuum and $1.38 \mathrm{MPa}(200 \mathrm{psi})$ autoclave pressure.

2. Heat to $644 \mathrm{~K}\left(700^{\circ} \mathrm{F}\right)$ at $1.7-2.8 \mathrm{~K}\left(3-5^{\circ} \mathrm{F}\right) /$ minute.

3. Hold at $644 \mathrm{~K}\left(700^{\circ} \mathrm{F}\right)$ for 30 minutes.

4. Cool to below $338 \mathrm{~K}\left(150^{\circ} \mathrm{F}\right)$ before releasing pressure.

5. Postcure--none.

\section{CURE 非 3}

1. Apply vacuum and $1.38 \mathrm{MPa}(200 \mathrm{psi})$ autoclave pressure.

2. Heat to $672 \mathrm{~K}\left(750^{\circ} \mathrm{F}\right)$ at $1.7-2.8 \mathrm{~K}\left(3-5^{\circ} \mathrm{F}\right) /$ minute.

3. Hold at $672 \mathrm{~K}\left(750^{\circ} \mathrm{F}\right)$ for 30 minutes.

4. Cool to below $338 \mathrm{~K}\left(150^{\circ} \mathrm{F}\right)$ before releasing pressure.

5. Postcure--none.

\section{CURE 非}

1. Apply vacuum and $1.38 \mathrm{MPa}(200 \mathrm{psi})$ autoclave pressure.

2. Heat to $602 \mathrm{~K}\left(625^{\circ} \mathrm{F}\right)$ at $1.7-2.8 \mathrm{~K}(3-50 \mathrm{~F}) /$ minute.

3. Hold at $602 \mathrm{~K}\left(625^{\circ} \mathrm{F}\right)$ for 2 hours.

4. Cool to below $338 \mathrm{~K}\left(150^{\circ} \mathrm{F}\right)$ before releasing pressure.

5. Postcure 6 hours at $588 \mathrm{~K}\left(600^{\circ} \mathrm{F}\right)$. 
Table 2.3.1-1 summarizes the lap shear strength data for each of the cure cycles used for the three adhesive systems. Individual test values for all lap shear coupons are listed in the Appendix.

The four cure cycles used to fabricate the LARC-13 test coupons did not appear to show significant differences in initial shear values. Cycles 1 and 4 test coupons after 6000 hours of $505 \mathrm{~K}\left(4500^{\circ} \mathrm{F}\right)$ exposure were also similar in shear strength. Apparently, the cure parameters investigated do not affect lap shear properties. See Figure 2.3.1-1.

Polyphenylquinoxaline cure cycle modifications concentrated on increasing the cure temperature from $644 \mathrm{~K}\left(600^{\circ} \mathrm{F}\right)$ to $672 \mathrm{~K}\left(750^{\circ} \mathrm{F}\right)$. Exposure of the chromic acid anodize to $672 \mathrm{~K}\left(750^{\circ} \mathrm{F}\right)$ for 60 minutes using PPQ causes complete separation of the oxide layer from the titanium surface at very low stress levels. The same cure cycle with a 15minute dwell at $672 \mathrm{~K}\left(750^{\circ} \mathrm{F}\right)$ did not affect the bond quality. Therefore, cure cycles to prepare PPQ test coupons utilizing $6 \mathrm{Al}-4 \mathrm{~V}$ titanium with chromic acid anodize should not exceed 15 minutes at $672 \mathrm{~K}\left(750^{\circ} \mathrm{F}\right)$. A possible explanation for the oxide failure is penetration/chemical interaction of the Cresol-xylene solvent (in the PPQ adhesive films) at the oxide-metal interface causing separation which results in bond failure. Figure 2.3.12 does not have a curve for cure cycle 非 4 because of very poor lap shear bonds.

NR056X cure cycles investigated were identical to those used for PPQ. The 644K (7000F) cures resulted in cohesive failures while the $672 \mathrm{~K}\left(750^{\circ} \mathrm{F}\right)$ cures failed in both adhesive and cohesive modes indicating a weakening of the oxide layer.

Thermal aging and test of lap shear coupons for this series continued to 6000 hours to determine if there is a thermal stability problem with chromic acid anodize oxide layer. See Figure 2.3.1-3.

The cure cycles selected based upon initial lap shear values and limited thermal exposure of $505 \mathrm{~K}\left(450^{\circ} \mathrm{F}\right)$ are:

\section{LARC-13 Cure Cycle $\$ 4$}

1. Apply vacuum and $0.069 \mathrm{MPa}$ (10 psi).

2. Heat to $588 \mathrm{~K}\left(600^{\circ} \mathrm{F}\right)$ at $1.7-2.8 \mathrm{~K}\left(3-5^{\circ} \mathrm{F}\right) /$ minute.

3. Apply $0.69 \mathrm{MPa}(100 \mathrm{psi})$ autoclave pressure as temperature reaches $575 \mathrm{~K}$ $\left(575^{\circ} \mathrm{F}\right)$. 


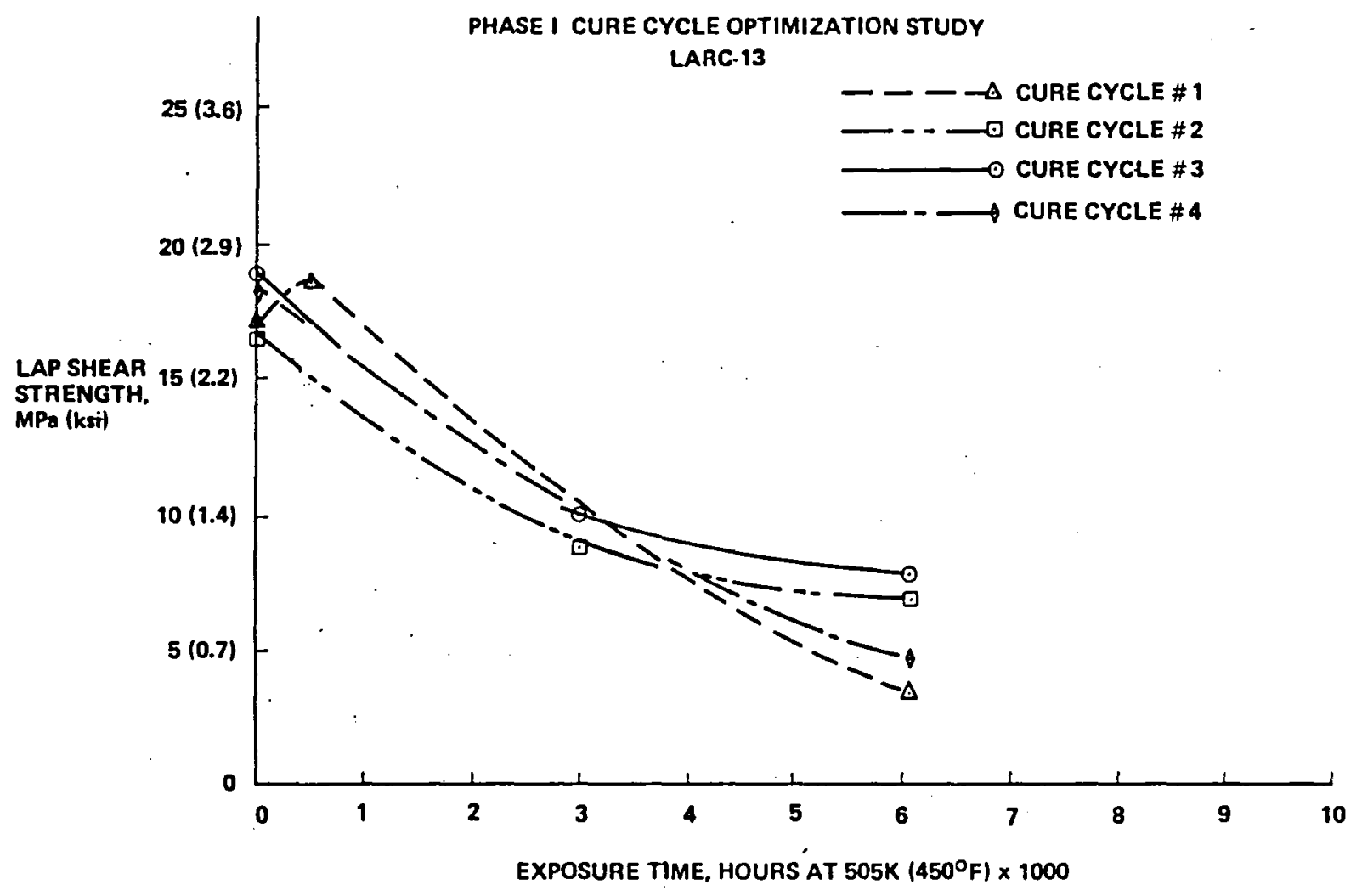

Figure 2.3.1-1: Effect of $505 K\left(450^{\circ} \mathrm{F}\right)$ Upon Adhesive Lap Shear 


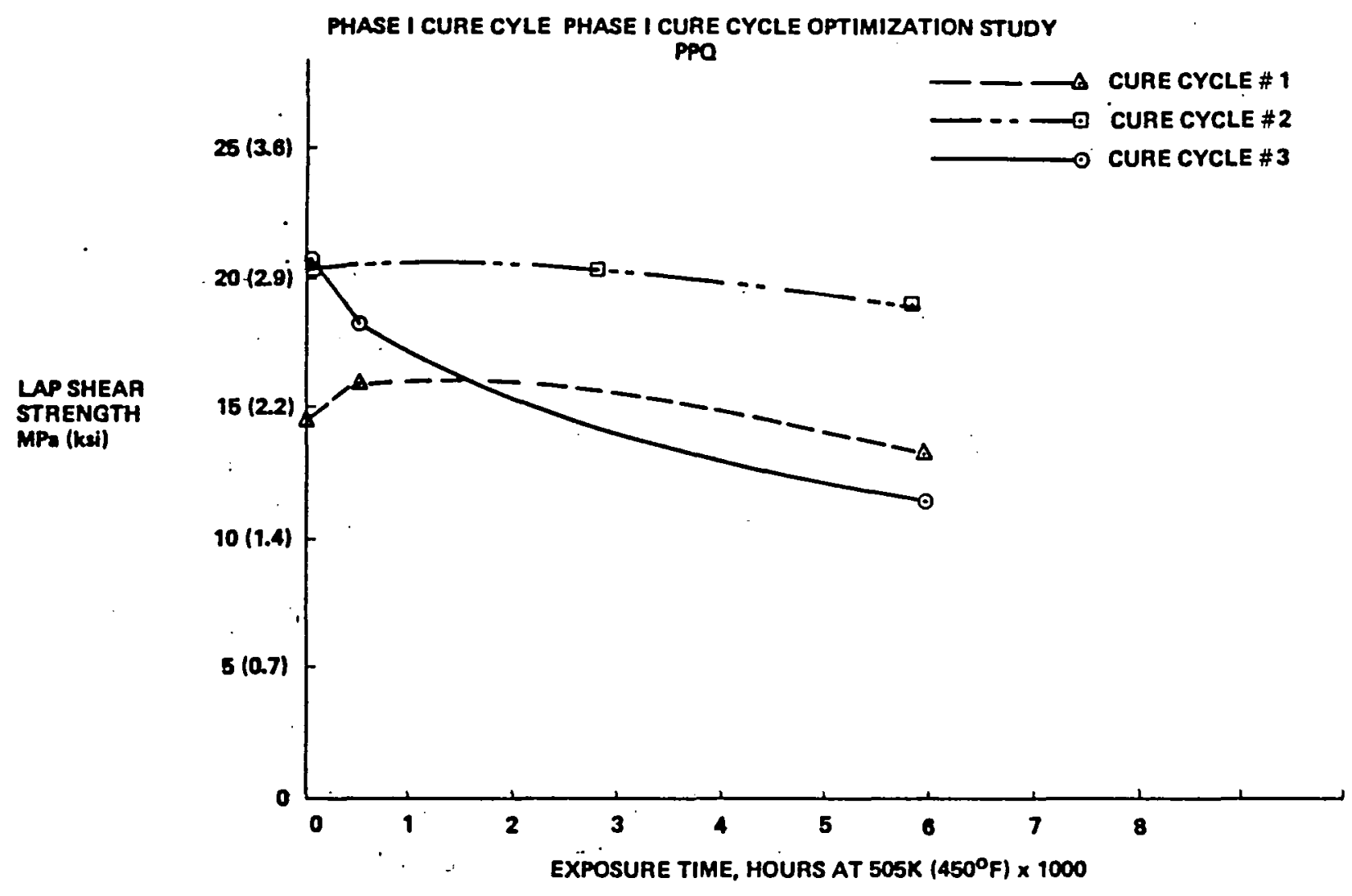

Figure 2.3.1-2: Effect of $505 \mathrm{~K}\left(450^{\circ} \mathrm{F}\right)$ Upon Adhesive Lap Shear 


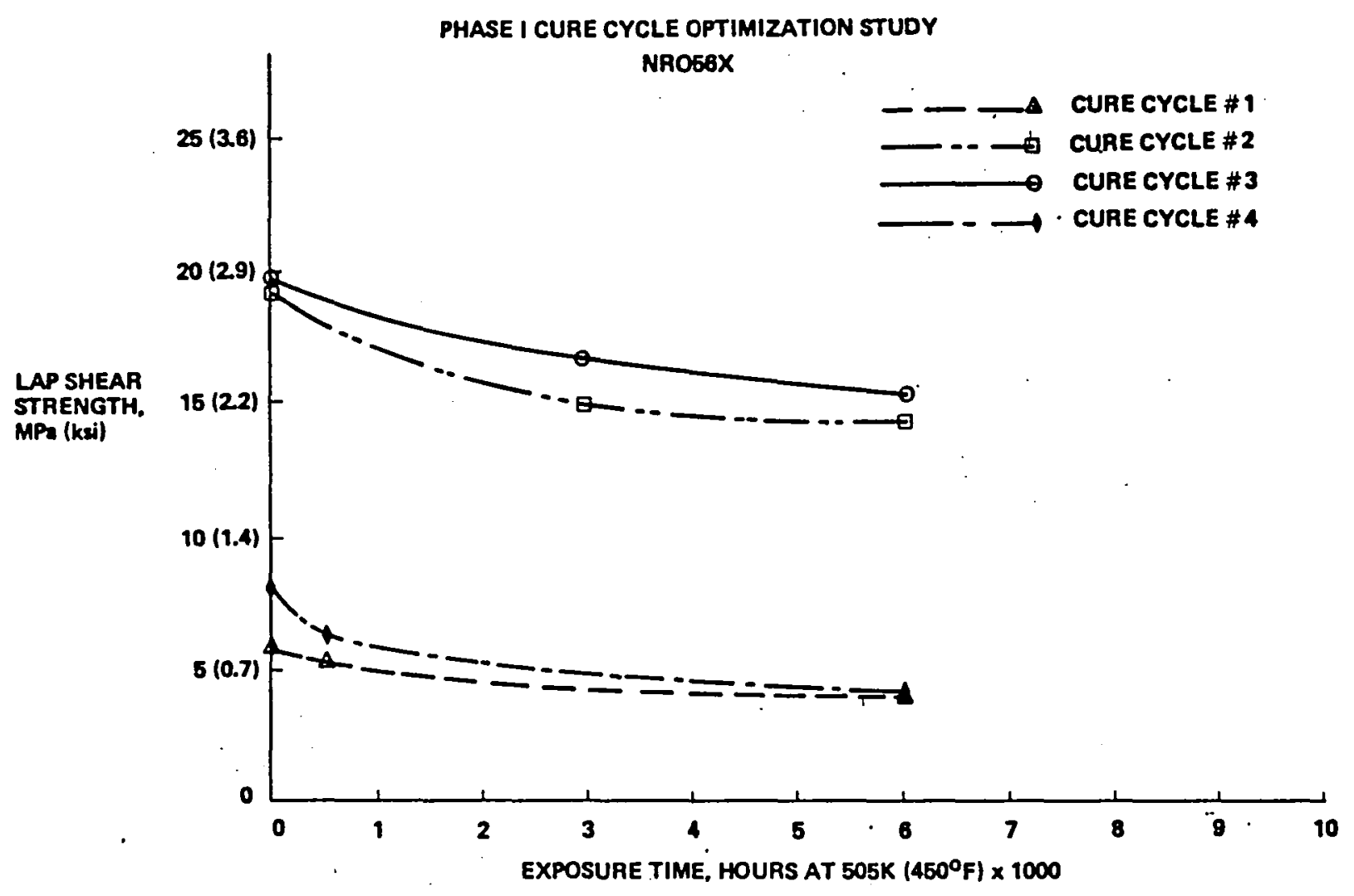

Figure 2.1.3-3: Effect of $505 \mathrm{~K}\left(450^{\circ} \mathrm{F}\right)$ Upon Adhesive Lap Shear 
4. Hold at $588 \mathrm{~K}(6000 \mathrm{~F})$ for 2 hours.

5. Cool to below $338 \mathrm{~K}(1500 \mathrm{~F})$ before releasing pressure.

6. Postcure 6 hours at $588 \mathrm{~K}\left(600^{\circ} \mathrm{F}\right)$.

Polyphenylquinoxaline (PPO) Cure Cycle \#1

1. Apply vacuum and $1.38 \mathrm{MPa}$ (200 psi) autoclave pressure.

2. Heat to $644 \mathrm{~K}\left(700^{\circ} \mathrm{F}\right)$ at $1.7-2.8 \mathrm{~K}\left(3-5^{\circ} \mathrm{F}\right) /$ minute.

3. Hold at $644 \mathrm{~K}\left(700^{\circ} \mathrm{F}\right)$ for 30 minutes.

4. Cool to below $338 \mathrm{~K}\left(150^{\circ} \mathrm{F}\right)$ before releasing pressure.

NR056X Cure Cycle \#2

1. Apply vacuum and $1.38 \mathrm{MPa}(200 \mathrm{psi})$ autoclave pressure.

2. Heat to $644 \mathrm{~K}\left(700^{\circ} \mathrm{F}\right)$ at $1.7-2.8 \mathrm{~K}(3-5 \circ \mathrm{F}) /$ minute.

3. Hold at $644 \mathrm{~K}\left(700^{\circ} \mathrm{F}\right)$ for 30 minutes.

4. Cool to below $338 \mathrm{~K}\left(150^{\circ} \mathrm{F}\right)$ before releasing pressure.

5. Postcure--none.

The cure cycle selected for LARC- 13 involving a $588 \mathrm{~K}\left(600^{\circ} \mathrm{F}\right)$ cure and postcure is considered the most suitable for producing a long term $505 \mathrm{~K}(450 \circ \mathrm{F})$ stable bond from this adhesive. This temperature strips away the thermally unstable portion of the polymer leaving an aromatic chain which should be relatively unaffected by $505 \mathrm{~K}\left(450^{\circ} \mathrm{F}\right)$.

The cure cycle for PPQ involving $644 \mathrm{~K}\left(700^{\circ} \mathrm{F}\right)$ for 30 minutes was selected over any of the others evaluated to minimize anticipated thermal degradation of the metal oxide/adhesive surface interface. Previous work in cure cycle evaluations and thermal exposure studies has produced lap bond adhesive failures which are suspected as originating at the oxide layer surface. A lower temperature of $644 \mathrm{~K}\left(700^{\circ} \mathrm{F}\right)$ did allow sufficient bond/flow of PPQ. As shown in the data tables specific to PPQ the $672 \mathrm{~K}$ $\left(750^{\circ} \mathrm{F}\right)$ cure for 60 minutes caused premature failure of the oxide in lap shear coupons.

Although NR050X can be processed at lower 588-616K $\left(600-650^{\circ} \mathrm{F}\right)$ temperatures, for small area bonds, special processing is required for large area bonds. The adhesive film is heated at $600^{\circ} \mathrm{F}$ prior to assembly. This reduces the volatile level to below 1 percent. Cure at $644 \mathrm{~K}\left(700^{\circ} \mathrm{F}\right)$ utilizes thermoplastic flow of the adhesive without volatile release-permitting structural wide area metal-to-metal bonds. Again, the $644 \mathrm{~K}\left(700^{\circ} \mathrm{F}\right) 30$ minute limitation is to reduce any possible thermal degradation of the oxide interface 
bond. These values reflect the partial adhesive failures encountered with higher cure temperature in cure cycles 1,3 , and 4 .

\subsubsection{1-Surface Treatment Study}

During the adhesive screening studies, much of the data indicated that titanium surface preparations may be sensitive to environmental degradation not apparent from data gathered at this stage of the program. To ensure as much data as possible relative to surface preparation, the base program was expanded in a "Surface Treatment Study" to determine long-range environmental effects. This portion of the program evaluated the long-term effects of $322 \mathrm{~K}(1200 \mathrm{~F}) / 95 \%$ relative humidity $(\mathrm{RH})$ and $505 \mathrm{~K}\left(450^{\circ} \mathrm{F}\right)$ thermal aging upon two different titanium surface treatments for each of the three primary adhesives. The titanium surface treatments evaluated were:

- LARC-13; 10-V chromic acid anodize (CAA) and Pasa-Jell

- PPQ; 5- and 10-V CAA

- NR056X; 10-V CAA and Pasa-Jell

The coupons remaining will fulfill the requirements for long-term $505 \mathrm{~K}\left(450^{\circ} \mathrm{F}\right)$ and $322 \mathrm{~K}$ $\left(120^{\circ} \mathrm{F}\right) / 95 \% \mathrm{RH}$ exposure requirements for Phase I. Coupons exposed to $322 \mathrm{~K}$. $\left(1200^{\circ} \mathrm{F}\right) / 95 \% \mathrm{RH}$ have been tested at 5000 hours. Coupons exposed to $505 \mathrm{~K}\left(450^{\circ} \mathrm{F}\right)$ have been tested at 10,000 hours.

Figures 2.3.2-1 through -12 illustrate the data obtained to 10,000 hours. Tables 2.3.2-A through $-\mathrm{N}$ list the summary value averages and individual test coupon values. (See Appendix.)

Analysis of LARC-13 Data. The $322 \mathrm{~K}\left(120^{\circ} \mathrm{F}\right) / 95 \% \mathrm{RH}$ data, shown in Figures 2.3.2-1 and 2.3.2-2 and as listed in Table 2.3.2-1 indicates that LARC-13 is unaffected by moisture to 5,000 hours. Ten volt chromic acid anodize shows some strength advantage over Pasa Jell.

Long term thermal exposure to $505 \mathrm{~K}\left(450^{\circ} \mathrm{F}\right)$ exhibited a change from cohesive to adhesive failure in lap shear between 5,000 and 10,000 hours. 


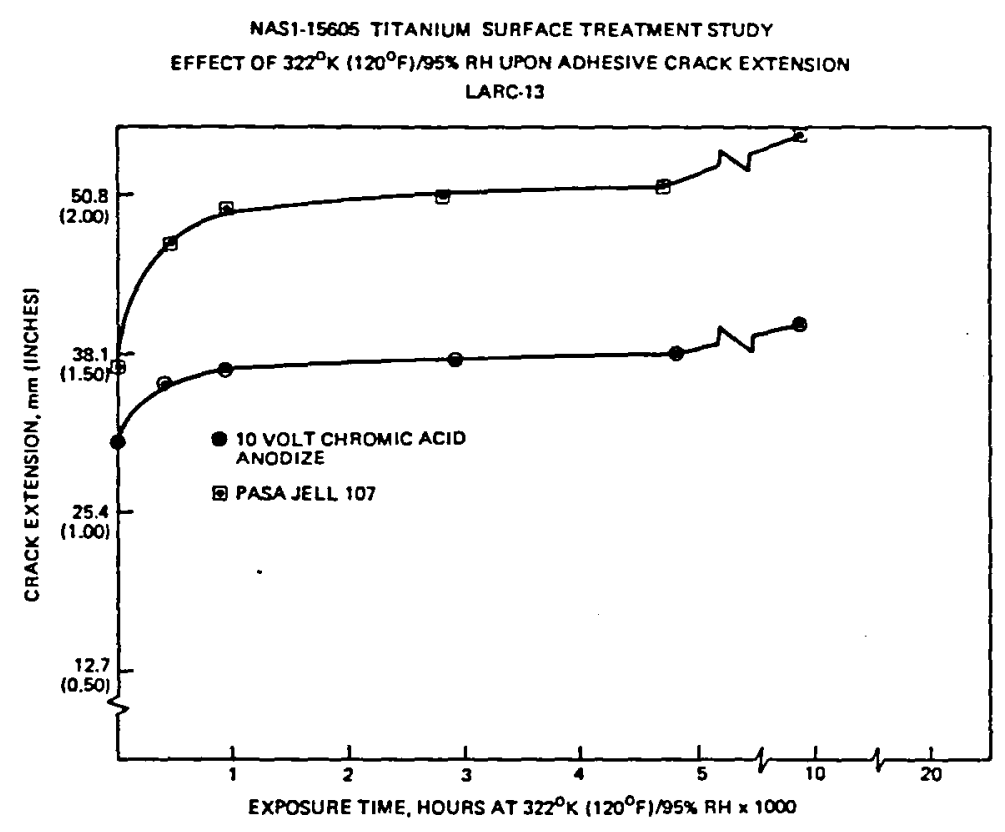

Figure 2.3.2-1

NASI-15605 SURFACE TREATMENT STUDY . EFFECT OF $505^{\circ} \mathrm{K}\left(450^{\circ} \mathrm{F}\right)$ EXPOSURE UPON ADHESIVE CAACK EXTENSION LARC-13

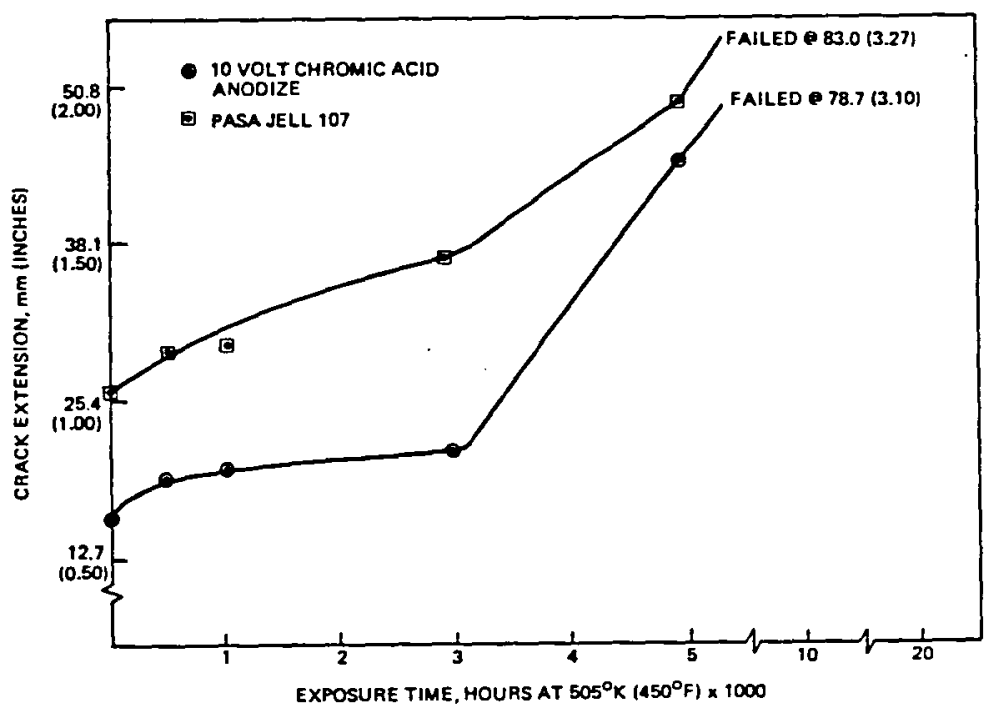

Figure 2.3.2-2 


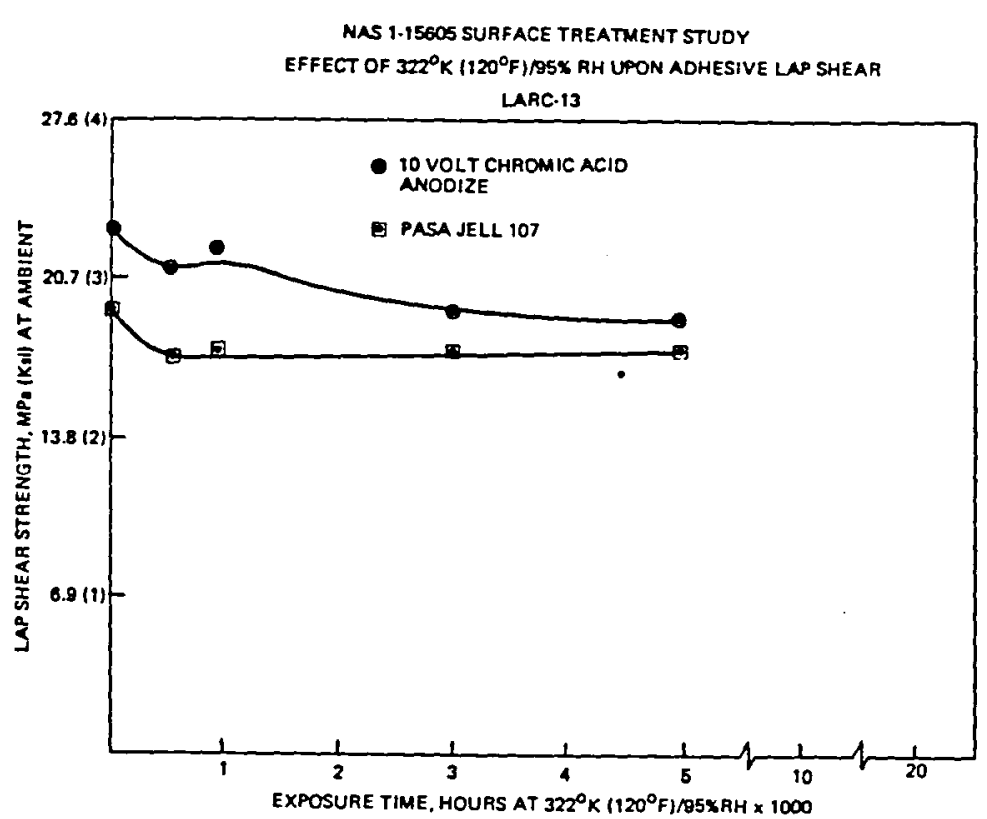

Figure 2.3.2-3

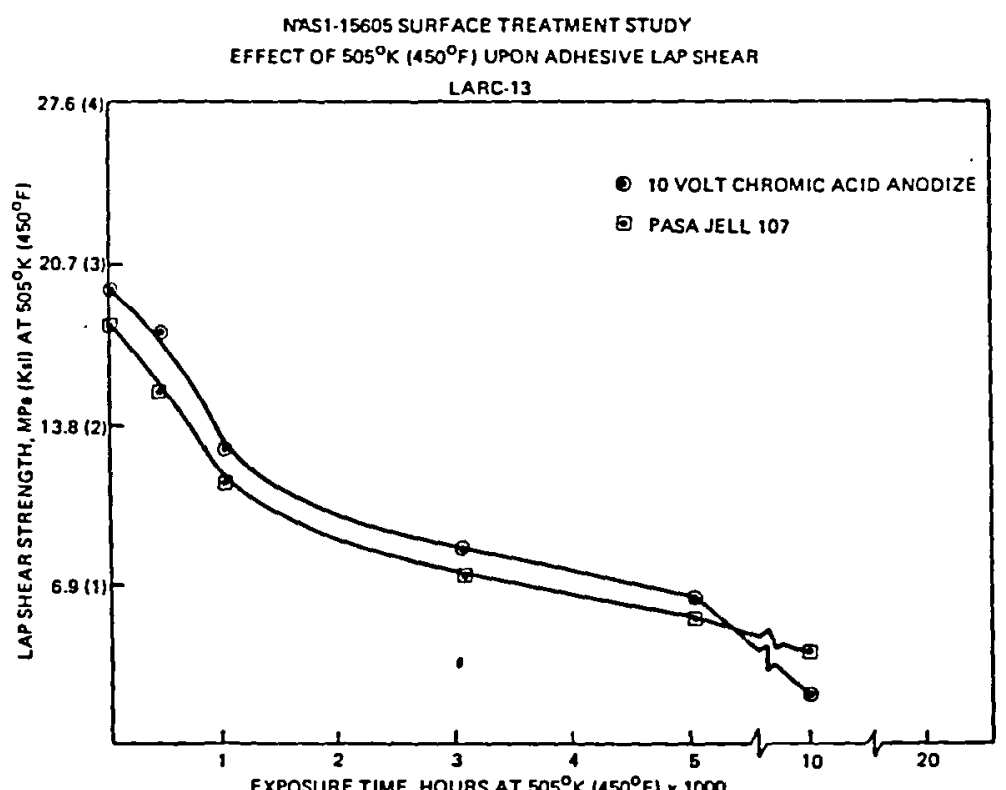

Figure 2.3.2-4 
NAS 1.15605 SURFACE TREATMENT STUDY

EFFECT OF $322^{\circ} \mathrm{K}\left(120^{\circ} \mathrm{F}\right) / 95 \times$ RH UPON AOHESIVE CRACK EXTENSION

NRO56X

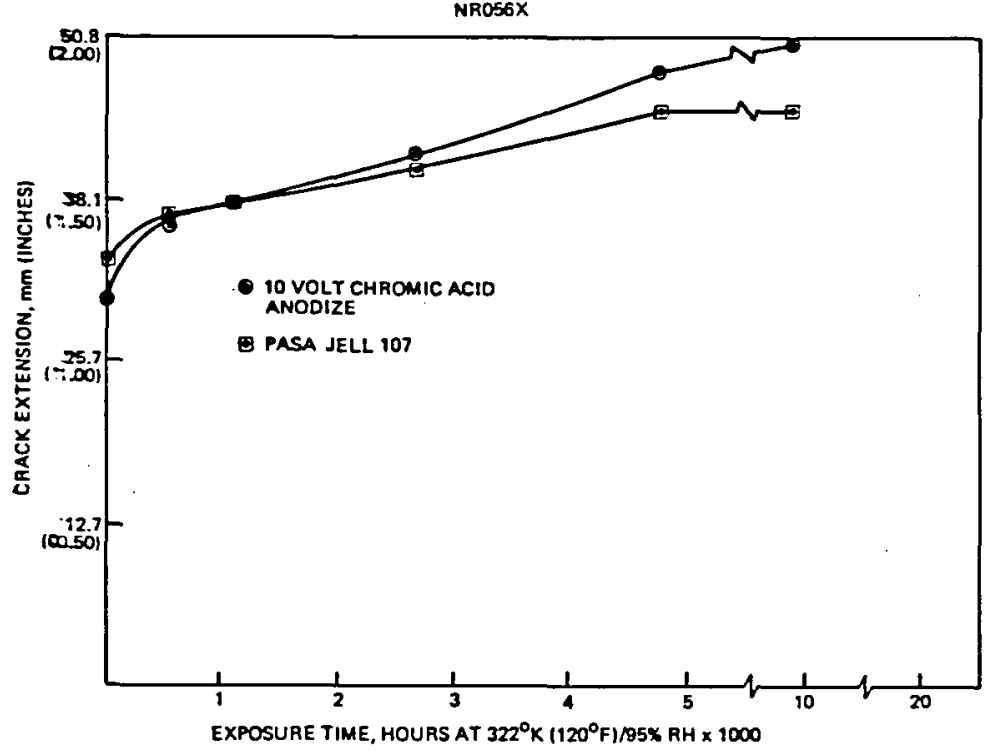

Figure 2.3.2-9

NAS1-15605 SURFACE TREATMENT STUDY

EFFECT OF $505^{\circ} \mathrm{K}\left(450^{\circ} \mathrm{F}\right)$ EXPOSURE UPON ADHESIVE CRACK EXTENSION NROS6X

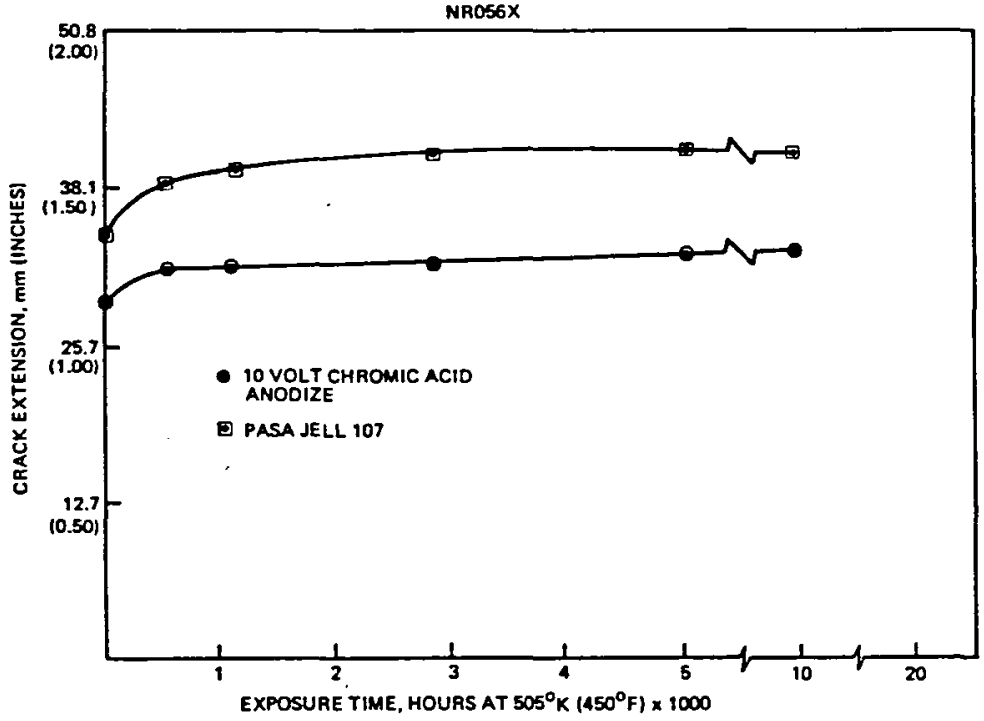

Figure 2.3.2-6 
NAS1.15605 SURFACE TREATMENT STUDY EFFECT OF $322^{\circ} \mathrm{K}\left(120^{\circ} \mathrm{F}\right) / 95 \%$ RH UPON ADHESIVE LAP SHEAR NRO56X

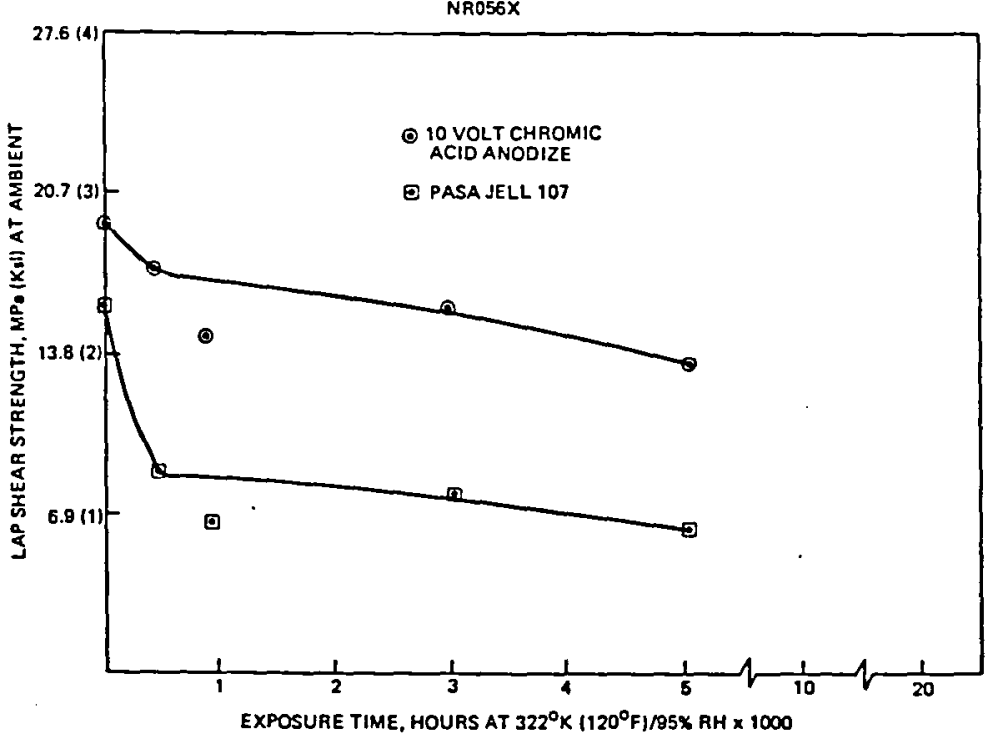

Figure 2.3.2-7

NAS1.15605 SURFACE TREATMENT STUDY EFFECT OF $505^{\circ} \mathrm{K}\left(450^{\circ} \mathrm{F}\right)$ UPON ADHESIVE LAP SHEAP NROS6X

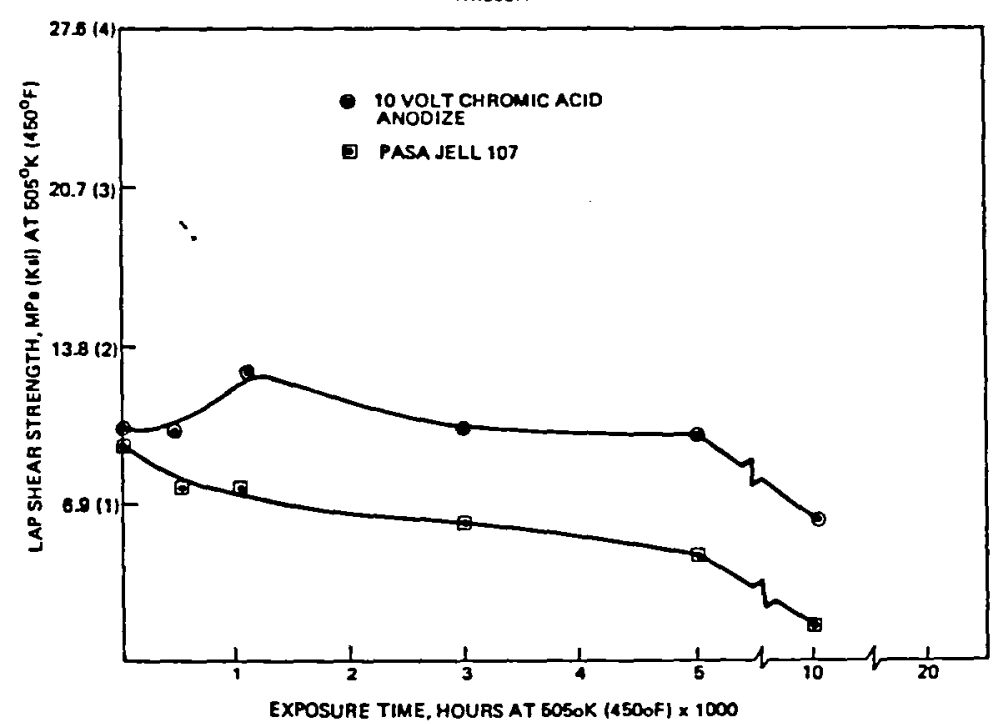

Figure 2.3.2-8 
NAS1-15605 SUAFACE TREATMENT STUOY

EFFECT OF $322^{\circ} \mathrm{K}\left(120^{\circ} \mathrm{F}\right) / 95 \%$ RH UPON ADHESIVE CRACK EXTENSION POLYPHENYLQUINOXALINE

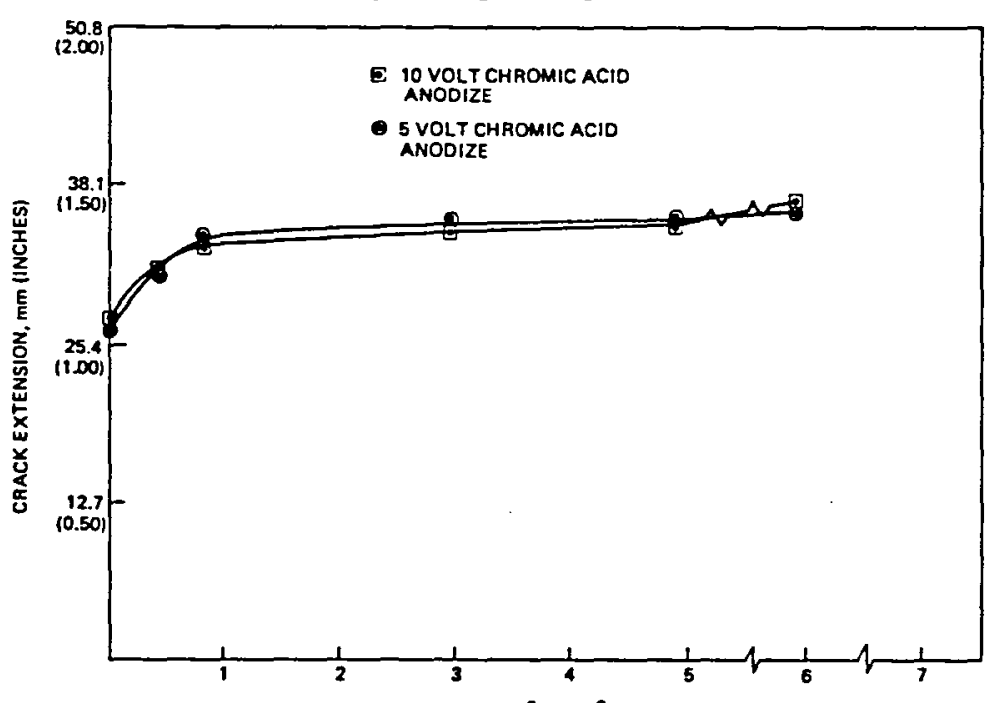

EXPOSURE TIME, HOURS AT $322^{\circ} \mathrm{K}\left(120^{\circ} \mathrm{F}\right) / 85 \times$ RH $\times 1000$

Figure 2.3.2-9

NAS1.1560S SURFACE TREATMENT STUDY EFFECT OF $505^{\circ} \mathrm{K}\left(460^{\circ} \mathrm{F}\right)$ EXPOSURE UPON ADHESIVE CRACK EXTENSION POLYPHENYLOUINOXALINE

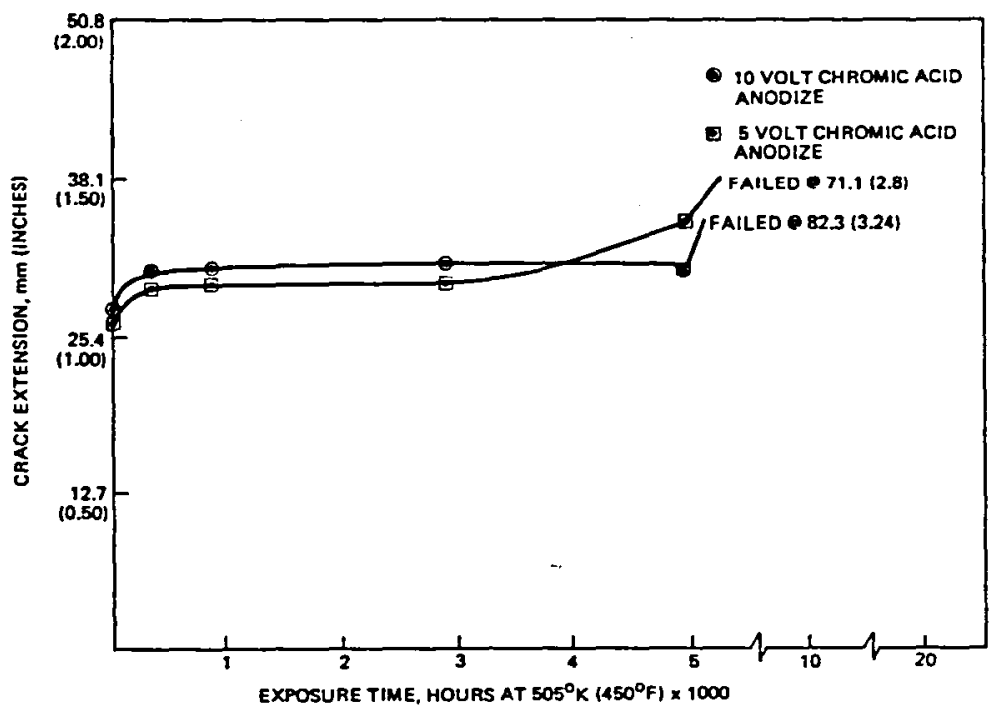

Figure 2.3.2-10 
NAS1-15605 SURFACE TREATMENT STUOY

EFFECT OF $322 \mathrm{~K}\left(120^{\circ} \mathrm{F}\right) / 95 \times$ RH UPON ADHESIVE LAP SHEAR POLYPHENYLOUINOXALINE
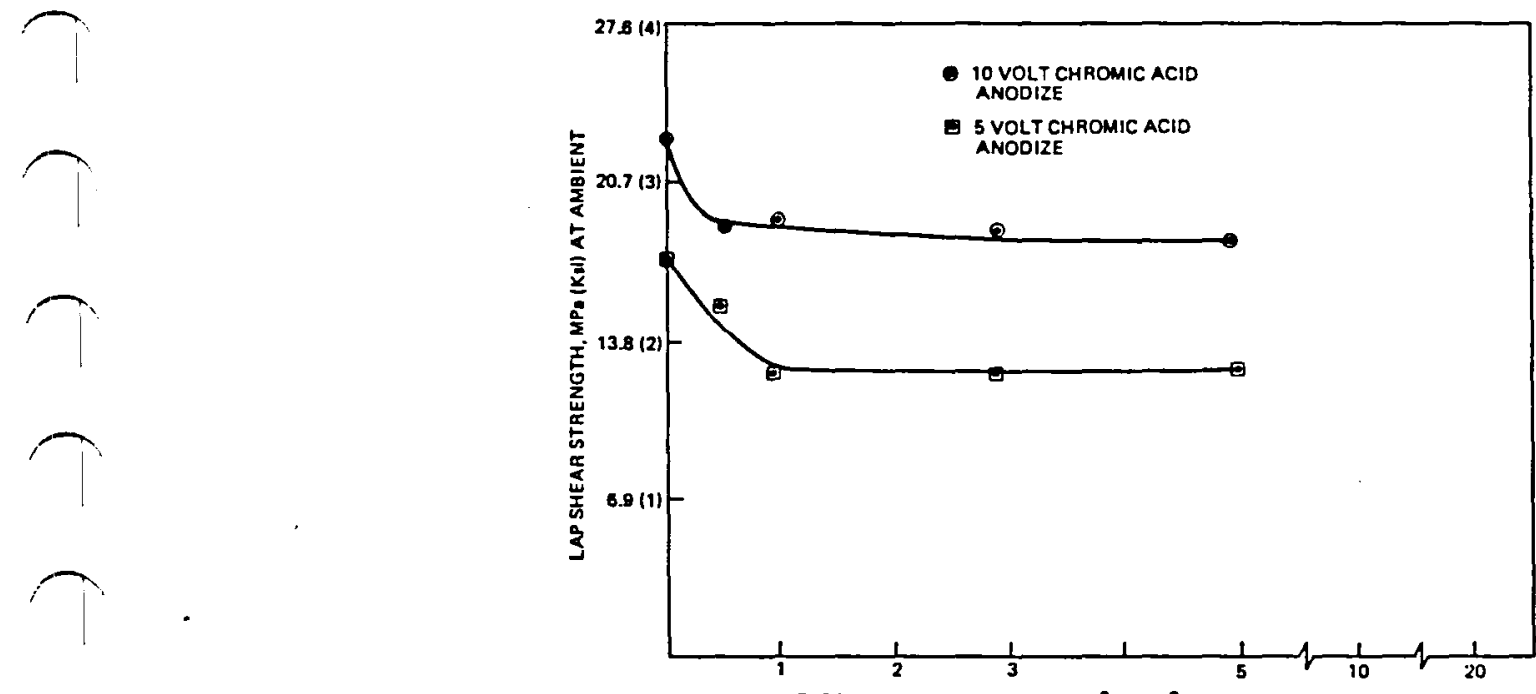

EXPOSURE TIME, hOUAS AT $322^{\circ} \mathrm{K}\left(120^{\circ} \mathrm{F}\right) / 95 \times R H \times 1000$

Figure 2.3.2-11

NAS1.15605 SURFACE TREATMENT STUDY EFFECT OF $505^{\circ} \mathrm{K}\left(450^{\circ} \mathrm{F}\right)$ UPON ADHESIVE LAP SHEAR POLYPHENYLQUINOXALINE

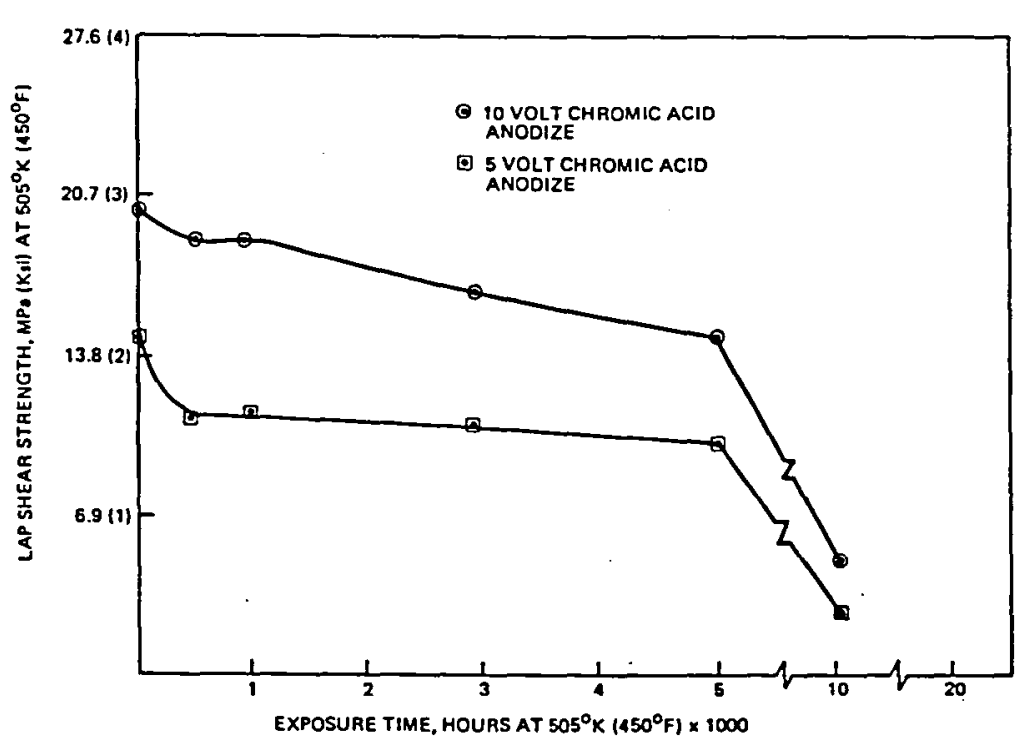

FIgüre 2.3.2-12 
LARC-13 experienced a relatively rapid drop in shear properties at $505 \mathrm{~K}(4500 \mathrm{~F})$ from the initiation of exposure. These test results were the major factor for concluding that this resin is not stable at $505 \mathrm{~K}(450 \circ \mathrm{F})$ and would not meet the long term 20,000 hour strength objectives of the program. The fact that adhesive bond failures occurred between 5,000 and 10,000 hours did not influence the overall decision that LARC-13 was no longer considered for the $505 \mathrm{~K}\left(450^{\circ} \mathrm{F}\right)$ portion of this study.

Analysis of NR056X Data. Long term 322K (120\% F)/95\% RH had slight effect upon crack growth in crack extension coupons (Figure 2.3.2-5). Exposure to $505 \mathrm{~K}(450 \circ \mathrm{F})$ had no effect upon crack extension (Figure 2.3.2-6), however, lap shear (Figure 2.3.2-8) dropped to very low values. Chromic acid anodize was clearly the superior surface treatment when compared to Pasa Jell. As shown in Figure 2.3.2-8, the shear strength at 10,000 hours are far too low to be considered structural, especially since one of the objectives was to retain about 2,000 psi to 20,000 hours. Since DuPont has withdrawn this product from the market, NR056X was withdrawn from further testing in this program.

Analysis of PPQ Data. As the long term exposure to both $322 \mathrm{~K}$ (1200F)/95\% RH (Figure 2.3.2-11) and $505 \mathrm{~K}\left(450^{\circ} \mathrm{F}\right)$ (Figure 2.3.2-12) progressed it seemed that PPQ could possibly meet the 20,000 hour thermal stability requirements. Moisture exposure to 5,000 hours had little or no effect upon crack extension on lap shear strength and $505 \mathrm{~K}\left(450^{\circ} \mathrm{F}\right)$ data to 5,000 hours was very good. However, the 10,000 hour values were very poor. Specimen failure changed from cohesive at 5,000 hours to $100 \%$ adhesive at 10,000 hours. The almost uniform failure of the three adhesive systems at 10,000 hour $505 \mathrm{~K}\left(450^{\circ} \mathrm{F}\right)$ exposure presents a serious barrier to achieving desired structural bonds at 20,000 hours exposure for these adhesive systems. Apparently the resin stability exhibited by PPQ (for instance) cannot be adequately demonstrated as long as the potential for failure of the structural bond exists.

Detailed discussion of the titanium surface structure created by various surface treatments and possible causes for failure in the anodize oxide when exposed to high temperature is presented in Section 2.4 . 


\section{$\rightarrow \rightarrow \rightarrow \rightarrow \rightarrow \rightarrow \rightarrow \rightarrow \rightarrow-\rightarrow \rightarrow-1$}

Table 2.3.1-1

Summary of Cure Cycle Effects on Lap Shear Strength

\begin{tabular}{|c|c|c|c|c|c|c|c|c|c|}
\hline \multirow[b]{2}{*}{$\begin{array}{l}\text { Adhesive } \\
\text { System }\end{array}$} & \multirow[b]{2}{*}{ Cure } & \multicolumn{4}{|c|}{ Initial Values, $\mathrm{MPa}(\mathrm{psi}) \underline{1 /}$} & \multicolumn{4}{|c|}{$450^{\circ} \mathrm{F}$ Aging Values, $\mathrm{MPa}$ (psi) $1 /$} \\
\hline & & $\mathrm{RT}$ & $-65^{\circ} \mathrm{F}$ & $+450^{\circ} \mathrm{F}$ & $100 \mathrm{Hr}$ & $300 \mathrm{Hr}$ & $500 \mathrm{Hr}$ & $3,000 \mathrm{Hr}$ & $6,000 \mathrm{Hr}$ \\
\hline \multirow[t]{4}{*}{ LARC-13 } & 1 & $22.3(3235)$ & $23.3(3380)$ & $16.7(2420)$ & $18.6(2695)$ & $16.6(2400)$ & $18.9(2740)$ & -- & $4.8(620)$ \\
\hline & 2 & $20.5(2970)$ & $20.1(2920)$ & $16.4(2380)$ & -- & -- & -- & $9.3(1,350)$ & $7.2(1050)$ \\
\hline & 3 & $23.0(3340)$ & $23.6(3420)$ & $18.3(2650)$ & -- & -- & -- & $10.4(1,510)$ & $8.2(1185)$ \\
\hline & 4 & $22.1(3200)$ & $23.3(3380)$ & $18.6(2690)$ & $17.4(2520)$ & $16.2(2355)$ & $18.1(2630)$ & -- & $5.0 \quad(720)$ \\
\hline \multirow{4}{*}{ PPQ } & 1 & $15.8(2290)$ & $19.0(2755)$ & $14.9(2165)$ & $15.3(2215)$ & $15.3(2225)$ & $15.8(2340)$ & -- & $13.0(1890)$ \\
\hline & 2 & $28.1(4080)$ & $31.6(4580)$ & $20.1(2930)$ & -- & -- & -- & $20.6(2,990)$ & $19.4(2820)$ \\
\hline & 3 & $24.5(3550)$ & $29.1(4225)$ & $20.5(2970)$ & $15.8(2290)$ & $15.9(2310)$ & $17.8(2575)$ & -- & $11.1(1610)$ \\
\hline & 4 & $\underline{2 I}$ & $\underline{21}$ & $\underline{21}$ & $\underline{21}$ & 21 & $\underline{21}$ & & \\
\hline \multirow[t]{4}{*}{ NR056X } & 1 & $8.1(1180)$ & $10.0(1450)$ & $5.7 \quad(830)$ & $6.2 \quad(905)$ & $6.4 \quad(930)$ & $5.4 \quad(780)$ & -- & $5.6(810)$ \\
\hline & 2 & $21.0(3050)$ & $22.8(3300)$ & $18.6(2690)$ & -- & -- & -- & $15.3(2,220)$ & $14.7(2130)$ \\
\hline & 3 & $13.2(1210)$ & $13.6(1970)$ & $19.4(2820)$ & -- & -- & -- & $17.2(2,490)$ & $5.7(2275)$ \\
\hline & 4 & $8.3(1210)$ & $12.3(1790)$ & $7.5(1090)$ & $8.1(1170)$ & $9.3(1350)$ & $6.0 \quad(870)$ & -- & $5.7 \quad(824)$ \\
\hline
\end{tabular}




\subsection{SURFACE CHARACTERIZATION AND FAILURE ANALYSIS}

\subsubsection{Introduction}

A variety of analytical techniques was available for characterization of adherend surfaces and failure analysis of bonded coupons. These techniques included electron microscopy and surface analysis; they will be described at the beginning of this section.

The analytical techniques were first applied to characterization of adherend surfaces: Phosphoric Acid Anodize (PAA): Pasa-Jell 107: Phosphate fluoride (Boeing Specification BAC 5514): Phosphate fluoride (Picatinny modified): Turco 5578 and Chromic Acid Anodize (CAA). Surface properties were correlated with lap-shear strengths.

Adhesive lap-shear coupons discussed in section 2.3.2 were aged for up to 10,000 hours at $505 \mathrm{~K}\left(450^{\circ} \mathrm{F}\right)$. Of the specimens examined, two adhesives (PPQ and LARC-13) changed from an adhesive failure mode at 5,000 hours aging to an adhesive failure mode after 10,000 hours. Four systems were subjected to detailed failure analysis: PPQ on 10VCAA and 5V CAA: LARC-13 on 1OVCAA and Pasa-Jell. The results of these analyses are described in detail.

\subsubsection{Analytical Techniques}

Details of the surface chemical analysis and electron microscopy techniques follow.

\subsubsection{Microscopy/In-Situ SEM-STEM}

Superior secondary electron micrographs were obtained on a scanning transmission electron microscope (STEM), using it as a high-resolution scanning electron microscope (SEM). While the mechanics of beam rastering and synchronous cathode ray tube displays are the same for the SEM and the STEM, there are distinct advantages to STEM over SEM, as well as severe disadvantages as described below. Rather than attempt to explain all the aspects of STEM versus SEM, attention will be given to the differences in secondary electron detection as they relate to spatial resolution. 


\section{ELECTRON-SCATTERING RESTRICTIONS}

The electron-scattering processes restricting ultimate resolution are the same for an SEM and for an STEM operating as an SEM. Therefore, the restrictions on resolution are the same for both systems due to electron-scattering effects.

\section{SIGNAL-TO-NOISE RATIO (SNR)}

SNR in an STEM can be improved dramatically over that in an SEM because of the electromagnetic fields around the specimens. Figure 2.4.2-1 shows schematically how secondary electrons are collected for image forming. Figure 2.4.2-1a illustrates the process for an SEM in which a secondary electron detector collects a small solid angle of the hemisphere of secondary electrons emitted.

Figure 2.4.2-1b illustrates the process of secondary electron collection in an STEM in which the lens field forces the secondary electrons up the column around the primary beam. This results in capture of a higher percentage of the secondary electrons than is possible in an SEM. The STEM is estimated to detect 10 times as many secondary electrons as a conventional SEM.

\section{LENS ABERRATIONS}

The chromatic and spherical aberration coefficients are reduced by factors of 3 to 4 in the STEM lens system. This occurs because the specimen is immersed inside the lens electromagnetic field in an STEM; in an SEM, the specimen must be outside the lens field. Thus, a finer probe can be focused on the specimen in an STEM for higher resolution.

\section{DISADVANTAGES OF STEM COMPARED TO SEM}

There are significant disadvantages in an STEM in terms of specimen handling and size restrictions.

For specimen handling, the geometry of the specimen holder usually restricts the tilt and rotation capabilities of stages. Certain views of a specimen may require removal and remounting of the specimen. This is a very serious restriction for imaging in the $50,000 \mathrm{x}$ 
magnification range, because the operator may not be able to find the same area in which the original feature was seen.

Specimen size is restricted in an STEM; a typical specimen must be no larger than 0.63 $\mathrm{cm}(0.25 \mathrm{in}$.$) in diameter and 0.32 \mathrm{~cm}(0.125 \mathrm{in}$.$) in height. These dimensions allow for$ little or no sample motion, so much smaller specimens are usually needed. This poses a problem for analysis of fracture faces, which often are much larger and require significant specimen translation and rotation.

Specialized studies using, for instance, tensile stages or voltage contrast of circuits often cannot be performed in an STEM due to the space restriction. The SEM, on the other hand, has sufficient room inside the chamber to allow these types of experiments.

\section{SUMMARY}

The STEM instrument operating in a secondary electron capture mode can give higher resolution micrographs because of (1) higher SNR due to the position of the specimen in the electromagnetic lens field, and (2) lower lens aberrations encountered in the STEM column design.

Disadvantages of the STEM instrument lie in the areas of restricted sample manipulation and the difficulty of preparing specimens of sufficiently small size to permit analysis.

One method of specimen preparation for both SEM and STEM analysis is illustrated in Figure 2.4.2-2. The specimen is lab-fractured to provide a profile view of oxide thickness and through-thickness morphology. Three-dimensional modeling of microstructure is thus possible when related to plan-view morphology.

Both plan-view and through-thickness fracture preparations require the application of a conductive coating. Boeing has developed coating techniques that result in magnifications in excess of $100,000 \times$ before coating artifacts become apparent. This involves the vapor-deposition of approximately $50 \mathrm{~A}$ of $\mathrm{Au} / \mathrm{Pd}$. The coating improves resolution both by conducting away any change accumulation from the area of incidence of the electron beam, and by reducing the volume of specimen generating the secondary electron signal. 
A JEOL JEM $100 \mathrm{C}$ belonging to the University of Washington was used by Boeing personnel. Also available on the instrument is an energy-dispersive X-ray elemental analysis (EDX) capability. EDX was used with the STEM in the transmission electron microscope (TEM) mode, for analysis of thin sections. Thin sections ( $\sim 50 \mathrm{~nm}$ thick) were cut on a Sorval MT2B ultramicrotome using a 550 diamond knife. EDX analysis of a thin section gives a detection limit of 1:10,000 for elements of atomic number $\geqslant 11$.

\subsubsection{Surface Analysis}

Surface chemical compositions were evaluated using two techniques: (1) Auger electron spectroscopy (AES), and (2) X-ray photoelectron spectroscopy, commonly referred to as electron spectroscopy for chemical analysis (ESCA). The technique will be referred to as ESCA in this report. Both techniques were performed in the same instrument, a Physical Electronics ESCA-SAM Spectrometer, Model 550.

\section{ESCA}

ESCA is based upon the detection of electron emission when a sample is irradiated by Xrays, in this case, magnesium $K_{\alpha} X$-rays. Since ESCA is an electron spectroscopy technique, its surface sensitivity derives from the short mean free path of electrons in a solid; approximately 10 to $50 \AA$ for an oxide. The advantage of ESCA is that it can be used for analysis of polymers as well as oxides, and so was used to evaluate the failure locus in mechanically tested specimens. (The spatial resolution of ESCA is approximately $4 \mathrm{~mm}^{2}$ ). ESCA is very sensitive to the chemical bonding state of the elements present. It provides a powerful method to identify chemical species on the adherend surface or on the surface of failed mechanical specimens.

\section{AES}

AES is based upon the electronic process of de-excitation, which produces an energetic electron, rather than the competing process of X-ray emission. In AES, the material is excited by impinging a focused electron beam upon the sample, creating an inner shell vacancy. The subsequent de-excitation by electron emission is the more probable event for the low atomic number elements present in the titanium samples. The focused electron beam allows some lateral definition with a resolution of 7 to $10 \mu \mathrm{m}$. The surface sensitivity of AES is the result of the maximum escape depth of the electrons emitted 
from the surface, which is 10 to $50 \AA$. Each element present on the surface will emit a characteristic energy pattern of Auger electrons, and so is the basis of identification. There are some overlap problems in identifications that result when the element is present at very low levels and only the major Auger line can be detected. Specific problems with resolution in this study include the element pairs chromium and oxygen, zinc and sodium.

The AES peak-to-peak heights are the basis for the quantitative data included in this report. The data is normalized for elemental sensitivity and reported as atom percent (i.e., number of atoms of element detected/total number of atoms detected). These data are included as a means of comparison between samples and are not absolute.

AES can be combined with argon ion beam sputtering to remove material from the surface. The computer monitors the Auger peak amplitudes as the material is removed, and plots of composition versus sputter time are obtained.

The technique of AES profiling was reported for each of the surface preparations in the third semi-annual progress report (May 1980). Profiles such as Figure 2.4.2-3 for 10VCAA showed a number of spurious peaks which do not indicate peaks in elemental concentration. Such profile plots are useful only to determine the relative $\mathrm{Ti}$ and $\mathrm{O}$ concentrations, and to give an indication of the oxide depth. By calibrating the sputtering rate to a known thickness of titanium oxide, an approximate depth scale can be obtained. Although such measurements always gave higher oxide depths than obtained from STEM micrographs, for oxides which were photographed in plan view only, the AES profile provided the only depth measurement available. The AES profiles were all recorded prior to May 1980, and since then the software on the spectrometer has been changed. These AES profiles have not been included in this report, since they are now considered to have minimal significance. They are, however, available in the Appendix, for the benefit of readers who wish to view them.

\subsubsection{Transmission Electron Microscopy (TEM)}

The TEM is the most definitive technique for the investigation of primer penetration into the oxide layer. The ultramicrotome is an instrument on which thin sections of materials can be cut, suitable for imaging by TEM. For a metal, this thickness is approximately $500 \AA$. The sections are cut with a 55-deg cutting angle diamond knife. The properties of 
the specimen block will affect the quality of the sections that result. In all sections, artifacts will be present as an inherent result of the forces experienced by the specimen during sectioning. Titanium was found to be a difficult material to section, resulting in significant sectioning artifacts. Sections were mounted on grids and examined in the TEM for ultrastructure and degree of primer penetration.

Sections were cut on a Sorvall MT2B ultramicrotome belonging to the University of Washington, operated by Boeing personnel. Sections were analyzed in a Phillips TEM 300 microscope, belonging to Boeing.

\subsubsection{Technical Discussion}

The analytical techniques described in section $\mathbf{2 . 4 . 2}$ were used for characterization of adherend surfaces and failure analysis of selected lap-shear fracture specimens.

\section{MORPHOLOGY}

The microstructure of the adherend oxide surface contributes to the adhesive bond by presenting more or less surface area for polymeric/oxide bonding. The degree to which the polymer can penetrate the oxide will influence the mechanical stability of the oxide/polymer bond. SEM and STEM techniques were used to evaluate the morphological aspects of the bare oxides, as well as the interaction of the bonded polymer/oxide. SEM was used for imaging the bare oxide for gross morphological features such as etch pits or contaminant particles. STEM was used for the evaluation of the ultrastructure of the oxide revealing such features as porosity, oxide cell structure, and overall integrity.

The penetration of the polymer into the oxide layer was also examined by TEM analysis of microtomed thin sections.

\section{COMPOSITION}

The surface chemistry of the adherend oxide influences the degree of chemical bonding between the polymer and oxide. The presence of contaminants on the top oxide surface can interfere with the chemical bond and/or provide a mechanically weak layer at the polymer/oxide interface. Both AES and ESCA provide a sensitive way of observing the 
chemical state of the titanium oxide at the surface and the extent of contamination at the surface.

ESCA was also used to evaluate the disbonded surfaces of mechanical test specimens to see if there was a chemical segregating layer at the disbonded surfaces, which would contribute to a mechanically weak layer. ESCA was also used to determine if the disbond was adhesive or cohesive.

To check the chemical purity of the titanium oxide throughout its thickness, AES sputter profiling was used. In this way, a chemically segregating layer within the oxide could be identified.

Characterization of the adherend surface and the adherend/primer interface under the influence of process variation and environmental exposure contributed to the understanding of the bonding mechanisms.

Chemical and morphological characterizations were performed on oxides, primers, and adhesives as a function of pretreatment, anodizing technique, and thermal exposure. The ultrastructure of the oxides and the interfaces between oxide, primer, and adhesive were studied and correlated with microchemical analytical data.

Also examined were chemical variations in the oxide as a function of post-treatment storage conditions prior to analysis, with emphasis on hydration occurring from variations in humidity and length of delay before analysis.

\subsubsection{Analytical Results}

\section{BASELINE STUDIES-OXIDE STORAGE}

Three samples were compared using ESCA. The first sample, 10V CAA, from a relatively "old bath" solution, was analyzed shortly after anodization. The second sample, 10V CAA, "old bath," high humidity, examined the effect of hydration. The third sample, 10V CAA, from a freshly prepared "new bath," was examined to check bath-to-bath variations. Results on the storage effects of the chromic acid anodize oxide are summarized in Tables 2.4.4-1 and 2.4.4-2. 
The major feature is the high level of organic contamination on the surface. The $10 \mathrm{~V}$ CAA, "old bath" sample shows the highest carbon level. The oxygen/titanium ratio for this sample was much lower than for the other two samples. A higher organic contamination level could account for this decrease. The aluminum level was found to be constant from sample to sample, while the fluorine and chromium levels fluctuated.

Morphological and compositional studies were performed on each of the surface preparations. These are described in the following sections 2.4.4.1 through 2.4.4.6.

\subsubsection{Phosphoric Acid Anodize (PAA) Treatment}

\section{PROCESS/ENVIRONMENTAL VARIABLES}

Phosphoric acid anodize (PAA) treatment was preceded by nitric/hydrofluoric acid pickle. The anodization was performed at 5 Volts. Additional hydrofluoric acid was added to the bath to control the current density. There was no thermal exposure.

\section{MORPHOLOGY}

The plan views at low magnification (figs. 2.4.4-1a and -1 b) show a surface dominated by scalloped features and pitting. At higher magnification (fig. 2.4.4-1c), the fine details on the surface indicate an open pore structure. The overall impression is of a uniform oxide film.

The profile view (figs. 2.4.4-2a and $-2 b$ ) indicates that the PAA oxide has an open pore structure. The oxide is well-organized and of uniform thickness. The thickness measured by SEM is $600 \mathrm{~A}$.

\section{COMPOSITION}

The oxide thickness measured by sputtering was $760 \AA$. The AES presputter survey showed phosphorus, carbon, calcium and copper (fig. 2.4.4-3). These nonmatrix elements were detected exclusively at the surface. The intermediate AES survey (fig. 2.4.4-4) showed the fluorine concentration decreasing from the surface value (fig. 2.4.4-3) through the intermediate level. The aluminum level in the oxide appeared lower than in the metal 
substrate. Vanadium was not detected at the surface (fig. 2.4.4-3) or within the oxide (fig. 2.4.4-4).

\subsubsection{Pasa-Jell 107 Treatment}

\section{PROCESS/ENVIRONMENTAL VARIABLES}

Pasa-Jell 107 treatment is an electroless immersion. It was preceded by a Turco alkaline pre-etch treatment. There was no thermal exposure.

\section{MORPHOLOGY}

The plan views at low magnification (figs. 2.4.4-5a and $-5 \mathrm{~b}$ ) show an oxide surface that is rough and disorganized. The predominant feature is the scalloping. Many surface particles are visible. At high magnification (fig. $2.4 .4-5 \mathrm{c}$ ), the oxide surface appears smooth with a scattering of very small particles.

The profile views (figs. 2.4.4-6a and $6 \mathrm{~b}$ ) show two phases. The first phase is randomly distributed and approximately $400 \mathrm{~A}$ thick. It has the appearance of contaminant particles. It does, however, have the composition of titanium oxide and is not a contaminant. The second phase is more smooth and continuous. It is less than $100 \AA$ thick.

\section{COMPOSITION}

The Pasa-Jell 107 process produced a $220 \AA$ thick oxide as measured by sputtering. The titanium oxide layer (fig. 2.4.4-7) incorporated fluorine and aluminum. Elements that appeared on the surface only were sulfur, chlorine, potassium, calcium, carbon, chromium, sodium, and silicon. Vanadium was not detected on the surface (fig. 2.4.4-7), but was observed (fig. 2.4.4-8) as the oxide/metal interface was reached.

\subsubsection{Phosphate Fluoride (Boeing Process, BAC 5514)}

\section{PROCESS/ENVIRONMENTAL VARIABLES}

Phosphate fluoride is an electroless immersion treatment. It was preceded by a nitric/hydrofluoric acid pickling step. There was no thermal exposure. 


\section{MORPHOLOGY}

The phosphate fluoride (BAC 5514) oxide in plan view at low magnification (figs. 2.4.4-9a and -9b) shows a typical scalloping with a fair amount of particulate present. The highmagnification photo (fig. 2.4.4-9c) indicates that the oxide layer is highly irregular.

\section{COMPOSITION}

Vanadium was not detected in the surface (fig. 2.4.4-10) or at an intermediate depth (fig. 2.4.4-11) in the oxide. Elements that were present on the surface only were chromium, sodium, chlorine, calcium, and carbon.

\subsubsection{Phosphate Fluoride (Picatinny Modified)}

\section{PROCESS/ENVIRONMENTAL VARIABLES}

The phosphate fluoride (Picatinny modified) is an electroless immersion. It was preceded by a nitric/hydrofluoric acid pickling step. There was no thermal exposure.

\section{MORPHOLOGY}

The phosphate fluoride (Picatinny modified) treatment in plan view at low magnification (figs. 2.4.4-12a and -12b) shows scalloping. The high-magnification micrograph (fig. 2.4.412c) shows a relatively smooth oxide.

\section{COMPOSITION}

The phosphate fluoride (Picatinny modified) treatment produced a $230^{\circ} \AA$ thick oxide, as measured by sputtering. Elements that appeared on the surface only were sodium, chromium, carbon, calcium, and chlorine (fig. 2.4.4-13). The intermediate AES survey showed the titanium oxide to contain fluoride, aluminum and a trace of copper (fig. 2.4.4-14). Vanadium was not on the surface (fig. 2.4.3-13), but did appear as the metal was reached. Aluminum also increased to alloy levels as the metal was reached. 


\subsubsection{Turco 5578 Treatment}

\section{PROCESS/ENVIRONMENTAL VARIABLES}

The Turco 5578 treatment is a hot alkaline immersion that is used as a pretreatment step before chromic acid anodizing. There was no thermal exposure. AES was performed on a second Turco sample that will be referred to as having a "mottled appearance."

\section{MORPHOLOGY}

The Turco 5578 treatment in plan view at low magnification (figs. 2.4.4-15a and -15b) shows a large amount of etching. The high-magnification photo (fig. 2.4.4-15) shows the details of the etching, plus a closeup of the particles that clustered along the ridges.

\section{COMPOSITION}

The Turco oxide was $600 \AA$ thick as measured by sputtering. The titanium oxide layer also included significant amounts of iron and copper (fig. 2.4.4-16). No fluorine was detected. Aluminum and vanadium were not detected until the metal/oxide interface was reached (fig. 2.4.4-17). The surface also had sulfur, chlorine, and carbon on it.

The Turco sample with mottled appearance was similar, except for the lack of iron (fig. 2.4.4-18).

\subsubsection{Chromic Acid Anodize (CAA)}

\section{PROCESS/ENVIRONMENTAL VARIABLES}

The CAA process was preceded by a Turco pre-etch. Hydrofluoric acid was added to the bath for control of the current density. Two voltage conditions were examined, $5 \mathrm{~V}$ and $10 \mathrm{~V}$. Two bath solutions were compared. Two 10V CAA oxides exposed to $588 \mathrm{~K}\left(600^{\circ} \mathrm{F}\right)$ and $644 \mathrm{~K}\left(700^{\circ} \mathrm{F}\right)$ for 1 hour also were compared. 


\section{MORPHOLOGY}

10V CAA, No Heat Treatment

The low-magnification plan view (figs. 2.4.4-19a and -19b) shows a flat platelet-like structure. A higher magnification photo (fig. 2.4.4-19c) indicates that there is a porous oxide layer beneath the platelet-like layer. There also is a fair amount of particulate contamination on the surface.

The profile view of this sample shows the duplex nature of the oxide layer (figs. 2.4.4-20a and $-20 \mathrm{~b})$. The top layer is more dense and less structured. The bottom layer is columnar and has a porous open structure.

10V CAA, 588K $\left(6000^{\circ}\right)$ for 1 hour

The profile view (fig. 2.4.4-21a) shows the duplex oxide layer. The higher magnification photo (fig. 2.4.4-2lb) again indicates that the top layer is a dense, less structured oxide and the bottom layer is a porous, columnar structure.

10V CAA, $672 \mathrm{~K}\left(750^{\circ} \mathrm{F}\right)$ for 1 hour

In the low-magnification profile view (fig. 2.4.4-22a), the two layers of oxide can be seen peeled away from each other. Two higher magnification photos (figs. 2.4.4-22b and -22c) show in detail the columnar structure of the bottom oxide layer.

\section{V CAA, No Heat Treatment}

The plan views at low magnification (figs. 2.4.4-23a and -23b) show a heavily pitted surface with islands of flat, dense oxide. The high-magnification photo (fig. $2.4 .4-23 \mathrm{c}$ ) indicates that even in the pits the oxide appears dense and with porous structure.

\section{IOV CAA, No Heat Treatment, New Bath}

The plan view at low magnification (figs. 2.4.4-24a and -24b) shows the pitting of the oxide layer. The higher magnification photo (fig. $2.4 .4-24 \mathrm{C}$ ) indicates that the top of the oxide surface has an open porous structure. 
In the profile view (figs. 2.4.4-25a and $-25 \mathrm{~b}$ ), the new-bath CAA oxide does not have the duplex oxide layers; instead, it is a single oxide with a porous columnar structure.

\section{COMPOSITION}

\section{IOV CAA No Heat Treatment, Old Bath}

This sample had a titanium oxide that was $2500 \AA$ deep measured by ion sputtering. The oxide also contained aluminum and fluorine (figs. 2.4.4-26 and -27). Elements also detected on the surface were sulfur and carbon. Chromium and vanadium were not detected.

\section{V CAA, 588K (6000 F) Heat Treatment for 1 hour, Old Bath}

The titanium oxide contained fluorine and aluminum (fig. 2.4.4-28). The fluorine decreased as the metal oxide interface was approached. The aluminum increased to the alloy level as the metal was reached. Iron and carbon also were detected on the surface. Chromium and vanadium were not detected.

\section{V CAA, 672K (750\%F) Heat Treatment for 1 hour, Old Bath}

The titanium oxide was measured to be $2500 \AA$ by sputtering. The oxide layer contained fluorine, aluminum and a trace of iron (figs. 2.4.4-29 and -30). The surface also had carbon, calcium, and sulfur. Chromium and vanadium were not detected.

\section{5-V CAA, No Heat Treatment, Old Bath}

The titanium oxide layer contained fluorine and aluminum (figs. 2.4.4-31 and -32). Chromium and vanadium were not detected. Carbon was on the surface only.

\subsubsection{Discussion}

\section{MORPHOLOGY}

The major trends in morphology are seen to correlate with anodization on one hand and chemical immersion on the other. The anodized oxides (PAA and CAA) are thicker and 
also tend to be more structured, with a pronounced porous columnar appearance. In the old bath CAA, there was a duplex oxide. The bottom layer was porous and the top was a dense, plate-like oxide. The nature of the top layer is not clear, but it degraded joint strength because of the reduced surface area relative to the porous columnar structure seen in the new bath CAA or the PAA oxide.

The immersion treatments, in general, produced much thinner oxides. These surfaces had very similar appearances at low magnification, typically with a large number of etch pits and debris on the surface. They also had a flat plate-like structure.

Among the immersion treatments, Turco exhibited the most pronounced etched surface. Because the Turco oxide lacked aluminum and vanadium, it is felt that the etching preferentially occurred in the aluminum/vanadium-rich zones.

Other factors that influenced the Turco etching are suggested by the surface morphology. The Turco surface exhibits regular angular plate-like features about $1 \mu \mathrm{m}$ in diameter. These features correlate with the metal grain size measured by optical metallography to be in the range of 1 to $6 \mu \mathrm{m}$. The correlation implies controlling factors such as grain structure, crystallographic orientation, and subgrain defects.

The Pasa-Jell and phosphate fluoride treatments are very similar in appearance. They show a flat, dense oxide with large amounts of surface debris.

\section{SURFACE ANALYSIS}

Elemental content in atomic percent versus pretreatment or anodizing process is summarized in Table 2.4.4-3. Several trends in the surface composition of the baseline oxides were observed. To make a comparison of these trends, the element of interest was ratioed to titanium. (Figures 2.4.4-33 to -37 ).

All laboratory samples analyzed with surface techniques had some ambient carbon contamination. It was noted that some of the oxide surfaces had more carbon than would be expected from this source. The degree of organic carbon contamination on the adherend surface could affect the bond integrity. The CAA oxide treatments exhibited a lower carbon/titanium ratio than the remaining oxides (fig. 2.4.4-33). Turco pretreatment showed the highest degree of carbon contamination. 
In Figure 2.4.4-34, the oxygen/titanium ratio indicates that the anodization treatments, CAA and PAA, have lower values ( 1.75 to 2.75), while the chemical immersion treatments (Turco, phosphate fluoride, Pasa-Jell) have higher values $(3.25$ to 4.0$)$. The PAA and CAA treatments have an oxygen/titanium ratio around 2.0, which is the expected ratio for rutile. The immersion treatments are oxygen rich; an explanation for this enrichment could be the increased amounts of silicon and sulfur possibly present as silicates and sulfates, or the high values could indicate the presence of hydroxides.

The aluminum trends are shown in Figure 2.4.4-35. The one definitive feature is the total absence of aluminum on the Turco oxide surface, indicating the preferential dissolution of the aluminum in the titanium metal. All of the other oxides had aluminum on the surface. These oxides did not show significant aluminum/titanium variations.

Figure 2.4.4-36 represents the fluorine variation on the oxide surfaces. The chart shows that the fluorine content is lower in the $10 \mathrm{~V} \mathrm{CAA}, 672 \mathrm{~K}\left(750^{\circ} \mathrm{F}\right)$ heat-treated sample than in the two non-heat-treated 1OV CAA and 5V CAA samples. No fluorine was detected in the Turco. Pasa-Jell and PAA both have higher levels of fluorine on the surface.

To gage the degree of added elements on the surface other than the major elements (titanium, oxygen, fluorine, and aluminum), a sum of the remaining elements was ratioed to titanium (fig. 2.4.4-37). This ratio will reflect the amount of surface contamination from rinse water and bath solution contaminants. The CAA oxides showed very little contamination. The $10-\mathrm{V}$ CAA $672 \mathrm{~K}\left(750^{\circ} \mathrm{F}\right)$ heat-treated surface was slightly higher. This is due to possible contamination from the oven. This sample also had some iron on the surface. The suspected source is the Turco pre-etch. The Turco oxide surface had the highest tramp element ratio, which reflects the large amount of iron and copper incorporated into this oxide from the bath solution. The Pasa-Jell and phosphate fluoride treatments also are high due to the large variety of elements introduced by these processes. The PAA oxide appears high because of the phosphorous concentration on the surface from the phosphoric acid, but does not indicate contamination.

Vanadium was not detected on any oxide surface. Because the lower limit for detection is approximately 0.2 atom percent, this means the vanadium must be preferentially dissolved in the oxide treatments. 
In summary, CAA and PAA would be expected to provide better bond surfaces because the oxides have fewer extraneous elements and lower contamination levels.

\subsubsection{Failure Analysis}

\subsubsection{Preliminary Analysis}

Three lap-shear specimens identified in Table 2.4.5-1 were analyzed. These specimens were anodized at Boeing and bonded and tested at NASA-Langley. The purpose of this analysis was to examine the cause of the adhesive failure after 6 months exposure.

A separate PPQ/10V CAA lap-shear specimen prepared at Boeing and exposed to $672 \mathrm{~K}$ $\left(750^{\circ} \mathrm{F}\right)$ for 1 hour that had debonded at very low strengths was analyzed by AES.

\section{SPECIMEN 1532P-2}

The plan view (figs. 2.4.5-la through -1c) of the metal-appearing side of the disbonded lapshear surface shows an oxide layer present. There is an impression that a thin layer of polymer could be on this oxide. However, the fracture view (figs. 2.4.5-2a and $-2 \mathrm{~b}$ ) does not confirm this interpretation.

\section{NASA SAMPLES}

Both disbonded surfaces of the three lap-shear samples were surface analyzed using ESCA. Specimens 1527P-3 and 1530P-3 disbonded in the adhesive, as can be seen in the ESCA spectra (figs. 2.4.5-3 through -6). These data show no titanium and high carbon, nitrogen, and oxygen. Specimen 1532P-2 shows a small amount of titanium (fig. 2.4.5-7), in addition to the adhesive polymer signature. This implies that the disbonding occurred at the primer/oxide interface.

\section{I0V CAA/PPQ EXPOSED TO 672K (750\%F) FOR 1 HOUR}

The metal side of the disbonded sample was analyzed by AES. The data (figs. 2.4.5-9 through -11 ) show a titanium oxide that measured $400 \mathrm{~A}$ thick. The oxide showed the usual trend of fluorine decreasing and aluminum increasing as the metal/oxide interface 
was approached. Vanadium was observed on the surface. No chromium was detected. The usual carbon contamination was seen on the surface.

Because this oxide was measured to be $2500 \AA$ in the baseline oxide study, it can be inferred that the lap shear failed very near the metal/oxide interface. The presence of vanadium also supports this conclusion.

\subsubsection{Failure Trends With Surface Properties}

Bond strength has been correlated with several properties of the various surface preparations, i.e., oxide thickness, aluminum content, range elements, and fluorine content.

Figure 2.4.5-12 illustrates the comparison of oxide thickness with initial bond strength. NR056X was selected for this illustration. As shown, CAA has an oxide thickness of about 2500 angstroms compared to PAA with about 750 angstroms. The other surface preparations are all about 250 angstroms thick. Lap shear strengths shown are proportional to the $29 \mathrm{MPa}$ (4200 psi) CAA values. In general, it appears that increasing oxide thickness results in higher lap shear strengths. Testing was conducted at ambient.

Since the titanium alloy $(6 \mathrm{Al}-4 \mathrm{~V})$ used as adherend has a significant amount of the other metal elements, analysis of the metal oxide chemistry was conducted in anticipation of other than pure titanium oxide on the surface. Figure 2.4.5-13 shows the atom percent of aluminum to titanium present in the oxide. The level of aluminum in the oxide was much higher than expected. As seen for CAA and PAA, the concentration of aluminum atoms to titanium atoms reaches about 0.65 and 0.50 respectively. Normal levels of aluminum based upon the alloy composition would be around 0.10 atom percent. The etch preparations also show high proportions of aluminum except Turco which produces only titanium oxide.

Some studies of titanium oxide surface used for bonding have indicated a correlation of fluorine concentration with bond strength (greater fluorine content reduces bond strength). Figure 2.4.5-14 shows the atom percent of fluorine found in the various surface oxides. PAA exhibited the highest fluorine content at about 0.33 atom percent while producing the second highest lap shear strengths. Turco 5578 did not yield any trace of 
fluorine. Based upon these results, no definite correlation of fluorine content (in the oxide) to lap shear strength was found.

The various surface treatments expose the adherend to other elements which are incorporated into the oxide. These elements are primarily silicon, sulfur, chlorine, calcium, iron, and copper. Figure 2.4.5-15 illustrates the total of other elements present in the oxide versus the lap shear strength. As shown, CAA and PAA are relatively "clean" oxides. The other four surfaces contain a relatively high proportion of these elements. The general conclusion is that greater bond strengths are produced when stray elements are not present.

\subsubsection{Baseline Studies for Detailed Failure Analysis}

Lap-shear testing of PPQ and LARC-13 bonded coupons showed an abrupt change from cohesive failure after 5,000 hours at $505 \mathrm{~K}\left(450^{\circ} \mathrm{F}\right)$ to adhesive failure after 10,000 hours at $505 \mathrm{~K}\left(450^{\circ} \mathrm{F}\right)$. To explain the change in failure mode an in-depth characterization and failure analysis was conducted.

\section{POLYMER THERMAL ANALYSIS}

Relative polymer thermal stabilities were determined by comparison of polymer glass transition temperatures before and after 10,000 hours aging at $505 \mathrm{~K}(450 \circ \mathrm{F})$. Glass transition measurements were made using Perkin-Elmer TMS-1 thermomechanical analyzer. The glass transition results are summarized in Table 2.4.5-2. No significant degradations were observed for any of the polymer systems, except for a slight reduction demonstrated by NR056X after aging.

A limited amount of baseline study was undertaken preliminary to the detailed failure analysis. The purpose of baseline studies generally is to characterize the materials systems undisturbed by other processes, such as bonding, aging, and mechanical testing, for further comparisons after processing. Specifically, one set of baseline samples was characterized because of earlier irregularities in microstructure of the oxide (Section 2.4.4.1); this study characterized a 10V CAA oxide produced from a fresh anodizing solution, and the primer infiltration into this more representative oxide structure. 


\section{OXIDE MORPHOLOGY, IOV CAA}

The plan view of a 10V CAA oxide (fig. 2.4.5-16) shows the top of the oxide with the oxide pores, approximately $30 \mathrm{~nm}$ in diameter, clearly in view. The lab-fractured view of the oxide (fig. 2.4.5-17) shows that the oxide has a columnar structure with a depth of about $120 \mathrm{~nm}$. This fractured view of a freshly prepared specimen is consistent with Figure 2.4.4-1b, but exhibits improved resolution.

\section{BASELINE PRIMER PENETRATION STUDY, IOV CAA}

To determine the degree of primer penetration into the oxide layer, a control specimen was prepared in which primer was applied to the oxide surface, without exposure to environmental effects. PPQ was selected as the primer for the control penetration study. Interpretation of lap-shear failure analysis data required baseline knowledge of the degree of primer penetration into a fresh oxide specimen.

Figure 2.4.5-18 is a stereographic pair of a fractured specimen, showing the primer penetrating to the base of the oxide. Figure 2.4.5-19 is a stereographic pair of another region of the fractured specimen. These micrographs show the primer being incompletely pulled away from the top of the oxide layer. This pulling away of the polymer is due to the fracturing technique used to prepare the specimens. It does show how the polymer can pull out of the oxide after penetrating the oxide to the base plate. These studies indicate that PPQ penetrates to the base of the oxide cell structure.

TEM analysis of thin sections is the most definitive method for assessment of the degree of primer penetration into the oxide layer.

Figure 2.4.5-20 shows a section of Ti-6A1-4V, 10V CAA with LARC-13 primer. The artifacts are labeled, because the interpretation of the micrograph requires an understanding of these artifacts.

The small, light areas $(F)$ are fracture lines that represent thinner areas of the section resulting from sectioning a brittle material. The dark bands $(C)$ are thicker areas of the specimen that result from compression during the cutting process. Titanium is a difficult metal to machine because of its tendency to smear, and this tendency is illustrated by the compression. 
Three regions are evident in the micrograph: metal, oxide, and polymer. There also is evidence of a boundary region between the metal and oxide.

The method was employed for two reasons: (1) to observe the ultrastructure of the oxide layer, and (2) to investigate the degree of primer penetration into the oxide layer.

The depth of the oxide layer is clearly visible and is approximately $0.2 \mu \mathrm{m}$. The structure of the oxide layer is difficult to define, but it is either columnar or cellular. The structure is more clearly defined by SEM techniques.

The polymer layer has significantly less electron opacity than either the oxide or the metal; the polymer is not directly visible within the oxide pores. There is, however, continuity of the section between oxide and primer, which indicates primer penetration. Also, the section has been viewed in an SEM and shows a smooth surface. If the primer had not penetrated the pores, gaps in the section surface would be evident. Therefore, it can be concluded from TEM micrographs of thin sections that the primer has penetrated the oxide layer.

The appearance of a boundary layer is consistent with SEM micrographs that show such a region clearly.

The TEM technique is expensive and time-consuming for ultrastructural studies, and more information can be obtained from SEM studies. The TEM data do, however, verify conclusions drawn from SEM micrographs.

\subsubsection{PPQ/10V CAA Lap Shear: 10,000 hours: 505K (450\%F)}

\section{MACROSCOPIC APPEARANCE}

The macroscopic appearance of the PPQ/10V CAA lap shear, aged at $505 \mathrm{~K}\left(450^{\circ} \mathrm{F}\right)$ for 10,000 hours, is shown in Figure 2.4.5-21. Both the adhesive and adherend surfaces clearly exhibit the regular woven pattern of the supporting scrim. Those areas that are light in appearance, region $A$, represent zones of fracture directly under the yarns of the scrim. Closer inspection of these regions revealed bright blue-green coloration on both surfaces, indicating apparent bare oxide. Those areas that are darker in appearance, region $B$, represent zones of fracture between the yarns of the scrim. Closer visual 
inspection of these regions reveals a heavy polymer coating on both the adherend and adhesive surfaces. These polymer areas do not exhibit any fracture features and appear to represent bondline porosity at the scrim nodes. This bondline porosity was found to be present in the unaged PPQ lap shear coupons as well.

\section{MICROSCOPIC APPEARANCE}

A plan view (fig. 2.4.5-22) taken from region $A$ in Figure 2.4.5-21 shows a thin, nonuniform layer of polymer remaining on the adherend surface. Figure 2.4.5-23 is a higher magnification plan view stereo pair of the same area. The details show polymer dispersed in discrete zones across an oxide layer. The 10V CAA titanium oxide layer is located in the micrograph by its characteristic open pore structure.

Transverse views of the adherend in region $A$ are shown in Figures 2.4.5-24 and 2.4.5-25, after lab bend fracturing. Apparent in Figure 2.4.5-24 is the open side wall structure of the IOV CAA oxide. The openness of this structure suggests that no primer penetration occurred in this area. Figure 2.4.5-25, a stereo pair of a similar area, emphasizes the overall lack of polymer penetration, except for some localized regions.

The plan view of the opposing adhesive failure surface is shown in Figure 2.4.5-26. The low-magnification view (fig. 2.4.5-26a) shows machining marks from the adherend titanium surface replicated by the polymer. Figure $2.4 .5-26 \mathrm{~b}$ shows more detail of the replicated surface. The surface undulations evident in this figure match those seen in the baseline oxide characterization (Figure 2.4.4-30). At higher magnification, Figure 2.4.5$26 \mathrm{c}$ shows a generally smooth surface morphology with depressions $\sim 90 \mathrm{~nm}$ in diameter and small, bright nodules $\sim 30 \mathrm{~nm}$ in diameter.

The same features are revealed in the transverse bend-fracture view shown in Figure 2.4.527. The size of the nodules suggests that they are formed by polymer pull-out from the oxide pores during lap-shear failure. The larger depressions, which are more evident in plan view, may be a result of polymer inhomogeneity or fracture deformation. 


\section{SURFACE COMPOSITION}

\section{ESCA}

The failed surface compositions as determined by ESCA are shown in Figures 2.4.5-28 and 2.4.5-29. The elements detected on the adhesive surface are carbon, nitrogen, oxygen, silicon, sulfur, chlorine, titanium, and lead. The adherend surface had carbon, nitrogen, oxygen, aluminum, silicon, sulfur, titanium, and lead on it. Silicon, sulfur, and chlorine are elements that are detected on most adhesive oxide fracture surfaces in varying amounts. The presence of small amounts of titanium on the adhesive surface implies that some material transfer of the titanium oxide layer occurred during failure. Also, the presence of carbon, nitrogen, and oxygen can be attributed to polymer regions $B$, shown in Figure 2.4.5-21. The resolution of this technique is not adequate to determine whether polymer transfer occurred in regions $A$. The presence of lead on the failed PPQ/1OV CAA surface is not believed to be significant. LARC-13/10V CAA failures have no detectable lead, yet both systems exhibit the same thermal strength degradation and failure mode.

\section{AES}

AES was used for increased lateral chemical resolution of the failed adherend. Figure 2.4.5-30 shows an inverted absorbed-current map of a failed adherend surface shown at lower magnification in Figure 2.4.5-21.

In this imaging mode, light areas correspond to areas of low conductivity and hence represent polymer. Darker areas have increased conductivity due to the presence of metal. The spectra show polymer alone $(\mathrm{C}, \mathrm{N}, \mathrm{O})$ in region $\mathrm{B}$, and a mixture of $\mathrm{Ti}$ oxide and polymer $(\mathrm{C}, \mathrm{N}, \mathrm{O}, \mathrm{Ti})$ in region $\mathrm{A}$. Also identified in region $\mathrm{A}$ were $\mathrm{Pb}, \mathrm{S}$, and $\mathrm{Cl}$. The increased lateral resolution of AES showed that the Ti oxide signal observed on the failed adherend surface by ESCA came only from the regions $A$.

\section{TEM/MICROTOMY}

The TEM/microtomy technique was used to determine if the Ti oxide signal from regions $A$ on the adhesive side of a failure (ESCA) was due to a thin layer of oxide or to thicker, discrete areas. The Ti signal would be the same under both conditions since ESCA does not have the resolution to distinguish between the two options. 
Bulk EDX in the SEM on the adhesive failed surface showed no Ti signal. A thin surface layer of $\mathrm{Ti}$ oxide may have been present, but below the detection limit of the bulk analysis technique. Thin sections were prepared on a microtome for EDX analysis in the STEM (transmission mode). A specimen from the failed surface was coated with a layer of $\mathrm{Au} / \mathrm{Pd}$ to a thickness of $\sim 30 \mathrm{~nm}$ to define the surface in the section. Any Ti oxide on the polymer surface would show sandwiched between the primer layer and the Au/Pd coating layer in the section. The Au/Pd layer clearly indicated the location of the failed polymer surface. No discrete areas of Ti oxide were visible in the TEM mode (fig. 2.4.531). The sectioned specimen was analyzed with EDX. No titanium was found in any of several different areas (see figs. 2.4.5-32 and 2.4.5-33). These figures show the spectra of typical areas analyzed and the elements found. The Au/Pd signals are due to the surface coating. The $\mathrm{Cu}$ and Mo are background signals from the instrument. No Ti signal was detected, indicating that the Ti detected by ESCA was due to a very thin Ti oxide layer spread over the polymer surface, not to discrete areas.

\subsubsection{PPQ/5V CAA Lap Shear}

\section{MORPHOLOGY}

\section{MACROSCOPIC APPEARANCE}

The thermally aged, failed surfaces of PPQ/5V CAA are shown in Figure 2.4.5-34. The macroscopic appearance is identical to that of the PPQ/10V CAA lap shears.

\section{MICROSCOPIC APPEARANCE}

Low-and high-magnification plan-view micrographs of region $A$ of the failed adherend surface are shown in Figures 2.4.5-35 and 2.4.5-36. Figure 2.4.5-35 shows the open pore structure characteristic of CAA Ti oxides. Figure 2.4.5-36, a higher magnification view of the same area, reveals the pore structure more clearly, as well as isolated areas of a thin film of polymer adhering to the surface.

Bend-fracture specimens of the same region are shown in Figure 2.4.5-37. The open-cell, columnar structure typical of CAA oxides is clearly revealed in these micrographs. This open structure indicates lack of polymer penetration. However, small regions of polymer adhering to the surface are visible. 


\section{SURFACE COMPOSITION}

\section{ESCA}

ESCA spectra of adhesive and adherend surfaces of the failed PPQ/5V CAA lap shear are shown in Figures 2.4.5-38 and 2.4.5-39. The adhesive surface (fig. 2.4.5-38) showed carbon, nitrogen, oxygen, aluminum, silicon, titanium, and lead. The adherend surface composition (fig. 2.4.5-39) was carbon, nitrogen, oxygen, aluminum, titanium, and lead. As for PPQ/10V CAA, the presence of titanium on the adhesive surface implies that some material transfer of the $\mathrm{Ti}$ oxide layer occurred during failure. Carbon, nitrogen, and oxygen on the adherend surface can be attributed to polymer regions $B$ shown in Figure 2.4.5-34. The resolution of ESCA is not adequate to determine whether polymer transfer occurred in regions $A$.

\section{AES}

An inverted absorbed-current image of the failed adherend surface is shown in Figure 2.4.5-40 together with AES spectra for regions $A$ and $B$. As for PPQ/10V CAA, region $B$ consisted of polymer alone, whereas region $A$ showed $\mathrm{Ti}$ oxide with polymer. Anomalous to the ESCA data on the adherend surface, lead was not detected by AES.

\subsubsection{LARC-13/10V CAA Lap Shear: 10,000 hours: $450^{\circ} \mathrm{F}$}

\section{MORPHOLOGY}

\section{MACROSCOPIC APPEARANCE}

The macroscopic appearance of failed 10,000-hour, 505K (4500F), LARC-13/10V CAA lap shears is shown in Figure 2.4.5-41. The appearance contrasts sharply with that of PPQ lapshear failures.

Extensive areas on both adherend surfaces appear to be predominantly exposed oxides, with exposed areas of polymer on the mating surfaces, the adhesive polymer flaking away from both surfaces. Also evident is a high degree of porosity at the scrim nodes. The white borders are due to segregation of aluminum filler particles. 
Both the segregation of Al filler particles and scrim node porosity were also observed in unaged samples.

\section{MICROSCOPIC APPEARANCE}

The failed adherend surface, shown in Figure 2.4.5-42, has distinct thick regions of polymer adhering to the oxide layer. There are also large areas of exposed oxide. Figure 2.4.543 is a high magnification view of the region indicated in Figure 2.4.5-42b.

Evident at this magnification (fig. 2.4.5-43b) is the typical open cell structure of $10 \mathrm{~V}$ CAA. Figure 2.4.5-43a shows the gradually diminishing polymer adhesion with distance from thick polymer zones. Figure 2.4.5-44 is a bend-fractured view of the adherend in a polymer/oxide transition zone. The higher magnification view reveals the open columnar structure of the oxide adjacent to a thick polymer layer. As with previous 10V CAA studies, there is no evident primer penetration into the oxide.

A stereographic fracture view of the adherend in an area well away from the polymer is shown in Figure 2.4.5-45. No polymer adhesion or penetration into the oxide structure is evident.

The adhesive side of the failure surface is shown in Figure 2.4.5-46. This surface has the replicated appearance of the adherend layer. At lower magnifications (fig. 2.4.5-46a), the replication shows machining grooves of the Ti surface. Figure $2.4 .5-46 \mathrm{~b}$ at higher magnification, reveals the replication of the undulating oxide morphology. Both figures show a dispersion of small, light particles within the polymer matrix. These are interpreted to be agglomerates of A1 particles based on their higher secondary electron yield.

The large, dark region in Figure 2.4.5-46a is a region where polymer has been torn from the adhesive surface. Figure $2.4 .5-42 \mathrm{a}$ represents a surface with a thick adhering polymer layer. Figure $2.4 .5-46 \mathrm{~b}$ reveals a localized region of aluminum interfacial separation. The analogous mating fracture on the adherend side is shown as a thin adhering polymer layer in Figure 2.4.5-42b.

Further, Figure 2.4.5-47 shows a fractured edge of the separation zone in Figure 2.4.546b. Figure 2.4.5-47 also reveals bright nodules $\sim 40 \mathrm{~nm}$ in diameter that were seen before in PPQ failures on 10V CAA (see figs. 2.4.5-26 and 2.4.5-27). 


\section{COMPOSITION}

\section{ESCA}

The ESCA surface compositions of the failed LARC-13/10V CAA adhesive and adherend are shown in Figures 2.4.5-48 and 2.4.5-49. The adhesive surface has carbon, nitrogen, oxygen, fluorine, aluminum, silicon, titanium, and chromium. The adherend surface has carbon, nitrogen, oxygen, aluminum, sulfur, titanium, and chromium. The aluminum is due to the filler particles.

The presence of $\mathrm{C}, \mathrm{N}, \mathrm{O}$ on the adherend surface indicates residual polymer. The presence of $\mathrm{Ti}$ on the adhesive side indicates transfer of $\mathrm{Ti}$ oxide to the adhesive during lapshear failure.

\section{AES}

Figure 2.4.5-50 shows an inverted absorbed-current image of an adherend side of the lapshear failure. The black regions are thick polymer layers, regions $C$. Regions $D$ represent apparent bare areas. The spectrum from region $\mathrm{D}$ showed both Ti oxide and polymer.

Chemical analysis could not be performed on region $C$ alone because the thickness of the polymer layer caused severe charging. To obtain a spectrum including a signal from region $\mathrm{C}$, the beam was focused half on region $\mathrm{C}$ and half on region $\mathrm{D}$. The resulting spectrum showed a higher signal for $C$ and $A 1$ on the composite region than on region $D$ alone.

\subsubsection{LARC-13/Pasa-Jell Lap Shear: 10,000 hours: 4500F}

\section{MORPHOLOGY}

\section{MACROSCOPIC APPEARANCE}

The failed lap-shear surface of LARC-13/Pasa-Jell long-term $505 \mathrm{~K}\left(450^{\circ} \mathrm{F}\right)$ is shown in Figure 2.4.5-51. The failure mode is identical to that exhibited by LARC-13/10V CAA failure. As in previous LARC-13 failures, scrim node porosity and AI filler particles are present. 


\section{COMPOSITION}

\section{ESCA}

The ESCA spectra for the failed surfaces are shown in Figures 2.4.5-52 and 2.4.5-53. The adhesive surface shows carbon, nitrogen, oxygen, aluminum, silicon, and a trace of titanium. The adherend surface has carbon, nitrogen, oxygen, aluminum, silicon, titanium, and chrominum. The trace levels of $\mathrm{Ti}$ on the adhesive surface suggest that little $\mathrm{Ti}$ transfer occurred during failure, in contrast to the other systems analyzed, with significant $\mathrm{Ti}$ signals.

\section{AES}

Figure 2.4.5-54 shows an inverted absorbed-current image of the adherend surface of a LARC-13/Pasa-Jell lap-shear failure. Regions C (white areas) represent regions of thick polymer as described for LARC-13/10V CAA. Regions D (grey areas) were bare oxide that AES spectra showed to have $\mathrm{C}, \mathrm{N}, \mathrm{O}$, and Ti signals. Fluorine, silicon, and sulfur were also detected in the apparent bare area.

Less charging was experienced with these samples, allowing definitive AES analysis of region $\mathrm{C}$ showing $\mathrm{C}, \mathrm{N}, \mathrm{O}$, and $\mathrm{Al}$. They therefore consist of polymer and $\mathrm{Al}$ filler particles.

\subsubsection{Summary of Failure Analysis Results}

\section{LARC-13 ON IOV CAA AND PPQ ON 5 AND 1OV CAA.}

- LARC-13 and PPQ exhibited extensive bondline porosity both at initial room temperature and after $505 \mathrm{~K}\left(450^{\circ} \mathrm{F}\right)$ thermal aging. Visual examination of failed samples revealed large regions of apparent bare oxide.

- SEM/STEM plan-view examination of the adherend side revealed mixed regions of exposed oxide with a thin layer of polymer.

- Both plan and transverse views revealed extensive regions of oxide with no apparent polymer. 
- SEM/STEM examinations of the opposing polymer side revealed good replication of the adherend surface, as well as small $5 \mathrm{~nm}$-diameter nodules.

- Surface analysis by both ESCA and AES revealed that visually apparent regions of bare oxide on the adherend are composed of titanium and polymer

- Analysis of the opposing polymer side similarly revealed both titanium and polymer, with reduced levels of titanium compared to the adherend. In addition, silicon, sulfur, chlorine, and chromium were found in trace amounts.

- Trace levels of lead were found on both the adherend and opposing adhesive surface on $\mathrm{PPQ} / 5$ and $10 \mathrm{~V}$ CAA samples after thermal aging.

\section{LARC-13 ON PASA-JELL}

- Visual examination of these samples showed large areas of apparent bare adherend.

- Surface analysis by both ESCA and AES on the adherend surface revealed that apparent bare adherend areas are composed of both polymer and titanium (see Table 2.4.53 for quantative analysis).

- Examination of the opposing polymer surface revealed that it is similarly composed of polymer with trace levels of titanium.

- Trace levels of sulfur, chlorine, fluorine and silicon were found on both failure surfaces. 

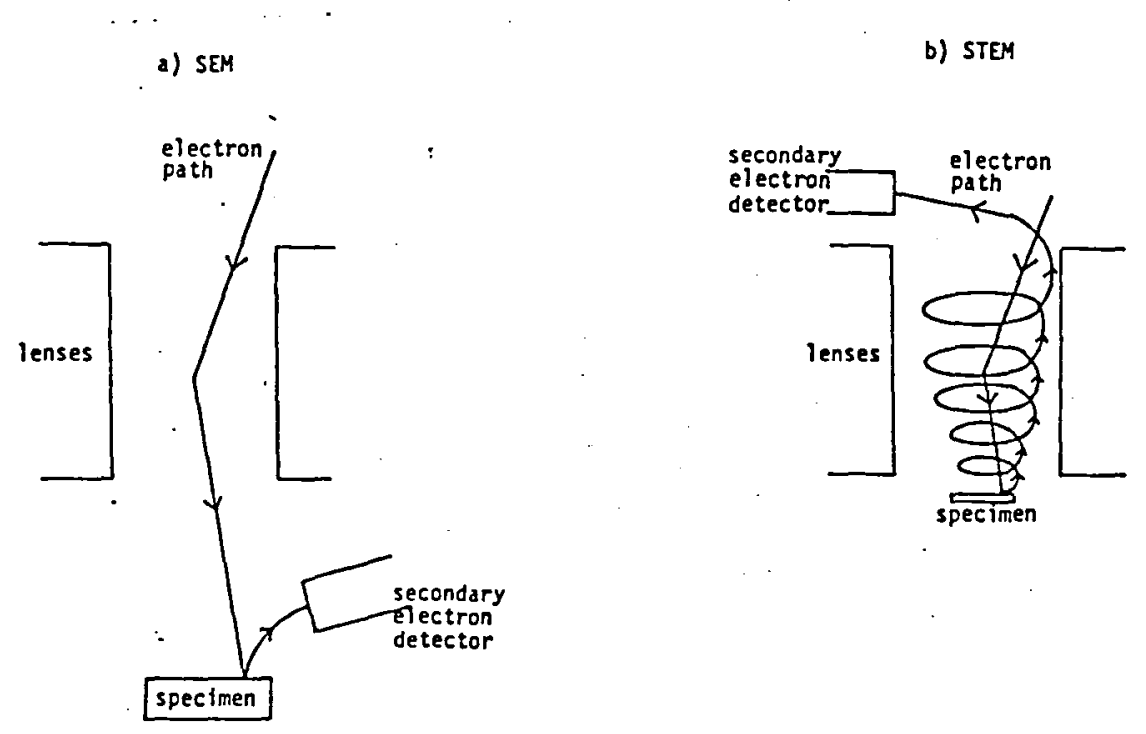

Figure 2.4.2-1 Secondary electron collection for:

a) scanning electron microscope (SEM)

b) scanning transmission electron microscope (STEM) 


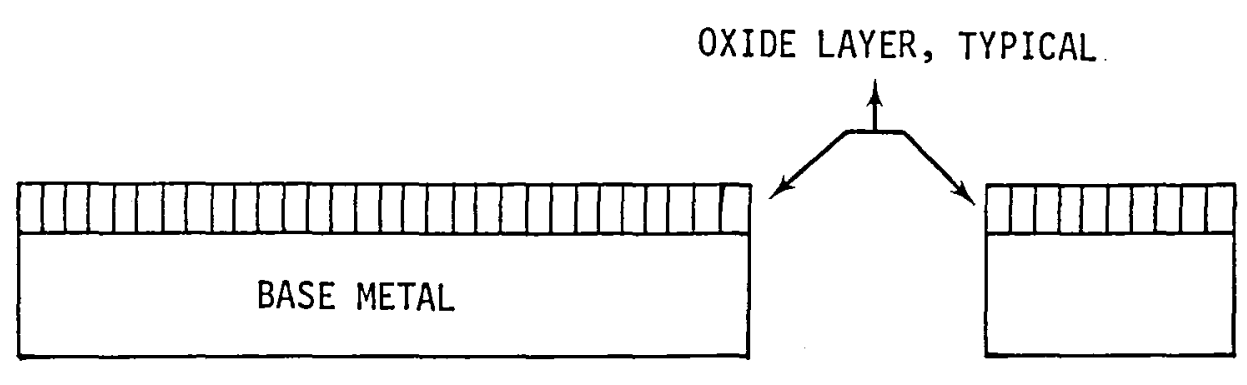

STRIP CUT FROM

PANEL. SIDE VIEW

END VIEW

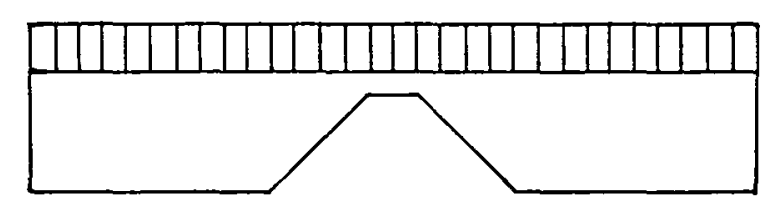

RELIEF CUT OUT

TO ALLOW FRACTURING

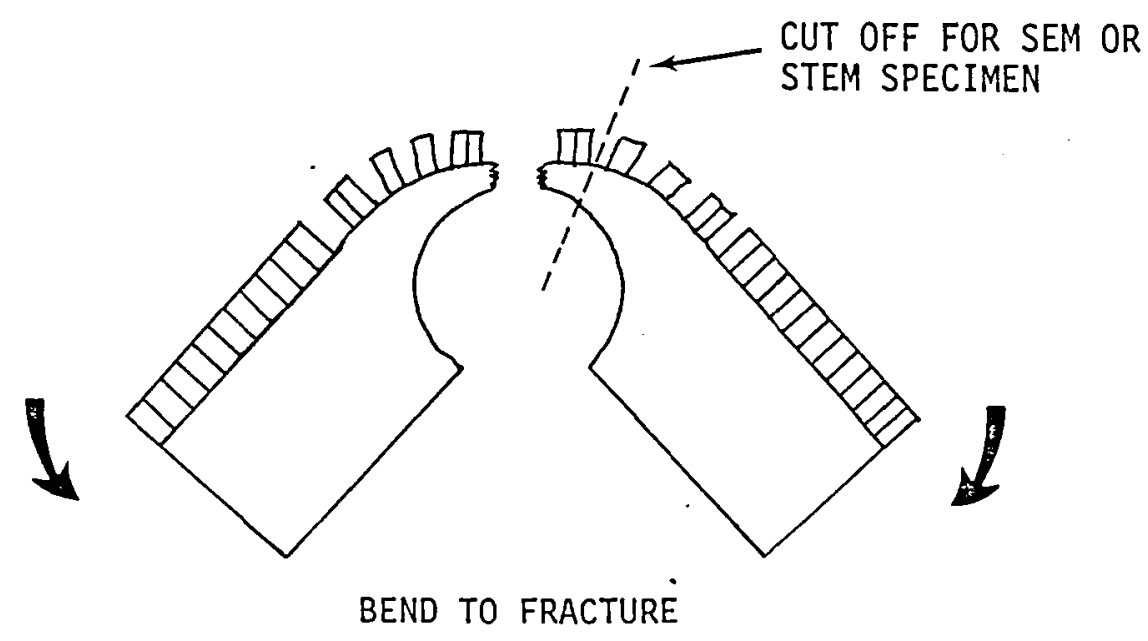

Figure 2.4.2-2 Schematic of Specimen Preparation 


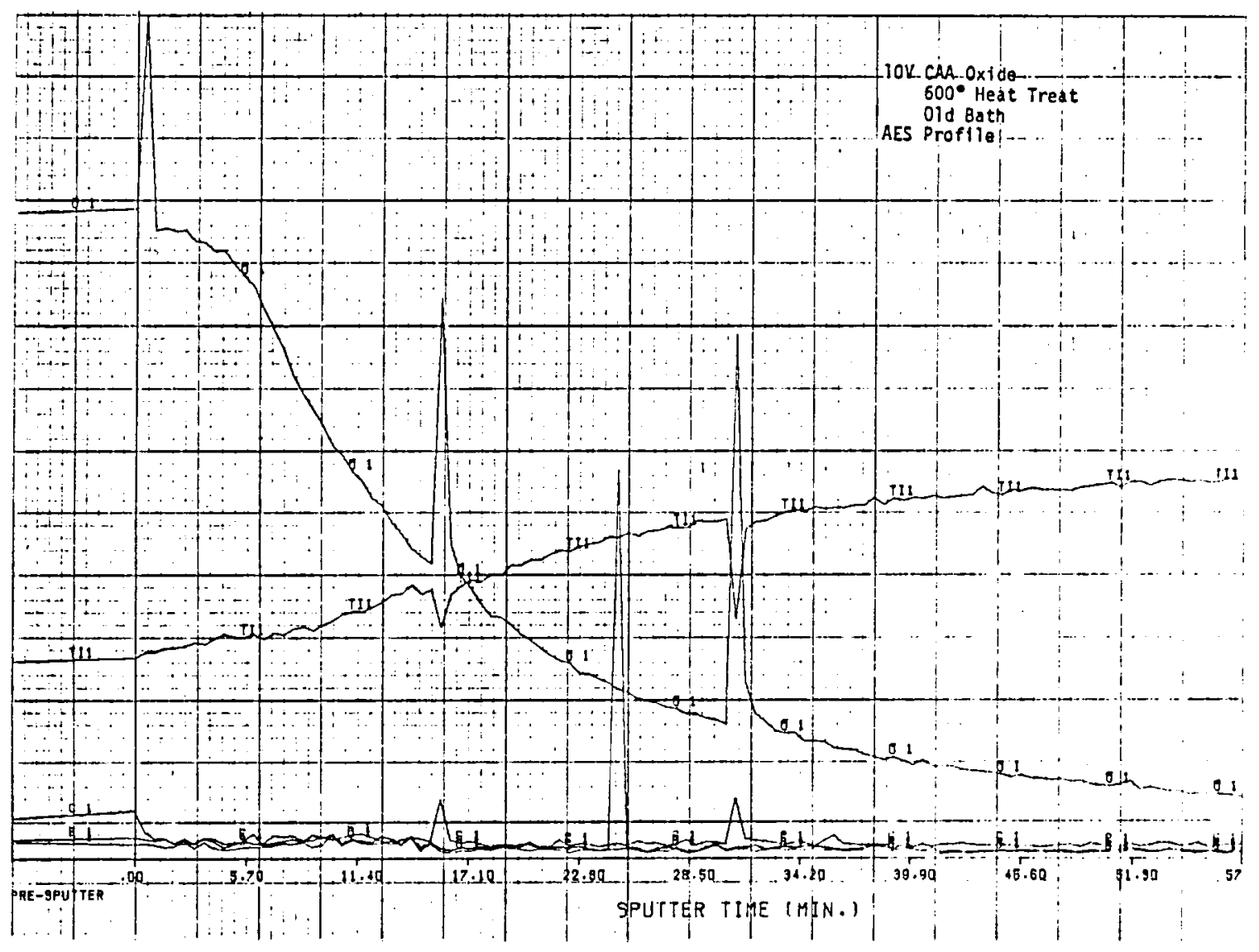

Figure 2.4.2-3 10-V CAA Oxide, $588 \mathrm{~K}\left(600^{\circ} \mathrm{F}\right)$ Heat Treat, Old Bath, AES Profile 

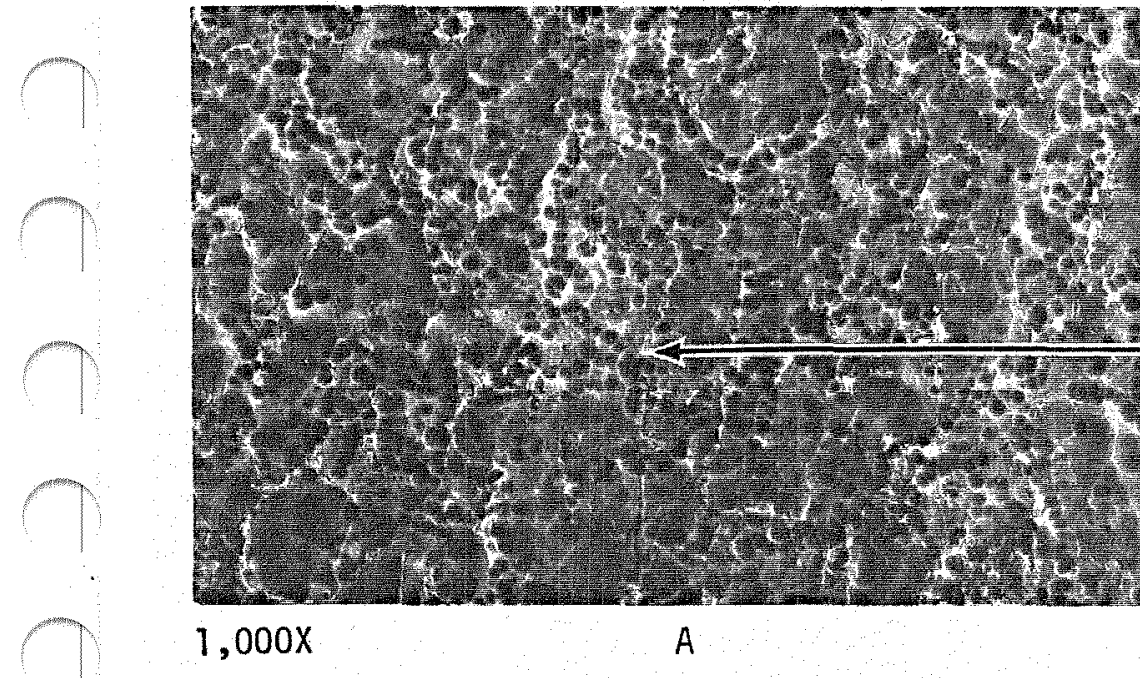

$1,000 x$

A

AREA SHOWN IN 20,000X

PHOTOGRAPH AT THE BOTTOM OF THIS PAGE

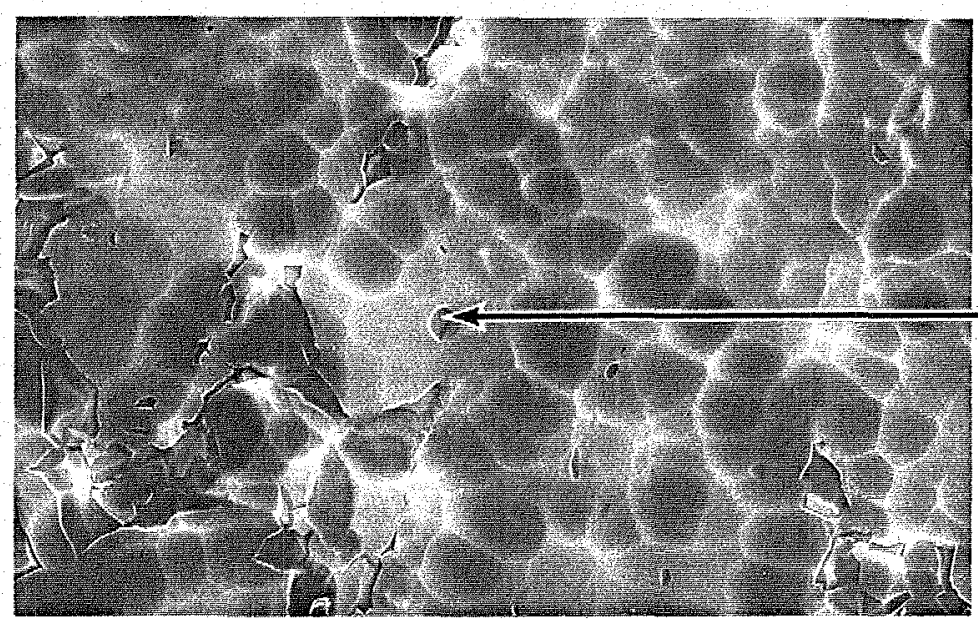

$5,000 x$

B

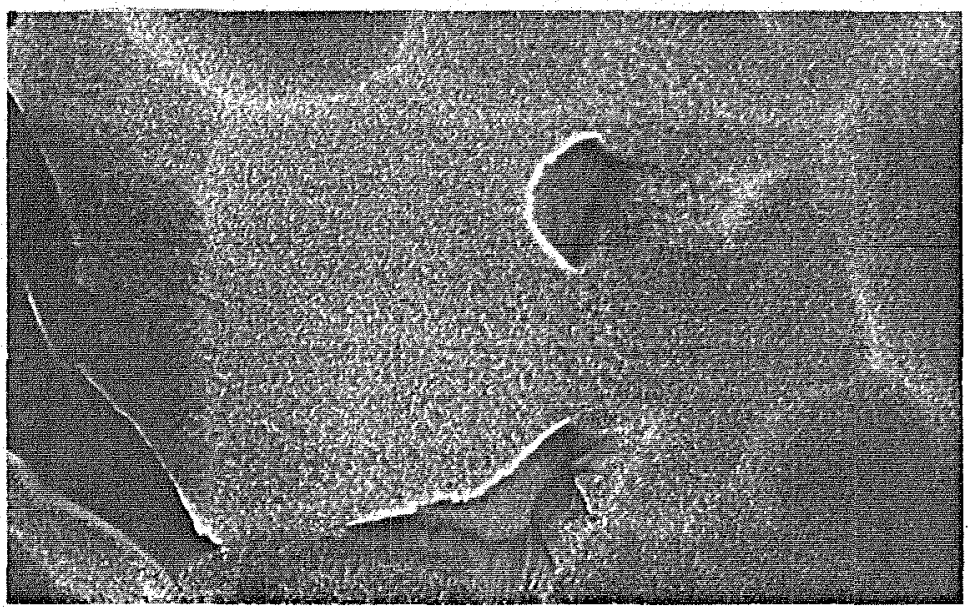

THE OXIDE STRUCTURE IS

UNIFORM OVER THE

SURFACE WITH ETCH

PITS VISIBLE

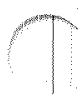

$20,000 x$

C

Figure 2.4.4-1 5-V Phosphoric Acid Anodize As-Received Surface 
Figure $2.4 .4-2 \quad 5-\mathrm{V}$ Phoshporic Acid Anodize As Lab-Fractured
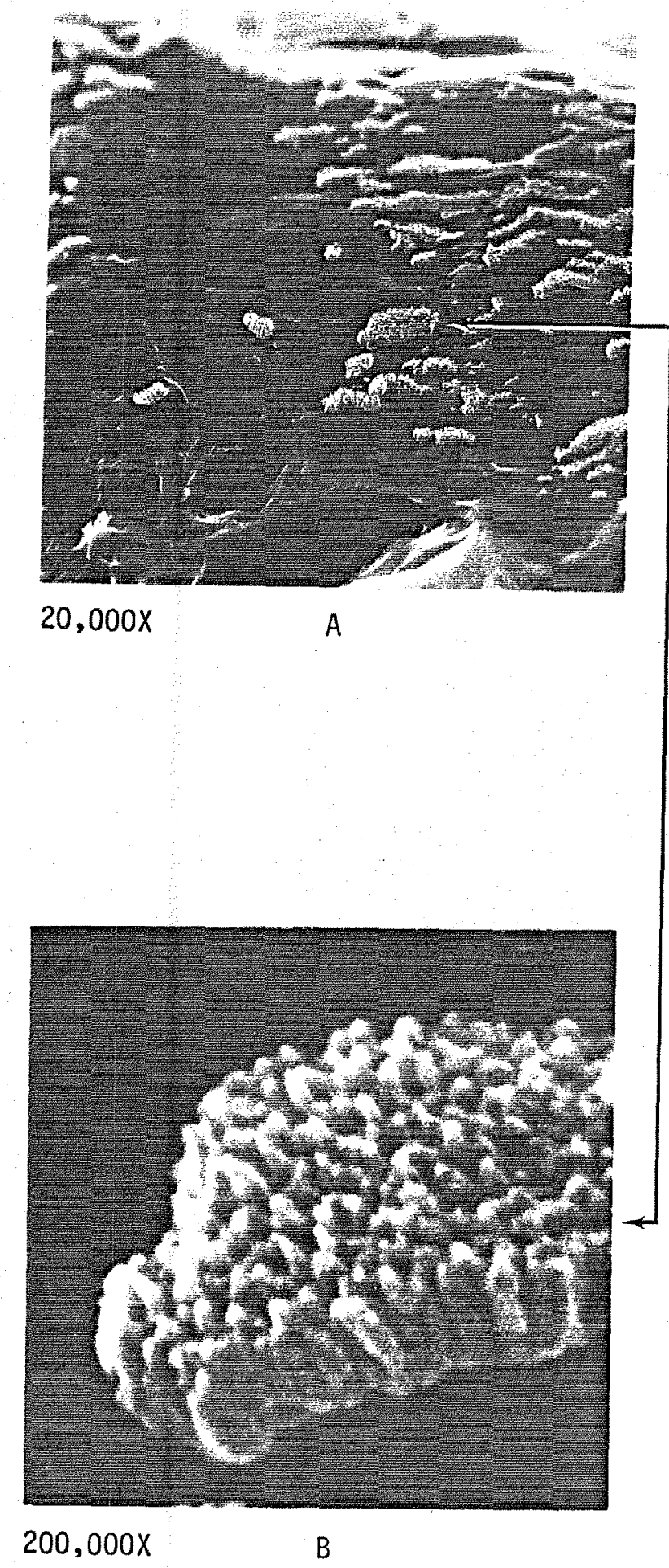

THE OXIDE STRUCTURE IS

COLUMNAR WITH A THICKNESS

OF $\approx 600 \AA$ 


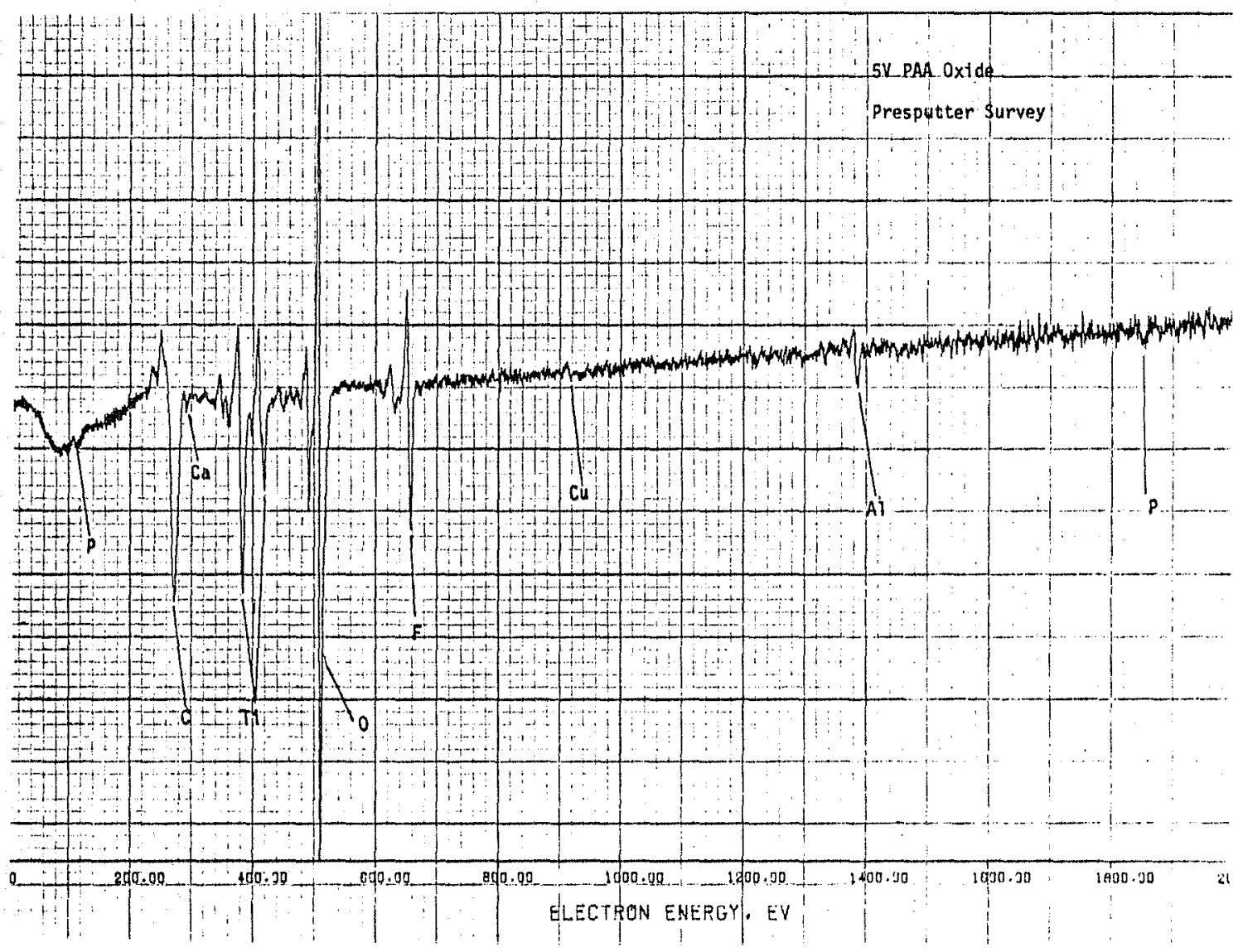

Figure 2.4.4-3 5-V PAA Oxide Presputter Survey 


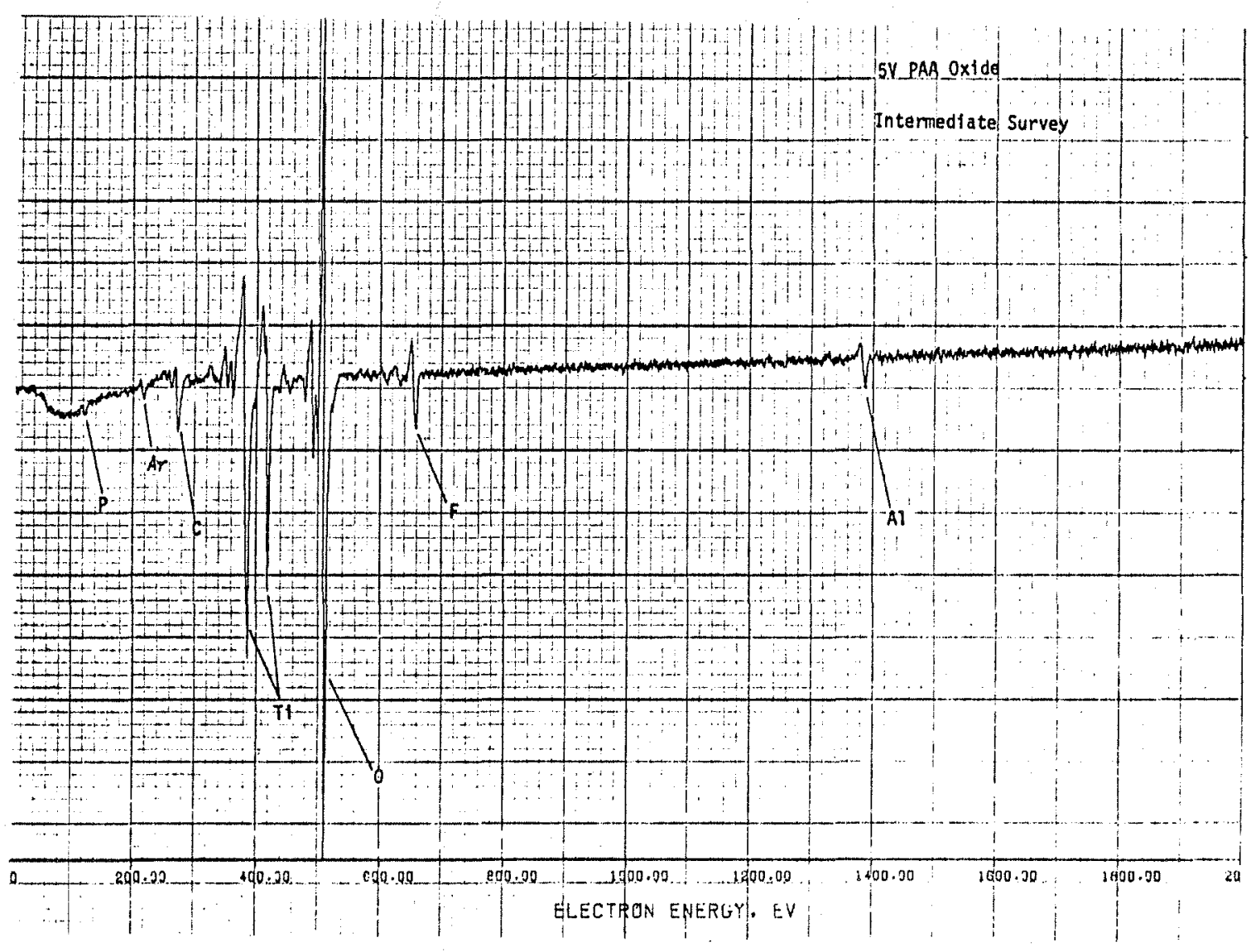

Figure 2.4.4-4 5-V PAA Oxide Intermediate Survey 


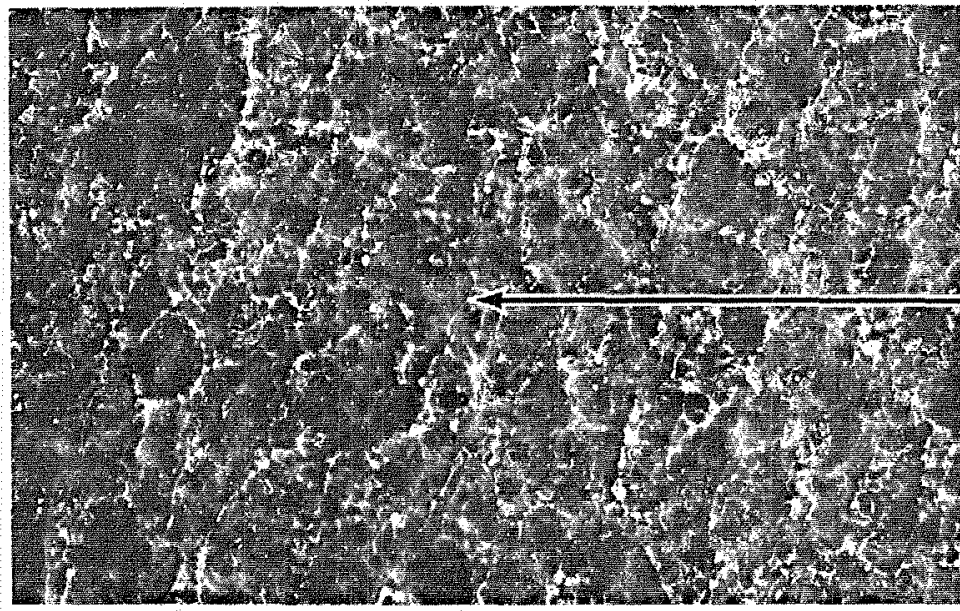

AREA SHOWN IN $20,000 X$

$1,000 x$

A

PHOTOGRAPH AT THE

BOTTOM OF THIS PAGE

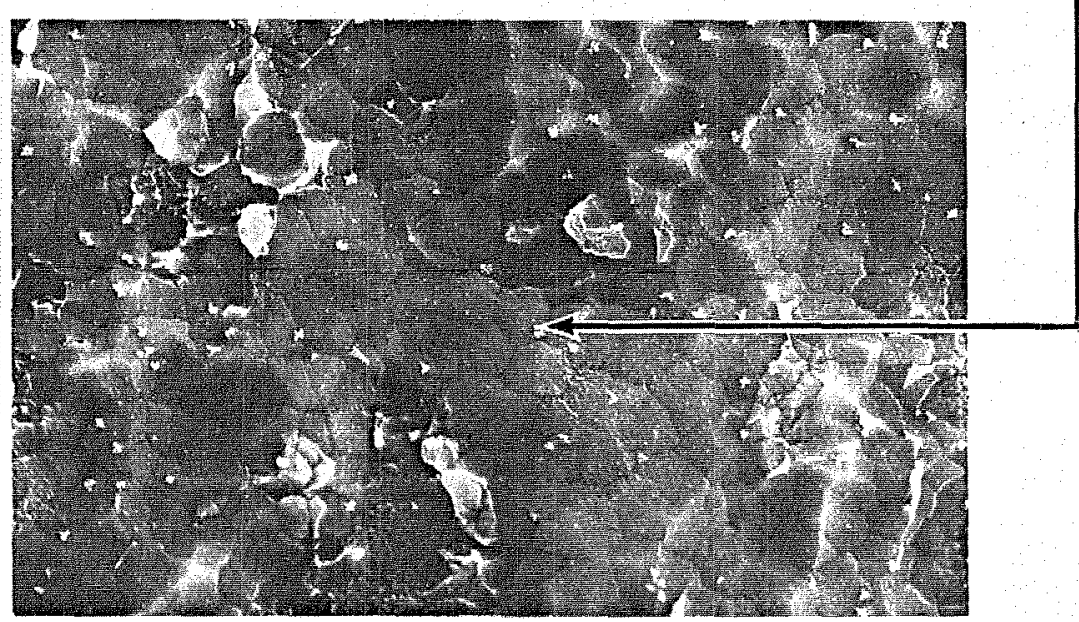

$5,000 x$

B

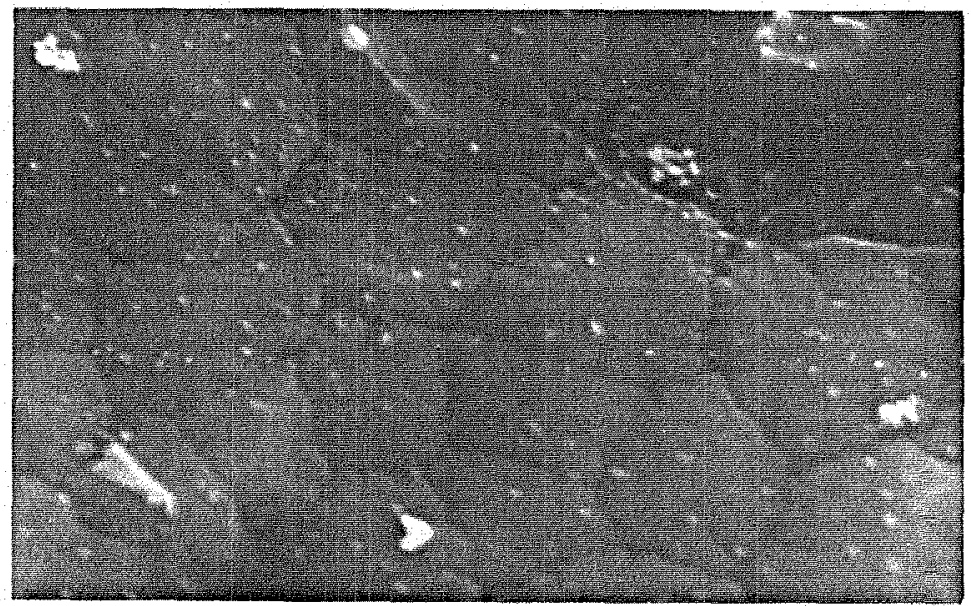

$20,000 x$

C

Figure $2.4 \cdot 4-5$

Pasa Jell 107 Treated, As Received Surface 
Figure 2.4.4-6 Pasa Jell 107 Treated, Lab-Fractured
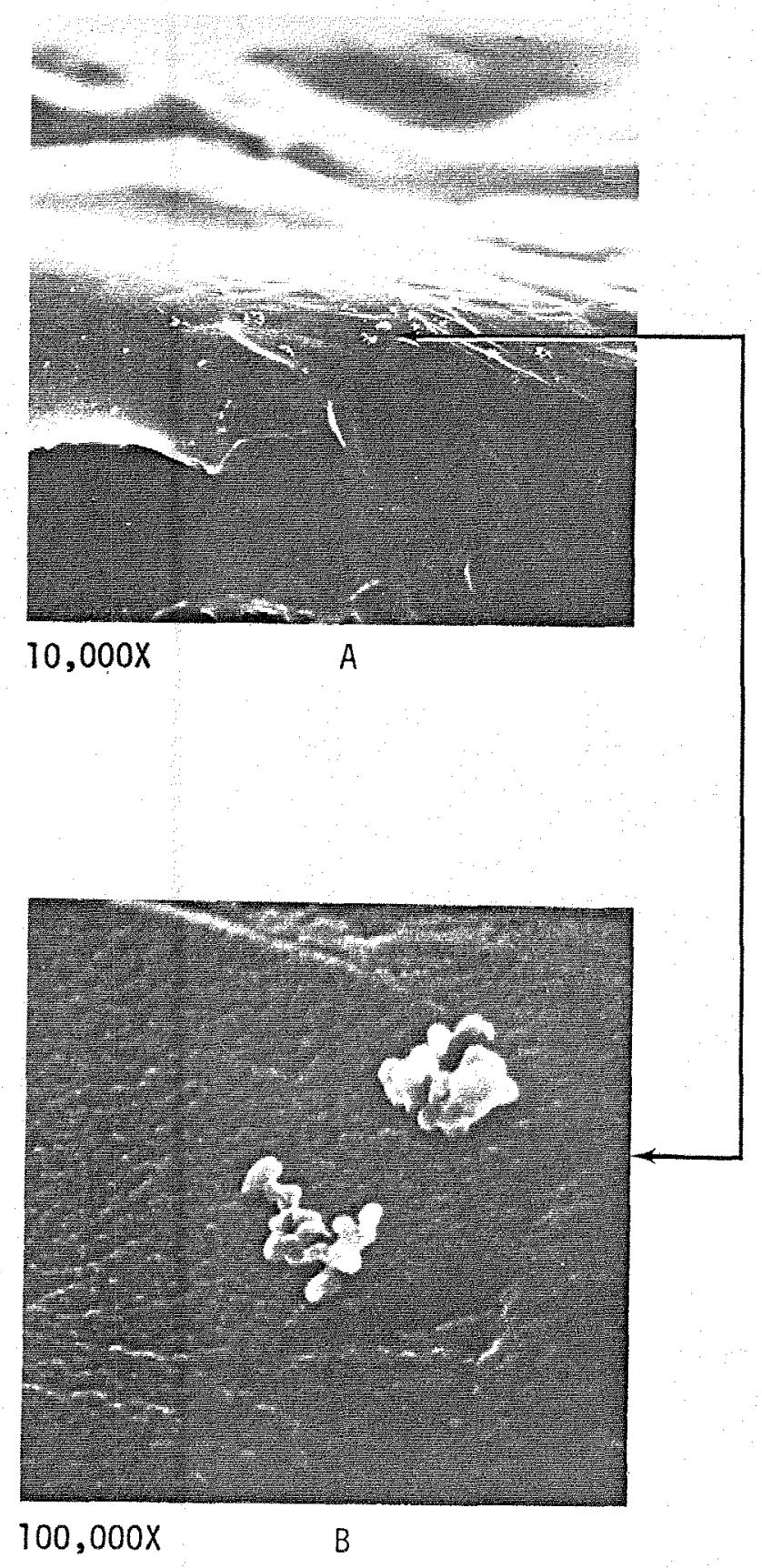

THE PASA-JELL 107 LAB-FRACTURED SPECIMEN SHOWS A SCATTERED PHASE WHICH IS $\approx 400 A^{\circ}$ THICK。 AN ADDITIONAL PHASE WHICH IS MUCH THINNER AND MORE CONTINUOUS ALSO APPEARS IN THE HIGH MAGNIFICATION PHOTOGRAPH OF THIS PAGE. THIS MORE CONTINUOUS LAYER IS LESS THAN $100 \mathrm{~A}^{\circ}$ THICK. 


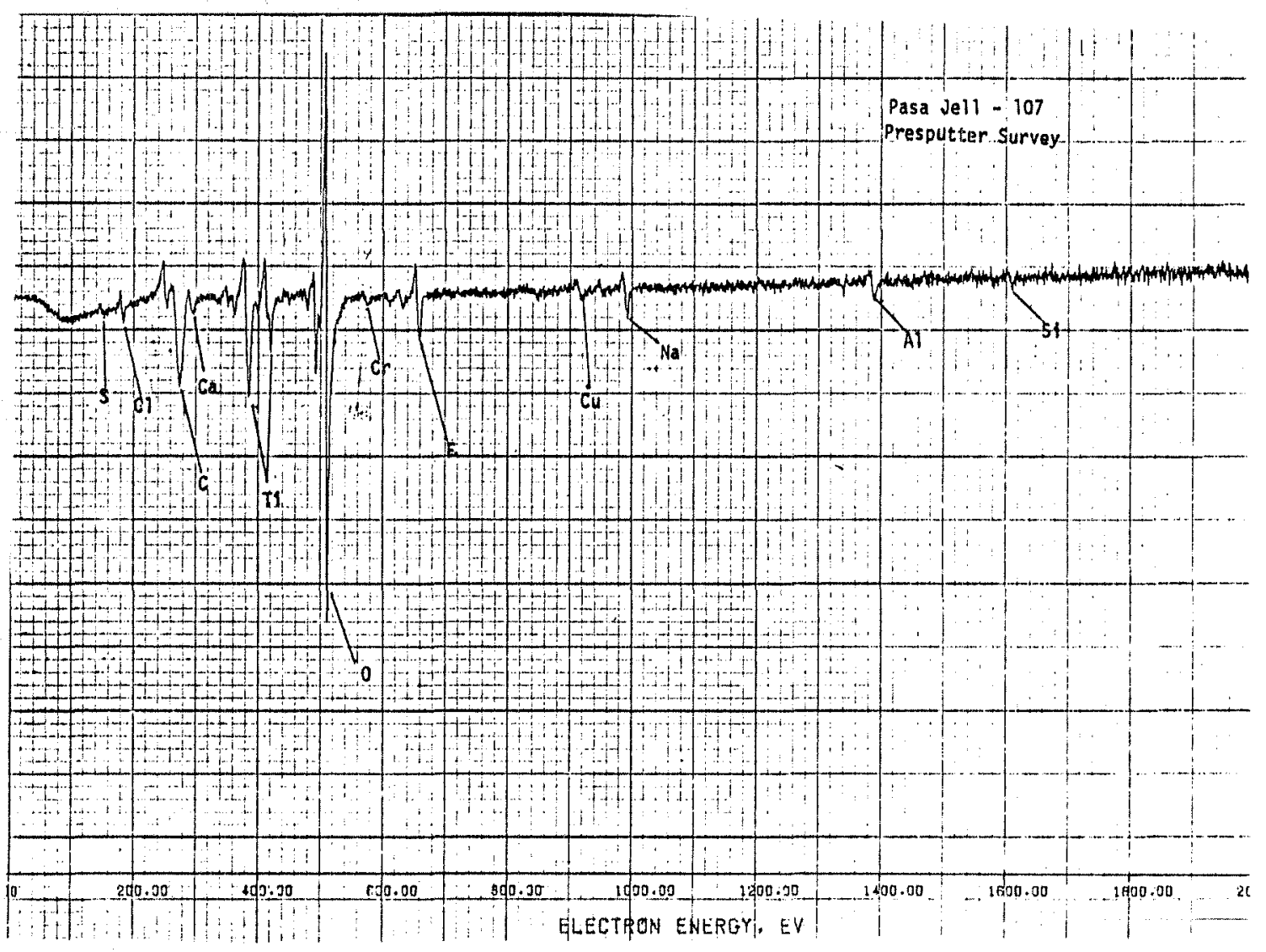

Figure 2.4.4-7 Pasa Jell 107 Presputter Survey 


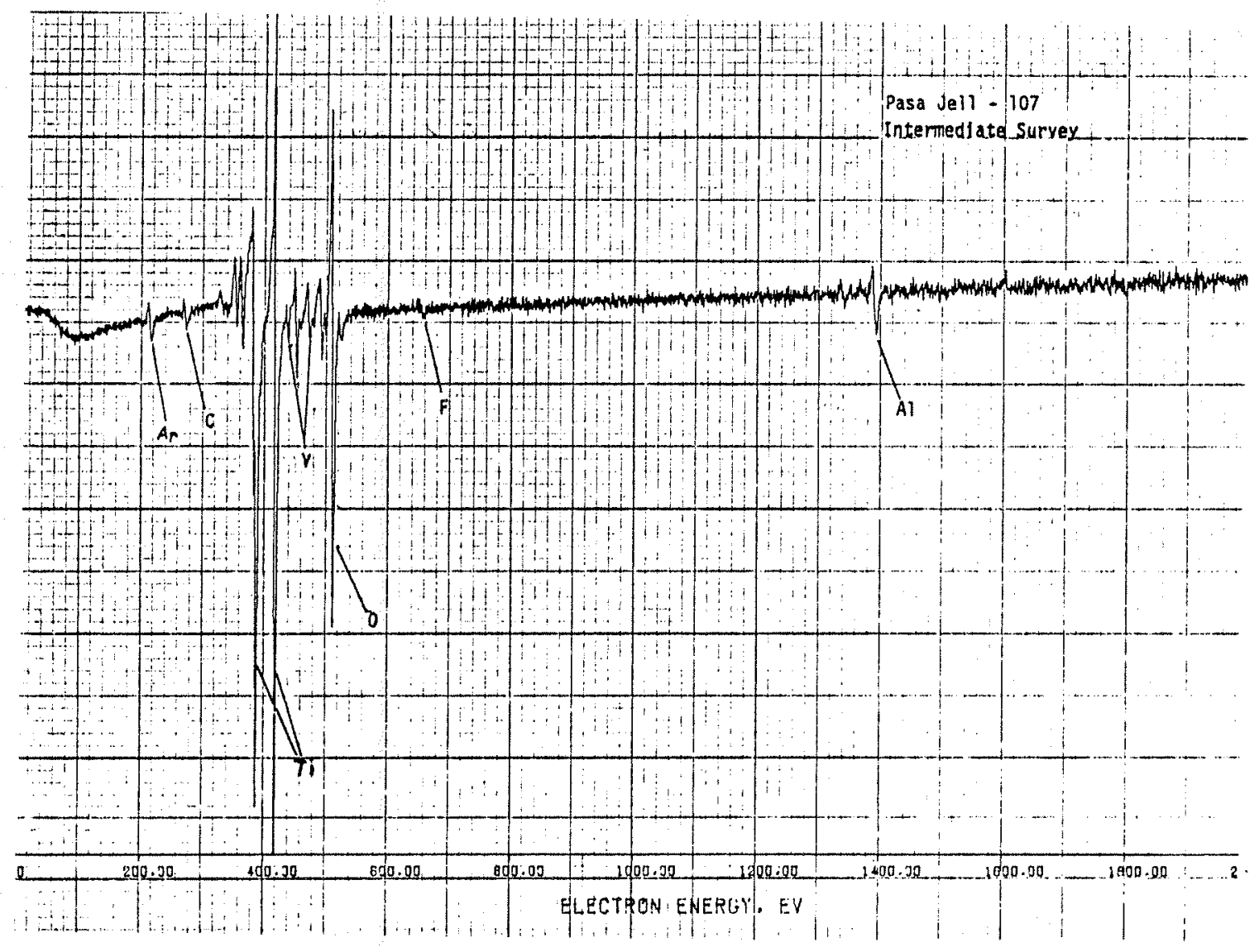

Figure 2.4.4-8 Pasa Jell 107 Intermediate Survey 
Figure 2.4.4-9 Phosphate Fluoride 5514 Treated, As-Received Surface

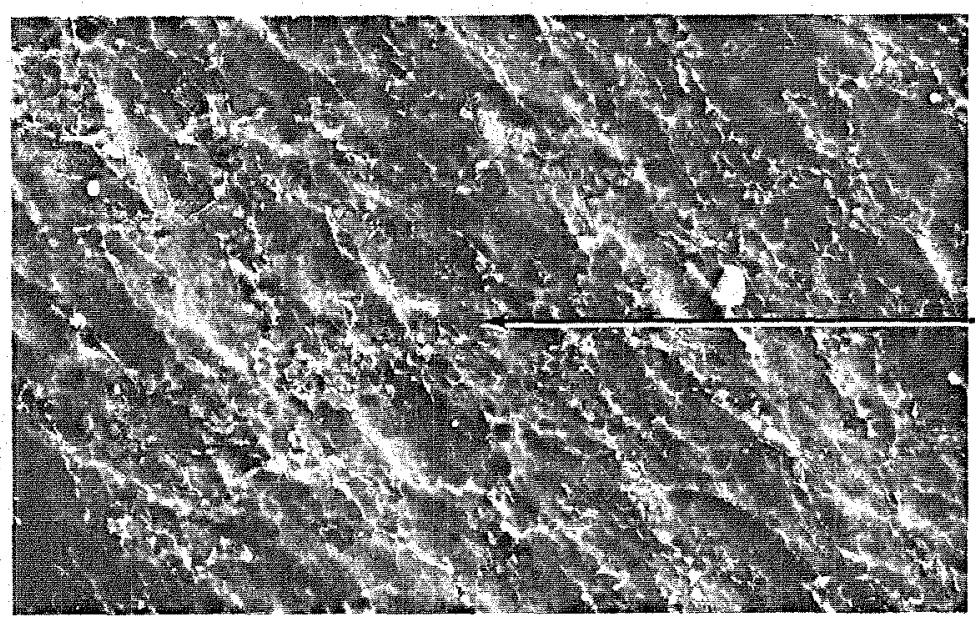

$1,000 x$

A

AREA SHOWN IN 20,000X

PHOTOGRAPH AT THE BOTTOM OF THIS PAGE

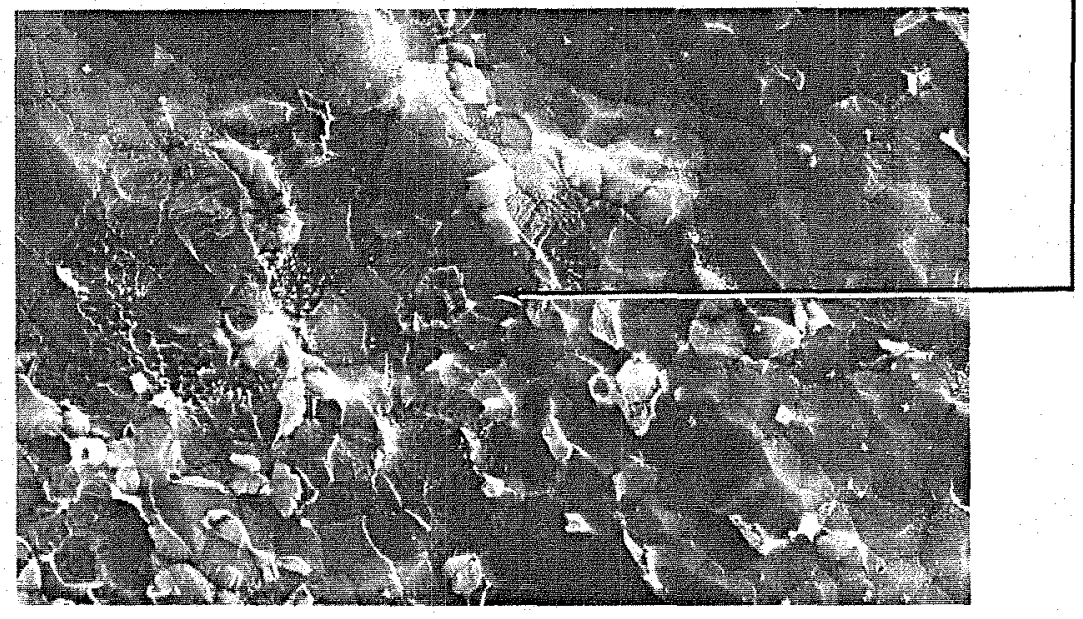

$5,300 x$

B

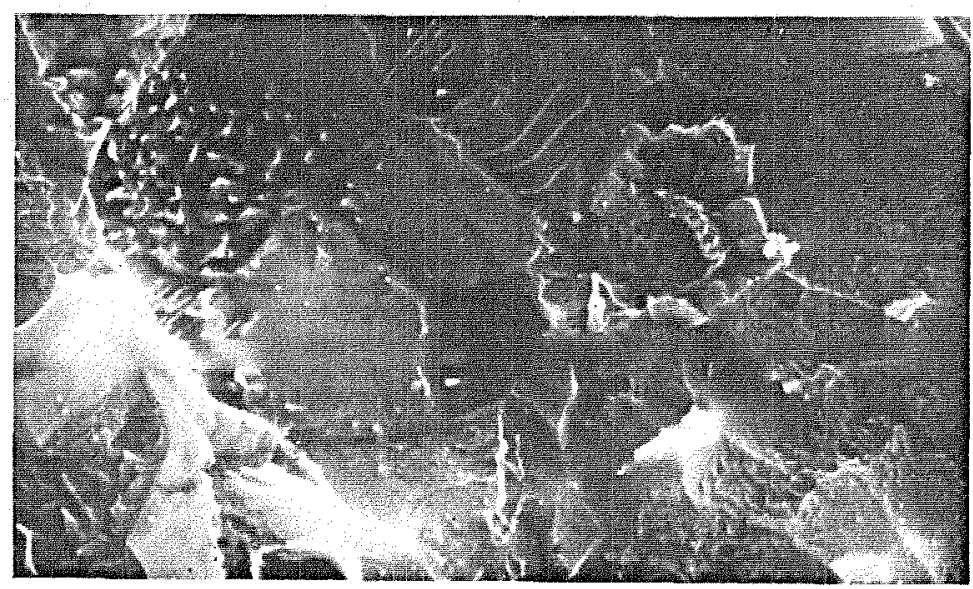

THESE PHOTOGRAPHS SHOW MORPHOLOGY SIMILAR TO FIGURE 2.4.3-6 


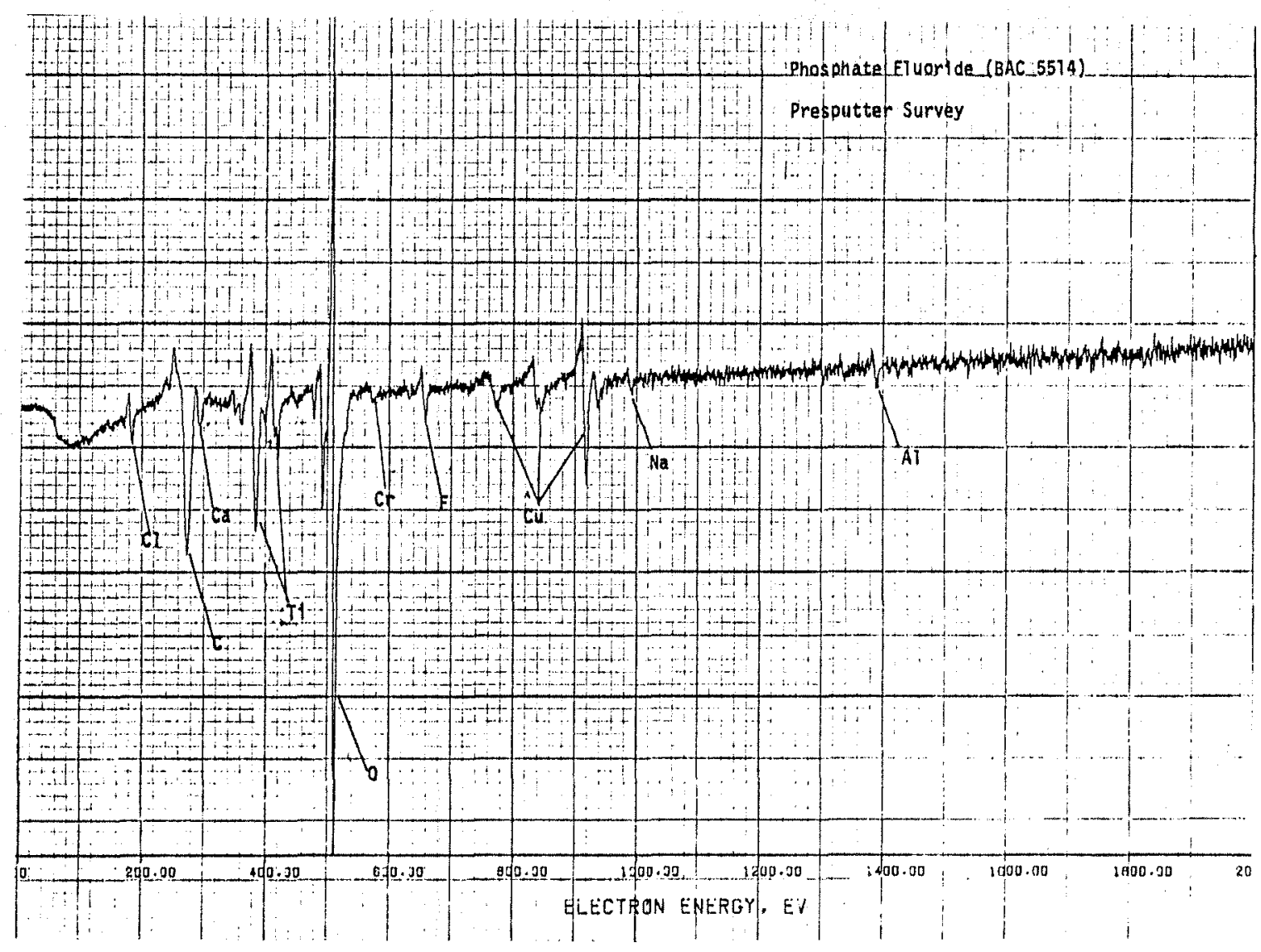

Figure 2.4.4-10 Phosphate Fluoride (BAC 5514) Presputter. Survey 


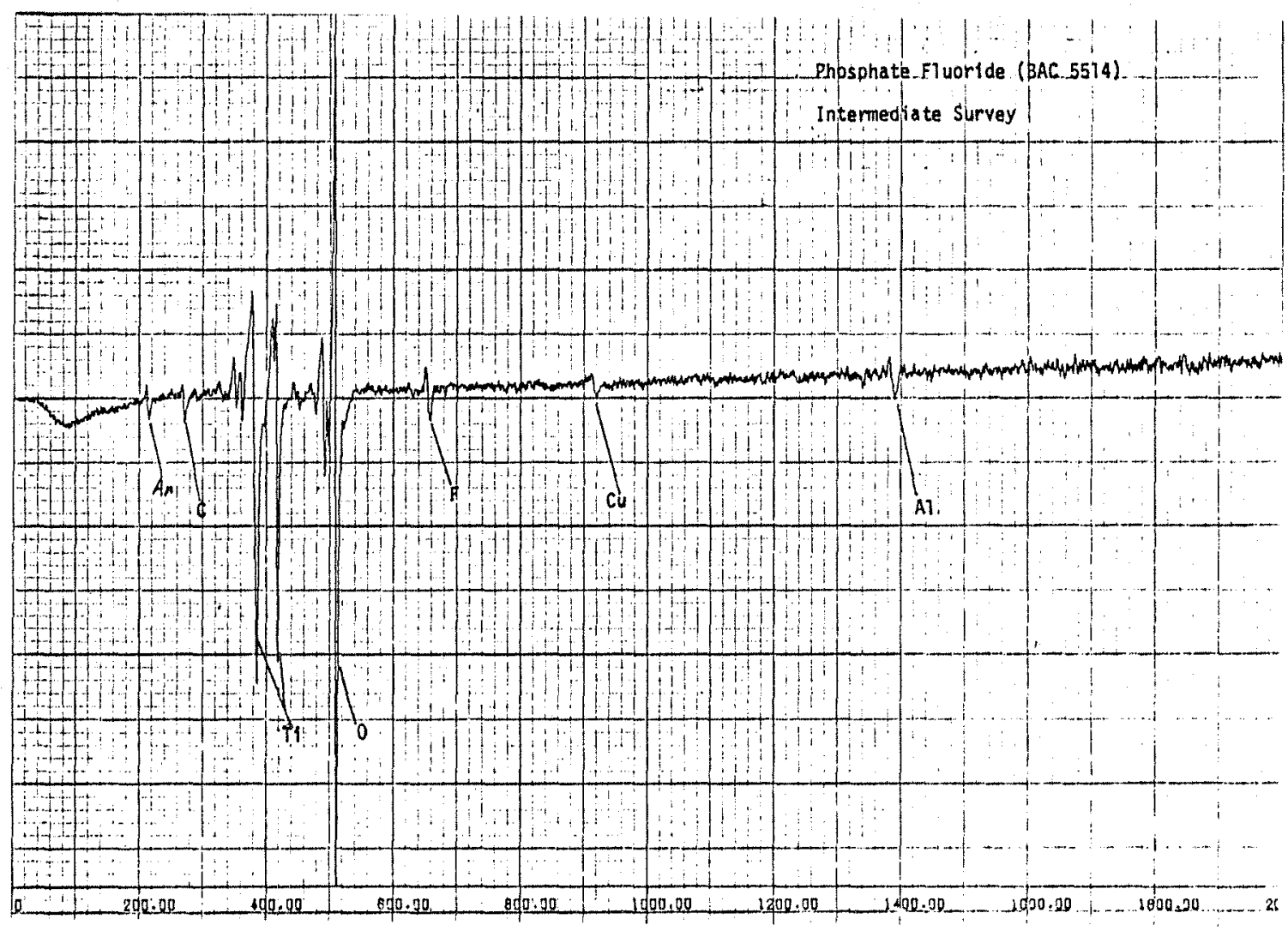

Figure 2.4.4-11 Phosphate Fluoride (BAC 5514) Intermediate Survey 
Figure 2.4.4-12 $\begin{aligned} & \text { Phosphate Fluoride Picatinny Modified Treatment, As-Received } \\ & \text { Surface }\end{aligned}$

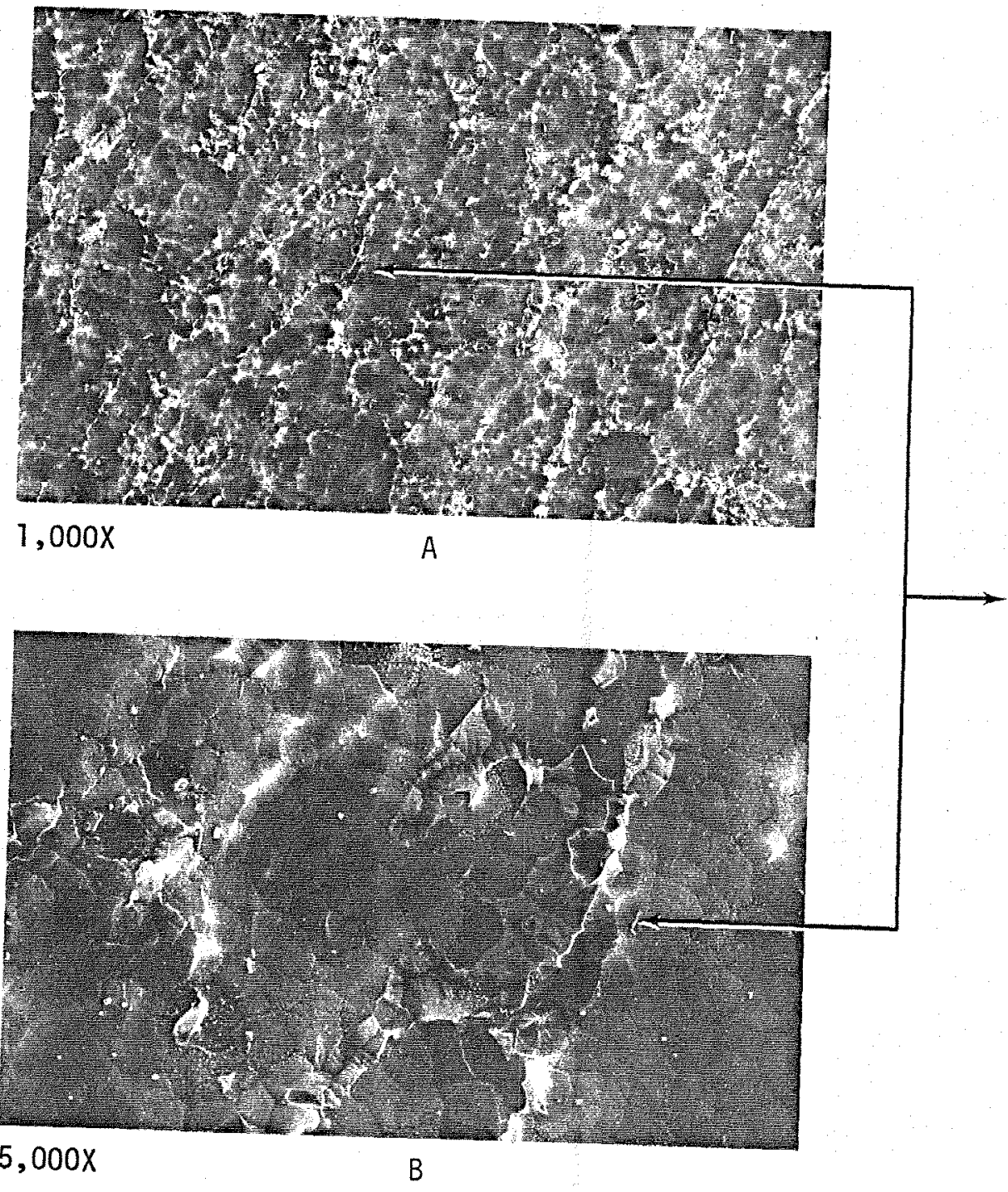

AREA SHOWN IN 20,000X

PHOTOGRAPH AT THE

BOTTOM OF THIS PAGE

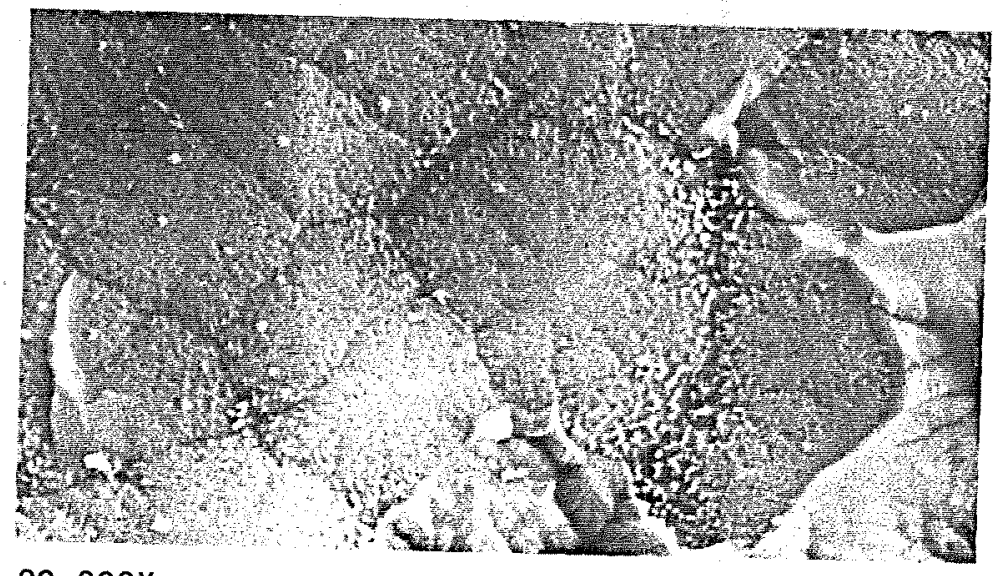

$20,000 x$

C 


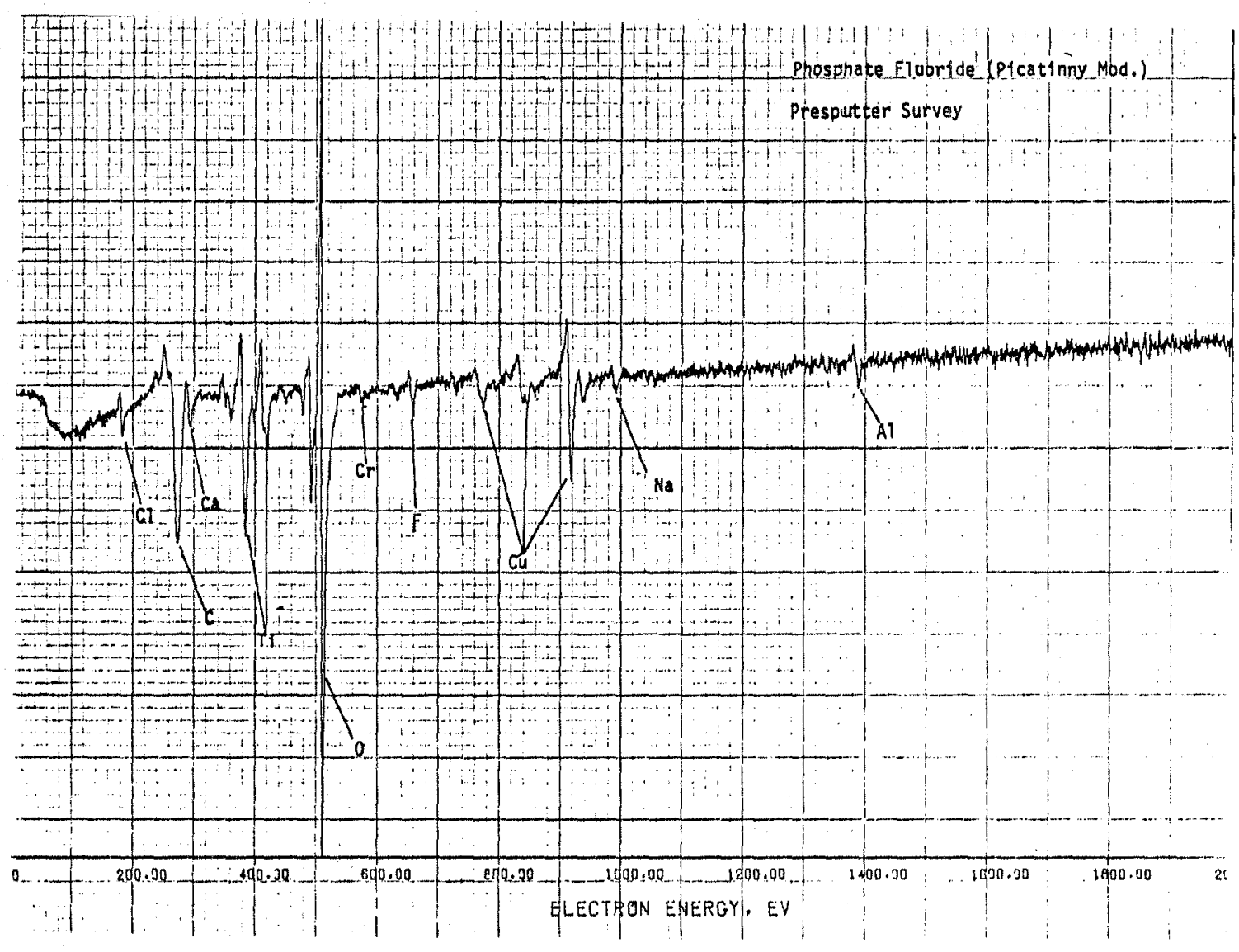

Figure 2.4.4-13 Phosphate Fluoride (Picatinny Mod.) Presputter Survey 


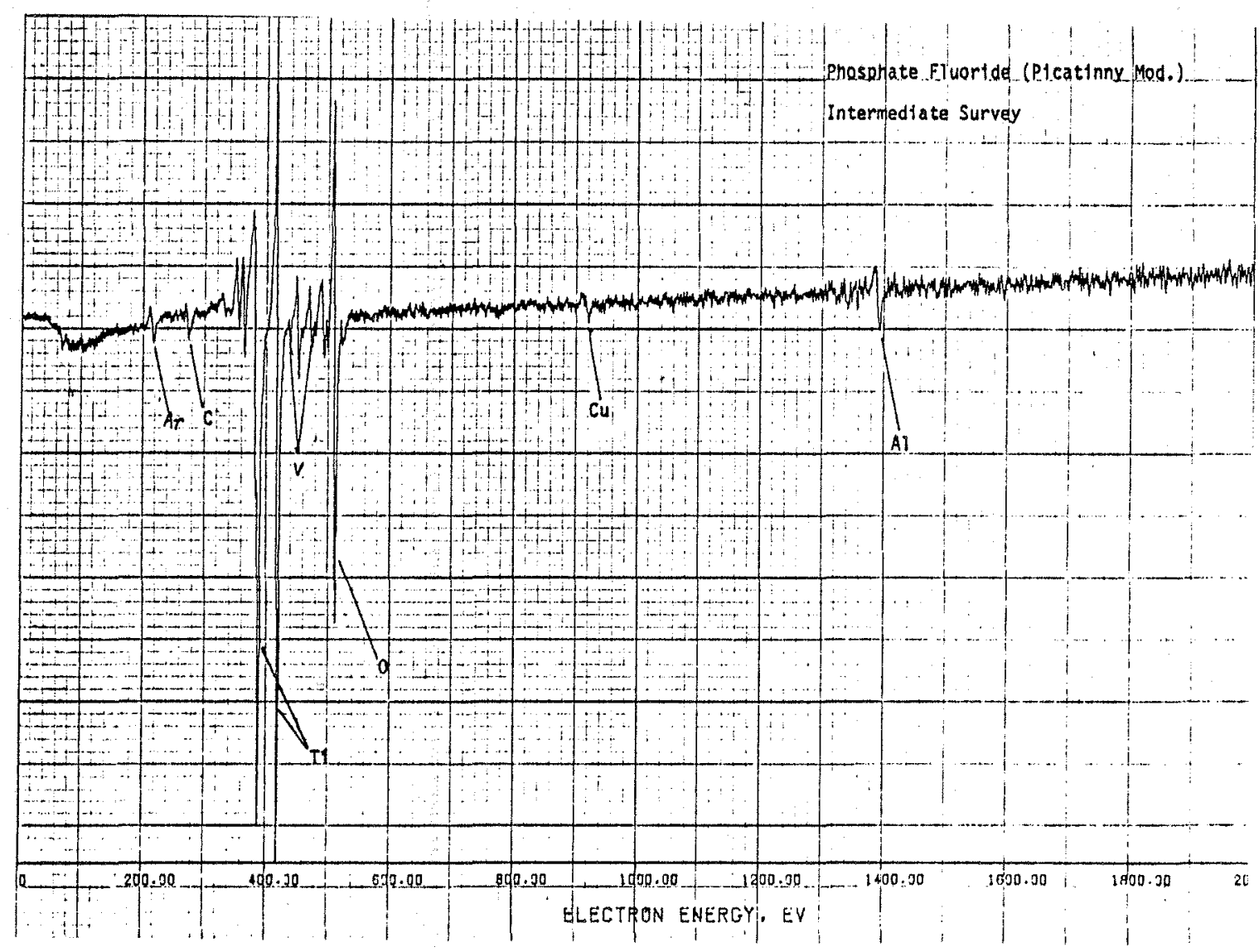

Figure 2.4.4-14 Phosphate Fluoride (Picatinny Mod.) Intermediate Survey 


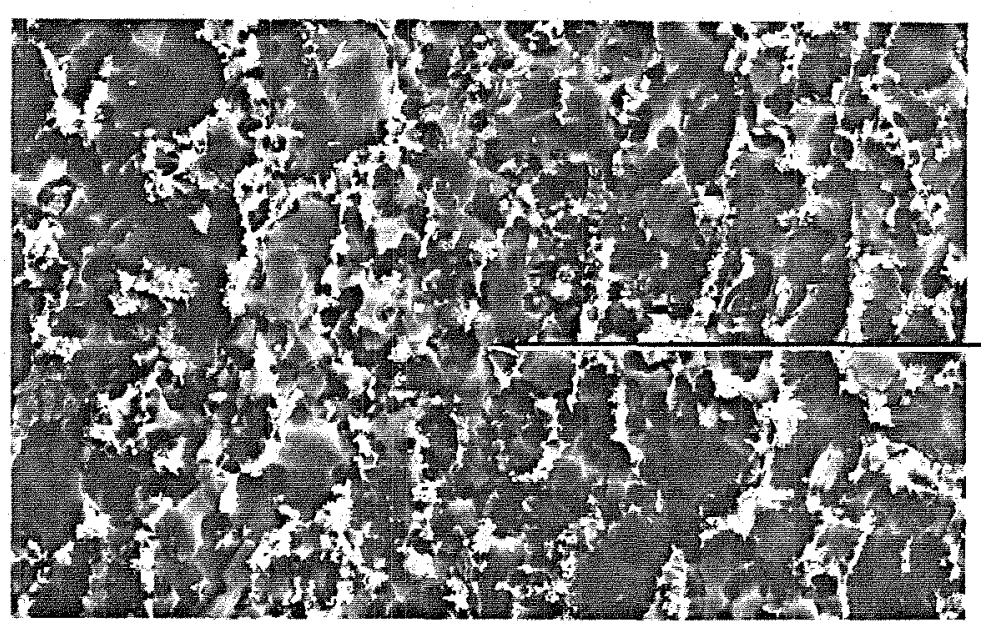

$1,000 x$

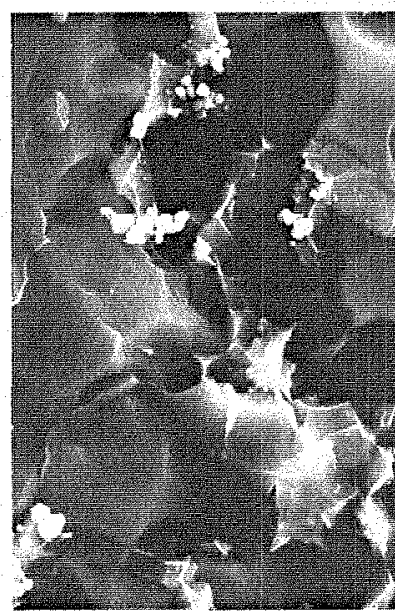

$5,000 x$

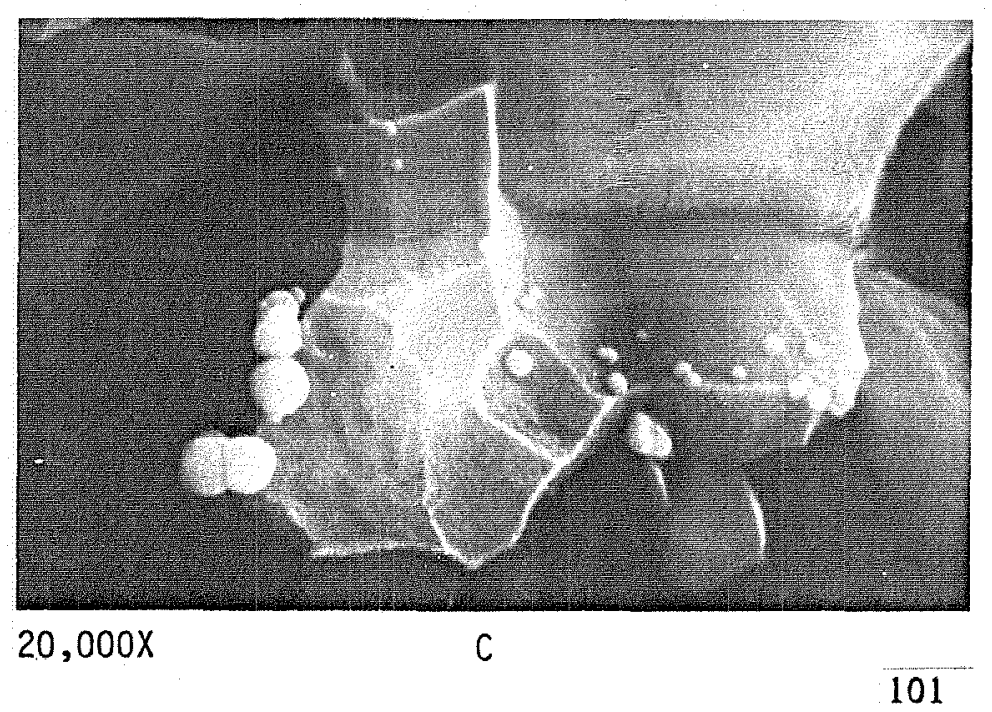

$20,000 x$
A

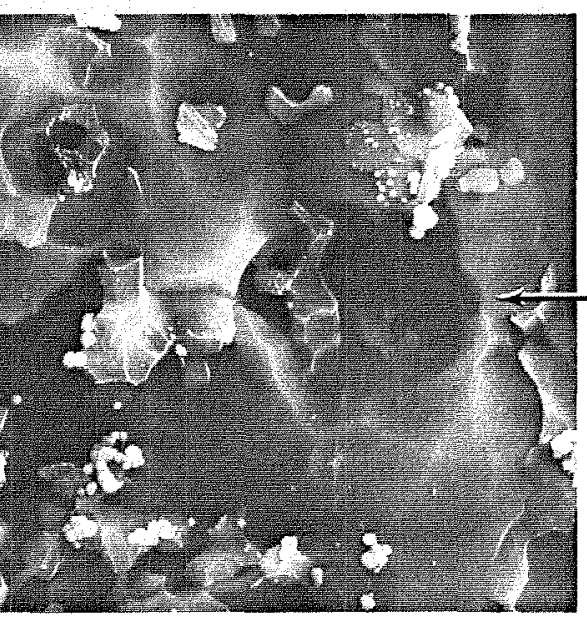

B
AREA SHOWN IN 20,000X

PHOTOGRAPH AT THE BOTTOM OF THIS: PAGE

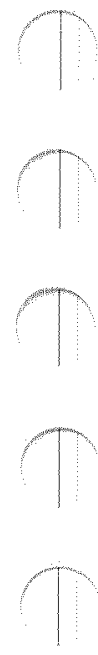

COMPARING THE 1000X FIGURES 2.4.3-6, $-11,-15$, AND -25 WITH THAT OF FIGURE 2.4.3-19, THE MACROSCOPIC FEATURES OF THE PASA-JELL, PHOSPHATE FLOURIDE, AND OLD BATH, IOV CAA STRUCTURES, RESPECTIVELY, ARE VERY SIMILAR TO THAT OF THE TURCO TREATMENT: . HOWEVER, NEITHER THE PASA-JELL NOR TURCO TREATMENTS INCLUDED A PRIOR HNO 3 /HF PICKLE AS DID THE PHOSPHATE FLOURIDE, CAA, AND PICATINNY-MODIFIED TREATMENTS: 


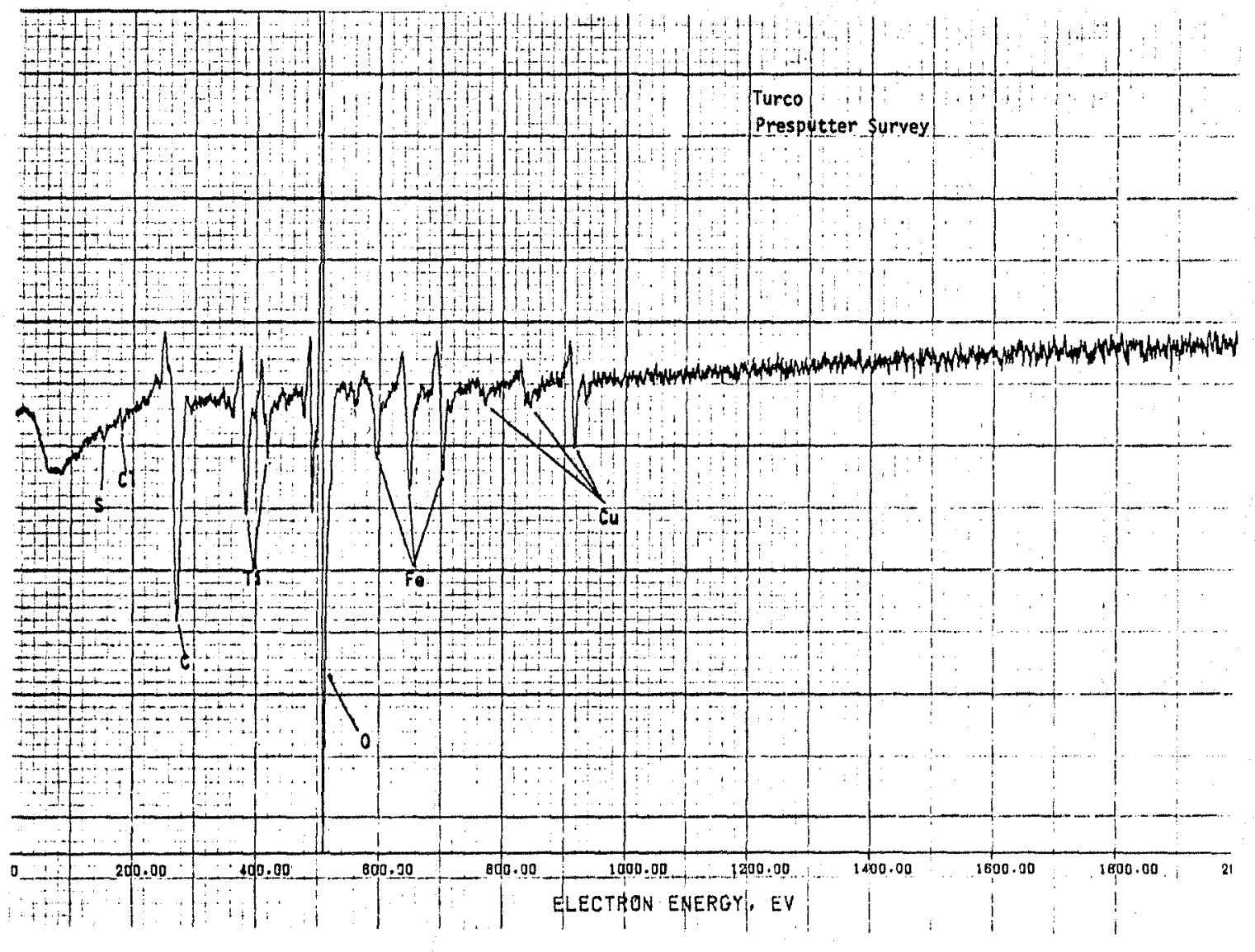

Figure 2.4.4-16 Turco Presputter Survey 


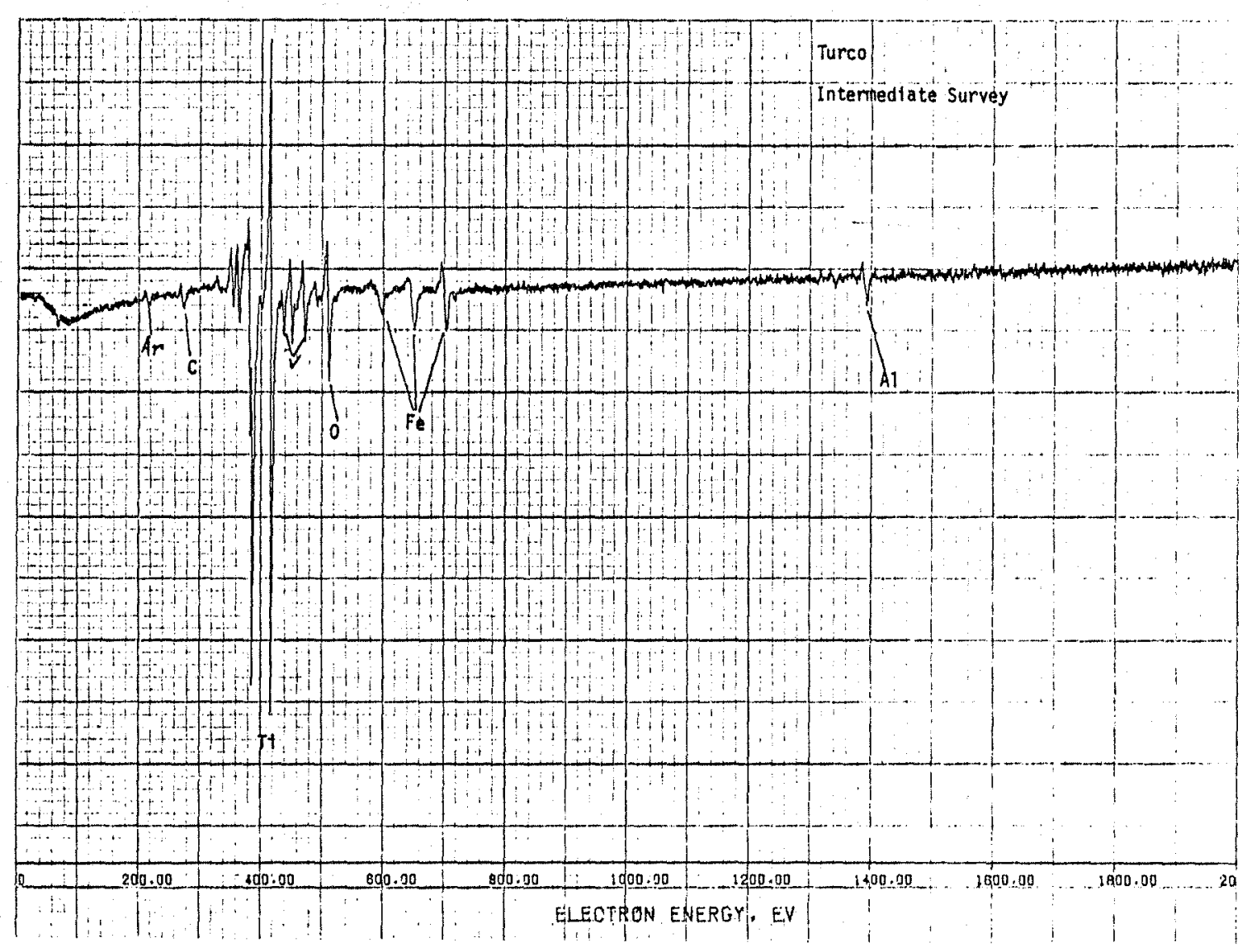

Figure 2.4.4-17 Turco Intermediate Survey 


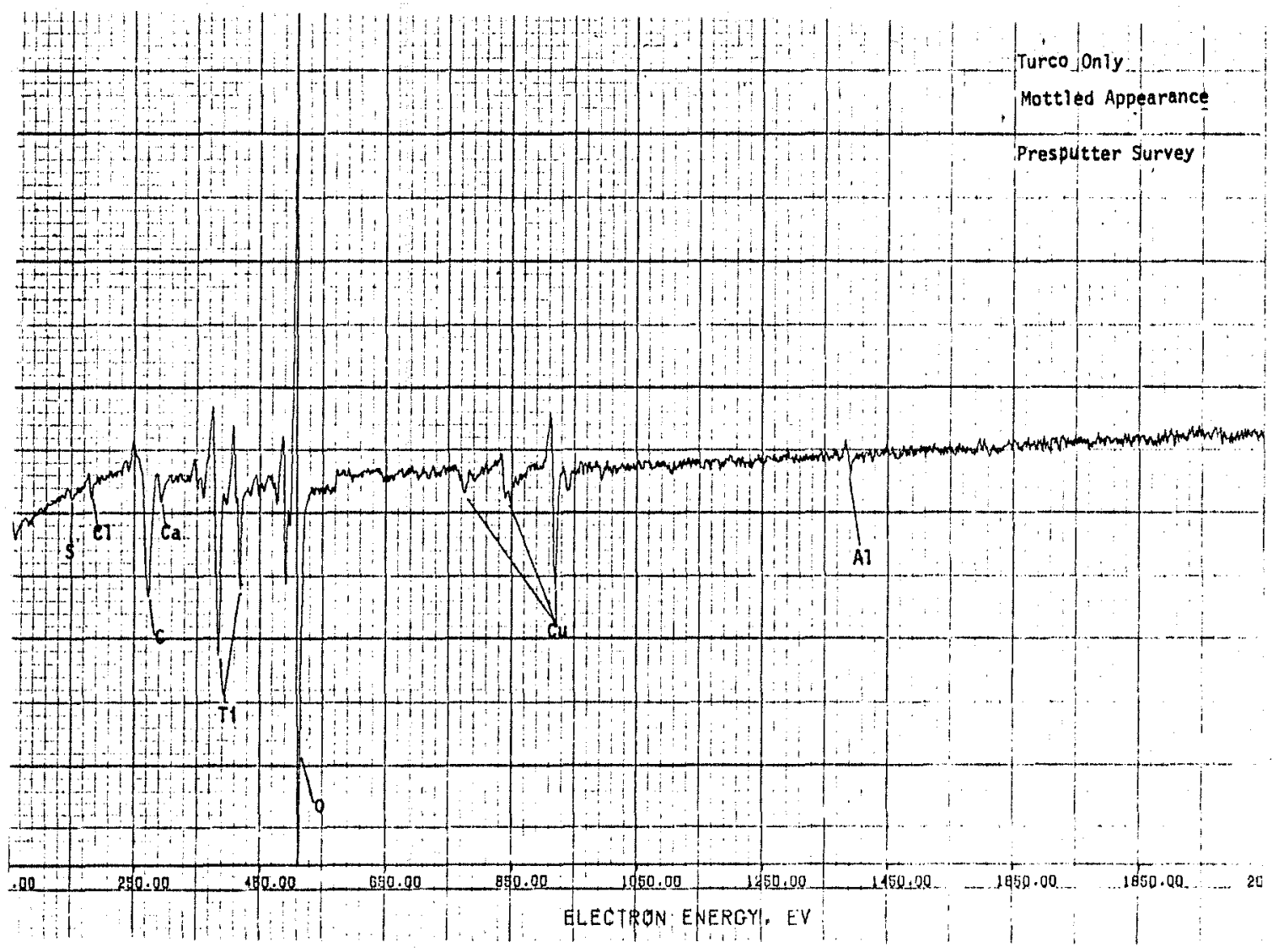

Figure 2.4.4-18 Turco Only Mottled Appearance Presputter Survey 
Figure 2.4.4-19 10-V Chromic Acid Anodize, No Heat Treatment, As-Received Surface, Old Bath
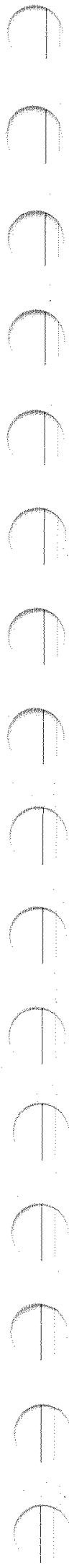

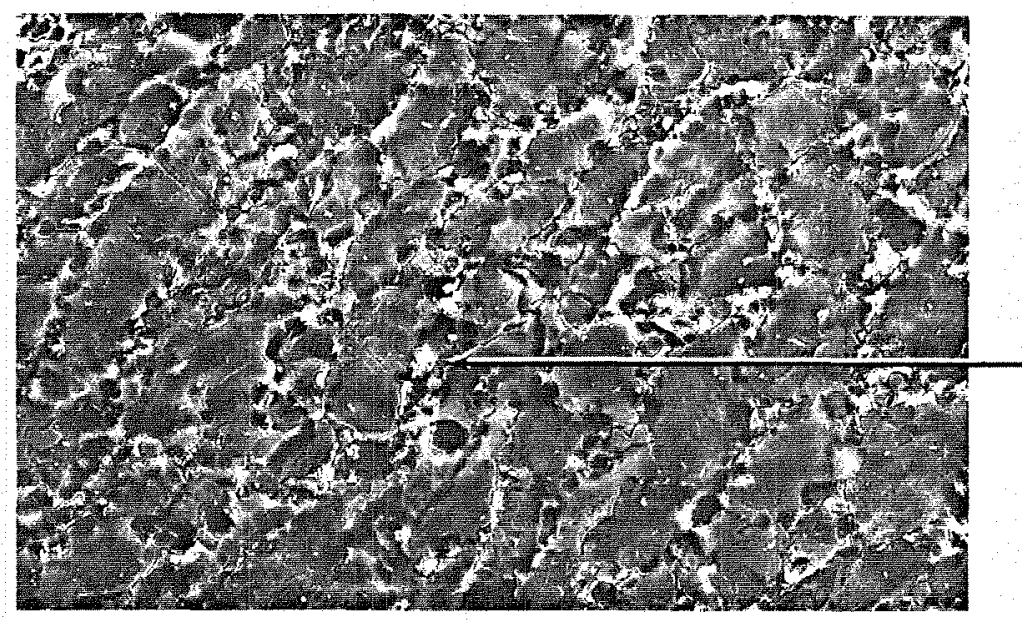

$1,000 x$

A

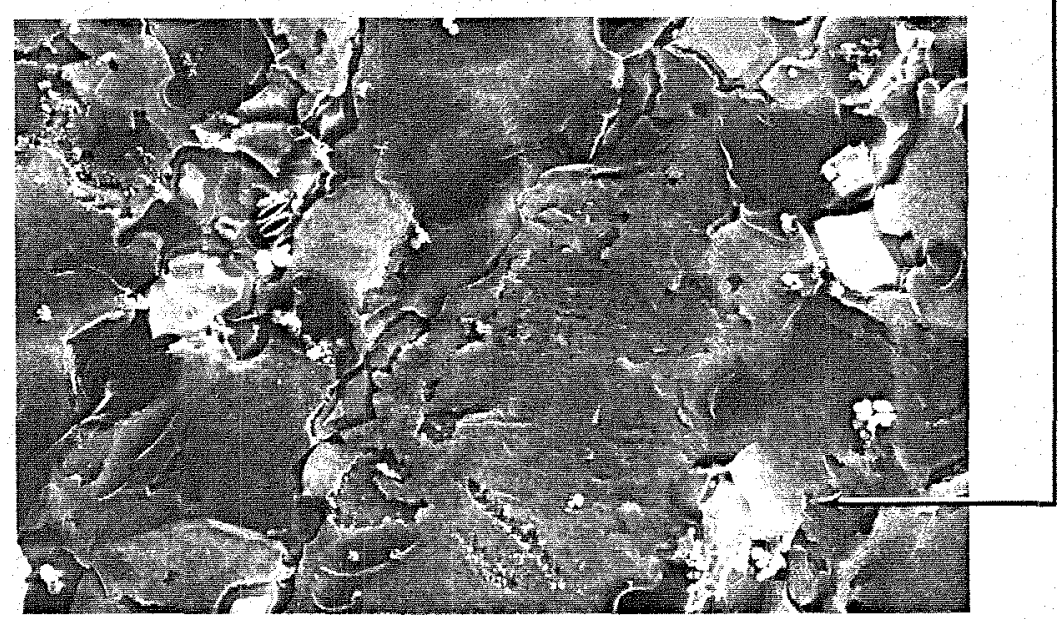

$5,000 x$

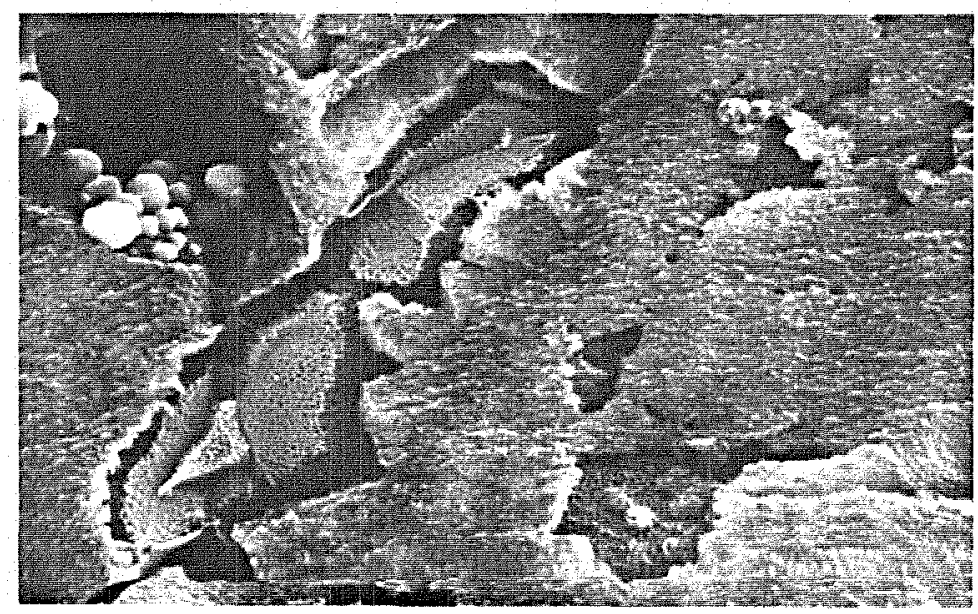

$20,000 x$
B

C
AREA SHOWN IN 20,000X

PFITOGRAPH AT THE

BOTTOM OF THIS PAGE
AN APPARENT SURFACE

CONTAMINANT OR DUPLEX OXIDE PRESENT OVERLAYING THE PRIMARY OXIDE 

$\begin{array}{ll}\text { Figure } 2.4 .4-20 & \text { 10-V Chromic Acid Anodize, No Heat Treatment, Lab-Fractured, } \\ \text { Old Bath }\end{array}$
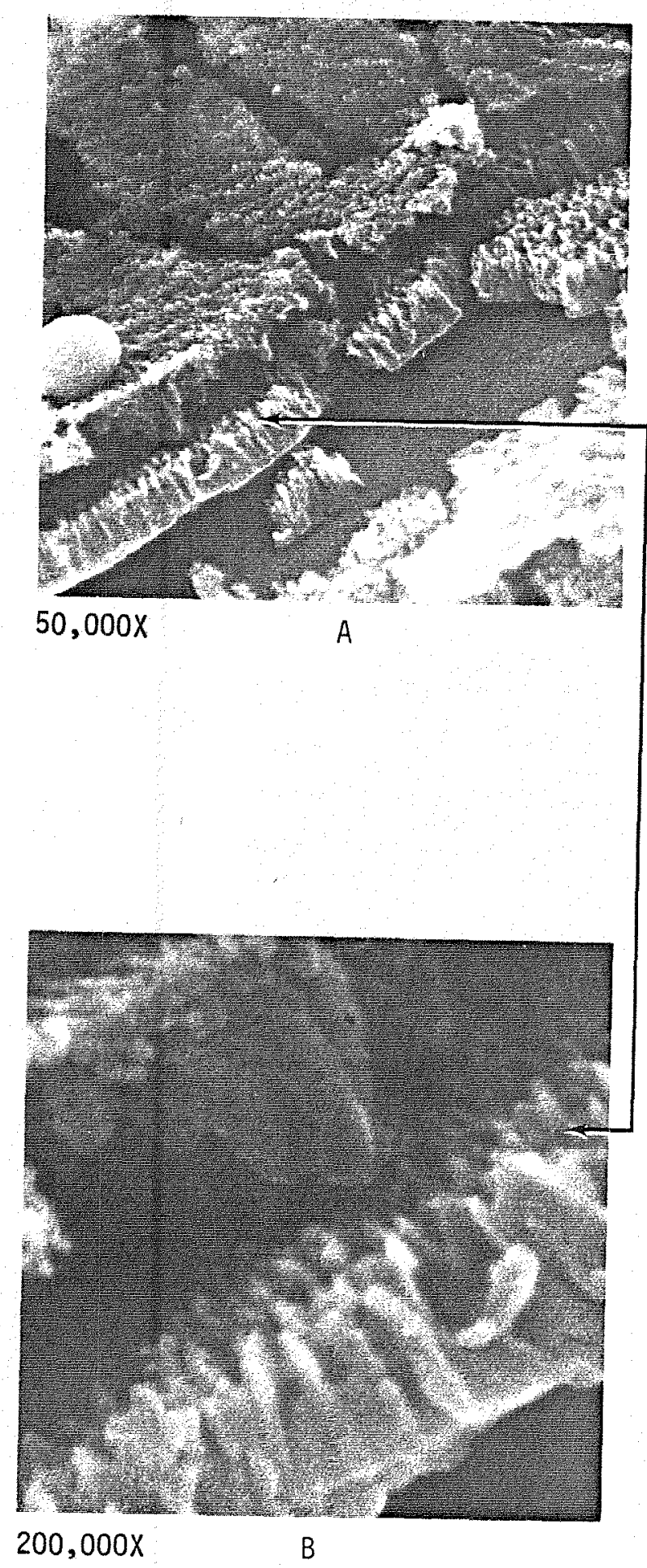

THE OXIDE HAS A COLUMNAR STRUCTURE WITH APPARENT CELL WALLS AND THICKNESS $O F \approx 1400 A^{\circ}$ 
Figure 2.4.4-21 10-V Chromic Acid Anodize, Heat Treated to $588 \mathrm{~K}\left(600^{\circ} \mathrm{F}\right)$ for 1 Hour, Lab-Fractured, Old Bath

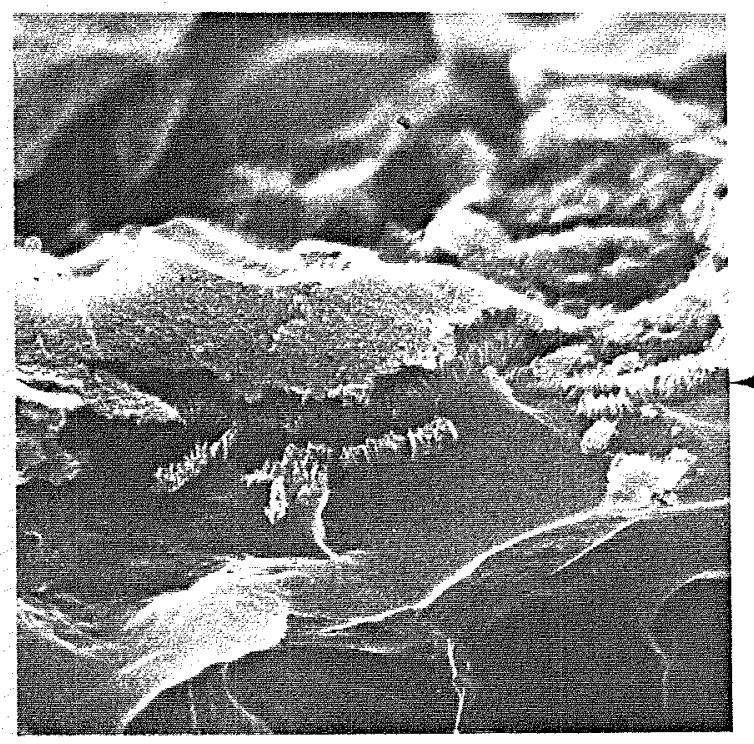

$20,000 x$

A

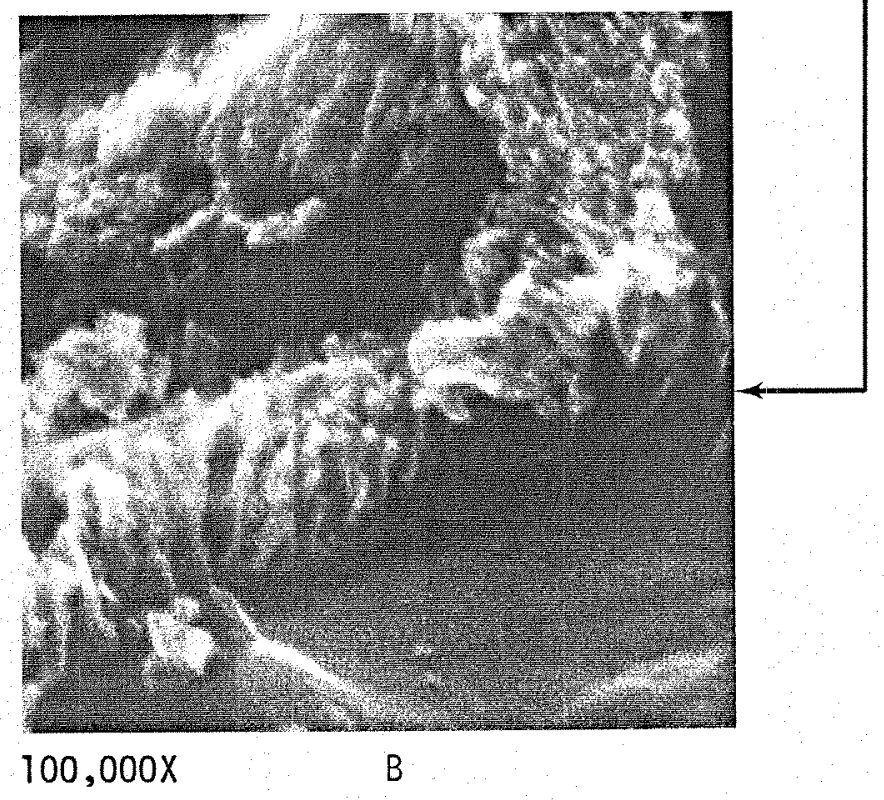

THE OXIDE STRUCTURE IS COLUMNAR WITH APPARENT CELL WALLS AND A THICKNESS OF $\approx 1300 \mathrm{~A}^{\circ}$ 
Figure 2.4.4-22 10-V Chromic Acid Anodize, Heat Treated to $672 \mathrm{~K}(750 \circ \mathrm{F})$ for 1 Hour, Lab-Fractured, Old Bath

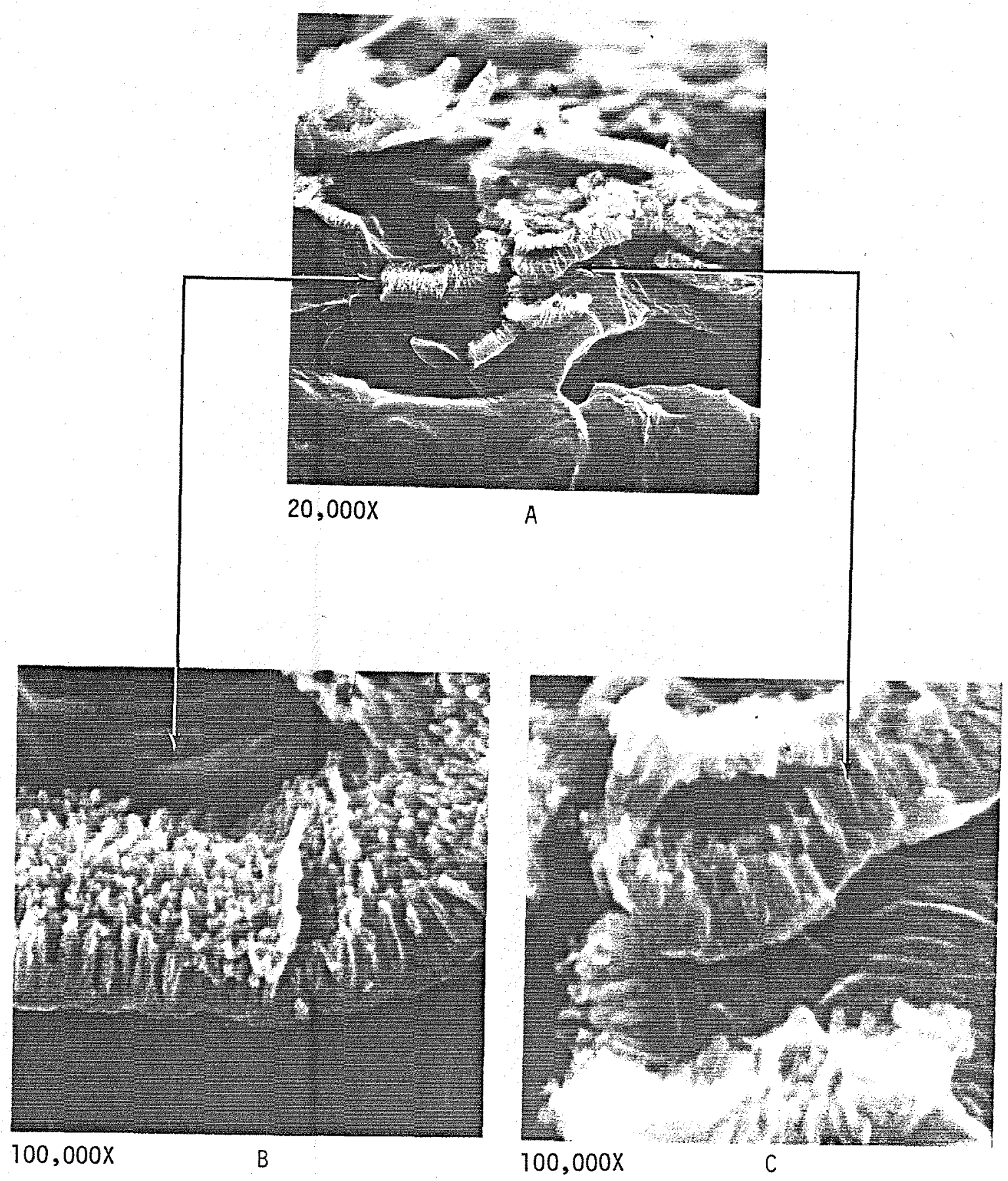

THE OXIDE STRUCTURE IS

COLUMNAR WITH APPARENT

CELL WALLS AND A

THICKNESS OF $\approx 1500 \AA$ 
Figure 2.4.4-23 5-V Chromic Acid Anodize, As-Received Surface, Old Bath

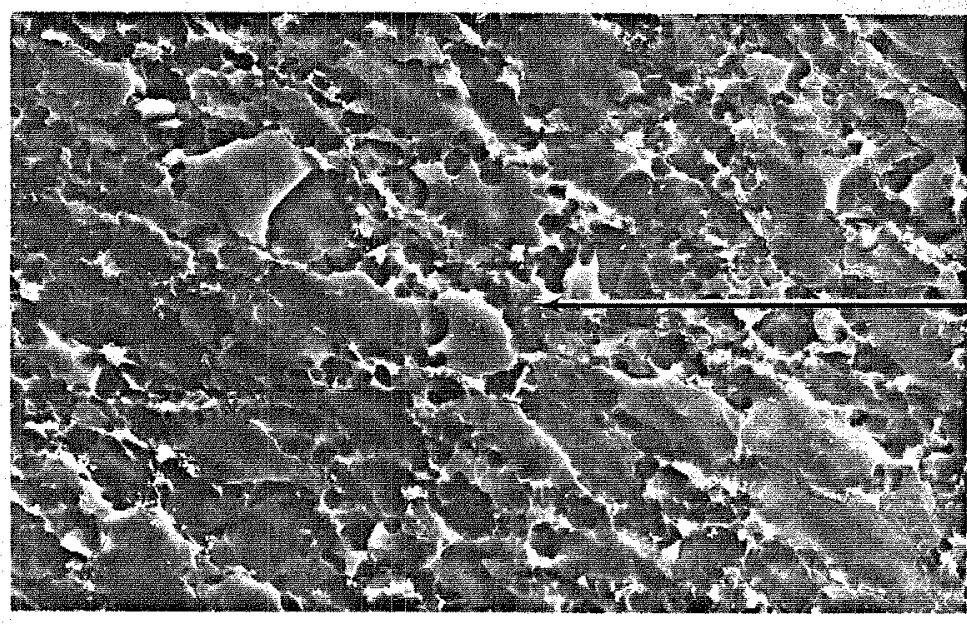

$1,000 x$

A

AREA SHOWN IN 20,000X

PHOTOGRAPH AT THE

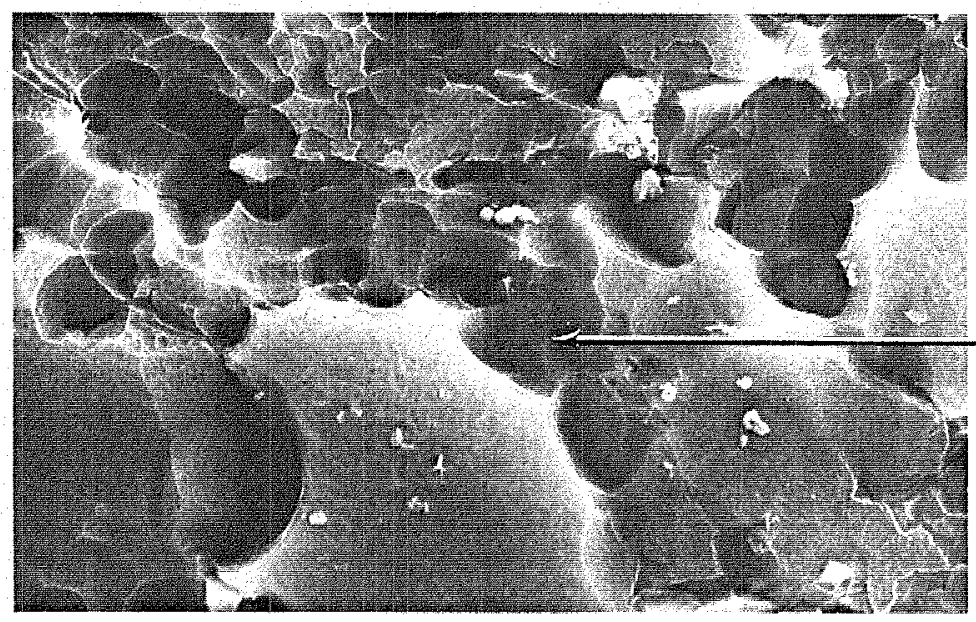

BOTTOM OF THIS PAGE

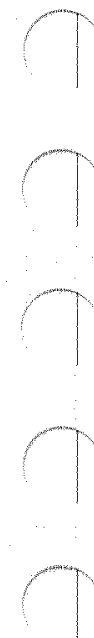

$5,000 x$

B

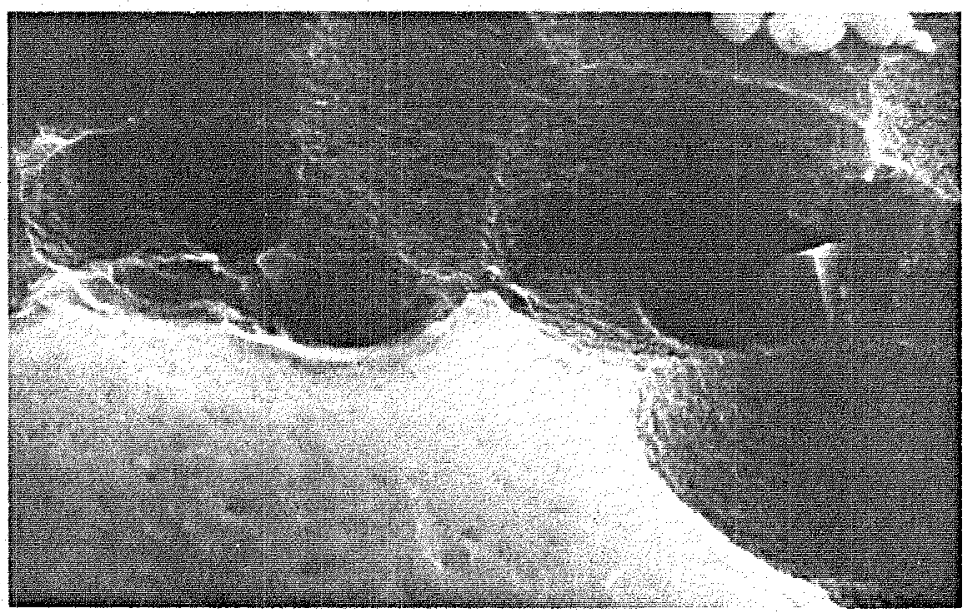

THIS OXIDE APPEARS

SUPERIOR TO THE OLD

BATH, 10 VOLTS CAA OXIDE

WHICH HAS AN ADDITIONAL

LAYER OF CONTAMINATION OR DUPLEX OXIDE.

$20,000 x$

C 
Figure 2.4.4-24 10-V Chromic Acid Anodize, As-Received Surface, New Bath

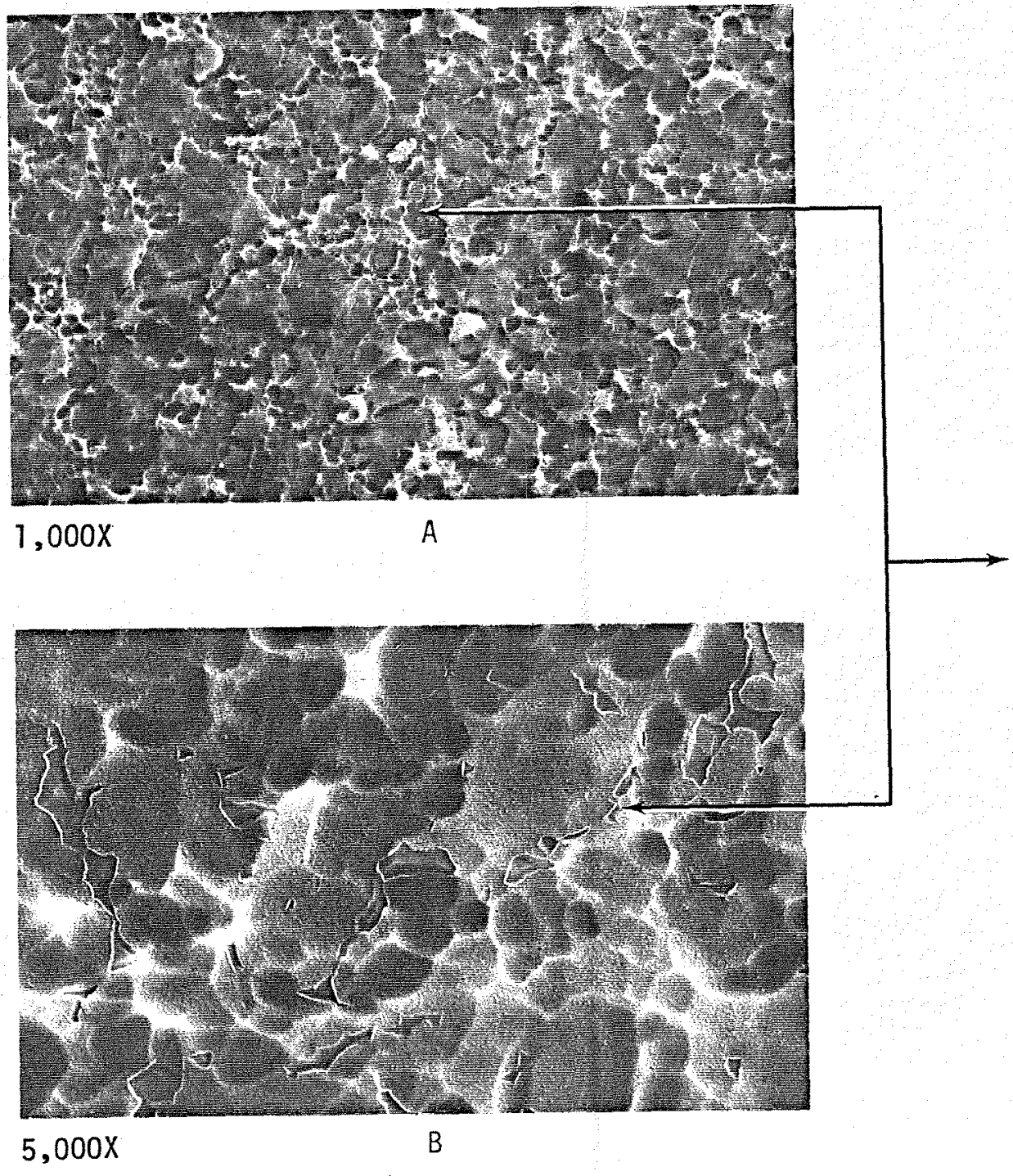

AREA SHOWN IN 20,000X

PHOTOGRAPH AT THE

BOTTOM OF THIS PAGE

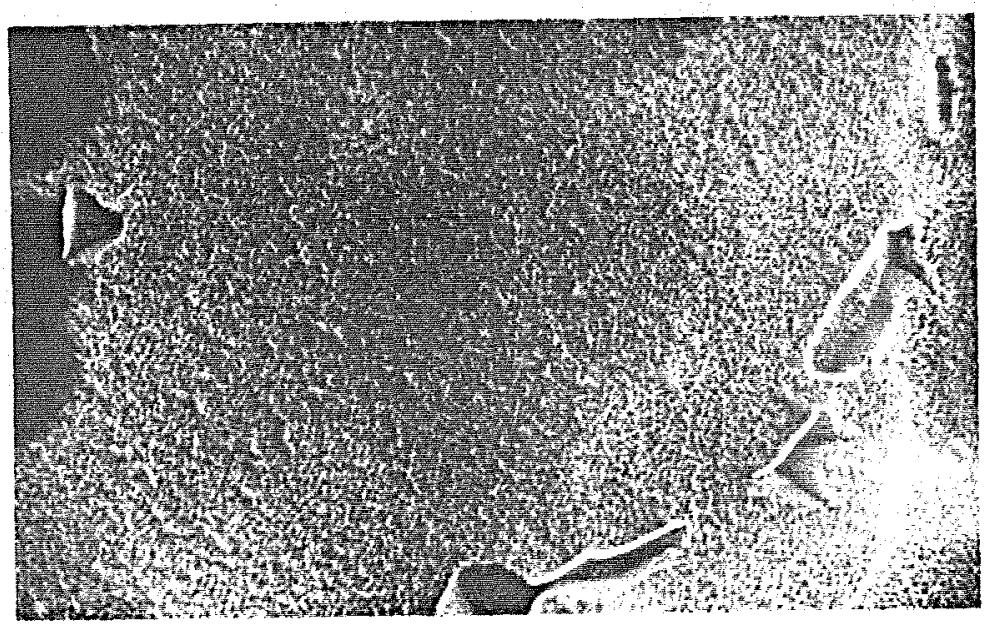

THE NEW BATH USED TO PRODUCE

THIS OXIDE HAS ALTERED THE MICROSTRUCTURE RELATIVE TO THAT PRODUCED BY THE OLD BATH, FIGURES 2.4.3-25 AND -29; THE CONTAMINATING LAYER HAS BEEN ELIMINATED. 
Figure 2.4.4-25 10-V Chromic Acid Anodize, No Heat Treatment, New Bath, LabFractured

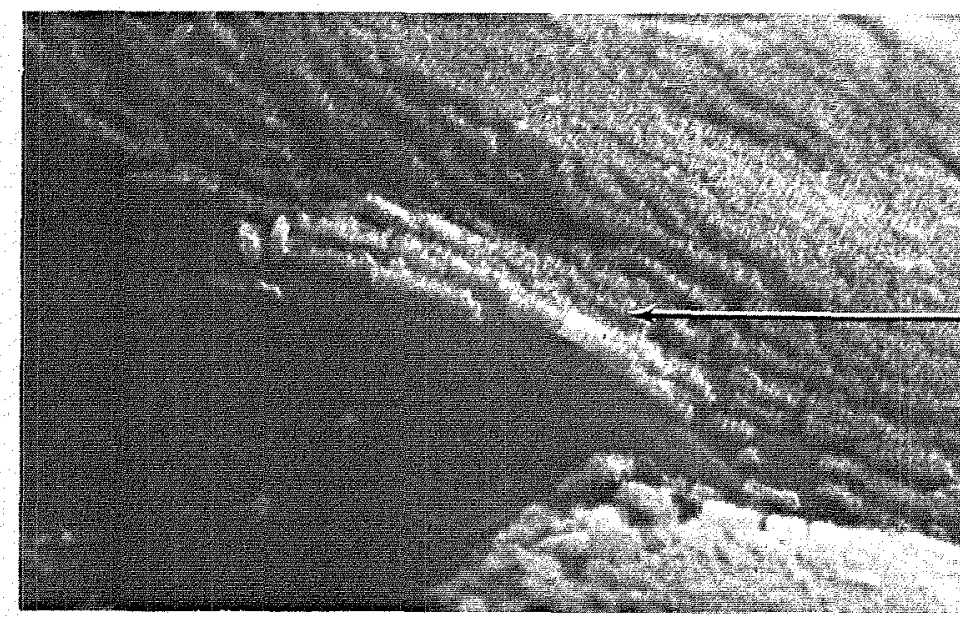

$20,000 x$

A

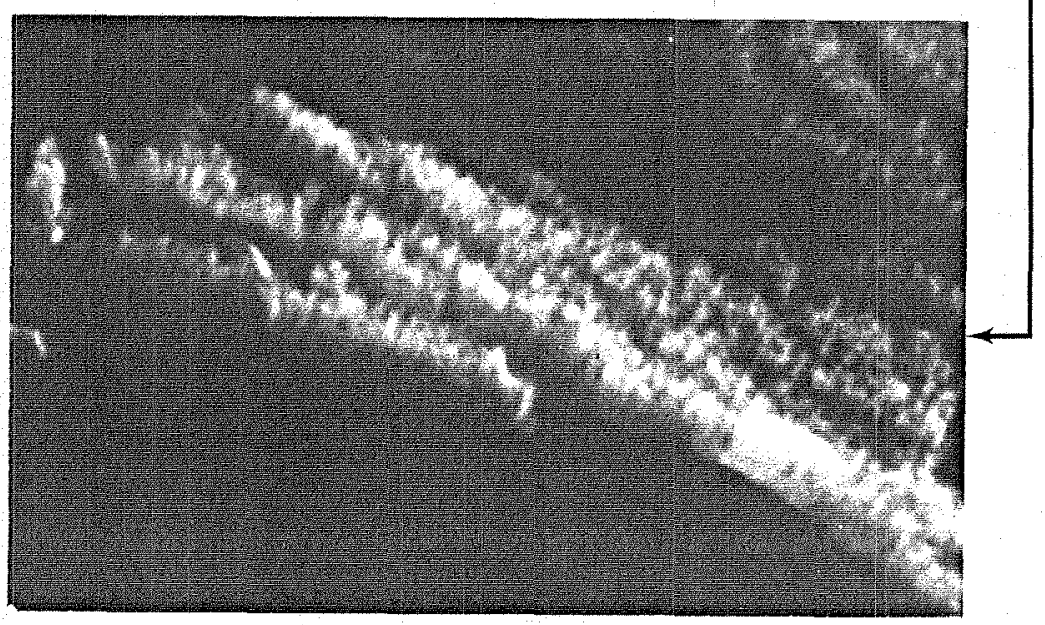

$50,000 x$

B

THESE PHOTOGRAPHS OF A

LAB-FRACTURED SPECIMEN DO

NOT SHOW AN OVERLAYING

CONTAMINANT OR OXIDE

(COMPARE WITH FIGURES

2.4.3-25 AND -28). OXIDE

THICKNESS IS $\approx 1200 \AA$. 


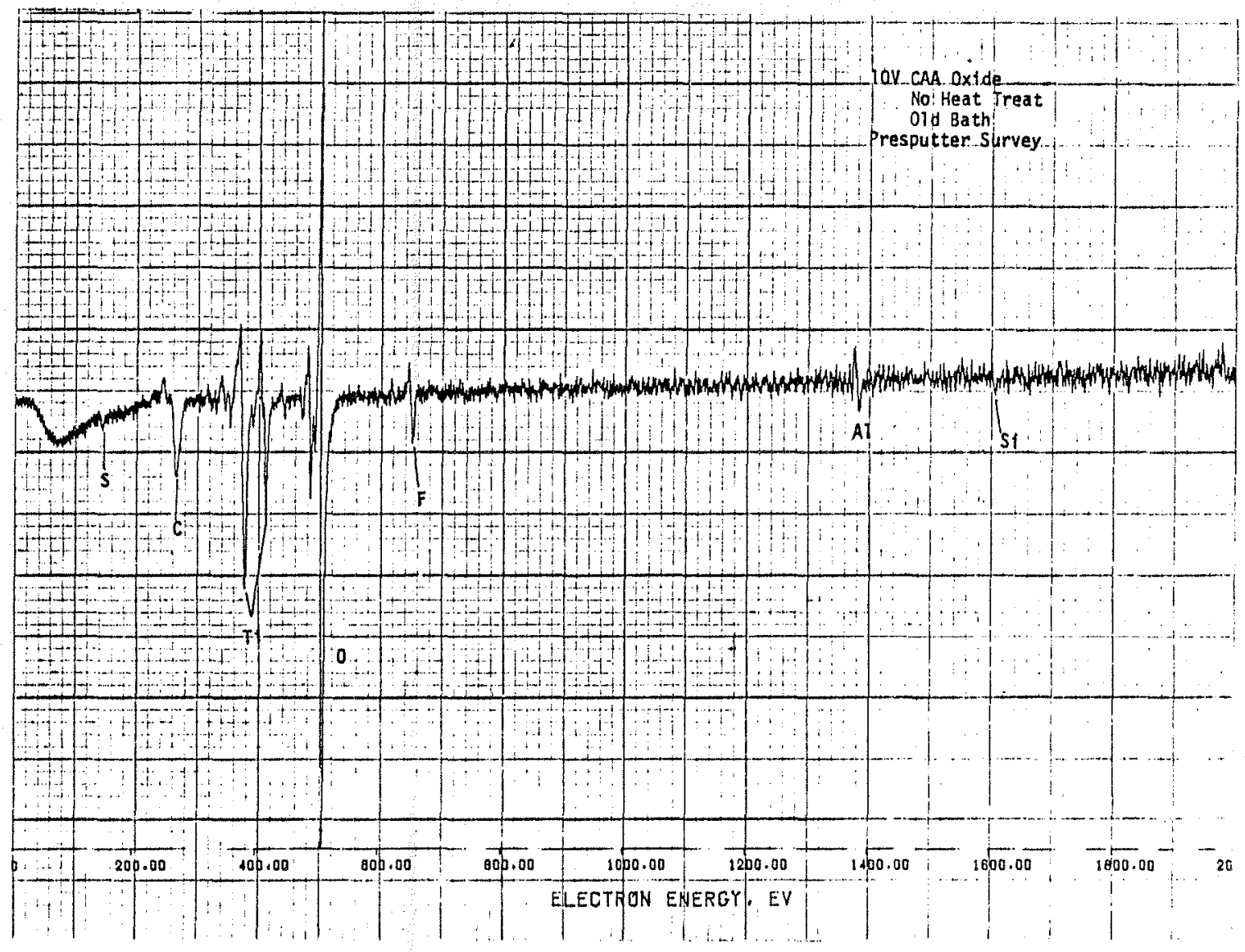

Figure 2.4.4-26 10-V CAA Oxide, No Heat Treat, Old Bath, Presputter Survey 


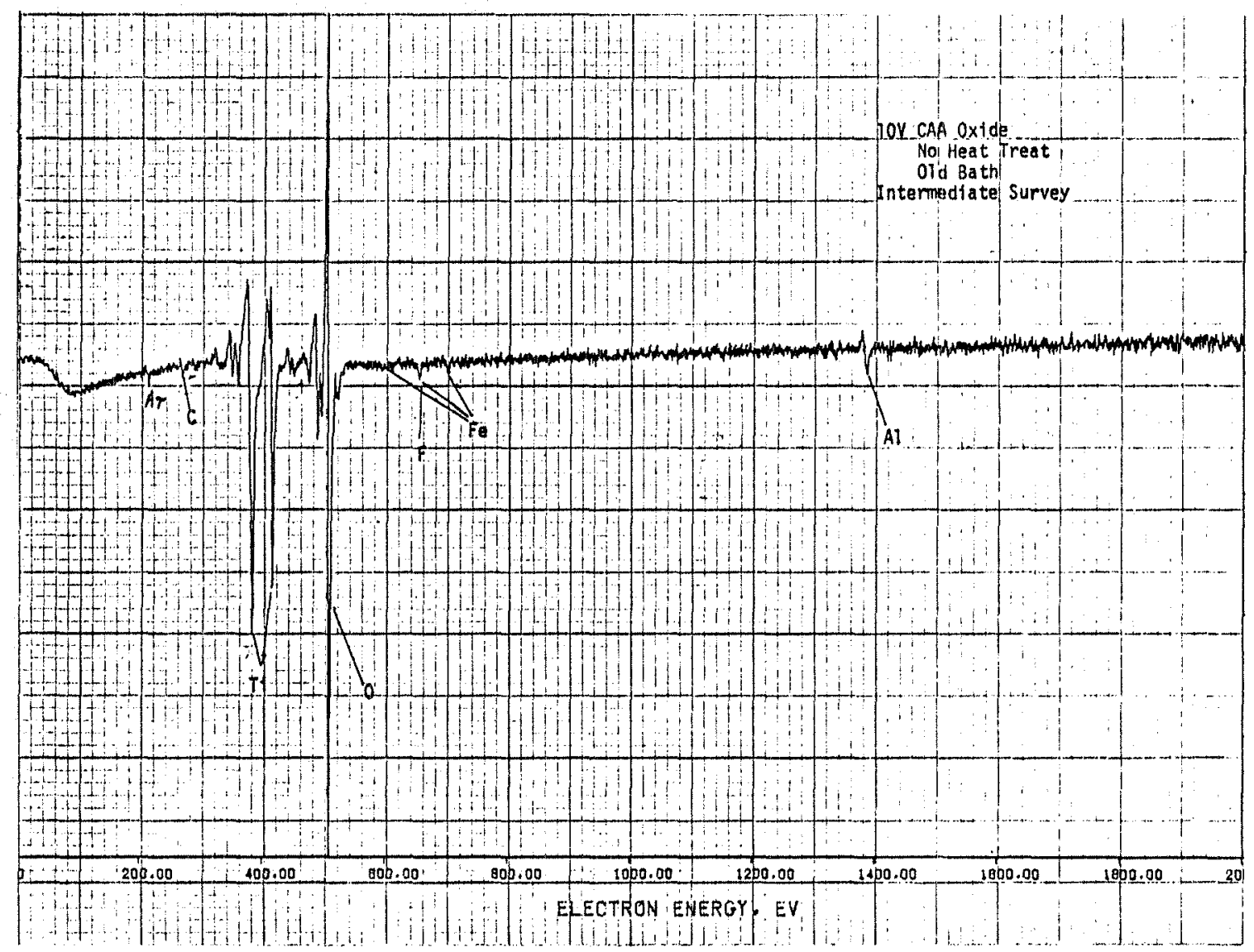

Figure 2.4.4-27 10-V CAA Oxide, No Heat Treat, Old Bath, Intermediate Survey 


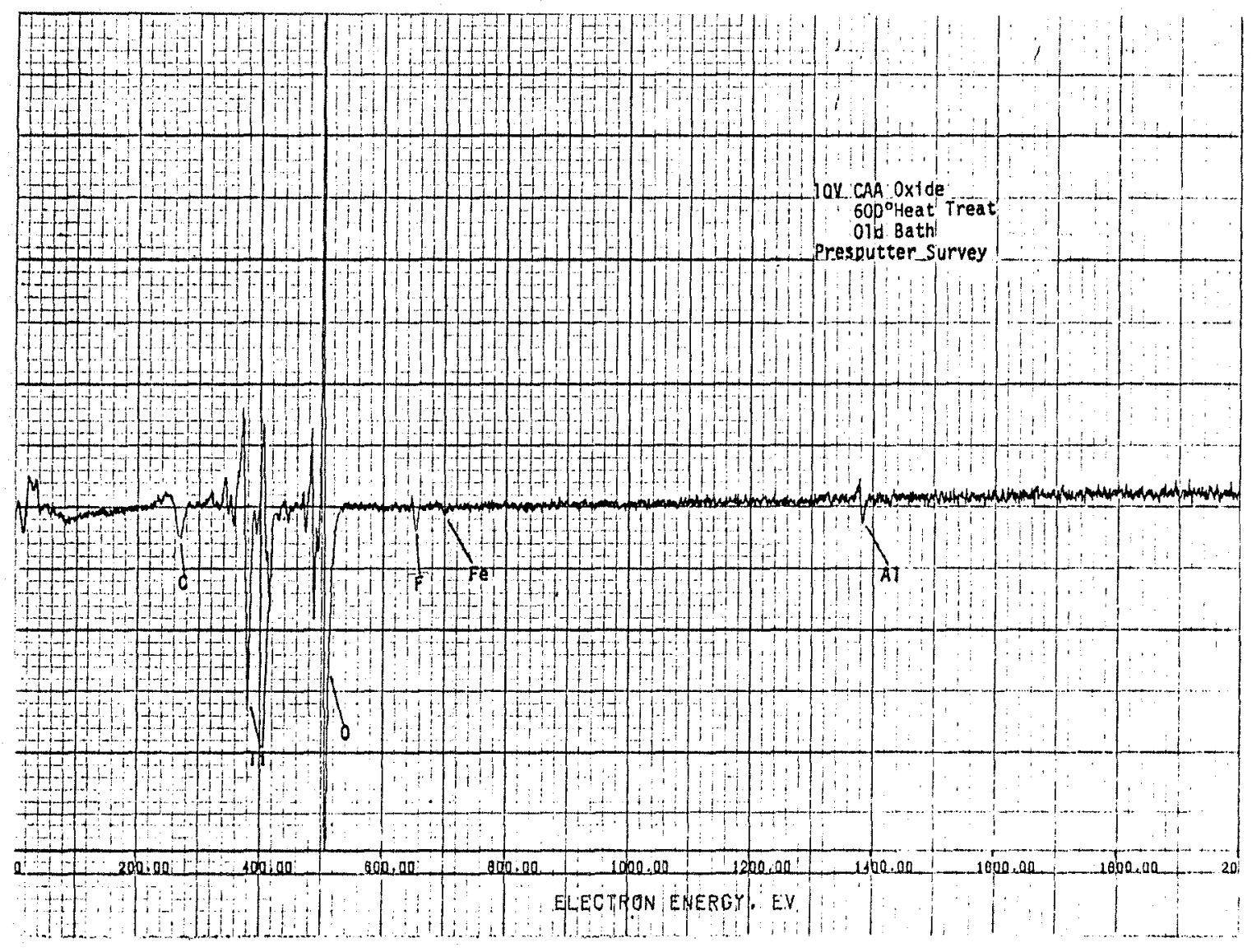

$\begin{array}{ll}\text { Figure 2.4.4-28 } & \begin{array}{l}\text { 10-V CAA Oxide, } 588 \mathrm{~K}\left(600^{\circ} \mathrm{F}\right) \text { Heat Treat, Old Bath, Presputter } \\ \text { Survey }\end{array}\end{array}$ 


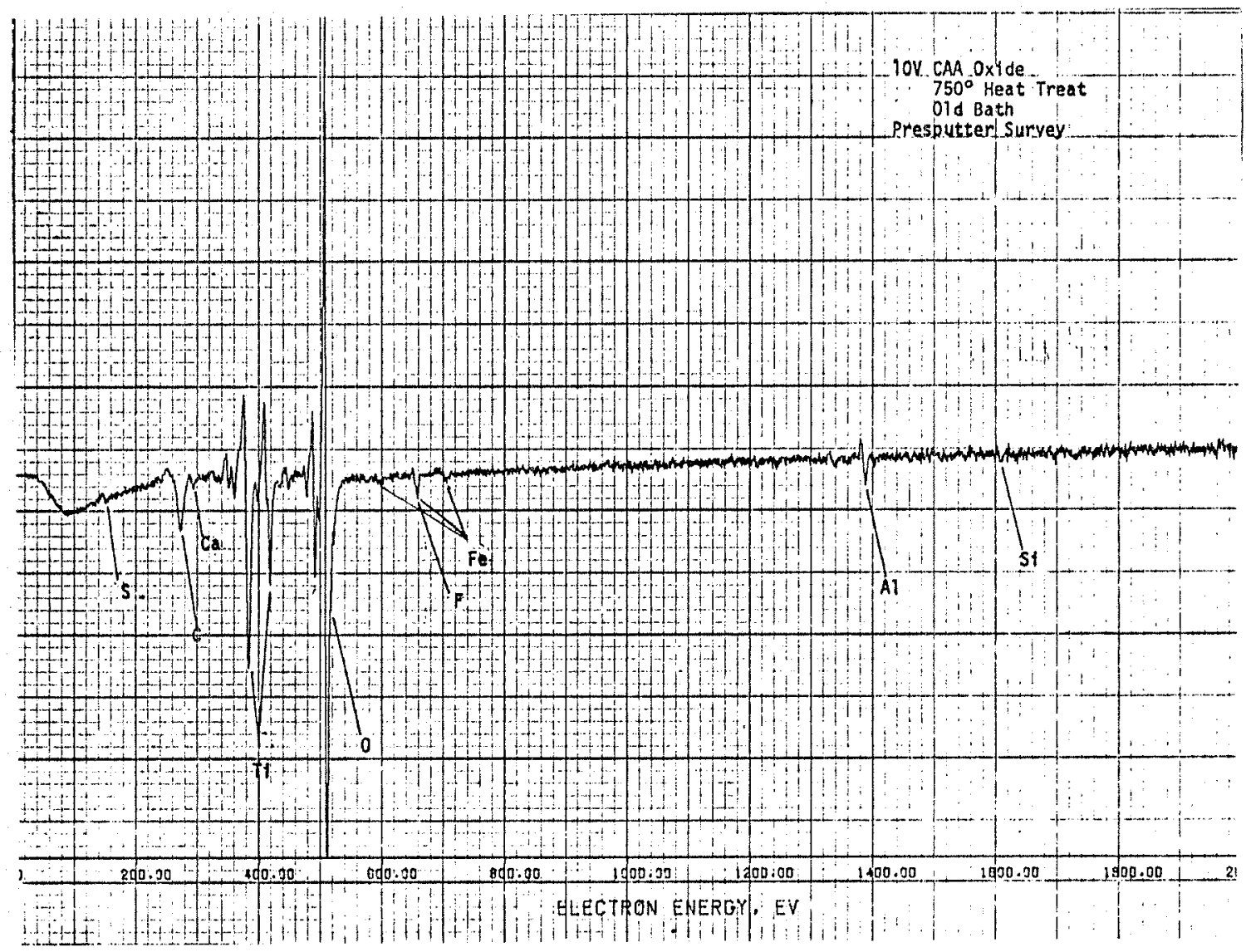

Figure 2.4.4-29 10-V CAA Oxide, $672 \mathrm{~K}\left(750^{\circ} \mathrm{F}\right)$ Heat Treat, Old Bath, Presputter Survey 


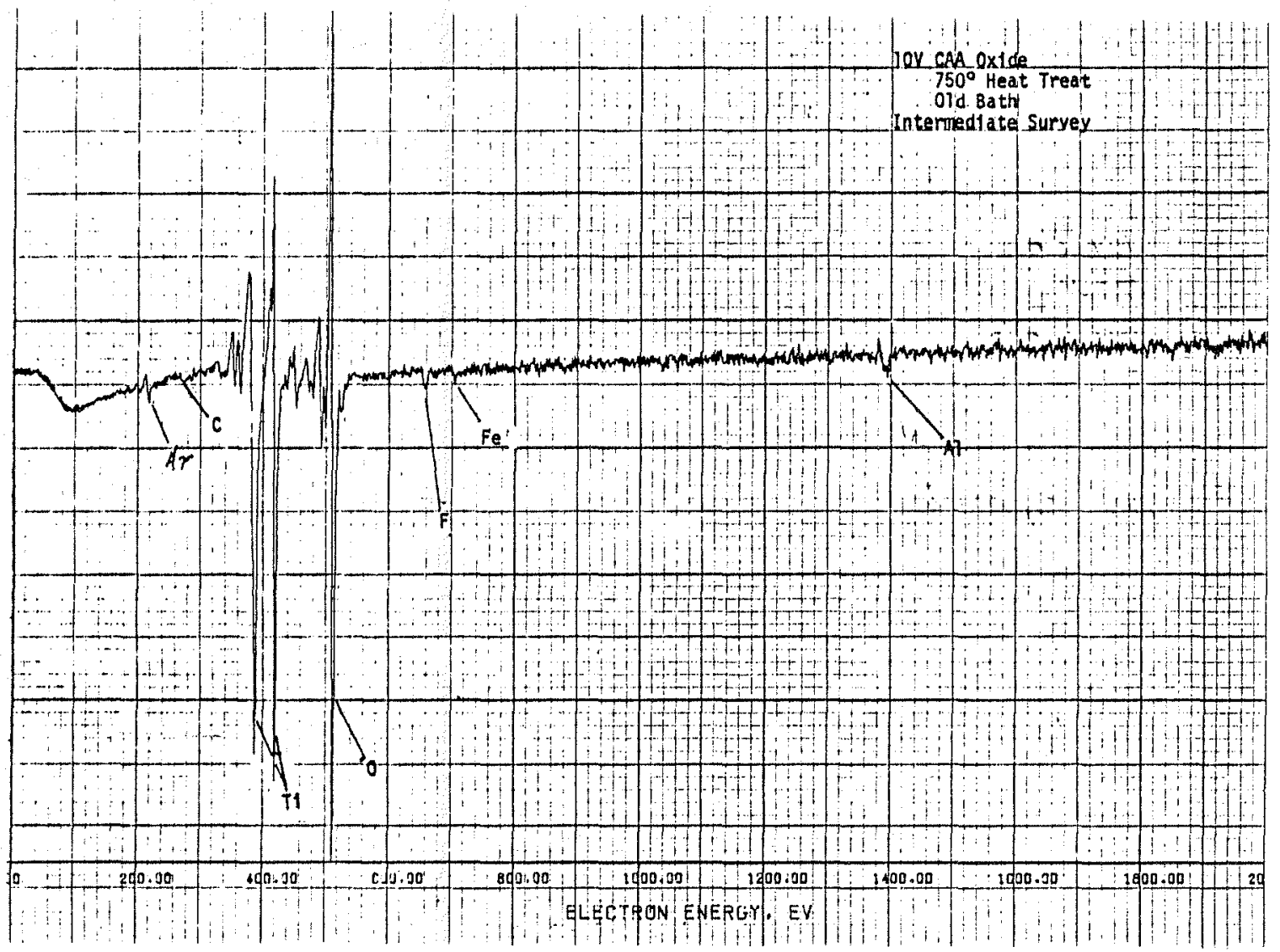

Figure 2.4.4-30

10-V CAA Oxide, $672 \mathrm{~K}\left(750^{\circ} \mathrm{F}\right)$ Heat Treat, Old Bath, Intermediate Survey 


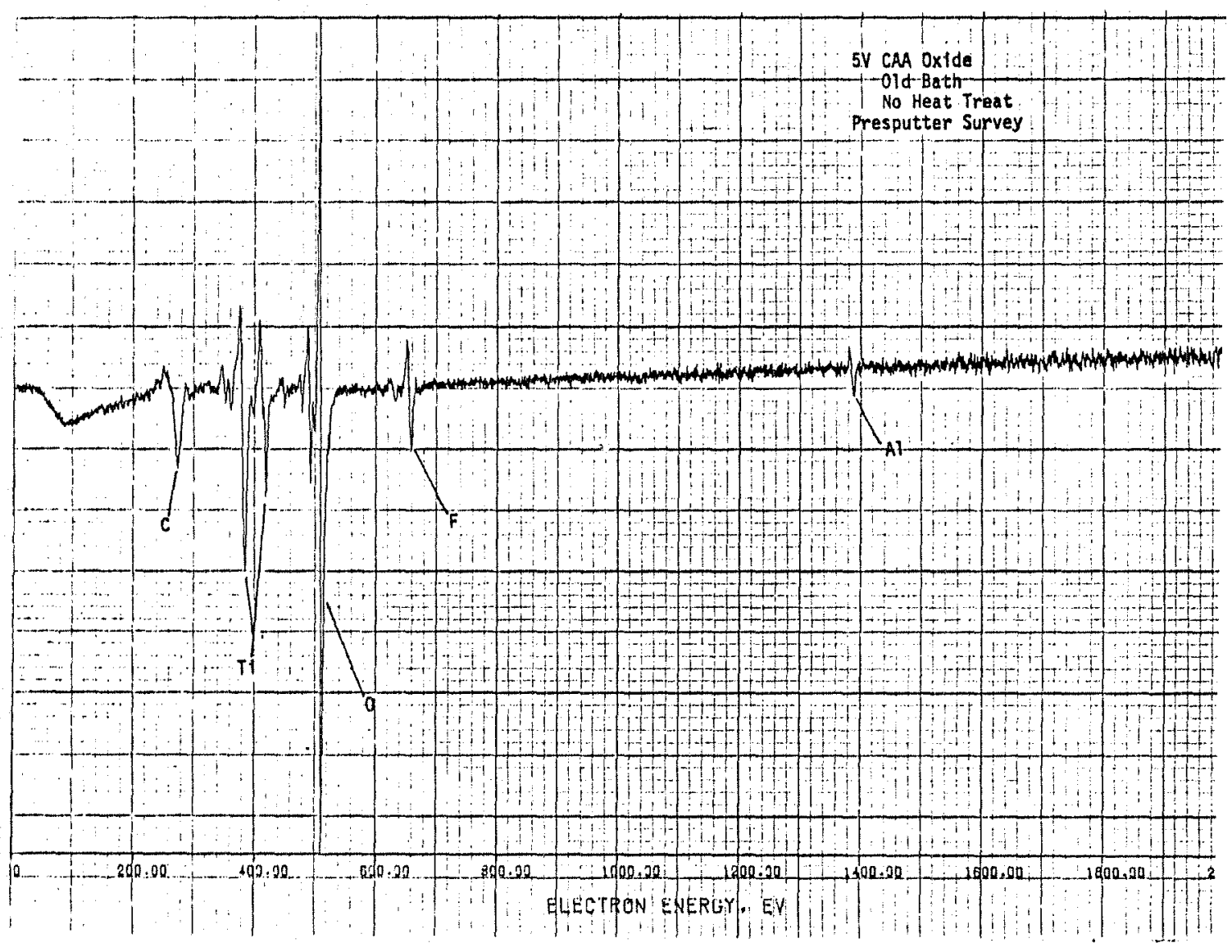

Figure 2.4.4-31 Survey $5-\mathrm{V}$ CAA Oxide, Old Bath, No Heat Treat, Presputter 


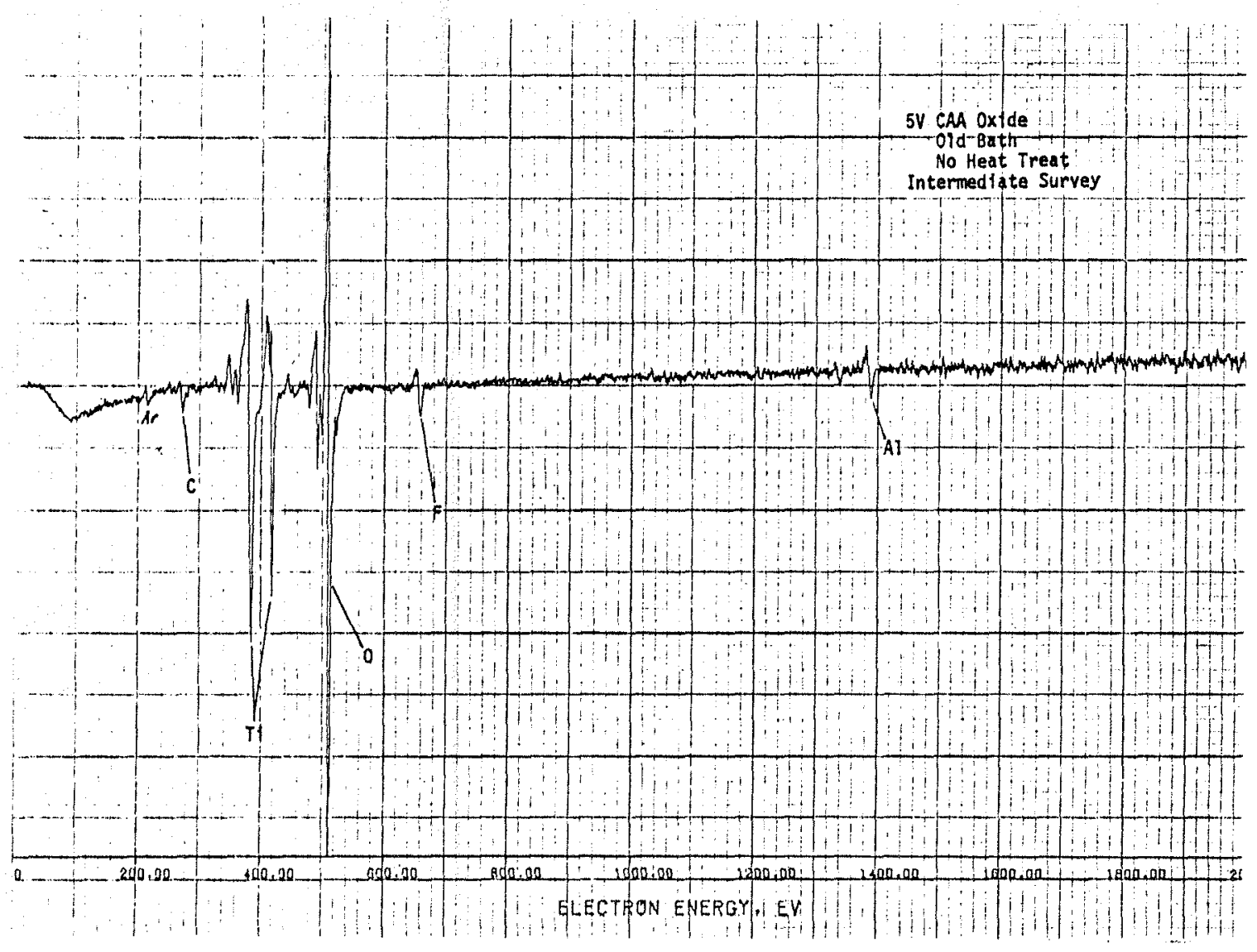

Figure 2.4.4-32 Figure 5-V CAA Oxide, Old Bath, No Heat Treat, Intermediate Survey 


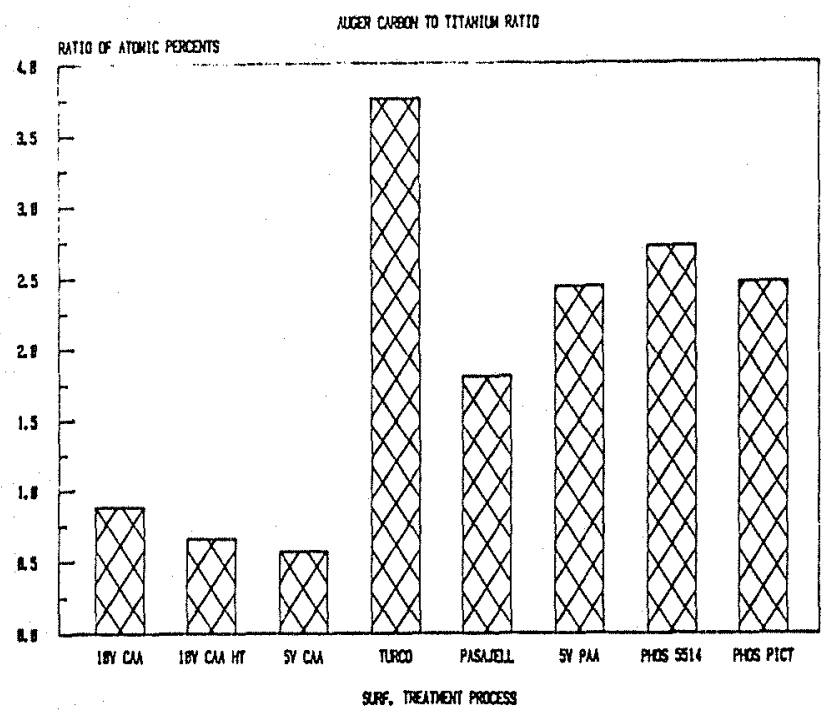

Figure 2.4.4-33
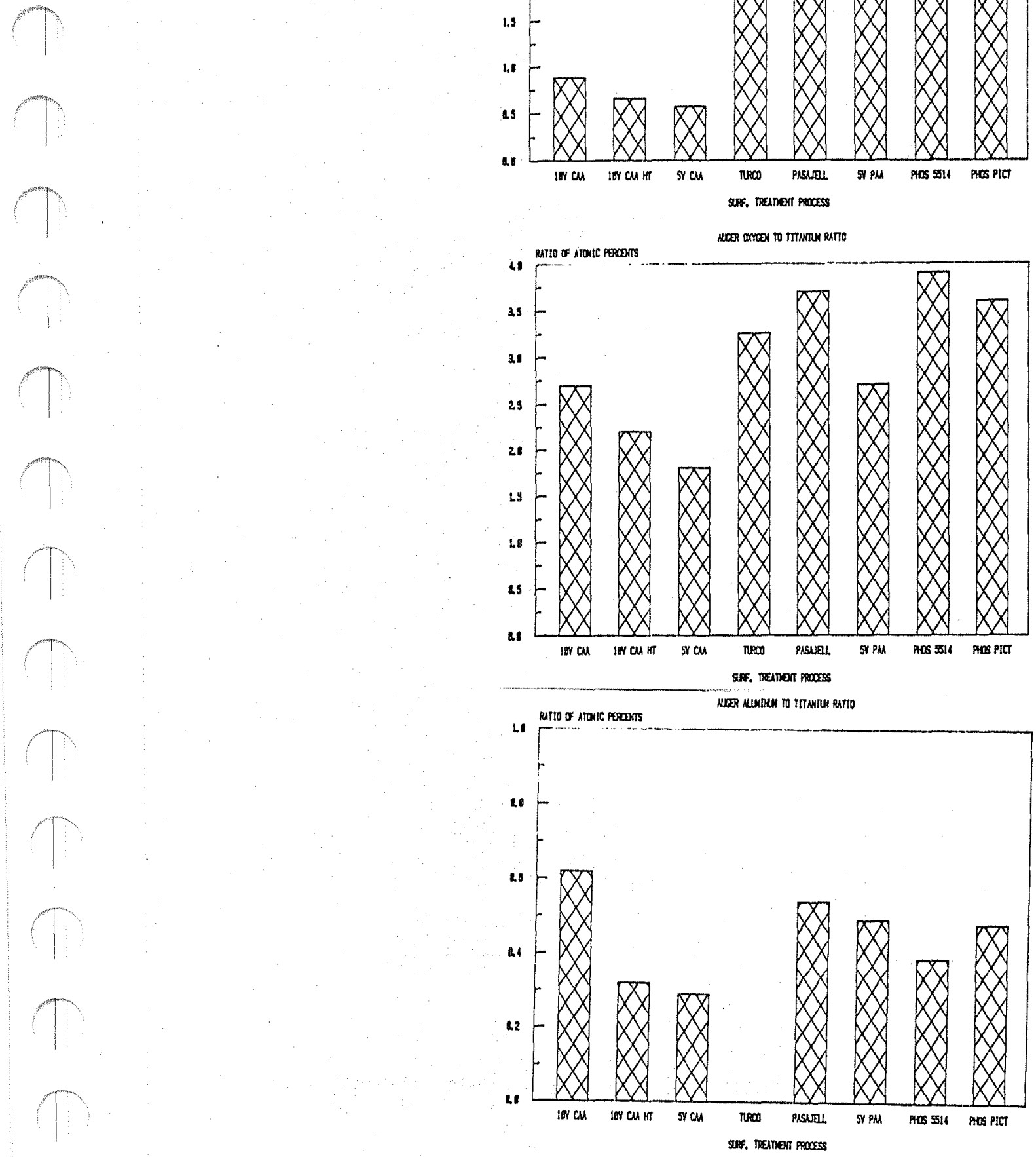

Figure 2.4.4-35

Auger Aluminum-toTitanium Ratio 


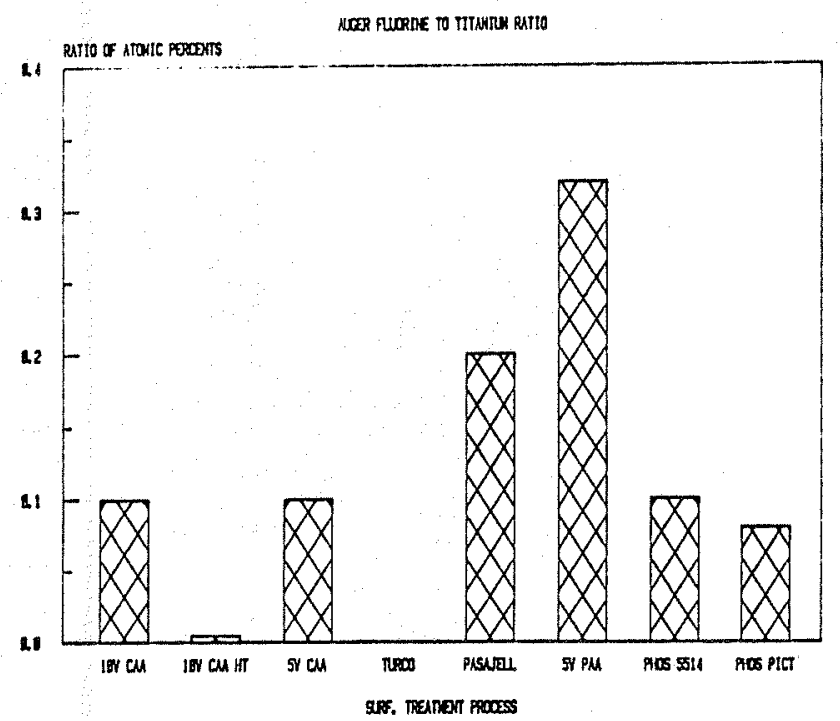

Figure 2.4.4-36 Auger Fluoride-to-Titanium Ratio

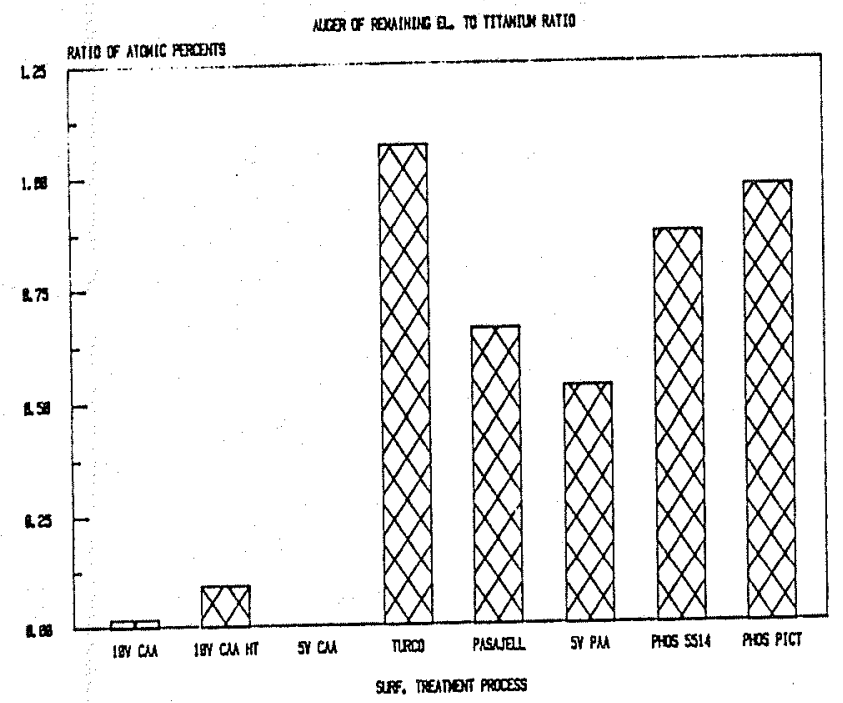

Figure 2.4.4-37 Auger Remaining Elements-to-Titanium Ratio 
Figure 2:4.5-1 10-V Chromic Acid Anodize, NASA "Slick" Lap-Shear Failure, As-Received Surface

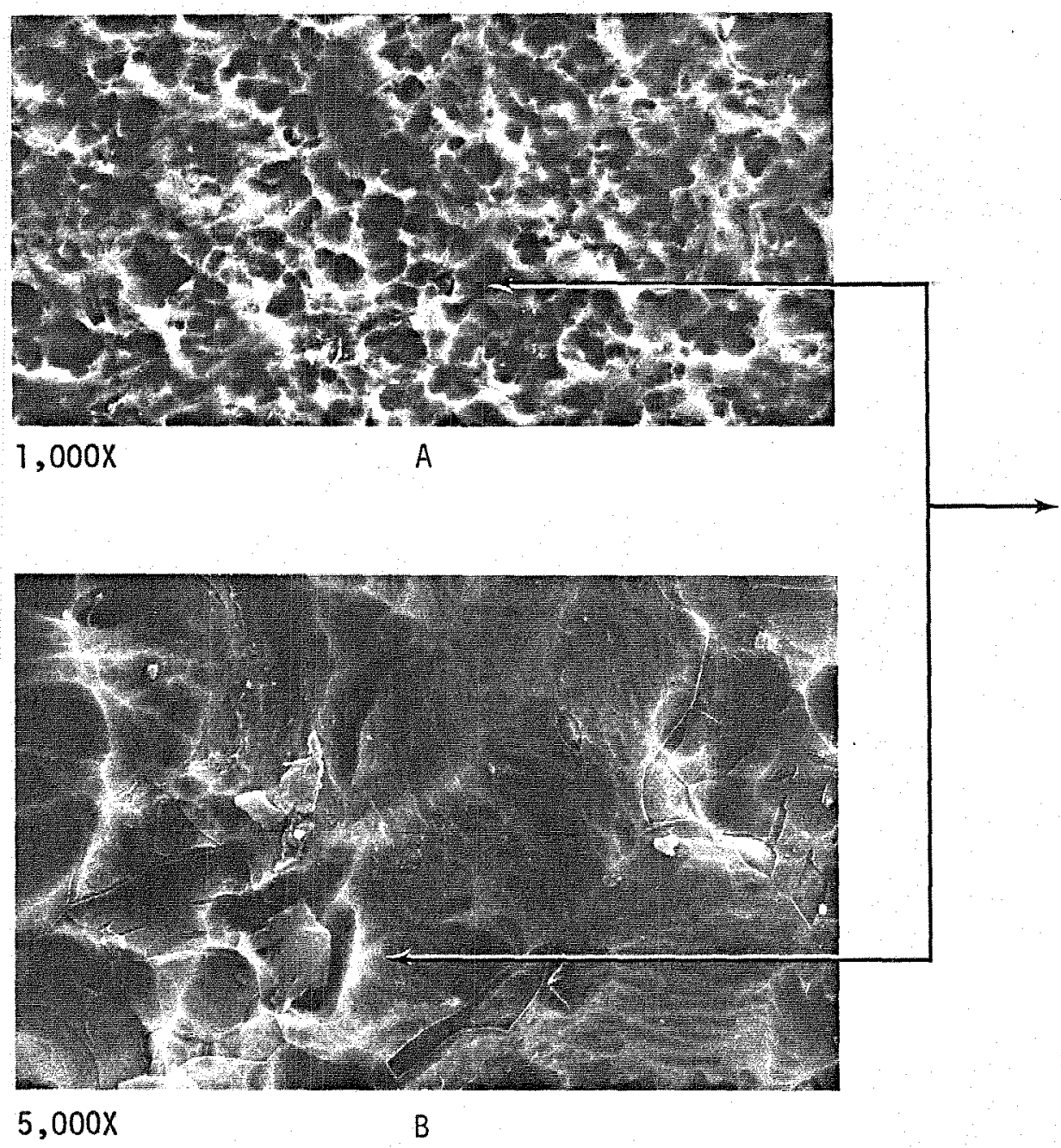

AREA SHOWN IN 20,000X

PHOTOGRAPH AT THE

BOTTOM OF THIS PAGE
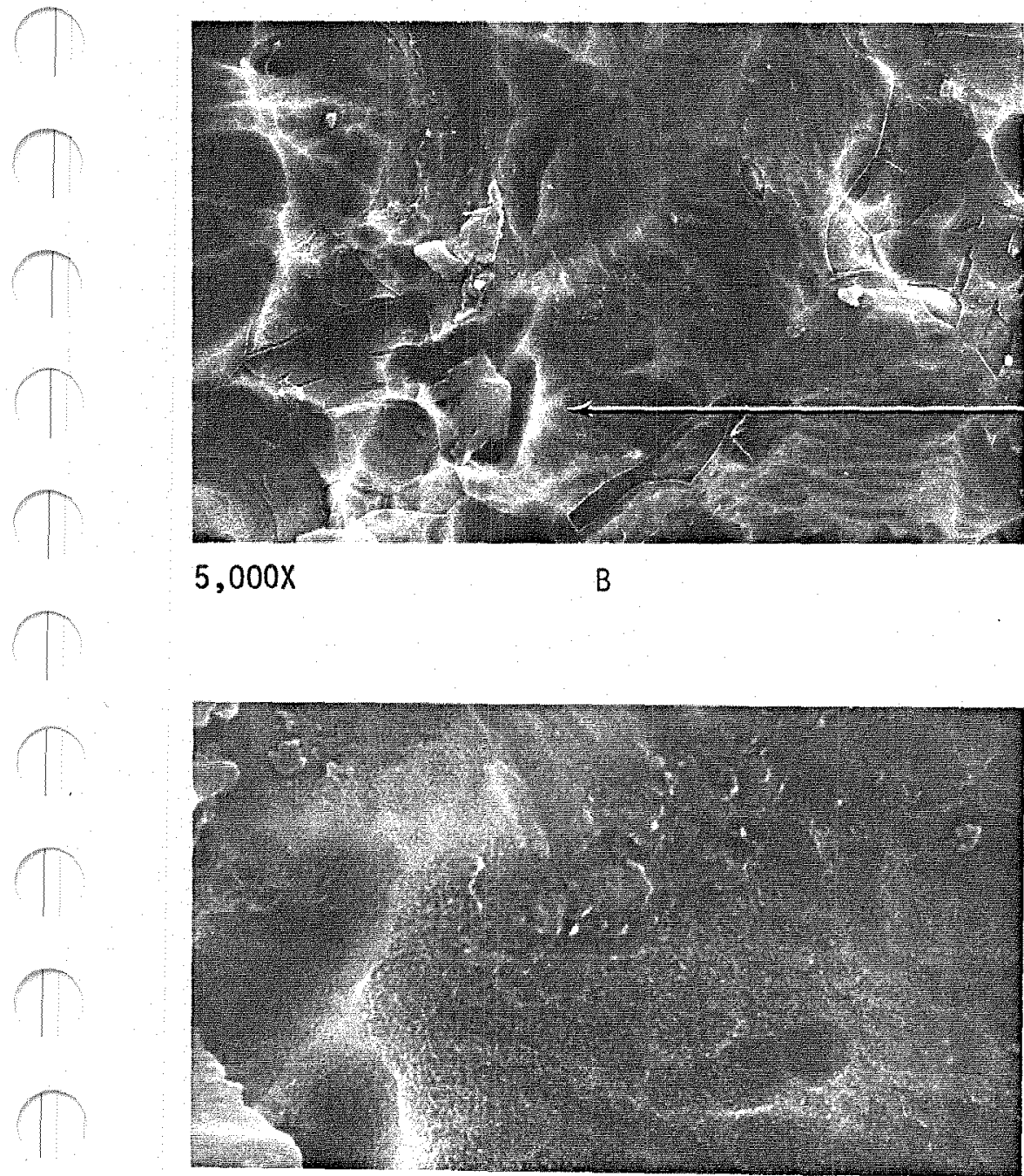

THE OXIDE SEEMS TO BE

PRESENT, WITH AN UNCONFIRMED
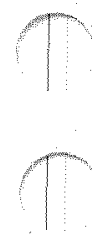

$20,000 x$

C 
$\begin{array}{ll}\text { Figure 2.4.5-2 } & \begin{array}{l}\text { 10-V Chromic Acid Anodize, NASA "Slick" Lap-Shear Failure, } \\ \text { Lab-Fractured Specimen }\end{array}\end{array}$

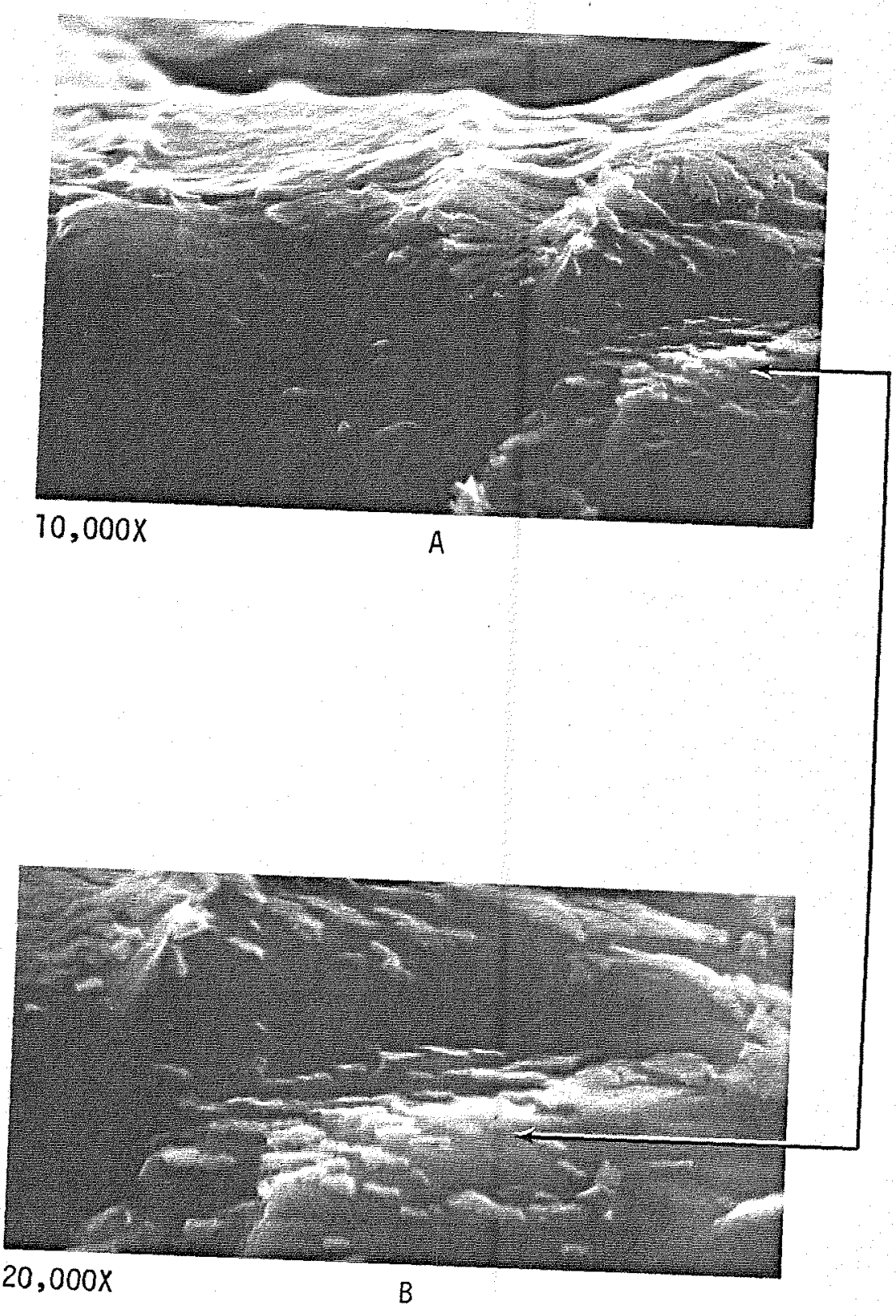

OXIDE CAN BE SEEN IN

THESE PHOTOGRAPHS BUT THE

PRESENCE OF POLYMERIC

MATERIALS IS NOT RESOLVABLE。

OXIDE THICKNESS IS $\approx 800 \AA^{\circ}$ 


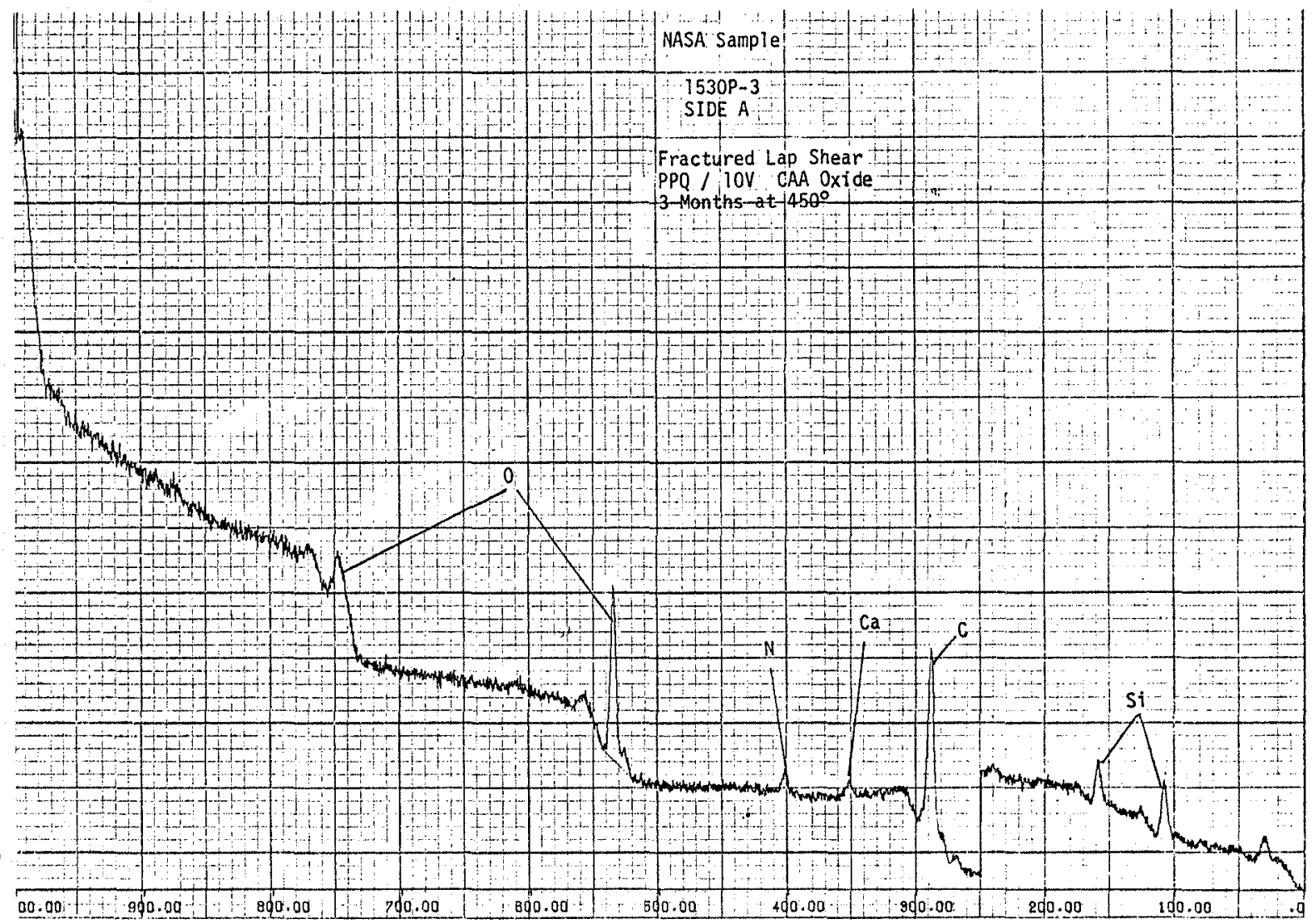

Figure 2.4.5-3. Fractured Lap Shear, NASA Sample 1530P-3, Side A, PPQ/10-V CAA Oxide, 3 months at $505 \mathrm{~K}\left(450^{\circ} \mathrm{F}\right)$ 


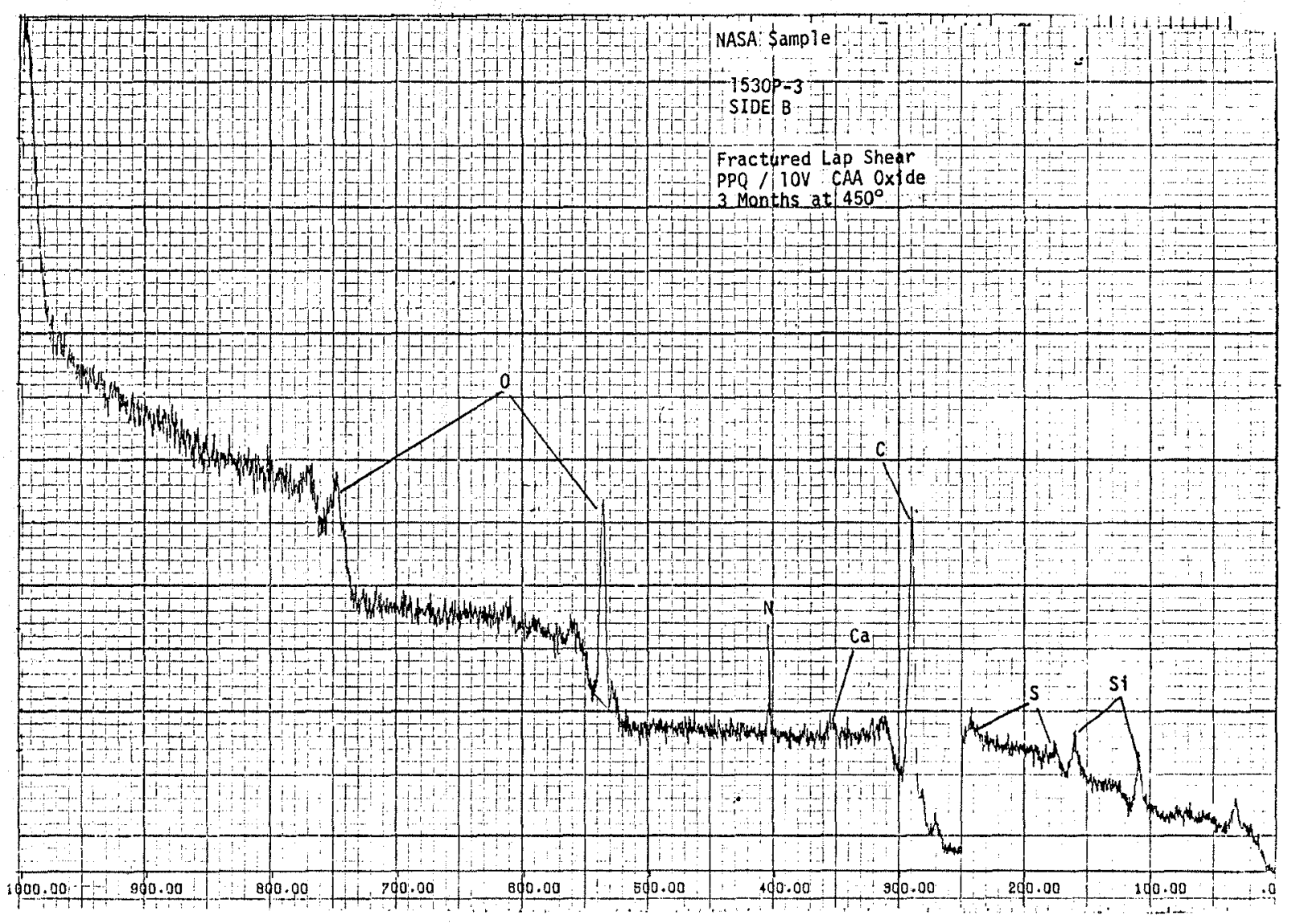

Figure 2.4.5-4. Fractured Lap Shear, NASA Sample 1530P-3, Side B, PPQ/10-V CAA Oxide, 3 months at $505 \mathrm{~K}\left(450^{\circ} \mathrm{F}\right)$ 


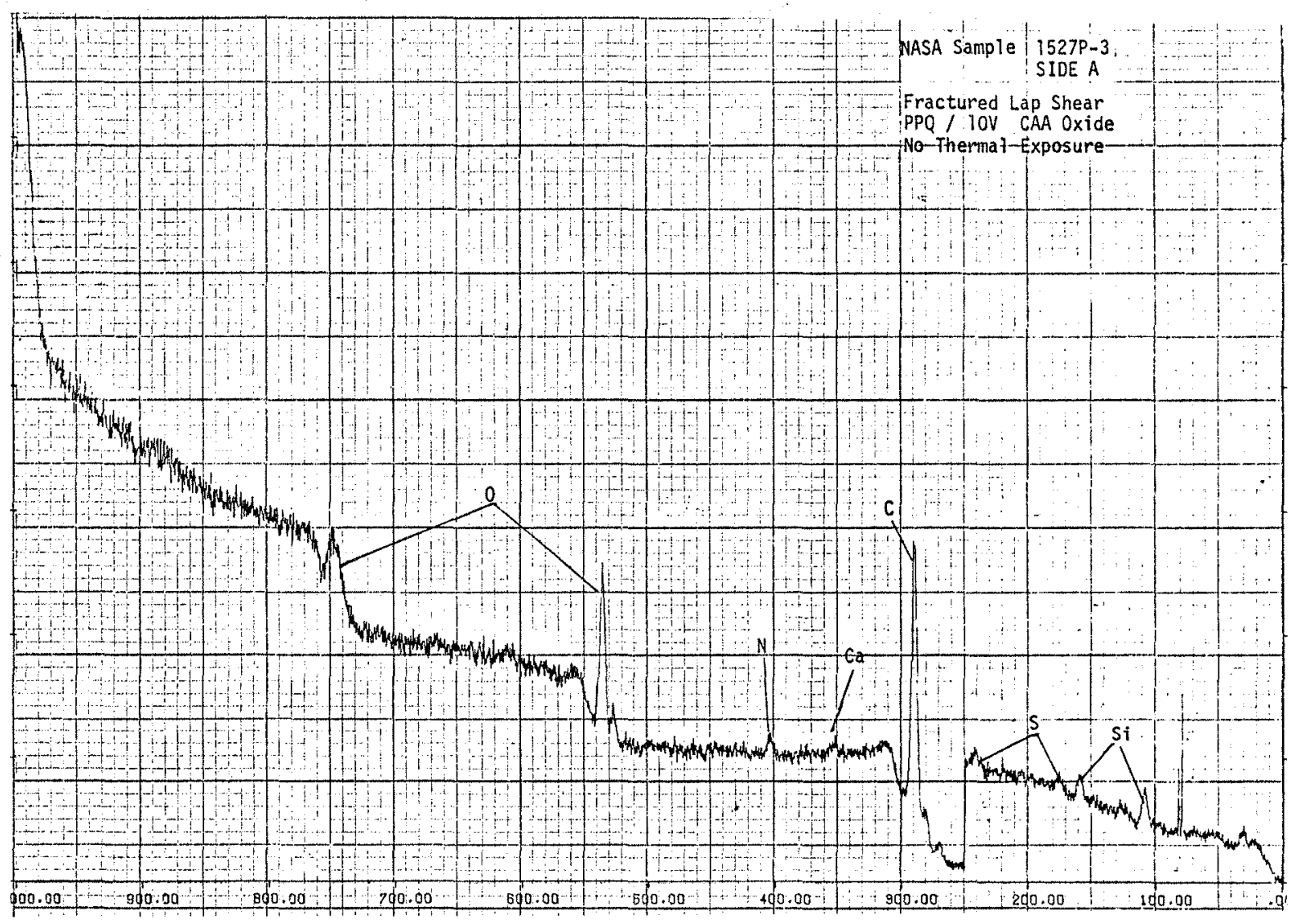

-Figure 2.4.5-5. - Fractured Lap Shear, NASA Sample 1527P-3, Side A, PPQ/10-V CAA Oxide, No thermat exposure 


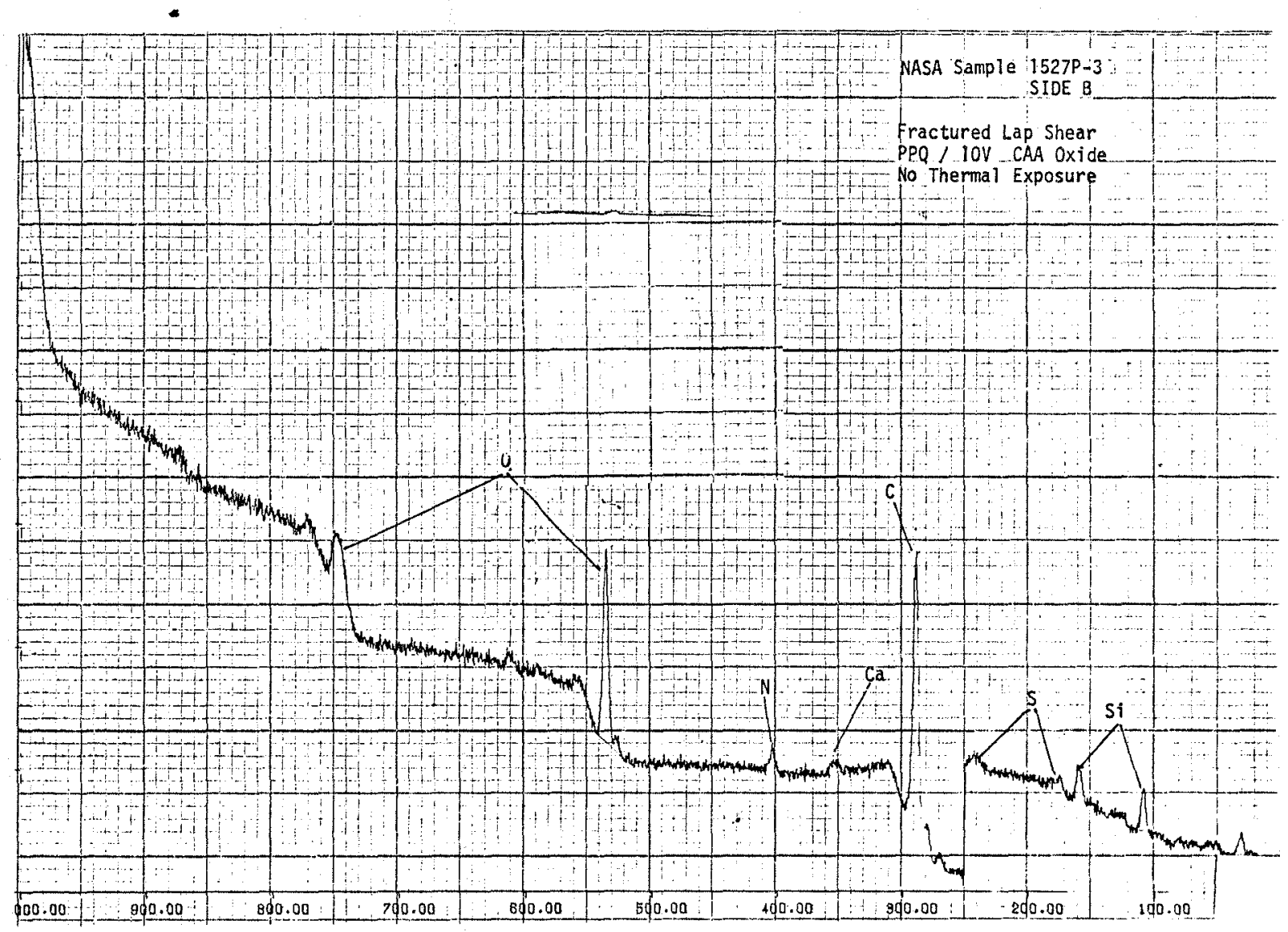

Figure 2.4.5-6. Fractured Lap Shear, NASA Sample 1527P-3, Side B, PPQ/10-V CAA Oxide, No thermal exposure 


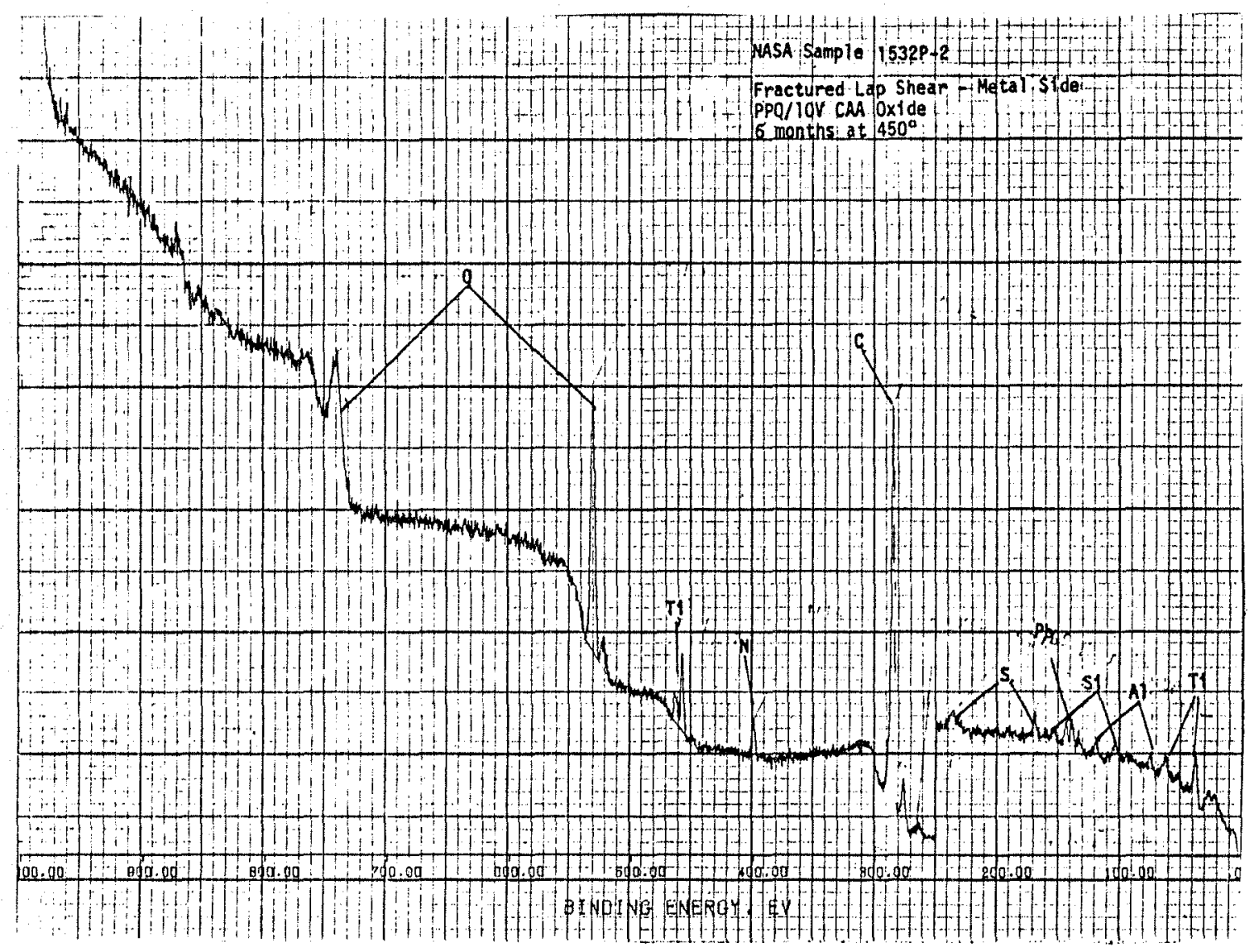

Figure 2.4.5-7. Fractured Lap Shear, NASA Sample 1532P--2, Metal Side, PPQ/ $10-\mathrm{V}$ CAA Oxide, 6 Months at $505 \mathrm{~K}\left(450^{\circ} \mathrm{F}\right)$ 


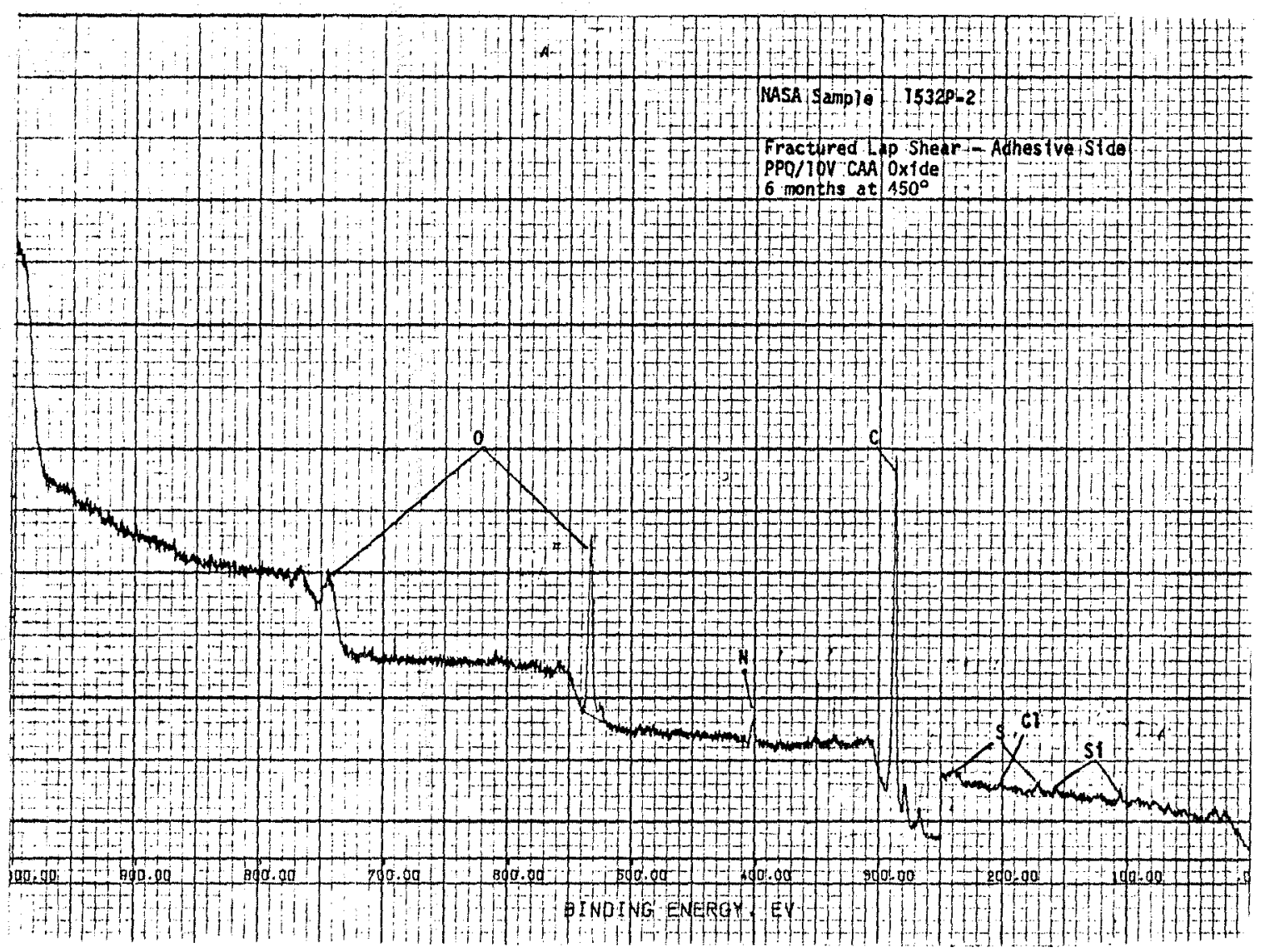

Figure 2.4.5-8. Fractured Lap Shear, NASA Sample 1532P-2, Adhesive Side, $\mathrm{PPQ} / 10-\mathrm{V}$ CAA Oxide, 6 Months at $505 \mathrm{~K}\left(450^{\circ} \mathrm{F}\right)$ 


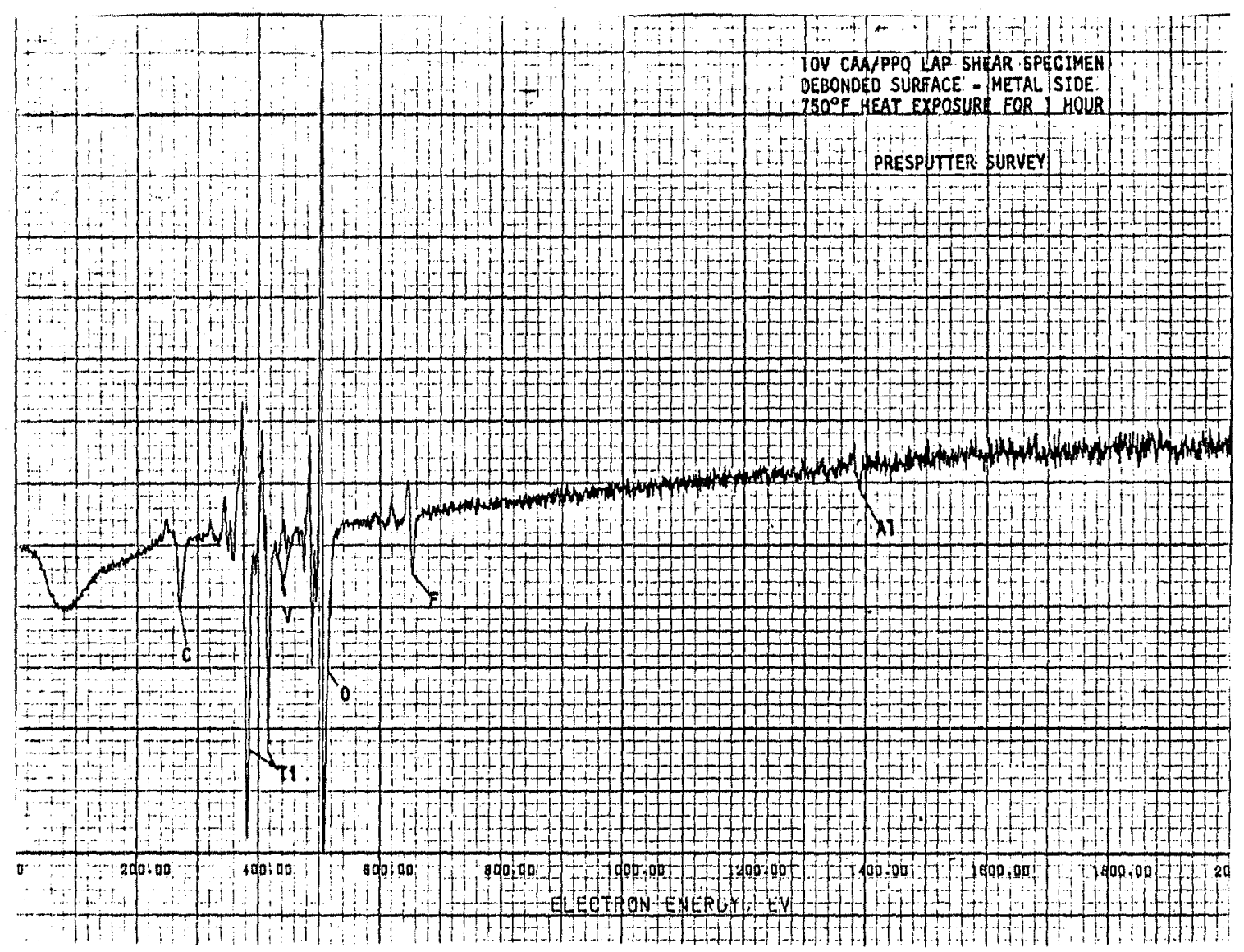

Figure 2.4.5-9. 10-V CAA/PPQ Lap-Shear Specimen, Disbonded Surface, Metal Side, 672K (750 $\mathrm{F})$ Heat Exposure for 1 Hour, Presputter Survey 


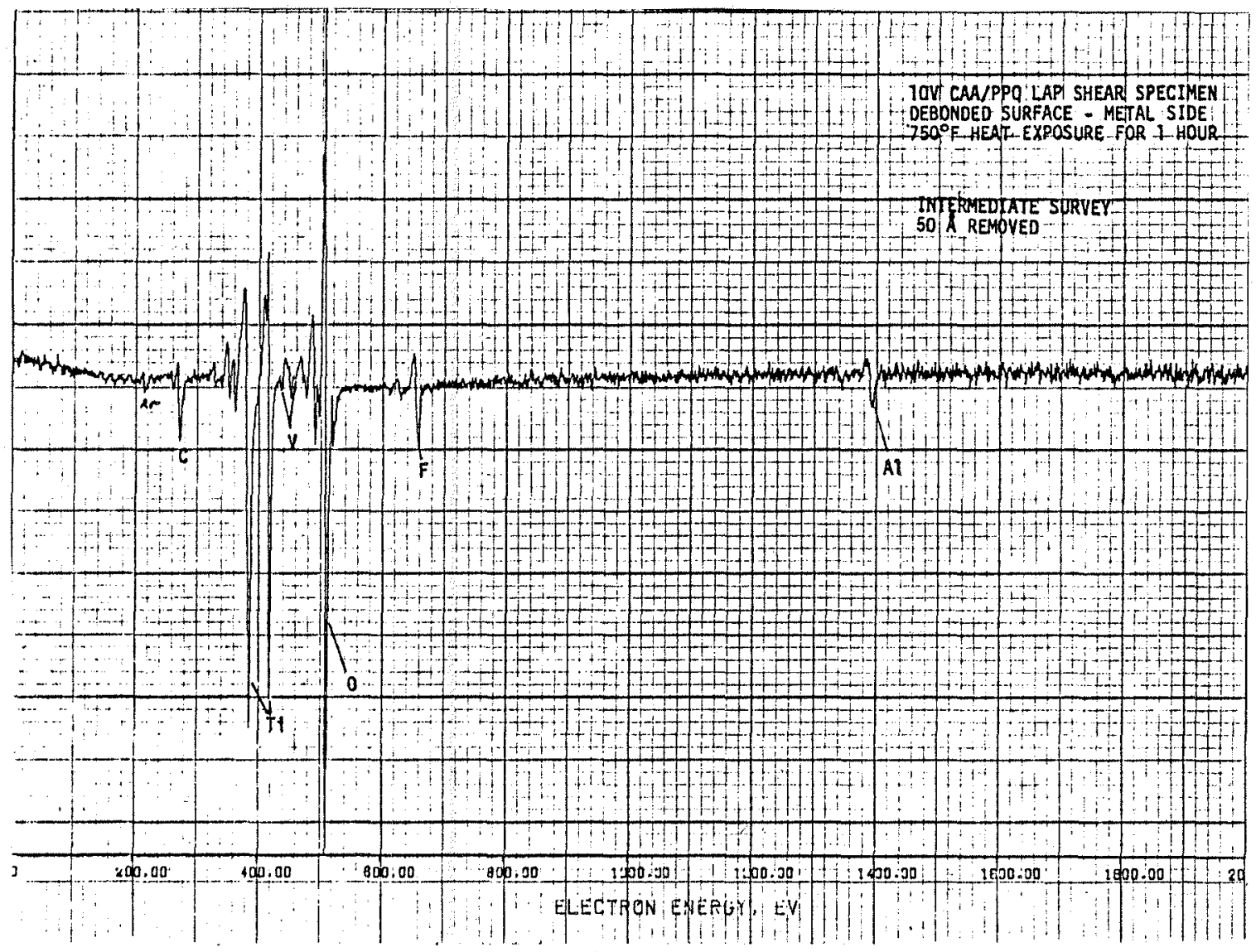

Figure 2.4.5-10. 10-V CAA/PPQ Lap-Shear Specimen, Disbonded Surface, Metal Side, $672 \mathrm{~K}\left(750^{\circ} \mathrm{F}\right)$ Heat Exposure for 1 Hour, Intermediate Survey, 50 A Removed 


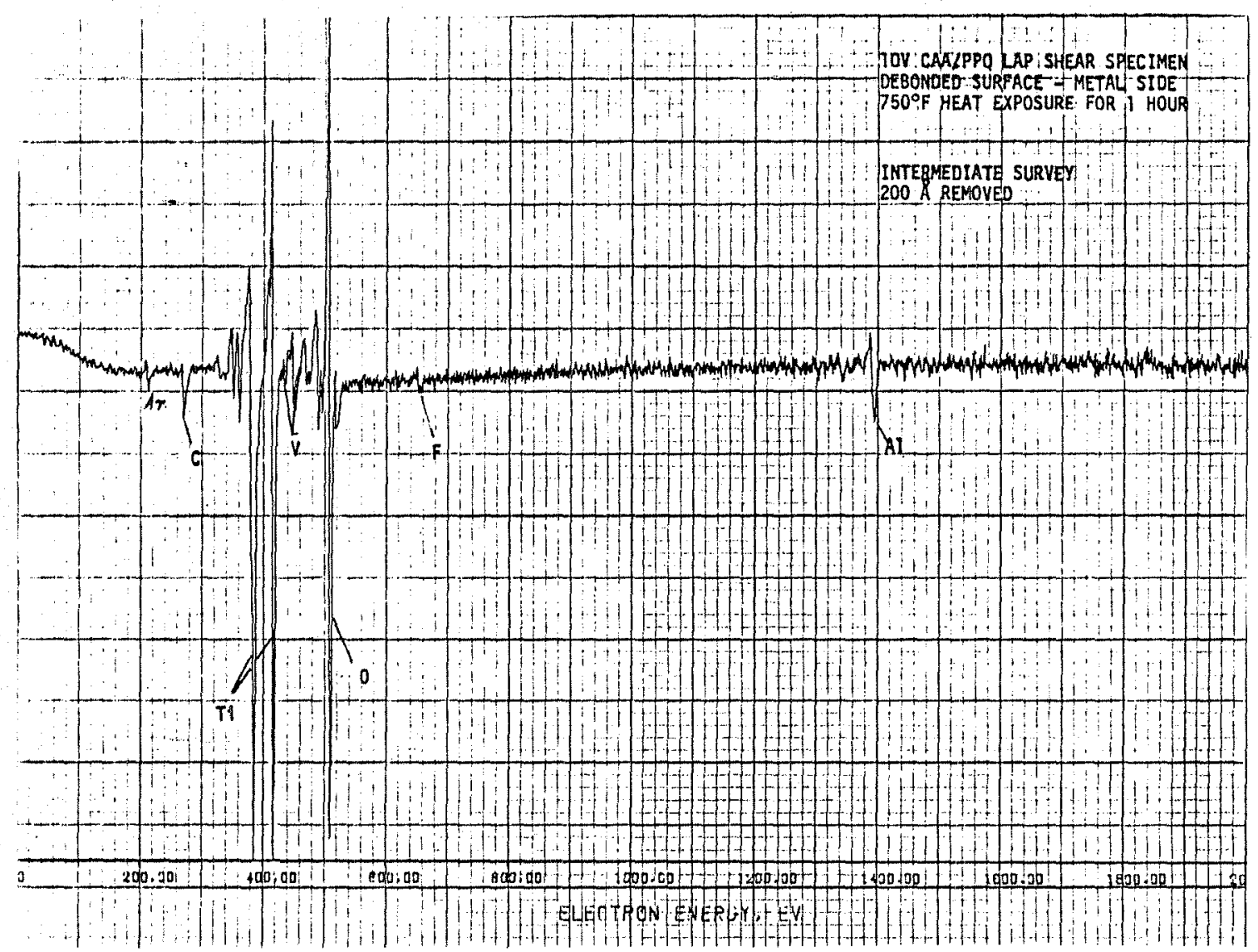

Figure 2.4.5-11. 10-V CAA/PPQ Lap-Shear Specimen, Disbonded Surface, Metal Side, $672 \mathrm{~K}\left(750^{\circ} \mathrm{F}\right)$ Heat Exposure for 1 Hour, Intermediate Survey, 200 A Removed 
Figure 2:4.5-12

Ti Surface Treatment vs. Oxide Thickness and Strength

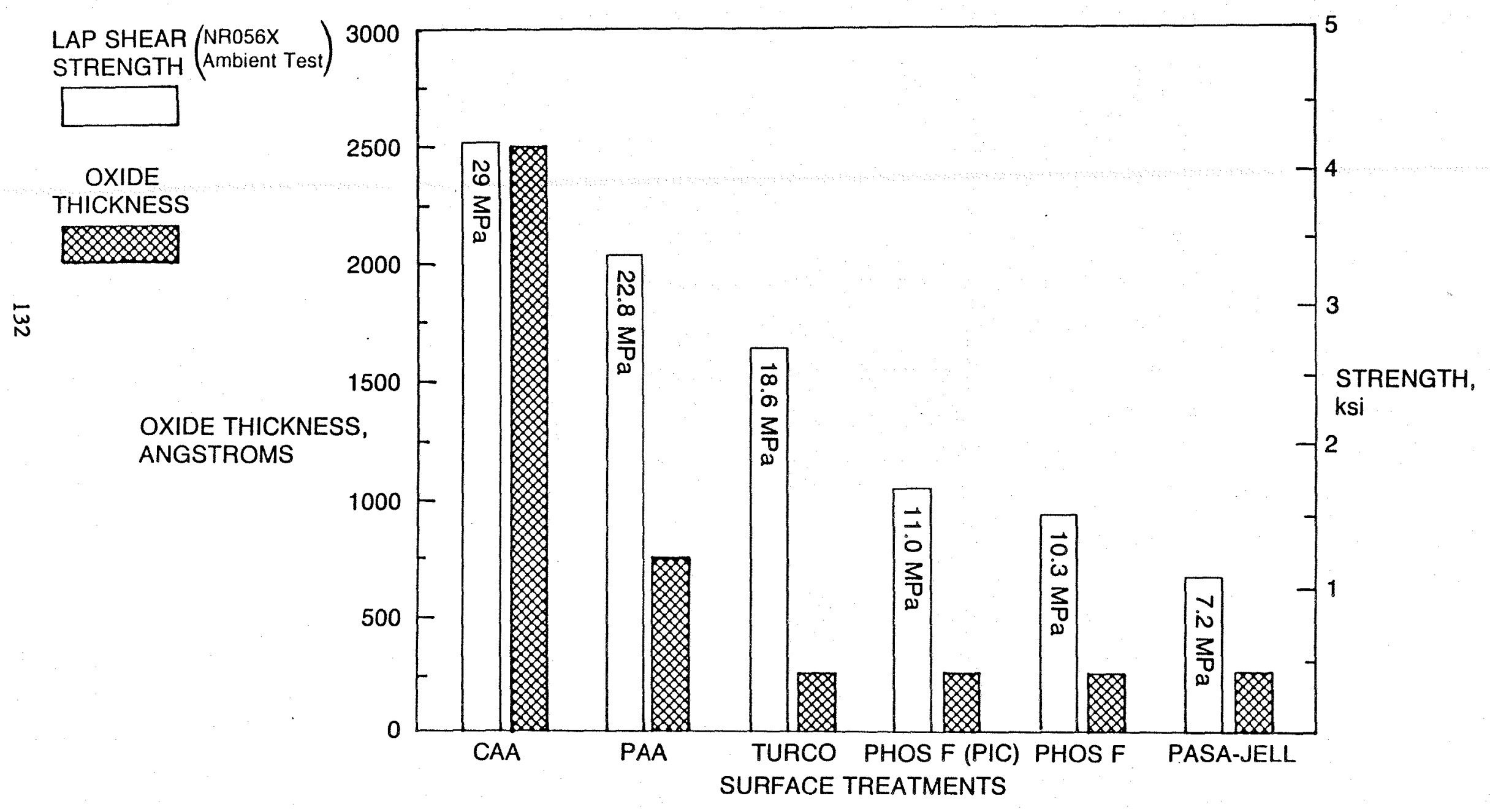


Figure 2.4.5-13

Ti Surface Treatment vs. Auger Aluminum/Titanium Ratio and Strength

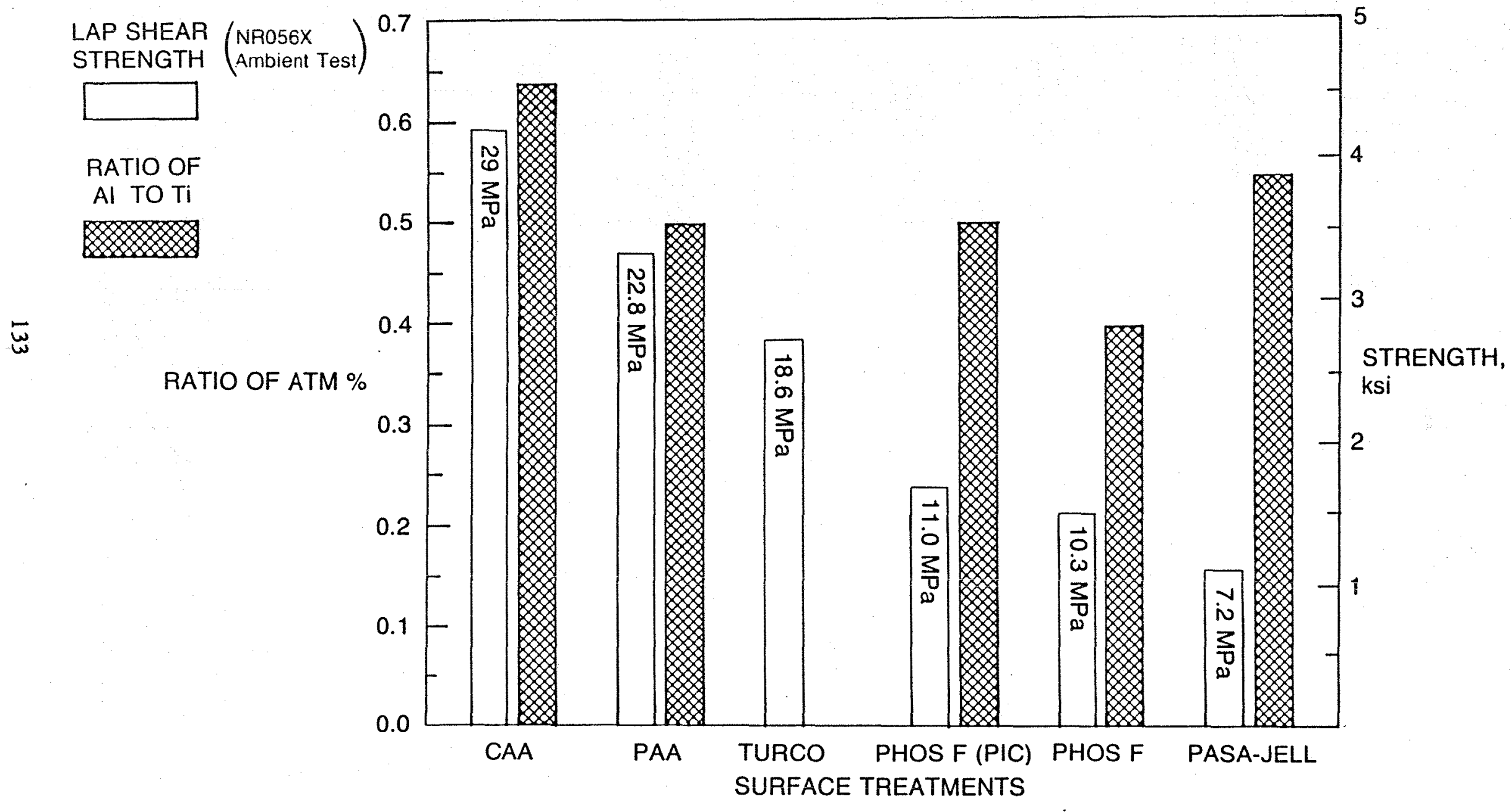


Figure 2.4.5-14

Ti Surface Treatment vs. Auger Fluorine/Titanium Ratio and Strength

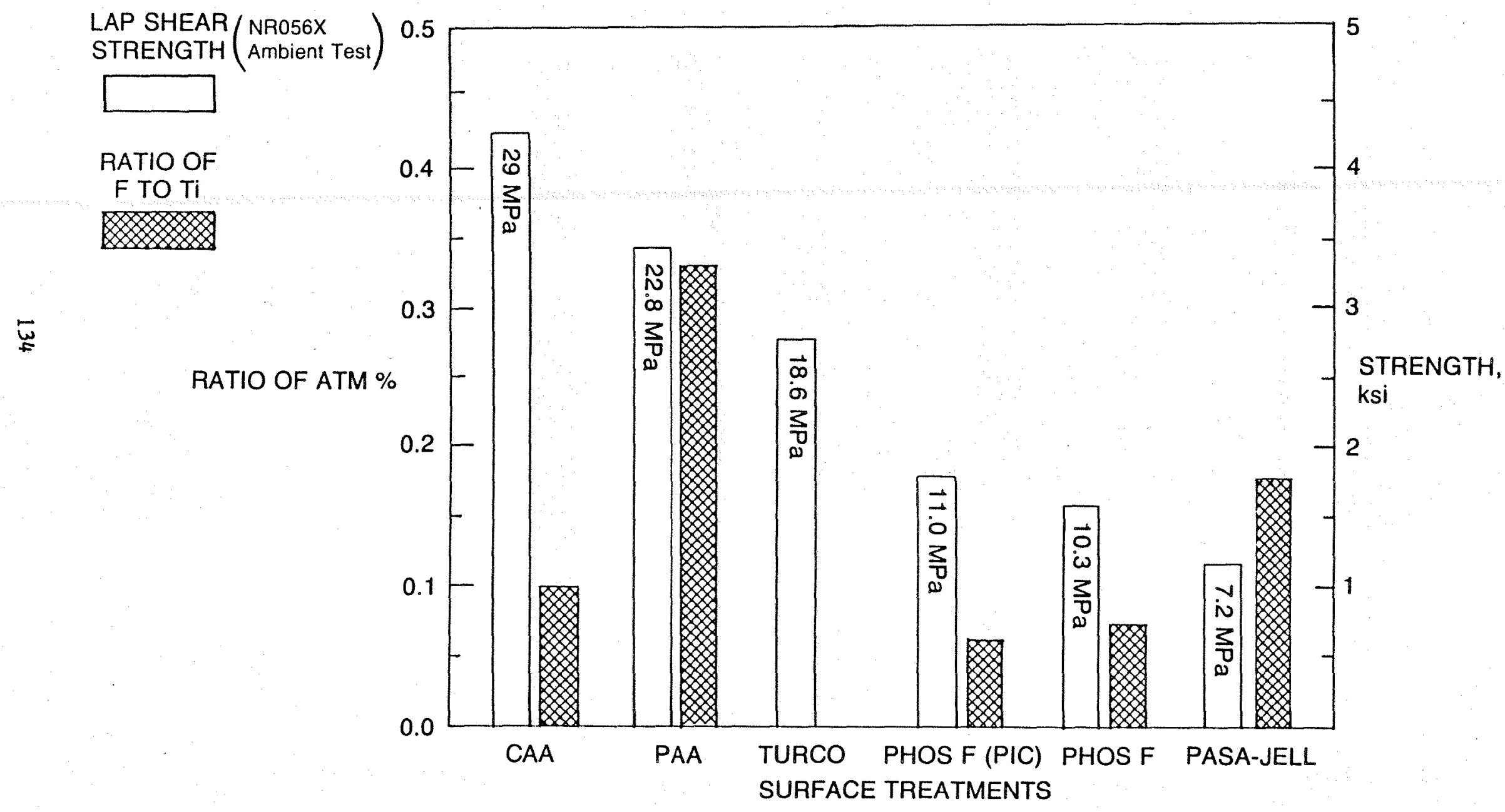


Figure 2.4 .5-15

Ti Surface Treatment vs. Remaining Elements/Titanium Ratio and Strength

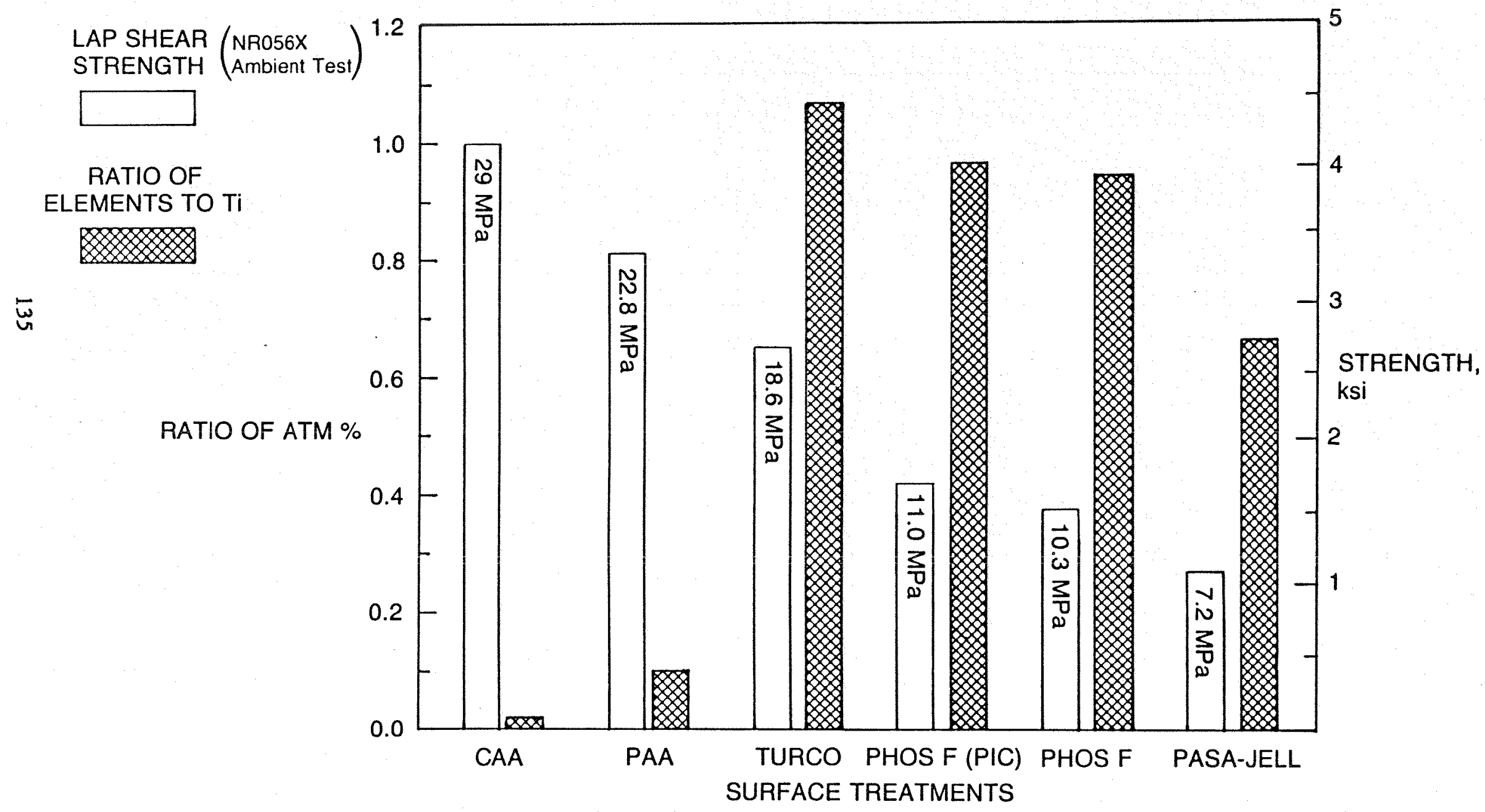




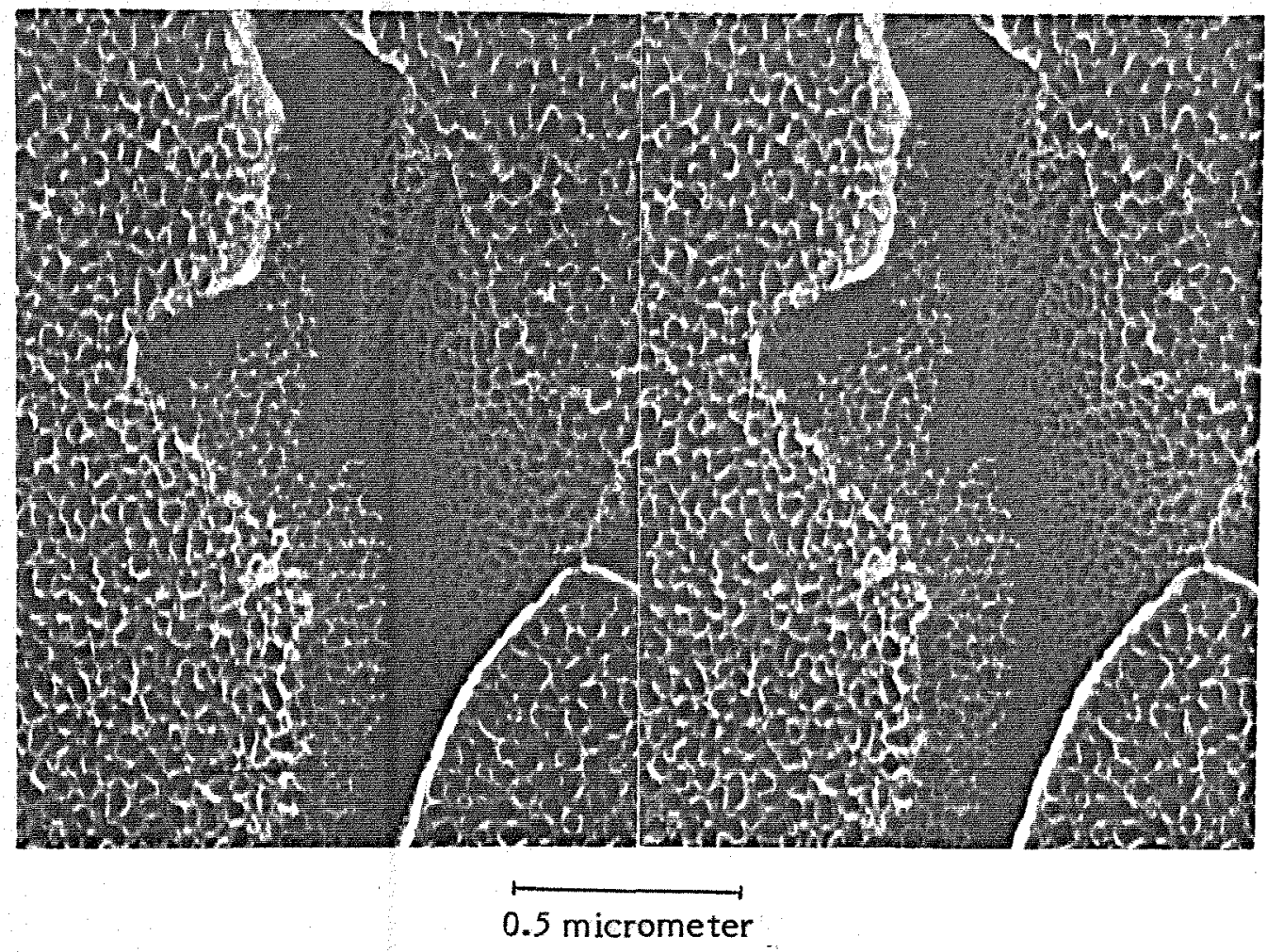

Figure 2.4.5-16. 10 V CAA as Anodized - No Additional Processing Plan view stereo pair showing oxide pores $(\sim 30 \mathrm{~nm}$ in diameter) 


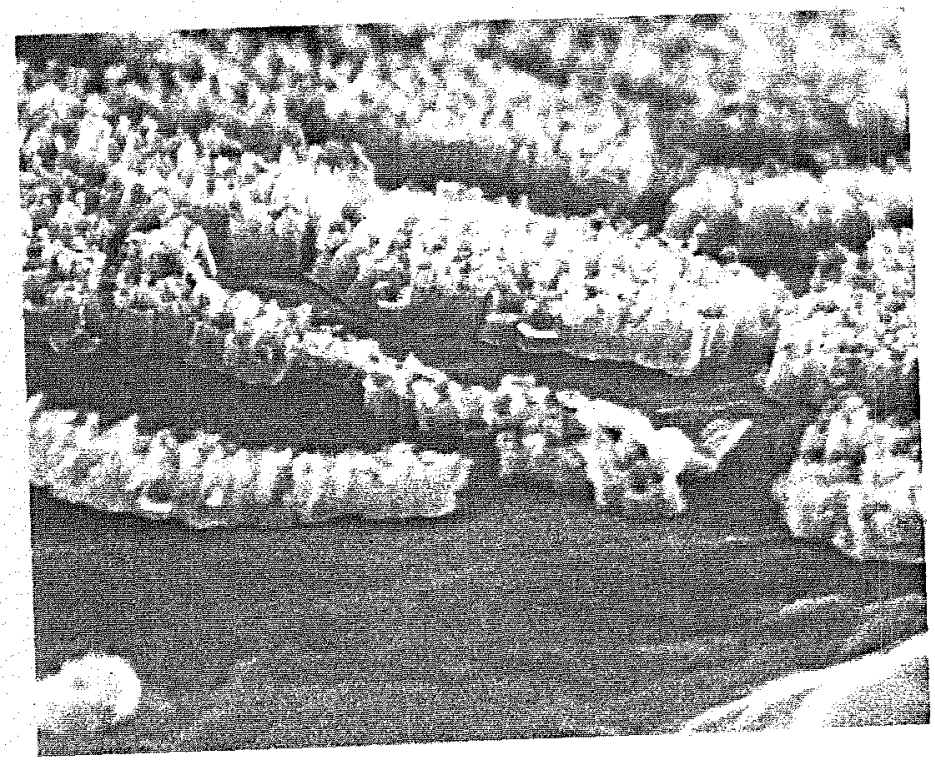

0.5 micrometer

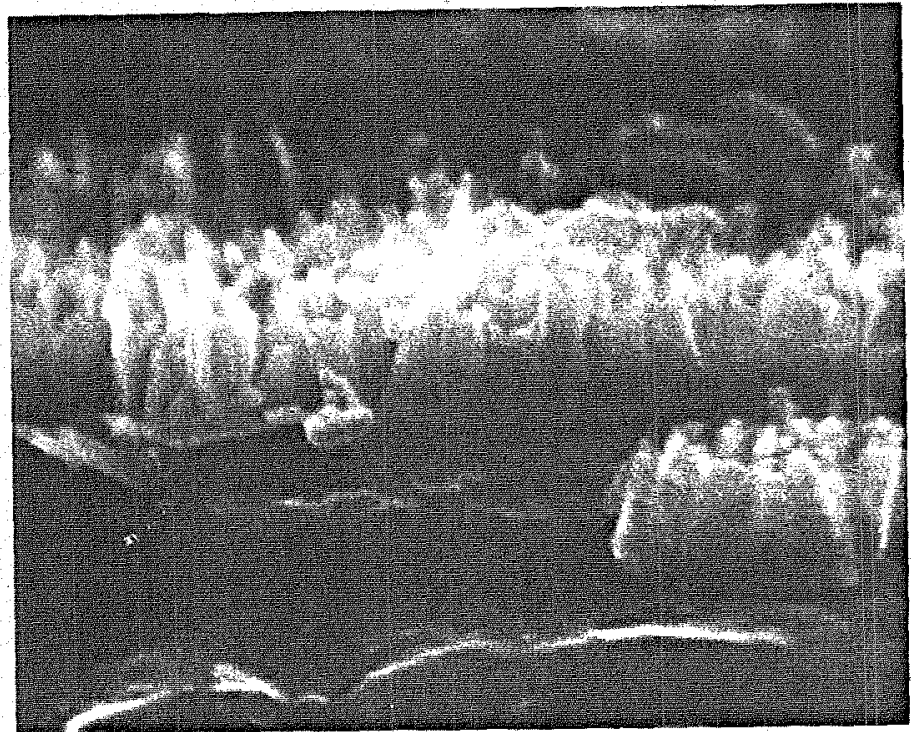

\section{2 micrometer}

Figure 2.4.5-17. 10V CAA as Anodized - No Additional Processing Profile view. The oxide has a columnar structure with a thickness of $\sim 120 \mathrm{~nm}$ 


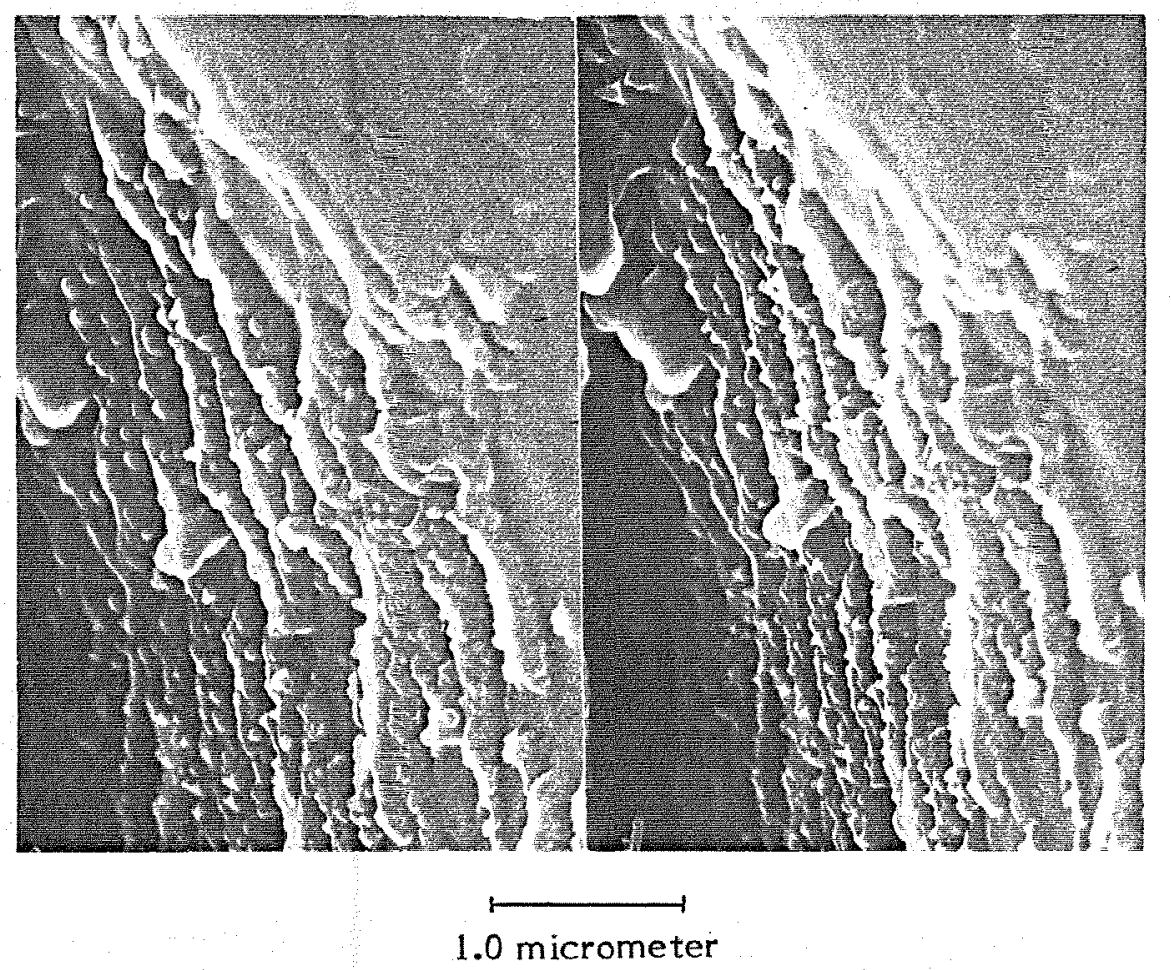

Figure 2.4.5-18. 10V CAA Primed with P.P.Q. - No Environmental Exposure. Stereo pair profile view showing primer penetration to the base of the oxide. 


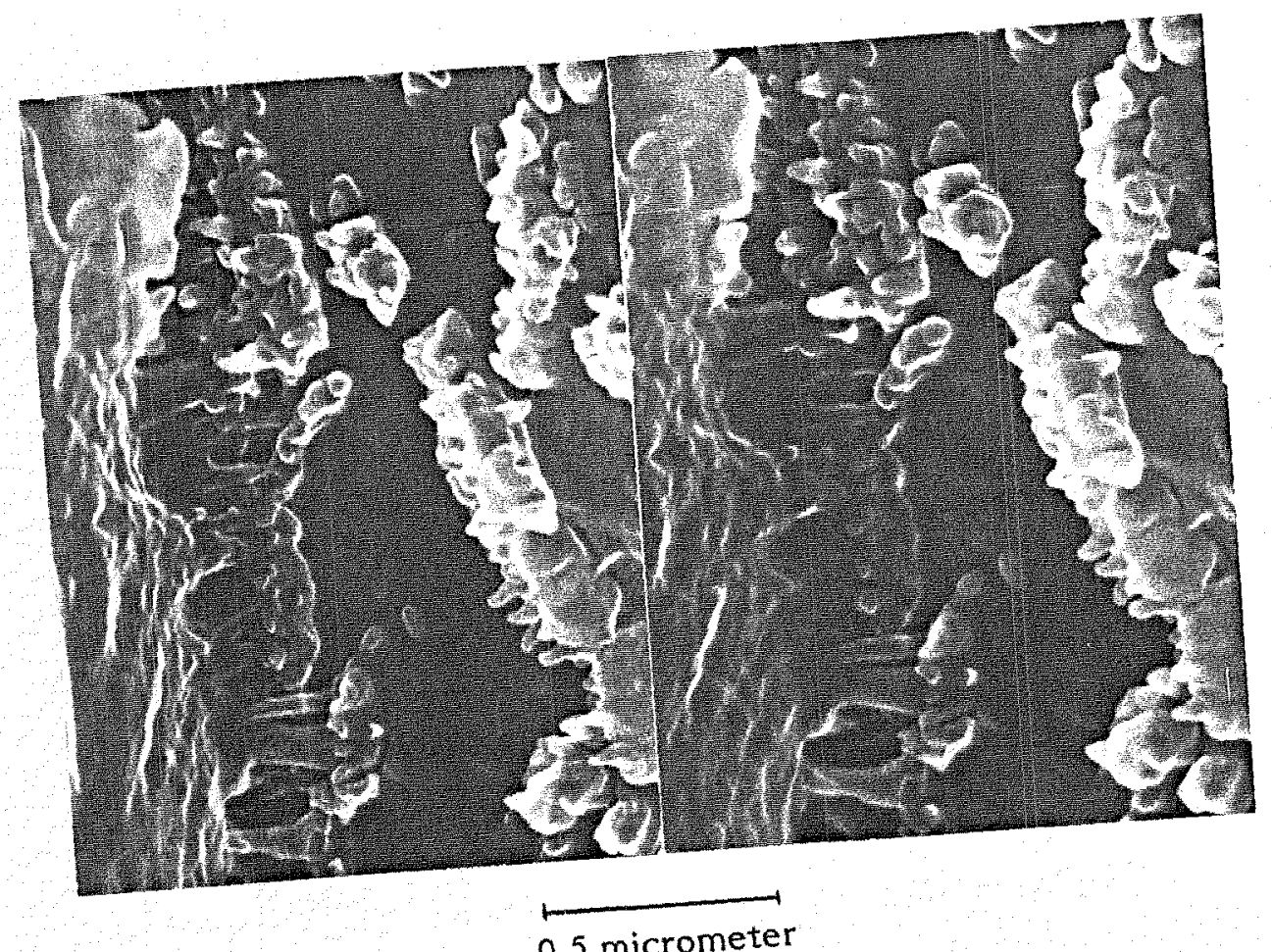

0.5 micrometer Figure 2.4.5-19. 10V CAA Primed with P.P.Q. - No Environmental
Exposure. Stereo pair profile view showing the primer pulling away from the oxide. 


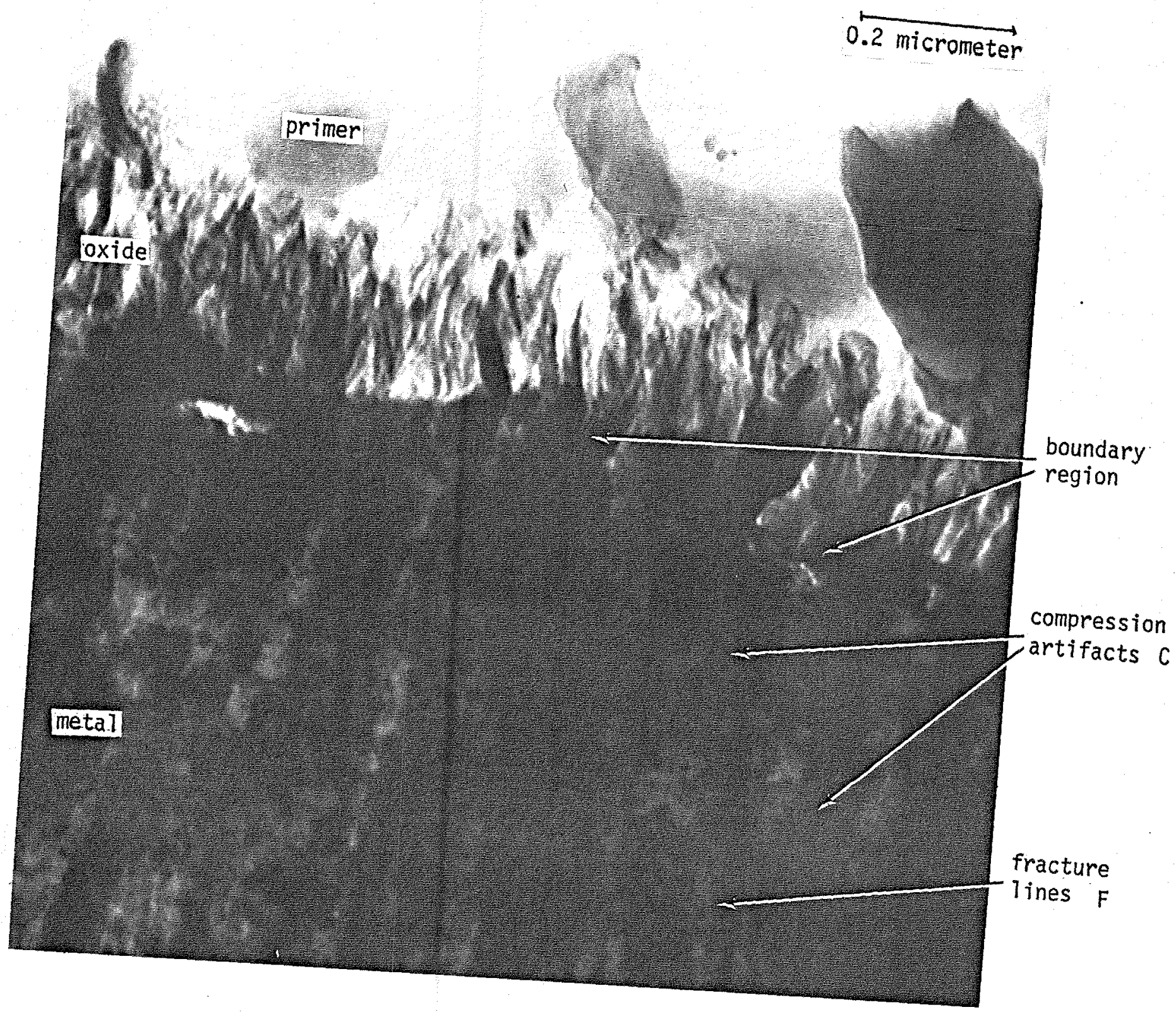

Figure 2. 4.5-20

Thin section of titanium with CAA oxide and LARC 13 primer. 


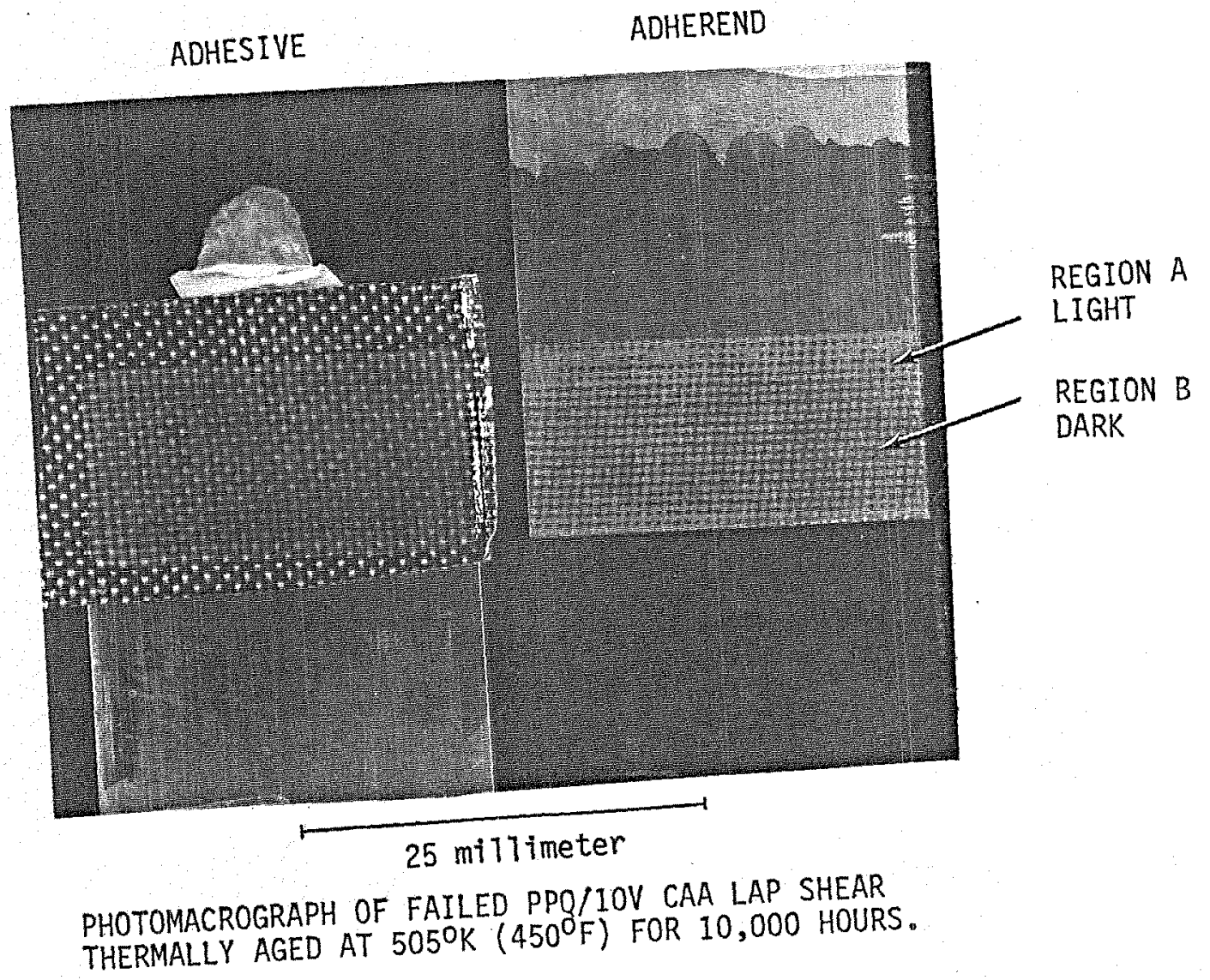

Figure $2.4 .5-21$ 


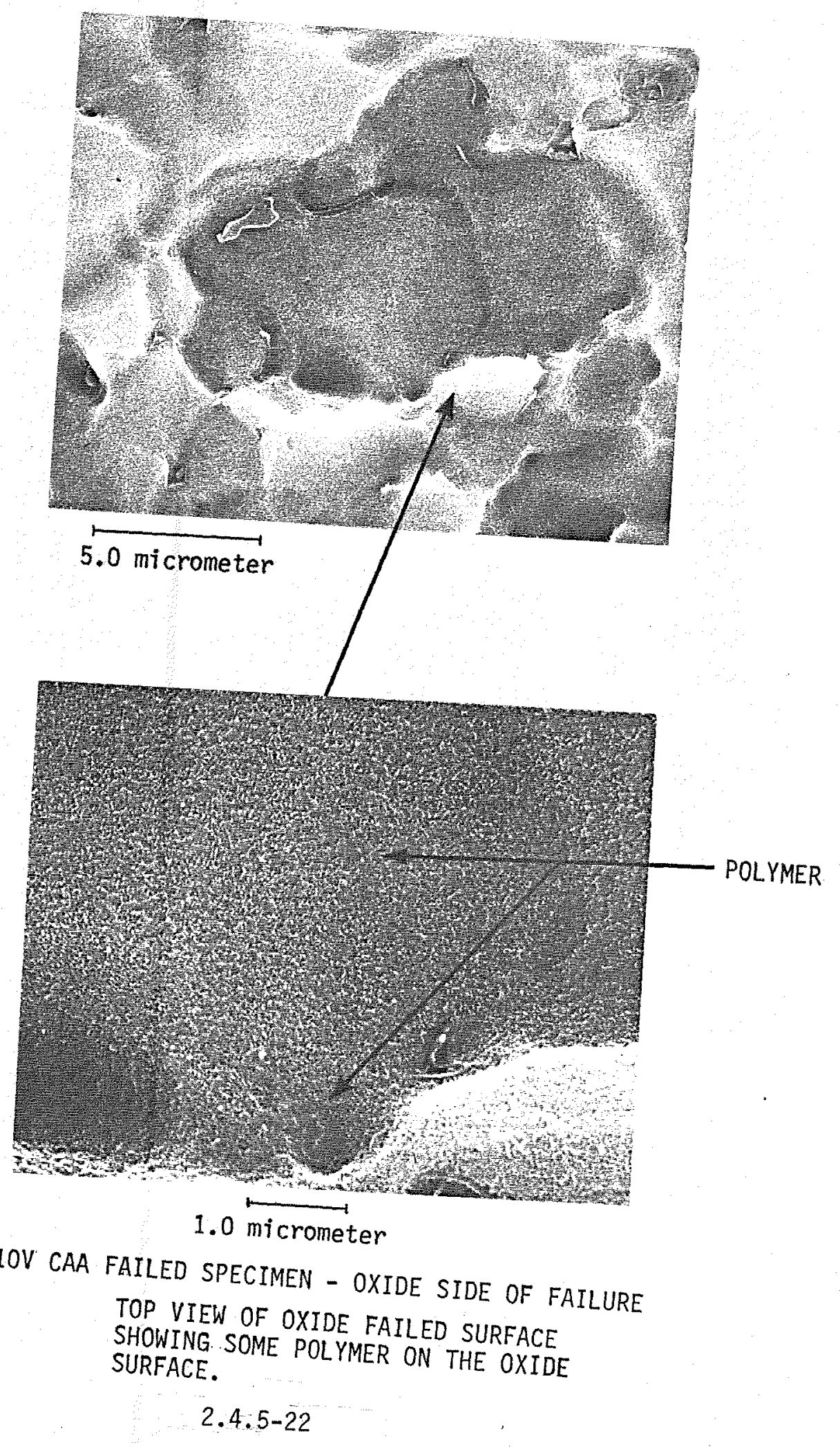




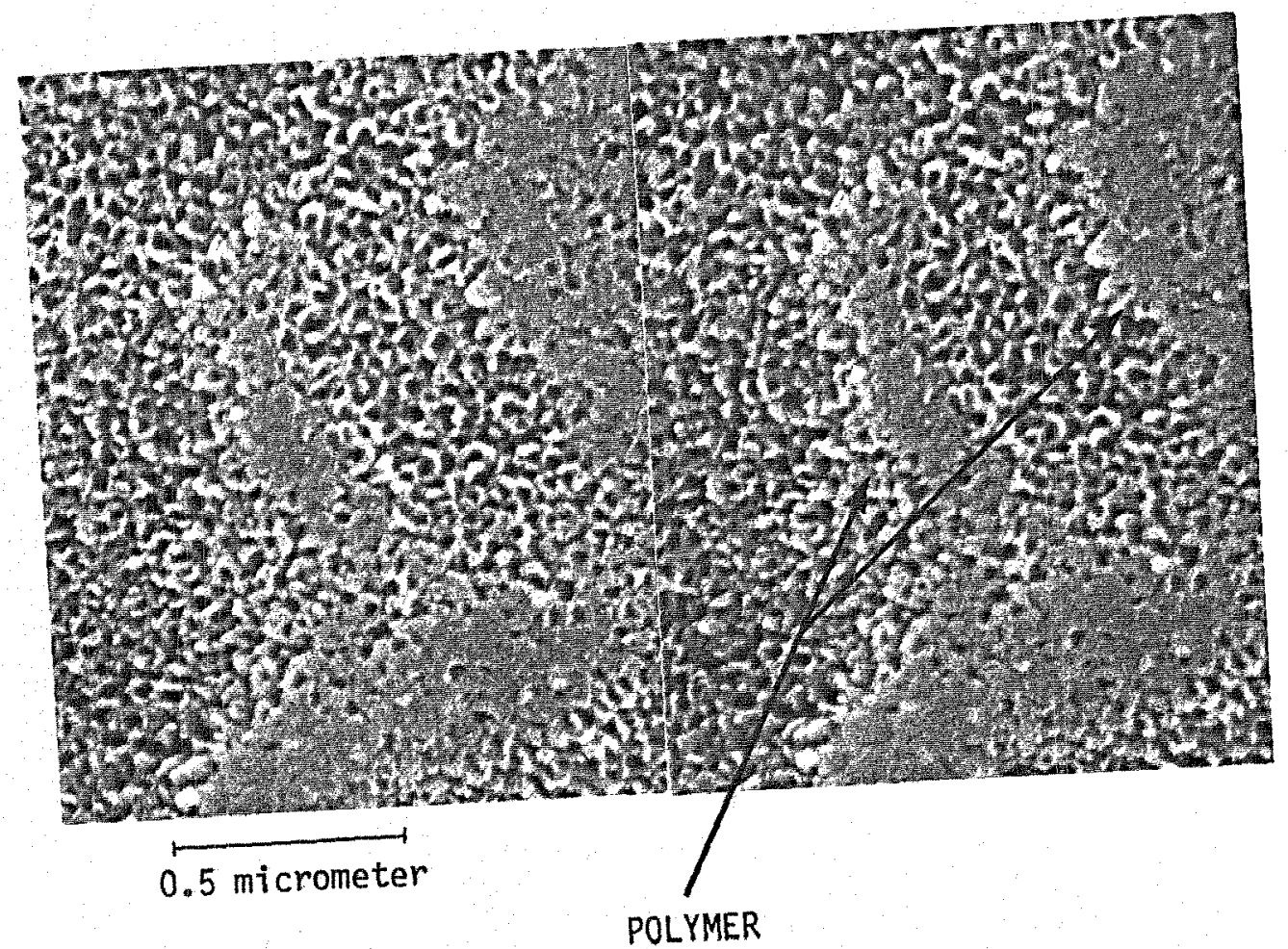

1OV CAA FAILED SPECIMEN - OXIDE SIDE OF FAILURE STEREO PAIR TOP VIEW OF OXIDE SHOWING POLYMER ON OXIDE (PORE SIZE $\sim 30 \mathrm{NM})$

Figure 2.4.5-23 


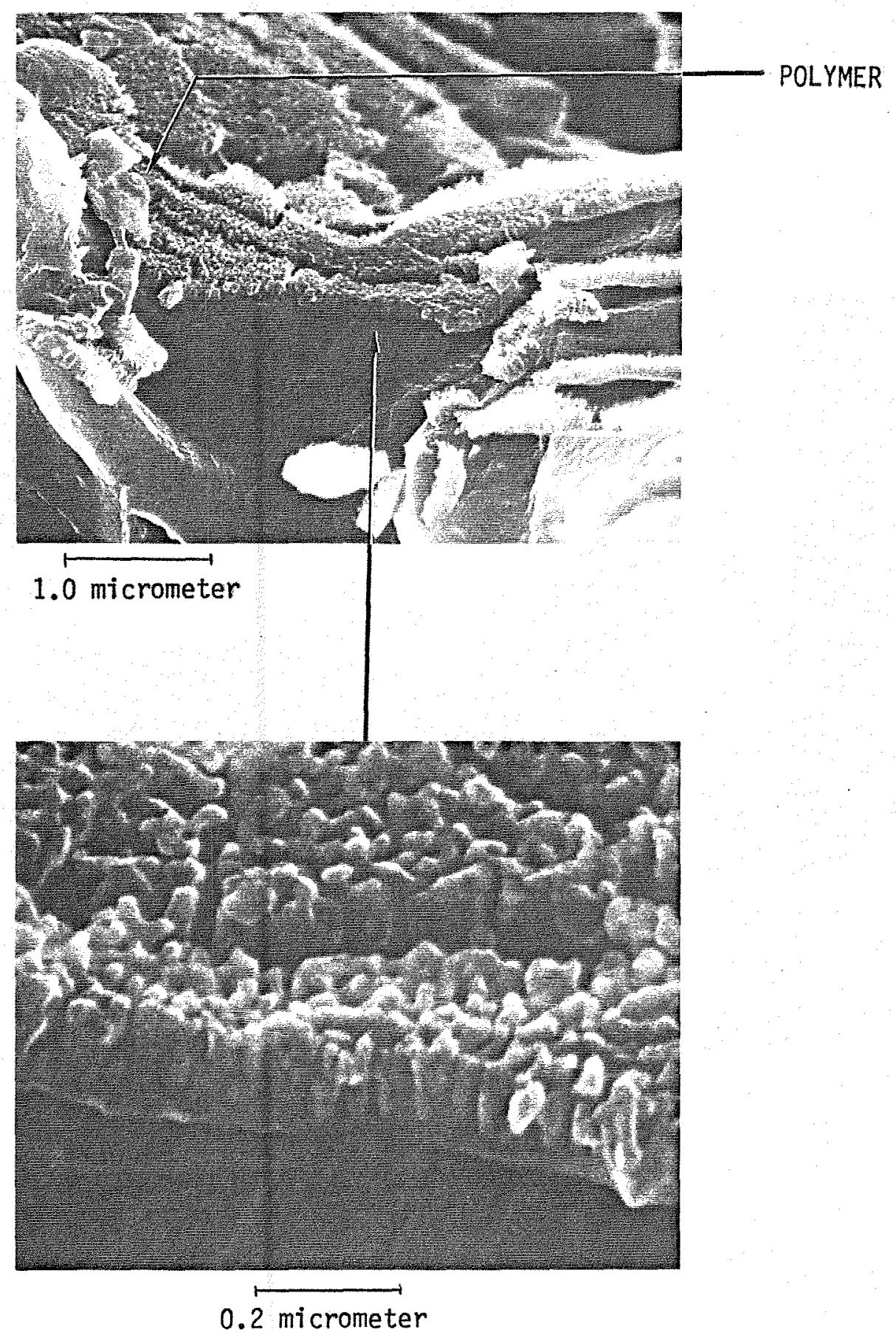

IOV CAA FAILED SPECIMEN - OXIDE SIDE OF FAILURE

FRACTURED OXIDE OF FAILED LAP SHEAR

SPECIMEN SHOWING SOME POLYMER ON

ON OXIDE (OXIDE THICKNESS $\sim 140 N M)$

Figure 2.4.5-24 


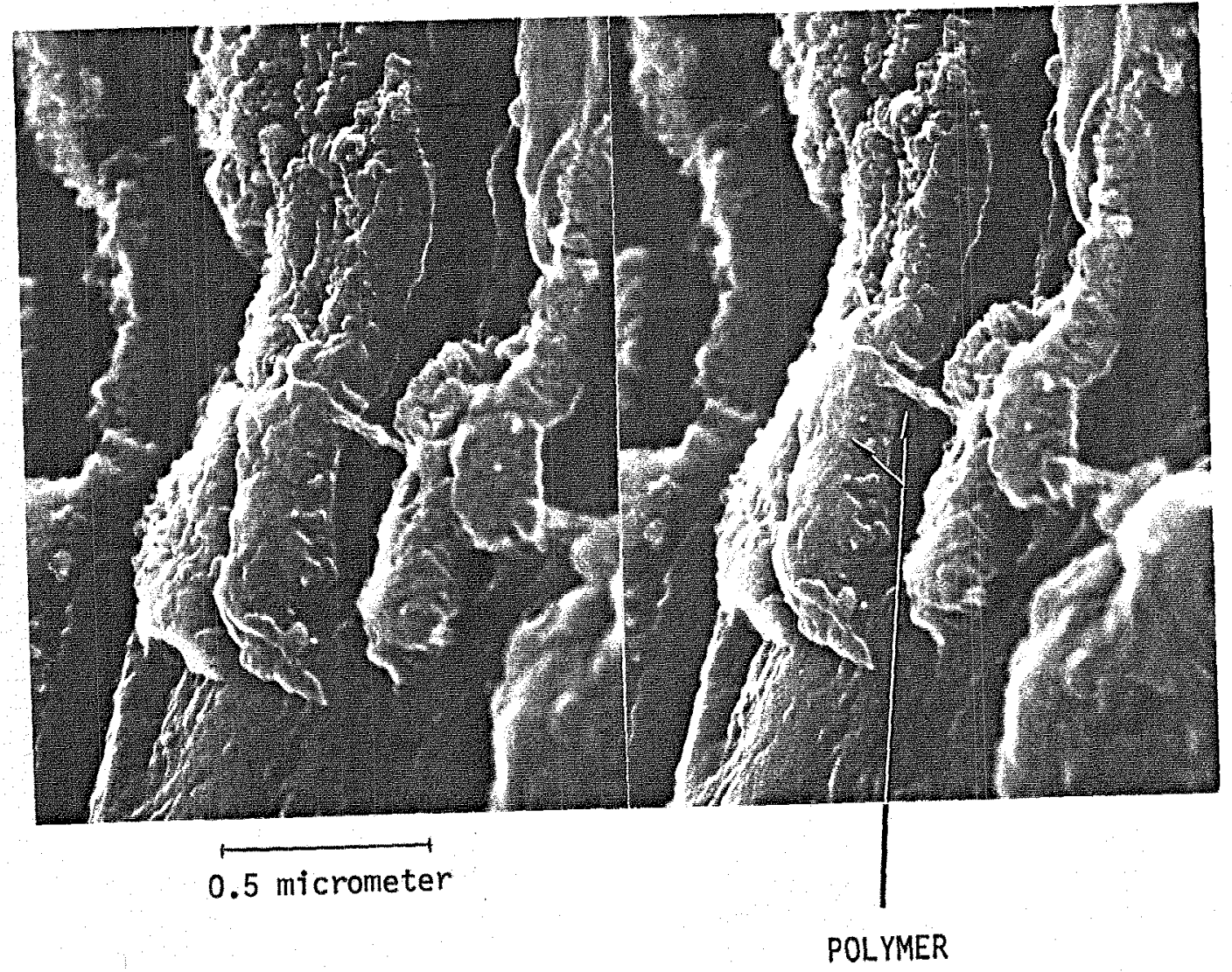

10V CAA FAILED SPECIMEN - OXIDE SIDE OF FAILURE STEREO PAIR OF FRACTURED OXIDE FROM FAILED LAP SHEAR SPECIMEN SHOWING POLYMER ON TOP OF OXIDE, POLYMER STRETCHING BETWEEN OXIDE ISLANDS, AND LIMITED POLYMER PENETRATION.

Figure $2 \cdot 4 \cdot 5-25$ 


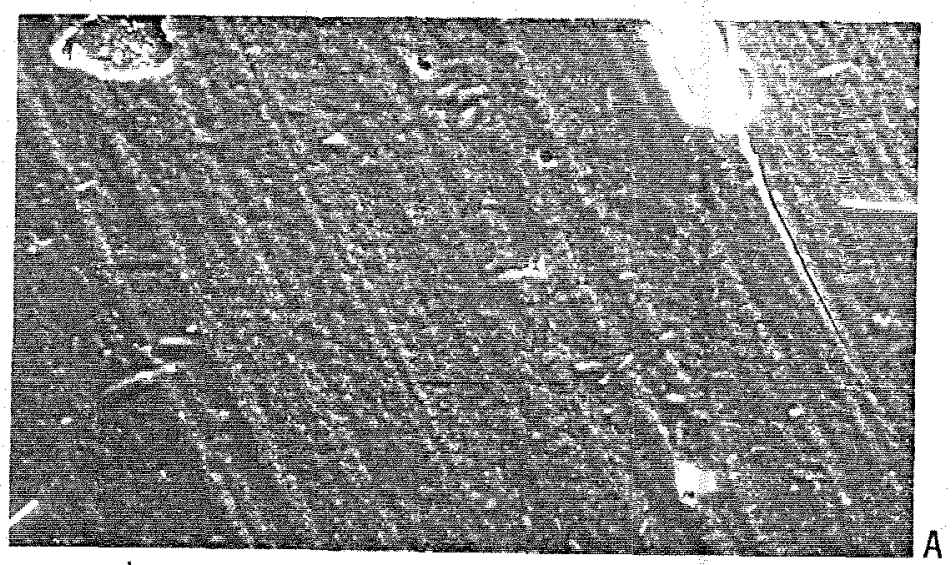

0.2 millimeter

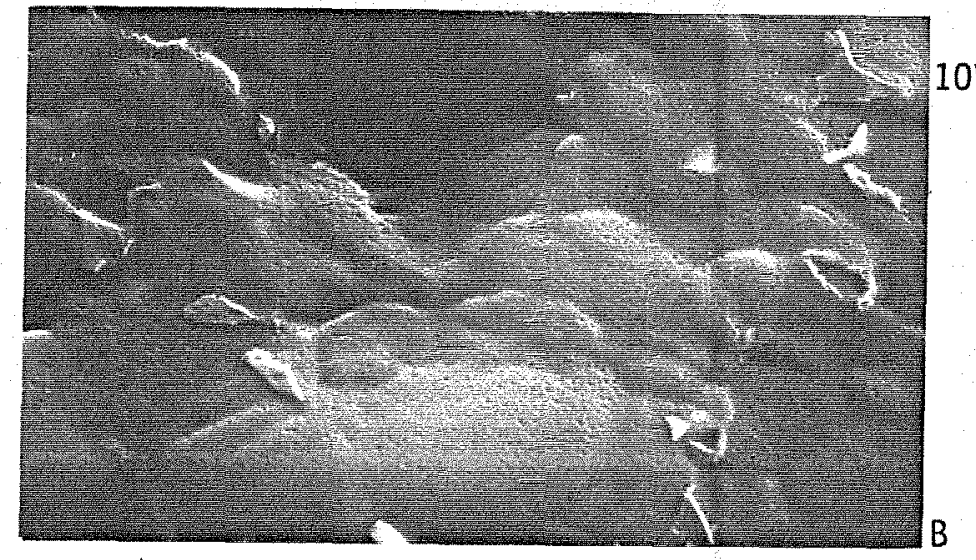

1OV CAA FAILED SPECIMEN - PRIMER SIDE OF FAILURE TOP VIEW OF POLYMER SIDE OF FAILED LAP SHEAR. AT 50,000X TWO FEATURES ARE SHOWN. THESE TWO FEATURES ARE DEPRESSIONS 9ONM IN DIAMETER AND SMALL BRIGHT NODULES. WHICH ARE $\sim 30 N M$ IN DIAMETER.

Figure $2 \cdot 4 \cdot 5-26$

5.0 micrometer

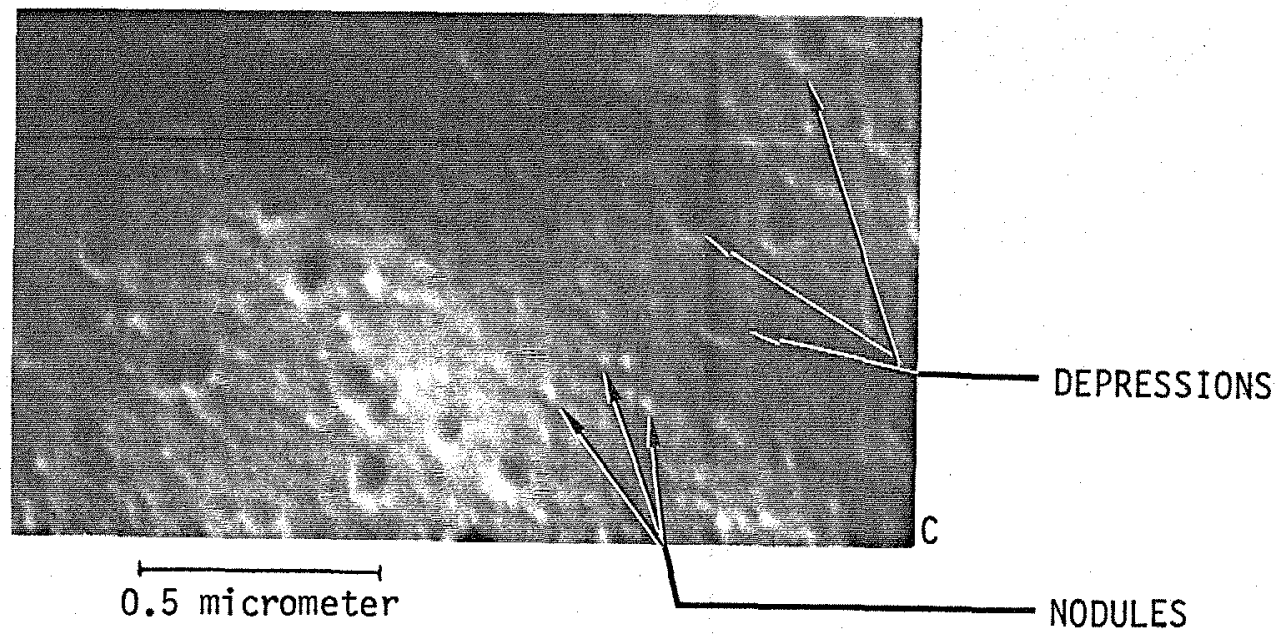




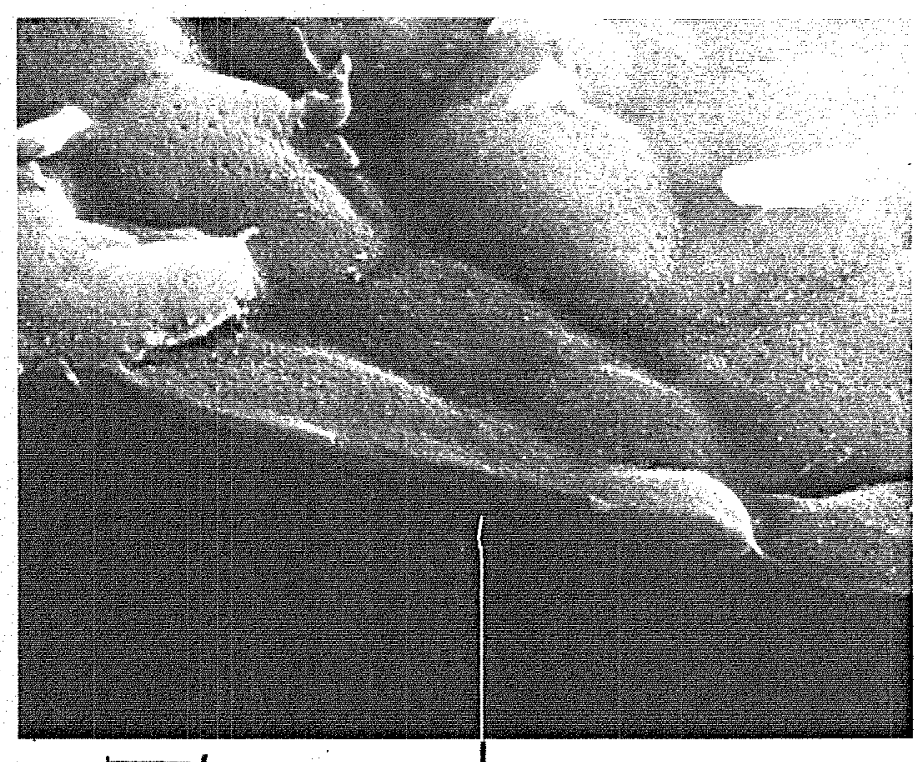

$1.0 \stackrel{\text { micrometer }}{\longrightarrow}$

0.5 micrometer

IOV CAA FAILED SPECIMEN - POLYMER SIDE OF FAILURE FRACTURED VIEW OF POLYMER SIDE OF FAILURE ALSO SHOWS BRIGHT NODULES AND DEPRESSIONS.

Figure $2.4 .5-27$ 


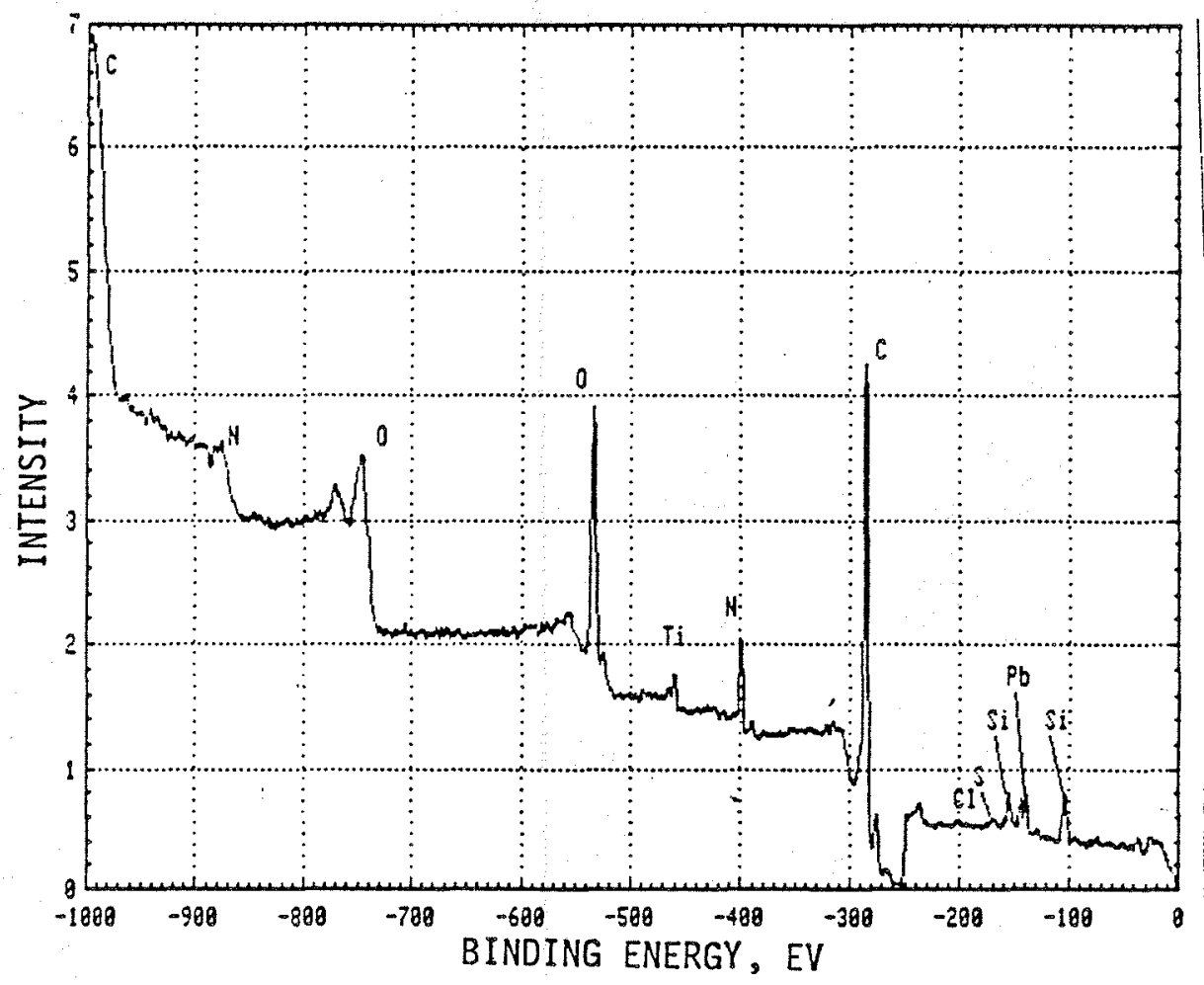

Figure 2.4.5-28 ESCA SPECTRUM OF THE FAILED PPQ/1OV CAA LAP SHEAR, ADHESIVE SURFACE.

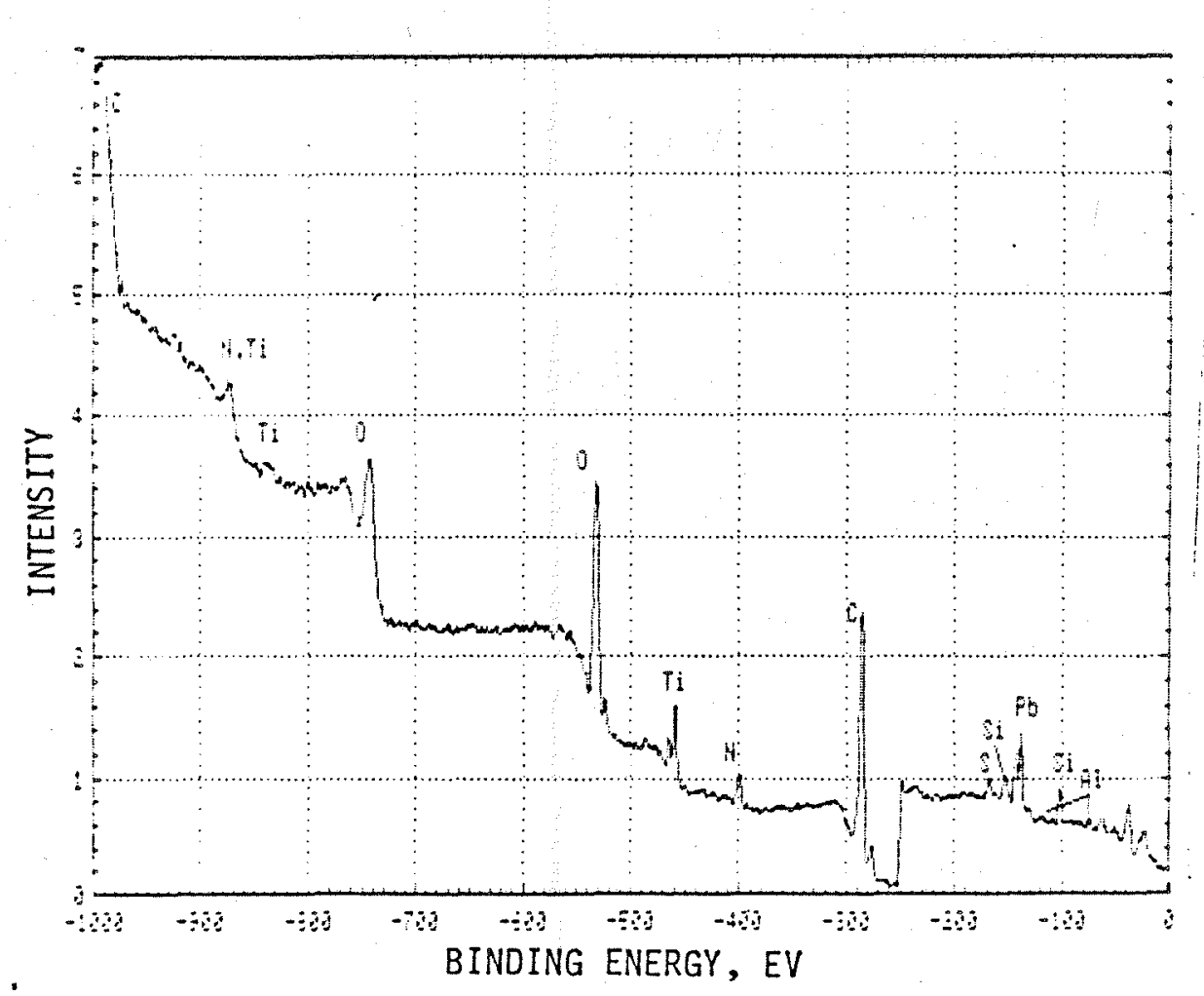

$\begin{array}{ll}\text { Figure } & 2.4 .5-29 \\ & \text { ESCA SPECTRUM OF THE FAILED PPQ/1OV CAA }\end{array}$ 

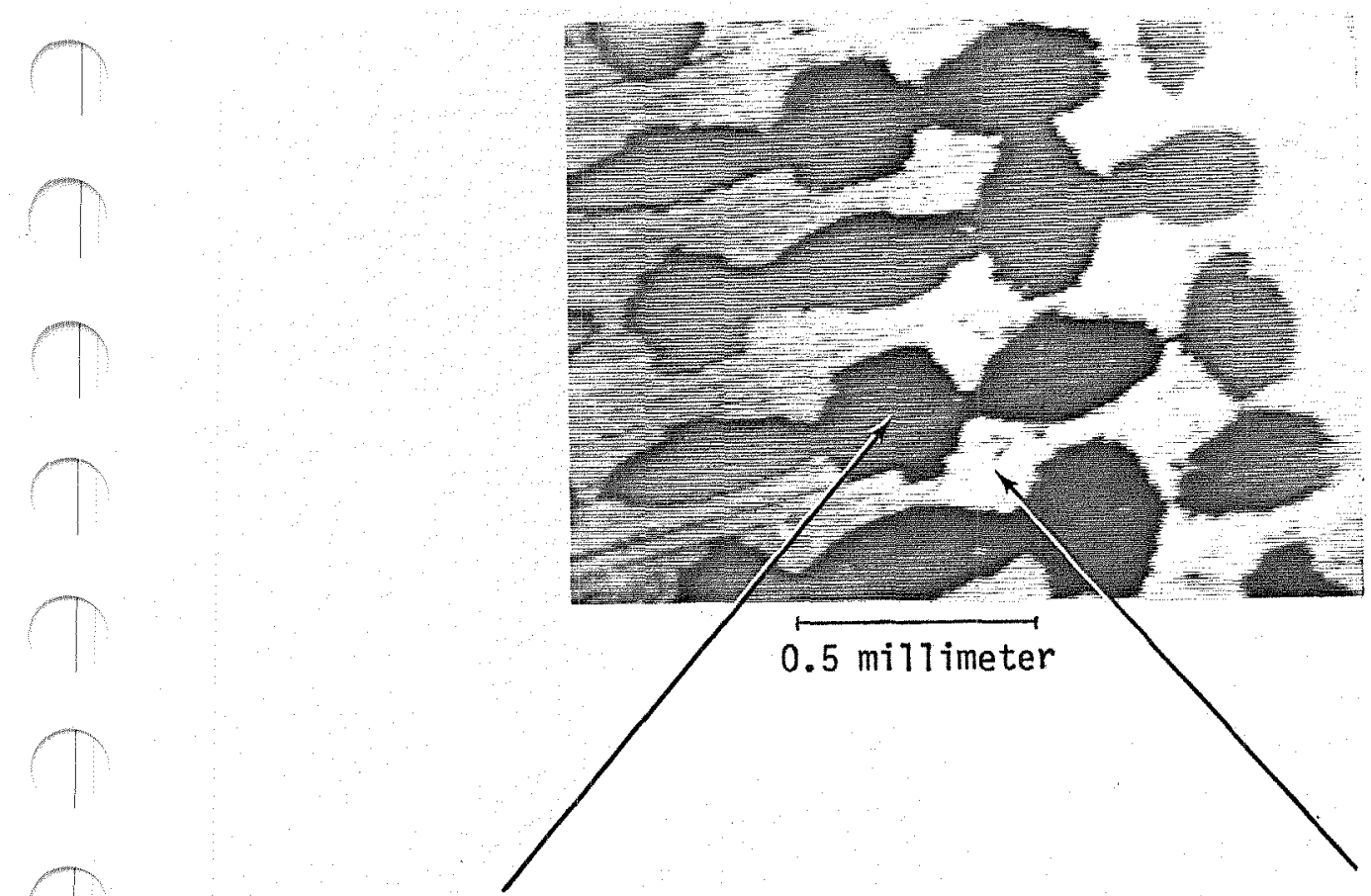

REGION A

REGION B
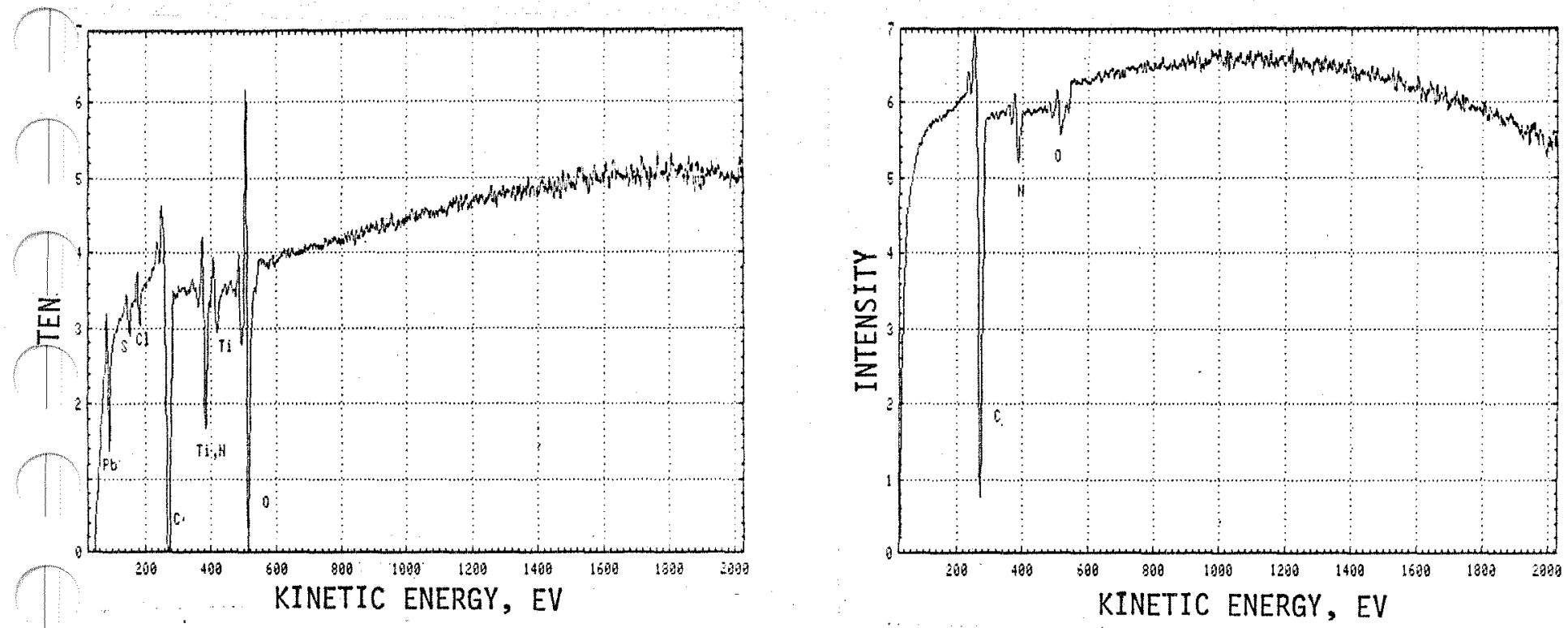

AES ANALYSIS OF REGIONS A AND B ON THE PPQ/10V CAA ADHEREND SURFACE (5OX INVERTED ABSORBED CURRENT IMAGE)

Figure $2.4 \cdot 5-30$ 


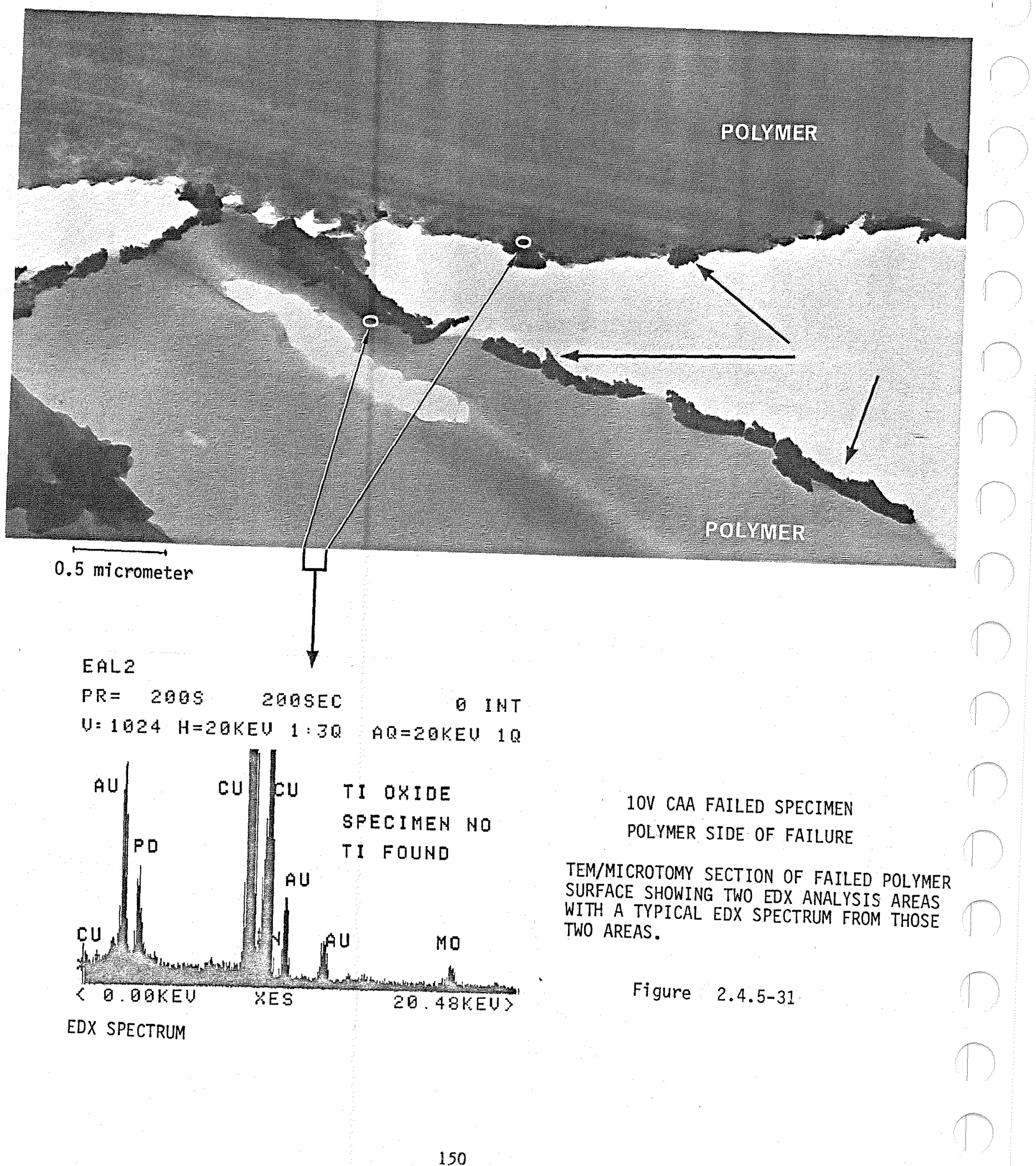




\section{AUGUST 27, 1981}

SPECTRUM EAL2

ENERGY COUNTS $X$-RAY LINES

1.65 406. AU MZ2, AU MZ1

2.14 6783. AU MA1, AU MA2, AU MB

2.83 2638. PD LA1, PD LA2, AU MD, AU MIN

8.01 107917. CU KA1, CU KA2

8.57 728. ZN KA2

8.87 15025. CU KB1

9.67 2602. ZN KB2, AU LA1, AU LA2

11.45 1071. AU LBI

17.39 484. MO KA2

EAL2

$P R=2905$ 2GQSEC 9 INT

$U=1024 \quad H=20 K E U \quad 1: 3 Q \quad A Q=20 K E U \quad 1 Q$

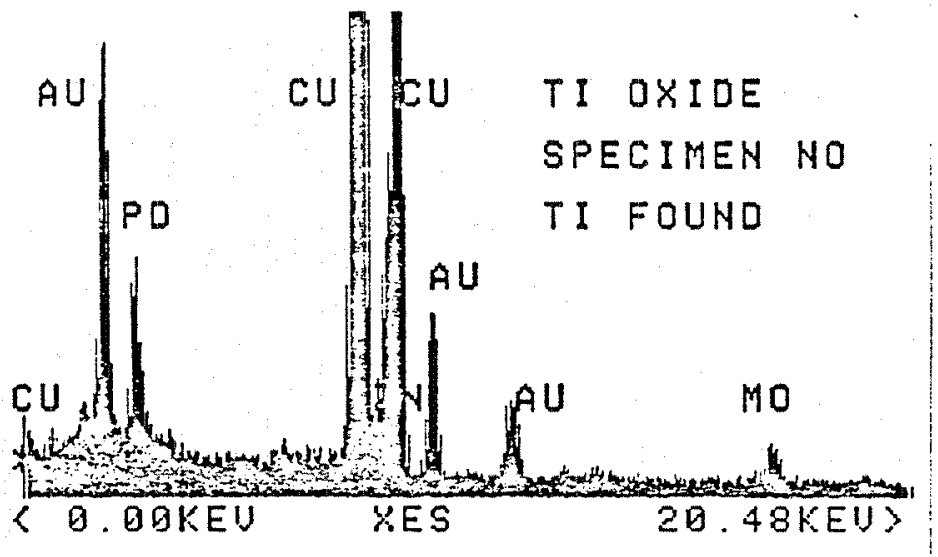

EDX SPECTRUM

IOV CAA FAILED SPECIMEN - POLYMER SIDE OF FAILURE PRINTOUT OF EDX SPECTRUM

Figure 2.4.5-32 


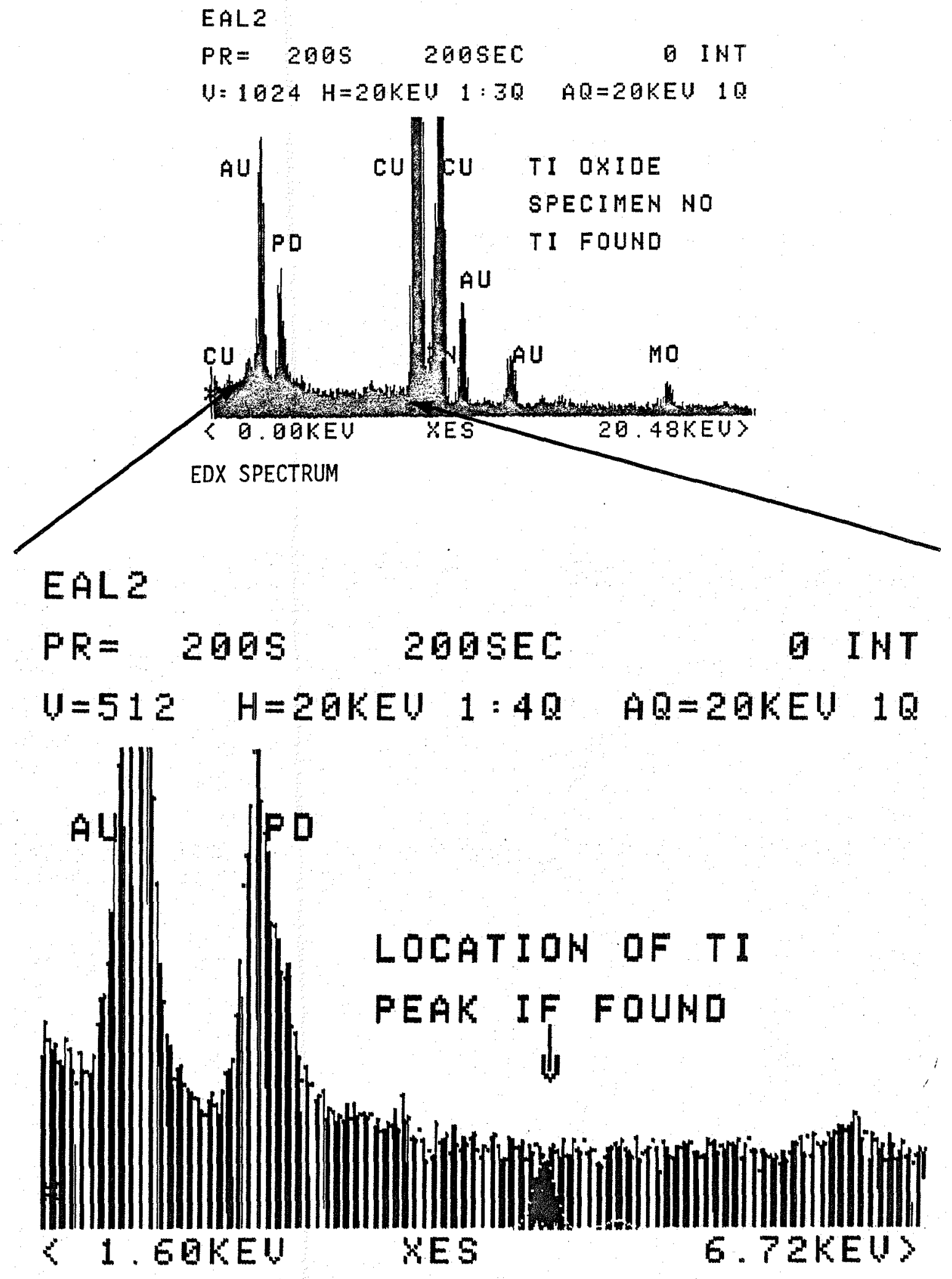

EDX SPECTRỤM

IOV CAA FAILED SPECIMEN - POLYMER SIDE OF FAILURE EDX SPECTRUM EXPANDED

Figure 2.4.5-33 


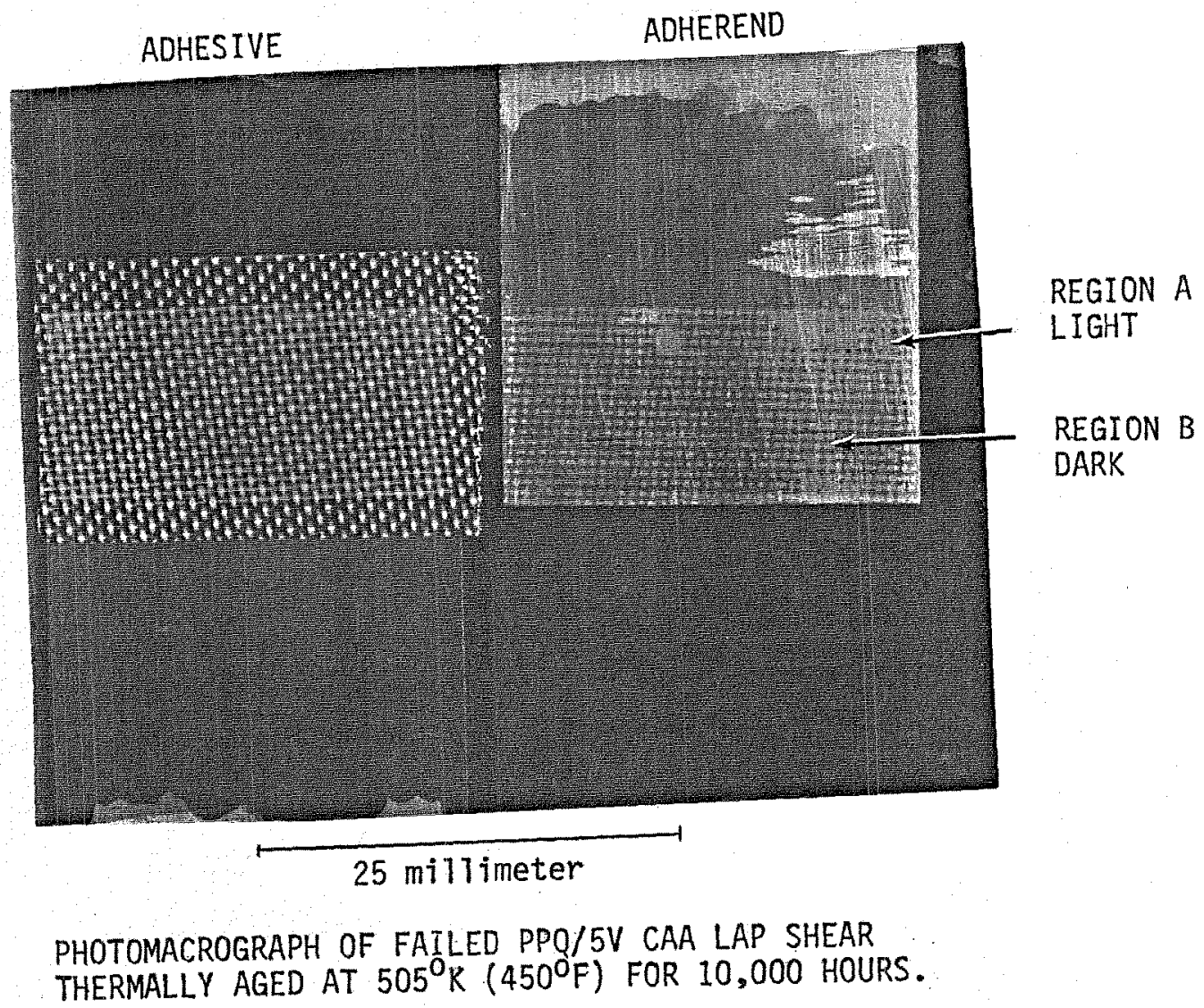

Figure 2.4.5-34 


\section{V CAA TEST FAILURE-OXIDE SIDE}

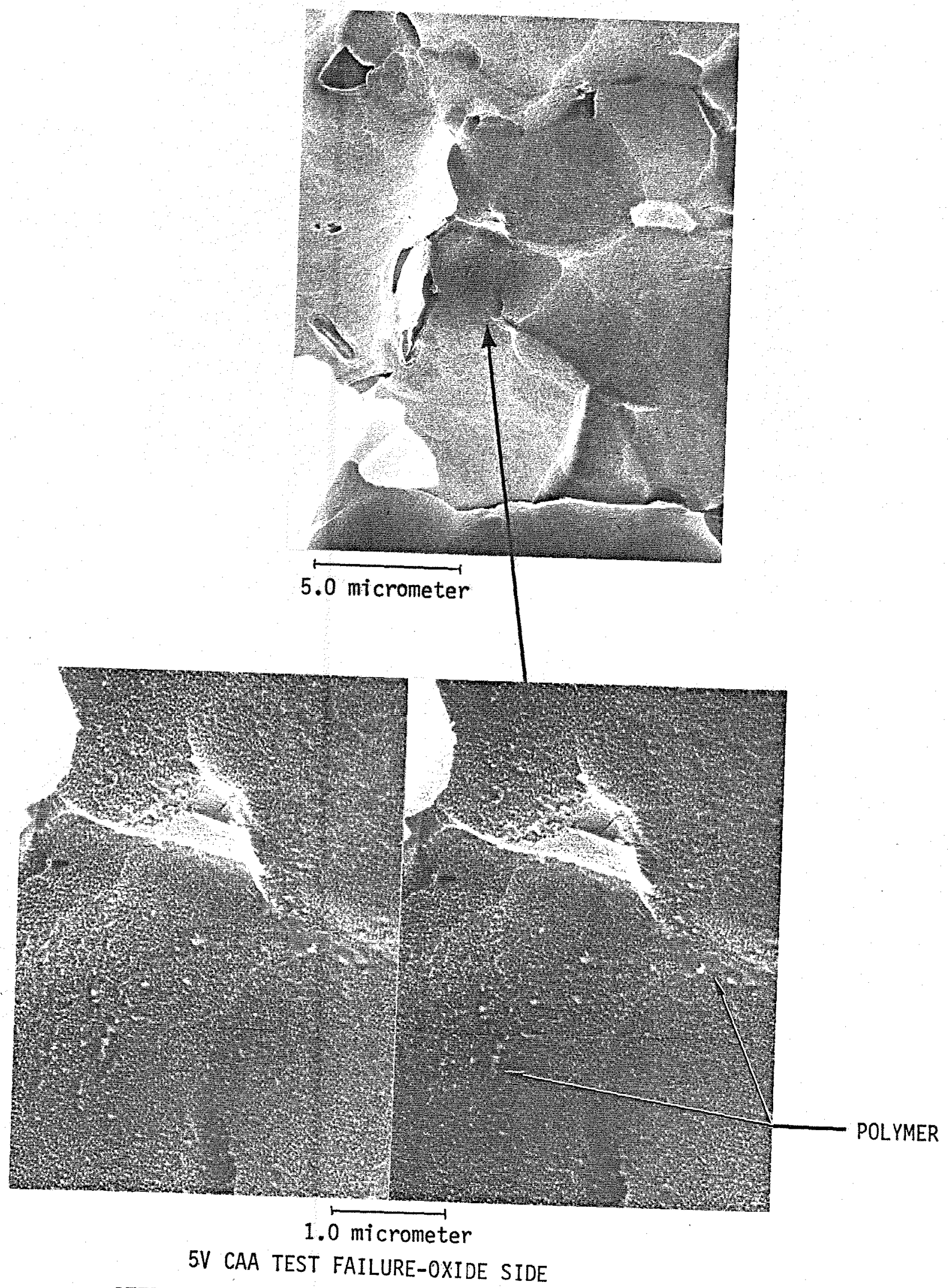

STEREO PAIR SHOWING TOP VIEW OF OXIDE WITH INDICATIONS OF THE PRESENCE OF SOME POLYYMER

Figure $2.4 .5-35$ 

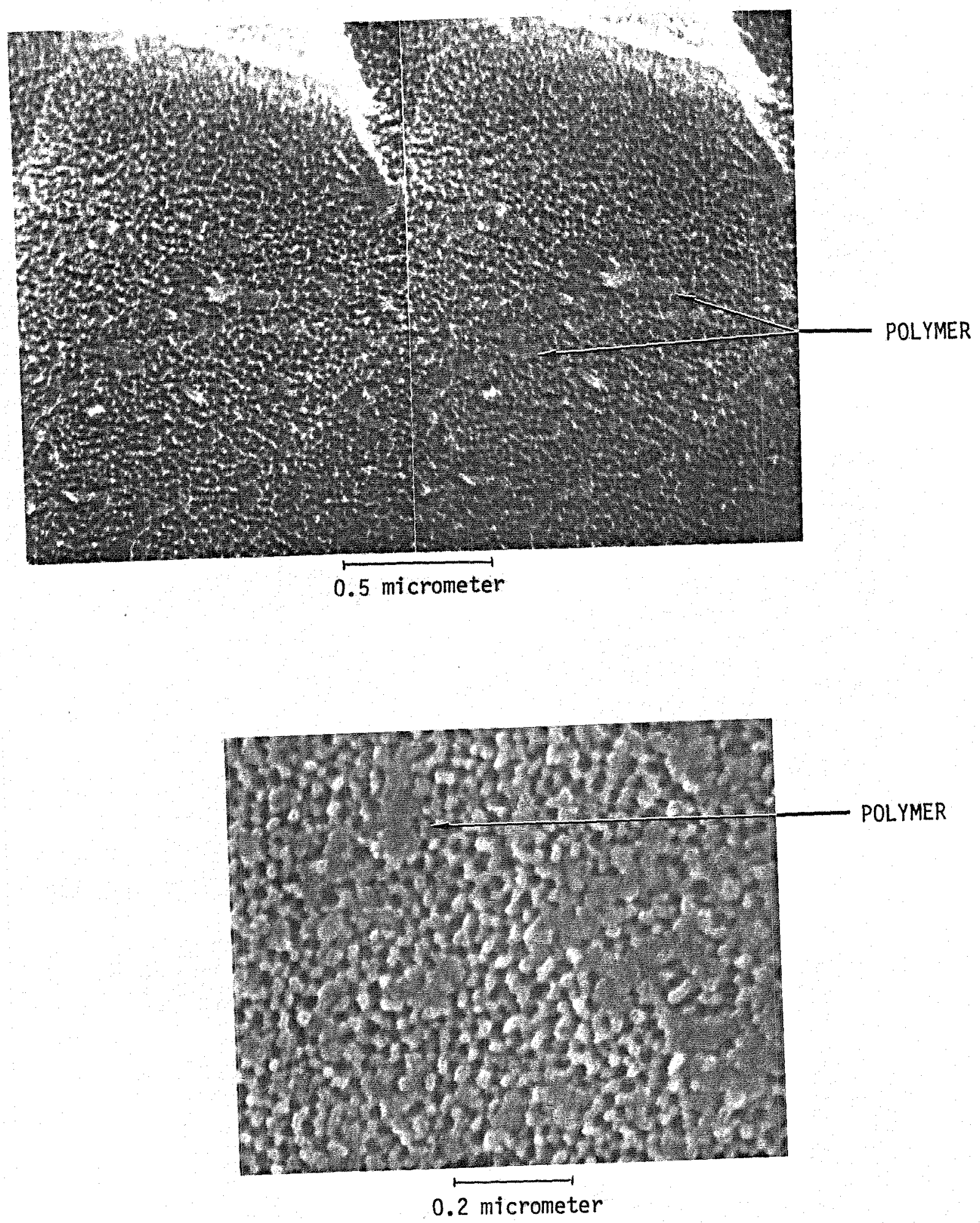

5V CAA TEST FAILURE-OXIDE SIDE

Figure 2.4.5-36 

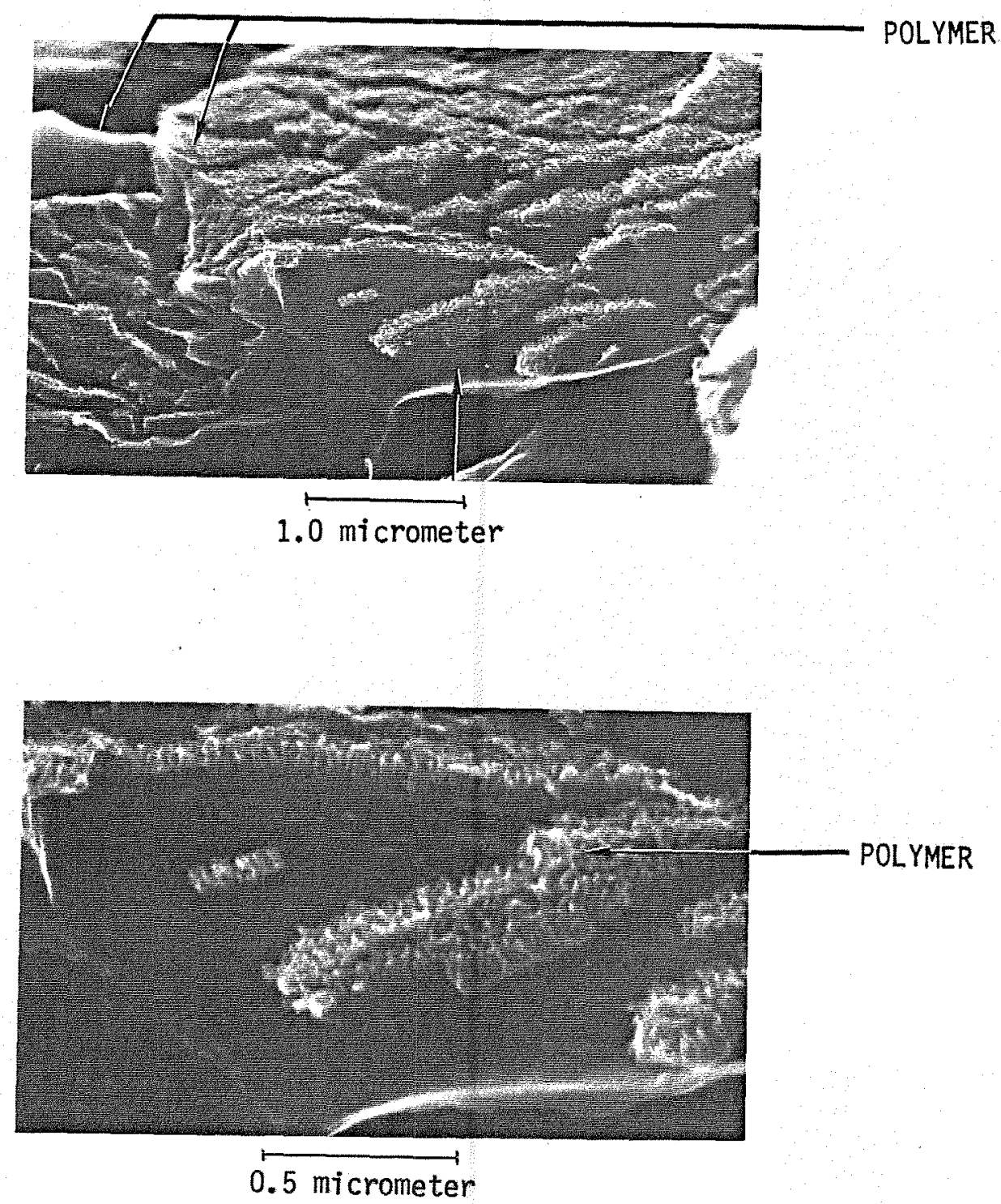

5V CAA TEST FAILURE-OXIDE SIDE

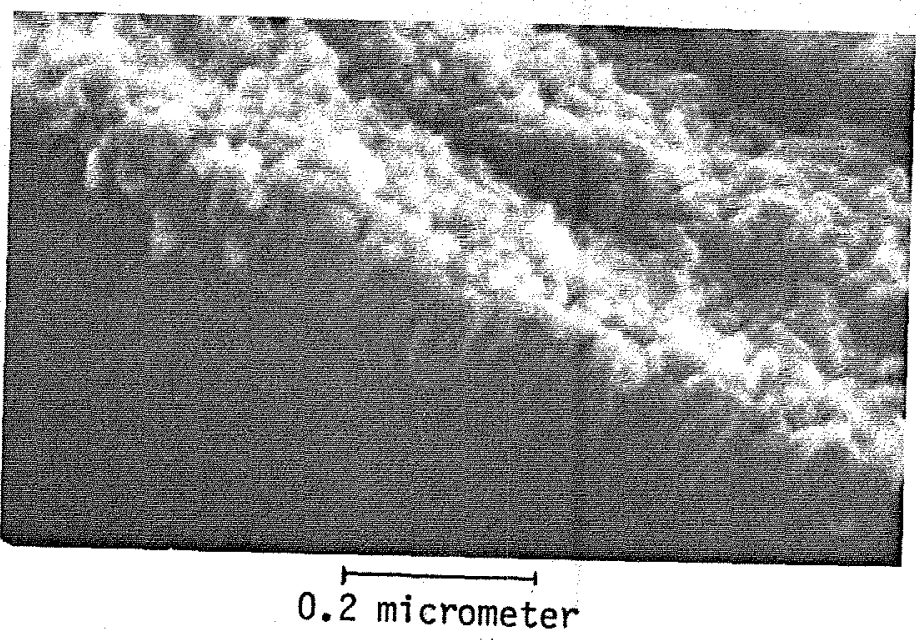

FRACTURED OXIDE WITH VERY SMALL AMOUNTS OF POLYMER PRESENT AND AN OXIDE THICKNESS OF $130 \mathrm{NM}$.

Figure $2.4 .5-37$ 


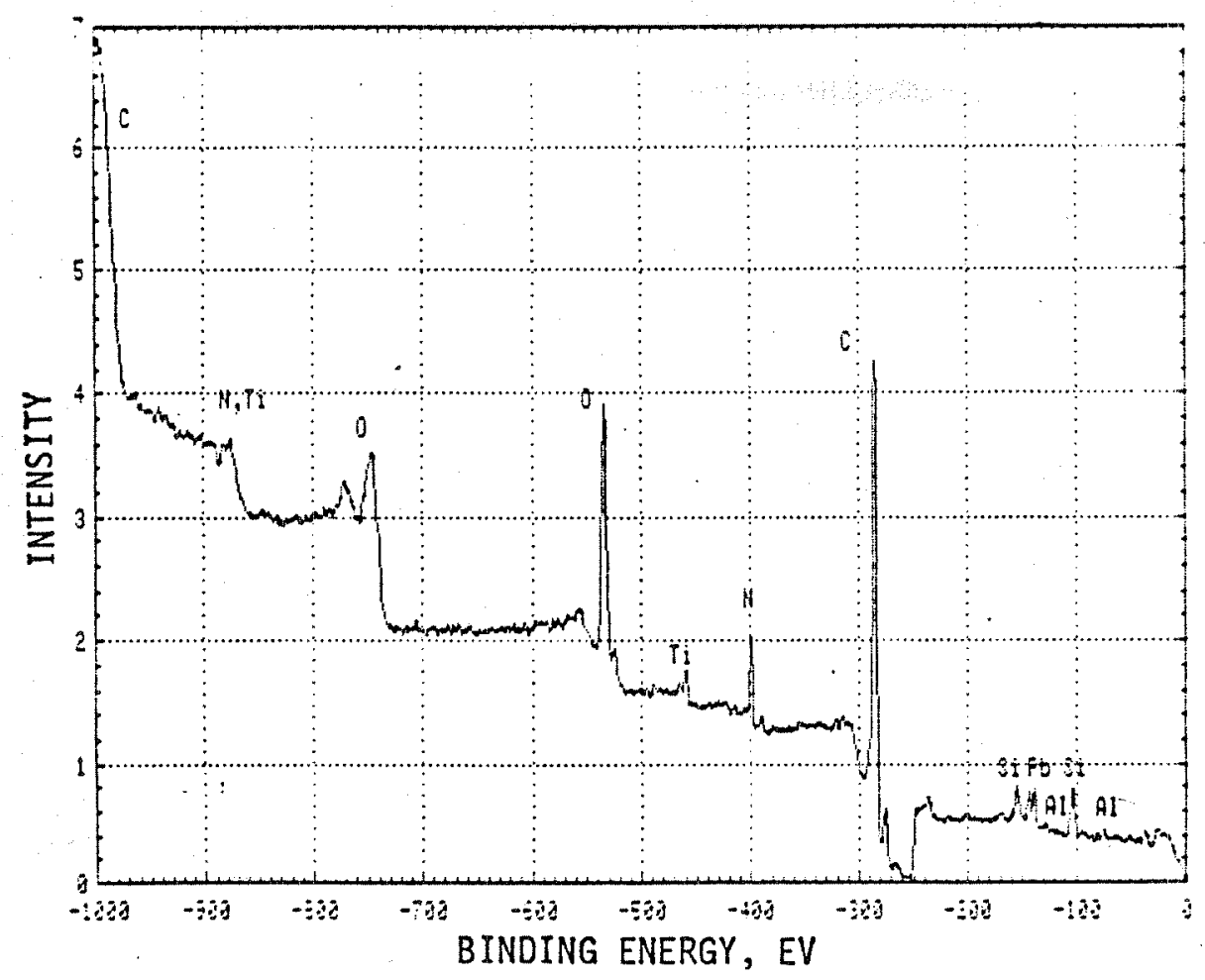

Figure 2.4.5-38 ESCA SPECTRUM OF THE FAILED PPQ/5V CAA LAP SHEAR, ADHESIVE SURFACE.

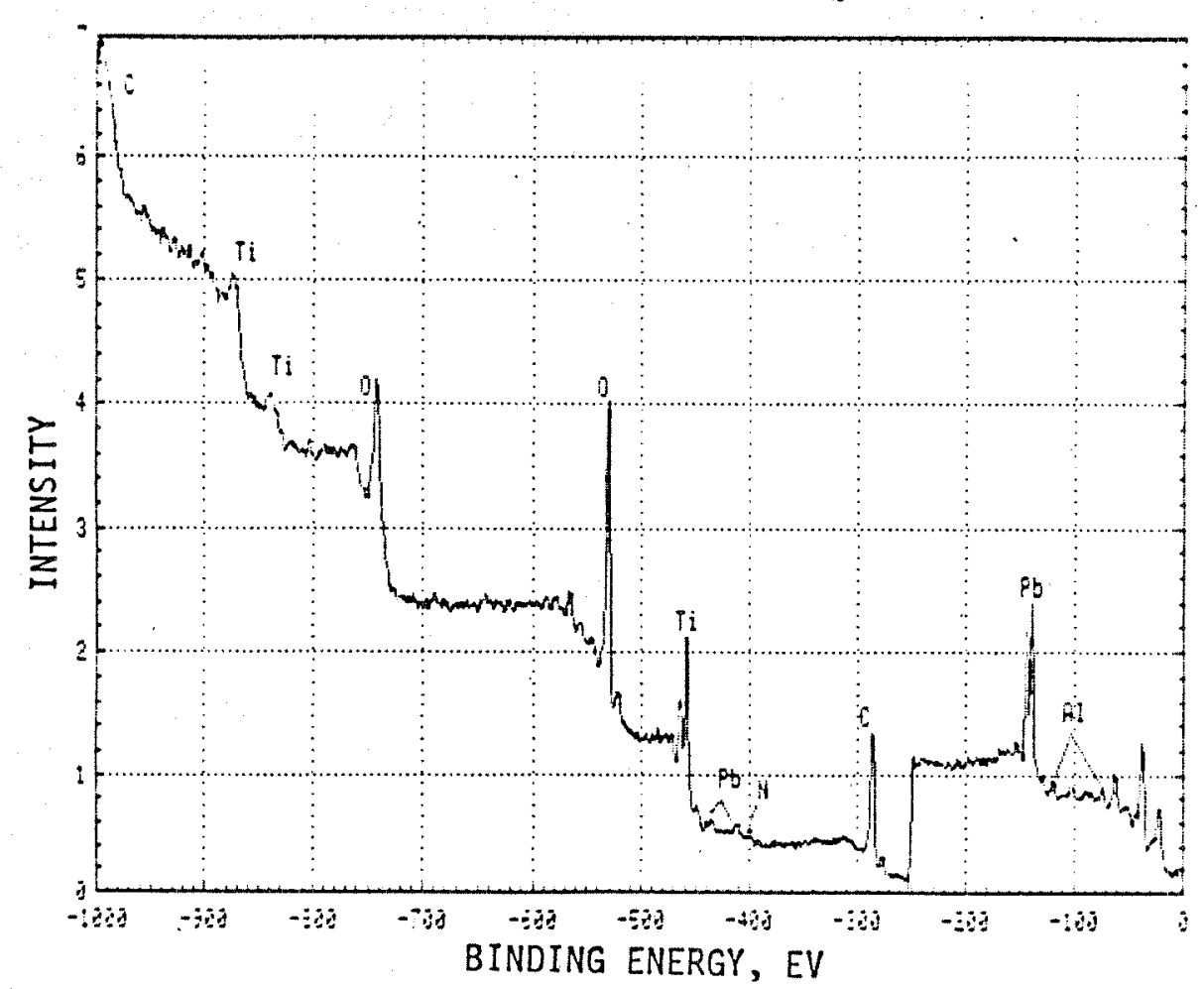
ADHEREND SURFACE 

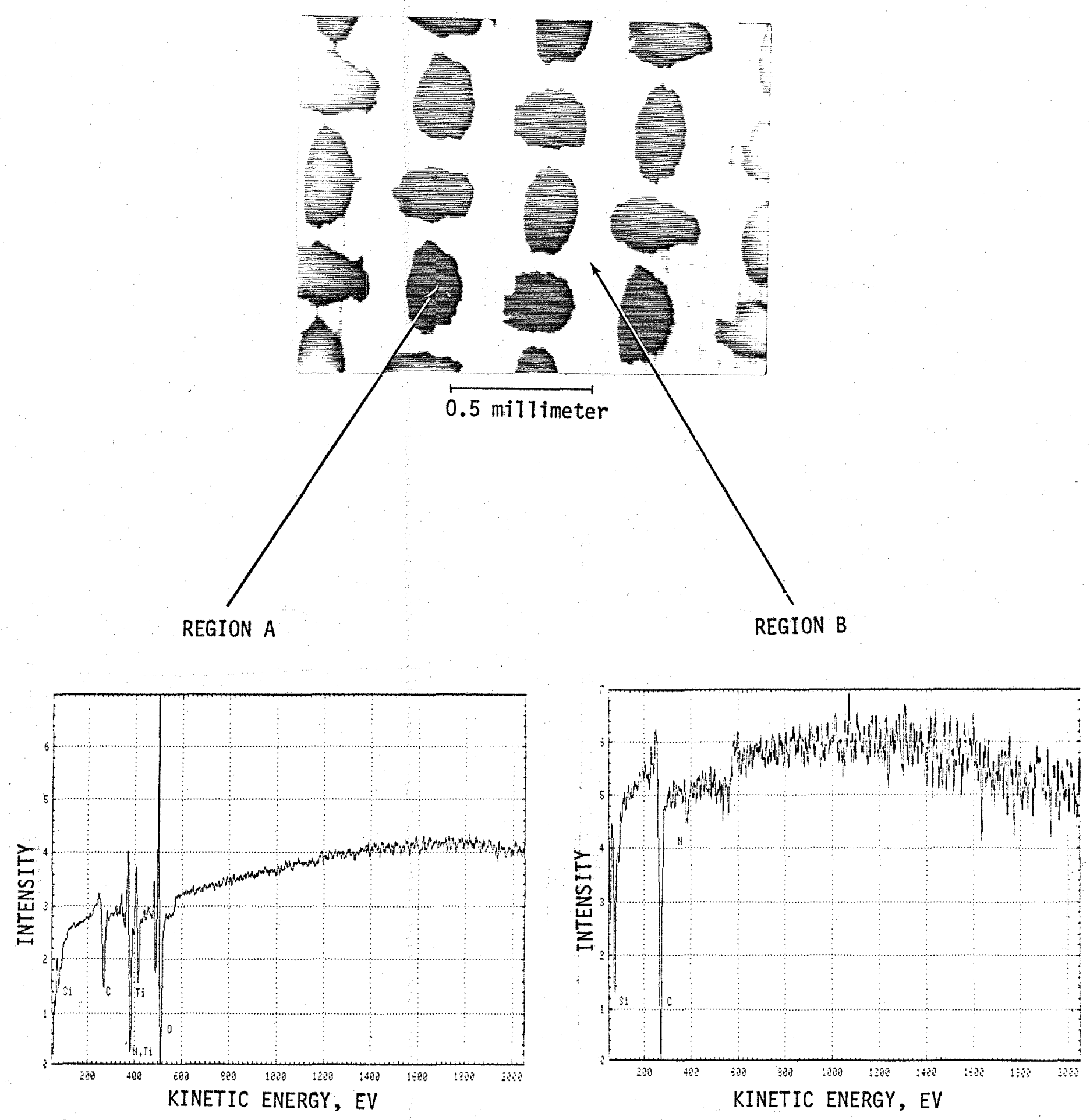

AES ANALYSIS OF REGIONS A AND B ON THE PPQ/5V CAA

ADHEREND SURFACE (5OX INVERTED ABSORBED CURRENT IMAGE).

Figure $2.4 .5-40$ 


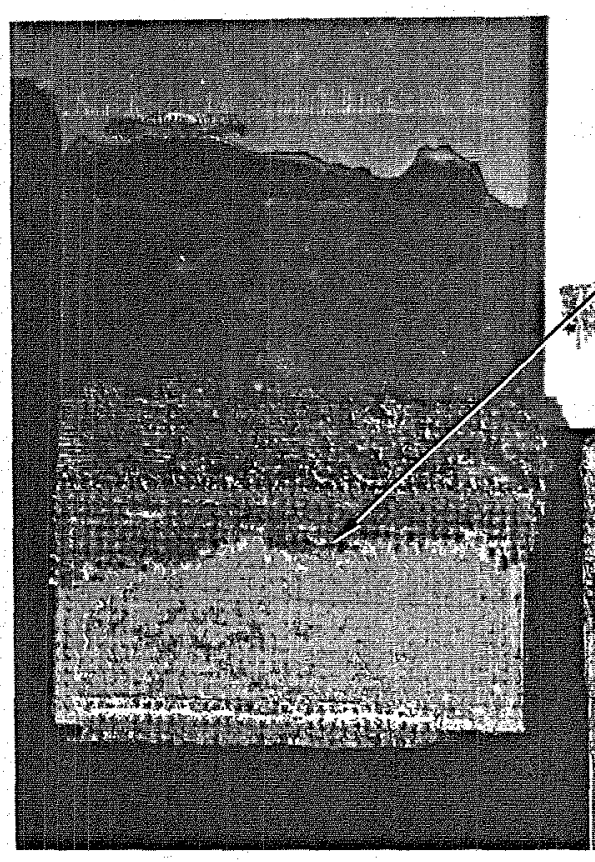

ADHEREND
ADHESIVE
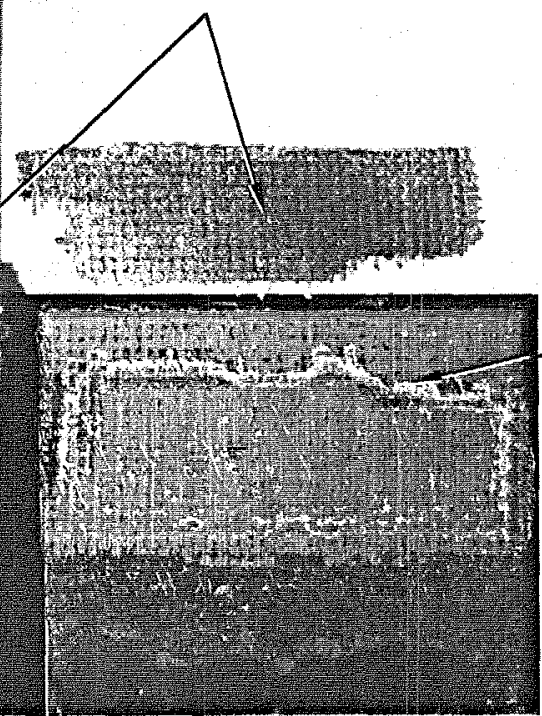

ADHEREND
ALUMINUM FILLER PARTICLES

PHOTOMACROGRAPH OF FAILED LARC-13/10V CAA LAP SHEAR

THERMALLY AGED AT 5050K (450 $\mathrm{F}$ ) FOR 10,000 HOURS.

Figure $2.4 .5-41$ 


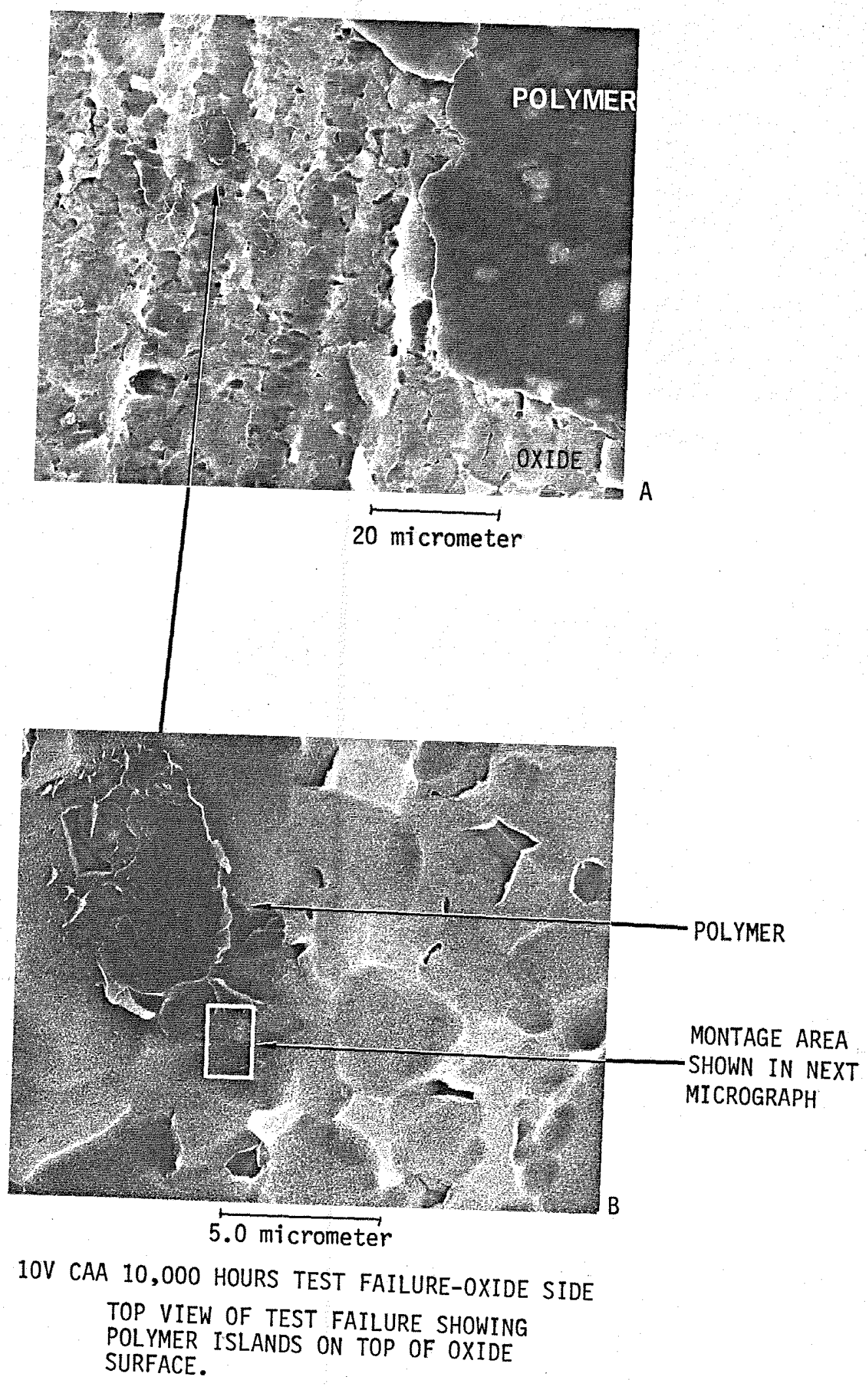

Figure 2.4.5-42 


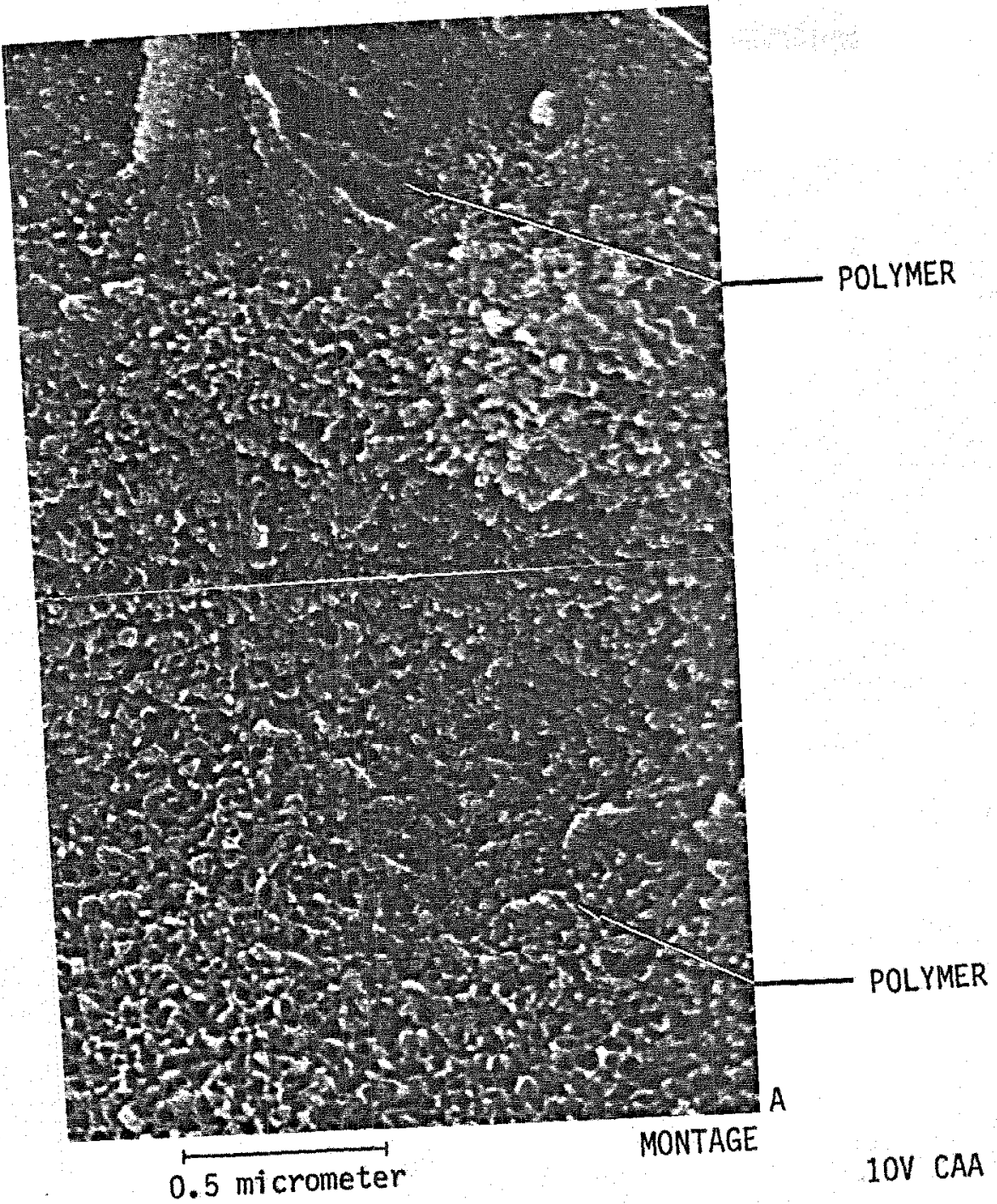

10V CAA 10,000 HOURS TEST FAILURE-OXIDE SIDE TOP VIEW SHOWING SOME POLYMER ATOP ESSENTIALLY OPEN-CELLED OXIDE (PORE SIZE 3ONM IN DIAMETER)

Figure 2.4.5-43

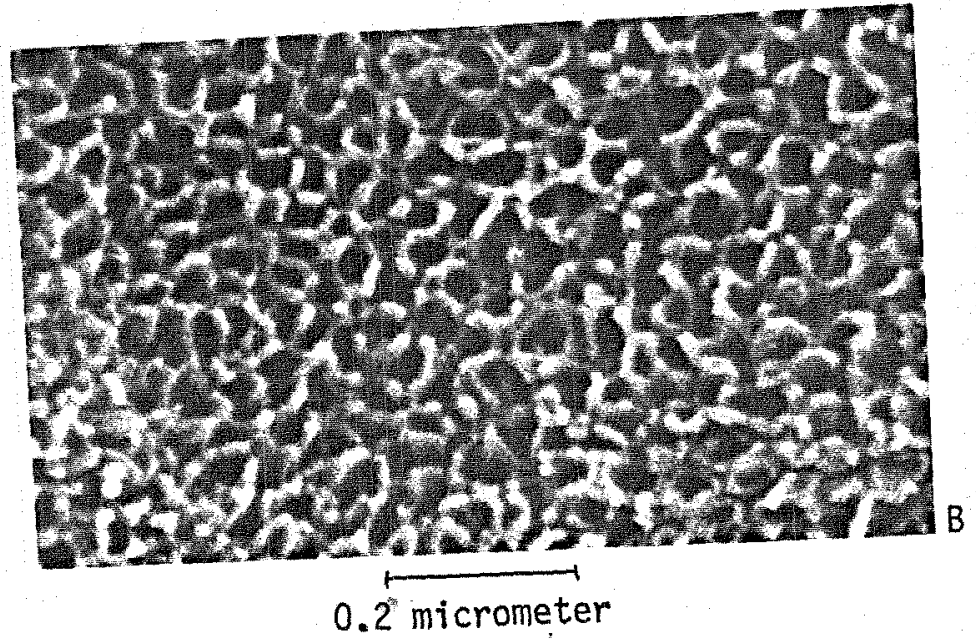




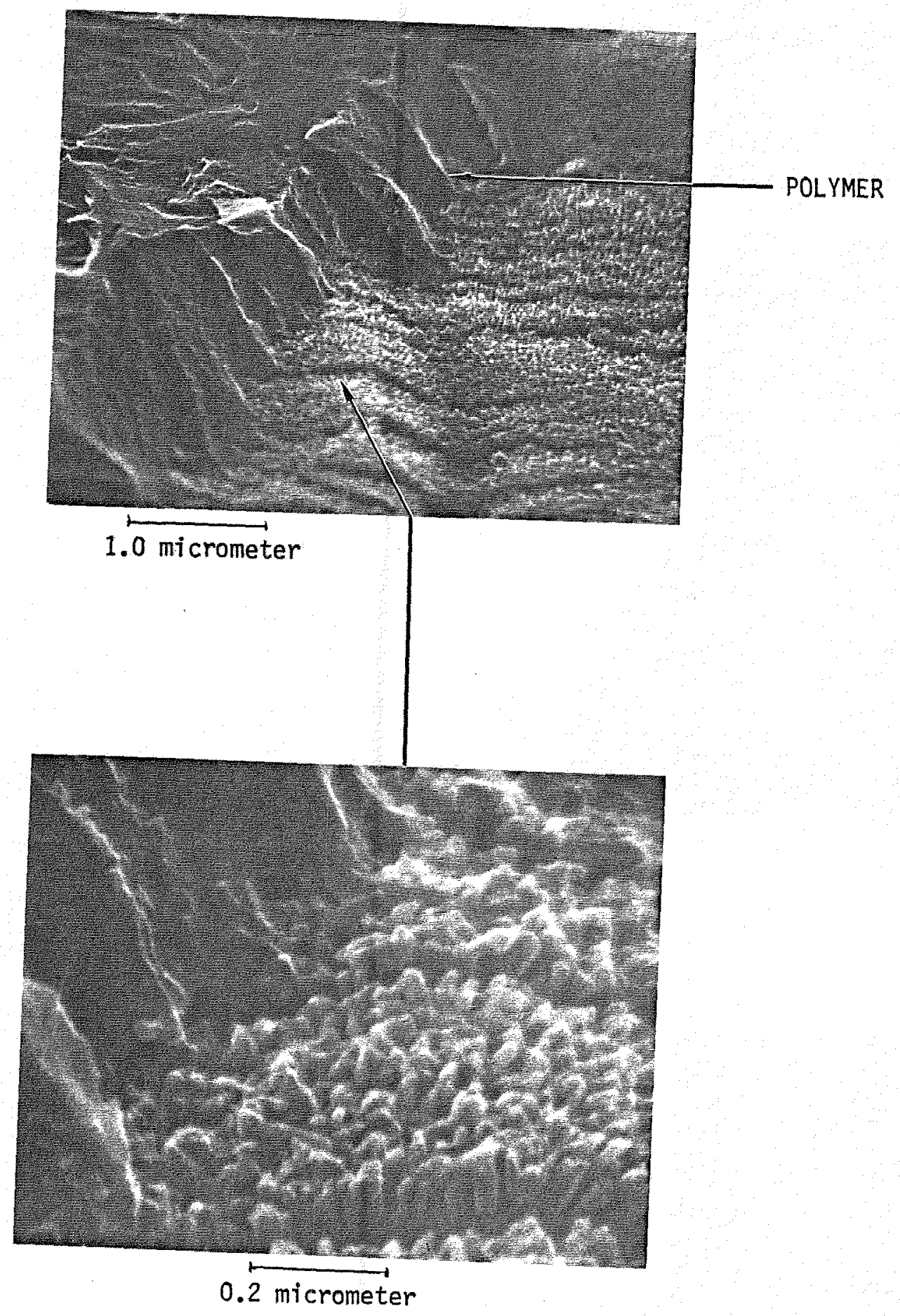

10V CAA 10,000 HOURS TEST FAILURE-OXIDE SIDE POLYMER/OXIDE INTERFACE SHOWN IN LAB-FRACTURED VIEWS

Figure 2.4.5-44 


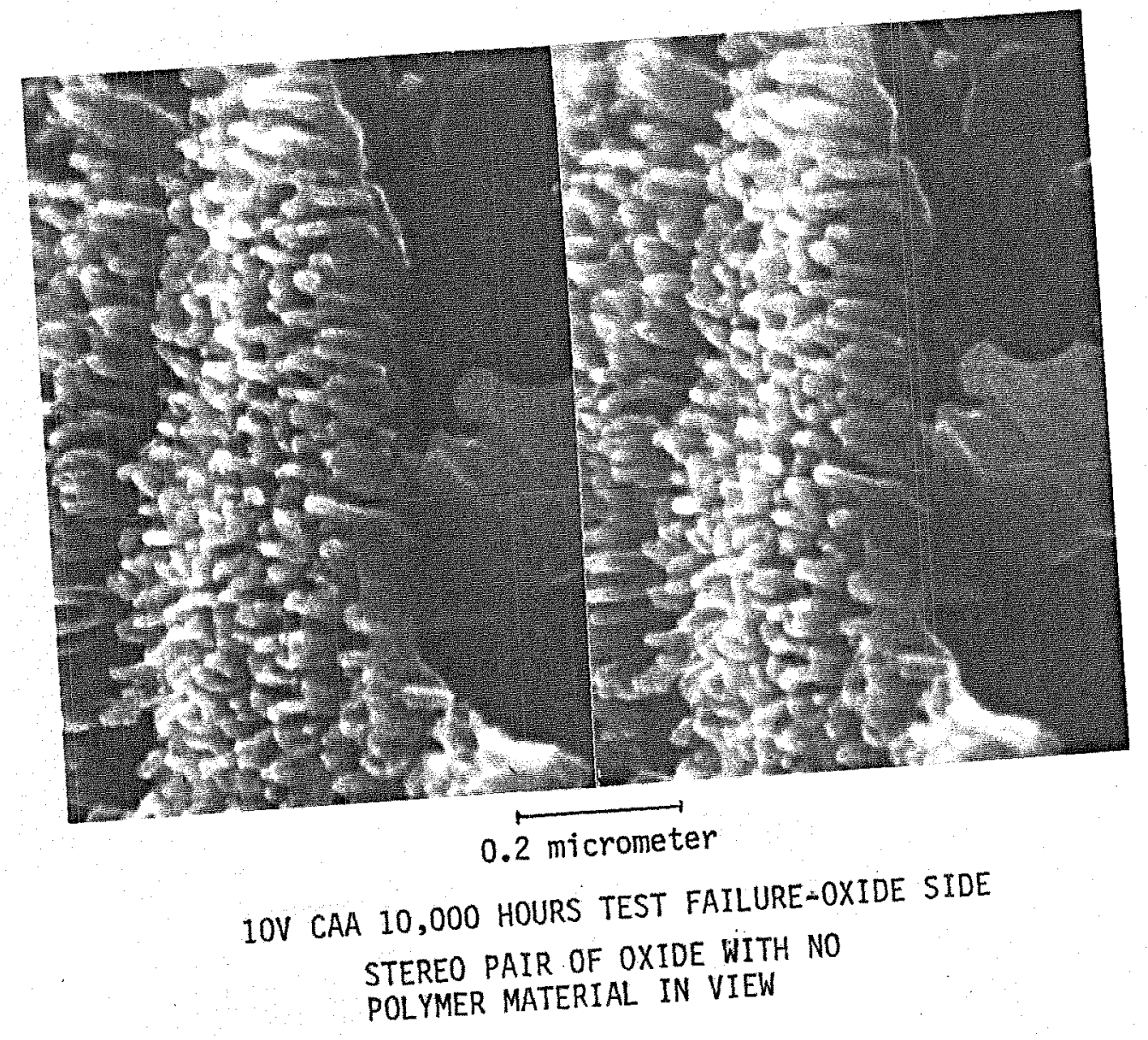

Figure 2.4.5-45 

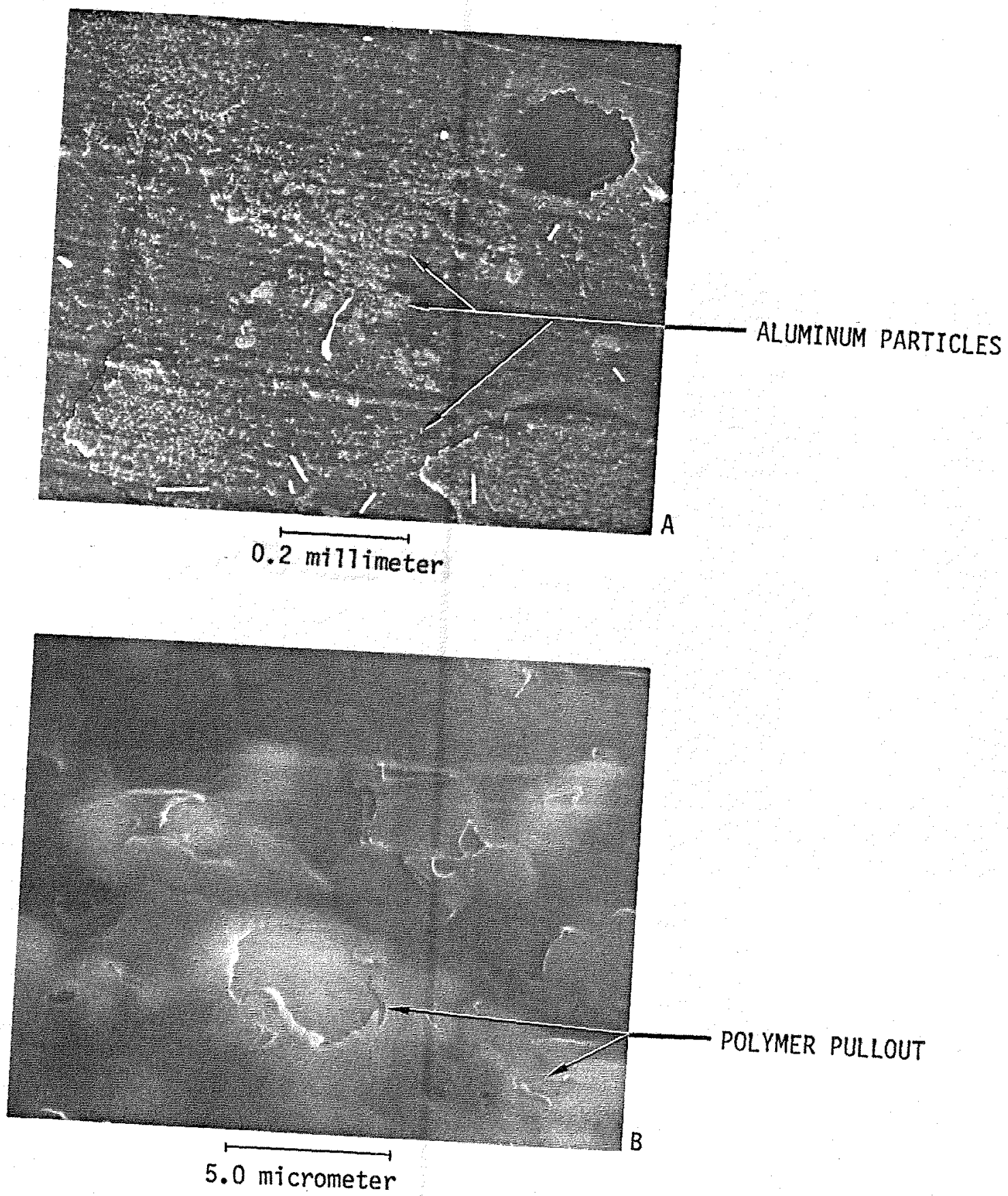

IOV CAA 10,000 HOURS TEST FAILURE-POLYMER SIDE

TOP VIEW OF POLYMER SIDE OF TEST

FAILURE SHOWING $(A)$, ALUMINUM

PARTICLES IN THE POLYMER AND (B), AREAS OF POLYMER/ALUMINUM PARTICLE
INTERFACIAL PULLOUT.

\section{4. $5-46$}




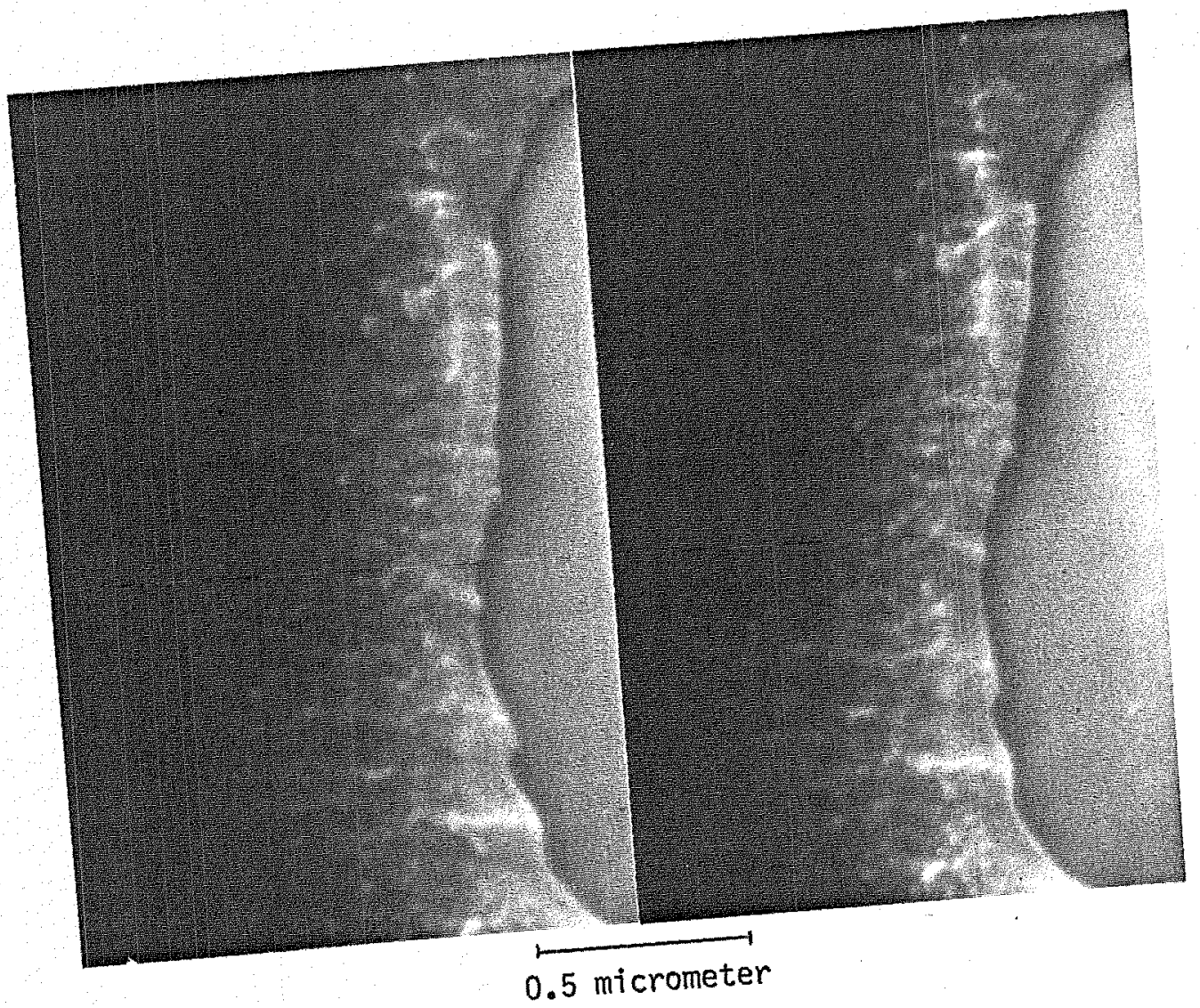

10V CAA 10,000 HOURS TEST FAILURE-POLYMER SIDE STEREO PAIR OF TOP VIEW OF A POLYMER PULLOUT AREA, SHOWING BRIGHT NODULES ON TOP OF THE POLYMER

$$
2.4 .5-47
$$




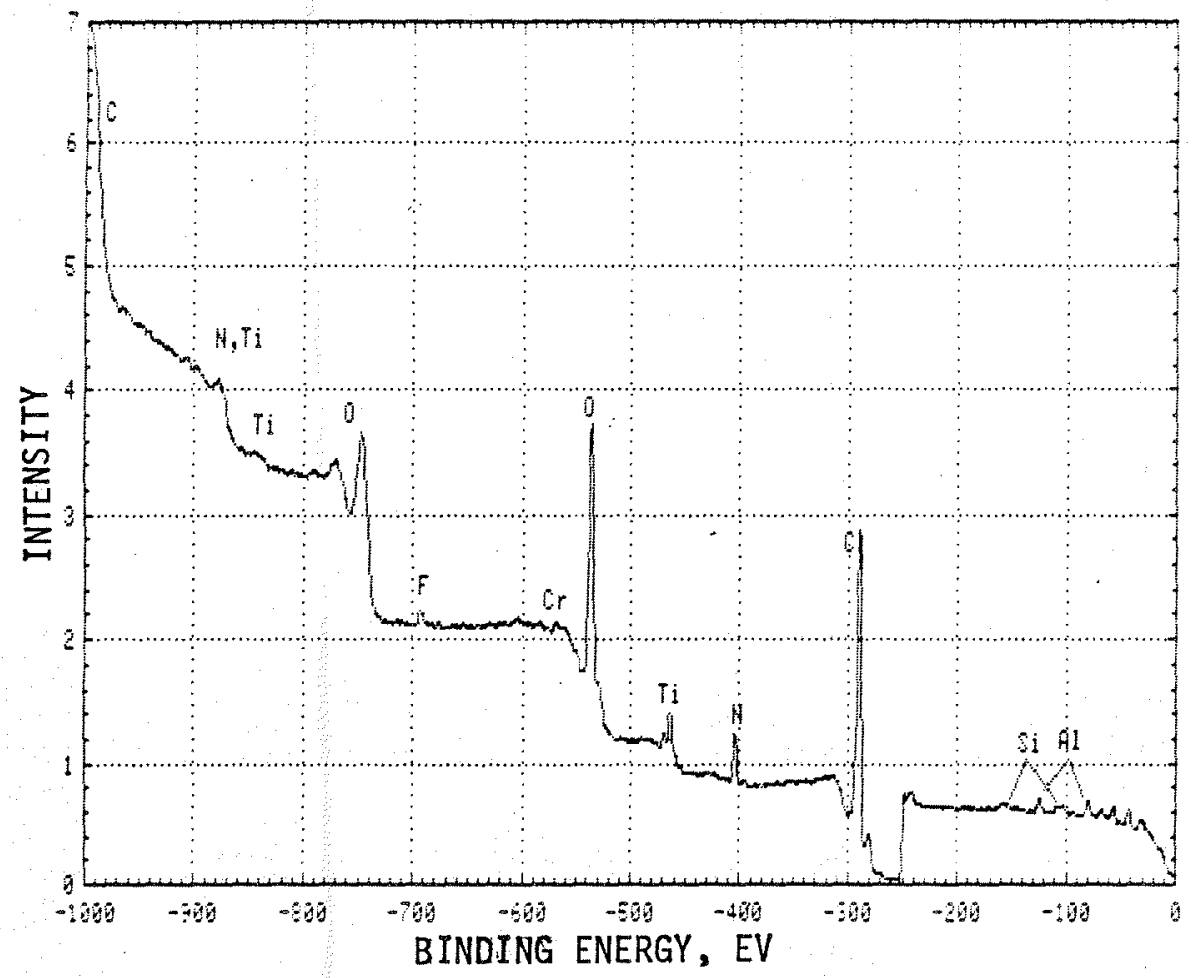

Figure 2.4.5-48

ESCA SPECTRUM OF THE FAILED LARC-13/IOV CAA LAP SHEAR, ADHESIVE SURFACE

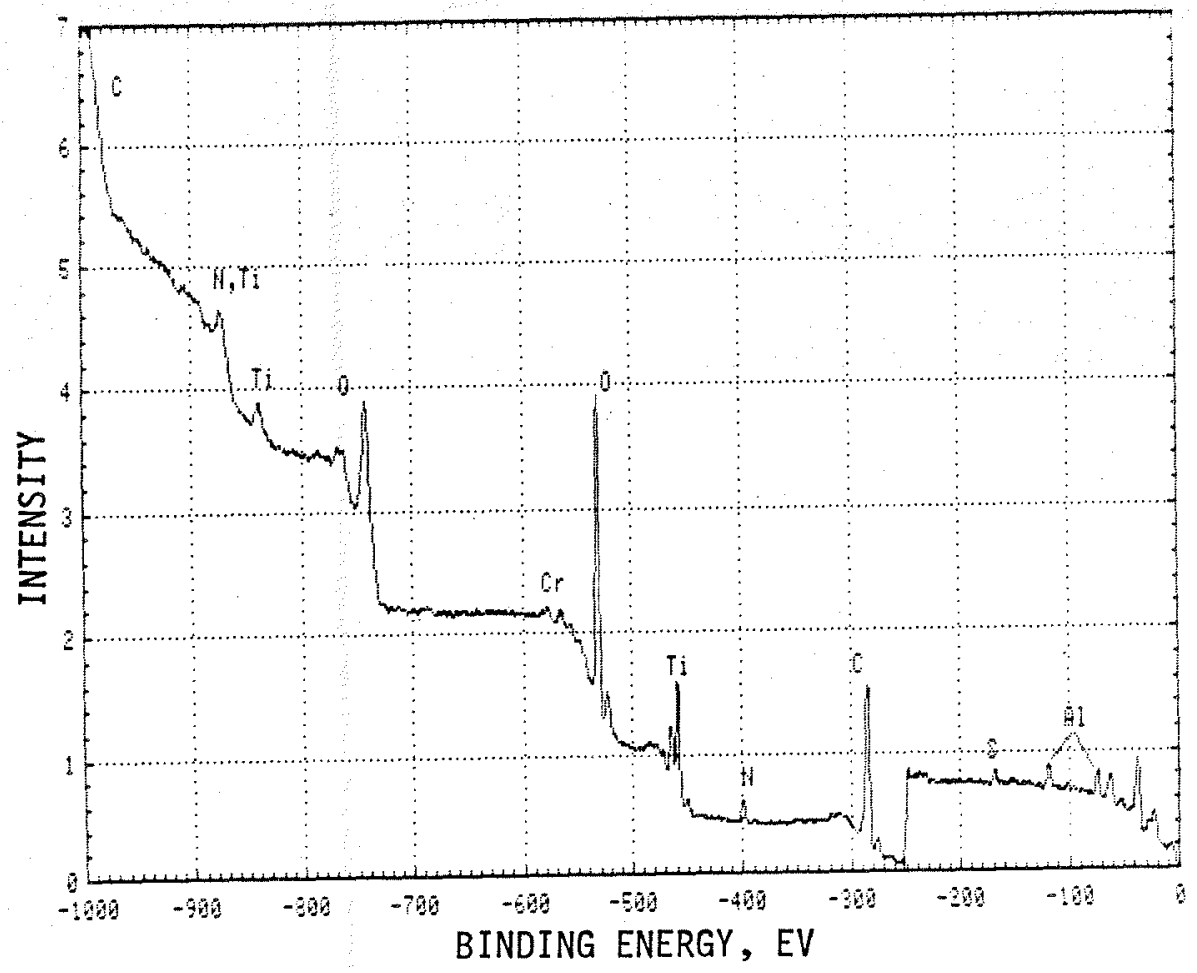

Figure 2.4.5-49 ESCA SPECTRUM OF THE FAILED LARC-13/10V. CAA LAP SHEAR, ADHEREND SURFACE. 

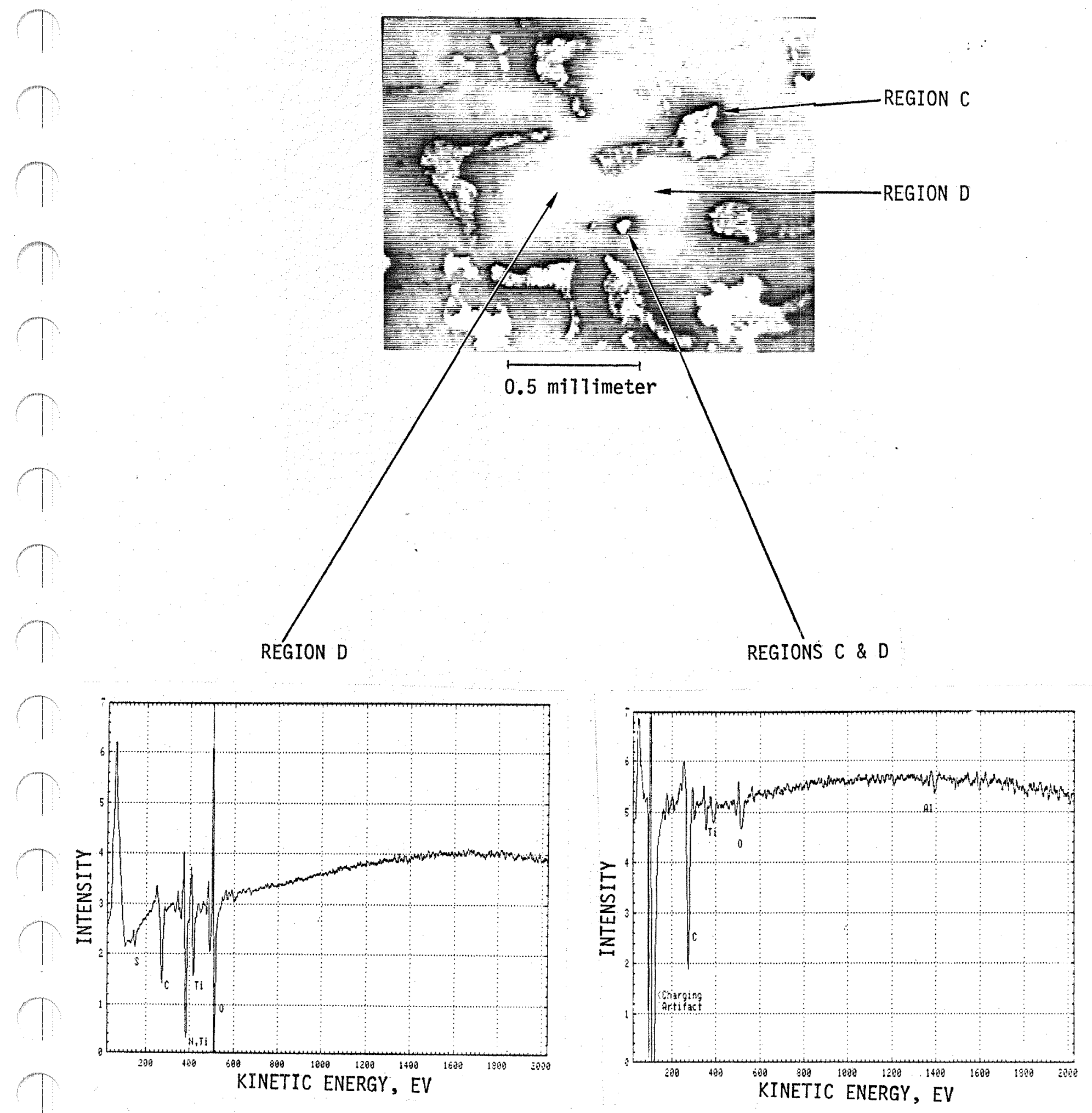

AES ANALYSIS OF REGIONS C AND D ON THE LARC $=13 / 10 \mathrm{~V}$ CAA ADHEREND SURFACE. (50X INVERTED ABSORBED CURRENT IMAGE).

Figure $2.4 .5-50$ 


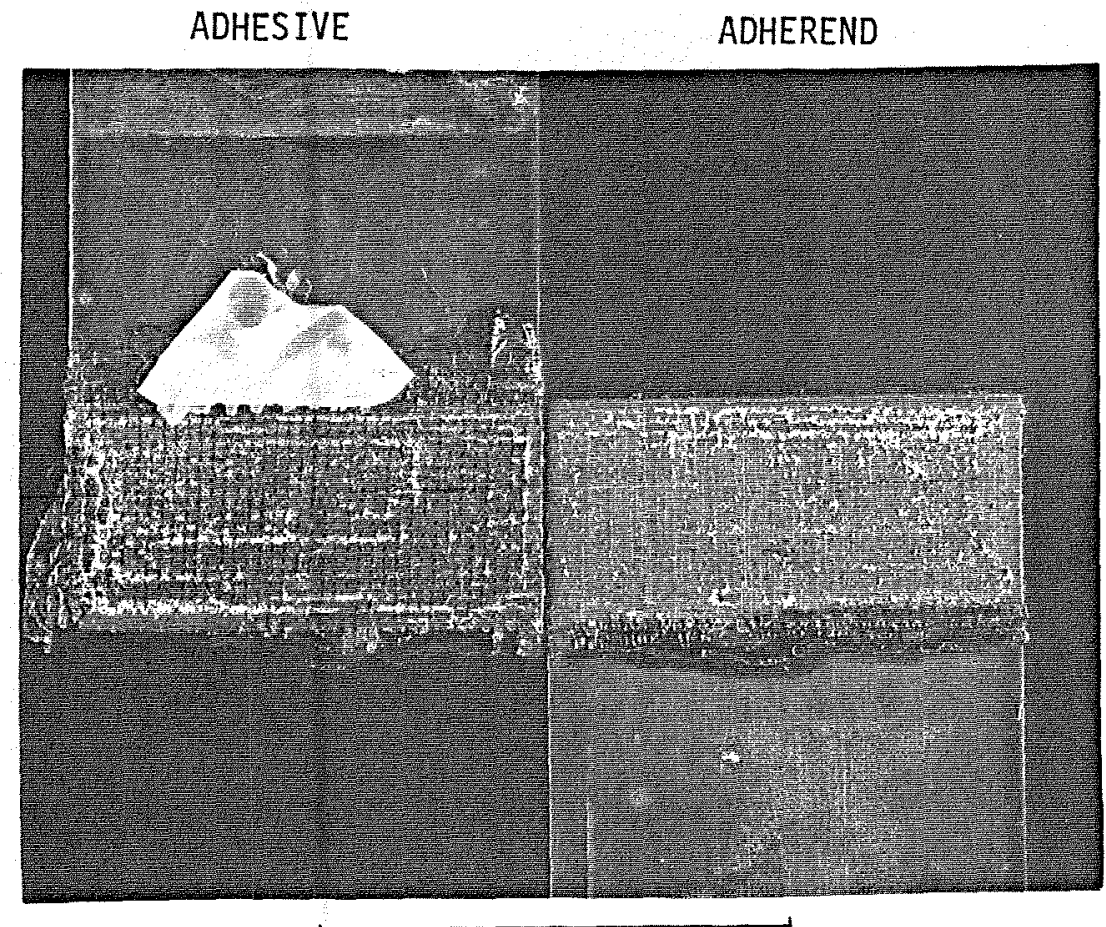

25 millimeter

PHOTOMACROGRAPH OF FAILED LARC-13/PASA JELL LAP SHEAR THERMALLY AGED AT $5050^{\circ} \mathrm{K}\left(450^{\circ} \mathrm{F}\right)$ FOR 10,000 HOURS.

Figure $2.4 .5-51$ 


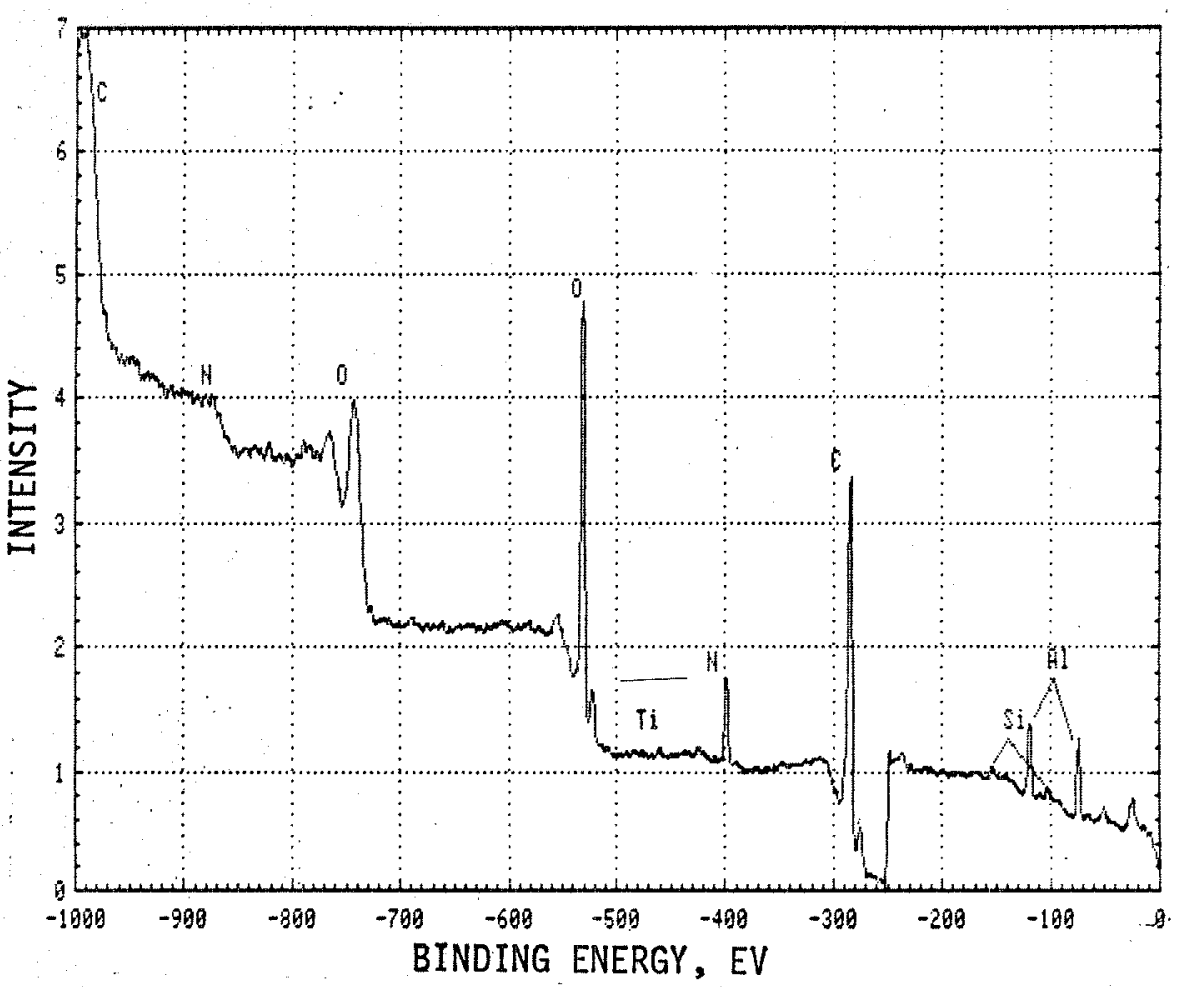

Figure 2.4.5-52 ESCA SPECTRUM OF THE FAILED LARC-13/PASA JELL LAP SHEAR, ADHESIVE SURFACE.

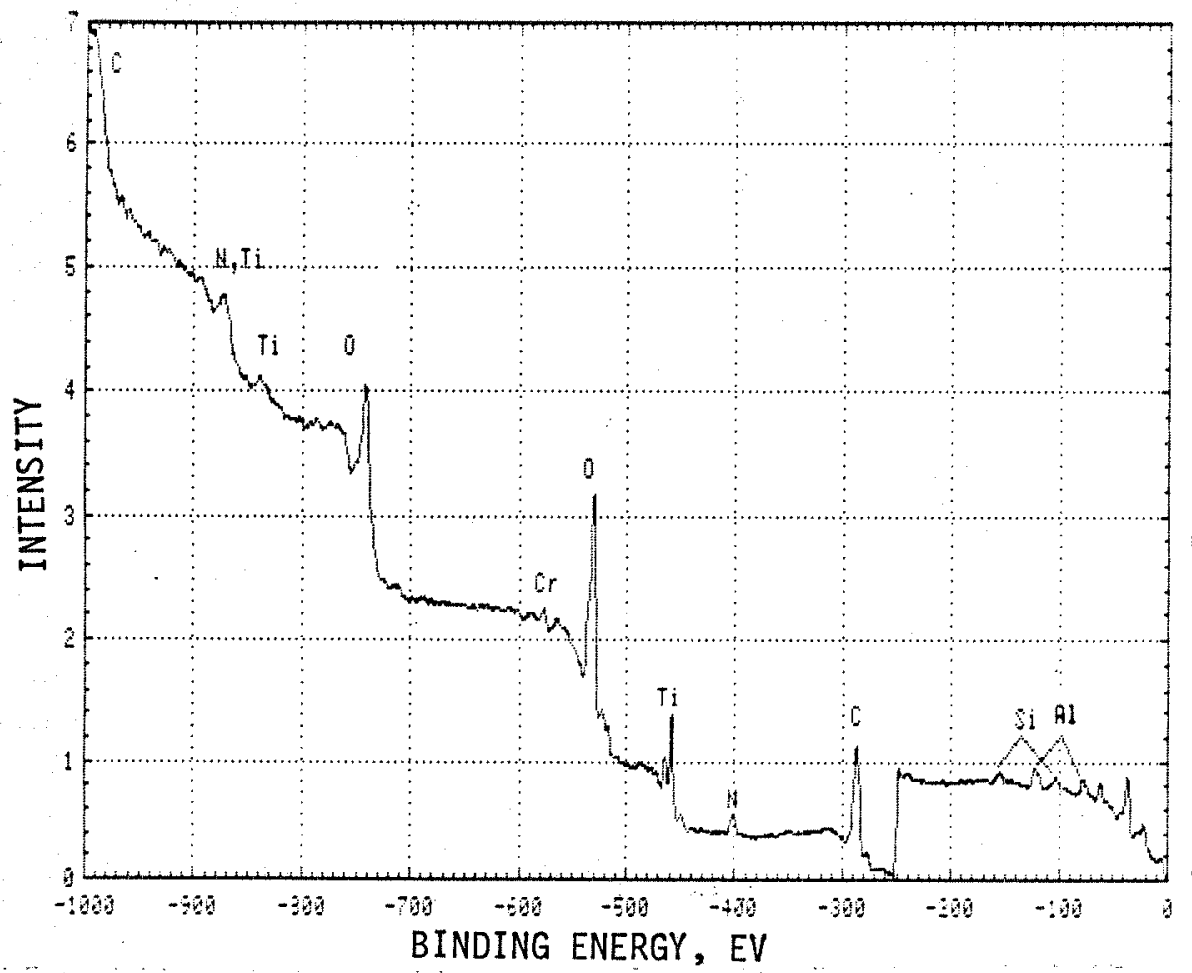

Figure 2.4.5-53

ESCA SPECTRUM OF THE FAILED LARC-13/PASA JELL LAP SHEAR, ADHEREND SURFACE. 

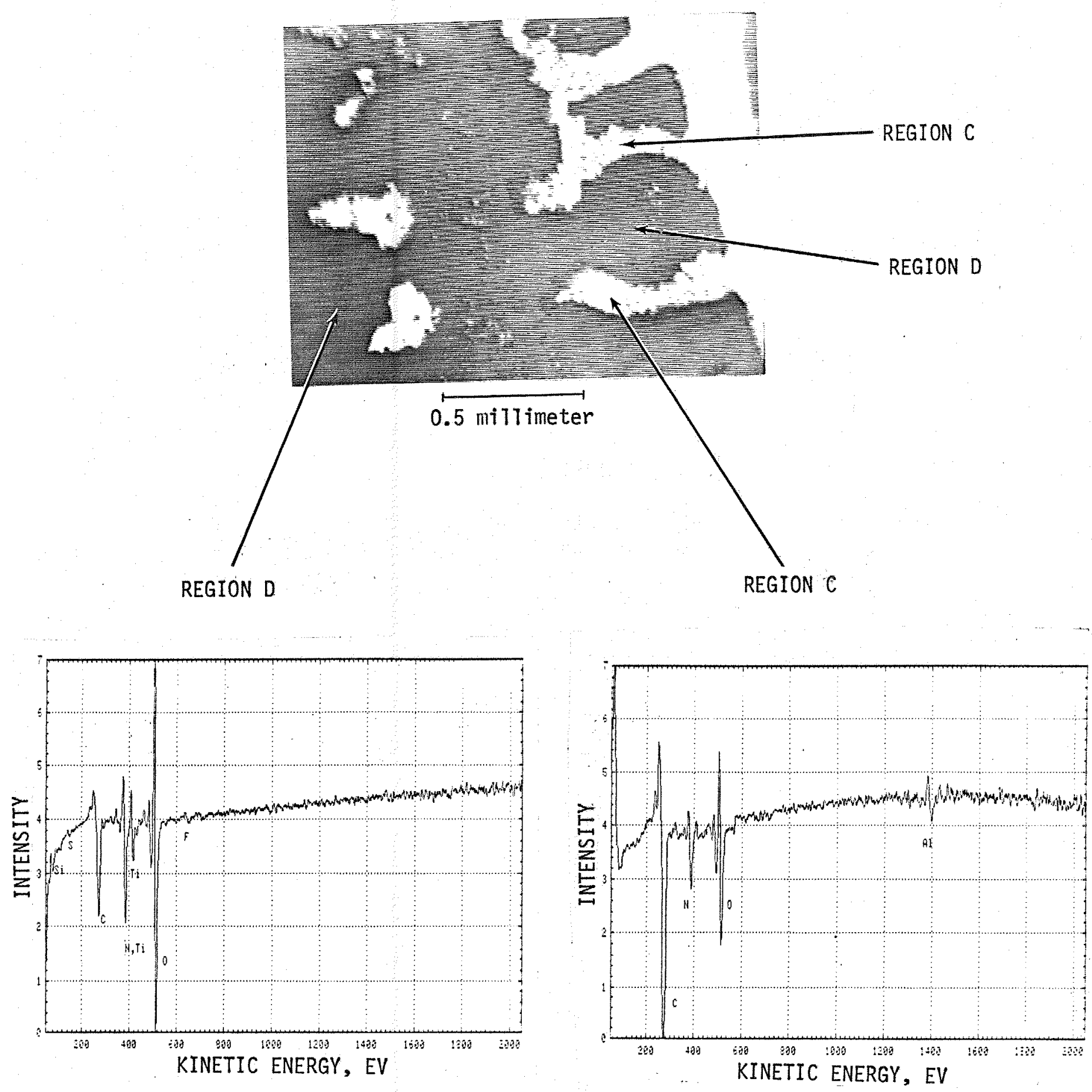

AES ANALYSIS OF REGIONS C AND D ON THE LARC-13/PASA JELL ADHEREND SURFACE. (50X INVERTED ABSORBED CURRENT IMAGE).

Figure 2.4.5-54 
Table 2.4-4-1 . CAA Surface Composition by ESCA Reported as Atom Percent

Titanium Surface Treatment Process

?

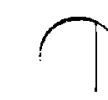

7

IOV CAA, No

Heat Treatment,

Element

Old Bath

10V CAA, No

Heat Treatment,

Old Bath,

High Humidity

IOV CAA, No

Heat Treatment,

New Bath

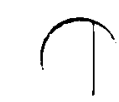

$\begin{array}{ll}C & 48.8\end{array}$

$\mathrm{N} \quad \mathrm{ND} \underline{1 /}$

O $33 . \overline{1}$

F $\quad 2.6$

Al 2.2

$\mathrm{Si}$

S

$\mathrm{Ti}$

$\checkmark 21$

Cr

ND

ND

12.6

ND

0.7

ND

36.5

1.0

42.8

2.2

2.5

ND

0.3

13.7

ND

0.9

ND

33.4

2.0

42.0

3.9

2.6

0.4

0.7

13.9

ND

$\mathrm{Cu}$

0.3

0.6

1/ ND = Element not detected.

2/ Vanadium overlaps with $01_{\mathrm{S}} \mathrm{K} \quad 3,4$ satellite, which lowers sensitivity. 
Table 2.4.4-2. Element Ratios

Titanium Surface Treatment Process

$\begin{array}{llll}\mathrm{C} / \mathrm{Ti} & 3.87 & 2.66 & 2.40 \\ \mathrm{O} / \mathrm{Ti} & 2.63 & 3.12 & 3.02 \\ \mathrm{Al} / \mathrm{Ti} & 0.11 & 0.18 & 0.19 \\ \mathrm{Cr} / \mathrm{Ti} & 0.056 & 0.066 & 0.021 \\ \mathrm{~F} / \mathrm{Ti} & 0.21 & 0.16 & 0.28\end{array}$

IOV CAA, No Heat Treatment,

Ratio
IOV CAA, No

Heat Treatment,

Old Bath,

High Humidity
IOV CAA, No Heat Treatment, New Bath

$\mathrm{F} / \mathrm{Ti}$

0.21

0.16

0.28 


\section{Table 2.4.4-3. Surface Composition of Baseline Oxides}

Reported as Atom Percent

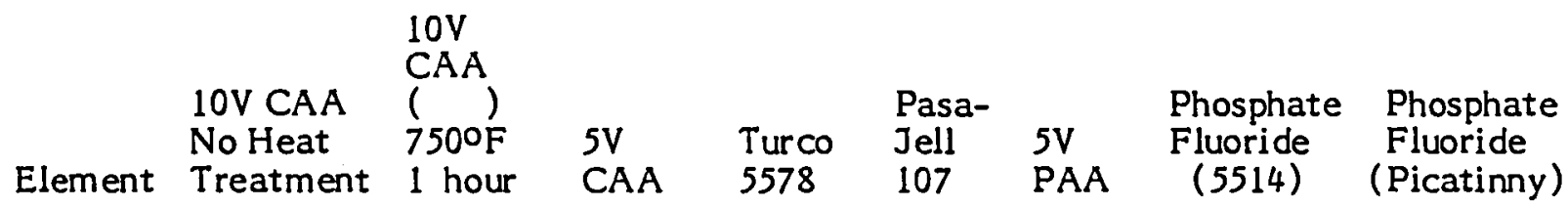

$\begin{array}{lcccccccc}\mathrm{C} & 16.7 & 15.3 & 15.6 & 41.4 & 22.9 & 32.4 & 30.1 & 26.2 \\ \mathrm{O} & 50.4 & 51.1 & 47.3 & 35.8 & 46.6 & 36.3 & 42.9 & 39.9 \\ \mathrm{~F} & 1.9 & 0.1 & 2.6 & \text { ND } 1 / & 2.5 & 4.3 & 1.1 & 0.9 \\ \mathrm{Na} & \mathrm{ND} & \mathrm{ND} & \mathrm{ND} & \mathrm{ND} & 2.9 & \text { ND } & 0.9 & 0.9 \\ \mathrm{Al} & 11.7 & 7.6 & 7.8 & \text { ND } & 6.9 & 6.6 & 4.3 & 5.9 \\ \mathrm{Si} & 0.4 & 0.4 & \text { ND } & \text { ND } & 1.2 & \text { ND } & \text { ND } & \text { ND } \\ \mathrm{P} & \text { ND } & \text { ND } & \text { ND } & \text { ND } & \text { ND } & 5.7 & \text { ND } & \text { ND } \\ \mathrm{S} & \text { ND } & 0.1 & \text { ND } & 0.3 & \text { ND } & \text { ND } & \text { ND } & \text { ND } \\ \mathrm{Cl} & \text { ND } & \text { ND } & \text { ND } & \text { ND } & 2.0 & 0.8 & 1.9 & 2.1 \\ \mathrm{Ca} & \text { ND } & 0.6 & \text { ND } & \text { ND } & 2.0 & 0.8 & 1.9 & 2.1 \\ \mathrm{Ti} & \text { 18.9 } & 23.1 & 26.7 & 11.0 & 12.7 & 13.3 & 11.1 & 15.0 \\ \mathrm{~V} 2 / & \text { ND } & \text { ND } & \text { ND } & \text { ND } & \text { ND } & \text { ND } & \text { ND } & \text { ND } \\ \mathrm{Cr} 3 / & \text { ND } & \text { ND } & \text { ND } & \text { ND } & \text { ND } & \text { ND } & \text { ND } & 1.7 \\ \mathrm{Fe} & \text { ND } & 1.6 & \text { ND } & 7.2 & \text { ND } & \text { ND } & \text { ND } & \text { ND }\end{array}$

1/ ND = element not detected.

2/ The lower limit for vanadium is approximately $0.2 \%$.

3/ The lower limit for chromium is approximately $0.6 \%$. 
Table 2.4.5-1. PPQ/10V CAA Bonded Lap-Shear Specimens

\begin{tabular}{|c|c|c|c|}
\hline & & Exposure & $\begin{array}{l}\text { Values, } \\
505 \mathrm{~K} \\
\text { ( } 4500 \mathrm{~F})\end{array}$ \\
\hline Specimen & Processing Conditions & Time & \\
\hline
\end{tabular}

1527 P-3 Full vacuum, 200 psi; RT

None

3370

Cohesive

644K (7000F); hold 20

min.; cool under pressure;

postcure at $644 \mathrm{~K}\left(700^{\circ} \mathrm{F}\right)$

for 1 hour

1530P-3 Same as above, without postcure

3 months $3600 \quad$ Cohesive

1532P-2 Same as above, without

6 months 2850

Adhesive postcure 
Table 2.4.5-2

GLASS TRANSISTION TEMPERATURE OF ADHESIVES BEFORE AND AFTER EXPOSURE AT 450\%F

PPQ

$557^{\circ} \mathrm{F}$

PPQ Exposed 10,000 Hrs

$557^{\circ} \mathrm{F}$

LARC-13

$5620 \mathrm{~F}$

LARC-13 Exposed 5,000 Hrs

$565^{\circ} \mathrm{F}$

NRO56X

$6480 \mathrm{~F}$

NRO56X Exposed 5,000 Hrs

$562 \mathrm{~F}^{\circ}$ 


\subsubsection{Discussion}

\section{GENERAL BEHAVIOR}

The most important observation on failed long-term $505 \mathrm{~K}\left(450^{\circ} \mathrm{F}\right)$ durability lap-shear specimens, is the shift from a cohesive failure (with no visually exposed oxide) to an apparently adhesive failure (with exposed oxide visible). The lack of base plate, oxide, or cohesive polymer fracture clearly indicates that the overall basic oxide and polymer are more stable than the bond between them, whether the bond is primarily chemical or mechanical. For the polymer, this observation is reinforced by the reproducibility of stable glass transition behaviors, even after 10,000 hours of aging at $505 \mathrm{~K}$ (450\% F).

Also significant in the trend from cohesive to adhesive failure is the observation of bond line (scrim node) porosity. Detailed examination of room-temperature-tested lap-shear specimens revealed a generally cohesive fracture. Bond line (scrim node) porosity was evident at the primer/adhesive interface bond. The existence of bondline porosity is not considered to be a significant aspect of fracture since the failures were cohesive. (Figure 2.4.6-1) shows a schematic diagram of the failure mode influenced by the scrim node porosity. As shown in Figure 2.4.5-21, the typical adhesive fracture after long-term aging exhibits $25-50 \%$ total area porosity. Such an observation suggests that the true stress seen by the interfacial bond with this failure mode is actually $25-50 \%$ higher than the calculated engineering stress. This result may be significant in the comparison of thermal degradation rates between polymer systems exhibiting adhesional fracture behavior.

\section{PPQ ON 5 AND 1OV CAA AND LARC-13 ON 10V CAA}

Long-term durability failures on PPQ on 5 and 1OV CAA and LARC-13 on 1OV CAA can be considered jointly, both on the basis of the generic similarity of 5 and 1OV CAA, and on their apparently identical failure morphologies and chemistries. The morphology of failed specimens continues to define the locus of failure within the top $4 \mathrm{~nm}$ of the oxide tips. The lack of severe deformation of either oxide or polymer indicates a relatively lowenergy adhesional failure. An interfacial separation is supported by the detailed replication of oxide surface details down to $5 \mathrm{~nm}$.

Plan and transverse views of the failed adherend surface revealed a general lack of polymer within the CAA oxide structure. This suggests poor polymer penetration into the 
oxide. However, detailed examinations of primed control samples revealed that good polymer penetration does in fact occur in these systems. The subsequent interpretation is that polymer penetration probably did occur, and that the small $30 \mathrm{~nm}$ nodules noted on the opposing polymer surface represent relaxed polymer pulled out of the CAA oxide porous structure. The interpretation of the nodules as polymer pulled out of the porous structure is primarily based on Boeing experience indicating that large amounts of polymer strain relaxation are possible.

The SEM/STEM results showed intact oxide morphology on the adherend side and no apparent oxide on the adhesive side.

ESCA and AES surface chemical analysis techniques, however, clearly indicated titanium and polymer on both the adherend and adhesive surfaces.

Detailed TEM/STEM/EDX analysis of thin sections of the adhesive fracture surface indicated that the titanium detected by ESCA must be present as several monolayers, rather than as discrete thicker regions. Transfer of several monolayers of titanium oxide to the adhesive side during fracture is not inconsistent with an interfacial failure mode. The detection of $\mathrm{Si}, \mathrm{Cl}, \mathrm{S}$ and $\mathrm{Cr}$ on the adherend failed surfaces also supports an interfacial failure interpretation since these elements were detected on baseline oxide studies. Lead was detected on PPQ/CAA long-term durability failures. Since $\mathrm{Pb}$ was not found on baseline CAA oxide studies, the PPQ must be the source of the Pb detected. However, the similarity in failure morphology and surface chemistry on both LARC-13 and PPQ failures strongly suggests that lead, detected in amounts less than 1 atom percent, is not principally related to long-term adhesional failures in the systems studied.

\section{LARC-13 ON PASA-JELL}

In general, the failure analysis results on Pasa-Jell/LARC-13 long-term $505 \mathrm{~K}\left(450^{\circ} \mathrm{F}\right)$ durability samples appeared very similar to those characterized on LARC-13 and PPQ CCA long-term durability failures. Although no SEM/STEM analyses were performed, the surface chemical data by AES and ESCA is clearly very similar to those results for CAA related failures. The adherend and adhesive surfaces exhibit combined polymer and titanium signals, with the level of titanium detected on the polymer surface significantly lower than that on the adherend. These results, as with CAA, suggest fracture of an adhesional nature with some minor titanium monolayer transfer. 


\section{GENERAL DISCUSSION OF RESULTS}

The proper interpretation of failed sample morphologies and chemistries requires that features observed be interpreted with respect to requirements for bond joint strength and durability. Adhesive bonding is generally well recognized to occur as a result of mechanical interlocking combined with interfacial chemical bonding. The aspect of bonding and determining bond joint strength generally depends on a number of variables, including polymer/oxide chemistry, polymer flow, and adherend surface structure. The general approach in bond joint optimization involves improvement of either mechanical interlocking or chemical bondability. Pasa-Jell and IOV CAA surface preparations represent generic extremes of these conditions on titanium. Pasa-Jell typifies a surfacecleaning type of preparation in which chemical bondability provides the dominant source of bond strength. On the other hand, 10V CAA represents the generic extreme of a mechanical interlocking type of bonding in which a large surface area, columnar oxide structure is generated. This data indicates that for PPQ, LARC-13, and NR056X, significant increases in bond joint strength are obtainable at room temperature by increased mechanical interlocking. It should not be forgotten that differences in surface chemical compositions will also influence bond strength.

In 5V CAA, or any of the reduced structure oxides, interim optimization levels are represented, where the reduction of mechanical bond surface area places an increasing emphasis on chemical bondability. Even an apparently improved system such as 10V CAA may still represent an interim compromised bonding state.

Thermal aging represents an additional perturbution of bond joint integrity. Thermally activated processes occur by which either chemical or mechanical bonding levels can be degraded. However, the extent to which the actual bond joint integrity is diminished will be largely a function of which bonding aspect is degraded.

The failure analysis performed thus far on PPQ on 5 and 1OV CAA and LARC-13 on 10V $\mathrm{CAA}$ and Pasa-Jell Clearly suggest failure induced by a lack of chemical cohesion. The surface chemistries exhibited by both Pasa-Jell and IOV CAA indicate that the failure plane is at the immediate oxide/polymer bond interface. Additionally, the SEM/STEM analyses performed demonstrate that no gross morphological oxide structure changes have occurred and that failure is, for the most part, interfacial to the extent that polymer pullout has even occurred. This conclusion is reinforced by the strong similarity in failure 
mode exhibited by LARC-13 on IOV CAA and Pasa-Jell, each relative surface optimization extremes.

\section{CONCLUSIONS}

The failure analysis performed indicates that long-term 505K (450\%) durability failures are chiefly related to chemical bond durability. The investigations described in this report have not enabled the causes of the bond degradation to be identified.

The fracture characteristics demonstrated interfacial failures on thermally aged samples on which surface chemistry and surface contamination represent major factors.

The results described suggest that mechanical properties of the bond may be improved by modifications of the surface chemistry and the elimination of surface contamination. The techniques described in this report, together with developments and improvements, can be applied to such an optimization study. 


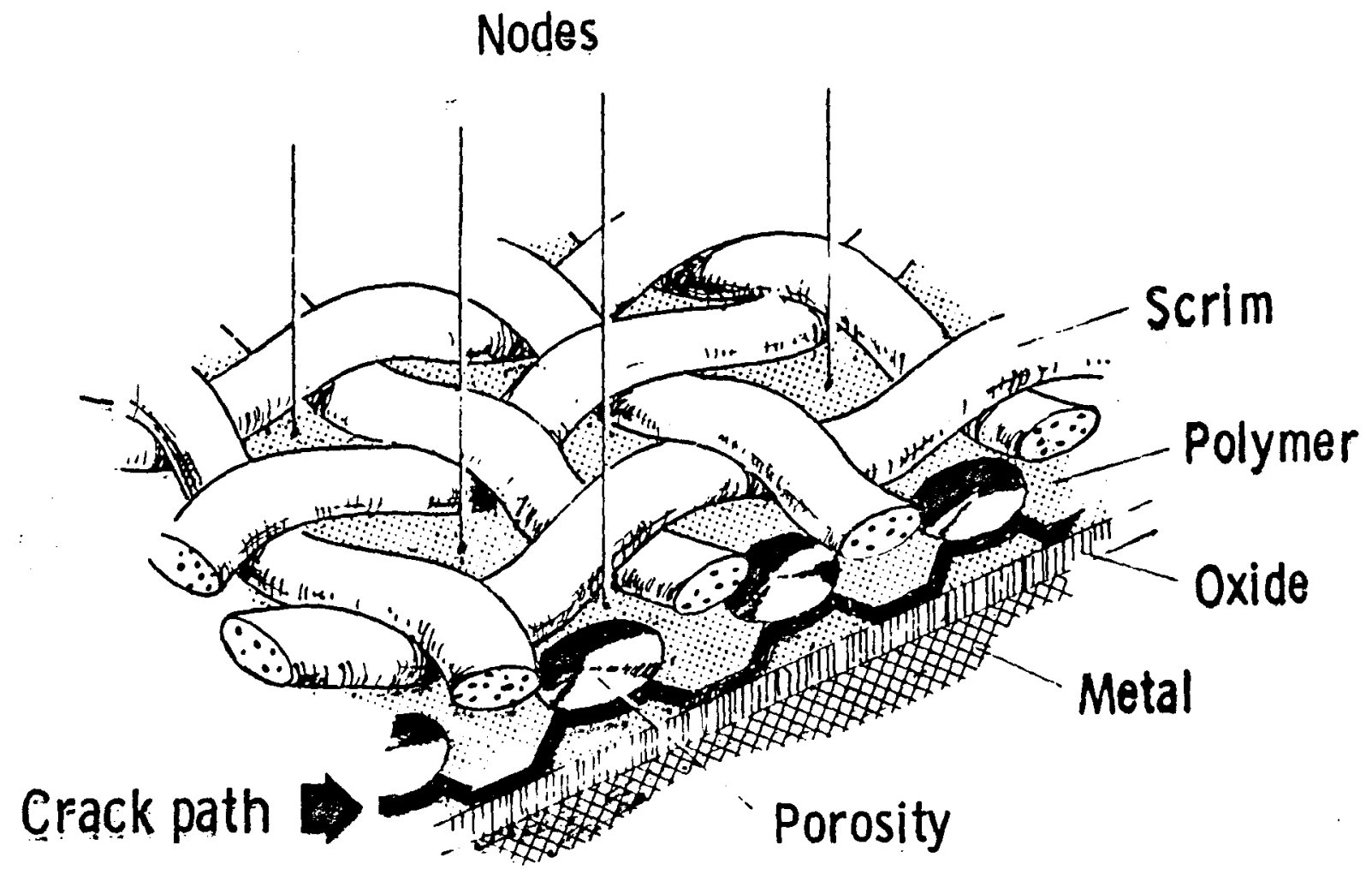

Figure 2.4.6-1 Schematic Diagram of crack propagation influenced by scrim node porosity. 


\subsection{LARGE AREA BOND STUDY}

Subsequent to the cure cycle and surface treatment studies on the three selected adhesives (LARC-13, PPQ, and NR056X), a preliminary large-area bond study was conducted. This preliminary study was included to confirm the process parameters established to date for each adhesive system. Stainless steel, $1.27 \mathrm{~mm}(0.050 \mathrm{inch})$, with grit-blast surface treatment was used in this task to demonstrate large-area bond capability. Titanium sheet was reserved for final large-area bond test articles and deliverable panels. The steel panels were bonded metal-to-metal $61 \mathrm{~cm} \times 122 \mathrm{~cm}(2 \mathrm{ft} \times 4 \mathrm{ft})$.

LARC-13 in this study did not produce good-quality, large-area, metal-to-metal bonds, as exhibited by $\mathrm{C}$-scan and poor hand peel. Large voids resulting from excessive volatile release during cure have been a consistent problem through four attempts at producing a large-area bond panel from this material.

This problem appears to be caused by a combination of improper cure cycle parameters and the chemical state of the LARC-13 resin. Apparently, the resin degrades during storage and handling such that precursor degradation products are contributing volatiles at the final stage of cure. At this point in the cure, pressure and vacuum prevent release of entrapped volatiles.

LARC-13 did produce good-quality steel honeycomb sandwich bonds, panel size $30.5 \times$ $30.5 \mathrm{~cm}(1 \times 1 \mathrm{ft}) \times 2.54$-cm (1-in.)-thick honeycomb. The relative large honeycomb space allows the volatiles to escape leaving a good dense bond line.

PPQ exhibited desirable dense bondlines in the large-area bond steel-to-steel panels. This adhesive was poor in bond strength, as demonstrated by hand peel adhesive failure. Evidently, $\mathrm{PPQ}$ is not compatible with grit-blast treatment of steel. However, since there was no evidence of void formation, for the purpose of this study, PPQ was classified as a suitable adhesive for production of good-quality, large-area, titanium bonded assemblies.

NR056X produced the best quality and toughest large-area steel-to-steel bonds as judged from C-scan and hand peel results. A 5-cm (2-in.)-wide strip was sheared lengthwise down the middle of each bonded panel. The NR056X strip could only be peeled by using considerable force, which stressed the steel beyond its yield point. The same strip for 
LARC-1 3 was very weak due to large voids. The PPQ strip was weak due to poor adhesion to the grit-blasted steel surface.

A second large-area bond study involving $30.5 \times 30.5-\mathrm{cm}(1 \times 1-\mathrm{ft})$ titanium metal-tometal and honeycomb sandwich panels was completed. Each of the three adhesives were processed to developed cure cycles and 10-V CAA surface preparation for titanium. Evaluation of the panels was conducted by $\mathrm{C}$-scan and flatwise tension.

The LARC-13 metal-to-metal exhibited only moderate-quality bonding, as shown by Cscan. This result corresponds with the poor steel metal-to-metal results obtained in the preliminary large-area bond study. However, not all metal-to-metal bonds with LARC-13 have had poor results (based upon Boeing IR\&D).

Large-area honeycomb sandwich panels prepared with LARC-13 have consistently produced good-quality bonds. Table 2.5-1 lists the flatwise tension test results obtained for LARC-13, as well as for PPQ and NR056X. As seen in the table, LARC-13 produced the highest tensile values at both ambient temperature and $505 \mathrm{~K}\left(450^{\circ} \mathrm{F}\right)$.

Metal-to-metal large-area bonds produced by PPQ have shown good dense bondlines by Cscan evaluation. Honeycomb sandwich panel bonds are highly dependent upon adequate adhesive for filleting. Sandwich flatwise tensile values of the initial panel average 0.4 $\mathrm{MPa}(61 \mathrm{psi})$ at ambient temperature and $0.3 \mathrm{MPa}(44 \mathrm{psi})$ at $505 \mathrm{~K}\left(450^{\circ} \mathrm{F}\right)$. A second $\mathrm{PPQ}$ panel with increased adhesive film thickness of about $0.38 \mathrm{~mm}(0.015 \mathrm{in}$.) produced tensile values of $2.3 \mathrm{MPa}(329 \mathrm{psi})$ at ambient temperature and $1.1 \mathrm{MPa}(156 \mathrm{psi})$ at $505 \mathrm{~K}\left(450^{\circ} \mathrm{F}\right)$.

NR056X titanium-to-titanium large-area bonds exhibited only moderate quality by C-scan evaluation. As noted previously, NR056X produced very good large-area steel-to-steel bonds. It is known from previous experience that the quality of bond may vary due to slight differences in cure cycle and/or film preparation, which affects the amount of volatile release during the critical stages of teh cure cycle. Honeycomb sandwich panels are difficult to fabricate with NR056X because of very low adhesive flow-filleting during cure. However, this can be covercome by using thick adhesive films or roller coating the core with adhesive paste prior to assembly. The data in 2.5-1 lists flatwise tensile values of the large-area titanium honeycomb sandwich prepared using NR056X optimized cure and 10-volt chromic acid anodize surface preparation. 
TABLE 2.5-1 LARGE-AREA BOND FLATWISE TENSILE STRENGTH

\begin{tabular}{|c|c|c|c|c|}
\hline $\begin{array}{l}\text { Adhesive } \\
\text { System }\end{array}$ & $\begin{array}{l}\text { Test } \\
\text { Temperature }\end{array}$ & $\begin{array}{l}\text { Load } \\
\mathrm{kg}(\mathrm{lb})\end{array}$ & $\begin{array}{l}\text { Load } \\
\text { MPs (spi) }\end{array}$ & $\begin{array}{l}\text { Average, } \\
\mathrm{MPa} \text { (psi) }\end{array}$ \\
\hline \multirow[t]{2}{*}{ LARC -13} & Ambient & $\begin{array}{r}833(1835) \\
1022(2250) \\
999(2200)\end{array}$ & $\begin{array}{ll}3.2 & (459) \\
3.9 & (562) \\
3.8 & (550)\end{array}$ & $3.6(524)$ \\
\hline & $505 \mathrm{~K}\left(450^{\circ} \mathrm{F}\right)$ & $\begin{array}{l}817(1800) \\
794(1750) \\
799(1760)\end{array}$ & $\begin{array}{ll}3.1 & (450) \\
3.0 & (438) \\
3.0 & (440)\end{array}$ & $3.1 \quad(443)$ \\
\hline \multirow[t]{2}{*}{ NR056X } & Ambient & $\begin{array}{ll}270 & (595) \\
277 & (610) \\
241 & (530)\end{array}$ & $\begin{array}{ll}1.0 & (149) \\
1.1 & (153) \\
0.9 & (133)\end{array}$ & $1.0(145)$ \\
\hline & $505 \mathrm{~K}\left(450^{\circ} \mathrm{F}\right)$ & $\begin{array}{ll}147 & (225) \\
170 & (375) \\
178 & (392)\end{array}$ & $\begin{array}{ll}0.6 & (81) \\
0.6 & (94) \\
0.7 & (98)\end{array}$ & $0.6 \quad(91)$ \\
\hline \multirow[t]{2}{*}{$\mathrm{PPQ}$} & Ambient & $\begin{array}{ll}118 & (260) \\
104 & (230) \\
099 & (240)\end{array}$ & $\begin{array}{ll}0.5 & (65) \\
0.4 & (58) \\
0.4 & (60)\end{array}$ & $0.4 \quad(61)$ \\
\hline & $505 \mathrm{~K}\left(450^{\circ} \mathrm{F}\right)$ & $\begin{array}{ll}71 & (157) \\
74 & (163) \\
95 & (210)\end{array}$ & $\begin{array}{ll}0.3 & (450) \\
0.3 & (438) \\
0.4 & (440)\end{array}$ & $0.3 \quad(44)$ \\
\hline \multirow[t]{2}{*}{$\begin{array}{l}\text { Remake } \\
\text { of } \mathrm{PPQ}\end{array}$} & Ambient & $\begin{array}{ll}626 & (1380) \\
577 & (1270) \\
586 & (1290)\end{array}$ & $\begin{array}{ll}2.4 & (345) \\
2.2 & (318) \\
2.2 & (323)\end{array}$ & $1.0(145)$ \\
\hline & $505 \mathrm{~K}\left(450^{\circ} \mathrm{F}\right)$ & $\begin{array}{ll}309 & (680) \\
247 & (545) \\
293 & (645)\end{array}$ & $\begin{array}{ll}1.2 & (170) \\
0.9 & (136) \\
1.1 & (161)\end{array}$ & $1.1(156)$ \\
\hline
\end{tabular}




\subsection{PHASE II ADHESIVE OPTIMIZATION AND CHARACTERIZATION}

The objective of this Phase was to conduct extensive studies on two (2) adhesive systems from Phase I to (1) further optimize processing parameters, (2) chemically characterize the adhesive base resins, and (3) establish long-term environmental durability data.

Phase II was divided into two separate tasks. Task I was an optimization and characterization study in which the two selected adhesives were improved to standards required for production hardware quality and reliability. Task II established long-term environmental and durability data on the improved adhesive systems.

The two (2) adhesive systems initially selected by Boeing and approved by NASA were--

1) PPQ Adhesive

PPQ Primer

10 Volt Chromic Acid Anodize Surface Treatment

2) NR056X Adhesive

NR056X Primer

10 Volt Chromic Acid Anodize Surface Treatment

A third System: LARC-13 Adhesive

LARC-13 Primer

10 Volt Chromic Acid Anodize Surface Treatment

was evaluated also as a back-up to the other two (2) systems. As the long-term 505K data became available from. Phase I, it was concluded that the LARC-13 System was not thermally stable, and therefore, not a suitable back-up. Another problem was created when NR056X was removed from the market by DuPont after considerable work of Phase II was completed. This left PPQ as the only system suitable (from Phase I data) for complete Phase II studies. To keep Phase II at a two (2) system level, LARC-TPI (LARC-2) was incorporated into the Program. An abbreviated Phase I study was conducted and this adhesive system was then brought into Phase II evaluation studies as--

LARC-TPI Adhesive

LARC-TPI Primer

10 Volt Chromic Acid Anodize Surface Treatment 
Therefore, the basis of Phase II studies rested with PPQ and LARC-TPI adhesive systems. Because considerable work was completed on LARC-13 and NR056X systems, the data generated on them is also presented in this section.

\subsection{TASK I - ADHESIVE OPTIMIZATION}

Extensive chemical characterization was conducted on LARC-13, PPQ, and NR056X adhesive systems, sufficient to prepare material and process specifications. Baseline data was generated from test coupons prepared using the defined specfications.

\subsubsection{Chemical Characterization}

The objective of this portion of the program was to characterize each of the three adhesives and determine (from the analysis of three resin batches of each adhesive) the batchto-batch variation. Resin batches analyzed are identified as follows:

\begin{tabular}{|c|c|c|}
\hline Resin & Resin Batch Number & Identification Code \\
\hline PPQ & PH 813-88 & $P-1$ \\
\hline PPQ & NAS1-15605-2 & $\mathrm{P}-2$ \\
\hline PPQ & NAS1-15605-3 & $P-3$ \\
\hline LARC -13 & NAS1-15644 & $L-1$ \\
\hline LARC -13 & REF-RE-816-8 & L-2 \\
\hline LARC -13 & BAC $10-13-80$ synthesis & $L-3$ \\
\hline NR056X & E17602-152-1 & $N-1$ \\
\hline NR056X & E17602-152-2 & $\mathrm{N}-2$ \\
\hline NR056X & E17602-152-3 & $N-3$ \\
\hline
\end{tabular}

The chemical/physical tests and instruments used for analysis are as follows:

- Infrared analysis--Digilab 15A Fourier Transform IR

- Thermogravimetric analysis--DuPont 990 Thermal Analyzer 
Data charts for all analyses are attached as part of the appendices.

\section{Polyphenylquinoxaline Analysis}

The individual batches of PPQ were purified by diluting the original solution with chloroform. PPQ resin was then precipitated in methanol and separated by filtration. The resin precipitate was redissolved in methanol, boiled for 30 minutes, and refiltered. The precipitate was then dried at $100^{\circ} \mathrm{C}$ under vacuum.

Infrared Analysis--Resin samples were prepared by evaporating a resin film to a salt block surface. Analysis was performed on a Digilab 15A Fourier Transform spectroscopy unit. The typical spectra of each batch were almost identical.

Thermal Gravimetric Analysis--Each of the PPQ batches were $16 \%$ resin content as determined from the weight loss curves. Analysis was conducted on a DuPont 990 Thermal Analyzer. Heatup rate was $5^{\circ} \mathrm{C} /$ minute with an air flow rate of $200 \mathrm{ml} /$ minute. The sample weight was recorded on each analysis and the weight loss recorded directly in percent. Thermal degradation initiated at $560^{\circ} \mathrm{C}$ for each of the resin batches.

Liquid Chromatography--Liquid chromatography analysis of the PPQ resin batches was conducted almost entirely using size-exclusion chromatography techniques. Two columns were used: PSM 60S and PSM 1000S from DuPont. The mobile phase used for PPQ was chloroform. The detector was set at $254 \mathrm{~nm}$ and $280 \mathrm{~nm}$. The three resin batches were all identical, with a single peak at $433 \mathrm{~nm}$ for P-1 and P-2 and $431 \mathrm{~nm}$ for P-3.

Differential Scanning Calorimetry--The PPQ resin samples were first heated to $325^{\circ} \mathrm{C}$ to remove excess solvent, then quick quenched in liquid nitrogen. The quenched samples were analyzed on a DuPont 990 thermal analyzer. Heatup rate was $20^{\circ} \mathrm{C} / \mathrm{minute}$. The DTA curve for each resin batch exhibited an endotherm at $300^{\circ} \mathrm{C}$ followed by an exotherm proceeding to the $380^{\circ} \mathrm{C}$ upper heating limit. 


\section{LARC-13 Analysis}

The various analyses were conducted on the resin portion only. A sample of each resin batch was centrifuged to separate solid fillers from the resin solution.

Infrared Analysis--Resin from each of the batches was cast on a salt block for analysis. Infrared scans of the resin films exhibited no apparent differences in the absorption spectra.

Thermal Gravimetric Analysis--The thermal profile of LARC-13 occurred in three steps; the first was apparently lower boiling solvent (dimethyl formamide) and the second weight loss was the result of condensation reaction volatiles. Rapid thermal degradation occurred at $540-550^{\circ} \mathrm{C}$. Direct comparison to the PPQ TGA curves would indicate the relative lack of thermal stability by LARC-13.

Liquid Chromatography--For this analysis (size-exclusion chromatography), two columns were used: PSM 60S and PSM 1000S. Methanol was used for the mobile phase. The three LARC-13 samples exhibited good consistency with four definite elution bands:

\section{Elution Time, minutes}

734

765

812

\section{Percent Absorption}

14.1

24.0

61.9

The fourth peak (band) was not computed by the integrator. In addition to size-exclusion chromatography, preliminary work was accomplished using partition and absorbtion chromatography. Both of these techniques resulted in detailed spectra that would take considerable effort to standardize for quality control requirements. Size-exclusion chromatography is the superior method of analysis for future quality control requirements.

Differential Scanning Calorimetry (DSC)/Differential Thermal Analysis (DTA)--LARC$13 \mathrm{DSC} / \mathrm{DTA}$ exhibited a broad endotherm between 150 and $225^{\circ} \mathrm{C}$ with strongest activity at about $200^{\circ} \mathrm{C}$. Exotherm response was very slight at about 325 and $350^{\circ} \mathrm{C}$. Some batchto-batch variation was seen in this analysis that may be related to the orginal volatile content of the individual resin samples. 


\section{NR056X Analysis}

The analyses were conducted on the resin portion only. Fillers and/or other solid materials were centrifuged to obtain relatively pure resin solutions.

Infrared Analysis--Resin from each of the batches was cast on a salt block surface for analysis. Each of the three batches produced spectra with no detectable differences.

Thermal Gravimetric Analysis--NR056X exhibited a three-stage breakdown. The first two weight losses were attributed to solvent evaporation. Thermal degradation began at about $450^{\circ} \mathrm{C}$ for each batch.

Liquid Chromatography--Size-exclusion chromatography was conducted identically to that for LARC-13 with PSM 60S and PSM 1000 S columns and methanol mobile phase. NR056X did show considerable variation in formulation. The data below illustrate these differences.

Batch $\mathrm{N}-1$

Elution

Time,

minutes

409

581

600

673
Batch N-2

Elution

Time,

$\underline{\text { minutes }}$

Area

56.0

405

606

642

682

2.8

38.9

Batch N-3

Elution

Time, Percent

minutes

Area

$\underline{\text { Area }} \underline{\text { minutes }}$ Area

$20.2 \quad 407$

28.9

3.1

603

0.9

0.6

645

0.5

76.1

678

69.7

For this specific study, size-exclusion chromatography could give sufficient characterization for quality control.

Differential Scanning Calorimetry (DSC)/Differential Thermal Analysis (DTA)--The analysis of NR056X (for the three resin batches) exhibited a significant exotherm at 130 to $175^{\circ} \mathrm{C}$ followed by an exotherm event that took place between 225 and $325^{\circ} \mathrm{C}$. Heatup rate for analysis was $10^{\circ} \mathrm{C}$ per minute. Sample size was $11.5 \mathrm{mg}$. 


\section{LARC-TPI Analysis}

Chemical characterization of LARC-TPI was not performed on this program. The original plan was to characterize only two systems. However, three had been characterized and a fourth would have diverted program funds from other more critical activities.

\section{Conclusions}

PPQ-The various analyses performed show excellent consistency among the three resin batches. Variation of test data would not be attributed to resin inconsistencies.

LARC-13--Reasonably good consistency in batch characteristics is maintained. Variations among the batches seem to lie in the amounts of volatiles and solvents present. The relative lack of thermal stability is a cause of some concern in consistency of thermal aging tests.

NR056X--Formulation variations among the batches seem to be significant for this resin. DSC and DTA results also show a wide range of endotherm and exotherm temperatures. To characterize the resin, IR analysis, TGA, and size-exclusion chromatography could be effectively used.

\subsubsection{Cure Cycle Optimization}

The primary objective of this work is to develop optimized cure cycles for the selected adhesives that:

- Result in the lowest possible cure temperature

- Produce structural metal-to-metal and honeycomb sandwich structural bonds stable at $505 \mathrm{~K}\left(450^{\circ} \mathrm{F}\right)$

- Provide for a common cure cycle for the selected adhesive systems

Three cure cycles were used for each adhesive system to process lap shear test coupons for $505 \mathrm{~K}$ exposure and test. These cure cycles were--

1. Apply $1.38 \mathrm{MPa}(200 \mathrm{psi})$ and $588 \mathrm{~K}\left(600^{\circ} \mathrm{F}\right)$. Hold at $588 \mathrm{~K}\left(600^{\circ} \mathrm{F}\right)$ for 90 minutes and cool under pressure. Postcure: 6 hours at $588 \mathrm{~K}\left(600^{\circ} \mathrm{F}\right)$. 
2. Apply $1.38 \mathrm{MPa}(200 \mathrm{psi})$ and heat to $602 \mathrm{~K}(6250 \mathrm{~F})$. Hold at $602 \mathrm{~K}(6250 \mathrm{~F})$ for 1 hour, release pressure, hold 1 additional hour, then cool. Postcure: 4 hours at $588 \mathrm{~K}$ (6000F).

3. Apply $1.38 \mathrm{MPa}(200 \mathrm{psi})$ and $616 \mathrm{~K}\left(650^{\circ} \mathrm{F}\right)$. Hold at $616 \mathrm{~K}\left(650^{\circ} \mathrm{F}\right)$ for 90 minutes and cool under pressure. Postcure: 2 hours at $588 \mathrm{~K}\left(600^{\circ} \mathrm{F}\right)$.

Adhesive film properties and drying cycles were --

$\begin{array}{lccl}\text { Areal Weight, } & \begin{array}{l}\text { Percent Weight } \\ \text { Volatiles at } \\ \text { Adhesive } \\ \mathrm{g} / \mathrm{cm}^{2}\left(\mathrm{lb} / \mathrm{ft}^{2}\right)\end{array} & \begin{array}{l}644 \mathrm{~K}\left(700^{\circ} \mathrm{F}\right) \\ \text { PPQ } \\ 0.022(0.045)\end{array} & \begin{array}{l}\text { Drying Time } \\ \text { and Temperature }\end{array} \\ \text { LARC-TPI } 0.036(0.073) & 8.3 & 2 \mathrm{hr} \text { at } 491 \mathrm{~K}\left(425^{\circ} \mathrm{F}\right) \\ \text { NR056X } & 0.064(0.13) & 10.8 & 1 \mathrm{hr} \text { at } 372 \mathrm{~K}\left(210^{\circ} \mathrm{F}\right)\end{array}$


Table 3.1.2-1 lists the lap shear summary test results obtained on PPQ LARC-2, and NR056X adhesive systems. Tables $3.1 .2-2,-3$, and -4 in the appendix list the individual test values.

Table 3.1.2-1.

Phase II Cure Cycle Optimization-Lap-Sheur Strength, MPa (psi) Data Summary

\begin{tabular}{|c|c|c|c|c|c|c|}
\hline \multirow[b]{2}{*}{ Adhersive } & \multirow{2}{*}{$\begin{array}{l}\text { Pure } \\
\text { No. }\end{array}$} & \multirow{2}{*}{$\begin{array}{l}\text { Ambient } \\
\text { Test }\end{array}$} & \multirow{2}{*}{$\begin{array}{l}\text { 505K }\left(450^{\circ} \mathrm{F}\right) \\
\text { Test }\end{array}$} & \multicolumn{3}{|c|}{$\begin{array}{l}\text { Thermal Aging at } 505 \mathrm{~K}\left(450^{\circ} \mathrm{F}\right) \\
\text { Tested at 505K }\left(450^{\circ} \mathrm{P}\right)\end{array}$} \\
\hline & & & & 500 hours & 1000 hours & 3000 hours \\
\hline pes & $\begin{array}{l}1 \\
2 \\
3\end{array}$ & $\begin{array}{l}30.2(+380) \\
37.0(5370) \\
33.0(4780)\end{array}$ & $\begin{array}{l}16.4^{\circ}(2380) \\
17.4^{\circ}(2530)^{\circ} \\
16.1^{\circ}(2340)^{\circ}\end{array}$ & $\begin{array}{l}19.6(2850) \\
24.4(3540) \\
21.4(3100)\end{array}$ & $\begin{array}{l}20.8(3010) \\
24.2(3510) \\
22.9(3320)\end{array}$ & $\begin{array}{ll}18.8 & (2720) \\
24.8 & (3600) \\
22.8 & (3310)\end{array}$ \\
\hline IAKC-2 & $\begin{array}{l}1 \\
2 \\
3\end{array}$ & $\begin{array}{l}19.9(2880) \\
19.3(2800) \\
27.6(4000)\end{array}$ & $\begin{array}{cc}5.6 * & (810) * \\
10.3 & (1500) \\
14.3 & (2070)\end{array}$ & $\begin{array}{l}14.8(2140) \\
13.0(1890) \\
15.6(2260)\end{array}$ & $\begin{array}{l}13.2(1910) \\
17.4(2520) \\
19.2(2790)\end{array}$ & $\begin{array}{l}15.6(2260) \\
16.6(2400) \\
19.7(2860)\end{array}$ \\
\hline NRes6X & $\begin{array}{l}1 \\
2 \\
3\end{array}$ & $\begin{array}{l}21.2(3080) \\
20.7(3000) \\
21.5(3120)\end{array}$ & $\begin{array}{ll}11.9 & (1730) \\
10.3 & (1500) \\
11.6 & (1698)\end{array}$ & $\begin{array}{l}13.4(1950) \\
10.8(1570) \\
13.0(1890)\end{array}$ & $\begin{array}{l}12.8(1850) \\
12.4(1800) \\
11.5(1670)\end{array}$ & $\begin{array}{r}9.7(1410) \\
10.2(1480) \\
12.1(1750)\end{array}$ \\
\hline
\end{tabular}

-Oven temperature controller not functioning properly-lest temperature exceeded $505 \mathrm{~K}\left(450^{\circ} \mathrm{F}\right)$.

For $\mathrm{PPQ}$, it appears that cure cycle 2 at $602 \mathrm{~K}\left(625^{\circ} \mathrm{F}\right)$ with a 4 -hour $588 \mathrm{~K}\left(600^{\circ} \mathrm{F}\right)$ postcure produces superior lap-shear strength. LARC-TPI cure cycle 3 at $616 \mathrm{~K}\left(650^{\circ} \mathrm{F}\right)$ with a 2-hour $288 \mathrm{~K}\left(600^{\circ} \mathrm{F}\right)$ postcure is the most suitable for best lap-shear strength in this study.

Both cure 1 and cure 3 appear to be comparable for NR056X. However, relative lap-shear strengths are significantly lower than for either PPQ or LARC-TPI. Since PPQ and LARC2 have been selected for Phase II studies, NR056X evaluation was discontinued. 


\subsection{TASK II ENVIRONMENTAL EXPOSURE DATA}

A critical aspect of determining the suitability of an adhesive for aerospace vehicle design is how well the adhesive bond performs in hostile environments. The purpose of this portion of the program was to determine the environmental durability of PPQ and LARC-TPI adhesive systems. The exposure conditions and test results follow.

\subsubsection{Unstressed Thermal Aging}

This study determined the effects of long term thermal exposure upon the bond properties of PPQ and LARC-TPI adhesive systems. Lap shear, T-Peel, and Crack extension coupons were exposed to $505 \mathrm{~K}$ for up to 5,000 hours. These coupons were tested at $219 \mathrm{~K}$, ambient, 422K, and 505K after 100, 500, 1,000, 2,000, and 5,000 hours. Tables 3.2.1-1 and 3.2.12 list the summary data generated on PPQ and LARC-TPI respectively. The mechanical bond properties of PPQ all show a decline from initial test values of from 30 to 50 percent depending upon test temperature. Crack extension was conducted at $533 \mathrm{~K}$ (in addition to the other temperatures listed). This exposure at $505 \mathrm{~K}$ resulted in adhesive failure of the coupons sometime between 2,000 and 5,000 hours. These results are consistent with the failures experienced with 10,000 hours exposure to $4500 \mathrm{~F}$ from the surface treatment study of Phase I. That is, an apparent change in the oxide or resin or both which causes an incompatibility between the two surfaces.

LARC-TPI unstressed thermal aging results show much more strength stability for all exposure temperatures. In fact, the values for $505 \mathrm{~K}$ exposure are increasing which suggests that some crosslinking may be occurring which reduces the thermoplastic properties of the polymer. All failures of LARC-TPI (to the limit of tests conducted during the course of this study) have been cohesive. However, the long term ( 10,000 hour) data is not yet available for this report. Table 3.2.1-A through 3.2.1-F in the Appendix list the individual test values for both systems.

\subsubsection{Stressed Thermal Aging}

This part of the program determined the effects of sustained stress loads of lap shear bonds on PPQ and LARC-TPI adhesive systems at various temperatures. At $219 \mathrm{~K}$ and ambient exposure the stress loads imposed were 25 and 30 percent of ultimate to 5,000 hours. At $505 \mathrm{~K}$ the stress loads were 25 and 50 percent of ultimate to 5,000 hours. 
TABLE 3.2.1-2

\section{UNSTRESSED THERMAL AGING, LARC-TPI}

\section{DATA SUMMARY}

Test Coupon

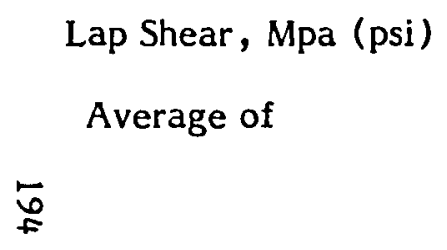

T Peel, N.M (lb/in)

Crack Extension, MM (inches) Growth
Test Temperature $\mathrm{K}$ (OF)

$\begin{array}{ll}219 & (-65) \\ \text { Ambient } \\ 422 & (300) \\ 505 & (450) \\ 533 & (500)\end{array}$

$219(-65)$

Ambient

422 (300)

$505(450)$

$533(500)$

$219 \quad(-65)$

Ambient

422 (300)

$505(450)$

$533(500)$
Initial

$\begin{array}{rr}32.8 & (4760) \\ 29.7 & (4310) \\ 23.6 & (3420) \\ 14.8 & (2150) \\ 7.0 & (1020)\end{array}$

$0.41 \quad(3.6)$

$0.51 \quad(4.5)$

$0.41 \quad(3.6)$

$0.81 \quad(7.2)$

$1.01 \quad(9.0)$

$\begin{array}{ll}0.25 & (0.01) \\ 0.00 & (0.00) \\ 0.76 & (0.03) \\ 1.52 & (0.06) \\ 5.08 & (0.20)\end{array}$

Exposure Time at $505 \mathrm{~K}$

$1000 \mathrm{Hr}$

$\begin{array}{ll}31.5 & (4570) \\ 25.3 & (3670) \\ 23.3 & (3380) \\ 19.7 & (2860)\end{array}$

$2000 \mathrm{Hr}$

$\begin{array}{ll}28.0 & (4060) \\ 24.3 & (3530) \\ 21.4 & (3100) \\ 20.8 & (3010)\end{array}$

$-\cdots$

$\begin{array}{ll}0.45 & (4.0) \\ 0.38 & (3.4) \\ 0.32 & (2.8) \\ 0.52 & (4.6)\end{array}$

0.43

(3.8)

0.33
$0.33 \quad(2.9)$

$0.45 \quad(4.0)$

$\begin{array}{ll}1.78 & (0.17) \\ 1.78 & (0.07) \\ 2.54 & (0.10) \\ 3.56 & (0.14)\end{array}$

$2.29 \quad(0.09)$

$2.29 \quad(0.09)$

$2.79 \quad(0.11)$

$3.81 \quad(0.15)$

-..-
$5000 \mathrm{Hr}$

$\begin{array}{ll}30.6 & (4440) \\ 28.1 & (4080) \\ 26.5 & (3840) \\ 21.7 & (3140)\end{array}$

$----$

$0.38 \quad(3.4)$

$0.34 \quad(3.0)$

$0.36 \quad(3.2)$

$0.50 \quad(4.4)$

$2.29 \quad(0.09)$

$2.29(0.09)$

$4.06^{---16)}$ 


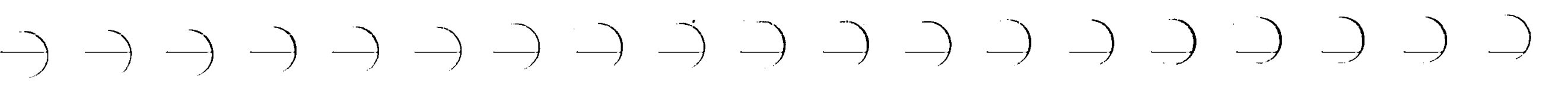

TABLE 3.2.2-1

STRESSED THERMAL AGING 505K(450\% F)-PPQ

DATA SUMMARY - LAP SHEAR (AVERAGE OF 5 COUPONS), Mpa (psi)

Exposure

and

$\underline{\text { Stress Level }}$

$25 \%(1200$ psi)

$30 \%(1500$ psi)

25\%(1200 psi)

6

\section{Temperature}

$212 \mathrm{~K}\left(-65^{\circ} \mathrm{F}\right)$

$212 \mathrm{~K}\left(-65^{\circ} \mathrm{F}\right)$

Ambient

Ambient

$505 \mathrm{~K}\left(450^{\circ} \mathrm{F}\right)$

$505 \mathrm{~K}\left(450^{\circ} \mathrm{F}\right)$

\section{Initial}

259(740 psi)

$50 \%(1480 \mathrm{psi})$
$29.8(4320)$

$30.6(4440)$

$31.2(4520)$

$33.5(4860)$

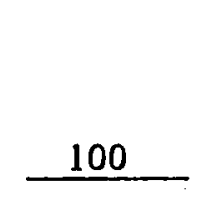

$34.9(5060)$

$34.0(4930)$

$33.7(4890)$

$34.5(5010)$

$21.3(3090)$

$22.0(3190)$

$19.6(2840)$

\section{Exposure \\ Time, Hours \\ 1000}

$37.6(5460)$

$36.5(5290)$

$30.3(4390)$

$32.1(4650)$

$31.3(4540)$

$28.7(4160)$

$28.8(4180)$

$34.5(5010)$

$19.8(2870)$

$16.2(2350)$

$21.3(3090)$

$16.7(2420)$

$0.9(1580)$

$11.8(1710)$ 
TABLE $\quad 3.2 .2-2$

STRESSED THERMAL AGING 505K(450\%F), LARC-TPI

DATA SUMMARY - LAP SHEAR (AVERAGE OF 5 COUPONS), Mpa (psi)

\begin{tabular}{|c|c|c|c|c|c|}
\hline & $\begin{array}{l}\text { Exposure } \\
\text { and }\end{array}$ & & \multicolumn{3}{|c|}{ Exposure Time } \\
\hline Stress Level & Temperature & Initial & 1000 Hours & 3000 Hours & 5000 Hours \\
\hline $29 \% 8.3(1200)$ & $219 K\left(-65^{\circ} \mathrm{F}\right)$ & $32.8(4760)$ & $33.0(4780)$ & $33.9(4920)$ & TBD \\
\hline $30 \% 10.3(1500)$ & $219 \mathrm{~K}\left(-65^{\circ} \mathrm{F}\right)$ & $32.8(4760)$ & $34.1(4950)$ & $32.0(4640)$ & \\
\hline $25 \% 8.3(1200)$ & Ambient & $29.7(4310)$ & $30.3(4390)$ & $28.3(4110)$ & \\
\hline $30 \% 10.3(1500)$ & Ambient & $29.7(4310)$ & $30.0(4350)$ & $29.5(4280)$ & \\
\hline $25 \% \quad 5.1(740)$ & $505 \mathrm{~K}\left(450^{\circ} \mathrm{F}\right)$ & $14.8(2150)$ & $22.5(3260)$ & $20.3(2950)$ & \\
\hline $50 \% 10.2(1480)$ & $505 \mathrm{~K}\left(450^{\circ} \mathrm{F}\right)$ & $14.8(2150)$ & $22.1(3200)$ & $21.4(3100)$ & \\
\hline
\end{tabular}


Tables 3.2.2-1 and 3.2.2-2 list the summary data of test values obtained. The $219 \mathrm{~K}$ and ambient exposed PPQ test coupons are unaffected by sustained stresses. The $505 \mathrm{~K}$ exposed coupons lose approximately 50 percent of initial shear strength after 5,000 hours.

Due to the relative insensitivity of sustained stress upon PPQ at $219 \mathrm{~K}$ and ambient, at exposure times under 1000 hours, LARC-TPI testing was reduced to 1,000 , and 5,000 hours at ambient and 505K. Tables 3.2.2-A and 3.2.2-B in the Appendix list the individual that values in this study.

\subsubsection{Humidity Exposure}

This study evaluated lap shear, T-Peel, and Crack extension metal-to-metal titanium bonds exposed to $312 \mathrm{~K} / 95 \% \mathrm{RH}$ for up to 2,000 hours. The test coupons were removed from exposure and immediately tested at $219 \mathrm{~K}$, ambient and 505K. Tables 3.2.3-1 and 3.2.3-2 list the data obtained on PPQ and LARC-TPI. The individual test values are listed in the Appendix.

The humidity exposure data on PPQ and LARC-TPI appears to have some degradative effect upon lap shear and crack extension after 2,000 hours. Table 3.2.3-1 data for PPQ shows a drop to $12.1 \mathrm{Mpa}$ shear strength after 2,000 hours exposure to $322 \mathrm{~K} / 95 \% \mathrm{RH}$, tested at 505K. Crack extension grew from an initial 1 hour exposure length of $4.8 \mathrm{~mm}$ to $22.1 \mathrm{~mm}$ at 2,000 hours.

LARC-TPI was only slightly less affected by the high humidity exposure. After 2,000 hours exposure and tested at 505K lap shear was $12.8 \mathrm{Mpa}$ and Crack extension was 17.8 mm. Table 3.1.2-1 lists the lap shear summary test results obtained on PPQ, LARC-2, and NRO56X adhesive systems. Tables 3.1.2-A and B in the Appendix list the individual test values.

\subsubsection{Aircraft Fluids Exposure}

In addition to thermal and humidity environments, adhesively bonded aircraft structures are subjected to a variety of fuels, lubricants, and hydraulic fluids. Many resins stable in the presence of heat and/or high humidity may be attacked by organic solvents which can significantly reduce bond properties. This study evaluated PPQ and LARC-TPI Titaniumto-titanium lap shear and crack extension coupons exposed to - 
TABLE 3.2.3-1 HUMIDITY EXPOSURE - PPQ

DATA SUMMARY

\begin{tabular}{|c|c|c|c|c|c|c|}
\hline \multirow[b]{2}{*}{ Test Coupon } & \multirow{2}{*}{$\begin{array}{l}\text { Test } \\
\text { Temperature } \\
\mathrm{K}(\mathrm{OF}) \\
\end{array}$} & & \multicolumn{2}{|c|}{ Exposure Time } & \multicolumn{2}{|c|}{$\begin{array}{l}\text { Failure Mode } \\
\text { Percent } \\
\text { Cohisive } \\
\end{array}$} \\
\hline & & & $\begin{array}{l}100 \\
\text { hours }\end{array}$ & $\begin{array}{l}2000 \\
\text { hours }\end{array}$ & $\begin{array}{l}1000 \\
\text { hours }\end{array}$ & $\begin{array}{l}2000 \\
\text { hours }\end{array}$ \\
\hline $\begin{array}{l}\text { Lap Shear, } \\
\text { MPa (psi) }\end{array}$ & $\begin{array}{l}219(-65) \\
\text { Ambient } \\
505(450)\end{array}$ & $\begin{array}{l}27.9 \\
25.8 \\
14.8\end{array}$ & $\begin{array}{l}(4040) \\
(3740) \\
(2150)\end{array}$ & $\begin{array}{ll}26.8 & (3890) \\
20.6 & (2980) \\
12.1 & (1760)\end{array}$ & $\begin{array}{l}90-100 \\
60-70 \\
85-90\end{array}$ & $\begin{array}{l}80-90 \\
60-70 \\
70-80\end{array}$ \\
\hline $\begin{array}{l}\text { T-Peel, N M } \\
\text { MPa (psi) }\end{array}$ & $\begin{array}{l}219(-65) \\
\text { Ambient } \\
505(450)\end{array}$ & $\begin{array}{l}0.50 \\
0.52 \\
0.77\end{array}$ & $\begin{array}{l}(4.4) \\
(4.6) \\
(6.8)\end{array}$ & $\begin{array}{ll}0.47 & (4.2) \\
0.38 & (3.4) \\
0.81 & (7.2)\end{array}$ & & \\
\hline
\end{tabular}

Crack Extension, mm (inch)

Initial crack, $24.4(0.96)$
Exposure Time

1 hour
24 hours
100 hours
500 hours
1000 hours
2000 hours

Extension

$\begin{array}{rr}4.8 & (0.19) \\ 14.5 & (0.57) \\ 18.8 & (0.74) \\ 20.1 & (0.79) \\ 21.3 & (0.84) \\ 22.1 & (0.87)\end{array}$

TABLE 3.2.3-2 DATA SUMMARY 332K $\left(120^{\circ} \mathrm{F}\right) / 99 \%$ RH EXPOSURE, LARC-TPI

\begin{tabular}{|c|c|c|c|c|c|c|}
\hline \multirow{3}{*}{$\begin{array}{l}\text { Test } \\
\text { Lap Shear, } \\
\text { MPa (psi) }\end{array}$} & \multirow{2}{*}{$\begin{array}{c}\text { Test } \\
\text { Temperture } \\
\mathrm{K}(\mathrm{OF}) \\
\end{array}$} & \multicolumn{5}{|c|}{$\begin{array}{c}\text { Exposure } \\
\text { Time, Hours }\end{array}$} \\
\hline & & \multicolumn{2}{|c|}{1000} & & \multicolumn{2}{|c|}{2000} \\
\hline & $\begin{array}{l}219 \quad(-65) \\
\text { Ambient } \\
505 \quad(450)\end{array}$ & $\begin{array}{l}26.9 \\
16.4 \\
14.5\end{array}$ & $\begin{array}{l}(3900) \\
(2380) \\
(2100)\end{array}$ & & $\begin{array}{l}26.1 \\
17.4 \\
12.8\end{array}$ & $\begin{array}{l}(3780) \\
(2520) \\
(1860)\end{array}$ \\
\hline $\begin{array}{l}\text { "T" Peel, } \\
\text { N M (lb/in) }\end{array}$ & $\begin{array}{l}219 \quad(-65) \\
\text { Ambient } \\
505 \quad(450)\end{array}$ & $\begin{array}{l}0.34 \\
0.29 \\
0.47\end{array}$ & $\begin{array}{l}(3.0) \\
(2.6) \\
(4.2)\end{array}$ & ' & $\begin{array}{l}0.37 \\
0.28 \\
0.50\end{array}$ & $\begin{array}{l}(3.3) \\
(2.5) \\
(4.4)\end{array}$ \\
\hline
\end{tabular}

Crack RT RH $\quad 100$

Extension, Initial Initial \begin{tabular}{l}
100 \\
$\mathrm{HR}$ \\
\hline
\end{tabular} $1 . \overline{78(0.07)} \quad 7 . \overline{6(0.30)}$ 500
$12 . \frac{\mathrm{HR}}{4(0.49)}$ 1000
$15.7(0.62)$ 2000 $17 . \frac{\mathrm{HR}}{8(0.70)} \frac{\mathrm{HR}}{\mathrm{TBD}}$ 


\title{
3.2.4 Aircraft Fluids Exposure
}

In addition to thermal and humidity environments, adhesively bonded aircraft structures are subjected to a variety of fuels, lubricants, and hydraulic fluids. Many resins stable in the presence of heat and/or high humidity may be attacked by organic solvents which can significantly reduce bond properties. This study evaluated PPQ and LARC-TPI Titaniumto-titanium lap shear and crack extension coupons exposed to -

\author{
JP-4 Aviation Fuel \\ MIL-H-5606 Lubrication Oil \\ Skydrol Hydraulic Fluid \\ $\mathrm{M}-\mathrm{H}-7808$ Engine Oil \\ Water/Ethylene Glycol De-icing Fluid
}

Tables 3.2.4-1 and 3.2.4-2 present summary data of the test results up to 5000 hour exposure. Individual test values are listed in the Appendix (see Tables 3.2.4-A, B, C, \& D).

General conclusions from this work with respect to PPQ are that; (1) of all exposure conditions, Skydrol induced Crack extension growth was the most significant bond degradation seen, and (2) all other exposure conditions did not appear to affect bond properties. For LARC-TPI, again, Skydrol effects on Crack extension were the only sign of bond degradation. No other exposure conditions in this test had altered significantly the bond strengths. 
TABLE 3.2.4-1 AIRCRAFT FLUID EXPOSURE - PPQ

DATA SUMMARY

\begin{tabular}{|c|c|c|c|c|c|c|c|c|}
\hline \multirow[b]{2}{*}{ Test Coupon } & \multirow[b]{2}{*}{ Duration } & \multirow[b]{2}{*}{$\begin{array}{l}\text { JP-4 } \\
\text { Ambient }\end{array}$} & \multicolumn{2}{|c|}{ MIL-H-5606 } & \multicolumn{2}{|c|}{ Skydrol } & \multirow[b]{2}{*}{$\begin{array}{l}\text { MIL-H-7808 } \\
\text { Ambient }\end{array}$} & \multirow{2}{*}{$\begin{array}{l}\text { Deicing } \\
\text { Fluid } \\
\text { Ambient }\end{array}$} \\
\hline & & & Ambient & $\begin{array}{r}344 \mathrm{KK} \\
\left(160^{\circ} \mathrm{F}\right)\end{array}$ & Ambient & $\begin{array}{l}334 \mathrm{~K} \\
\left(160^{\circ} \mathrm{F}\right)\end{array}$ & & \\
\hline \multirow{2}{*}{$\begin{array}{l}\text { LAP Shear, } \\
\text { Mpa (psi) }\end{array}$} & 30 days & $33.0(4780)$ & $32.1(4660)$ & $35.3(5120)$ & $34.7(5030)$ & $26.3(3810)$ & $27.7(4020)$ & $33.3(4830)$ \\
\hline & 60 days & $32.8(4750)$ & $30.8(4470)$ & $35.0(5080)$ & $30.6(4430)$ & $26.3(3810)$ & $33.0(4780)$ & $34.7(5030)$ \\
\hline \& & $5000 \mathrm{Hr}$ & $(4190)$ & $(4330)$ & - & $(4030)$ & -- & $(4270)$ & $(4660)$ \\
\hline \multirow{3}{*}{$\begin{array}{l}\text { Crack } \\
\text { Extension, } \\
\text { mm (inches) } \\
\text { growth }\end{array}$} & 30 days & $3.3(0.13)$ & $3.3(0.13)$ & $5.6(0.22)$ & $18.5(0.73)$ & $31.8(1.25)$ & $13.2(0.52)$ & $3.8(0.15)$ \\
\hline & 60 days & $3.3(0.13)$ & $9.1(0.36)$ & $6.8(0.27)$ & $19.6(0.77)$ & $33.8(1.29)$ & $13.2(0.52)$ & $3.8(0.15)$ \\
\hline & $5000 \mathrm{Hr}$ & $3.8(0.15)$ & $9.4(0.37)$ & $8.1(0.32)$ & $19.8(0.78)$ & $40.9(1.61)$ & $13.7(0.54)$ & $4.3(0.17)$ \\
\hline
\end{tabular}

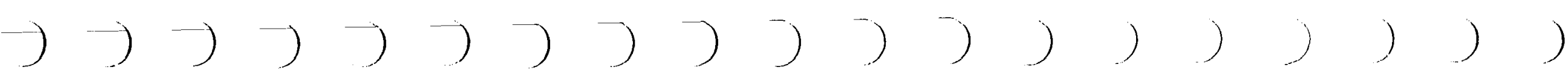




\section{$\rightarrow \rightarrow \rightarrow \rightarrow \rightarrow \rightarrow \rightarrow \rightarrow \rightarrow \rightarrow \rightarrow \rightarrow \rightarrow \rightarrow \rightarrow \rightarrow \rightarrow \rightarrow \rightarrow$}

TABLE 3.2.4-2 AIRCRAFT FLUID EXPOSURE - LARC-TPI

DATA SUMMARY

\begin{tabular}{|c|c|c|c|c|c|c|c|c|}
\hline \multirow{2}{*}{$\begin{array}{l}\text { Test Coupon } \\
\text { LAP Shear, }\end{array}$} & \multirow{2}{*}{ Duration } & \multirow{2}{*}{$\begin{array}{l}\text { JP-4 } \\
\text { Ambient } \\
27.7(4020)\end{array}$} & \multicolumn{2}{|c|}{$\begin{array}{l}\text { MIL-H-5606 } \\
\text { Ambient } 344 \mathrm{~K}\left(160^{\circ} \mathrm{F}\right)\end{array}$} & \multicolumn{2}{|c|}{$\begin{array}{c}\text { Skydrol } \\
\text { Ambient } 344 \mathrm{~K}\left(160^{\circ} \mathrm{F}\right)\end{array}$} & \multirow{2}{*}{$\begin{array}{c}\begin{array}{c}\text { MIL-H-7808 } \\
\text { Ambient }\end{array} \\
29.0(4210)\end{array}$} & \multirow{2}{*}{$\begin{array}{l}\text { Deicing } \\
\text { Fluid } \\
\text { Ambient }\end{array}$} \\
\hline & & & $26.4(3830)$ & $31.6(4590)$ & $29.1(4220)$ & $21.0(3040)$ & & \\
\hline \multirow[t]{2}{*}{ Mpa (psi) } & 60 days & $27.9(4050)$ & $29.0(4210)$ & $27.9(4050)$ & $27.3(3970)$ & $20.3(2950)$ & $26.1(3790)$ & $26.7(3870)$ \\
\hline & $5000 \mathrm{Hr}$ & $29.3(4240)$ & $26.7(3880)$ & & $26.7(3880)$ & & $28.6(4150)$ & $23.9(3460)$ \\
\hline Crack & 30 days & $1.8(0.07)$ & $2.8(0.11)$ & $3.0(0.12)$ & $3.3(0.13)$ & $10.7(0.42)$ & $2.3(0.09)$ & $4.1(0.16)$ \\
\hline Extension & 60 days & $3.0(0.12)$ & $3.3(0.13)$ & $3.5(0.14)$ & $4.3(0.17)$ & $14.0(0.55)$ & $3.0(0.12)$ & $5.8(0.23)$ \\
\hline $\mathrm{mm}$ (inches) & $5000 \mathrm{Hr}$ & $3.0(0.12)$ & $4.1(0.16)$ & $3.8(0.15)$ & $4.3(0.17)$ & $17.0(0.67)$ & $4.1(0.16)$ & $9.9(0.39)$ \\
\hline
\end{tabular}




\subsection{STRUCTURAL COMPONENT}

To demonstrate the production feasibility of the selected PPQ and LARC-TPI adhesive systems and the prepared material and process specifications, a large area bond titanium panel $122 \mathrm{~cm}$ by $81 \mathrm{~cm}$ was fabricated from each system. Each panel was half metal-tometal and half honeycomb sandwich (see Figure 3.3-1). Titanium 6A1-4U honeycomb core was used in the sendwich sections. The core was roller coated with BR-34 primer to build up sufficient fillet for structural bond. The tapered area in the center of the panels was given additional treatment to enhance bonding. In the PPQ panel three additional strips of adhesive film (PPQ) was placed along the tapered area. The LARC-TPI panel utilized Boeing polyimide structural foam (BMA-8-126) along the tapered area. In both panels the bond in the tapered area was not as good as would normally be experted. A tap fest indicated some areas not strongly bonded. However, all other areas of the metal-tometal and sandwich sections in both panels exhibited very good bonds.

As a side note, extreme care must be exercised in cutting all titanium honeycomb sandwich panels. The titanium core may ignite if sparks are generated by sawing and/or machining. The problem was avoided in the above panels by use of a Freon liquid stream impinging at the cutting surface. 


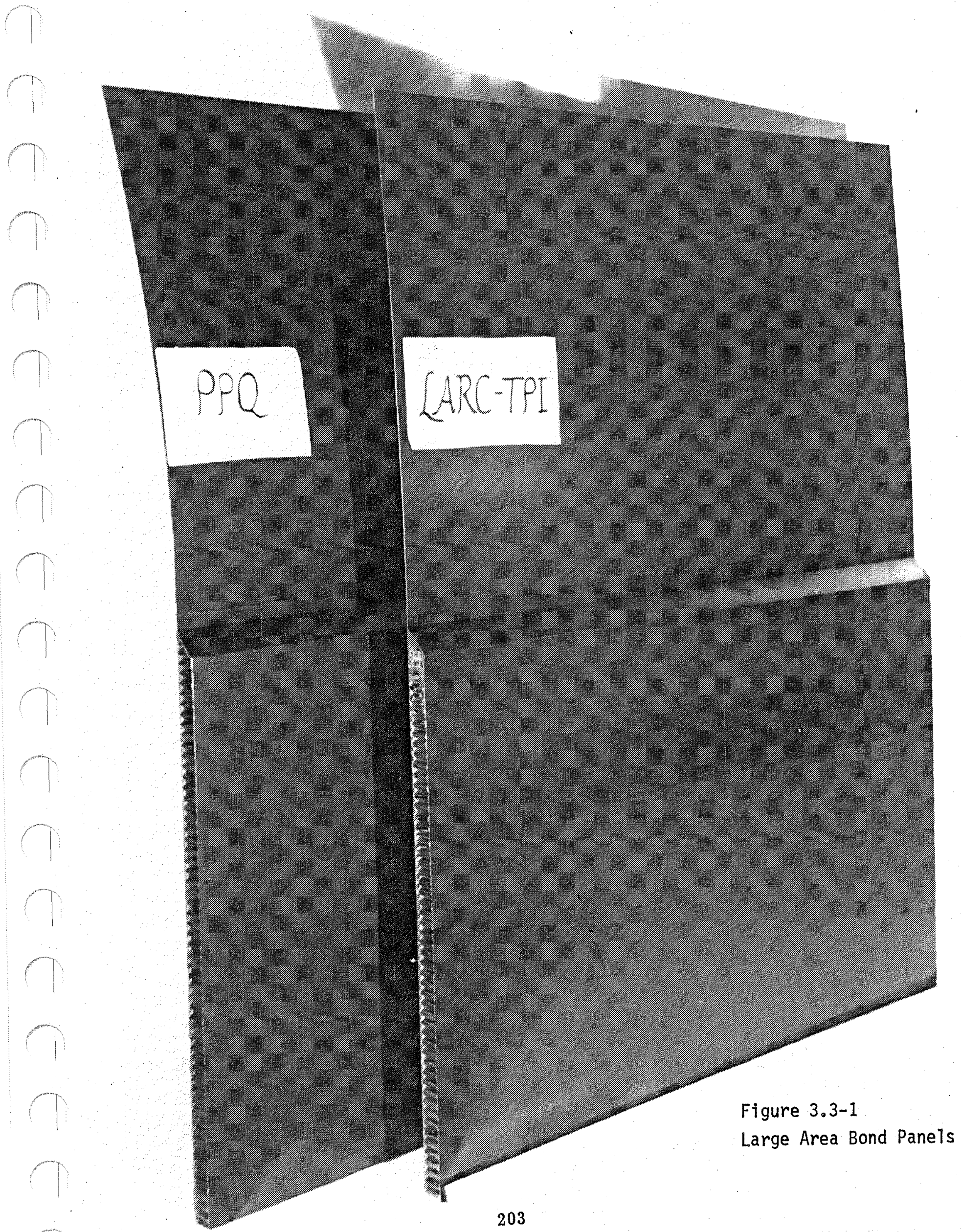




\subsection{CONCLUSIONS AND RECOMMENDATIONS}

Based upon the results of data generated by this program the following conclusions were made -

- Some Polyimide and Polyphenylguinoxaline based adhesive resins are stable in simulated supersonic cruise vehicle operating environments of long term thermal $505 \mathrm{~K}$ $\left(450^{\circ} \mathrm{F}\right)$, high humidity, and fuels/fluids.

- The specific adhesive systems LARC-TPI/10 volt chromic acid anodize and PPQ/10 volt chromic acid anodize produced the best overall bonded titanium assemblies.

- Titanium bonds are dependent upon chemical reaction and/or mechanical interlocking of the adhesive primer and the prepared metal surface.

- Adhesive bond strengths were greatest in relatively thick metal oxide surfaces produced by 10 volt chromic acid anodize. The result of a large predominate mechanical interlocking of primer and oxide.

- PPQ resin adhesive/primer/metal oxide bond strength is greatly degraded by long time ( 10,000 hours) high temperature (505K) exposure and short time ( 1 hour) very high temperature $(672 \mathrm{~K})$ through an unknown mechanism that destroys mechanical interlocking and/or chemical bond.

- LARC-TPI adhesive/primer/metal oxide bond strength appears to be unaffected by any of the simulated supersonic cruise environments.

o Polyimide and LARC-TPI adhesive systems evaluated are not as "tough" (low peel strength) as formulated epoxy adhesives.

- Characterization of bond surfaces and analysis of failed bond lines using STEM, SEM and AUGER is essential to understanding of adhesive bonding mechanisms.

The information generated in this program has revealed certain areas of investigation which were not addressed that are critical to high temperature adhesive bonding technology and its application to airframe structures. 
The recommendations are:

- Continued development of high temperature stable adhesives with emphasis on improved "thoughness" as measured by peel strength and crack propagationn resistance.

- Investigation of composite-to-composite and composite-to-metal adhesive bond properties.

- Development of adhesive resins with lower temperature and pressure processing requirements which maintain thermal stability for extended time.

- Determination of adhesive bond properties at temperatures for extended times at temperatures ranging from $350^{\circ} \mathrm{F}$ to $800^{\circ} \mathrm{F}$.

- Determination of limits and tolerances in chromic acid anodizing surface treatment process to maximize metal bond properties and produce predictable/repeatable bond performance.

- Use of STEM, SEM, and AUGER in all investigations to fully understand resin/adherend interface mechanisms. 


\section{REFERENCES}

1. S. G. Hill and J. T. Hoggatt, Development of Thermoplastic Structural Adhesives, "NASC Contract N00019-76-C-0170," Report No. D180-18753-3, March 1977.

2. "Environmental Exposure of Thermoplastic Adhesives," NASC Contract N0001977-C0340, The Boeing Company, August 1977 to August 1978.

3. R. F. Wegman and M. J. Bodnar, "Preproduction Evaluation of an Improved Titanium Prebonding Surface," 20th National SAMPE Symposium, 1975.

4. T. B. Frazier and A. D. Lajoie, "Durability of Adhesive Bonded Joints," Contract F33615-71-C-1668, Report AFML-TR-74-26, March 1974.

5. S. G. Hill, C. H. Sheppard, and J. C. Johnson, "LARC-13 Adhesive Development," Contract NAS1-15562, Report No. NASA CR-159317, June 1980. 


\section{APPENDIX}

\section{Page}

Phase I Adherend Surface Treatment Processes

Candidate Adhesives Cure Cycles

Phase I Primer Evaluation, Individual Test Values

Phase I Initial Adhesive System Evaluation, Individual Test Values

Phase I Cure Cycle Study

Phase I Titanium Surface Treatment Study

Phase I Surface Characterization

Phase II Cure Cycle Optimization

Phase II Unstressed Thermal Aging Individual Test Values

Phase II Stressed Thermal Aging Individual Test Values

Phase II Humidity Exposure Individual Test Values

Phase II Fluid Exposure Individual Test Values

Material Specification

Process Specification 
PHASE I ADHEREND SURFACE TREATMENT PROCESSES

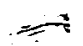
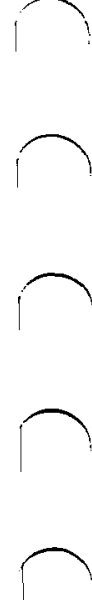

$-$
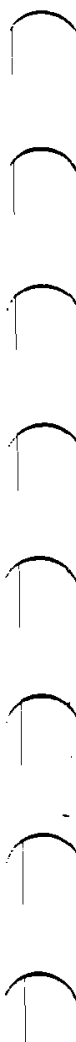
Adherend Surface Treatment Processes

A brief description of each surface treatment is provided in this protion of the appendix.

A. Chromic Acid Anodize

The process procedures used for this surface treatment are found in Boeing specification BAC 5890. These procedures included:
(1) Alkaline clean (Turco 2623) 15 minutes @ 333K (140\% F)
(2) Hot rinse
(3) Nitric - Hydrofluoric Etch 90 seconds @ 294K (700F)
(4) Cold rinse
(5) $\mathrm{CrO}_{3}$ Anodize - 5 volts, 12.7 Amps/ $\mathrm{M}^{2}$ (1.2 Amps/FT $)$
- $\mathrm{CrO}_{3} 48.8 \mathrm{gm} /$ liter $(6.5 \mathrm{oz} /$ gallon)
- 20 minutes@ $291 \mathrm{~K}\left(65^{\circ} \mathrm{F}\right)$

(6) Cold rinse

(7) Hot air dry @ $338 \mathrm{~K}\left(150^{\circ} \mathrm{F}\right)$

B. Phosphoric Acid Anodize

The process procedures for this surface treatment are as specified in Boeing specification BAC 5555. General procedures are:
(1) Alkaline clean (Turco 2623) 15 minutes @ 333K (140\% F)
(2) Hot rinse
(3) Nitric - Hydrofluoric Etch 90 seconds @ 294K (70\% F)
(4) Cold rinse
(5) Phosphoric Acid Anodize - 5 volts, 19 Amps $/ \mathrm{M}^{2}$ (1.8 Amps/FT2)
- $\mathrm{H}_{3} \mathrm{PO}_{4}-112.5 \mathrm{gm} /$ liter ( $15 \mathrm{oz} /$ gallon)
- 20 minutes@ 297K (750F)

(6) Cold rinse

(7) Hot air dry @ $338 \mathrm{~K}\left(150^{\circ} \mathrm{F}\right)$ 
C. Pasa-Jell 107

These process procedures for this treatment are:

(1) Alkaline clean (Turco 2623) 15 minutes @ 333K (140\% F)

(2) Hot rinse

(3) Nitric-Hydrofluoric etch 90 seconds @ $294 \mathrm{~K}\left(700^{\circ} \mathrm{F}\right)$

(4) Pasa-Jell 10712 minute immersion in jelled Pasa-Jell 107

(5) Hot air dry @ $338 \mathrm{~K}\left(150^{\circ} \mathrm{F}\right)$

D. Phosphate Fluoride

Process procedures for this surface treatment are as specified in Boeing specification BAC 5514. General procedures are:

(1) Alkaline clean (Turco 2623) 15 minutes @ 333K (140\% F)

(2) Hot rinse

(3) Nitric - Hydrofluoric Etch 90 seconds @ 294K (70\% F)

(4) Cold rinse

(5) Phosphate Fluoride treat per BAC 5514105 seconds @ 294K (700F)

(6) Cold rinse

(7) Hot water leach 15 minutes @ $355 \mathrm{~K}\left(180^{\circ} \mathrm{F}\right)$

(8) Hot air dry @ $338 \mathrm{~K}\left(150^{\circ} \mathrm{F}\right)$

E. Phosphate Fluoride (Picatinny Modified)

General procedures afor this surface treatment are:

(1) Alkaline clean (Turco 2623) 15 minutes @ 333K (140\%F)

(2) Hot rinse

(3) Nitric-Hydrofluoric Etch, BAC 5514 Method II with $7.5 \mathrm{~g} / \mathrm{liter}$ (28.4 oz/gallon) anhydrous sodium sulfate added, 90 seconds @ $294 \mathrm{~K}\left(70^{\circ} \mathrm{F}\right)$

(4) Cold rinse

(5) Phosphate fluoride per BAC 5514, 105 seconds @ $294 \mathrm{~K}$ (70\%F)

(6) Cold rinse 
(7) Hot water leach 15 minutes @ $355 \mathrm{~K}$ (1800F)

(8) Hot air dry @ 338K (150\%F)

\section{F. RAE Process}

General procedures for this British developed process are:

(1) Vacuum blast with 90 grit Aluminum Oxide @ $0.21 \mathrm{MPa}$ (30 psi)

(2) Alkaline clean (Turco 2623) 15 minutes @ $333 \mathrm{~K}\left(140^{\circ} \mathrm{F}\right)$

(3) Hot rinse

(4) Immerse in solution of $20 \mathrm{~g} /$ liter $(76 \mathrm{oz} / \mathrm{gallon})$ sodium hydroxide plus $30 \%$ hydrogen peroxide $22.5 \mathrm{ml} / \mathrm{liter}$

(5) Hot rinse

(6) Hot air dry @ $338 \mathrm{~K}\left(150^{\circ} \mathrm{F}\right)$

G. Turco 5578

General procedures for this process are:

(1) Alkaline clean (Turco 2623) 15 minutes @ 333K (140\% F)

(2) Hot rinse

(3) Turco 5578 immersion, 10 minutes @ $361 \mathrm{~K}\left(190^{\circ} \mathrm{F}\right)$ solution $=432 \mathrm{gms} /$ liter $(3.6$ $\mathrm{lb} /$ gallon)

(4) Hot rinse

(5) Hot air dry @ $338 \mathrm{~K}\left(150^{\circ} \mathrm{F}\right)$

H. Phosphate Fluoride With Grit Blast

This procedure is identical to process $D$ above except for the grit blast. The general process is:

(1) Vacuum blast with 80 grit aluminum oxide (a $0.21 \mathrm{MPa}$ (30 psi)

(2) Alkaline clean (Turco 2623) 15 minutes @ 333K (140\% F)

(3) Hot rinse

(4) Nitric-Hydrofluoric Etch 90 seconds @ 294K (700 F)

(5) Cold rinse 
(6) Phosphate fluoride treat per BAC 5514105 seconds @ 294K (700F)

(7) Hot water leach @ $355 \mathrm{~K}\left(180^{\circ} \mathrm{F}\right)$

(8) Hot air dry @ $338 \mathrm{~K}\left(150^{\circ} \mathrm{F}\right)$

Common solutions for the above surface treatments using BAC 5514 are:

(1) Turco 2623 Alkaline cleaner

Concentration: 37.5 - $60 \mathrm{gm} / \mathrm{liter}$ ( $5-8 \mathrm{oz} /$ gallon)

operating temperature: $330-352 \mathrm{~K}\left(135-175^{\circ} \mathrm{F}\right)$

(2) Nitric - Hydrofluoric etch solution

- Nitric Acid (40-42 DEG BE) = 300 - $450 \mathrm{gm} / \mathrm{liter}$ (40-60 oz/gallon)

- Hydrofluoric acid (70\%) - sufficient to maintain etch rate

- FC -95 wetting agent - surface tension of 35-45 dynes/cm

- Operating temperature $=29 \mathrm{I}-305 \mathrm{~K}\left(65-90^{\circ} \mathrm{F}\right)$

- Etch rate $0.008-0.020 \mathrm{~mm}(0.002-0.005$ inch) /surface/hour

(3) Phosphate Fluoride Solution

- Sodium phosphate $\left(\mathrm{Na}_{3} \mathrm{PO}_{4} \cdot 12 \mathrm{H}_{2} \mathrm{O}\right), 45-50 \mathrm{gm} /$ liter (6.3-6.7 oz/gallon)

- Potassium fluoride (KF $\cdot 2 \mathrm{H}_{2} \mathrm{O}$ ), $19-30 \mathrm{gm} / \mathrm{liter}$ (2.5-4.0 oz/gallon)

- Hydrofluoric acid (HF), 15-21 gm/liter (2.0-2.8 oz/gallon)

- Operating temperature $=$ ambient

Cure cycles used for each of the candidate adhesive resins to prepare bonded specimens for test are shown in A1 through A8. 


\section{PHASE I CURE CYCLES}
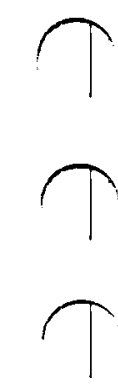

T

$T$

$T$

$T$

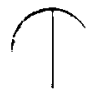

$T$

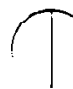

$T$

$T$

T

T

T

T 


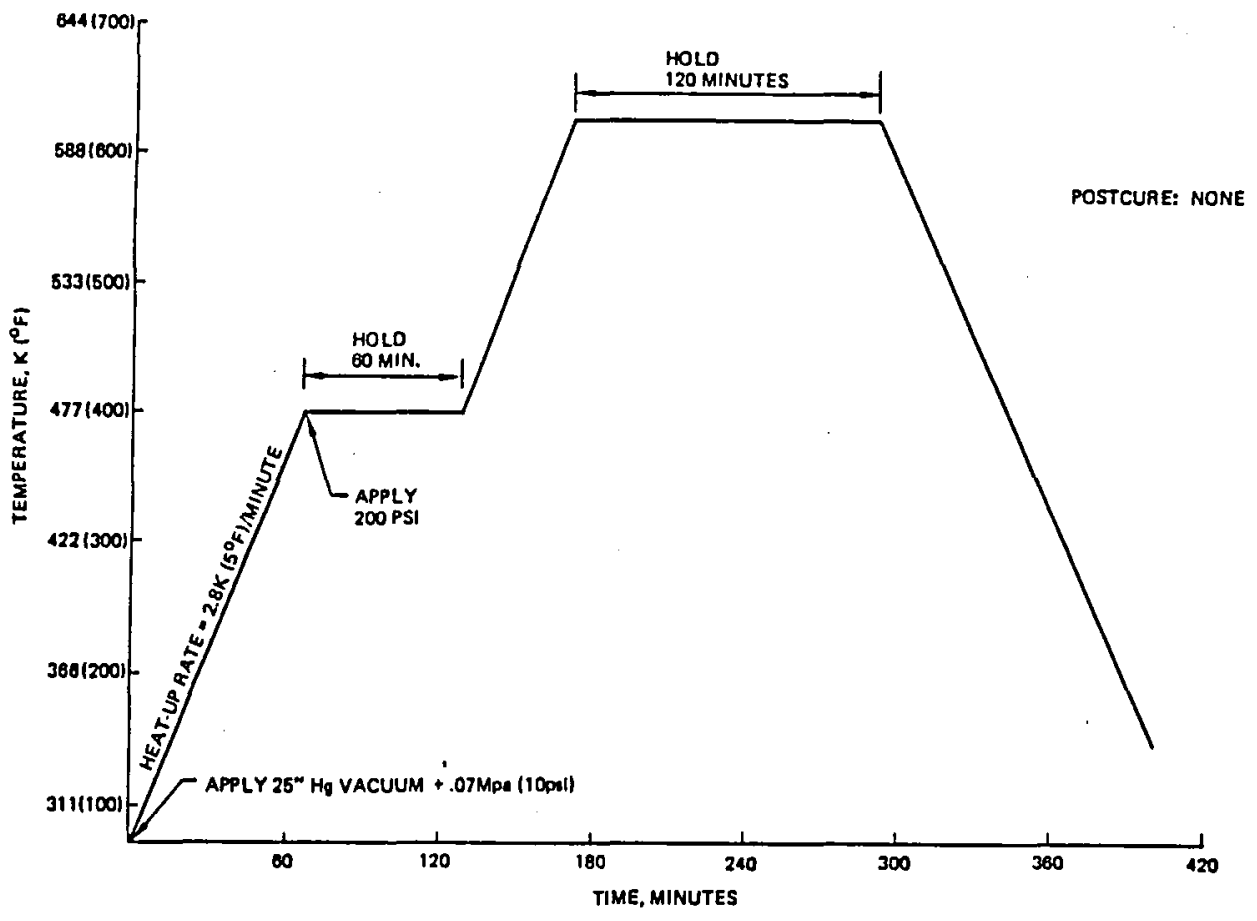

Figure A2 : LARC.13 Mddiflcation 1 and Modification 2 Cure $\mathrm{Crcle}$
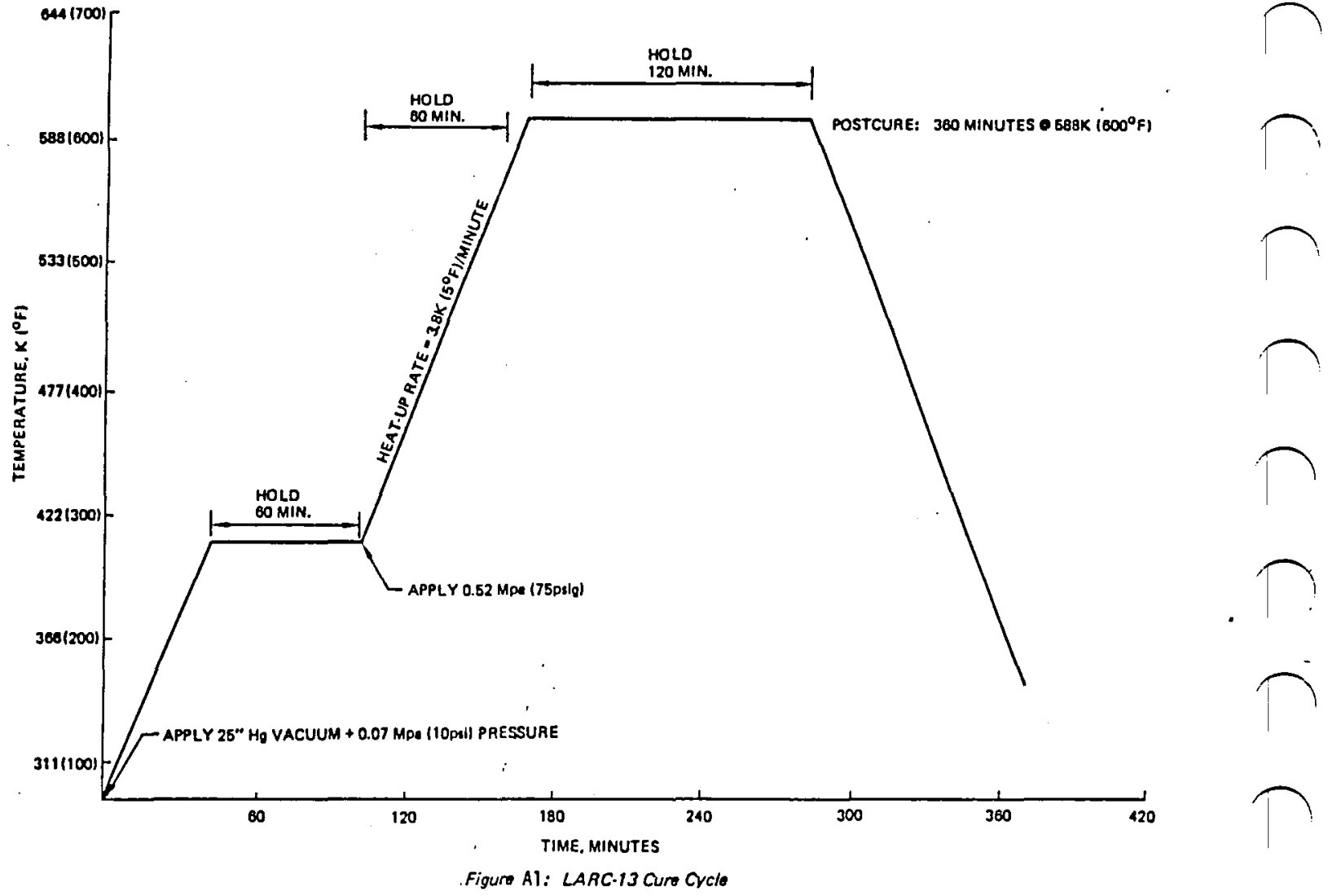

Figure A1: LARC-13 Cure Crcle 


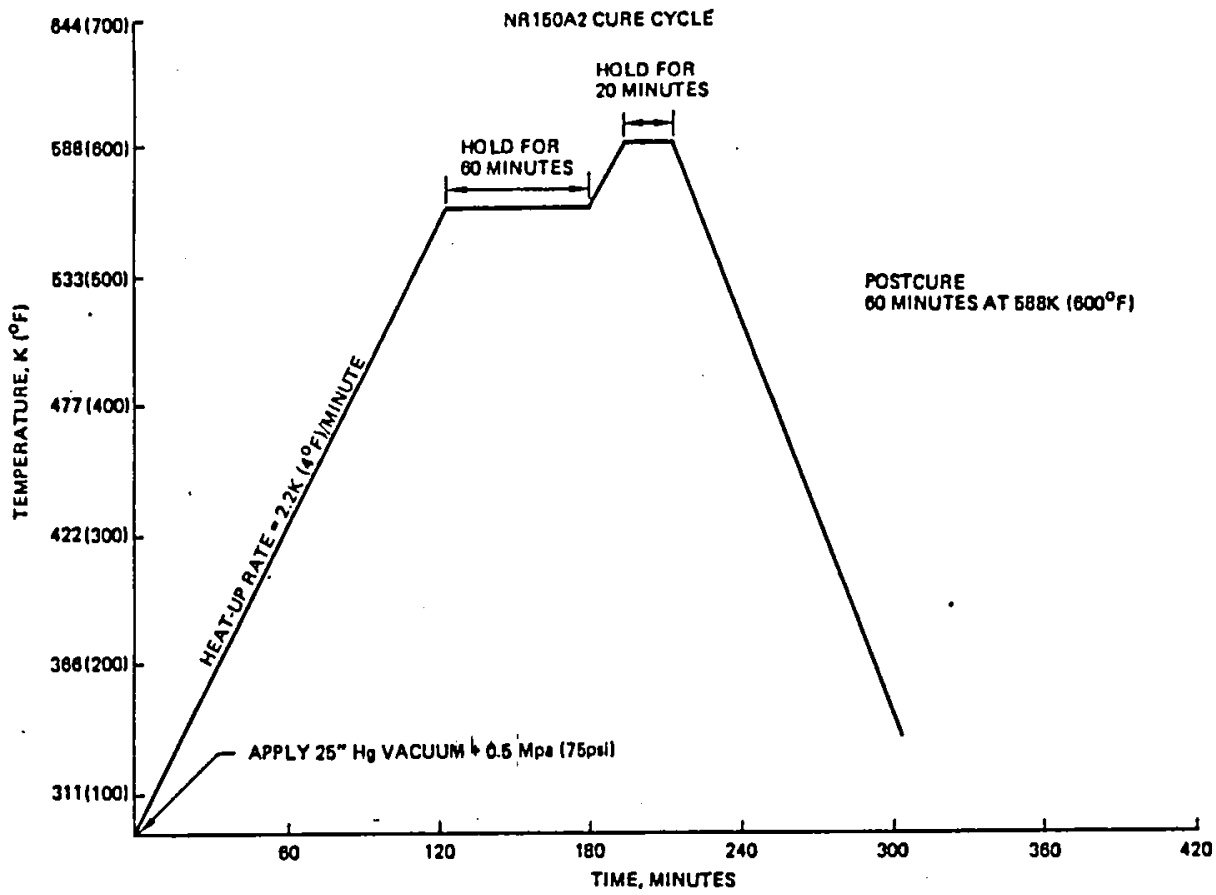

Figure A4: NR150A2 Cure Cralo
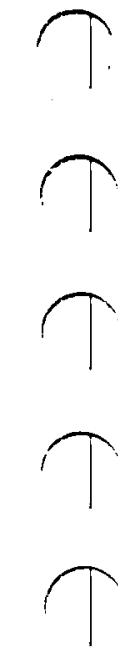

1
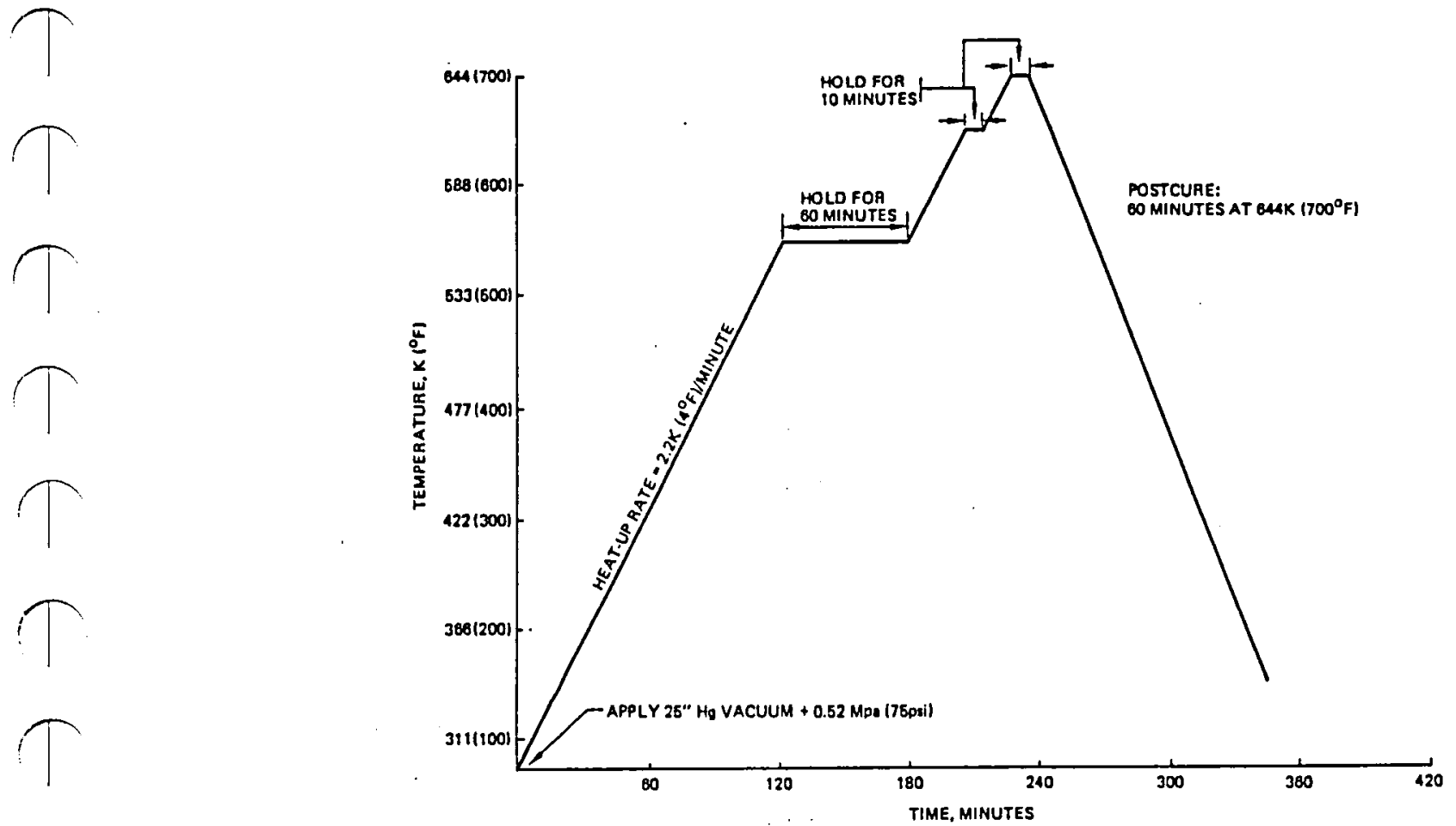

Figure A3: NR150B2 Cure Cyclo 


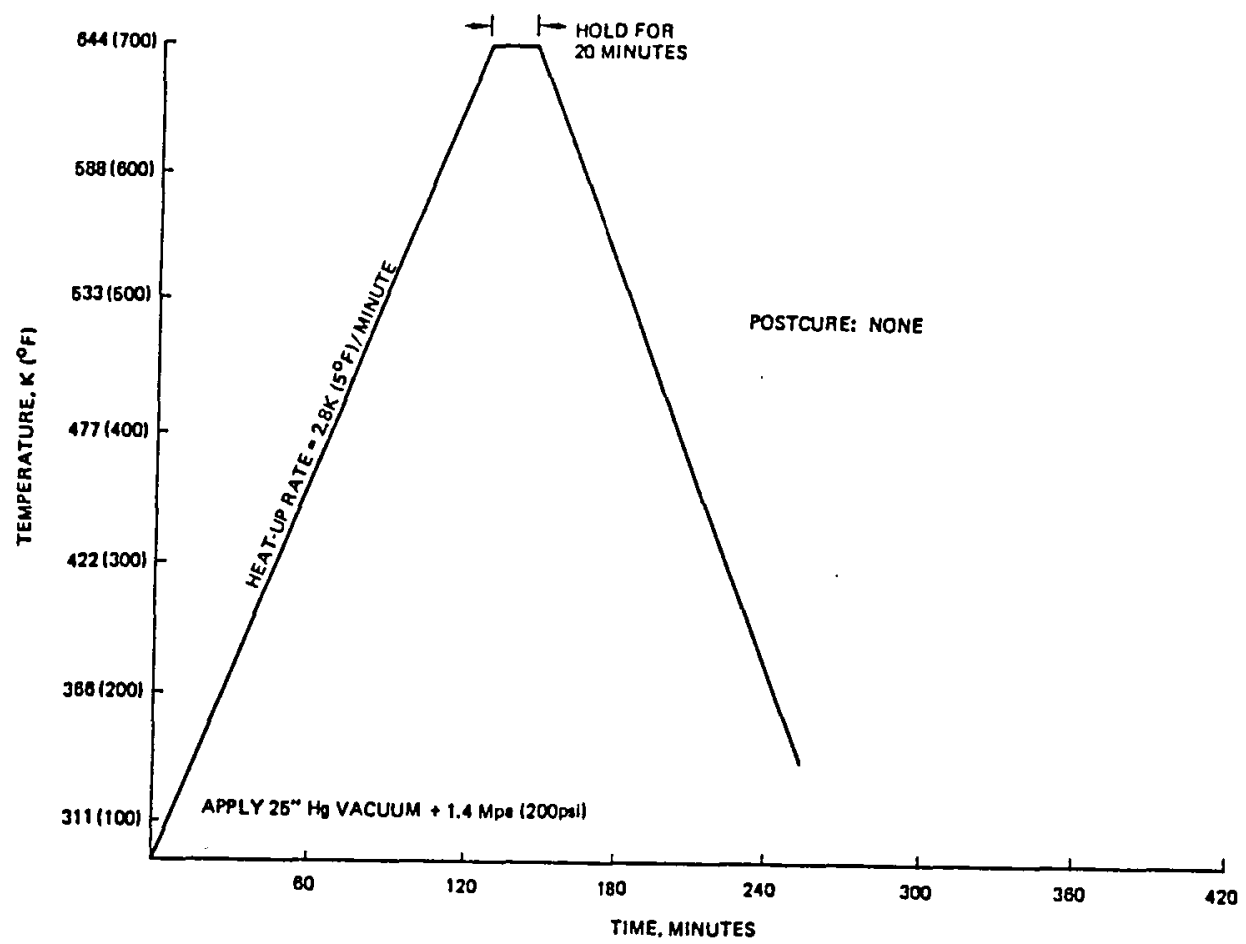

Figur A6: PPO and PPQ MOD 1 Cure Crelo

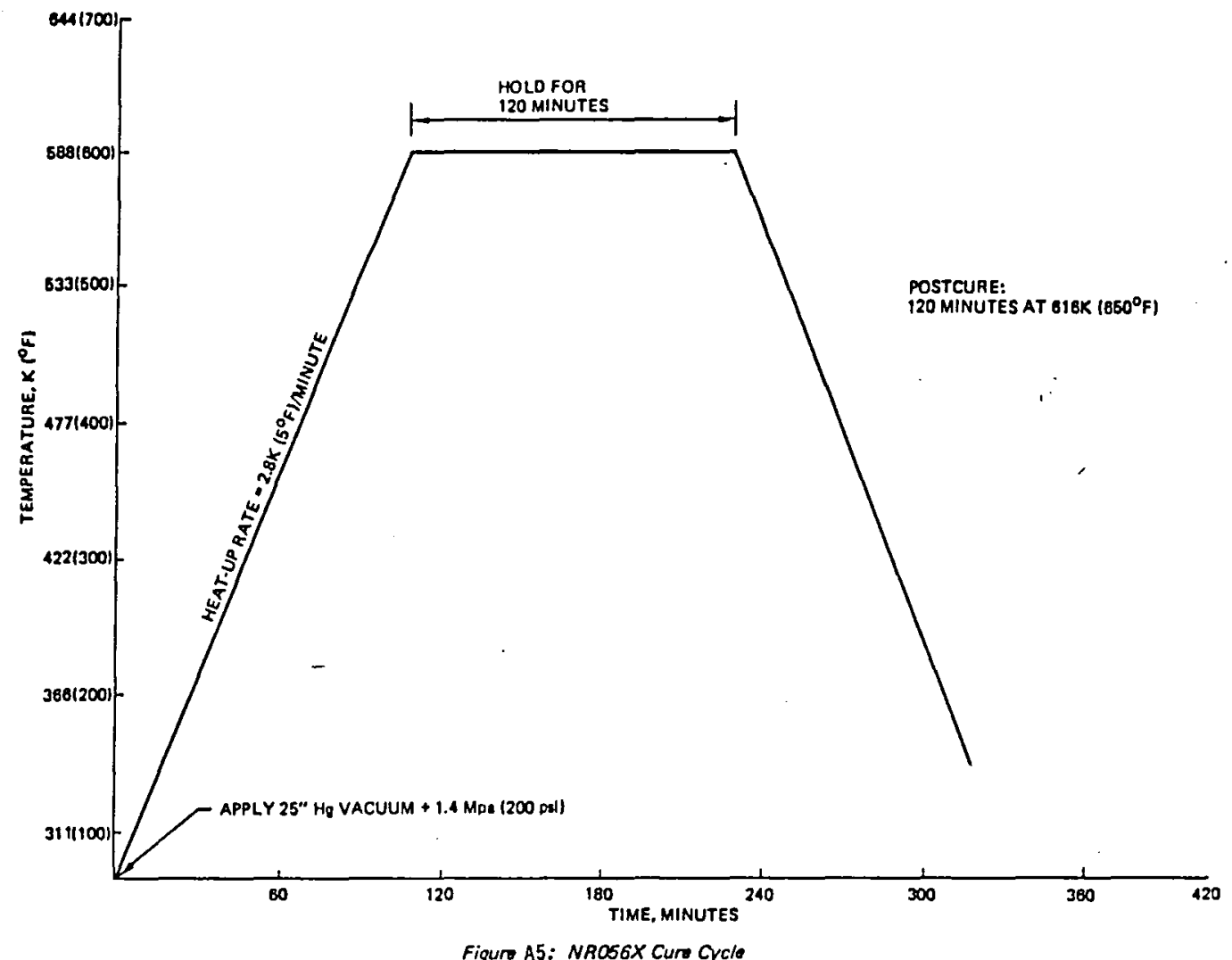


7<smiles>CCCCC</smiles><smiles>CCCC</smiles><smiles>CCCC</smiles><smiles>C1CC2CCCC2C1</smiles><smiles>CCCC</smiles><smiles>CCCC</smiles><smiles>CCCC</smiles><smiles>C1CCCCC1</smiles><smiles>CCCC</smiles><smiles>C1CCCCC1</smiles><smiles>CCCC</smiles><smiles>CCCCC</smiles><smiles>CCCC</smiles><smiles>C1CC1</smiles><smiles>CCC</smiles>
.
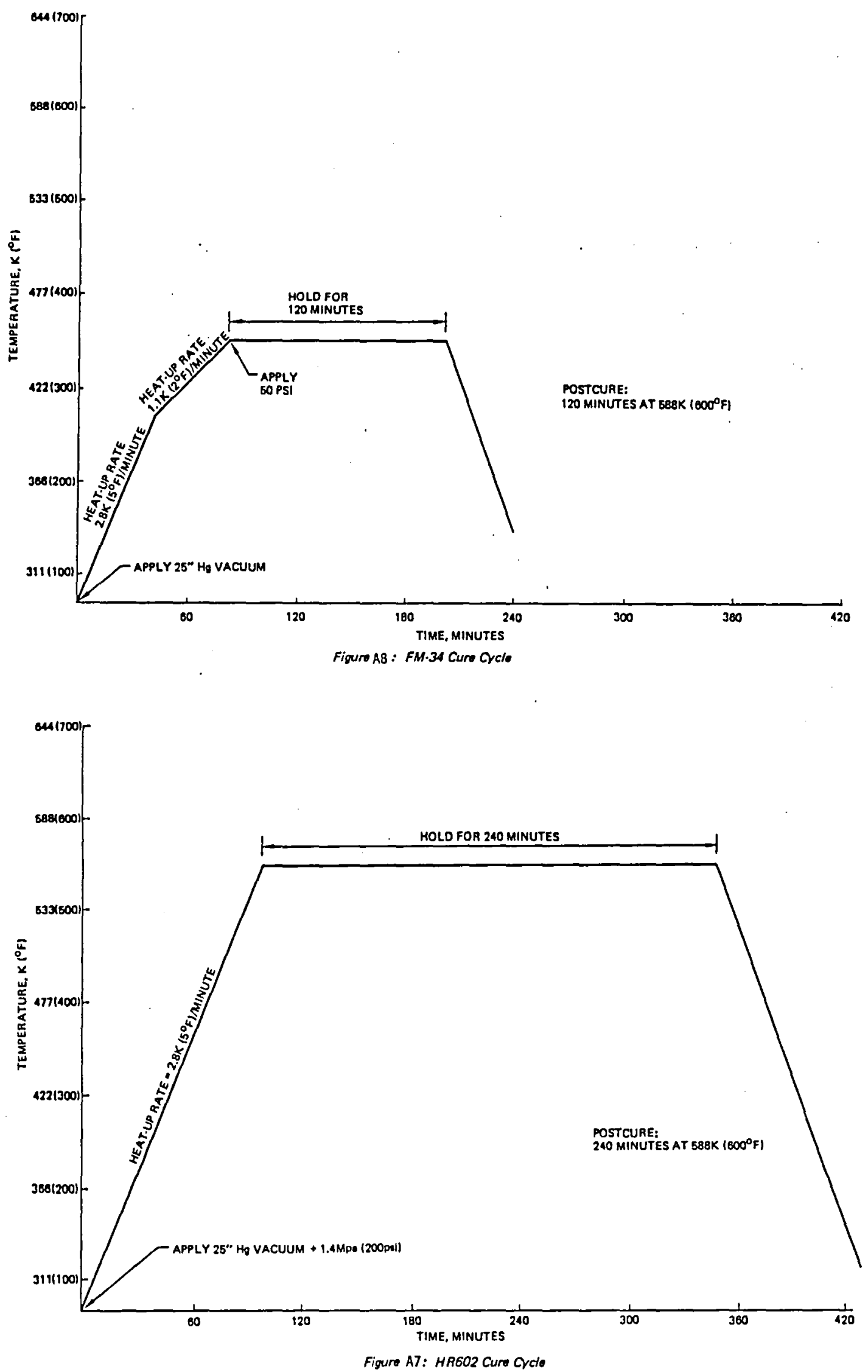
PHASE I INITIAL ADHESIVE SYSTEM EVALUATION, INDIVIDUAL TEST VALUES
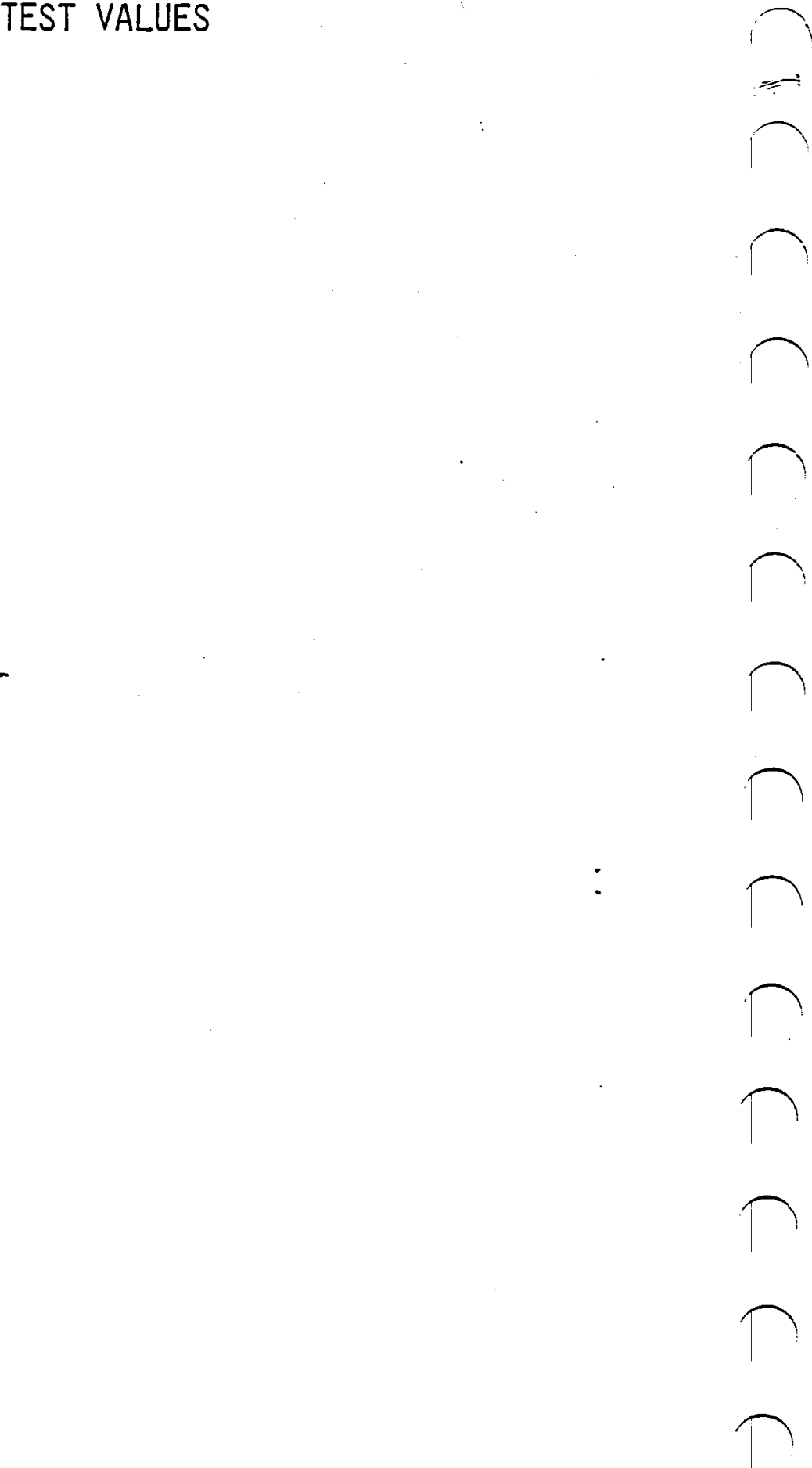
TABLE 2.2-A

PHASE I INITIAL ADHESIVE SYSTEM EVALUATION

LAP SHEAR STRENGTH LARC-13

\begin{tabular}{|c|c|c|c|c|c|}
\hline \multirow{2}{*}{$\begin{array}{l}\text { TITANIUM } \\
\text { SURFACE } \\
\text { PREPARATION } \\
\text { CHROMIC ACID } \\
\text { ANODIZE }\end{array}$} & \multicolumn{2}{|c|}{$\begin{array}{l}\text { ROOM TEMPERATURE } \\
\mathrm{MPa}\end{array}$} & & $\begin{array}{l}505 \mathrm{~K} \\
\mathrm{MPa}\end{array}$ & $\begin{array}{l}\left(450^{\circ} \mathrm{F}\right) \\
(\mathrm{PSI})\end{array}$ \\
\hline & $\begin{array}{ll}\text { 1. } & 20.5 \\
2 . & 17.7 \\
3 . & 20.7 \\
\text { 4. } & 21.8 \\
5 . & 22.1\end{array}$ & $\begin{array}{l}2970 \\
2570 \\
3000 \\
3160 \\
3210\end{array}$ & $\begin{array}{l}1 . \\
2 . \\
3 . \\
4 . \\
5 .\end{array}$ & $\begin{array}{l}16.0 \\
15.4 \\
14.3 \\
15.2 \\
15.0\end{array}$ & $\begin{array}{l}2320 \\
2240 \\
2070 \\
2200 \\
2180\end{array}$ \\
\hline AVERAGE & 20.5 & 2980 & & 15.2 & 2200 \\
\hline PHOSPHORIC ACID & 16.5 & 2400 & 1 . & 11.6 & 1680 \\
\hline ANODIZE & $\begin{array}{ll}2 . & 16.0 \\
3 . & 18.1 \\
4 . & 19.7 \\
5 . & 15.4\end{array}$ & $\begin{array}{l}2320 \\
2620 \\
2860 \\
2240\end{array}$ & $\begin{array}{l}2 . \\
3 . \\
5 .\end{array}$ & $\begin{array}{l}12.4 \\
16.3 \\
13.6 \\
16.0\end{array}$ & $\begin{array}{l}1800 \\
2360 \\
1970 \\
2320\end{array}$ \\
\hline AVERAGE & 17.2 & 2490 & & $\frac{10.0}{14.0}$ & 2030 \\
\hline PASA-JELL 107 & $\begin{array}{l}1 . \\
2 . \\
3 . \\
4 . \\
5 .\end{array}$ & $\begin{array}{l}820 \\
930 \\
780 \\
940 \\
800\end{array}$ & $\begin{array}{l}1 . \\
2 . \\
3 . \\
4 . \\
5 .\end{array}$ & $\begin{array}{l}3.9 \\
3.0 \\
3.7 \\
4.8 \\
3.9\end{array}$ & $\begin{array}{l}560 \\
430 \\
530 \\
690 \\
560\end{array}$ \\
\hline AVERAGE & 5.9 & 850 & & $\frac{.0}{3.9}$ & $\frac{000}{560}$ \\
\hline PHOSPHATE & 10.3 & 1500 & 1 . & 10.2 & 1480 \\
\hline FLUORIDE, BAC 5514 & $\begin{array}{rr} & \\
3 . & 12.3 \\
4 . & 12.2 \\
5 . & 9.7\end{array}$ & $\begin{array}{l}1780 \\
1770 \\
1400 \\
1770\end{array}$ & $\begin{array}{l}2 . \\
3 . \\
4 .\end{array}$ & $\begin{array}{r}9.9 \\
1.4 \\
9.1 \\
10.8\end{array}$ & $\begin{array}{l}1440 \\
1650 \\
1320 \\
1560\end{array}$ \\
\hline AVERAGE & 11.4 & 1650 & & 10.3 & 1490 \\
\hline PHOSPHATE FLUORIDE & 11.3 & 1640 & 1 . & 9.7 & 1400 \\
\hline (PICATINNY MODIFIED) & $\begin{array}{ll}2 . & 11.1 \\
3 . & 10.5 \\
4 . & 10.9 \\
5 . & 11.6\end{array}$ & $\begin{array}{l}1610 \\
1530 \\
1580 \\
1690\end{array}$ & $\begin{array}{l}2 . \\
3 . \\
4 .\end{array}$ & $\begin{array}{r}11.7 \\
8.5 \\
6.6 \\
8.1\end{array}$ & $\begin{array}{r}1700 \\
1240 \\
960 \\
1170\end{array}$ \\
\hline AVERAGE & 11.1 & 1610 & & $\frac{0.1}{8.9}$ & $\frac{110}{1290}$ \\
\hline RAE PROCESS & 16.5 & 2400 & 1 . & 11.9 & 1720 \\
\hline$\left(\mathrm{H}_{2} \mathrm{O}_{2}+\mathrm{NAOH}\right)$ & $\begin{array}{ll}2 . & 16.5 \\
3 . & 15.6 \\
4 . & 13.8 \\
5 . & 16.8\end{array}$ & $\begin{array}{l}2400 \\
2270 \\
2000 \\
2320\end{array}$ & $\begin{array}{l}2 . \\
3 . \\
4 .\end{array}$ & $\begin{array}{l}11.4 \\
15.2 \\
14.6 \\
12.9\end{array}$ & $\begin{array}{l}1650 \\
2200 \\
2120 \\
1870\end{array}$ \\
\hline AVERAGE & 15.7 & 2280 & & 13.2 & 1910 \\
\hline TURCO 5578 & $\begin{array}{ll}. & 14.1 \\
2 . & 15.3 \\
3 . & 14.8 \\
4 . & 15.2 \\
5 . & 13.5 \\
\end{array}$ & $\begin{array}{l}2050 \\
2220 \\
2150 \\
2200 \\
1960 \\
\end{array}$ & $\begin{array}{l}1 . \\
2 . \\
3 . \\
4 . \\
5 .\end{array}$ & $\begin{array}{l}14.1 \\
11.4 \\
13.6 \\
10.8 \\
13.6 \\
\end{array}$ & $\begin{array}{l}2040 \\
1660 \\
1980 \\
1560 \\
1980 \\
\end{array}$ \\
\hline AVERAGE & 14.6 & 2120 & & 12.7 & 1840 \\
\hline PHOSPHATE FLUORIDE & 10.9 & 1580 & T. & 8.1 & 1180 \\
\hline WITH GRIT BLAST & $\begin{array}{rr}\text { 2. } & 9.2 \\
\text { 3. } & 9.7 \\
\text { 4. } & 10.5\end{array}$ & $\begin{array}{l}1340 \\
1400 \\
1520\end{array}$ & $\begin{array}{l}2 . \\
4 .\end{array}$ & $\begin{array}{l}7.9 \\
8.5 \\
8.3\end{array}$ & $\begin{array}{l}1140 \\
1240 \\
1200\end{array}$ \\
\hline AVERAGE & 5. $\quad 10.3$ & $\frac{1490}{1470}$ & 5. & $\frac{7.8}{8.1}$ & $\frac{1130}{1180}$ \\
\hline
\end{tabular}


TABLE 2.2-B

PHASE I INITIAL ADHESIVE SYSTEM EVALUATION

LAP SHEAR STRENGTH LARC-13 MOD 1

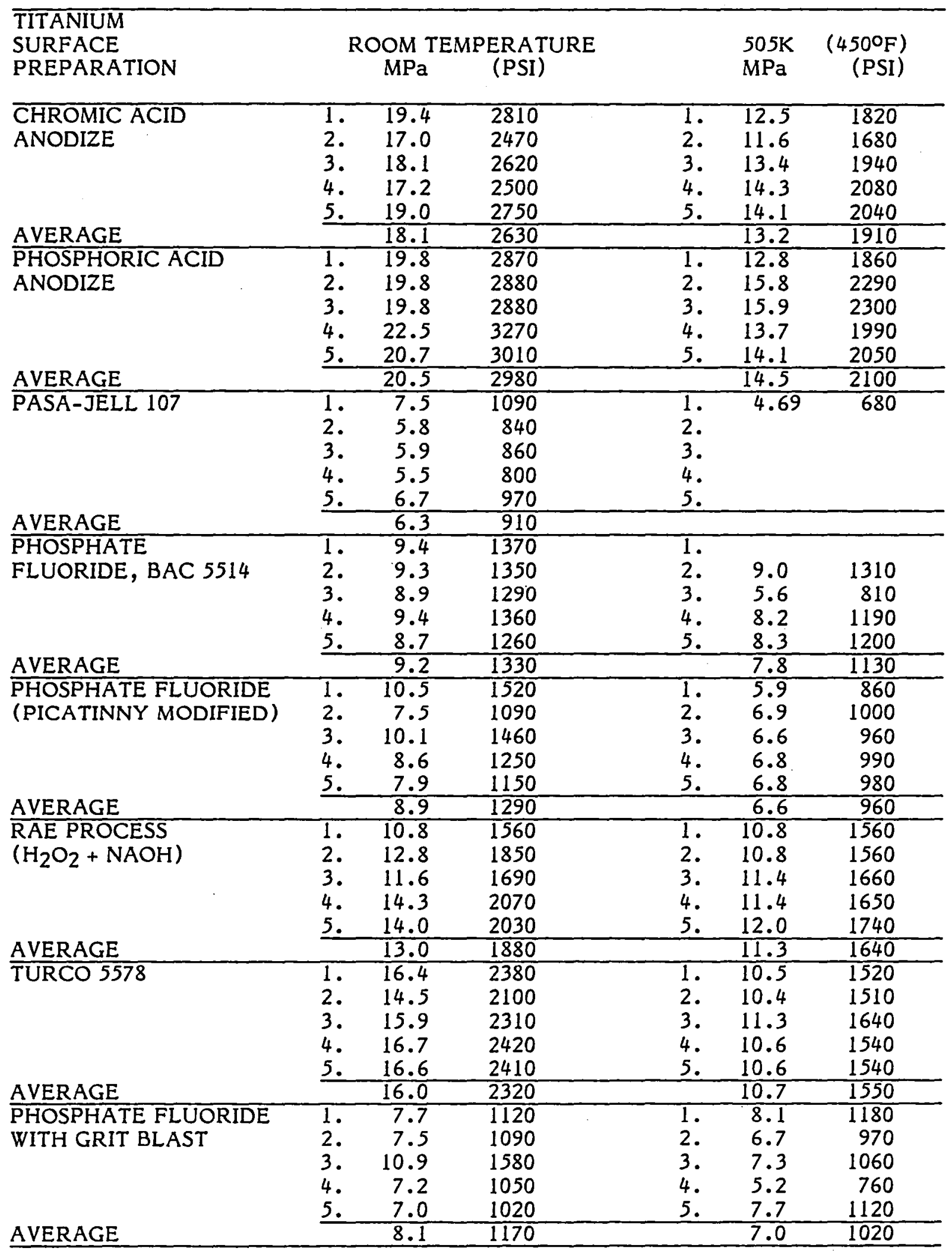


TABLE 2.2-C

PHASE I INITIAL ADHESIVE SYSTEM EVALUATION

LAP SHEAR STRENGTH LARC-13 MOD 2

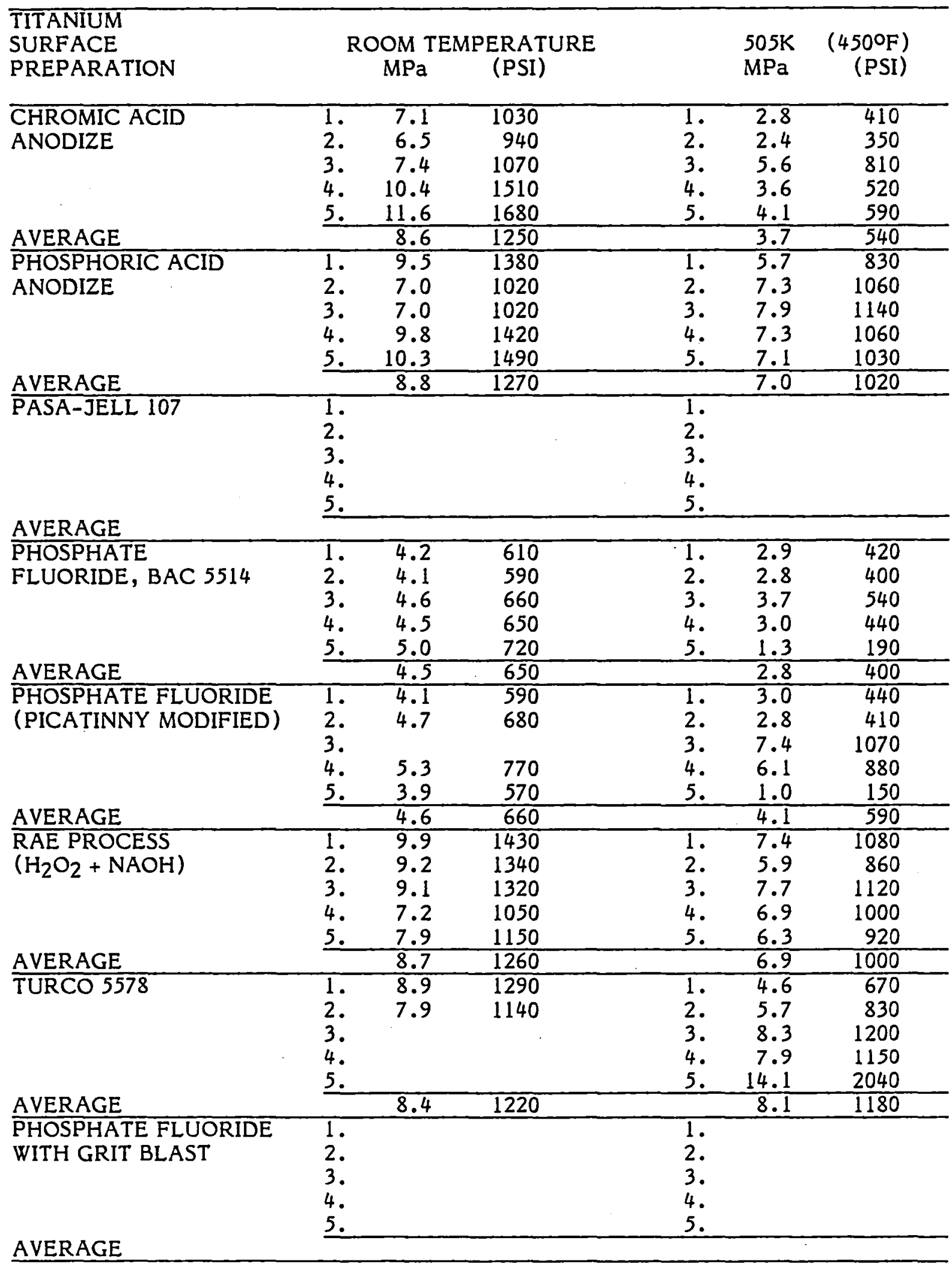


TABLE 2.2-D

PHASE I INITIAL ADHESIVE SYSTEM EVALUATION LAP SHEAR STRENGTH FM 34

\begin{tabular}{|c|c|c|c|c|c|}
\hline $\begin{array}{l}\text { TITANIUM } \\
\text { SURFACE } \\
\text { PREPARATION }\end{array}$ & $\begin{array}{r}\mathrm{ROOM} T \\
\mathrm{MPa}\end{array}$ & $\begin{array}{l}\text { ERATURE } \\
\text { (PSI) }\end{array}$ & & $\begin{array}{l}505 \mathrm{~K} \\
\mathrm{MPa}\end{array}$ & $\begin{array}{r}\left(450^{\circ} \mathrm{F}\right) \\
(\mathrm{PSI})\end{array}$ \\
\hline $\begin{array}{l}\text { CHROMIC ACID } \\
\text { ANODIZE }\end{array}$ & $\begin{array}{ll}1 . & 24.7 \\
2 . & 28.3 \\
3 . & 25.9 \\
4 . & 22.5 \\
5 . & 28.2 \\
\end{array}$ & $\begin{array}{l}3580 \\
4110 \\
3760 \\
3270 \\
4090 \\
\end{array}$ & $\begin{array}{l}1 . \\
2 . \\
3 . \\
4 . \\
5 .\end{array}$ & $\begin{array}{l}13.8 \\
13.5 \\
18.6 \\
14.9 \\
19.0 \\
\end{array}$ & $\begin{array}{l}2000 \\
1960 \\
2700 \\
2160 \\
2760 \\
\end{array}$ \\
\hline AVERAGE & 25.9 & 3760 & & 16.0 & 2320 \\
\hline PHOSPHORIC ACID & 22.1 & 3200 & 1. & 20.5 & 2970 \\
\hline ANODIZE & $\begin{array}{ll}\text { 2. } & 18.5 \\
\text { 3. } & 22.3 \\
\text { 4. } & 18.5 \\
\text { 5. } & 20.7 \\
\end{array}$ & $\begin{array}{l}2680 \\
3240 \\
2690 \\
3000 \\
\end{array}$ & $\begin{array}{l}2 . \\
3 . \\
4 . \\
5 .\end{array}$ & $\begin{array}{l}11.7 \\
18.3 \\
16.8 \\
18.7 \\
\end{array}$ & $\begin{array}{l}1700 \\
2650 \\
2440 \\
2710 \\
\end{array}$ \\
\hline AVERAGE & 20.4 & 2960 & & 17.2 & 2490 \\
\hline$\overline{\text { PASA-JELL } 107}$ & $\begin{array}{ll}\text { 1. } & 19.3 \\
\text { 2. } & 18.5 \\
\text { 3. } & 19.8 \\
\text { 4. } & 19.8 \\
5 . & 19.4 \\
\end{array}$ & $\begin{array}{l}2800 \\
2680 \\
2880 \\
2880 \\
2820 \\
\end{array}$ & $\begin{array}{l}1 . \\
2 . \\
3 . \\
4 . \\
5 .\end{array}$ & $\begin{array}{l}12.3 \\
12.1 \\
12.9 \\
17.5 \\
19.3 \\
\end{array}$ & $\begin{array}{l}1780 \\
1760 \\
1870 \\
2540 \\
2800 \\
\end{array}$ \\
\hline AVERAGE & 19.4 & 2810 & & 14.8 & 2150 \\
\hline$\overline{\text { PHOSPHATE }}$ & 18.9 & 2740 & 1. & 14.8 & 2150 \\
\hline FLUORIDE, BAC 5514 & $\begin{array}{ll}\text { 2. } & 21.2 \\
3 . & 20.6 \\
\text { 4. } & 19.7 \\
5 . & 21.8 \\
\end{array}$ & $\begin{array}{l}3080 \\
2990 \\
2860 \\
3160 \\
\end{array}$ & $\begin{array}{l}2 . \\
3 . \\
4 . \\
5 .\end{array}$ & $\begin{array}{l}19.5 \\
16.8 \\
17.4 \\
19.8 \\
\end{array}$ & $\begin{array}{l}2830 \\
2440 \\
2520 \\
2880 \\
\end{array}$ \\
\hline AVERAGE & 20.5 & 2970 & & 17.6 & 2560 \\
\hline $\begin{array}{l}\text { PHOSPHATE FLUORIDE } \\
\text { (PICATINNY MODIFIED) }\end{array}$ & $\begin{array}{ll}1 . & 20.7 \\
2 . & 20.0 \\
3 . & 20.3 \\
\text { 4. } & 18.5 \\
5 . & 20.7 \\
\end{array}$ & $\begin{array}{l}3000 \\
2900 \\
2940 \\
2690 \\
3010 \\
\end{array}$ & $\begin{array}{l}1 . \\
2 . \\
3 . \\
4 . \\
5 .\end{array}$ & $\begin{array}{l}16.8 \\
18.1 \\
16.3 \\
18.3 \\
13.3 \\
\end{array}$ & $\begin{array}{l}2440 \\
2620 \\
2370 \\
2660 \\
1930 \\
\end{array}$ \\
\hline AVERAGE & 20.1 & 2910 & & 16.5 & 2400 \\
\hline RAE PROCESS & 18.1 & 2620 & 1. & 13.8 & 2000 \\
\hline$\left(\mathrm{H}_{2} \mathrm{O}_{2}+\mathrm{NAOH}\right)$ & $\begin{array}{ll}2 . & 19.7 \\
3 . & 20.7 \\
4 . & 18.5 \\
5 . & 21.2 \\
\end{array}$ & $\begin{array}{l}2860 \\
3000 \\
2680 \\
3080 \\
\end{array}$ & $\begin{array}{l}2 . \\
3 . \\
4 . \\
5 .\end{array}$ & $\begin{array}{l}16.1 \\
18.3 \\
19.0 \\
18.7 \\
\end{array}$ & $\begin{array}{l}2340 \\
2650 \\
2760 \\
2720 \\
\end{array}$ \\
\hline AVERAGE & 19.6 & 2850 & & 17.2 & 2490 \\
\hline TURCO 5578 & $\begin{array}{ll}1 . & 15.4 \\
2 . & 21.2 \\
3 . & 19.2 \\
\text { 4. } & 21.2 \\
5 . & 18.7 \\
\end{array}$ & $\begin{array}{l}2240 \\
3070 \\
2780 \\
3080 \\
2720 \\
\end{array}$ & $\begin{array}{l}1 . \\
2 . \\
3 . \\
4 . \\
5 .\end{array}$ & $\begin{array}{l}17.4 \\
16.0 \\
18.7 \\
16.0 \\
18.4 \\
\end{array}$ & $\begin{array}{l}2520 \\
2320 \\
2710 \\
2320 \\
2670 \\
\end{array}$ \\
\hline AVERAGE & 19.2 & 2780 & & 17.3 & 2510 \\
\hline PHOSPHATE FLUORIDE & 20.3 & 2940 & 1. & 1.4 & 200 \\
\hline WITH GRIT BLAST & $\begin{array}{ll}\text { 2. } & 20.3 \\
\text { 3. } & 21.4 \\
\text { 4. } & 20.5 \\
5 . & 18.7 \\
\end{array}$ & $\begin{array}{l}2940 \\
3100 \\
2970 \\
2720 \\
\end{array}$ & $\begin{array}{l}2 . \\
3 . \\
4 . \\
5 .\end{array}$ & $\begin{array}{l}17.6 \\
15.3 \\
15.0 \\
14.2 \\
\end{array}$ & $\begin{array}{l}2560 \\
2220 \\
2180 \\
2060 \\
\end{array}$ \\
\hline AVERAGE & 20.2 & 2930 & & 12.7 & 1840 \\
\hline
\end{tabular}


TABLE 2.2-E

PHASE I INITIAL ADHESIVE SYSTEM EVALUATION

LAP SHEAR STRENGTH NR150B2

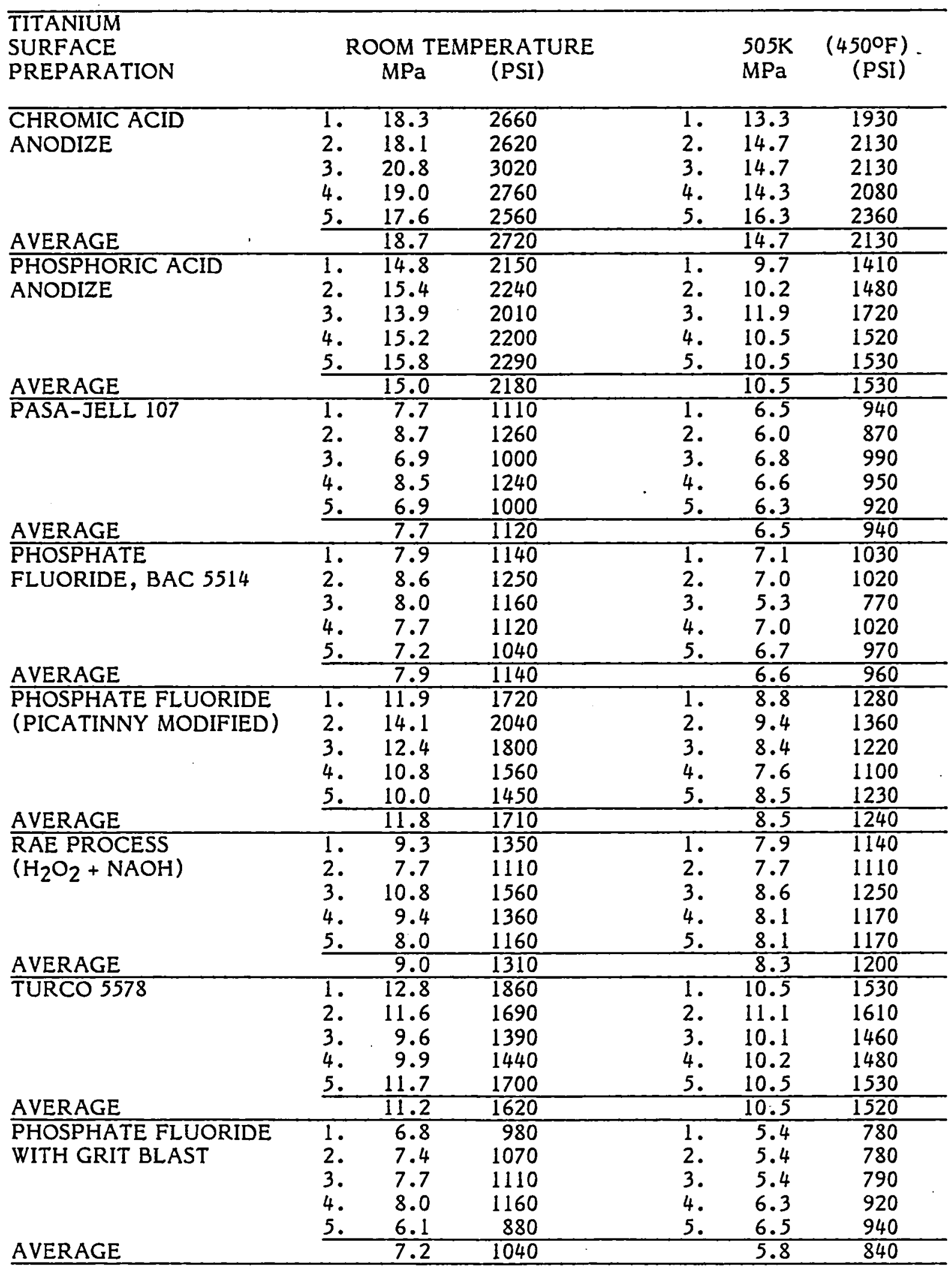


TABLE 2.2-F

PHASE I INITIAL ADHESIVE SYSTEM EVALUATION

LAP SHEAR STRENGTH NR150A2

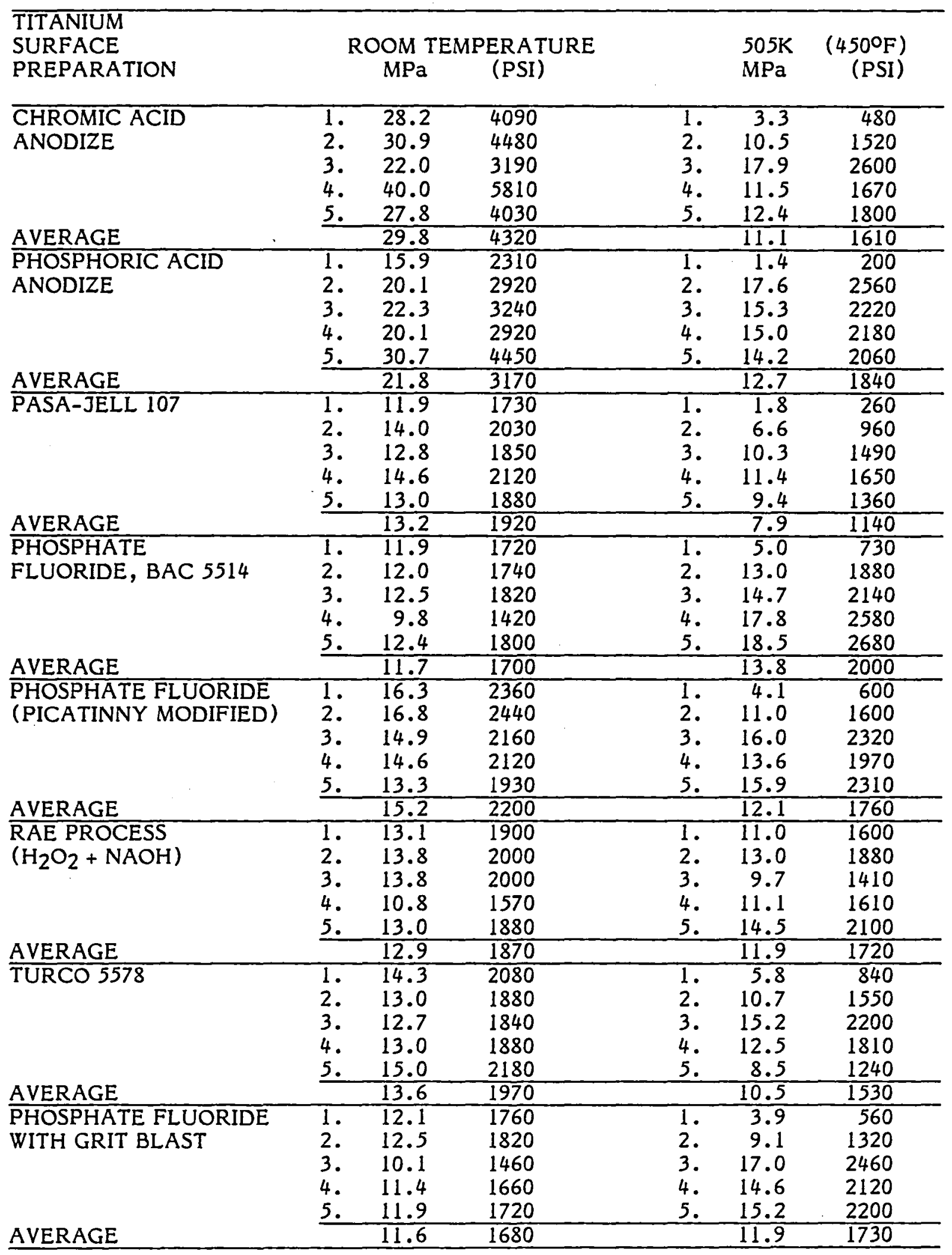


TABLE 2.2-G

PHASE I INITIAL ADHESIVE SYSTEM EVALUATION LAP SHEAR STRENGTH NR056X

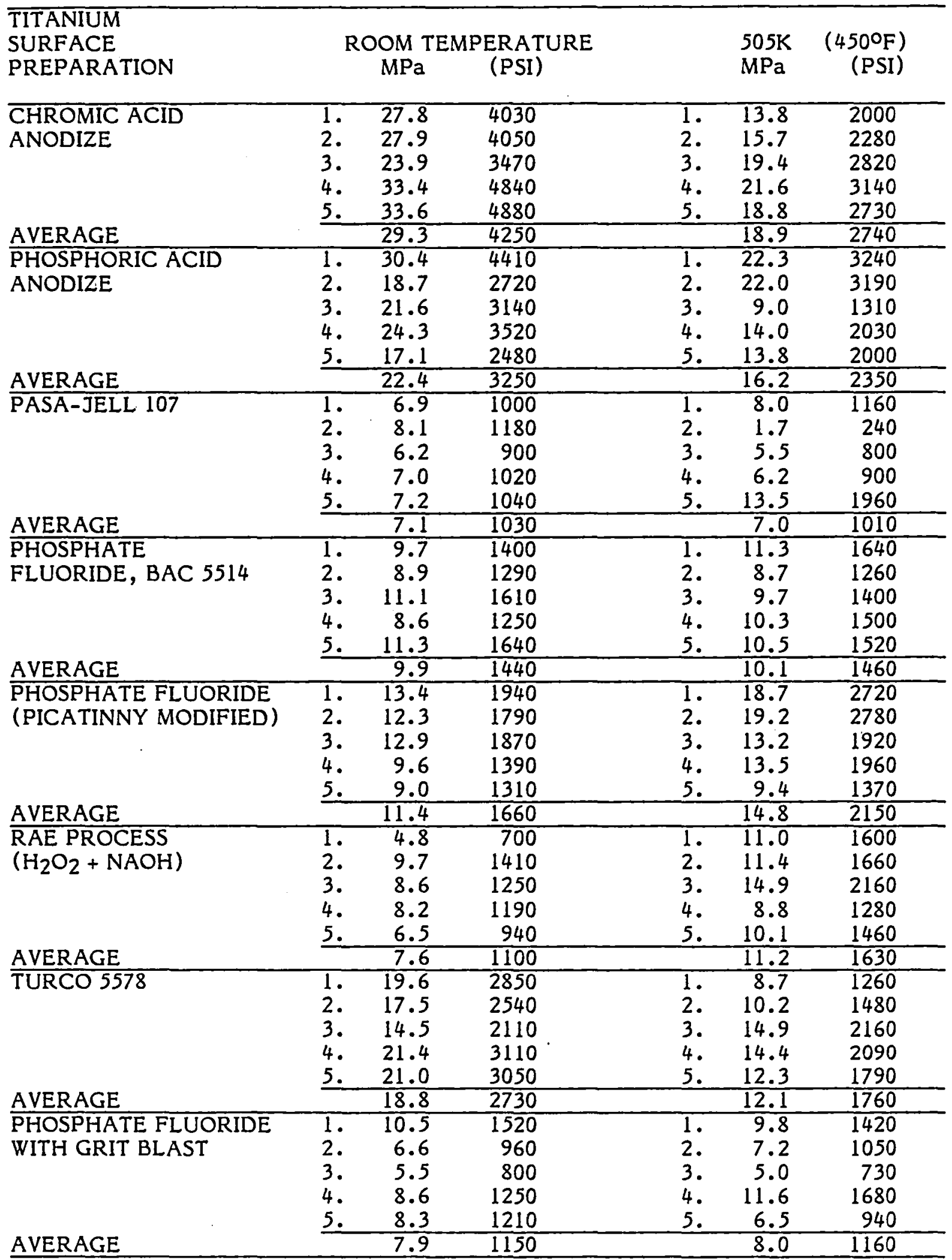


TABLE 2.2-H

PHASE I INITIAL ADHESIVE SYSTEM EVALUATION LAP SHEAR STRENGTH PPQ

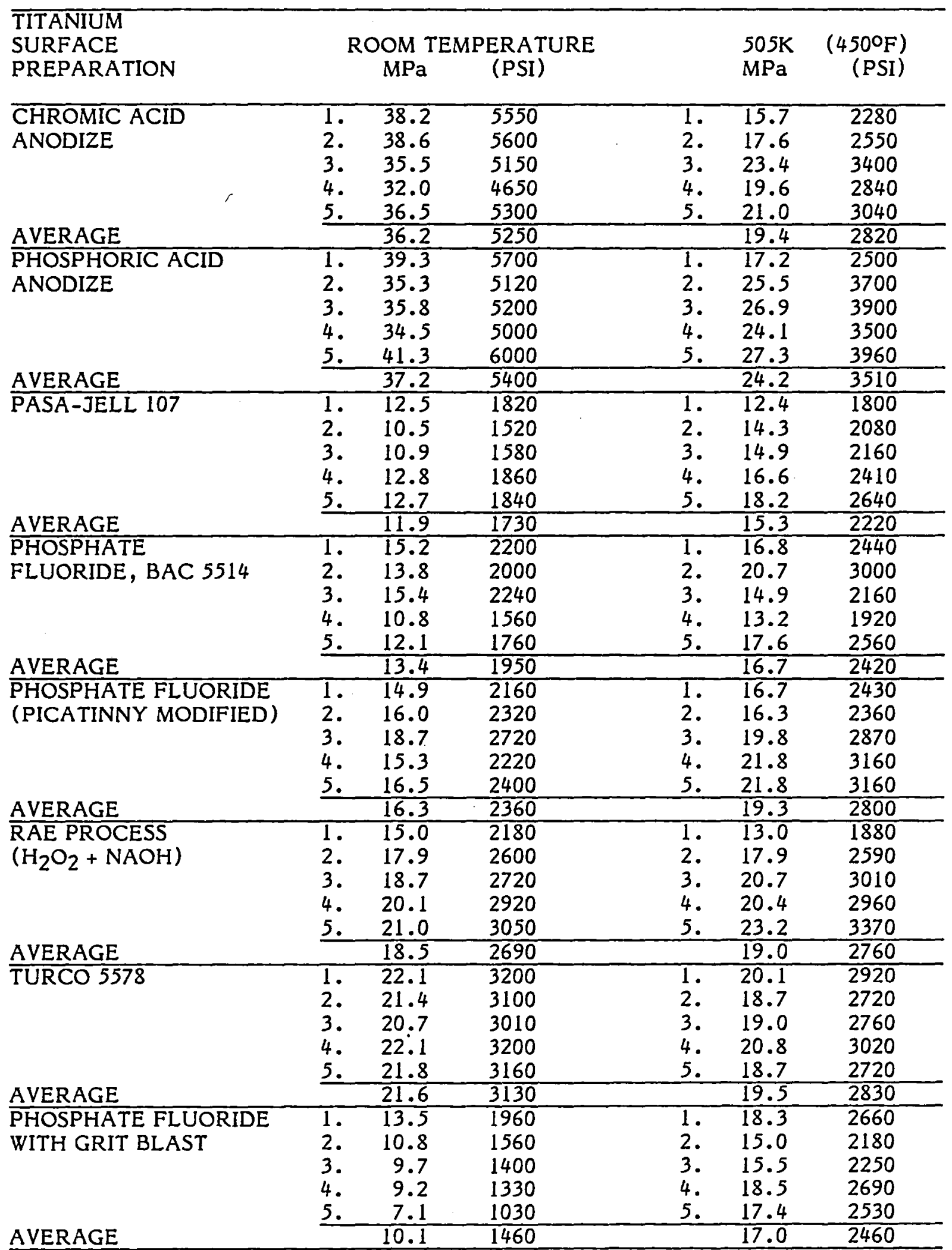


TABLE 2.2-I

PHASE I INITIAL ADHESIVE SYSTEM EVALUATION

LAP SHEAR STRENGTH PPQ MOD 1

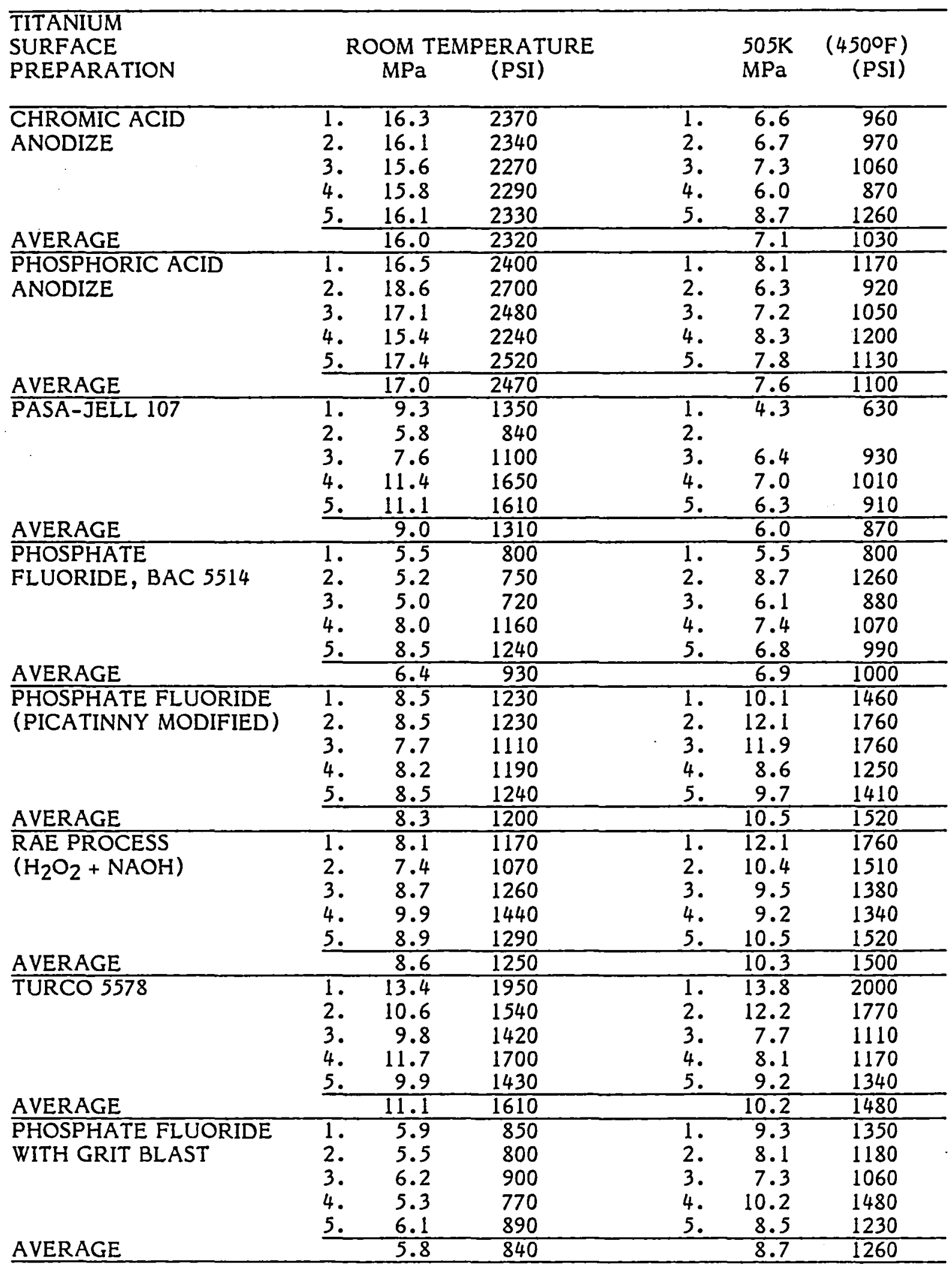


TABLE 2.2-J

PHASE I INITIAL ADHESIVE SYSTEM EVALUATION

LAP SHEAR STRENGTH HR 602

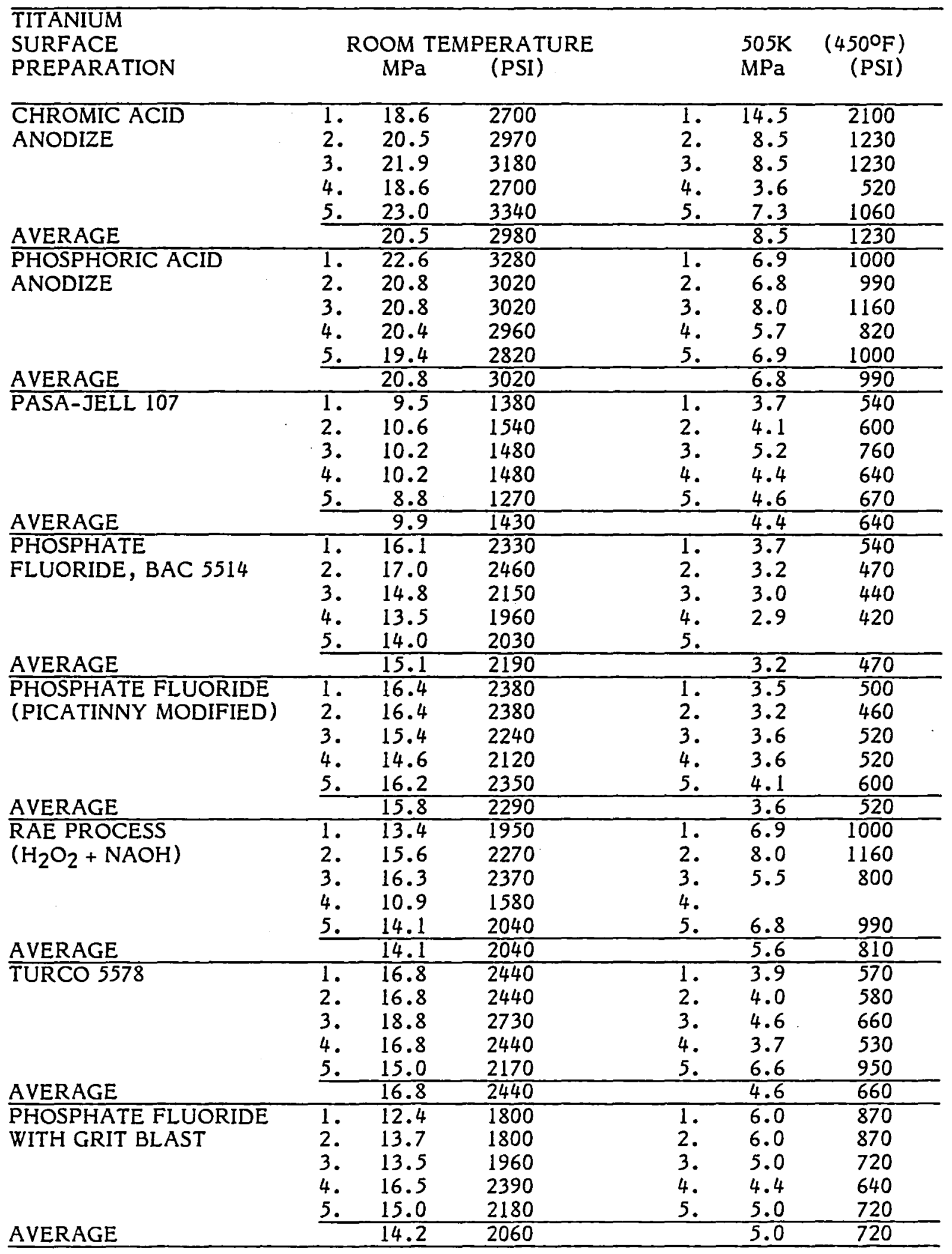




\section{PHASE I PRIMER EVALUATION,} INDIVIDUAL TEST VALUES

$\pi$

T

$T$

$T$

$T$

$T$

$T$

$\pi$

T

$T$

$T$

$T$

T 
TABLE 2.1.3-A

LARC-13 CRACK EXTENSION TEST RESULTS - CRACK LENGTH

\begin{tabular}{|c|c|c|c|c|}
\hline \multirow{2}{*}{$\begin{array}{l}\text { SURFACE } \\
\text { TREATMENT }\end{array}$} & \multirow{2}{*}{ PRIMER } & \multicolumn{3}{|c|}{ EXPOSURE } \\
\hline & & INITIAL & MOISTURE & $505 \mathrm{~K}\left(450^{\circ} \mathrm{F}\right)$ \\
\hline CID & $\begin{array}{l}\mathrm{P} 1 \\
\mathrm{P} 1 \\
\mathrm{P} 2 \\
\mathrm{P} 2\end{array}$ & $\begin{array}{ll}26.2 \mathrm{~mm} & (1.03 \mathrm{in}) \\
24.4 \quad(0.96 \mathrm{in}) \\
23.1 \quad(0.91 \mathrm{in}) \\
25.9 \quad(1.02 \mathrm{in}) \\
\end{array}$ & $\begin{array}{l}1 \\
32.0 \mathrm{~mm}(1.26 \mathrm{in}) \\
28.2 \quad(1.11 \mathrm{in})\end{array}$ & $\begin{array}{c}2 \\
32.0 \mathrm{~mm}(1.26 \mathrm{in}) \\
35.3 \mathrm{~mm}(1.39 \mathrm{in})\end{array}$ \\
\hline $\begin{array}{l}\text { PHOSPHORIC } \\
\text { ACID } \\
\text { ANODIZE }\end{array}$ & $\begin{array}{l}\text { P1 } \\
\text { P1 } \\
\text { P2 } \\
\text { P2 }\end{array}$ & $\begin{array}{ll}28.7 \mathrm{~mm} & (1.13 \mathrm{in}) \\
36.1 & (1.42 \mathrm{in}) \\
27.9 & (1.10 \mathrm{in}) \\
33.8 & (1.33 \mathrm{in}) \\
\end{array}$ & $\begin{array}{l}38.1 \mathrm{~mm}(1.50 \mathrm{in}) \\
32.0 \mathrm{~mm}(1.26 \mathrm{in})\end{array}$ & $\begin{array}{l}40.4 \mathrm{~mm}(1.59 \mathrm{in}) \\
52.7 \quad(1.68 \mathrm{in}) \\
\end{array}$ \\
\hline $\begin{array}{c}\text { PASA-JELL } \\
107\end{array}$ & $\begin{array}{l}\text { P1 } \\
\text { P1 } \\
\text { P2 } \\
\text { P2 }\end{array}$ & $\begin{array}{ll}32.0 \mathrm{~mm} & (1.26 \mathrm{in}) \\
50.5 & (1.99 \mathrm{in}) \\
52.3 & (2.06 \mathrm{in}) \\
52.1 & (2.05 \mathrm{in}) \\
\end{array}$ & $\begin{array}{l}94.7 \mathrm{~mm}(3.73 \mathrm{in}) \\
87.4 \mathrm{~mm}(3.44 \mathrm{in})\end{array}$ & $\begin{array}{l}60.7 \mathrm{~mm}(2.39 \mathrm{in}) \\
60.2 \mathrm{~mm}(2.37 \mathrm{in}) \\
\end{array}$ \\
\hline $\begin{array}{l}\text { PHOSPHATE } \\
\text { FLUORIDE } \\
\text { (BAC 5514) }\end{array}$ & $\begin{array}{l}\mathrm{P} 1 \\
\mathrm{P} 1 \\
\mathrm{P} 2 \\
\mathrm{P} 2\end{array}$ & $\begin{array}{ll}35.3 \mathrm{~mm} & (1.39 \mathrm{in}) \\
39.9 & (1.57 \mathrm{in}) \\
27.4 & (1.08 \mathrm{in}) \\
34.8 & (1.37 \mathrm{in}) \\
\end{array}$ & $\begin{array}{l}51.0 \mathrm{~mm}(2.01 \mathrm{in}) \\
39.1 \mathrm{~mm}(1.54 \mathrm{in})\end{array}$ & $\begin{array}{l}44.4 \mathrm{~mm}(1.75 \mathrm{in}) \\
39.1 \mathrm{~mm}(1.54 \mathrm{in})\end{array}$ \\
\hline $\begin{array}{l}\text { PHOSPHATE } \\
\text { FLUORIDE } \\
\text { (PICATINNY } \\
\text { MDIFIED) } \\
\end{array}$ & $\begin{array}{l}\mathrm{P} 1 \\
\mathrm{P} 1 \\
\mathrm{P} 2 \\
\mathrm{P} 2\end{array}$ & $\begin{array}{ll}37.8 \mathrm{~mm} & (1.49 \mathrm{in}) \\
43.7 & (1.72 \mathrm{in}) \\
27.9 & (1.10 \mathrm{in}) \\
32.2 & (1.27 \mathrm{in}) \\
\end{array}$ & $\begin{array}{l}48.5 \mathrm{~mm}(1.91 \mathrm{in}) \\
33.8 \mathrm{~mm}(1.33 \mathrm{in})\end{array}$ & $\begin{array}{l}49.8 \mathrm{~mm}(1.96 \mathrm{in}) \\
38.6 \mathrm{~mm}(1.52 \mathrm{in}) \\
\end{array}$ \\
\hline $\begin{array}{l}\text { PHOSPHATE } \\
\text { FLUORIDE } \\
\text { WITH GRIT } \\
\text { BLAST } \\
\end{array}$ & $\begin{array}{l}\mathrm{P} 1 \\
\mathrm{P} 1 \\
\mathrm{P} 2 \\
\mathrm{P} 2\end{array}$ & $\begin{array}{ll}27.7 \mathrm{~mm} & (1.09 \mathrm{in}) \\
26.9 & (1.06 \mathrm{in}) \\
24.6 & (0.97 \mathrm{in}) \\
25.6 & (1.01 \mathrm{in}) \\
\end{array}$ & $\begin{array}{l}44.4 \mathrm{~mm}(1.75 \mathrm{in}) \\
42.4 \mathrm{~mm}(1.67 \mathrm{in})\end{array}$ & $\begin{array}{l}35.6 \mathrm{~mm}(1.40 \mathrm{in}) \\
32.0 \mathrm{~mm}(1.26 \mathrm{in}) \\
\end{array}$ \\
\hline TURCO 5578 & $\begin{array}{l}\mathrm{P} 1 \\
\mathrm{P} 1 \\
\mathrm{P} 2 \\
\mathrm{P} 2\end{array}$ & $\begin{array}{ll}44.9 \mathrm{~mm} & (1.77 \mathrm{in}) \\
32.2 & (1.27 \mathrm{in}) \\
27.7 & (1.09 \mathrm{in}) \\
24.9 & (0.98 \mathrm{in}) \\
\end{array}$ & $\begin{array}{l}56.4 \mathrm{~mm}(2.22 \mathrm{in}) \\
47.8 \mathrm{~mm}(1.88 \mathrm{in})\end{array}$ & $\begin{array}{l}40.4 \mathrm{~mm}(1.59 \mathrm{in}) \\
28.4 \mathrm{~mm}(1.12 \mathrm{in}) \\
\end{array}$ \\
\hline $\begin{array}{l}\mathrm{RAE} \\
\mathrm{H}_{2} \mathrm{O}_{2}, \mathrm{NAOH} \\
\text { PROCESS }\end{array}$ & $\begin{array}{l}\mathrm{P} 1 \\
\mathrm{P} 1 \\
\mathrm{P} 2 \\
\mathrm{P} 2\end{array}$ & $\begin{array}{ll}32.8 \mathrm{~mm} & (1.29 \mathrm{in}) \\
40.1 & (1.58 \mathrm{in}) \\
24.9 & (0.98 \mathrm{in}) \\
27.9 & (1.10 \mathrm{in}) \\
\end{array}$ & $\begin{array}{l}50.3 \mathrm{~mm}(1.98 \mathrm{in}) \\
31.2 \mathrm{~mm}(1.23 \mathrm{in})\end{array}$ & $\begin{array}{l}45.5 \mathrm{~mm}(1.79 \mathrm{in}) \\
34.8 \mathrm{~mm}(1.37 \mathrm{in})\end{array}$ \\
\hline
\end{tabular}

$1 \quad 322 \mathrm{~K}\left(120^{\circ} \mathrm{F}\right) / 100 \% \mathrm{R}$. H. Seven Days

$2 \quad 505 \mathrm{~K}\left(450^{\circ} \mathrm{F}\right)$ Five Days 
TABLE 2.1.3-B

NR150 B2 CRACK EXTENSION TEST RESULTS - CRACK LENGTH

\begin{tabular}{|c|c|c|c|c|}
\hline \multirow[b]{2}{*}{$\begin{array}{l}\text { SURFACE } \\
\text { TREATMENT }\end{array}$} & \multirow{2}{*}{ PRIMER } & \multicolumn{3}{|c|}{ EXPOSURE } \\
\hline & & INITIAL & MOISTURE & $505 \mathrm{~K}\left(450^{\circ} \mathrm{F}\right)$ \\
\hline $\begin{array}{l}\text { AIC ACID } \\
\text { ZE }\end{array}$ & $\begin{array}{l}\mathrm{P} 1 \\
\mathrm{P} 1 \\
\mathrm{P} 2 \\
\mathrm{P} 2\end{array}$ & $\begin{array}{ll}21.8 \mathrm{~mm}(0.86 \mathrm{in}) \\
23.9 \quad(0.96 \mathrm{in}) \\
24.9 \quad(0.98 \mathrm{in}) \\
26.9 \quad(1.06 \mathrm{in}) \\
\end{array}$ & $\begin{array}{l}1 \\
31.0 \mathrm{~mm}(1.22 \mathrm{in}) \\
30.0 \mathrm{~mm}(1.18 \mathrm{in})\end{array}$ & $\begin{array}{c}2 \\
27.4 \mathrm{~mm}(1.08 \mathrm{in}) \\
29.5 \mathrm{~mm}(1.16 \mathrm{in})\end{array}$ \\
\hline $\begin{array}{l}\text { PHORIC } \\
\text { IZE }\end{array}$ & $\begin{array}{l}\text { P1 } \\
\text { P1 } \\
\text { P2 } \\
\text { P2 }\end{array}$ & $\begin{array}{ll}21.1 \mathrm{~mm}(0.83 \mathrm{in}) \\
27.4 \quad(1.08 \mathrm{in}) \\
26.2 \quad(1.03 \mathrm{in}) \\
24.4 \quad(0.96 \mathrm{in}) \\
\end{array}$ & $\begin{array}{l}37.6 \mathrm{~mm}(1.48 \mathrm{in}) \\
46.5 \mathrm{~mm}(1.83 \mathrm{in})\end{array}$ & $\begin{array}{l}30.2 \mathrm{~mm}(1.19 \mathrm{in}) \\
31.5 \mathrm{~mm}(1.24 \mathrm{in})\end{array}$ \\
\hline $\begin{array}{c}\text { PASA-JELL } \\
107\end{array}$ & $\begin{array}{l}\mathrm{P} 1 \\
\mathrm{P} 1 \\
\mathrm{P} 2 \\
\mathrm{P} 2\end{array}$ & $\begin{array}{ll}33.5 \mathrm{~mm} & (1.32 \mathrm{in}) \\
39.4 \quad(1.55 \mathrm{in}) \\
27.4 \quad(1.08 \mathrm{in}) \\
31.0 \quad(1.22 \mathrm{in})\end{array}$ & $\begin{array}{l}67.6 \mathrm{~mm}(2.66 \mathrm{in}) \\
85.1 \mathrm{~mm}(3.35 \mathrm{in})\end{array}$ & $\begin{array}{l}46.5 \mathrm{~mm}(1.83 \mathrm{in}) \\
48.8 \mathrm{~mm}(1.92 \mathrm{in}) \\
\end{array}$ \\
\hline $\begin{array}{l}\text { PHOSPHATE } \\
\text { FLUORIDE } \\
\text { (BAC 5514) }\end{array}$ & $\begin{array}{l}\mathrm{P} 1 \\
\mathrm{P} 1 \\
\mathrm{P} 2 \\
\mathrm{P} 2\end{array}$ & $\begin{array}{l}26.7 \mathrm{~mm}(1.05 \mathrm{in}) \\
33.5 \quad(1.32 \mathrm{in}) \\
28.4 \quad(1.12 \mathrm{in}) \\
25.9 \quad(1.02 \mathrm{in})\end{array}$ & $\begin{array}{l}41.4 \mathrm{~mm}(1.63 \mathrm{in}) \\
42.4 \mathrm{~mm}(1.67 \mathrm{in})\end{array}$ & $\begin{array}{l}36.8 \mathrm{~mm}(1.45 \mathrm{in}) \\
32.5 \mathrm{~mm}(1.28 \mathrm{in}) \\
\end{array}$ \\
\hline $\begin{array}{l}\text { PHOSPHATE } \\
\text { FLUORIDE } \\
\text { (PICATINNY } \\
\text { MDIFIED) } \\
\end{array}$ & $\begin{array}{l}\mathrm{P} 1 \\
\mathrm{P} 1 \\
\mathrm{P} 2 \\
\mathrm{P} 2\end{array}$ & $\begin{array}{ll}30.7 \mathrm{~mm} & (1.21 \mathrm{in}) \\
28.7 \quad(1.13 \mathrm{in}) \\
25.6 \quad(1.01 \mathrm{in}) \\
25.1 \quad(0.99 \mathrm{in}) \\
\end{array}$ & $\begin{array}{l}47.5 \mathrm{~mm}(1.87 \mathrm{in}) \\
48.0 \mathrm{~mm}(1.89 \mathrm{in})\end{array}$ & $\begin{array}{l}34.3 \mathrm{~mm}(1.35 \mathrm{in}) \\
30.2 \mathrm{~mm}(1.19 \mathrm{in}) \\
\end{array}$ \\
\hline $\begin{array}{l}\text { PHOSPHATE } \\
\text { FLUORIDE } \\
\text { WITH GRIT } \\
\text { BLAST } \\
\end{array}$ & $\begin{array}{l}\mathrm{P} 1 \\
\mathrm{P} 1 \\
\mathrm{P} 2 \\
\mathrm{P} 2\end{array}$ & $\begin{array}{ll}30.2 \mathrm{~mm} & (1.19 \mathrm{in}) \\
29.7 & (1.17 \mathrm{in}) \\
25.6 \quad(1.01 \mathrm{in}) \\
24.9 \quad(0.98 \mathrm{in}) \\
\end{array}$ & $\begin{array}{l}53.6 \mathrm{~mm}(2.11 \mathrm{in}) \\
44.2 \mathrm{~mm}(1.74 \mathrm{in})\end{array}$ & $\begin{array}{l}35.3 \mathrm{~mm}(1.39 \mathrm{in}) \\
28.9 \mathrm{~mm}(1.14 \mathrm{in}) \\
\end{array}$ \\
\hline TURCO 5578 & $\begin{array}{l}\mathrm{P} 1 \\
\mathrm{P} 1 \\
\mathrm{P} 2 \\
\mathrm{P} 2\end{array}$ & $\begin{array}{ll}50.3 \mathrm{~mm} & (1.87 \mathrm{in}) \\
48.8 & (1.92 \mathrm{in}) \\
31.8 & (1.25 \mathrm{in}) \\
34.3 & (1.35 \mathrm{in}) \\
\end{array}$ & $\begin{array}{l}58.4 \mathrm{~mm}(2.30 \mathrm{in}) \\
43.9 \mathrm{~mm}(1.73 \mathrm{in})\end{array}$ & $\begin{array}{r}55.9 \mathrm{~mm}(2.20 \mathrm{in}) \\
38.9 \mathrm{~mm}(1.53 \mathrm{in}) \\
\end{array}$ \\
\hline $\begin{array}{l}\mathrm{RAE} \\
\mathrm{H}_{2} \mathrm{O}_{2}, \mathrm{NAOH} \\
\text { PROCESS }\end{array}$ & $\begin{array}{l}\mathrm{P} 1 \\
\mathrm{P} 1 \\
\mathrm{P} 2 \\
\mathrm{P} 2\end{array}$ & $\begin{array}{ll}27.4 \mathrm{~mm} & (1.08 \mathrm{in}) \\
29.2 & (1.15 \mathrm{in}) \\
27.2 & (1.07 \mathrm{in}) \\
26.2 & (1.03 \mathrm{in}) \\
\end{array}$ & $\begin{array}{l}42.9 \mathrm{~mm}(1.69 \mathrm{in}) \\
46.6 \mathrm{~mm}(1.83 \mathrm{in})\end{array}$ & $\begin{array}{l}34.8 \mathrm{~mm}(1.37 \mathrm{in}) \\
29.7 \mathrm{~mm}(1.17 \mathrm{in}) \\
\end{array}$ \\
\hline
\end{tabular}

$1322 \mathrm{~K}\left(120^{\circ} \mathrm{F}\right) / 100 \% \mathrm{R}$. H. Seven Days

$2 \quad 505 \mathrm{~K}\left(450^{\circ} \mathrm{F}\right)$ Five Days 
TABLE 2.1.3-C

NR150 A2 CRACK EXTENSION TEST RESULTS - CRACK LENGTH

\begin{tabular}{|c|c|c|c|c|}
\hline \multirow[b]{2}{*}{$\begin{array}{l}\text { SURFACE } \\
\text { TREATMENT }\end{array}$} & \multirow{2}{*}{ PRIMER } & \multicolumn{3}{|c|}{ EXPOSURE } \\
\hline & & INITIAL & MOISTURE & $505 \mathrm{~K}(450 \circ \mathrm{F})$ \\
\hline $\begin{array}{l}\text { CHROMIC ACID } \\
\text { ANODIZE }\end{array}$ & $\begin{array}{l}\mathrm{P} 1 \\
\mathrm{P} 1 \\
\mathrm{P} 2 \\
\mathrm{P} 2\end{array}$ & $\begin{array}{l}43.7 \mathrm{~mm}(1.72 \mathrm{in}) \\
40.6 \quad(1.60 \mathrm{in}) \\
53.8 \quad(2.12 \mathrm{in}) \\
44.2 \quad(1.74 \mathrm{in}) \\
\end{array}$ & $\begin{array}{l}50.8 \mathrm{~mm}(2.00 \mathrm{in}) \\
56.6 \mathrm{~mm}(2.23 \mathrm{in})\end{array}$ & $\begin{array}{c}2 \\
48.0 \mathrm{~mm}(1.89 \mathrm{in}) \\
57.2 \mathrm{~mm}(2.25 \mathrm{in})\end{array}$ \\
\hline $\begin{array}{l}\text { PHOSPHORIC } \\
\text { ACID } \\
\text { ANODIZE }\end{array}$ & $\begin{array}{l}\text { P1 } \\
\text { P1 } \\
\text { P2 } \\
\text { P2 }\end{array}$ & $\begin{array}{ll}42.4 \mathrm{~mm} & (1.67 \mathrm{in}) \\
44.9 & (1.77 \mathrm{in}) \\
62.5 & (1.46 \mathrm{in}) \\
43.5 & (1.91 \mathrm{in}) \\
\end{array}$ & $\begin{array}{l}64.5 \mathrm{~mm}(2.54 \mathrm{in}) \\
79.2 \mathrm{~mm}(3.12 \mathrm{in})\end{array}$ & $\begin{array}{l}61.2 \mathrm{~mm}(2.41 \mathrm{in}) \\
59.7 \mathrm{~mm}(2.35 \mathrm{in})\end{array}$ \\
\hline $\begin{array}{c}\text { PASA-JELL } \\
107\end{array}$ & $\begin{array}{l}\text { P1 } \\
\text { P1 } \\
\text { P2 } \\
\text { P2 }\end{array}$ & $\begin{array}{ll}37.6 \mathrm{~mm} & (1.48 \mathrm{in}) \\
39.9 & (1.57 \mathrm{in}) \\
37.8 & (1.49 \mathrm{in}) \\
48.3 & (1.98 \mathrm{in}) \\
\end{array}$ & $\begin{array}{l}57.9 \mathrm{~mm}(2.28 \mathrm{in}) \\
50.0 \mathrm{~mm}(1.97 \mathrm{in})\end{array}$ & $\begin{array}{l}50.5 \mathrm{~mm}(1.99 \mathrm{in}) \\
61.2 \mathrm{~mm}(2.41 \mathrm{in}) \\
\end{array}$ \\
\hline $\begin{array}{l}\text { PHOSPHATE } \\
\text { FLUORIDE } \\
\text { (BAC 5514) }\end{array}$ & $\begin{array}{l}\text { P1 } \\
\text { P1 } \\
\text { P2 } \\
\text { P2 }\end{array}$ & $\begin{array}{l}31.8 \mathrm{~mm}(1.25 \mathrm{in}) \\
41.4 \quad(1.63 \mathrm{in}) \\
43.9 \quad(1.73 \mathrm{in}) \\
46.0 \quad(1.81 \mathrm{in}) \\
\end{array}$ & $\begin{array}{l}38.1 \mathrm{~mm}(1.50 \mathrm{in}) \\
56.1 \mathrm{~mm}(2.21 \mathrm{in})\end{array}$ & $\begin{array}{l}53.1 \mathrm{~mm}(2.09 \mathrm{in}) \\
50.3 \mathrm{~mm}(2.15 \mathrm{in}) \\
\end{array}$ \\
\hline $\begin{array}{l}\text { PHOSPHATE } \\
\text { FLUORIDE } \\
\text { (PICATINNY } \\
\text { MDIFIED) } \\
\end{array}$ & $\begin{array}{l}\mathrm{P} 1 \\
\mathrm{P} 1 \\
\mathrm{P} 2 \\
\mathrm{P} 2\end{array}$ & $\begin{array}{ll}37.3 \mathrm{~mm} & (1.32 \mathrm{in}) \\
38.6 \quad(1.52 \mathrm{in}) \\
39.6 \quad(1.56 \mathrm{in}) \\
45.0 \quad(1.77 \mathrm{in}) \\
\end{array}$ & $\begin{array}{l}49.5 \mathrm{~mm}(1.95 \mathrm{in}) \\
49.3 \mathrm{~mm}(1.94 \mathrm{in})\end{array}$ & $\begin{array}{l}50.3 \mathrm{~mm}(1.98 \mathrm{in}) \\
56.9 \mathrm{~mm}(2.24 \mathrm{in}) \\
\end{array}$ \\
\hline $\begin{array}{l}\text { PHOSPHATE } \\
\text { FLUORIDE } \\
\text { WITH GRIT } \\
\text { BLAST } \\
\end{array}$ & $\begin{array}{l}\mathrm{P} 1 \\
\mathrm{P} 1 \\
\mathrm{P} 2 \\
\mathrm{P} 2\end{array}$ & $\begin{array}{ll}33.5 \mathrm{~mm} & (1.32 \mathrm{in}) \\
42.7 & (1.68 \mathrm{in}) \\
42.7 \quad(1.68 \mathrm{in}) \\
35.0 \quad(1.38 \mathrm{in}) \\
\end{array}$ & $\begin{array}{l}64.5 \mathrm{~mm}(2.54 \mathrm{in}) \\
59.4 \mathrm{~mm}(2.34 \mathrm{in})\end{array}$ & $\begin{array}{l}59.9 \mathrm{~mm}(2.36 \mathrm{in}) \\
60.4 \mathrm{~mm}(2.38 \mathrm{in})\end{array}$ \\
\hline IURCO 5578 & $\begin{array}{l}\mathrm{P} 1 \\
\mathrm{P} 1 \\
\mathrm{P} 2 \\
\mathrm{P} 2\end{array}$ & $\begin{array}{ll}37.6 \mathrm{~mm} & (1.48 \mathrm{in}) \\
32.2 & (1.27 \mathrm{in}) \\
36.8 & (1.45 \mathrm{in}) \\
30.0 & (1.18 \mathrm{in}) \\
\end{array}$ & $\begin{array}{l}50.1 \mathrm{~mm}(2.05 \mathrm{in}) \\
49.8 \mathrm{~mm}(1.96 \mathrm{in})\end{array}$ & $\begin{array}{l}39.4 \mathrm{~mm}(1.55 \mathrm{in}) \\
38.1 \mathrm{~mm}(1.50 \mathrm{in})\end{array}$ \\
\hline $\begin{array}{l}\mathrm{RAE} \\
\mathrm{H}_{2} \mathrm{O}_{2}, \mathrm{NAOH} \\
\text { PROCESS }\end{array}$ & $\begin{array}{l}\mathrm{P} 1 \\
\mathrm{P} 1 \\
\mathrm{P} 2 \\
\mathrm{P} 2\end{array}$ & $\begin{array}{ll}31.5 \mathrm{~mm} & (1.24 \mathrm{in}) \\
34.5 & (1.36 \mathrm{in}) \\
47.8 & (1.88 \mathrm{in}) \\
49.8 & (1.96 \mathrm{in}) \\
\end{array}$ & $\begin{array}{l}46.5 \mathrm{~mm}(1.83 \mathrm{in}) \\
67.3 \mathrm{~mm}(2.65 \mathrm{in})\end{array}$ & $\begin{array}{l}42.4 \mathrm{~mm}(1.67 \mathrm{in}) \\
63.0 \mathrm{~mm}(2.48 \mathrm{in}) \\
\end{array}$ \\
\hline
\end{tabular}

$1 \quad 322 \mathrm{~K}\left(120^{\circ} \mathrm{F}\right) / 100 \% \mathrm{R} . \mathrm{H}$. Seven Days

$2 \quad 505 \mathrm{~K}\left(450^{\circ} \mathrm{F}\right.$ ) Five Days 
TABLE 2.1.3-D

PPQ CRACK EXTENSION TEST RESULTS - CRACK LENGTH

\begin{tabular}{|c|c|c|c|c|}
\hline \multirow[b]{2}{*}{$\begin{array}{l}\text { SURFACE } \\
\text { TREATMENT }\end{array}$} & \multirow{2}{*}{ PRIMER } & \multicolumn{3}{|c|}{ EXPOSURE } \\
\hline & & INITIAL & MOISTURE & $505 \mathrm{~K}\left(450^{\circ} \mathrm{F}\right)$ \\
\hline $\begin{array}{l}\text { CHROMIC ACID } \\
\text { ANODIZE }\end{array}$ & $\begin{array}{l}\mathrm{P} 1 \\
\mathrm{P} 1 \\
\mathrm{P} 2 \\
\mathrm{P} 2\end{array}$ & $\begin{array}{l}23.9 \mathrm{~mm}(0.94 \mathrm{in}) \\
24.9 \mathrm{~mm}(0.98 \mathrm{in})\end{array}$ & 1 & $\begin{array}{c}2 \\
48.0 \mathrm{~mm}(1.89 \mathrm{in}) \\
26.4 \mathrm{~mm}(1.04 \mathrm{in})\end{array}$ \\
\hline $\begin{array}{l}\text { PHOSPHORIC } \\
\text { ACID } \\
\text { ANODIZE }\end{array}$ & $\begin{array}{l}\mathrm{P} 1 \\
\mathrm{P} 1 \\
\mathrm{P} 2 \\
\mathrm{P} 2\end{array}$ & $\begin{array}{l}23.9 \mathrm{~mm}(0.94 \mathrm{in}) \\
23.4 \mathrm{~mm}(0.92 \mathrm{in})\end{array}$ & & $\begin{array}{l}25.4 \mathrm{~mm}(1.00 \mathrm{in}) \\
26.4 \mathrm{~mm}(1.04 \mathrm{in})\end{array}$ \\
\hline $\begin{array}{c}\text { PASA-JELL } \\
107\end{array}$ & $\begin{array}{l}\mathrm{P} 1 \\
\mathrm{P} 1 \\
\mathrm{P} 2 \\
\mathrm{P} 2\end{array}$ & $\begin{array}{l}40.6 \mathrm{~mm}(1.60 \mathrm{in}) \\
62.7 \mathrm{~mm}(2.47 \mathrm{in})\end{array}$ & $\begin{array}{l}45.7 \mathrm{~mm}(1.80 \mathrm{in}) \\
73.4 \mathrm{~mm}(2.98 \mathrm{in})\end{array}$ & . \\
\hline $\begin{array}{l}\text { PHOSPHATE } \\
\text { FLUORIDE } \\
\text { (BAC 5514) }\end{array}$ & $\begin{array}{l}\mathrm{P} 1 \\
\mathrm{P} 1 \\
\mathrm{P} 2 \\
\mathrm{P} 2\end{array}$ & $\begin{array}{l}28.2 \mathrm{~mm}(1.11 \mathrm{in}) \\
73.1 \mathrm{~mm}(1.24 \mathrm{in})\end{array}$ & $\begin{array}{l}77.8 \mathrm{~mm}(1.32 \mathrm{in}) \\
47.0 \mathrm{~mm}(1.85 \mathrm{in})\end{array}$ & \\
\hline $\begin{array}{l}\text { PHOSPHATE } \\
\text { FLUORIDE } \\
\text { (PICATINNY } \\
\text { MDIFIED) } \\
\end{array}$ & $\begin{array}{l}\mathrm{P} 1 \\
\mathrm{P} 1 \\
\mathrm{P} 2 \\
\mathrm{P} 2\end{array}$ & $\begin{array}{l}31.2 \mathrm{~mm}(1.23 \mathrm{in}) \\
28.7 \mathrm{~mm}(1.13 \mathrm{in})\end{array}$ & $\begin{array}{l}41.1 \mathrm{~mm}(1.62 \mathrm{in}) \\
41.6 \mathrm{~mm}(1.64 \mathrm{in})\end{array}$ & \\
\hline $\begin{array}{l}\text { PHOSPHATE } \\
\text { FLUORIDE } \\
\text { WITH GRIT } \\
\text { BLAST } \\
\end{array}$ & $\begin{array}{l}\mathrm{P} 1 \\
\mathrm{P} 1 \\
\mathrm{P} 2 \\
\mathrm{P} 2 \\
\end{array}$ & $\begin{array}{l}25.1 \mathrm{~mm}(0.99 \mathrm{in}) \\
27.2 \mathrm{~mm}(1.07 \mathrm{in})\end{array}$ & $\begin{array}{l}30.2 \mathrm{~mm}(1.19 \mathrm{in}) \\
50.0 \mathrm{~mm}(1.97 \mathrm{in})\end{array}$ & \\
\hline TURCO 5578 & $\begin{array}{l}\mathrm{P} 1 \\
\mathrm{P} 1 \\
\mathrm{P} 2 \\
\mathrm{P} 2\end{array}$ & $\begin{array}{l}28.9 \mathrm{~mm}(1.14 \mathrm{in}) \\
38.1 \mathrm{~mm}(1.50 \mathrm{in})\end{array}$ & $\begin{array}{l}36.1 \mathrm{~mm}(1.42 \mathrm{in}) \\
52.1 \mathrm{~mm}(2.05 \mathrm{in})\end{array}$ & \\
\hline $\begin{array}{l}\mathrm{RAE} \\
\mathrm{H}_{2} \mathrm{O}_{2}, \mathrm{NAOH} \\
\text { PROCESS }\end{array}$ & $\begin{array}{l}\mathrm{P} 1 \\
\mathrm{P} 1 \\
\mathrm{P} 2 \\
\mathrm{P} 2\end{array}$ & $\begin{array}{l}31.2 \mathrm{~mm}(1.23 \mathrm{in}) \\
42.2 \mathrm{~mm}(1.66 \mathrm{in})\end{array}$ & $\begin{array}{l}42.2 \mathrm{~mm}(1.66 \mathrm{in}) \\
54.6 \mathrm{~mm}(2.15 \mathrm{in})\end{array}$ & \\
\hline
\end{tabular}

$1322 \mathrm{~K}\left(120^{\circ} \mathrm{F}\right) / 100 \% \mathrm{R}$. H. Seven Days

$2 \quad 505 \mathrm{~K}\left(450^{\circ} \mathrm{F}\right)$ Five Days 
TABLE 2.1.3-E

FM-34 CRACK EXTENSION TEST RESULTS - CRACK LENGTH

\begin{tabular}{|c|c|c|c|c|}
\hline \multirow[b]{2}{*}{$\begin{array}{l}\text { SURFACE } \\
\text { TREATMENT }\end{array}$} & \multirow{2}{*}{ PRIMER } & \multicolumn{3}{|c|}{ EXPOSURE } \\
\hline & & INITIAL & MOISTURE & $505 \mathrm{~K}\left(450^{\circ} \mathrm{F}\right)$ \\
\hline IIC ACID & $\begin{array}{l}\mathrm{P} 1 \\
\mathrm{P} 1 \\
\mathrm{P} 2 \\
\mathrm{P} 2\end{array}$ & $\begin{array}{ll}26.9 \mathrm{~mm} & (1.06 \mathrm{in}) \\
28.2 & (1.11 \mathrm{in}) \\
27.2 & (1.07 \mathrm{in}) \\
29.2 & (1.15 \mathrm{in}) \\
\end{array}$ & $\begin{array}{l}1 \\
29.0 \mathrm{~mm}(1.41 \mathrm{in}) \\
35.3 \mathrm{~mm}(1.39 \mathrm{in})\end{array}$ & $\begin{array}{c}2 \\
36.8 \mathrm{~mm}(1.45 \mathrm{in}) \\
34.3 \mathrm{~mm}(1.35 \mathrm{in})\end{array}$ \\
\hline $\begin{array}{l}\text { PHOSPHORIC } \\
\text { ACID } \\
\text { ANODIZE }\end{array}$ & $\begin{array}{l}\mathrm{P} 1 \\
\mathrm{P} 1 \\
\mathrm{P} 2 \\
\mathrm{P} 2\end{array}$ & $\begin{array}{ll}27.9 \mathrm{~mm} & (1.10 \mathrm{in}) \\
30.2 & (1.19 \mathrm{in}) \\
29.5 & (1.16 \mathrm{in}) \\
32.5 & (1.28 \mathrm{in}) \\
\end{array}$ & $\begin{array}{l}35.0 \mathrm{~mm}(1.38 \mathrm{in}) \\
38.4 \mathrm{~mm}(1.37 \mathrm{in})\end{array}$ & $\begin{array}{l}36.8 \mathrm{~mm}(1.45 \mathrm{in}) \\
39.1 \quad(1.54 \mathrm{in}) \\
\end{array}$ \\
\hline $\begin{array}{c}\text { PASA-JELL } \\
107\end{array}$ & $\begin{array}{l}\text { P1 } \\
\text { P1 } \\
\text { P2 } \\
\text { P2 }\end{array}$ & $\begin{array}{lc}28.2 \mathrm{~mm} & (1.11 \mathrm{in}) \\
32.8 & (1.29 \mathrm{in}) \\
31.2 & (1.23 \mathrm{in}) \\
32.2 & (1.27 \mathrm{in}) \\
\end{array}$ & $\begin{array}{l}35.8 \mathrm{~mm}(1.41 \mathrm{in}) \\
51.6 \mathrm{~mm}(2.03 \mathrm{in})\end{array}$ & $\begin{array}{l}40.6 \mathrm{~mm}(1.60 \mathrm{in}) \\
42.2 \mathrm{~mm}(1.66 \mathrm{in})\end{array}$ \\
\hline $\begin{array}{l}\text { PHOSPHATE } \\
\text { FLUORIDE } \\
(\text { BAC 5514) }\end{array}$ & $\begin{array}{l}\text { P1 } \\
\text { P1 } \\
\text { P2 } \\
\text { P2 }\end{array}$ & $\begin{array}{ll}29.7 \mathrm{~mm} & (1.17 \mathrm{in}) \\
28.4 & (1.12 \mathrm{in}) \\
30.0 & (1.18 \mathrm{in}) \\
25.9 & (1.02 \mathrm{in}) \\
\end{array}$ & $\begin{array}{l}39.1 \mathrm{~mm}(1.54 \mathrm{in}) \\
39.4 \mathrm{~mm}(1.55 \mathrm{in})\end{array}$ & $\begin{array}{l}36.3 \mathrm{~mm}(1.43 \mathrm{in}) \\
32.8 \mathrm{~mm}(1.29 \mathrm{in}) \\
\end{array}$ \\
\hline $\begin{array}{l}\text { PHOSPHATE } \\
\text { FLUORIDE } \\
\text { (PICATINNY } \\
\text { MDIFIED) } \\
\end{array}$ & $\begin{array}{l}\mathrm{P} 1 \\
\mathrm{P} 1 \\
\mathrm{P} 2 \\
\mathrm{P} 2\end{array}$ & $\begin{array}{ll}25.6 & (1.01 \mathrm{in}) \\
28.7 & (1.13 \mathrm{in}) \\
31.8 & (1.25 \mathrm{in}) \\
31.5 & (1.24 \mathrm{in}) \\
\end{array}$ & $\begin{array}{l}34.3 \mathrm{~mm}(1.35 \mathrm{in}) \\
39.3 \mathrm{~mm}(1.57 \mathrm{in})\end{array}$ & $\begin{array}{l}36.3 \mathrm{~mm}(1.43 \mathrm{in}) \\
38.6 \mathrm{~mm}(1.52 \mathrm{in}) \\
\end{array}$ \\
\hline $\begin{array}{l}\text { PHOSPHATE } \\
\text { FLUORIDE } \\
\text { WITH GRIT } \\
\text { BLAST } \\
\end{array}$ & $\begin{array}{l}\mathrm{P} 1 \\
\mathrm{P} 1 \\
\mathrm{P} 2 \\
\mathrm{P} 2\end{array}$ & $\begin{array}{ll}25.6 \mathrm{~mm} & (1.01 \mathrm{in}) \\
30.0 \quad(1.18 \mathrm{in}) \\
32.8 \quad(1.29 \mathrm{in}) \\
33.0 \quad(1.30 \mathrm{in}) \\
\end{array}$ & $\begin{array}{l}45.7 \mathrm{~mm}(1.80 \mathrm{in}) \\
55.4 \mathrm{~mm}(2.18 \mathrm{in})\end{array}$ & $\begin{array}{l}36.8 \mathrm{~mm}(1.45 \mathrm{in}) \\
37.8 \mathrm{~mm}(1.49 \mathrm{in})\end{array}$ \\
\hline TURCO 5578 & $\begin{array}{l}\mathrm{P} 1 \\
\mathrm{P} 1 \\
\mathrm{P} 2 \\
\mathrm{P} 2\end{array}$ & $\begin{array}{ll}26.7 \mathrm{~mm} & (1.05 \mathrm{in}) \\
26.9 & (1.06 \mathrm{in}) \\
27.4 & (1.08 \mathrm{in}) \\
30.0 & (1.18 \mathrm{in}) \\
\end{array}$ & $\begin{array}{l}33.3 \mathrm{~mm}(1.31 \mathrm{in}) \\
41.1 \mathrm{~mm}(1.62 \mathrm{in})\end{array}$ & $\begin{array}{l}31.8 \mathrm{~mm}(1.25 \mathrm{in}) \\
35.3 \mathrm{~mm}(1.39 \mathrm{in})\end{array}$ \\
\hline $\begin{array}{l}\mathrm{RAE} \\
\mathrm{H}_{2} \mathrm{O}_{2}, \mathrm{NAOH} \\
\text { PROCESS }\end{array}$ & $\begin{array}{l}\text { P1 } \\
\text { P1 } \\
\text { P2 } \\
\text { P2 }\end{array}$ & $\begin{array}{ll}25.6 \mathrm{~mm} & (1.01 \mathrm{in}) \\
30.5 & (1.20 \mathrm{in}) \\
26.9 & (1.06 \mathrm{in}) \\
32.0 & (1.26 \mathrm{in})\end{array}$ & $\begin{array}{l}35.8 \mathrm{~mm}(1.41 \mathrm{in}) \\
36.8 \mathrm{~mm}(1.45 \mathrm{in})\end{array}$ & $\begin{array}{l}37.1 \mathrm{~mm}(1.46 \mathrm{in}) \\
36.8 \mathrm{~mm}(1.45 \mathrm{in})\end{array}$ \\
\hline
\end{tabular}

$1322 \mathrm{~K}\left(120^{\circ} \mathrm{F}\right) / 100 \%$ R. H. Seven Days

$2505 \mathrm{~K}\left(450^{\circ} \mathrm{F}\right)$ Five Days 
$T$

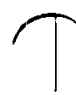

7

$T$

$T$

7

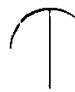

$T$

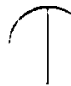

1

$T$

$T$

$T$

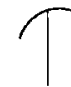

ก 
Table 2.2-1. Phase II Cure Cycle Optimization-Lap-Shear Strength, MPa (psi) Data Summary

\begin{tabular}{|c|c|c|c|c|c|c|}
\hline \multirow[b]{2}{*}{ Adhesive } & \multirow[b]{2}{*}{$\begin{array}{l}\text { Cure } \\
\text { No. }\end{array}$} & \multirow[b]{2}{*}{$\begin{array}{l}\text { Ambient } \\
\text { Test }\end{array}$} & \multirow[b]{2}{*}{$\begin{array}{l}505 K\left(450^{\circ} \mathrm{F}\right) \\
\text { Test }\end{array}$} & \multicolumn{3}{|c|}{$\begin{array}{l}\text { Thermal Aging at } 505 \mathrm{~K}\left(450^{\circ} \mathrm{F}\right) \\
\text { Tested at } 505 \mathrm{~K}\left(450^{\circ} \mathrm{F}\right)\end{array}$} \\
\hline & & & & 500 hours & 1000 hours & 3000 hours \\
\hline $\mathbf{P P Q}$ & $\begin{array}{l}1 \\
2 \\
3\end{array}$ & $\begin{array}{l}30.2(4380) \\
37.0(5370) \\
33.0(4780)\end{array}$ & $\begin{array}{l}16.4 *(2380) * \\
17.4^{*}(2530) * \\
16.1 *(2340) *\end{array}$ & $\begin{array}{l}19.6(2850) \\
24.4(3540) \\
21.4(3100)\end{array}$ & $\begin{array}{l}20.8(3010) \\
24.2(3510) \\
22.9(3320)\end{array}$ & $\begin{array}{ll}18.8 & (2720) \\
24.8 & (3600) \\
22.8 & (3310)\end{array}$ \\
\hline LARC-2 & $\begin{array}{l}1 \\
2 \\
3\end{array}$ & $\begin{array}{l}19.9(2880) \\
19.3(2800) \\
27.6(4000)\end{array}$ & $\begin{aligned} 5.6 * & (810) * \\
10.3 & (1500) \\
14.3 & (2070)\end{aligned}$ & $\begin{array}{l}14.8(2140) \\
13.0(1890) \\
15.6(2260)\end{array}$ & $\begin{array}{l}13.2(1910) \\
17.4(2520) \\
19.2(2790)\end{array}$ & $\begin{array}{ll}15.6 & (2260) \\
16.6 & (2400) \\
19.7 & (2860) \\
. & \end{array}$ \\
\hline NR056X & $\begin{array}{l}1 \\
2 \\
3\end{array}$ & $\begin{array}{l}21.2(3080) \\
20.7(3000) \\
21.5(3120)\end{array}$ & $\begin{array}{ll}11.9 & (1730) \\
10.3 & (1500) \\
11.6 & (1690)\end{array}$ & $\begin{array}{l}13.4(1950) \\
10.8(1570) \\
13.0(1890)\end{array}$ & $\begin{array}{l}12.8(1850) \\
12.4(1800) \\
11.5(1670)\end{array}$ & $\begin{aligned} 9.7 & (1410) \\
10.2 & (1480) \\
12.1 & (1750)\end{aligned}$ \\
\hline
\end{tabular}

- Oven temperature controller not functioning properly-test temperature exceeded $505 \mathrm{~K}\left(450^{\circ} \mathrm{F}\right)$.

Table 2.2-2. Phase Il Cure Cycle Optimization-PPQ-Lap-Shear Strength, MPa (psi)

\begin{tabular}{|c|c|c|c|c|c|}
\hline \multirow[b]{2}{*}{ Cure No. } & \multirow[b]{2}{*}{$\begin{array}{l}\text { Ambient } \\
\text { Test, Initial }\end{array}$} & \multirow[b]{2}{*}{$\begin{array}{l}505 \mathrm{~K}\left(450^{\circ} \mathrm{P}\right) \\
\text { Test, Initial }\end{array}$} & \multicolumn{3}{|c|}{$\begin{array}{l}\text { Thermal Aging at } 505 \mathrm{~K}\left(450^{\circ} \mathrm{F}\right) \\
\text { Tested at } 505 \mathrm{~K}\left(450^{\circ} \mathrm{F}\right)\end{array}$} \\
\hline & & & 500 hours & 1000 hours & 3000 hours \\
\hline Average & $\begin{array}{l}30.5(4420) \\
29.0(4200) \\
31.4(4560) \\
32.1(4660) \\
27.9(4040) \\
\frac{30.2}{30.2}(4380)\end{array}$ & $\begin{array}{l}17.7(2570) \\
13.9(2020) \\
17.1(2480) \\
17.0(2460) \\
16.3(2360) \\
16.4(2380)\end{array}$ & $\begin{array}{l}17.6(2560) \\
21.1(3060) \\
20.6(2980) \\
19.0(2760) \\
19.9(2880) \\
19.6(2850)\end{array}$ & $\begin{array}{l}20.8(3020) \\
17.0(2470) \\
21.5(3130) \\
21.3(3100) \\
23.1(3350) \\
20.7(3010)\end{array}$ & $\begin{array}{cc}18.0 & (2610) \\
19.6 & (2840) \\
-- & -- \\
-- & -- \\
-- & -- \\
18.8 & (2720)\end{array}$ \\
\hline Average & $\begin{array}{l}34.8(5040) \\
37.6(5460) \\
38.3(5560) \\
38.8(5620) \\
35.7(5180) \\
37.0(5370)\end{array}$ & $\begin{array}{l}17.0(2460) \\
16.2(2350) \\
17.6(2550) \\
19.2(2780) \\
17.4(2530) \\
17.4(2530)\end{array}$ & $\begin{array}{l}24.2(3510) \\
24.0(3480) \\
25.2(3660) \\
23.9(3470) \\
24.7(3580) \\
24.4(3540)\end{array}$ & $\begin{array}{l}24.9(3610) \\
23.4(3400) \\
22.6(3280) \\
24.4(3540) \\
25.5(3700) \\
24.2(3510)\end{array}$ & $\begin{array}{cc}23.5 & (3410) \\
26.1 & (3780) \\
-- & -- \\
-- & =- \\
-- & -- \\
24.8 & (3600)\end{array}$ \\
\hline Average & $\begin{array}{l}31.2(4520) \\
33.8(4900) \\
32.6(4720) \\
34.6(5020) \\
32.5(4720) \\
33.0(4780)\end{array}$ & $\begin{array}{l}13.8(2000) \\
17.8(2580) \\
17.0(2470) \\
15.6(2270) \\
16.3(2370) \\
16.1(2340)\end{array}$ & 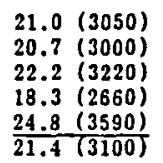 & $\begin{array}{l}21.7(3150) \\
21.6(3140) \\
24.3(3530) \\
23.6(3430) \\
23.1(3360) \\
22.9(3320)\end{array}$ & $\begin{array}{cc}24.1 & (3490) \\
21.6 & (3130) \\
-- & -- \\
-- & -- \\
-- & -- \\
22.8 & (3310)\end{array}$ \\
\hline
\end{tabular}


Table 2.2-3. Phase II Cure Cycle Optimization-LARC-2-Lap-Shear Strength, MPa (psi)

\begin{tabular}{|c|c|c|c|c|c|}
\hline \multirow[b]{2}{*}{ Cure No. } & \multirow[b]{2}{*}{$\begin{array}{l}\text { Ambient } \\
\text { Test, Initlal }\end{array}$} & \multirow[b]{2}{*}{$\begin{array}{l}505 \mathrm{~K}\left(450^{\circ} \mathrm{F}\right) \\
\text { Test, Initial }\end{array}$} & \multicolumn{3}{|c|}{$\begin{array}{l}\text { Thermal Aging at } 505 \mathrm{~K}(4500 \mathrm{~F}) \\
\text { Tested at } 505 \mathrm{~K}\left(450^{\circ} \mathrm{B}\right)\end{array}$} \\
\hline & & & 500 hours & 1000 hours & 3000 hours \\
\hline Average & $\begin{array}{l}19.9(2880) \\
25.2(3660) \\
16.6(2400) \\
18.5(2680) \\
19.3(2800) \\
19.9(2880)\end{array}$ & 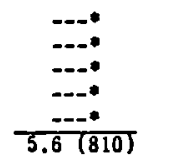 & $\begin{array}{l}13.8(2000) \\
15.0(2180) \\
13.1(1900) \\
15.0(2180) \\
16.8(2440) \\
14.8(2140)\end{array}$ & $\begin{array}{r}13.9(2010) \\
17.2(2490) \\
7.8(1130) \\
\ldots 13.2(1920) \\
13.9(2010) \\
13.2(1910)\end{array}$ & $\begin{array}{cc}21.4 & (3110) \\
9.8 & (1420) \\
-- & -- \\
-- & -- \\
- & -- \\
15.6 & (2260)\end{array}$ \\
\hline Average & $\begin{array}{l}16.8(2440) \\
15.0(2180) \\
19.6(2840) \\
26.2(3800) \\
19.0(2760) \\
19.3(2800)\end{array}$ & $\begin{aligned} & 11.6(1680) \\
& 11.6(1690) \\
& 6.6(950) \\
& 7.7(1120) \\
& 14.1(2040) \\
& 10.3(1500)\end{aligned}$ & $\begin{array}{r}13.0(1890) \\
11.0(1600) \\
9.4(1360) \\
12.3(1780) \\
19.3(2800) \\
13.0(1890)\end{array}$ & $\begin{array}{l}21.5(3120) \\
15.0(2170) \\
23.6(3430) \\
10.8(1560) \\
15.9(2300) \\
17.4(2520)\end{array}$ & $\begin{array}{cc}21.8 & (3160) \\
11.3 & (1640) \\
- & -- \\
-- & -- \\
-- & -- \\
16.6 & (2400)\end{array}$ \\
\hline Average & $\begin{array}{l}24.5(3560) \\
35.3(5120) \\
28.3(4100) \\
19.9(2880) \\
30.1(4360) \\
27.6(4000)\end{array}$ & $\begin{array}{l}14.7(2130) \\
14.9(2160) \\
15.6(2260) \\
11.3(1640) \\
14.8(2150) \\
14.3(2070)\end{array}$ & $\begin{array}{l}18.1(2620) \\
10.0(1450) \\
13.3(1930) \\
22.1(3200) \\
14.4(2090) \\
15.6(2260)\end{array}$ & $\begin{array}{r}18.7(2710) \\
18.5(2680) \\
25.7(3730) \\
23.7(3440) \\
9.9(1440) \\
19.2(2790)\end{array}$ & $\begin{array}{cc}25.2 & (3660) \\
14.1 & (2050) \\
-- & =- \\
-- & -- \\
-- & -- \\
19.7 & (2860)\end{array}$ \\
\hline
\end{tabular}

-Temperature controller not operating properly, tested above 505K (450\% F).

Table 2.2-4. Phase II Cure Cycle Optimization-NR056X-Lap-Shear Strength, MPa (psi)

\begin{tabular}{|c|c|c|c|c|c|}
\hline \multirow[b]{2}{*}{ Cure No. } & \multirow[b]{2}{*}{$\begin{array}{l}\text { Ambient } \\
\text { Test, Initial }\end{array}$} & \multirow[b]{2}{*}{$\begin{array}{l}505 \mathrm{~K}\left(450^{\circ} \mathrm{F}\right) \\
\text { Test, Initial }\end{array}$} & \multicolumn{3}{|c|}{$\begin{array}{l}\text { Thermal Aging at } 505 \mathrm{~K}\left(450^{\circ} \mathrm{F}\right) \\
\text { Tested at } 505 \mathrm{~K}\left(450^{\circ} \mathrm{F}\right)\end{array}$} \\
\hline & & & 500 hours & 1000 hours & 3000 hours \\
\hline Average & $\begin{array}{l}21.1(3060) \\
22.6(3280) \\
25.0(3620) \\
15.7(2280) \\
21.6(3140) \\
21.2(3080)\end{array}$ & $\begin{array}{l}13.0(1880) \\
11.6(1690) \\
11.6(1680) \\
13.4(1940) . \\
10.2(1480) \\
11.9(1730)\end{array}$ & $\begin{array}{l}14.2(2060) \\
13.4(1950) \\
14.5(2100) \\
14.0(2030) \\
11.2(1630) \\
13.4(1950)\end{array}$ & $\begin{array}{l}14.1(2040) \\
12.4(1800) \\
11.2(1620) \\
12.7(1840) \\
13.3(1930) \\
12.8(1850)\end{array}$ & $\begin{array}{r}12.3(1790) \\
10.8(1570) \\
9.2(1330) \\
7.6(1110) \\
8.6(1240) \\
9.7(1410)\end{array}$ \\
\hline Average & $\begin{array}{l}20.0(2900) \\
22.2(3220) \\
17.2(2500) \\
23.0(3340) \\
21.0(3040) \\
20.7(3000)\end{array}$ & $\begin{array}{c}12.0(1740)) \\
10.6(1540) \\
9.4(1370) \\
6.6(960) \\
13.0(1890) \\
10.3(1500)\end{array}$ & $\begin{array}{r}8.4(1220) \\
13.0(1880) \\
8.8(1280) \\
12.8(1860) \\
11.2(1620) \\
10.8(1570)\end{array}$ & $\begin{array}{r}11.0(1600) \\
8.9(1290) \\
12.7(1840) \\
15.7(2280) \\
13.7(1990) \\
12.4(1800)\end{array}$ & $\begin{array}{r}12.4(1800) \\
10.1(1470) \\
10.6(1540) \\
9.2(1330) \\
8.6(1240) \\
10.2(1480)\end{array}$ \\
\hline Average & $\begin{array}{l}21.9(3180) \\
22.6(3280) \\
24.1(3500) \\
18.6(2700) \\
20.1(2920) \\
21.5(3120)\end{array}$ & $\begin{array}{r}12.1(1760) \\
10.3(1500) \\
9.3(1350) \\
13.1(1900) \\
.13 .5(1960) \\
11.6(1690)\end{array}$ & $\begin{array}{r}11.8(1710) \\
9.9(1430) \\
15.0(2170) \\
13.0(1890) \\
15.6(2260) \\
13.0(1890)\end{array}$ & $\begin{array}{r}10.8(1560) \\
11.9(1730) \\
11.1(1610) \\
9.8(1420) \\
13.9(2020) \\
11.5(1670)\end{array}$ & $\begin{array}{r}15.4(2240) \\
13.9(2020) \\
8.6(1240) \\
11.4(1660) \\
10.8(1570) \\
12.1(1750)\end{array}$ \\
\hline
\end{tabular}


PHASE I TITANIUM SURFACE TREATMENT STUDY
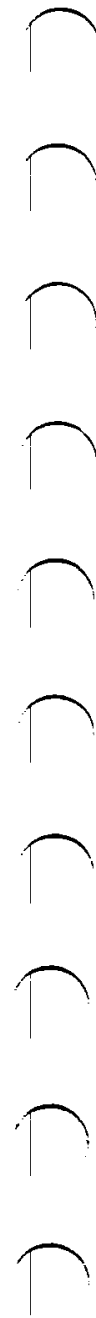
Table 2.3.2-A Summary Values, Titanium Surface Treatment Study-Lap-Shear Strength, MPa (psi)

\begin{tabular}{|c|c|c|c|c|c|c|c|c|}
\hline \multirow[b]{2}{*}{ Adhesive } & \multirow[b]{2}{*}{$\begin{array}{l}\text { Surface } \\
\text { Preparation }\end{array}$} & \multirow[b]{2}{*}{ Initial } & \multicolumn{6}{|c|}{ Exposure Time, hours } \\
\hline & & & 500 & 1000 & 3000 & 5000 & 10,000 & 20,000 \\
\hline \multicolumn{9}{|c|}{$322 \mathrm{~K}\left(120^{\circ} \mathrm{F}\right) / 100 \% \mathrm{RH}$, Ambient Test } \\
\hline LARC-13 & $\begin{array}{l}\text { 10-V CAA } \\
\text { Pasa-Jell }\end{array}$ & $\begin{array}{l}23.9(3470) \\
18.7(2750)\end{array}$ & $\begin{array}{l}21.1(3060) \\
16.9(2490)\end{array}$ & $\begin{array}{l}22.3(3230) \\
17.4(2530)\end{array}$ & $\begin{array}{l}19.3(2890) \\
17.4(2520)\end{array}$ & $\begin{array}{l}20.0(2900) \\
18.0(2610)\end{array}$ & & \\
\hline PPQ & $\begin{array}{l}\text { 10-V CAA } \\
5-V \text { CAA }\end{array}$ & $\begin{array}{l}23.7(3440) \\
16.6(2400)\end{array}$ & $\begin{array}{l}18.7(2710) \\
14.6(2120)\end{array}$ & $\begin{array}{l}19.6(2840) \\
12.8(1850)\end{array}$ & $\begin{array}{l}17.7(2570) \\
12.6(1820)\end{array}$ & $\begin{array}{l}18.2(2640) \\
12.7(1840)\end{array}$ & & \\
\hline NR056X & $\begin{array}{l}\text { 10-V CAA } \\
\text { Pasa-Jell }\end{array}$ & $\begin{array}{l}19.4(2810) \\
15.2(2200)\end{array}$ & $\begin{array}{r}17.0(2460) \\
7.8(1130)\end{array}$ & $\begin{array}{rr}14.1 & (2040) \\
6.5 & (940)\end{array}$ & $\begin{array}{r}16.1(2330) \\
7.3(1060)\end{array}$ & $\begin{aligned} 14.1 & (2040) \\
6.5 & (940)\end{aligned}$ & & \\
\hline \multicolumn{9}{|c|}{ 505K (4500F) Exposure, 505K (4500F) Test } \\
\hline LARC-13 & $\begin{array}{l}\text { 10-V CAA } \\
\text { Pasa-Jell }\end{array}$ & $\begin{array}{l}20.1(2920) \\
18.8(2770)\end{array}$ & $\begin{array}{l}17.5(2450) \\
15.2(2240)\end{array}$ & $\begin{array}{l}13.5(1960) \\
12.1(1760)\end{array}$ & $\begin{array}{l}9.0(1300) \\
9.4(1260)\end{array}$ & $\begin{array}{ll}6.8 & (980) \\
7.5 & (1090)\end{array}$ & $\begin{array}{l}2.4(350) \\
5.1(740)\end{array}$ & THD \\
\hline PPQ & $\begin{array}{l}10-V \text { CAA } \\
5-V \text { CAA }\end{array}$ & $\begin{array}{l}20.2(2930) \\
14.1(2040)\end{array}$ & $\begin{array}{l}18.8(2720) \\
11.2(1630)\end{array}$ & $\begin{array}{l}19.0(2750) \\
11.6(1690)\end{array}$ & $\begin{array}{l}16.8(2440) \\
11.3(1640)\end{array}$ & $\begin{array}{l}15.4(2240) \\
10.3(1500)\end{array}$ & $\begin{array}{l}5.2(750) \\
3.8(550)\end{array}$ & TBD \\
\hline NR056X & $\begin{array}{l}\text { 10-Y CAA } \\
\text { Pasa-Jell }\end{array}$ & $\begin{array}{l}11.1(1610) \\
10.3(1500)\end{array}$ & $\begin{array}{r}11.2(1630) \\
7.8(1130)\end{array}$ & $\begin{array}{r}13.0(1880) \\
7.6(1100)\end{array}$ & $\begin{array}{rr}11.1 & (1610) \\
6.4 & (930)\end{array}$ & $\begin{array}{l}-(1660) \\
=(770)\end{array}$ & $\begin{array}{l}7.9(1140) \\
3.0(430)\end{array}$ & TBD \\
\hline
\end{tabular}

Table 2.3.2-B Summary Values, Titanium Surface Treatment Study-Crack Extension, mm (in.)

\begin{tabular}{|c|c|c|c|c|c|c|c|c|}
\hline \multirow[b]{2}{*}{ Adhesive } & \multirow[b]{2}{*}{$\begin{array}{l}\text { Surface } \\
\text { Preparation }\end{array}$} & \multirow[b]{2}{*}{ Initial } & \multicolumn{6}{|c|}{ Exposure Time, hours } \\
\hline & & & 500 & 1000 & 3000 & 5000 & 10,000 & 20,000 \\
\hline \multicolumn{9}{|c|}{$322 \mathrm{~K}\left(120^{\circ} \mathrm{F}\right) / 100 \%$ RH Exposure } \\
\hline LARC-13 & $\begin{array}{l}\text { 10-V CAA } \\
\text { Pasa-Jell }\end{array}$ & $\begin{array}{l}31.0(1.22) \\
37.6(1.48)\end{array}$ & $\begin{array}{r}4.6(0.18) \\
10.6(0.41)\end{array}$ & $\begin{array}{r}6.3(0.25) \\
13.2(0.52)\end{array}$ & $\begin{array}{r}7.4(0.29) \\
15.2(0.60)\end{array}$ & $\begin{array}{r}7.4(0.29) \\
16.0(0.63)\end{array}$ & $\begin{array}{r}9.4(0.37) \\
18.0(0.71)\end{array}$ & TBD \\
\hline PPQ & $\begin{array}{l}10-V \text { CAA } \\
5-V \text { CAA }\end{array}$ & $\begin{array}{l}26.7(1.05) \\
27.9(1.10)\end{array}$ & $\begin{array}{l}4.8(0.19) \\
4.1(0.16)\end{array}$ & $\begin{array}{l}7.6(0.30) \\
5.1(0.20)\end{array}$ & $\begin{array}{l}9.6(0.38) \\
7.4(0.29)\end{array}$ & $\begin{array}{l}9.9(0.39) \\
8.1(0.32)\end{array}$ & $\begin{array}{r}11.2(0.44) \\
8.6(0.34)\end{array}$ & TBD \\
\hline NR056X & $\begin{array}{l}\text { 10-V CAA } \\
\text { Pasa-Jell }\end{array}$ & $\begin{array}{l}28.2(1.11) \\
34.0(1.34)\end{array}$ & $\begin{array}{l}8.1(0.32) \\
6.6(0.26)\end{array}$ & $\begin{array}{l}9.4(0.37) \\
7.4(0.29)\end{array}$ & $\begin{array}{r}13.2(0.52) \\
9.6(0.38)\end{array}$ & $\begin{array}{l}19.0(0.75) \\
13.0(0.51)\end{array}$ & $\begin{array}{l}20.3(0.80) \\
13.7(0.54)\end{array}$ & TBD \\
\hline \multicolumn{9}{|c|}{ 505K (450\% F) Exposure } \\
\hline LARC-13 & $\begin{array}{l}\text { I0-V CAA } \\
\text { Pasa-Jell }\end{array}$ & $\begin{array}{l}29.2(1.15) \\
39.4(1.55)\end{array}$ & $\begin{array}{l}2.8(0.11) \\
3.0(0.12)\end{array}$ & $\begin{array}{l}3.3(0.13) \\
3.8(0.15)\end{array}$ & $\begin{array}{r}6.1(0.24) \\
13.0(0.51)\end{array}$ & $\begin{array}{l}28.4(1.12) \\
23.9(0.94)\end{array}$ & $\begin{array}{c}53.8(2.12) \\
\text { (Failed) } \\
39.4(1.55) \\
\text { (Failed) }\end{array}$ & TBD \\
\hline PPQ & $\begin{array}{l}\text { 10-V CAA } \\
5-Y \text { CAA }\end{array}$ & $\begin{array}{l}28.4(1.12) \\
26.4(1.04)\end{array}$ & $\begin{array}{l}2.3(0.09) \\
2.5(0.10)\end{array}$ & $\begin{array}{l}2.5(0.10) \\
3.3(0.13)\end{array}$ & $\begin{array}{l}3.3(0.13) \\
3.6(0.14)\end{array}$ & $\begin{array}{l}3.3(0.13) \\
9.4(0.37)\end{array}$ & $\begin{array}{l}42.7(1.68) \\
\text { (Failed) } \\
55.9(2.20) \\
\text { (Failed) }\end{array}$ & TBD \\
\hline NR056X & $\begin{array}{l}\text { 10-V CAA } \\
\text { Pasa-Jell }\end{array}$ & $\begin{array}{l}29.4(1.16) \\
31.2(1.23)\end{array}$ & $\begin{array}{l}3.0(0.12) \\
5.1(0.20)\end{array}$ & $\begin{array}{l}3.8(0.15) \\
6.4(0.25)\end{array}$ & $\begin{array}{l}4.6(0.18) \\
7.1(0.28)\end{array}$ & $\begin{array}{l}5.3(0.21) \\
7.9(0.31)\end{array}$ & $\begin{array}{l}6.1(0.24) \\
7.9(0.31)\end{array}$ & THD \\
\hline
\end{tabular}


Table 2.3.2-C Surface Treatment Study-Lap-Shear Strength, MPa (psi), LARC-13 Exposure to $322 \mathrm{~K}\left(120^{\circ} \mathrm{F}\right) / 95 \% \mathrm{RH}$, Tested at Ambient

\begin{tabular}{|c|c|c|c|c|}
\hline \multirow[b]{2}{*}{ Initial } & \multicolumn{4}{|c|}{ Exposure Time, hours } \\
\hline & 500 & 1000 & 3000 & 5000 \\
\hline \multicolumn{5}{|l|}{ 10-V CAA } \\
\hline $\begin{array}{l}24.3(3520) \\
23.0(3330) \\
23.4(3400) \\
25.9(3750) \\
23.0(3330) \\
23.9(3470) \text { Avg. }\end{array}$ & $\begin{array}{l}22.1(3200) \\
17.1(2480) \\
23.2(3360) \\
20.7(3000) \\
22.6(3280) \\
21.1(3060) \text { Avg. }\end{array}$ & $\begin{array}{l}23.2(3360) \\
19.4(2820) \\
23.7(3440) \\
22.3(3230) \\
22.7(3290) \\
22.3(3230) \text { Avg. }\end{array}$ & $\begin{array}{l}21.4(3110) \\
15.6(2270) \\
20.0(2900) \\
22.1(3210) \\
20.5(2970) \\
19.3(2890) \text { Avg. }\end{array}$ & $\begin{array}{l}21.6(3130) \\
19.4(2810) \\
20.3(2940) \\
18.8(2720) \\
20.0(2900) \\
20.0(2900) \text { Avg. }\end{array}$ \\
\hline \multicolumn{5}{|l|}{ Pasa-Jell } \\
\hline $\begin{array}{l}15.9(2320) \\
17.8(2600) \\
17.9(2630) \\
21.0(3080) \\
21.3(3130) \\
18.7(2750) \text { Avg. }\end{array}$ & $\begin{array}{l}18.7(2750) \\
18.0(2640) \\
14.3(2100) \\
18.6(2740) \\
15.0(2200) \\
\frac{16.9(2490) \text { Avg. }}{16.9}\end{array}$ & $\begin{array}{l}16.9(2450) \\
20.6(2980) \\
15.4(2230) \\
17.2(2500) \\
16.5(2390) \\
17.4(2530) \text { Avg. }\end{array}$ & $\begin{array}{l}18.6(2690) \\
18.0(2610) \\
18.3(2650) \\
15.2(2210) \\
16.8(2440) \\
\frac{17.4(2520)}{17 v g .}\end{array}$ & $\begin{array}{l}16.4(2380) \\
20.3(2950) \\
17.2(2490) \\
19.2(2790) \\
16.7(2420) \\
18.0(2610) \text { Avg. }\end{array}$ \\
\hline
\end{tabular}

Table 2.3.2-D Titanium Surface Treatment Study-Lap-Shear Strength, MPa (psi), LARC-13 Exposure to $505 \mathrm{~K}\left(450^{\circ} \mathrm{F}\right)$ Thermal Aging, Tested at $505 \mathrm{~K}\left(450^{\circ} \mathrm{F}\right)$

\begin{tabular}{|c|c|c|c|c|c|c|}
\hline \multirow[b]{2}{*}{ Initial } & \multicolumn{5}{|c|}{ Exposure Time, hours } & \multirow[b]{2}{*}{20,000} \\
\hline & 500 & 1000 & 3000 & 5000 & 10,000 & \\
\hline \multicolumn{7}{|l|}{ 10-V CAA } \\
\hline $\begin{array}{l}17.7(2570) \\
19.3(2800) \\
21.0(3050) \\
21.6(3130) \\
21.0(3050) \\
20.1(2920) \text { Avg. }\end{array}$ & $\begin{array}{l}18.6(2690) \\
19.3(2800) \\
13.2(1920) \\
16.0(2320) \\
17.5(2540) \\
17.5(2450) \text { Avg. }\end{array}$ & $\begin{array}{l}12.4(1800) \\
13.4(1950) \\
14.2(2060) \\
12.9(1870) \\
14.5(2100) \\
\frac{13.5(1960)}{13.5} \text { Avg. }\end{array}$ & $\begin{array}{r}8.6(1250) \\
8.4(1220) \\
10.1(1470) \\
8.3(1200) \\
9.4(1360) \\
9.0(1300) \text { Avg. }\end{array}$ & $\begin{array}{l}5.4(790) \\
8.1(1180) \\
7.8(1130) \\
5.6(820) \\
6.7(970) \\
\frac{6.8(980)}{\text { Avg. }}\end{array}$ & $\begin{array}{l}3.8(550) \\
0.3(40) \\
1.8(260) \\
2.1(300) \\
4.1(600) \\
2.4(350) \text { Avg. }\end{array}$ & TBD \\
\hline \multicolumn{7}{|l|}{ Pasa-Jell } \\
\hline $\begin{array}{l}17.8(2620) \\
18.0(2650) \\
18.0(2640) \\
20.2(2970) \\
20.3(2990) \\
18.8(2770) \text { Avg. }\end{array}$ & $\begin{array}{l}12.9(1900) \\
15.0(2200) \\
16.5(2420) \\
15.5(2280) \\
16.3(2400) \\
15.2(2240) \text { Avg. }\end{array}$ & $\begin{array}{l}11.0(1600) \\
12.2(1770) \\
12.3(1780) \\
12.6(1820) \\
12.6(1830) \\
\frac{12.1(1760)}{\text { Avg. }}\end{array}$ & $\begin{array}{l}8.3(1200) \\
8.5(1230) \\
9.4(1360) \\
8.6(1240) \\
8.9(1290) \\
9.4(1260) \text { Avg. }\end{array}$ & $\begin{array}{l}6.2(900) \\
6.8(990) \\
8.3(1200) \\
8.0(1160) \\
8.3(1200) \\
7.5(1090) \text { Avg. }\end{array}$ & $\begin{array}{l}4.3(620) \\
3.6(530) \\
4.8(700) \\
7.2(1050) \\
5.6(810) \\
5.1(740) \text { Avg. }\end{array}$ & TBD \\
\hline
\end{tabular}


Table 2.3.2-E Titanium Surface Treatment Study-Crack Extension, mm (in.) LAKC-13 Exposure to $322 \mathrm{~K}(1200 \mathrm{~F}) / 95 \% \mathrm{RH}$

\begin{tabular}{|c|c|c|c|c|c|c|c|c|c|}
\hline \multirow[b]{2}{*}{ Initial } & \multicolumn{9}{|c|}{ Exposure Time, hours } \\
\hline & 500 & & 1000 & & 3000 & 5000 & & 10,000 & 20,000 \\
\hline \multicolumn{10}{|l|}{ 10-V CAA } \\
\hline $\begin{array}{l}30.7(1.21) \\
31.5(1.24) \\
30.7(1.21) \\
30.7(1.21) \\
31.0(1.22) \text { Avg. }\end{array}$ & $\begin{array}{l}5.1(0.20) \\
4.3(0.17) \\
5.1(0.20) \\
4.1(0.16) \\
4.6(0.18)\end{array}$ & Avg. & $\begin{array}{l}6.8(0.27) \\
5.6(0.22) \\
7.4(0.29) \\
5.1(0.20) \\
6.3(0.25)\end{array}$ & Avg. & $\begin{array}{l}8.1(0.32) \\
6.8(0.27) \\
8.1(0.32) \\
5.8(0.23) \\
7.4(0.29) \text { Avg. }\end{array}$ & $\begin{array}{l}8.1(0.32) \\
6.8(0.27) \\
8.1(0.32) \\
5.8(0.23) \\
7.4(0.29)\end{array}$ & Avg. & $\begin{array}{r}9.4(0.37) \\
7.9(0.31) \\
10.9(0.43) \\
11.4(0.45) \\
9.4(0.37)\end{array}$ & Avg. \\
\hline \multicolumn{10}{|l|}{ Pasa-Jell } \\
\hline $\begin{array}{l}37.6(1.48) \\
32.8(1.29) \\
43.2(1.70) \\
36.3(1.43) \\
37.6(1.48) \text { Avg. }\end{array}$ & $\begin{array}{r}6.6(0.26) \\
11.4(0.45) \\
11.9(0.47) \\
12.4(0.49) \\
10.6(0.41)\end{array}$ & Avg. & $\begin{array}{r}9.6(0.38) \\
14.7(0.58) \\
15.2(0.60) \\
13.2(0.52) \\
13.2(0.52)\end{array}$ & Avg. & $\begin{array}{l}12.2(0.48) \\
16.8(0.66) \\
17.8(0.70) \\
13.4(0.55) \\
15.2(0.60) \text { Avg. }\end{array}$ & $\begin{array}{l}13.5(0.53) \\
18.0(0.71) \\
17.8(0.70) \\
15.0(0.59) \\
16.0(0.63)\end{array}$ & Avg. & $\begin{array}{l}16.2(0.64) \\
19.3(0.76) \\
19.3(0.76) \\
17.3(0.68) \\
18.0(0.71)\end{array}$ & Avg. \\
\hline
\end{tabular}

Table 2.3.2-F Titanium Surface Treatment Study-Crack Extension, mm (in.) LARC-13 Exposure to $505 \mathrm{~K}$ (450\%)

\begin{tabular}{|c|c|c|c|c|c|c|c|}
\hline \multirow[b]{2}{*}{ Initial } & \multicolumn{7}{|c|}{ Exposure Time, hours } \\
\hline & 500 & 1000 & & 3000 & 5000 & 10,000 & 20,000 \\
\hline \multicolumn{8}{|l|}{ 10-V CAA } \\
\hline $\begin{array}{r}29.2(1.15) \\
29.0(1.14) \\
3,3(0.13) \\
30.0(1.18) \\
29.2(1.15) \text { Avg. }\end{array}$ & $\begin{array}{l}3.8(0.15) \\
2.8(0.11) \\
4.1(0.16) \\
2.0(0.08) \\
2.8(0.11) \text { Avg. }\end{array}$ & $\begin{array}{r}3.8(0.15) \\
2.8(0.11) \\
30.2(1.19) \\
3.3(0.13) \\
3.3(0.13)\end{array}$ & Avg. & $\begin{array}{c}6.6(0.26) \\
10.7(0.42) \\
54.6(2.12) \text { Failed } \\
\frac{3.3(0.13)}{6.1(0.24)} \text { Avg. }\end{array}$ & $\begin{array}{l}24.6(0.97) \\
28.4(1.12) \\
\frac{30.0(1.18)}{28.4(1.12)}\end{array}$ & $\begin{array}{r}53.8(2.12) \\
53.8(2.12) \\
54.6(2.15) \\
53.1(2.09) \\
\text { Avg. } 53.8(2.12) \\
-\end{array}$ & $\begin{array}{l}\text { Failed } \\
\text { Failed } \\
\text { Failed } \\
\text { Failed } \\
\text { Avg. } \\
\text { Failed }\end{array}$ \\
\hline \multicolumn{8}{|l|}{ Pasa-Jell } \\
\hline $\begin{array}{l}33.5(1.32) \\
35.8(1.41) \\
42.7(1.68) \\
45.2(1.78) \\
39.4(1.55) \text { Avg. }\end{array}$ & $\begin{array}{l}2.3(0.09) \\
4.1(0.16) \\
3.0(0.12) \\
2.3(0.09) \\
3.0(0.12) \text { Avg. }\end{array}$ & $\begin{array}{l}3.0(0.12) \\
5.6(0.22) \\
3.0(0.12) \\
3.0(0.12) \\
3.8(0.15)\end{array}$ & Avg. & $\begin{array}{r}12.4(0.49) \\
29.5(1.16) \\
5.1(0.20) \\
\frac{4.8(0.19)}{13.0(0.51)} \mathrm{AVg} .\end{array}$ & $\begin{array}{l}29.7(1.17) \\
31.0(1.22) \\
18.3(0.72) \\
16.0(0.63) \\
23.9(0.94)\end{array}$ & $\begin{array}{r}49.8(1.96) \\
47.5(1.87) \\
39.6(1.56) \\
20.6(0.81) \\
\text { Avg. } 39.4(1.55)\end{array}$ & $\begin{array}{l}\text { Failed } \\
\text { Failed } \\
\text { Failed } \\
\text { Avg. }\end{array}$ \\
\hline
\end{tabular}


Table 2.3.2-G Titanium Surface Treatment Study-Lap-Shear Strength, MPa (psi), NR056X Exposure to $322 \mathrm{~K}\left(120^{\circ} \mathrm{F}\right) / 95 \% \mathrm{RH}$, Tested at Ambient

\begin{tabular}{|c|c|c|c|c|c|c|}
\hline \multirow[b]{2}{*}{ Initial } & \multicolumn{6}{|c|}{ Exposure Time, hours } \\
\hline & 500 & 1000 & & 3000 & & 5000 \\
\hline \multicolumn{7}{|l|}{ 10-V CAA } \\
\hline $\begin{array}{l}22.3(3240) \\
19.6(2840) \\
23.4(3390) \\
13.7(1990) \\
17.9(2600) \\
19.4(2810) \text { Avg. }\end{array}$ & $\begin{array}{l}22.9(3320) \\
15.0(2180) \\
15.0(2180) \\
14.6(2110) \\
17.2(2490) \\
17.0(2460) \text { Avg. }\end{array}$ & $\begin{array}{l}13.8(2000) \\
16.0(2320) \\
12.4(1800) \\
13.1(1900) \\
15.3(2220) \\
14.1(2040)\end{array}$ & Avg. & $\begin{array}{r}19.7(2860) \\
20.9(3030) \\
9.5(1380) \\
16.1(2340) \\
14.1(2040) \\
16.1(2330)\end{array}$ & Avg. & $\begin{array}{r}18.8(2730) \\
18.8(2720) \\
9.6(1400) \\
9.2(1340) \\
13.7(1990) \\
14.1(2040) \text { Avg. }\end{array}$ \\
\hline \multicolumn{7}{|l|}{ Pasa-Jell } \\
\hline $\begin{array}{l}15.1(2190) \\
11.5(1670) \\
14.8(2140) \\
22.3(3240) \\
12.2(1770) \\
15.2(2200) \text { Avg. }\end{array}$ & $\begin{array}{l}7.2(1050) \\
5.5(800) \\
8.2(1190) \\
9.1(1320) \\
9.1(1320) \\
\frac{7.8(1130) \text { Avg. }}{7.8}\end{array}$ & $\begin{array}{ll}6.8 & (980) \\
6.4 & (930) \\
6.7 & (970) \\
5.9 & (860) \\
6.4 & (930) \\
6.5 & (940)\end{array}$ & Avg. & $\begin{array}{l}9.6(1400) \\
7.4(1070) \\
8.8(1280) \\
5.1(740) \\
5.4(790) \\
7.3(1060)\end{array}$ & Avg. & $\begin{array}{l}8.8(1280) \\
3.0(440) \\
8.2(1190) \\
7.4(1070) \\
\frac{4.8(700)}{6.5(940)} \text { Avg. }\end{array}$ \\
\hline
\end{tabular}

Table 2.3.2-H Titanium Surface Treatment Study-Lap-Shear Strength, MPa (psi), NR056X Exposure to $505 \mathrm{~K}\left(450^{\circ} \mathrm{F}\right)$, Tested at $505 \mathrm{~K}\left(450^{\circ} \mathrm{F}\right)$

\begin{tabular}{|c|c|c|c|c|c|c|c|c|c|}
\hline \multirow[b]{2}{*}{ Initial } & \multicolumn{9}{|c|}{ Exposure Time, hours } \\
\hline & 500 & 1000 & & 3000 & & 5000 & & 10,000 & 20,000 \\
\hline \multicolumn{10}{|l|}{$10-V$ CAA } \\
\hline $\begin{array}{r}11.6(1680) \\
11.4(1660) \\
7.6(1100) \\
11.0(1600) \\
14.0(2030) \\
\frac{11.1(1610)}{110.1} \text { Avg. }\end{array}$ & $\begin{array}{r}12.1(1760) \\
13.7(1990) \\
8.7(1260) \\
10.3(1500) \\
\frac{11.0(1590)}{11.2(1620)} \text { Avg. }\end{array}$ & $\begin{array}{l}12.9(1870) \\
14.5(2100) \\
12.4(1800) \\
13.3(1930) \\
11.9(1720) \\
13.0(1880)\end{array}$ & Avg. & $\begin{array}{r}12.0(1740) \\
12.6(1830) \\
7.8(1130) \\
9.3(1350) \\
13.9(2020) \\
11.1(1610)\end{array}$ & Avg. & $\begin{array}{r}8.7(1260) \\
14.3(2080) \\
9.4(1360) \\
9.4(1360) \\
15.3(2220) \\
11.4(1660)\end{array}$ & Avg. & $\begin{array}{r}7.6(1100) \\
6.8(990) \\
3.7(540) \\
9.0(1310) \\
12.1(1760) \\
7.9(1140)\end{array}$ & $\begin{array}{l}\text { TBD } \\
\text { Avg. }\end{array}$ \\
\hline \multicolumn{10}{|l|}{ Pasa-Jell } \\
\hline $\begin{array}{r}9.9(1440) \\
8.1(1180) \\
11.0(1600) \\
11.6(1690) \\
11.1(1610) \\
10.3(1500) \text { Avg. }\end{array}$ & $\begin{array}{l}6.9(1000) \\
9.4(1360) \\
8.4(1220) \\
7.0(1020) \\
\frac{7.2(1040)}{7.8(1130)} \text { Avg. }\end{array}$ & $\begin{array}{l}7.5(1090) \\
6.3(920) \\
8.6(1240) \\
8.6(1250) \\
7.0(1020) \\
7.6(1100)\end{array}$ & Avg. & 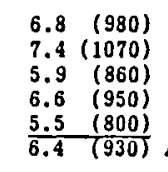 & Avg. & $\begin{array}{l}5.5(800) \\
3.7(540) \\
5.6(820) \\
6.1(880) \\
5.5(800) \\
\frac{5.3(770)}{A} \text { A }\end{array}$ & Avg. & $\begin{array}{l}3.6(530) \\
3.0(440) \\
4.6(660) \\
2.1(310) \\
1.5(220) \\
3.0(430)\end{array}$ & $\begin{array}{l}\text { TBD } \\
\text { Avg. }\end{array}$ \\
\hline
\end{tabular}


Table 2.3.2-I Titanium Surface Treatment Study-Lap-Shear Strength, MPa (psi), $\mathrm{PPQ}$ Exposure to $322 \mathrm{~K}\left(120^{\circ} \mathrm{F}\right) / 95 \% \mathrm{KH}$, Tested at Ambient

\begin{tabular}{|c|c|c|c|c|}
\hline \multirow[b]{2}{*}{ Initial } & \multicolumn{4}{|c|}{ Exposure Time, hours } \\
\hline & 500 & 1000 & 3000 & 5000 \\
\hline \multicolumn{5}{|l|}{$10-V$ CAA } \\
\hline $\begin{array}{l}22.1(3200) \\
22.2(3220) \\
21.7(3150) \\
25.5(3700) \\
27.0(3920) \\
23.7(3440) \text { Avg. }\end{array}$ & $\begin{array}{l}18.3(2650) \\
19.1(2770) \\
18.1(2620) \\
18.3(2650) \\
19.6(2850) \\
\frac{18.7(2710)}{\text { Avg. }}\end{array}$ & $\begin{array}{l}21.5(3110) \\
20.1(2920) \\
17.9(2590) \\
18.2(2640) \\
20.3(2940) \\
19.6(2840) \text { Avg. }\end{array}$ & $\begin{array}{l}20.0(2900) \\
19.4(2810) \\
19.6(2850) \\
16.6(2400) \\
19.3(2800) \\
19.0(2750) \text { Avg. }\end{array}$ & $\begin{array}{l}20.1(2920) \\
19.9(2880) \\
19.2(2790) \\
14.0(2030) \\
17.9(2600) \\
18.2(2640) \text { Avg. }\end{array}$ \\
\hline \multicolumn{5}{|l|}{ Pasa-Jell } \\
\hline $\begin{array}{l}24.8(3590) \\
14.2(2060) \\
14.6(2120) \\
13.4(1940) \\
15.8(2290) \\
16.6(2400) \text { Avg. }\end{array}$ & $\begin{array}{r}18.2(2640) \\
16.6(2400) \\
16.8(2430) \\
9.9(1440) \\
11.6(1690) \\
14.6(2120) \text { Avg. }\end{array}$ & $\begin{array}{r}17.8(2580) \\
13.4(1940) \\
10.1(1460) \\
8.3(1200) \\
14.3(2070) \\
12.8(1850) \text { Avg. }\end{array}$ & $\begin{array}{r}18.2(2640) \\
13.0(1890) \\
8.3(1210) \\
11.0(1600) \\
12.1(1750) \\
12.6(1820) \text { Avg. }\end{array}$ & $\begin{array}{r}18.8(2730) \\
12.3(1780) \\
8.6(1250) \\
11.6(1690) \\
11.9(1730) \\
12.7(1840) \text { Avg. }\end{array}$ \\
\hline
\end{tabular}

Table 2.3.2-J Titanium Surface Treatment Study-Lap-Shear Strength, MPa (psi), PPQ Exposure to $505 \mathrm{~K}\left(450^{\circ} \mathrm{F}\right)$, Tested at $505 \mathrm{~K}\left(450^{\circ} \mathrm{F}\right)$

\begin{tabular}{|c|c|c|c|c|c|c|c|}
\hline \multirow[b]{2}{*}{ Initial } & \multicolumn{6}{|c|}{ Exposure Time, hours } & \multirow[b]{2}{*}{20,000} \\
\hline & 500 & 1000 & & 3000 & 5000 & 10,000 & \\
\hline \multicolumn{8}{|l|}{$10-V$ CAA } \\
\hline $\begin{array}{l}21.6(3130) \\
20.6(2980) \\
18.1(2620) \\
19.9(2880) \\
21.0(3040) \\
20.2(2930) \text { Avg. }\end{array}$ & $\begin{array}{l}15.4(2240) \\
21.7(3150) \\
17.0(2470) \\
17.6(2560) \\
21.9(3180) \\
18.8(2720) \text { Avg. }\end{array}$ & $\begin{array}{l}18.6(2690) \\
20.8(3020) \\
18.8(2730) \\
20.5(2970) \\
16.0(2320) \\
19.0(2750)\end{array}$ & Avg. & $\begin{array}{l}16.8(2430) \\
19.9(2880) \\
13.8(2000) \\
16.6(2410) \\
17.0(2460) \\
16.8(2440) \text { Avg. }\end{array}$ & $\begin{array}{l}14.7(2130) \\
16.4(2380) \\
18.3(2660) \\
14.6(2120) \\
13.0(1890) \\
15.4(2240) \text { AVE. }\end{array}$ & $\begin{array}{l}4.6(660) \\
4.6(670) \\
6.3(910) \\
6.7(970) \\
3.7(530) \\
5.2(750) \text { Avg. }\end{array}$ & TBD \\
\hline \multicolumn{8}{|l|}{ 5-V CAA } \\
\hline $\begin{array}{l}18.5(2680) \\
20.8(3010) \\
12.5(1810) \\
8.6(1250) \\
9.9(1440) \\
\frac{9.9(2040)}{14.1} \text { Avg.: }\end{array}$ & $\begin{array}{r}16.6(2400) \\
14.0(2030) \\
9.9(1440) \\
7.6(1110) \\
8.0(1160) \\
11.2(1630) \text { Avg. }\end{array}$ & $\begin{array}{r}16.3(2360) \\
17.4(2520) \\
10.3(1500) \\
7.9(1150) \\
6.3(920) \\
11.6(1690)\end{array}$ & Avg. & $\begin{array}{r}15.9(2300) \\
14.2(2060) \\
11.9(1720) \\
7.7(1120) \\
6.9(1000) \\
11.3(1640) \text { Avg. }\end{array}$ & $\begin{array}{l}13.3(1930) \\
17.1(2480) \\
10.5(1520) \\
2.8(400) \\
7.9(1140) \\
10.3(1500) \text { Avg. }\end{array}$ & $\begin{array}{l}2.9(420) \\
2.7(390) \\
5.0(720) \\
5.8(840) \\
2.5(360) \\
3.8(550) \text { Avg. }\end{array}$ & TBD \\
\hline
\end{tabular}


Table 2.3.2-K Titanium Surface Treatment Study-Crack Extension, $m m$ (ino), $\mathrm{PPQ}$ Exposure to $322 \mathrm{~K}\left(120^{\circ} \mathrm{F}\right) / 95 \% \mathrm{RH}$

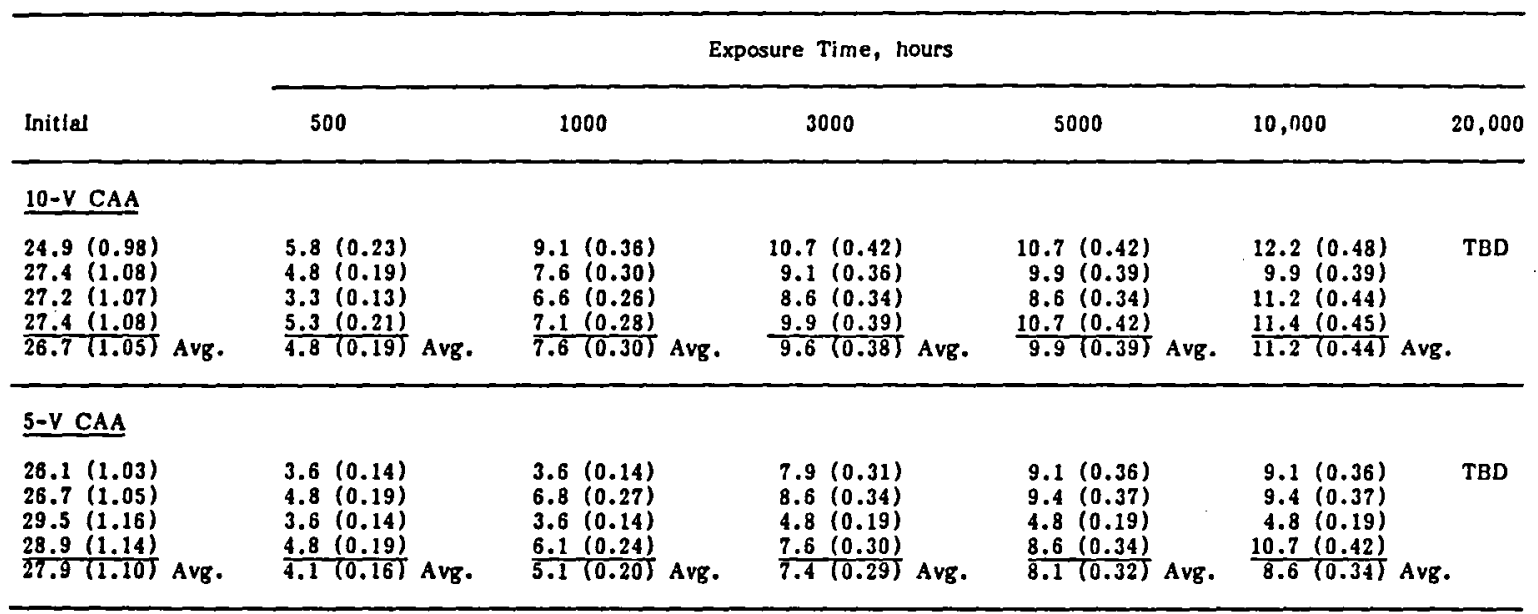

Table 2.3.2-L Titanjum Surface Treatment Study-Crack Extension, $\mathrm{mm}$ (in.), $P P Q$ Exposure to $505 \mathrm{~K}\left(450^{\circ} \mathrm{F}\right)$

\begin{tabular}{|c|c|c|c|c|c|c|c|}
\hline \multirow[b]{2}{*}{ Initial } & \multicolumn{6}{|c|}{ Exposure Time, hours } & \multirow[b]{2}{*}{20,000} \\
\hline & 500 & 1000 & & 3000 & 5000 & 10,000 & \\
\hline \multicolumn{8}{|l|}{$10-V$ CAA } \\
\hline $\begin{array}{l}27.4(1.08) \\
27.9(1.10) \\
29.5(1.16) \\
29.5(1.16) \\
28.4(1.12) \text { Avg. }\end{array}$ & $\begin{array}{l}2.8(0.11) \\
2.5(0.10) \\
1.3(0.05) \\
2.5(0.10) \\
2.3(0.09) \text { Avg. }\end{array}$ & $\begin{array}{l}2.8(0.11) \\
3.6(0.14) \\
1.3(0.05) \\
2.5(0.10) \\
2.5(0.10)\end{array}$ & Avg. & $\begin{array}{l}4.1(0.16) \\
3.6(0.14) \\
2.5(0.10) \\
2.5(0.10) \\
3.3(0.13) \text { Avg. }\end{array}$ & $\begin{array}{l}4.1(0.16) \\
3.6(0.14) \\
2.5(0.10) \\
\frac{2.5(0.10)}{3.3(0.13)} \text { Avg. }\end{array}$ & $\begin{array}{l}45.2(1.78) \\
35.3(1.39) \\
50.8(2.00) \\
37.3(1.47) \\
42.7(1.68)\end{array}$ & $\begin{array}{l}\text { TBD } \\
\text { Avg. }\end{array}$ \\
\hline \multicolumn{8}{|l|}{ 5-V CAA } \\
\hline $\begin{array}{l}26.9(1.06) \\
25.9(1.02) \\
27.2(1.07) \\
25.9 \frac{(1.02)}{26.4} \frac{(1.04) \text { Avg. }}{(1.04}\end{array}$ & $\begin{array}{l}1.8(0.07) \\
3.8(0.15) \\
2.0(0.08) \\
\frac{3.0(0.12)}{2.5(0.10)} \text { Avg. }\end{array}$ & $\begin{array}{l}2.5(0.10) \\
4.3(0.17) \\
2.8(0.11) \\
3.0(0.12) \\
3.3(0.13)\end{array}$ & Avg. & $\begin{array}{l}2.5(0.10) \\
5.3(0.21) \\
2.8(0.11) \\
3.0(0.12) \\
3.6(0.14) \text { Avg. }\end{array}$ & $\begin{array}{r}2.5(0.10) \\
5.3(0.21) \\
11.4(0.45) \\
18.3(0.72) \\
9.4(0.37) \text { Avg. }\end{array}$ & $\begin{array}{l}54.6(2.15) \\
56.6(2.23) \\
54.6(2.15) \\
57.1(2.25) \\
55.9(2.20)\end{array}$ & Avg. \\
\hline
\end{tabular}


Table 2.3.2-M Titanium Surface Treatment Study-Crack Extension, $\mathrm{mm}$ (in.), NR056X Exposure to 322K (1200 F)/95\% RH

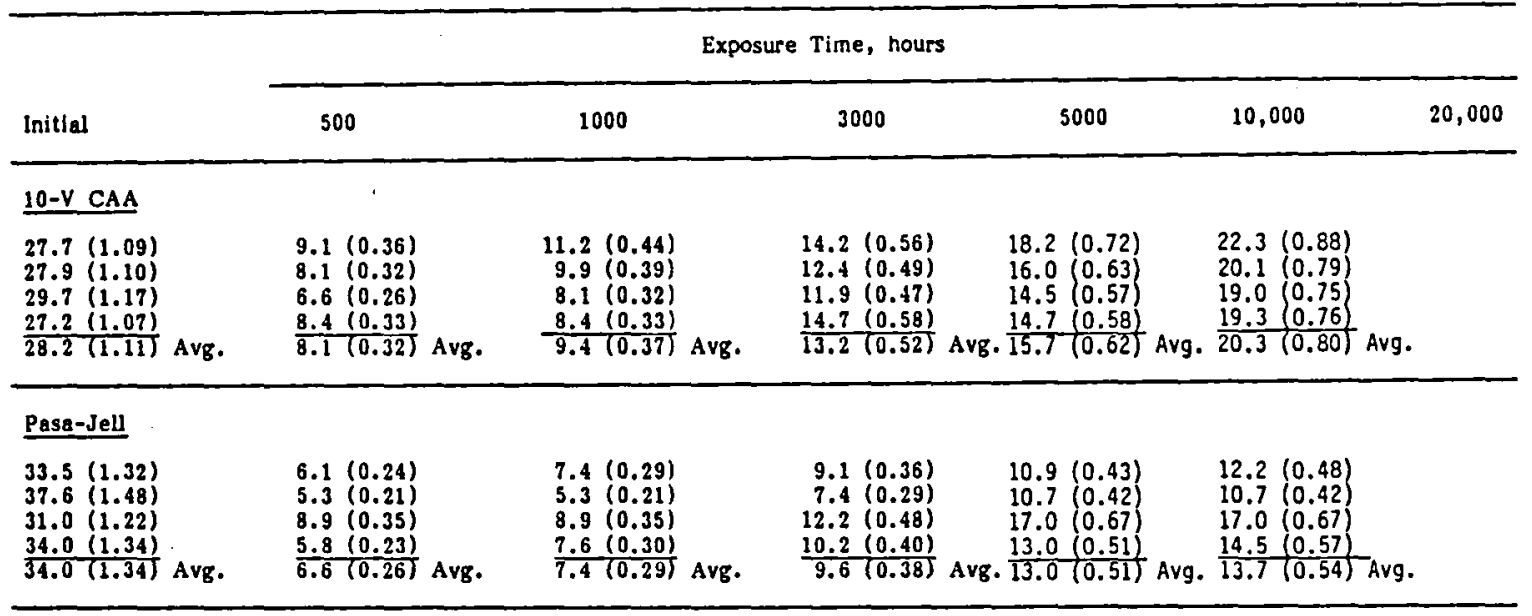

Table 2.3.2-N Titanium Surface Treatment Study-Crack Extension, mm (in.), NR056X Exposure to $505 \mathrm{~K}\left(450^{\circ} \mathrm{F}\right)$

\begin{tabular}{|c|c|c|c|c|c|c|c|c|c|c|}
\hline \multirow[b]{2}{*}{ Initial } & \multicolumn{9}{|c|}{ Exposure Time, hours } & \multirow[b]{2}{*}{20,000} \\
\hline & 500 & & 1000 & & 3000 & & 5000 & 10,000 & & \\
\hline \multicolumn{11}{|l|}{ 10-V CAA } \\
\hline $\begin{array}{l}27.4(1.08) \\
30.2(1.19) \\
29.4(1.16) \\
31.0(1.22) \\
\frac{29.4(1.16)}{\text { Avg. }}\end{array}$ & $\begin{array}{l}3.8(0.15) \\
2.0(0.08) \\
2.5(0.10) \\
3.8(0.15) \\
3.0(0.12)\end{array}$ & Avg. & $\begin{array}{l}3.8(0.15) \\
3.6(0.14) \\
3.8(0.15) \\
3.8(0.15) \\
3.8(0.15)\end{array}$ & Avg. & $\begin{array}{l}5.3(0.21) \\
4.6(0.18) \\
4.8(0.19) \\
3.8(0.15) \\
4.6(0.18)\end{array}$ & Avg. & $\begin{array}{l}7.1(0.28) \\
4.6(0.18) \\
4.8(0.19) \\
4.6(0.18) \\
5.3(0.21)\end{array}$ & $\begin{array}{r}8.4(0.33) \\
5.6(0.22) \\
4.6(0.18) \\
4.6(0.18) \\
\text { Avg. } 6.1(0.24)\end{array}$ & Avg. & TBD \\
\hline \multicolumn{11}{|l|}{ Pasa-Jell } \\
\hline $\begin{array}{l}29.4(1.16) \\
30.5(1.20) \\
33.3(1.31) \\
32.0(1.26) \\
31.2(1.23) \text { Avg. }\end{array}$ & $\begin{array}{l}5.1(0.20) \\
6.6(0.26) \\
4.6(0.18) \\
4.3(0.17) \\
5.1(0.20)\end{array}$ & Avg. & $\begin{array}{l}7.4(0.29) \\
6.6(0.26) \\
5.8(0.23) \\
5.8(0.23) \\
6.4(0.25)\end{array}$ & Avg. & $\begin{array}{l}8.9(0.35) \\
7.6(0.30) \\
5.8(0.23) \\
5.8(0.23) \\
7.1(0.28)\end{array}$ & Avg. & $\begin{array}{r}10.4(0.41) \\
7.6(0.30) \\
7.1(0.28) \\
5.3(0.23) \\
7.9(0.31)\end{array}$ & $\begin{array}{r}10.4(0.41) \\
7.6(0.30) \\
7.1(0.28) \\
5.3(0.23) \\
\text { Avg. } 7.9(0.31)\end{array}$ & Avg. & TBD \\
\hline
\end{tabular}


PHASE I SURFACE CHARACTERIZATION

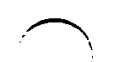

$\frown$
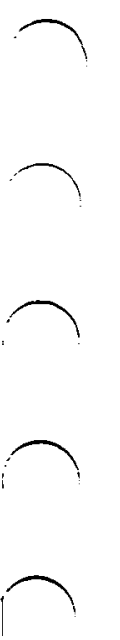

- 
7

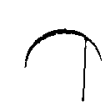

7
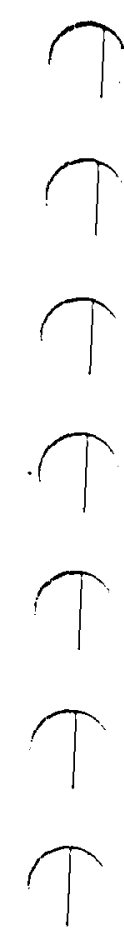

$T$

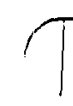

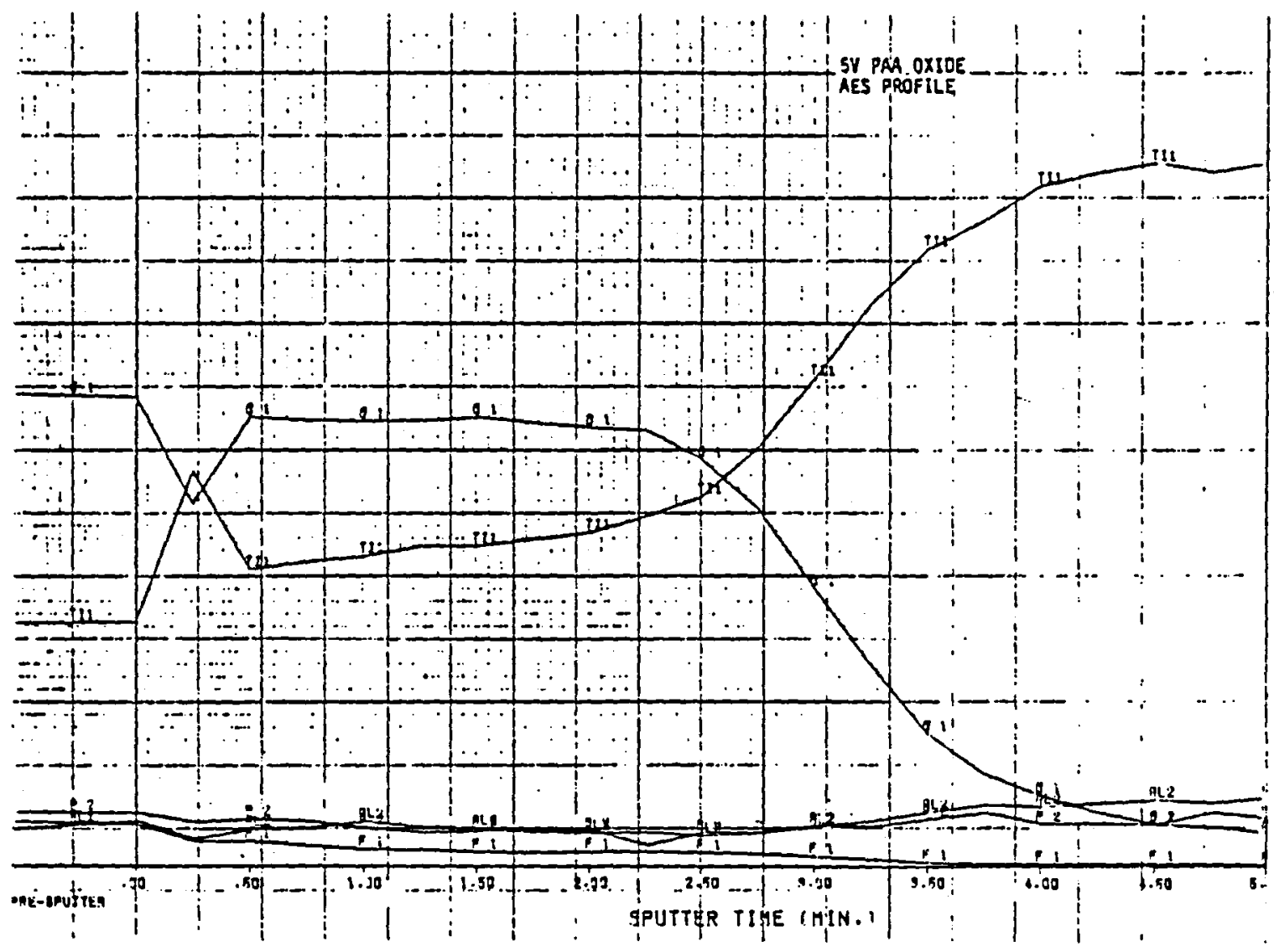

T

Figure A.2.4-1 5-V PAA Oxide AES Profile

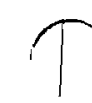

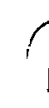

T 


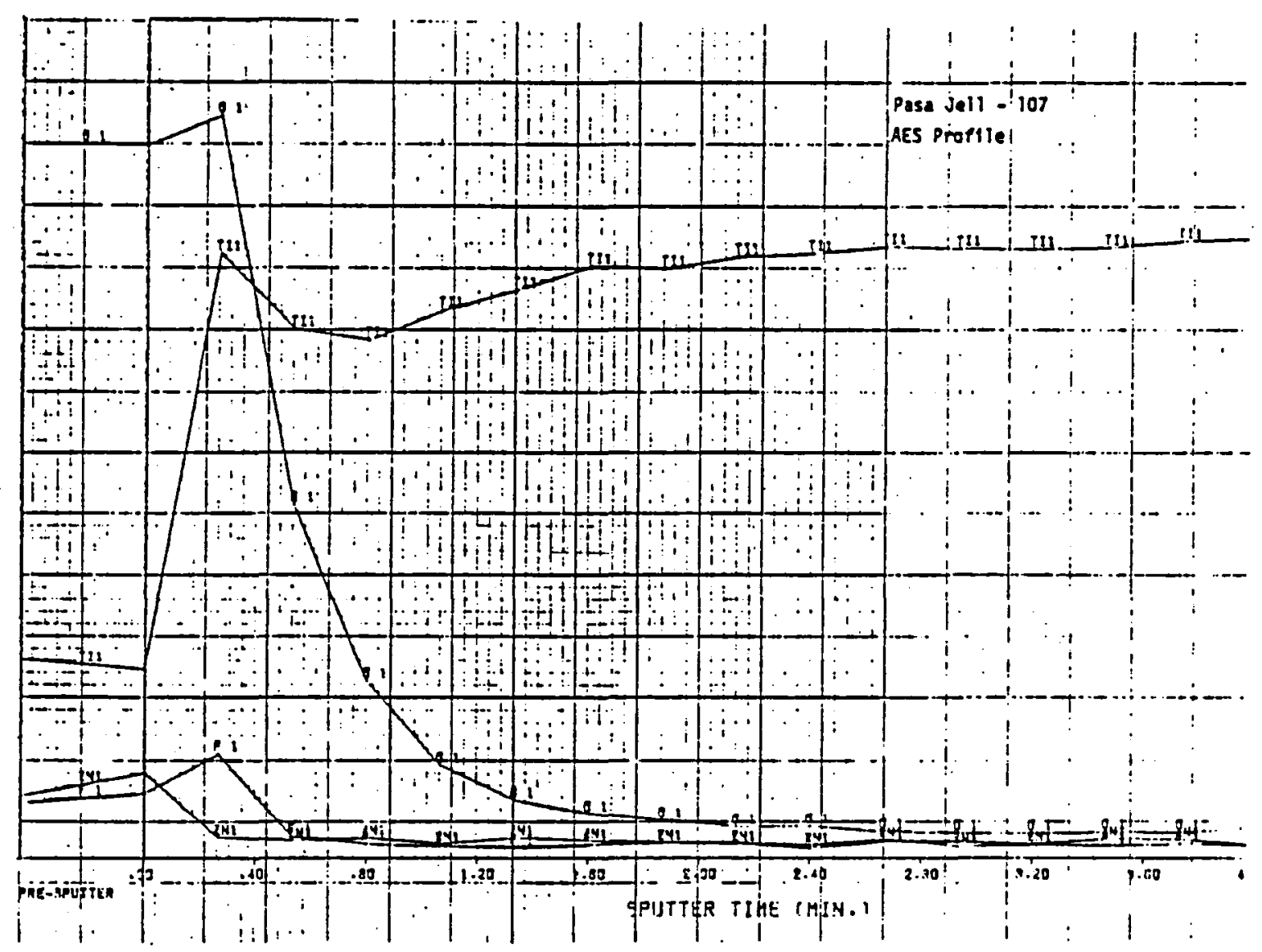

Figure A.2.4-2 Pasa Jell 107 AES Profile 


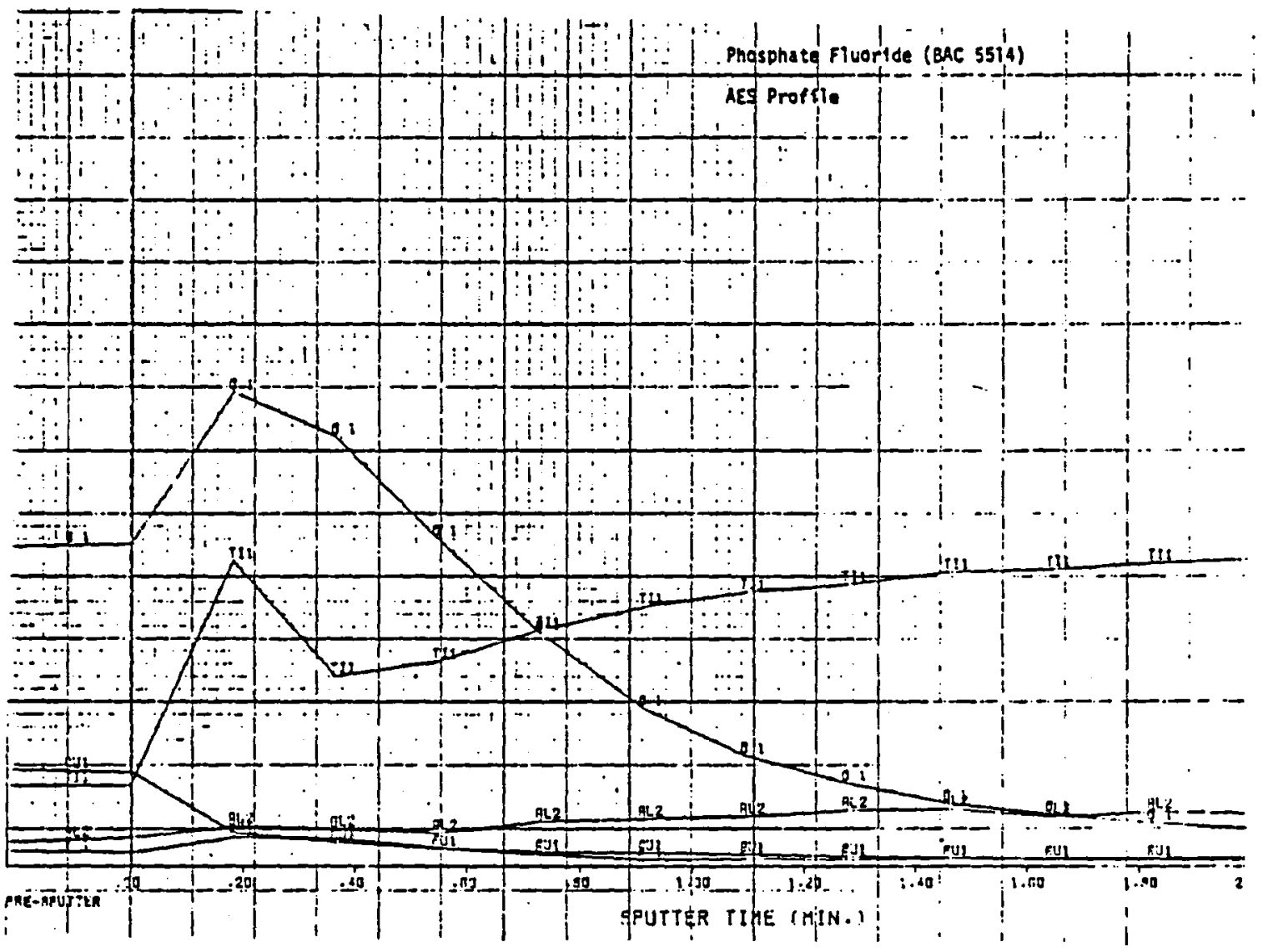

Figure A.2.4-3 Phosphate Fluoride (BAC 5514) AES Profile

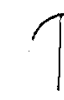

$\Gamma$

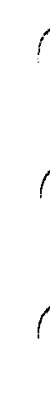

7

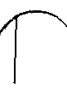




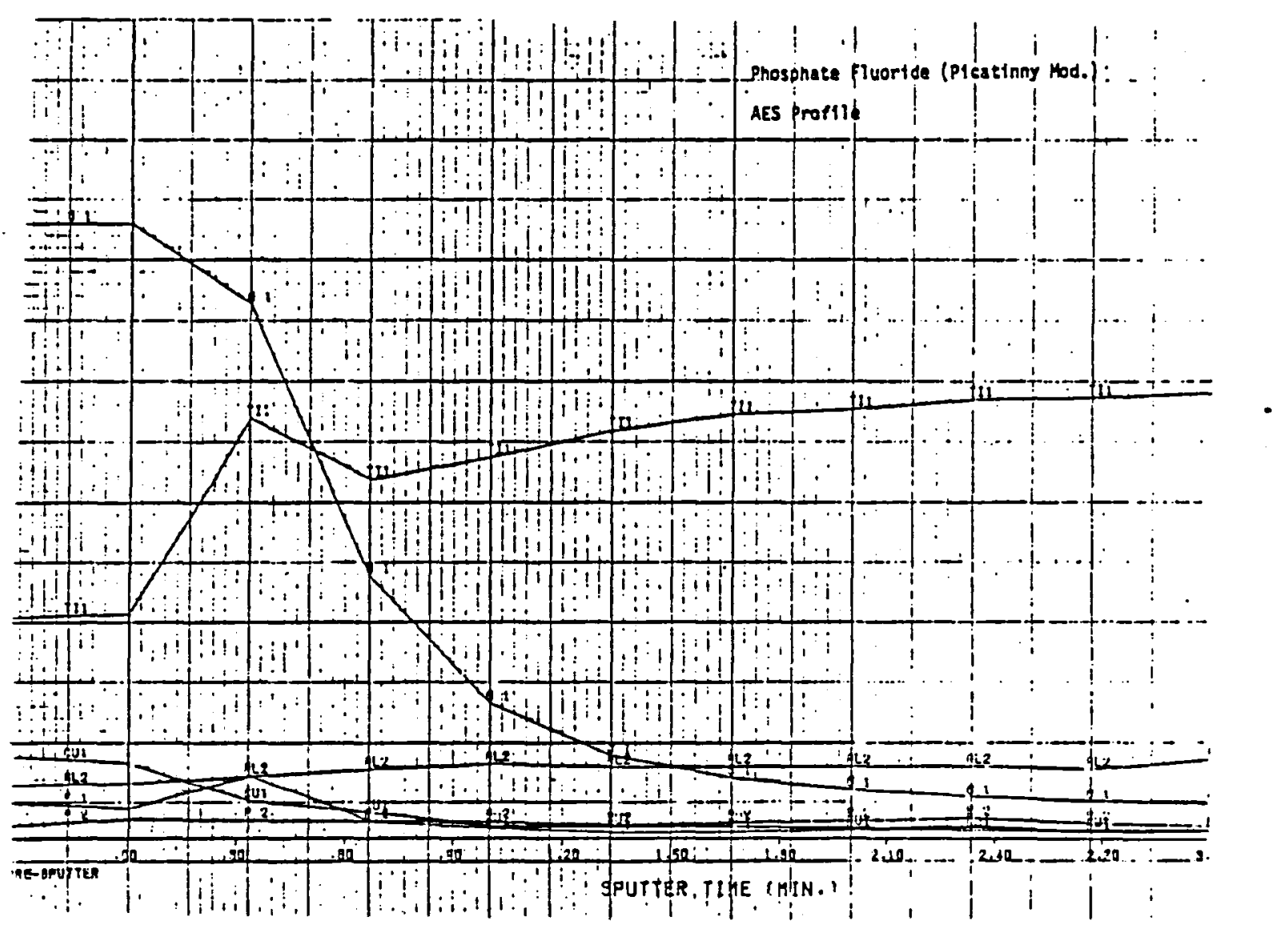

Figure A.2.4-4 Phosphate Fluoride (Picatinny Mod.) AES Profile 
7

T

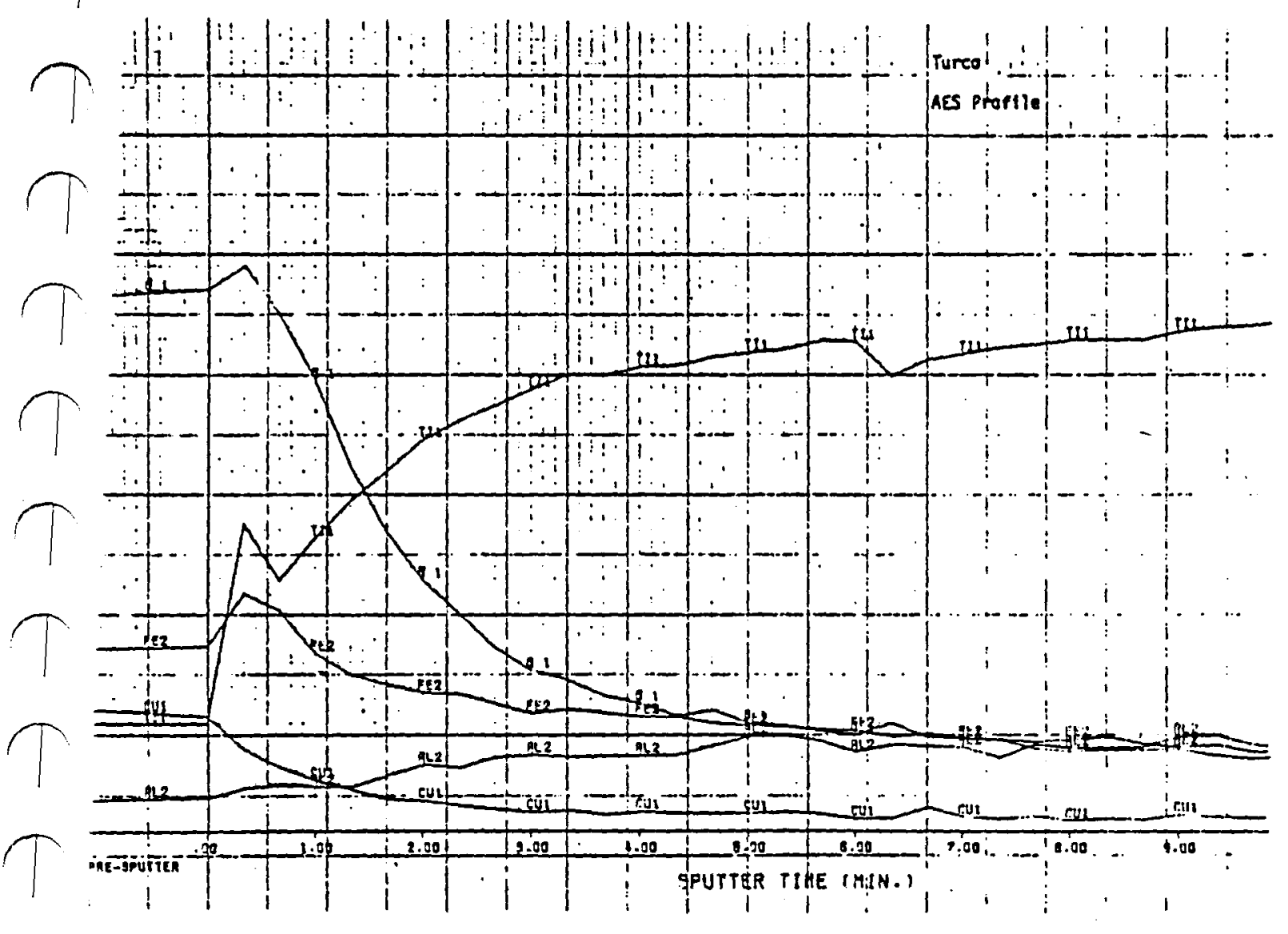

T

?

Figure A.2.4-5 Turco AES Profile 


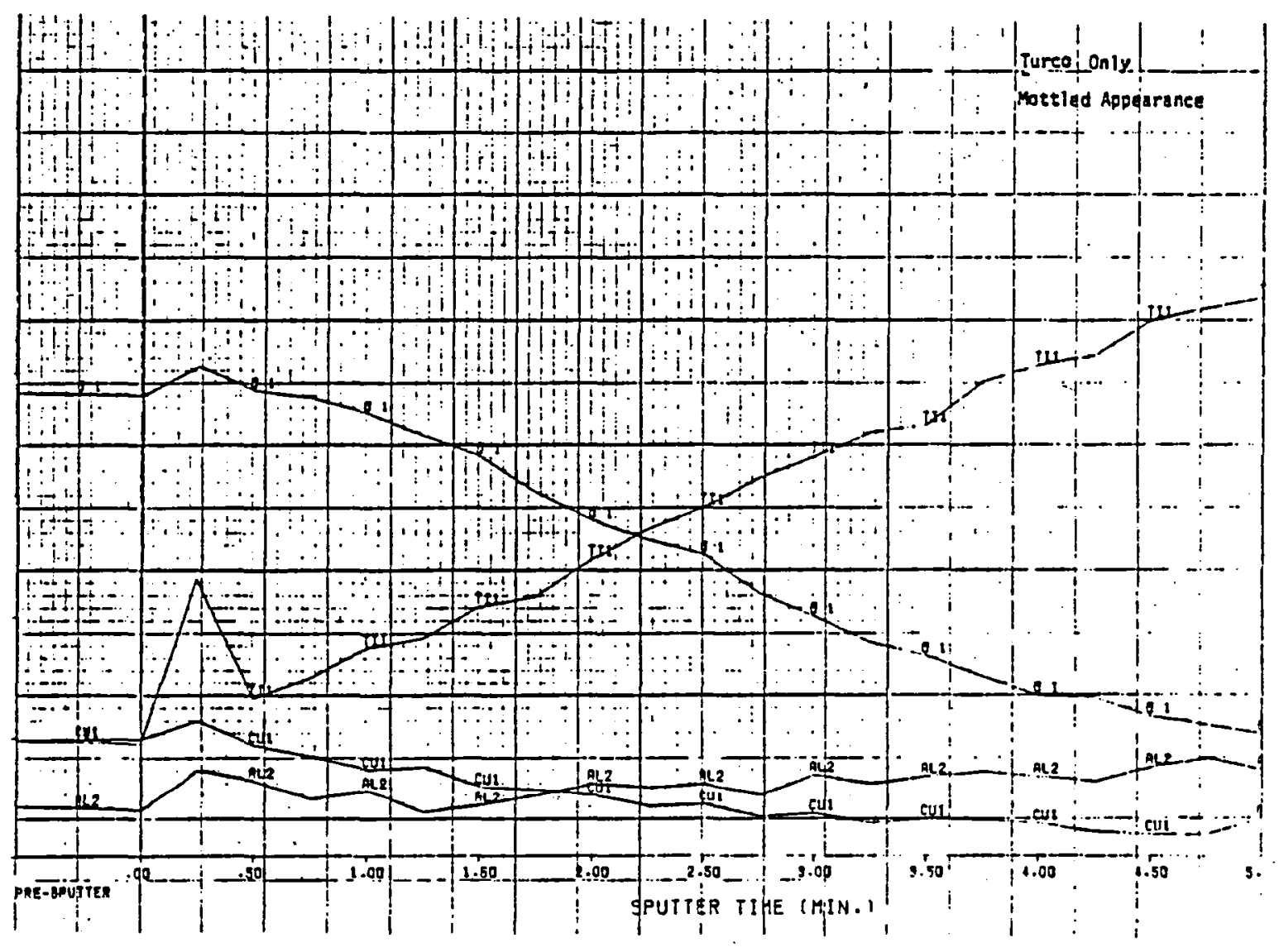

Figure A.2.4-6 Turco Only Mottled Appearance 


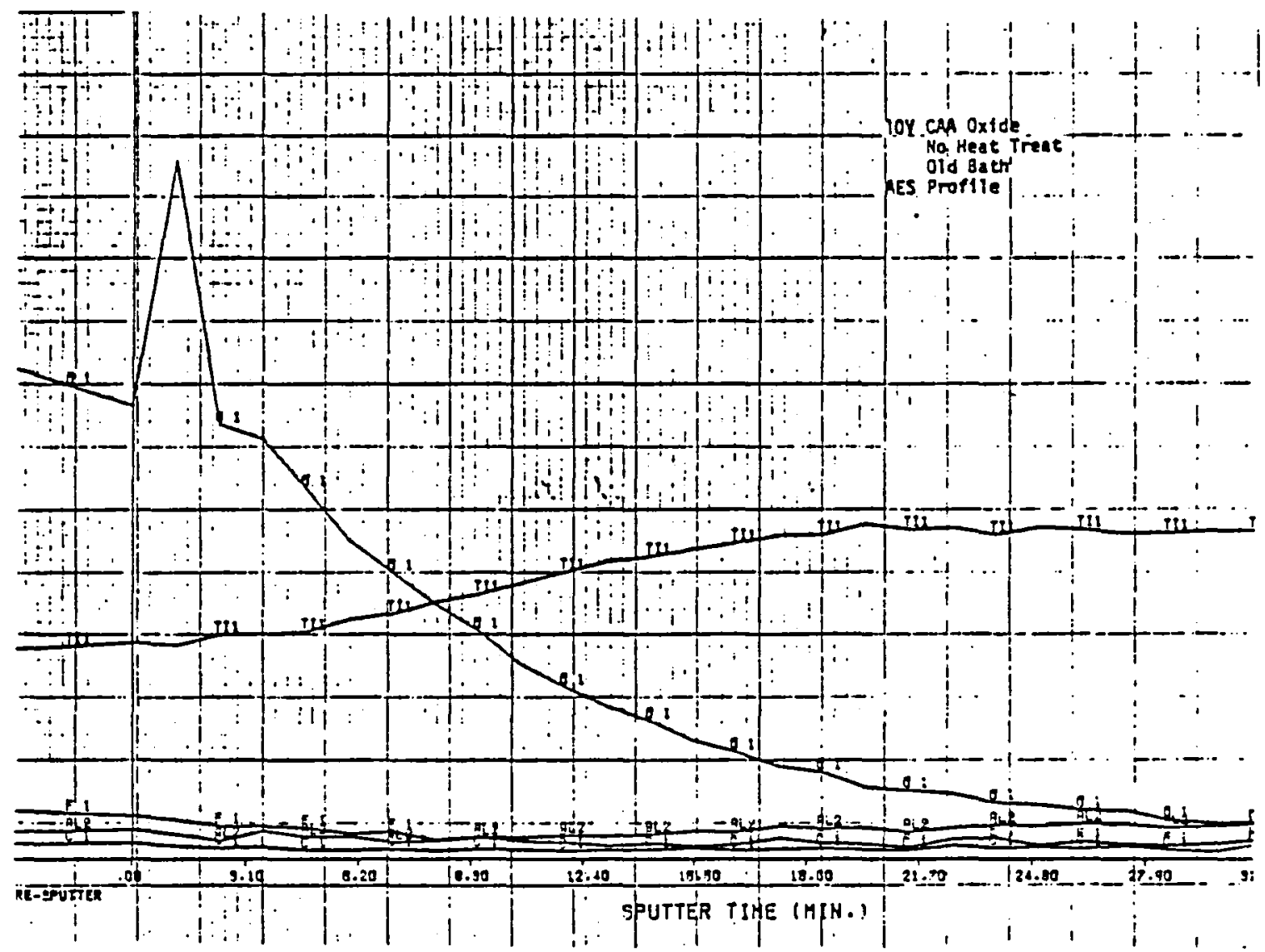

$T$
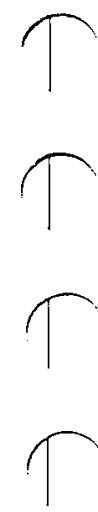


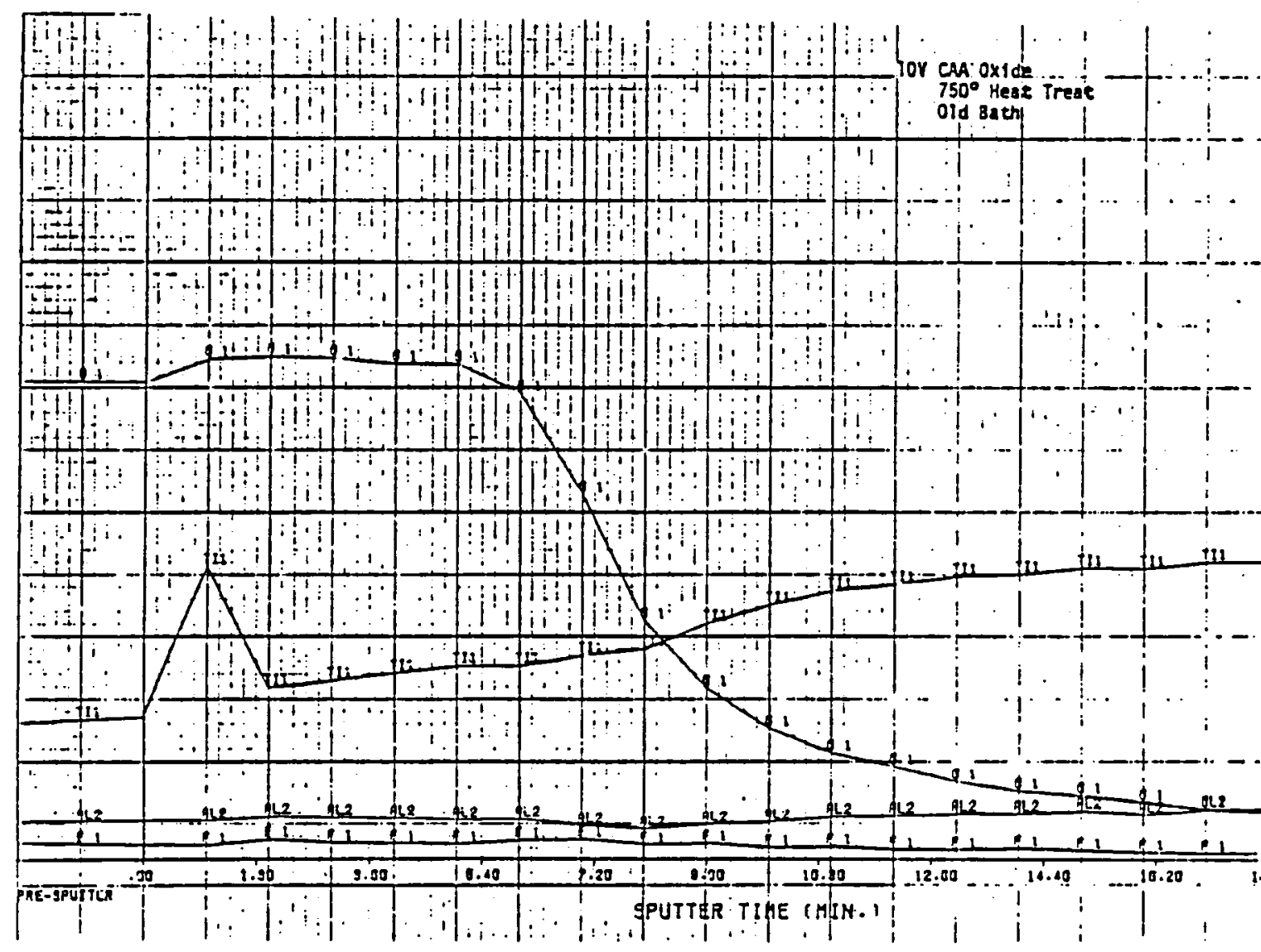

Figure A.2.4-8

\section{Profile}

10-V CAA Oxide, 672K (750 $\mathrm{OF}$ ) Heat Treat, Old Bath, AES 

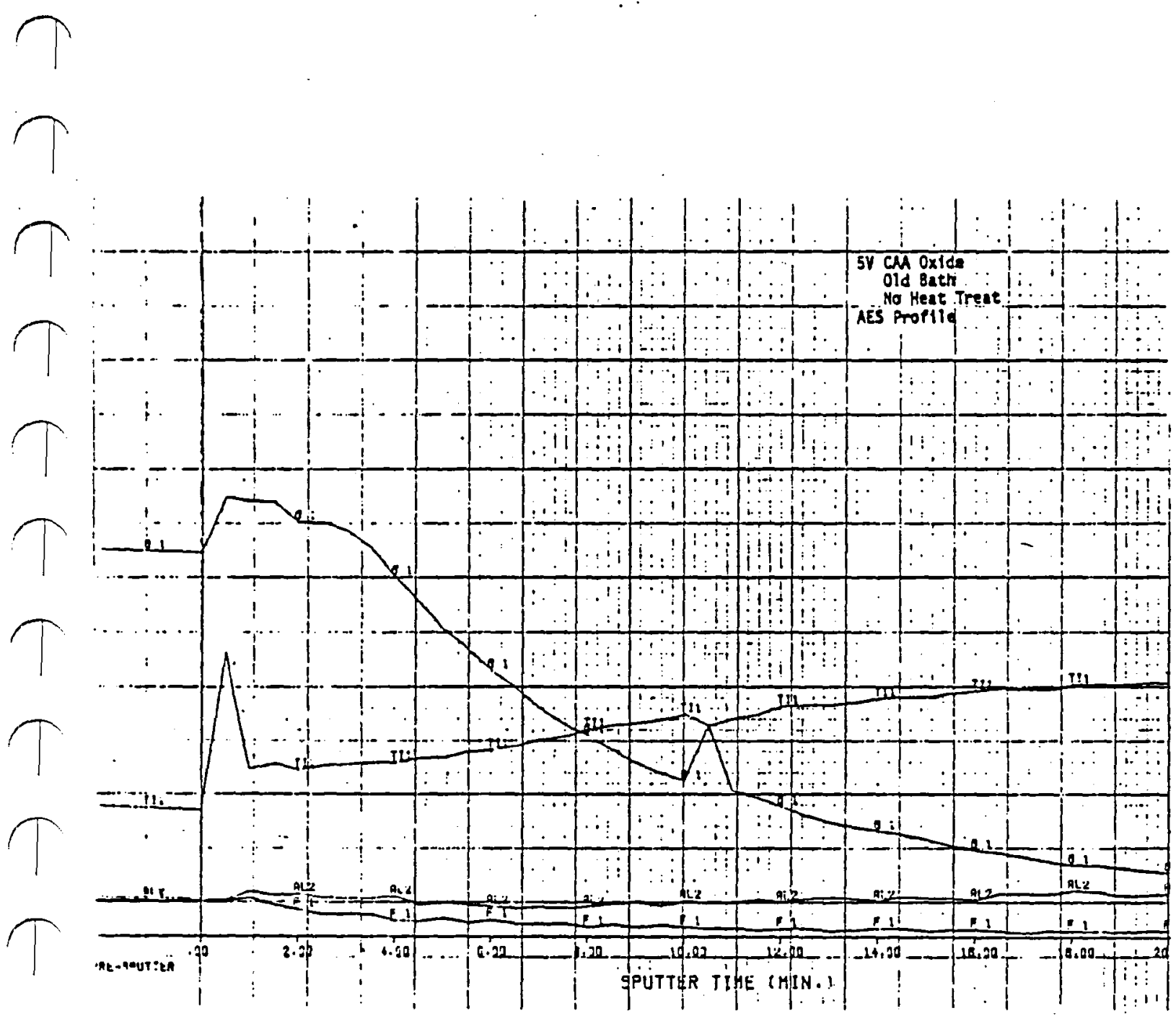

$T$

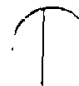

Figure A.2.4-9 5-V CAA Oxide, Old Bath, No Heat Treat, AES Profile

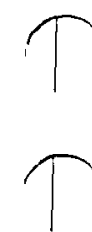

\section{(}

, 


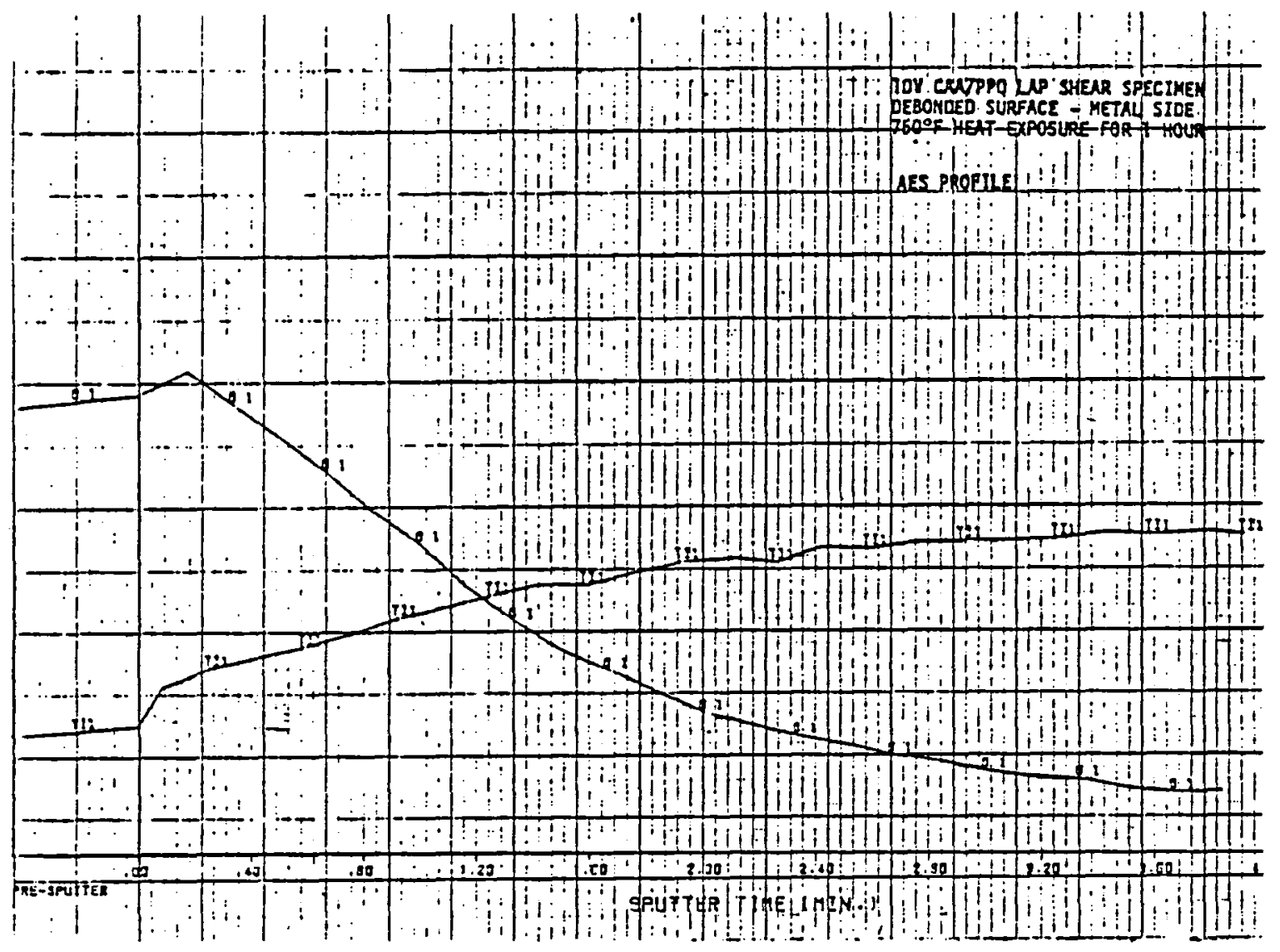

Figure A.2.4-10 10-V CAA/PPQ Lap-Shear Specimen, Disbonded Surface, Metal Side, $672 \mathrm{~K}\left(750^{\circ} \mathrm{F}\right)$ Heat Exposure for 1 Hour, AES Profile 
Table 3.1.2-2 Phase Il Cure Cycle Optimization-PPQ-Lap-Shear Strength, MPa (psi)

\begin{tabular}{|c|c|c|c|c|c|}
\hline \multirow[b]{2}{*}{ Cure No. } & \multirow[b]{2}{*}{$\begin{array}{l}\text { Ambient } \\
\text { Test, Initial }\end{array}$} & \multirow[b]{2}{*}{$\begin{array}{l}505 \mathrm{~K}\left(450^{\circ} \mathrm{P}\right) \\
\text { Test, Initial }\end{array}$} & \multicolumn{3}{|c|}{$\begin{array}{l}\text { Thermal Aging at } 505 \mathrm{~K}\left(4500^{\circ}\right) \\
\text { Tested at } 505 \mathrm{~K}\left(450^{\circ} \mathrm{F}\right)\end{array}$} \\
\hline & & & 500 hours & 1000 hours & 3000 hours \\
\hline Averago & $\begin{array}{l}30.5(4420) \\
29.0(4200) \\
31.4(4560) \\
32.1(4660) \\
27.9(4040) \\
30.2(4380)\end{array}$ & $\begin{array}{l}17.7(2570) \\
13.9(2020) \\
17.1(2480) \\
17.0(2460) \\
16.3(2360) \\
16.4(2380)\end{array}$ & $\begin{array}{l}17.6(2560) \\
21.1(3060) \\
20.6(2980) \\
19.0(2760) \\
19.9(2880) \\
19.6(2850)\end{array}$ & $\begin{array}{l}20.8(3020) \\
17.0(2470) \\
21.5(3130) \\
21.3(3100) \\
23.1(3350) \\
20.7(3010)\end{array}$ & $\begin{array}{cc}18.0 & (2610) \\
19.6 & (2840) \\
-- & -- \\
-- & -- \\
-- & -- \\
18.8 & (2720)\end{array}$ \\
\hline Average & $\begin{array}{l}34.8(5040) \\
37.6(5460) \\
38.3(5560) \\
38.8(5620) \\
35.7(5180) \\
37.0(5370)\end{array}$ & $\begin{array}{l}17.0(2460) \\
16.2(2350) \\
17.6(2550) \\
19.2(2780) \\
17.4(2530) \\
17.4(2530)\end{array}$ & $\begin{array}{l}24.2(3510) \\
24.0(3480) \\
25.2(3660) \\
23.9(3470) \\
24.7(3580) \\
24.4(3540)\end{array}$ & $\begin{array}{l}24.9(3610) \\
23.4(3400) \\
22.6(3280) \\
24.4(3540) \\
25.5(3700) \\
24.2(3510)\end{array}$ & $\begin{array}{cc}23.5 & (3410) \\
26.1 & (3780) \\
-- & -- \\
-- & -- \\
-- & -- \\
24.8 & (3600)\end{array}$ \\
\hline Average & $\begin{array}{l}31.2(4520) \\
33.8(4900) \\
32.6(4720) \\
34.6(5020) \\
32.5(4720) \\
33.0(4780)\end{array}$ & $\begin{array}{l}13.8(2000) \\
17.8(2580) \\
17.0(2470) \\
15.6(2270) \\
16.3(2370) \\
16.1(2340)\end{array}$ & $\begin{array}{l}21.0(3050) \\
20.7(3000) \\
22.2(3220) \\
18.3(2660) \\
24.8(3590) \\
21.4(3100)\end{array}$ & $\begin{array}{l}21.7(3150) \\
21.6(3140) \\
24.3(3530) \\
23.6(3430) \\
23.1(3360) \\
22.9(3320)\end{array}$ & $\begin{array}{cc}24.1 & (3490) \\
21.6 & (3130) \\
-- & -- \\
-- & -- \\
-- & -- \\
22.8 & (3310)\end{array}$ \\
\hline
\end{tabular}

Table 3.1.2-3 Phase II Cure Cycle Optimization-LARC-2-Lap-Shear Strength, MPa (psi)

\begin{tabular}{|c|c|c|c|c|c|}
\hline \multirow[b]{2}{*}{ Cure No. } & \multirow[b]{2}{*}{$\begin{array}{l}\text { Ambient } \\
\text { Test, Initial }\end{array}$} & \multirow[b]{2}{*}{$\begin{array}{l}505 K \quad(4500 \mathrm{~F}) \\
\text { Test, Initial }\end{array}$} & \multicolumn{3}{|c|}{$\begin{array}{l}\text { Thermal Aging at } 505 \mathrm{~K}\left(450^{\circ} \mathrm{F}\right) \\
\text { Tested at } 505 \mathrm{~K}\left(450^{\circ} \mathrm{F}\right)\end{array}$} \\
\hline & & & 500 hours & 1000 hours & 3000 hours \\
\hline Average & $\begin{array}{l}19.9(2880) \\
25.2(3660) \\
16.6(2400) \\
18.5(2680) \\
19.3(2800) \\
19.9(2880)\end{array}$ & 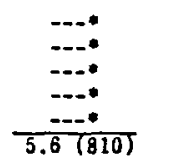 & $\begin{array}{l}13.8(2000) \\
15.0(2180) \\
13.1(1900) \\
15.0(2180) \\
16.8(2440) \\
14.8(2140)\end{array}$ & $\begin{array}{r}13.9(2010) \\
17.2(2490) \\
7.8(1130) \\
13.2(1920) \\
13.9(2010) \\
13.2(1910)\end{array}$ & $\begin{array}{cc}21.4 & (3110) \\
9.8 & (1420) \\
-- & -- \\
-- & -- \\
-- & -- \\
15.6 & (2260)\end{array}$ \\
\hline Average & $\begin{array}{l}16.8(2440) \\
15.0(2180) \\
19.6(2840) \\
26.2(3800) \\
19.0(2760) \\
19.3(2800)\end{array}$ & $\begin{array}{r}11.6(1680) \\
11.6(1690) \\
6.6(950) \\
7.7(1120) \\
14.1(2040) \\
10.3(1500)\end{array}$ & $\begin{array}{r}13.0(1890) \\
11.0(1600) \\
9.4(1360) \\
12.3(1780) \\
19.3(2800) \\
13.0(1890)\end{array}$ & $\begin{array}{l}21.5(3120) \\
15.0(2170) \\
23.6(3430) \\
10.8(1560) \\
15.9(2300) \\
17.4(2520)\end{array}$ & $\begin{array}{cc}21.8 & (3160) \\
11.3 & (1640) \\
-- & -- \\
-- & -- \\
-- & -- \\
16.6 & (2400)\end{array}$ \\
\hline Average & $\begin{array}{l}24.5(3560) \\
35.3(5120) \\
28.3(4100) \\
19.9(2880) \\
30.1(4360) \\
27.6(4000)\end{array}$ & $\begin{array}{l}14.7(2130) \\
14.9(2160) \\
15.6(2260) \\
11.3(1640) \\
14.8(2150) \\
14.3(2070)\end{array}$ & $\begin{array}{l}18.1(2620) \\
10.0(1450) \\
13.3(1930) \\
22.1(3200) \\
14.4(2090) \\
15.6(2260)\end{array}$ & $\begin{array}{r}18.7(2710) \\
18.5(2680) \\
25.7(3730) \\
23.7(3440) \\
9.9(1440) \\
19.2(2790)\end{array}$ & $\begin{array}{cc}25.2 & (3660) \\
14.1 & (2050) \\
-- & -- \\
-- & -- \\
-- & -- \\
19.7 & (2860)\end{array}$ \\
\hline
\end{tabular}

-Temperature controller not operating properly, tested above $505 \mathrm{~K}$ (450\% F). 
Table 3.1.2-4 Phase II Cure Cycle Optimization-NR056X-Lap-Shear Strength, MPa (psi)

\begin{tabular}{|c|c|c|c|c|c|}
\hline \multirow[b]{2}{*}{ Cure No. } & \multirow[b]{2}{*}{$\begin{array}{l}\text { Ambient } \\
\text { Test, Initial }\end{array}$} & \multirow[b]{2}{*}{$\begin{array}{l}505 \mathrm{~K}\left(450^{\circ} \mathrm{F}\right) \\
\text { Test, Initial }\end{array}$} & \multicolumn{3}{|c|}{$\begin{array}{l}\text { Thermal Aging at } 505 \mathrm{~K}\left(450^{\circ} \mathrm{F}\right) \\
\text { Tested at } 505 \mathrm{~K}\left(450^{\circ} \mathrm{F}\right)\end{array}$} \\
\hline & & & 500 hours & 1000 hours & 3000 hours \\
\hline Average & $\begin{array}{l}21.1(3060) \\
22.6(3280) \\
25.0(3620) \\
15.7(2280) \\
21.6(3140) \\
21.2(3080)\end{array}$ & $\begin{array}{l}13.0(1880) \\
11.6(1690) \\
11.6(1680) \\
13.4(1940) \\
10.2(1480) \\
11.9(1730)\end{array}$ & $\begin{array}{l}14.2(2060) \\
13.4(1950) \\
14.5(2100) \\
14.0(2030) \\
11.2(1630) \\
13.4(1950)\end{array}$ & $\begin{array}{l}14.1(2040) \\
12.4(1800) \\
11.2(1620) \\
12.7(1840) \\
13.3(1930) \\
12.8(1850)\end{array}$ & $\begin{array}{r}12.3(1790) \\
10.8(1570) \\
9.2(1330) \\
7.6(1110) \\
8.6(1240) \\
9.7(1410)\end{array}$ \\
\hline Average & $\begin{array}{l}20.0(2900) \\
22.2(3220) \\
17.2(2500) \\
23.0(3340) \\
21.0(3040) \\
20.7(3000)\end{array}$ & $\begin{array}{r}12.0(1740)) \\
10.6(1540) \\
9.4(1370) \\
6.6(960) \\
13.0(1890) \\
10.3(1500)\end{array}$ & $\begin{array}{r}8.4(1220) \\
13.0(1880) \\
8.8(1280) \\
12.8(1860) \\
11.2(1620) \\
10.8(1570)\end{array}$ & $\begin{array}{r}11.0(1600) \\
8.9(1290) \\
12.7(1840) \\
15.7(2280) \\
13.7(1990) \\
12.4(1800)\end{array}$ & $\begin{array}{r}12.4(1800) \\
10.1(1470) \\
10.6(1540) \\
9.2(1330) \\
8.6(1240) \\
10.2(1480)\end{array}$ \\
\hline Averago & $\begin{array}{l}21.9(3180) \\
22.6(3280) \\
24.1(3500) \\
18.6(2700) \\
20.1(2920) \\
21.5(3120)\end{array}$ & $\begin{array}{r}12.1(1760) \\
10.3(1500) \\
9.3(1350) \\
13.1(1900) \\
13.5(1960) \\
11.6(1690)\end{array}$ & $\begin{array}{r}11.8(1710) \\
9.9(1430) \\
15.0(2170) \\
13.0(1890) \\
15.6(2260) \\
13.0(1890)\end{array}$ & $\begin{array}{r}10.8(1560) \\
11.9(1730) \\
11.1(1610) \\
9.8(1420) \\
13.9(2020) \\
11.5(1670)\end{array}$ & $\begin{array}{r}15.4(2240) \\
13.9(2020) \\
8.6(1240) \\
11.4(1660) \\
10.8(1570) \\
12.1(1750)\end{array}$ \\
\hline
\end{tabular}


INDIVIDUAL TEST VALUES

\section{PHASE II UNSTRESSED THERMAL AGING}

.
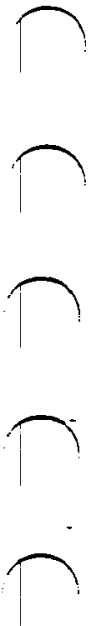
Table 3.2.1-A Phase II. Unstressed Thermal Aging-PPQ Individual Test Values-Lap Shear

Initial Values

\begin{tabular}{|c|c|c|c|c|c|c|c|c|c|}
\hline \multicolumn{2}{|c|}{$219 \mathrm{~K}(-650 \mathrm{~F})$} & \multicolumn{2}{|c|}{ Ambient } & \multicolumn{2}{|c|}{$422 \mathrm{~K}\left(300^{\circ} \mathrm{F}\right)$} & \multicolumn{2}{|c|}{$505 \mathrm{~K}\left(450^{\circ} \mathrm{F}\right)$} & \multicolumn{2}{|c|}{$533 \mathrm{~K}\left(500^{\circ} \mathrm{F}\right)$} \\
\hline $\mathrm{MPa}$ & psi & $\mathrm{MPa}$ & psi & $\mathrm{MPa}$ & psi & $\mathrm{MPa}$ & psi & $\mathrm{MPa}$ & psi \\
\hline $\begin{array}{l}36.8 \\
30.1 \\
22.2 \\
32.8 \\
35.2 \\
36.6 \\
32.7 \\
35.3 \\
33.8 \\
36.1 \\
33.2\end{array}$ & $\begin{array}{l}(5330) \\
(4360) \\
(3220) \\
(4760) \\
(5100) \\
(5310) \\
(4740) \\
(5130) \\
(4900) \\
(5240) \\
(4810)\end{array}$ & $\begin{array}{l}29.3 \\
35.2 \\
29.1 \\
31.0 \\
33.2 \\
34.2 \\
33.2 \\
30.9 \\
35.4 \\
31.2 \\
32.3\end{array}$ & $\begin{array}{l}(4260) \\
(5100) \\
(4220) \\
(4500) \\
(4820) \\
(4960) \\
(4820) \\
(4480) \\
(5140) \\
(4520) \\
(4680)\end{array}$ & $\begin{array}{l}25.0 \\
26.1 \\
25.8 \\
21.7 \\
22.7 \\
29.6 \\
27.9 \\
24.7 \\
25.5 \\
23.4 \\
25.2\end{array}$ & $\begin{array}{l}(3620) \\
(3780) \\
(3740) \\
(3150) \\
(3290) \\
(4300) \\
(4050) \\
(3580) \\
(3700) \\
(3380) \\
(3660)\end{array}$ & $\begin{array}{l}18.3 \\
21.3 \\
17.8 \\
20.9 \\
22.6 \\
23.2 \\
20.7 \\
19.8 \\
21.8 \\
18.6 \\
20.5\end{array}$ & $\begin{array}{l}(2660) \\
(3090) \\
(2580) \\
(3030) \\
(3280) \\
(3360) \\
(3000) \\
(2870) \\
(3160) \\
(2700) \\
(2970)\end{array}$ & $\begin{array}{l}11.0 \\
13.9 \\
15.6 \\
12.7 \\
19.7 \\
17.0 \\
14.1 \\
16.4 \\
10.6 \\
20.8 \\
15.2\end{array}$ & $\begin{array}{r}(1600) \\
(2020) \\
(2270) \\
(1840) \\
(2860) \\
(2460) \\
(2050) \\
(2380) \\
(1530) \\
(3020) \\
(2200) \\
\text { Average }\end{array}$ \\
\hline
\end{tabular}

Lap Shear 100 Hours Aging at 505K (450\%)

\begin{tabular}{|c|c|c|c|c|c|c|c|c|}
\hline \multirow{2}{*}{\multicolumn{2}{|c|}{$219 \mathrm{~K}(-650 \mathrm{~F})$}} & \multirow{2}{*}{\multicolumn{4}{|c|}{$\begin{array}{l}\text { Test Temperature } \\
422 \mathrm{~K}\left(300^{\circ} \mathrm{F}\right)\end{array}$}} & \multirow{2}{*}{\multicolumn{2}{|c|}{$505 \mathrm{~K}\left(450^{\circ} \mathrm{F}\right)$}} & \\
\hline & & & & & & & & \\
\hline $\mathrm{MPa}$ & psi & $\underline{\mathrm{MPa}}$ & psi & $\mathrm{MPa}$ & psi & $\mathrm{MPa}$ & psi & \\
\hline $\begin{array}{l}37.7 \\
35.6 \\
33.3 \\
35.0 \\
32.8 \\
34.9\end{array}$ & $\begin{array}{l}(5470) \\
(5170) \\
(4830) \\
(5070) \\
(4760) \\
(5060)\end{array}$ & $\begin{array}{l}34.9 \\
30.3 \\
33.6 \\
34.3 \\
28.7 \\
32.3\end{array}$ & $\begin{array}{l}(5060) \\
(4400) \\
(4870) \\
(4980) \\
(4160) \\
(4690)\end{array}$ & $\begin{array}{l}25.4 \\
16.9 \\
19.3 \\
28.5 \\
28.1 \\
23.6\end{array}$ & $\begin{array}{l}(3690) \\
(2450) \\
(2800) \\
(4130) \\
(4070) \\
(3430)\end{array}$ & $\begin{array}{l}20.0 \\
24.1 \\
20.4 \\
21.2 \\
18.0 \\
20.8\end{array}$ & $\begin{array}{l}(2900) \\
(3490) \\
(2960) \\
(3070) \\
(2610) \\
(3010)\end{array}$ & Average \\
\hline
\end{tabular}

500 Hours Aging at $505 \mathrm{~K}\left(450^{\circ} \mathrm{F}\right)$

\begin{tabular}{|c|c|c|c|c|c|c|c|c|}
\hline $\mathrm{MPg}$ & psi & $\mathrm{MPa}$ & psi & $\mathrm{MPa}$ & $\mathrm{psi}$ & $\mathrm{MPa}$ & psi & \\
\hline $\begin{array}{l}34.9 \\
32.1 \\
36.4 \\
33.7 \\
28.5 \\
33.1\end{array}$ & $\begin{array}{l}(5060) \\
(4660) \\
(5280) \\
(4890) \\
(4130) \\
(4800)\end{array}$ & $\begin{array}{l}35.9 \\
35.4 \\
33.9 \\
30.1 \\
36.1 \\
34.3\end{array}$ & $\begin{array}{l}(5200) \\
(5140) \\
(4920) \\
(4360) \\
(5240) \\
(4970)\end{array}$ & $\begin{array}{l}28.6 \\
24.2 \\
21.2 \\
27.4 \\
25.7 \\
25.4\end{array}$ & $\begin{array}{l}(4140) \\
(3510) \\
(3080) \\
(3970) \\
(3730) \\
(3690)\end{array}$ & $\begin{array}{l}24.1 \\
22.1 \\
21.9 \\
21.2 \\
23.6 \\
22.6\end{array}$ & $\begin{array}{l}(3490) \\
(3200) \\
(3180) \\
(3080) \\
(3420) \\
(3270)\end{array}$ & Average \\
\hline
\end{tabular}

1000 Hours Aging at $505 \mathrm{~K}\left(450^{\circ} \mathrm{F}\right)$

\begin{tabular}{|c|c|c|c|c|c|c|c|}
\hline $\mathrm{MPa}$ & psi & $\mathrm{MPa}$ & psi & $\mathrm{MPa}$ & psi & $\mathrm{MPg}$ & psi \\
\hline $\begin{array}{l}27.9 \\
30.3 \\
33.9 \\
26.5 \\
32.8 \\
30.3\end{array}$ & $\begin{array}{r}(4050) \\
(4390) \\
(4910) \\
(3840) \\
(4760) \\
(4390)\end{array}$ & $\begin{array}{l}37.9 \\
33.0 \\
28.6 \\
27.7 \\
35.2 \\
32.5\end{array}$ & $\begin{array}{l}(5490) \\
(4790) \\
(4140) \\
(4020) \\
(5110) \\
(4710)\end{array}$ & $\begin{array}{l}30.3 \\
24.1 \\
25.1 \\
27.0 \\
27.6 \\
26.8\end{array}$ & $\begin{array}{l}(4400) \\
(3500) \\
(3640) \\
(3920) \\
(4000) \\
(3890)\end{array}$ & $\begin{array}{l}25.8 \\
27.2 \\
24.1 \\
24.8 \\
25.1 \\
25.4\end{array}$ & $\begin{array}{l}(3740) \\
(3940) \\
(3500) \\
(3600) \\
(3640) \\
(3680) \text { Average }\end{array}$ \\
\hline
\end{tabular}

2000 Hours Aging at $505\left(450^{\circ} \mathrm{F}\right)$

\begin{tabular}{|c|c|c|c|c|c|c|c|}
\hline $\mathrm{MPa}$ & psi & $\mathrm{MPa}$ & psi & $\mathrm{MPa}$ & psi & $\underline{\mathrm{MPa}}$ & psi \\
\hline $\begin{array}{l}31.0 \\
32.7 \\
18.5 \\
23.4 \\
27.7 \\
26.7\end{array}$ & $\begin{array}{l}(4500) \\
(4740) \\
(2680) \\
(3400) \\
(4020) \\
(3870)\end{array}$ & $\begin{array}{l}28.6 \\
21.1 \\
14.6 \\
29.5 \\
24.8 \\
23.7\end{array}$ & $\begin{array}{l}(4140) \\
(3060) \\
(2120) \\
(4280) \\
(3600) \\
(3440)\end{array}$ & $\begin{array}{l}29.0 \\
21.2 \\
21.4 \\
20.0 \\
24.8 \\
23.3\end{array}$ & $\begin{array}{l}(4200) \\
(3080) \\
(3100) \\
(2900) \\
(3600) \\
(3380)\end{array}$ & $\begin{array}{l}22.3 \\
20.7 \\
19.4 \\
20.3 \\
22.8 \\
21.1\end{array}$ & $\begin{array}{l}(3240) \\
(3000) \\
(2820) \\
(2940) \\
(3310) \\
(3060) \text { Average }\end{array}$ \\
\hline
\end{tabular}

5000 Hours Aging at $505 \mathrm{~K}\left(450^{\circ} \mathrm{F}\right)$

\begin{tabular}{|c|c|c|c|c|c|c|c|}
\hline $\mathrm{MPa}$ & psi & $\mathrm{MPa}$ & psi & $\mathrm{MPa}$ & osi & $\mathrm{MPa}$ & psi \\
\hline $\begin{array}{l}21.9 \\
13.0 \\
10.8 \\
12.0 \\
22.1 \\
15.9\end{array}$ & $\begin{array}{l}\left(\begin{array}{l}3180) \\
1880 \\
1570\end{array}\right) \\
(1740) \\
3200 \\
(2310)\end{array}$ & $\begin{array}{r}24.0 \\
14.1 \\
7.9 \\
19.0 \\
18.2 \\
16.6\end{array}$ & $\begin{array}{l}\left(\begin{array}{l}3480) \\
2040\end{array}\right. \\
1140) \\
2760) \\
2640) \\
(2410)\end{array}$ & $\begin{array}{l}16.4 \\
16.1 \\
13.3 \\
16.7 \\
13.4 \\
15.2\end{array}$ & $\begin{array}{r}(2380) \\
(2340) \\
1930) \\
(2420) \\
(1950) \\
(2200)\end{array}$ & $\begin{array}{r}12.5 \\
16.6 \\
9.6 \\
14.6 \\
18.6 \\
14.3\end{array}$ & $\begin{array}{l}\left(\begin{array}{l}1810 \\
2400 \\
1400\end{array}\right. \\
2110 \\
2690 \\
2080\end{array}$ \\
\hline
\end{tabular}


Table 3.2.1-B Phase II Unstressed Thermal Aging-PPQ

Individual Test Values-Peel

Initial Values

\begin{tabular}{|c|c|c|c|c|c|c|c|c|c|}
\hline \multicolumn{2}{|c|}{$219 \mathrm{~K}(-650 \mathrm{~F})$} & \multicolumn{2}{|c|}{ Ambient } & \multicolumn{2}{|c|}{$422 \mathrm{~K}\left(300^{\circ} \mathrm{F}\right)$} & \multicolumn{2}{|c|}{$505 \mathrm{~K}\left(450^{\circ} \mathrm{E}\right)$} & \multicolumn{2}{|c|}{$533 \mathrm{~K}\left(500^{\circ} \mathrm{F}\right)$} \\
\hline$\underline{N} \cdot \mathrm{M}$ & $\mathrm{lb} /$ in & $\underline{N} \cdot M$ & $10 /$ in & $\underline{N} \cdot M$ & $1 \mathrm{~b} / \mathrm{in}$ & $\underline{N} \cdot M$ & $\mathrm{lb} /$ in & $\underline{N \cdot M}$ & $\mathrm{lb} /$ in \\
\hline $\begin{array}{l}0.56 \\
0.58 \\
0.81 \\
0.61 \\
0.77 \\
0.67\end{array}$ & $\begin{array}{l}(5.0) \\
(5.2) \\
(7.2) \\
(5.4) \\
(6.8) \\
(5.9)\end{array}$ & $\begin{array}{l}0.56 \\
0.58 \\
0.61 \\
0.63 \\
0.58 \\
0.60\end{array}$ & $\begin{array}{r}(5.0) \\
(5.2) \\
(5.4) \\
(5.6) \\
(5.2) \\
(5.3)\end{array}$ & $\begin{array}{l}0.77 \\
0.86 \\
0.79 \\
0.86 \\
0.68 \\
0.79\end{array}$ & $\begin{array}{l}(6.8) \\
(7.6) \\
(7.0) \\
(7.6) \\
(6.0) \\
(7.0)\end{array}$ & $\begin{array}{l}1.22 \\
0.45 \\
0.90 \\
1.04 \\
0.97 \\
0.91\end{array}$ & $\begin{array}{l}(10.8) \\
(4.0) \\
(8.0) \\
(9.2) \\
(8.6) \\
(8.1)\end{array}$ & $\begin{array}{l}1.02 \\
0.31 \\
0.93 \\
0.97 \\
1.31 \\
0.90\end{array}$ & $\begin{array}{l}(9.0) \\
(2.8) \\
(8.2) \\
(8.6) \\
(11.6) \\
(8.0)\end{array}$ \\
\hline & & & Afte & Hours & ing a & $(450$ & & & \\
\hline$\underline{N} \cdot M$ & $\mathrm{lb} / \mathrm{in}$ & $\underline{N} \cdot M$ & $1 b /$ in & $\underline{N \cdot M}$ & $\mathrm{lb} / \mathrm{in}$ & $\underline{N} \cdot M$ & $\mathrm{lb} / \mathrm{in}$ & & \\
\hline $\begin{array}{l}0.58 \\
0.58 \\
0.58 \\
0.58 \\
0.74 \\
0.61\end{array}$ & $\begin{array}{r}(5.2) \\
(5.2) \\
(5.2) \\
(5.0) \\
(6.6) \\
(5.4)\end{array}$ & $\begin{array}{l}0.58 \\
0.63 \\
0.58 \\
0.54 \\
0.74 \\
0.62\end{array}$ & $\begin{array}{l}(5.2) \\
(5.6) \\
(5.2) \\
(4.8) \\
(6.6) \\
(5.5)\end{array}$ & $\begin{array}{l}0.74 \\
0.74 \\
0.70 \\
0.56 \\
0.70 \\
0.69\end{array}$ & $\begin{array}{l}(6.6) \\
(6.6) \\
(6.2) \\
(5.0) \\
(6.2) \\
(6.1)\end{array}$ & $\begin{array}{l}0.81 \\
0.70 \\
0.68 \\
0.77 \\
0.77 \\
0.74\end{array}$ & $\begin{array}{l}(7.2) \\
(6.2) \\
(6.0) \\
(6.8) \\
(6.8) \\
(6.6)\end{array}$ & & \\
\hline
\end{tabular}

After 500 Hours Aging at 505K (450\%)

\begin{tabular}{|c|c|c|c|c|c|c|c|}
\hline$N \cdot M$ & $1 \mathrm{~b} /$ in & $N \cdot M$ & $\mathrm{lb} / \mathrm{in}$ & $N \cdot M$ & $\mathrm{lb} / \mathrm{in}$ & $\mathrm{N} \cdot \mathrm{M}$ & $\mathrm{lb} / \mathrm{in}$ \\
\hline $\begin{array}{l}0.56 \\
0.66 \\
0.70 \\
0.63 \\
0.54 \\
0.62\end{array}$ & $\begin{array}{l}(5.0) \\
(5.8) \\
(6.2) \\
(5.6) \\
(4.8) \\
(5.5)\end{array}$ & $\begin{array}{l}0.79 \\
0.66 \\
0.56 \\
0.56 \\
0.63 \\
0.64\end{array}$ & $\begin{array}{l}(7.0) \\
(5.8) \\
(5.0) \\
(5.0) \\
(5.6) \\
(5.7)\end{array}$ & $\begin{array}{l}0.61 \\
0.61 \\
0.61 \\
0.61 \\
0.61 \\
0.61\end{array}$ & $\begin{array}{l}(5.4) \\
(5.4) \\
(5.4) \\
(5.4) \\
(5.4) \\
(5.4)\end{array}$ & $\begin{array}{l}0.70 \\
0.88 \\
0.88 \\
0.56 \\
0.72 \\
0.74\end{array}$ & $\begin{array}{l}(6.2) \\
(7.8) \\
(7.8) \\
(5.0) \\
(6.4) \\
(6.6)\end{array}$ \\
\hline
\end{tabular}

After 1000 Hours Aging at $505 \mathrm{~K}\left(450^{\circ} \mathrm{F}\right)$

\begin{tabular}{|c|c|c|c|c|c|c|c|}
\hline$N \cdot M$ & $1 \mathrm{~b} /$ in & $\underline{N} \cdot M$ & $\mathrm{lb} / \mathrm{in}$ & $\underline{N} \cdot \mathbf{M}$ & $\mathrm{lb} / \mathrm{in}$ & $\mathrm{N} \cdot \mathrm{M}$ & $\mathrm{lb} / \mathrm{in}$ \\
\hline $\begin{array}{l}0.63 \\
0.77 \\
0.63 \\
0.84 \\
0.54 \\
0.68\end{array}$ & $\begin{array}{l}(5.6) \\
(6.8) \\
(5.6) \\
(7.4) \\
(4.8) \\
(6.0)\end{array}$ & $\begin{array}{l}0.68 \\
0.66 \\
0.66 \\
0.61 \\
0.70) \\
0.66\end{array}$ & $\begin{array}{l}(6.0) \\
(5.8) \\
(5.8) \\
(5.4) \\
(6.2) \\
(5.8)\end{array}$ & $\begin{array}{l}0.77 \\
0.77 \\
0.77 \\
0.68 \\
0.77 \\
0.75\end{array}$ & $\begin{array}{l}(6.8) \\
(6.8) \\
(6.8) \\
(6.0) \\
(6.8) \\
(6.6)\end{array}$ & $\begin{array}{l}0.61 \\
0.99 \\
0.68 \\
0.75 \\
0.81 \\
0.77\end{array}$ & $\begin{array}{l}(5.4) \\
(8.8) \\
(6.0) \\
(6.6) \\
(7.2) \\
(6.8)\end{array}$ \\
\hline
\end{tabular}

After 2000 Hours Aging at $505 \mathrm{~K}\left(450^{\circ} \mathrm{F}\right)$

\begin{tabular}{|c|c|c|c|c|c|c|c|}
\hline $\mathrm{N} \cdot \mathrm{M}$ & $\mathrm{lb} / \mathrm{in}$ & $N \cdot M$ & $\mathrm{lb} / \mathrm{in}$ & $\underline{N} \cdot M$ & $\mathrm{lb} / \mathrm{in}$ & $\underline{N \cdot M}$ & $10 /$ in \\
\hline $\begin{array}{l}0.54 \\
0.56 \\
0.50 \\
0.36 \\
0.45 \\
0.48\end{array}$ & $\begin{array}{l}(4.8) \\
(5.0) \\
(4.4) \\
(3.2) \\
(4.0) \\
(4.3)\end{array}$ & $\begin{array}{l}0.43 \\
0.50 \\
0.45 \\
0.66 \\
0.50 \\
0.51\end{array}$ & $\begin{array}{r}(3.8) \\
(4.4) \\
(4.0) \\
(5.8) \\
(4.4) \\
(4.5)\end{array}$ & $\begin{array}{l}0.41 \\
0.41 \\
0.34 \\
0.54 \\
0.54 \\
0.45\end{array}$ & $\begin{array}{l}(3.6) \\
(3.6) \\
(3.0) \\
(4.8) \\
(4.8) \\
(4.0)\end{array}$ & $\begin{array}{l}0.56 \\
0.90 \\
0.56 \\
0.81 \\
0.95 \\
0.76\end{array}$ & $\begin{array}{l}(5.0) \\
(8.0) \\
(5.0 \\
(7.2) \\
(8.4) \\
(6.7)\end{array}$ \\
\hline
\end{tabular}

After 5000 Hours Aging at $505 \mathrm{~K}\left(450^{\circ} \mathrm{F}\right)$

\begin{tabular}{|c|c|c|c|c|c|c|c|}
\hline$\underline{N \cdot M}$ & $1 b /$ ln & $\underline{N \cdot M}$ & $1 \mathrm{~b} /$ in & $N \cdot M$ & $1 \mathrm{~b} / \mathrm{in}$ & $\underline{N \cdot M}$ & $\mathrm{lb} / \mathrm{in}$ \\
\hline $\begin{array}{l}0.29 \\
0.27 \\
0.38 \\
0.45 \\
0.38 \\
0.36\end{array}$ & $\begin{array}{r}(2.6) \\
\left(\begin{array}{l}2.4 \\
3.4\end{array}\right) \\
(4.0) \\
(3.4)\end{array}$ & $\begin{array}{l}0.43 \\
0.43 \\
0.40 \\
0.40 \\
0.36 \\
0.40\end{array}$ & $\begin{array}{l}(3.8) \\
(3.8) \\
(3.6) \\
3.6) \\
3.2)\end{array}$ & $\begin{array}{l}0.43 \\
0.38 \\
0.29 \\
0.36 \\
0.13 \\
0.31\end{array}$ & $\begin{array}{l}(3.8) \\
(3.4) \\
(2.6) \\
(3.2) \\
(1.2)\end{array}$ & $\begin{array}{l}0.51 \\
0.43 \\
0.51 \\
0.36 \\
0.31 \\
0.43\end{array}$ & $\begin{array}{l}(4.6) \\
(3.8) \\
(4.6) \\
(3.2) \\
(2.8) \\
(3.8)\end{array}$ \\
\hline
\end{tabular}


Table 3.2.1-C Phase II Unstressed Thermal Aging - PPQ

Individual Test Values - Crack Extension

Initial Values

$\Upsilon$

$\bigcap$

7

\begin{tabular}{|c|c|c|c|c|c|c|c|c|c|}
\hline $219 \mathrm{~K}$ & $\left.-65^{\circ} \mathrm{F}\right)$ & \multicolumn{2}{|c|}{ Ambient } & \multicolumn{2}{|c|}{$422 \mathrm{~K}\left(300^{\circ} \mathrm{F}\right)$} & \multicolumn{2}{|c|}{$505 \mathrm{~K}\left(450^{\circ} \mathrm{F}\right.$} & \multicolumn{2}{|c|}{$533 \mathrm{~K}\left(500^{\circ} \mathrm{F}\right)$} \\
\hline$\underline{\mathrm{mr}}$ & Inch & $\mathrm{mm}$ & Inch & $\mathrm{mm}$ & Inch & $\mathrm{mm}$ & Inch & $\mathrm{mm}$ & Inch \\
\hline & $(0$ & 2 & & & $(0$ & 23.1 & & 0 & \\
\hline & & & & & & & & & \\
\hline 24 & 10.5 & 23.4 & $(0$. & 25 & 1 & 24 & 10 & 25.4 & 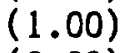 \\
\hline 28 & (1. & & (0. & 63 & & 23 & & & \\
\hline 23. & 10. & 24.4 & $(0$. & 22.6 & & 23.6 & & 24.1 & \\
\hline 4. & 10. & 24.9 & $(0.98)$ & 23.9 & & 23.6 & 10. & 24.6 & \\
\hline
\end{tabular}

Avg. $24.6(0.97) \quad \frac{23.9}{24.9(0.98)} \quad \frac{22.6}{23.9}(0.94) \quad \frac{23.6}{23.6}(0.93) \quad \frac{1.9}{24.6}(0.97)$

7

One Hour Aging At $505 \mathrm{~K}\left(450^{\circ} \mathrm{F}\right)$

$T$

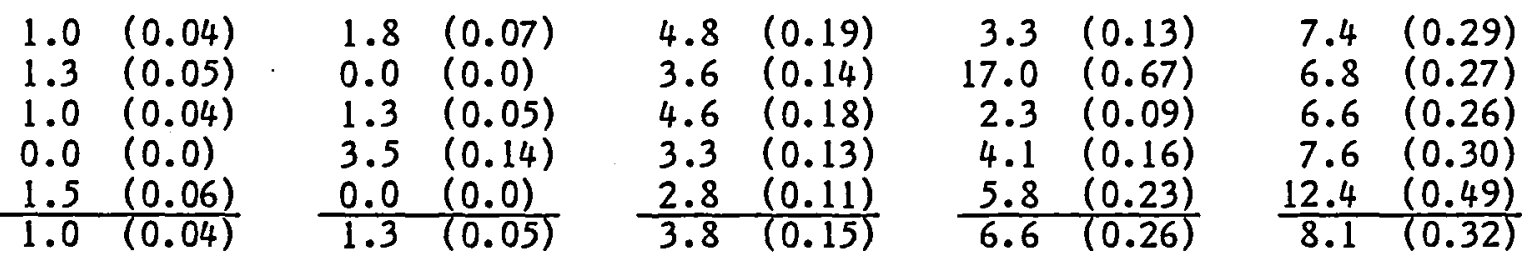

100 Hours Aging At $505 \mathrm{~K}\left(450^{\circ} \mathrm{F}\right)$

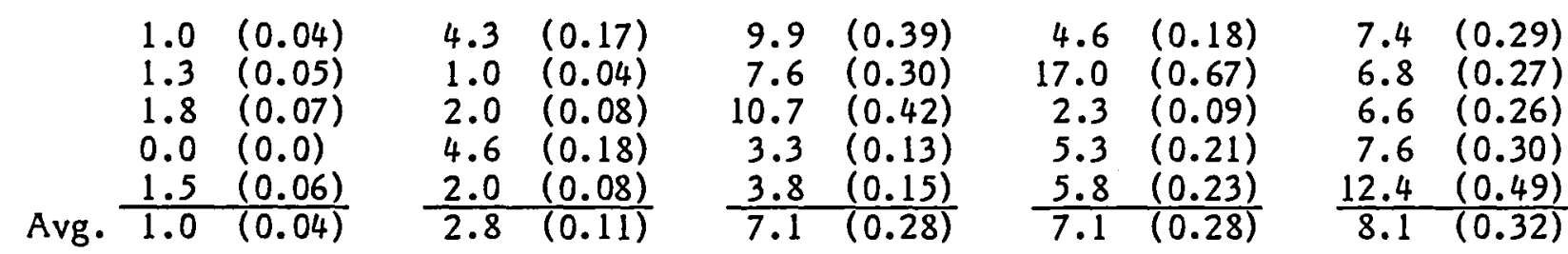

500 Hours Aging At 505K (450\% F)

$T$

$T$

Avg. $\begin{array}{lllllllll}1.5 & (0.06) \\ 1.0 & (0.04) & 0.0(0.0) & \frac{0.0}{1.3}(0.05) & \frac{2.8}{3.8}(0.11) & \frac{5.8}{6.15)} & (0.23) & \frac{12.4}{6.6} & (0.26)\end{array}$

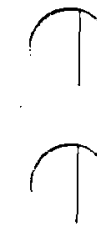

T

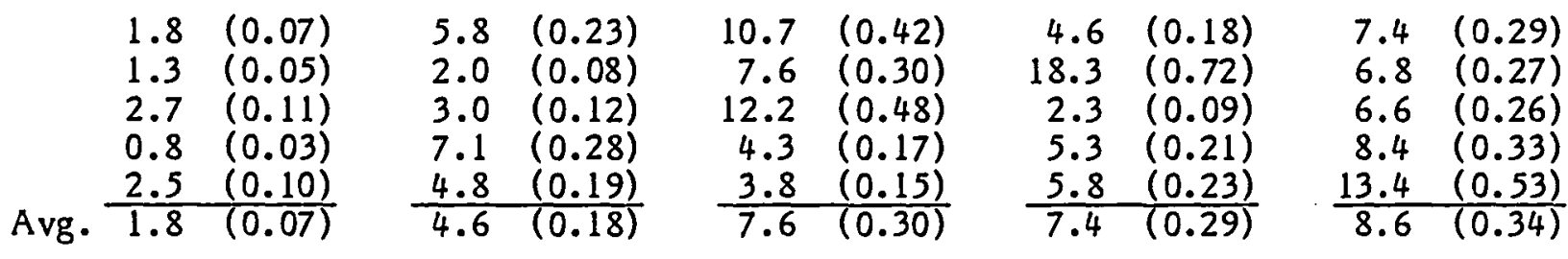

1000 Hours Aging At $505 \mathrm{~K}(450 \circ \mathrm{F})$

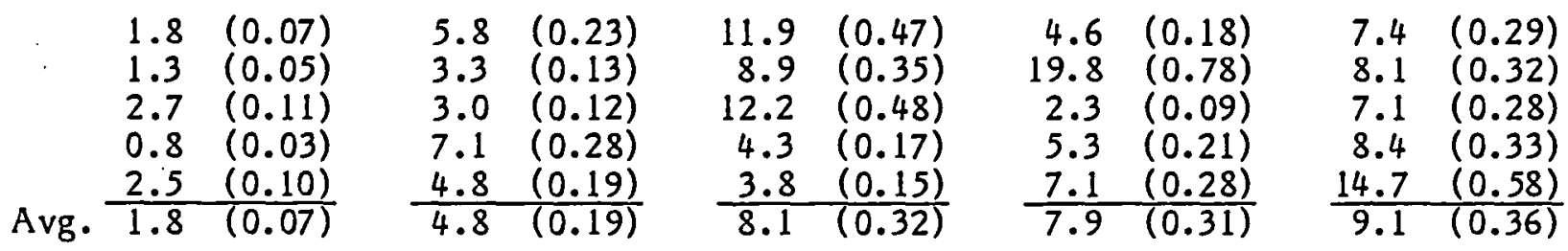


Table 3.2.1-C Phase II Unstressed Thermal Aging - PPQ Individual Test Values - Crack Extension (continued)

Initial Values

\begin{tabular}{lllllll}
$219 \mathrm{~K}(-650 \mathrm{~F})$ & Ambient & $422 \mathrm{~K}(3000 \mathrm{~F})$ & $505 \mathrm{~K}(450 \circ \mathrm{F}$ & \multicolumn{2}{c}{$533 \mathrm{~K}\left(5000^{\circ} \mathrm{F}\right)$} \\
$\mathrm{mm}$ & Inch & $\mathrm{mm}$ Inch & $\mathrm{mm}$ Inch & $\mathrm{mm}$ Inch & $\mathrm{mm}$ Inch \\
\hline
\end{tabular}

2000 Hours Aging At 505K (4500F)

\begin{tabular}{|c|c|c|c|c|c|c|c|c|c|}
\hline $\begin{array}{l}1.8 \\
1.3 \\
2.7 \\
0.8 \\
3.3 \\
2.0\end{array}$ & $\begin{array}{l}(0.07) \\
(0.05) \\
(0.11) \\
(0.03) \\
(0.13) \\
(0.08)\end{array}$ & $\begin{array}{l}5.8 \\
3.3 \\
3.8 \\
8.1 \\
4.8 \\
5.1\end{array}$ & $\begin{array}{r}(0.23) \\
(0.13) \\
(0.15) \\
(0.32) \\
(0.19) \\
(0.20)\end{array}$ & $\begin{array}{r}12.9 \\
9.6 \\
12.2 \\
5.1 \\
4.6 \\
8.9\end{array}$ & $\begin{array}{l}(0.51) \\
(0.38) \\
(0.48) \\
(0.20) \\
(0.18) \\
(0.35)\end{array}$ & $\begin{array}{r}4.6 \\
20.6 \\
2.3 \\
5.3 \\
7.1 \\
7.9\end{array}$ & $\begin{array}{l}(0.18) \\
(0.81) \\
(0.09) \\
(0.21) \\
(0.28) \\
(0.31)\end{array}$ & $\begin{array}{l}39.1 \\
20.3 \\
15.2 \\
17.5 \\
18.8 \\
22.1\end{array}$ & $\begin{array}{l}(1.54) \\
(0.80) \\
(0.60) \\
(0.69) \\
(0.74) \\
(0.87)\end{array}$ \\
\hline
\end{tabular}


Table 3.2.1-D. Phase II Unstressed Thermal Aging - LARC-TPI Individual Test Values - LAPSHEAR

Initial Values

$\frac{219 \mathrm{~K}(-650 \mathrm{~F})}{\mathrm{MPa}} \quad \frac{\text { Ambient }}{\mathrm{Psi}} \quad \frac{422 \mathrm{~K}(3000 \mathrm{~F})}{\mathrm{MPa}} \quad \frac{505 \mathrm{~K}(4500 \mathrm{~F})}{\mathrm{Mpa}} \quad \frac{533 \mathrm{~K}(5000 \mathrm{~F})}{\mathrm{Mpa}}$

$\begin{array}{llllllllll}34.8 & (5040) & 32.1 & (4660) & 21.9 & (3180) & 13.5 & (1960) & 6.6 & (960)\end{array}$

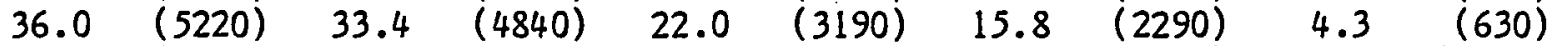

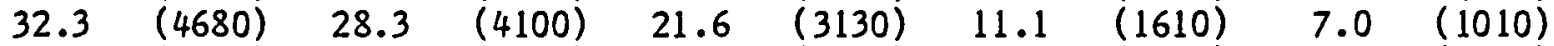

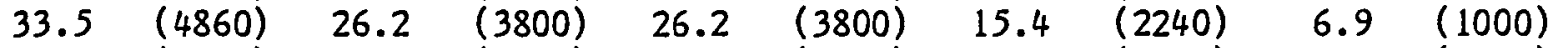

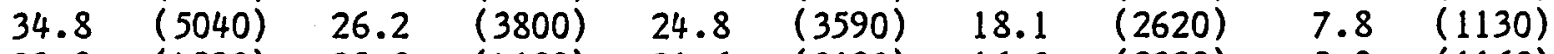

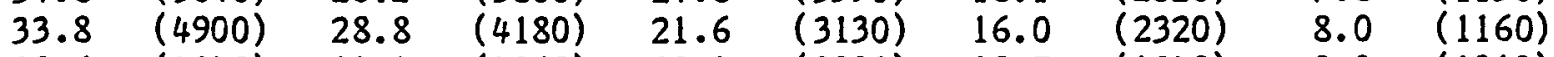

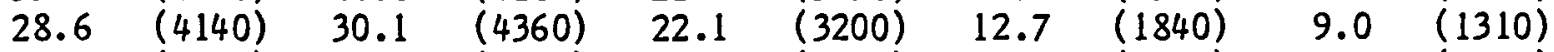

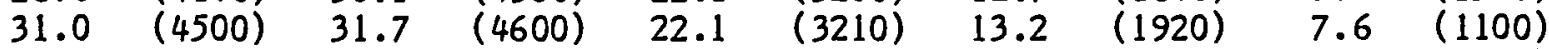

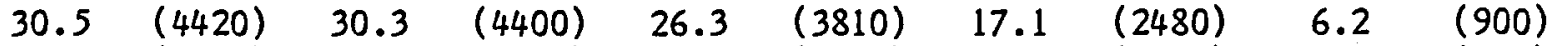

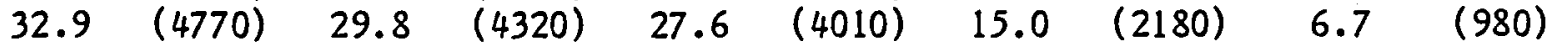

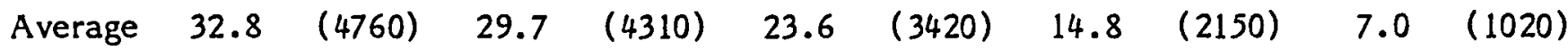

1000 Hours Aging at $505 \mathrm{~K}(450 \circ \mathrm{F})$

\begin{tabular}{llllllllll}
$\mathrm{MPa}$ & Psi & $\mathrm{Mpa}$ & $\mathrm{Psi}$ & $\mathrm{MPa}$ & $\mathrm{Psi}$ & $\mathrm{Mpa}$ & Psi \\
\hline
\end{tabular}

$\begin{array}{llllllll}30.6 & (4430) & 24.6 & (3560) & 23.2 & (3370) & 19.4 & (2810)\end{array}$

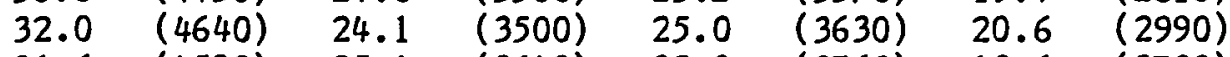

$\begin{array}{llllllll}31.6 & (4580) & 25.1 & (3640) & 25.9 & (3760) & 18.6 & (2700)\end{array}$

$\begin{array}{llllllll}29.7 & (4310) & 25.2 & (3650) & 20.1 & (2920) & 20.7 & (3000)\end{array}$

$\begin{array}{llllllll}33.6 & (4880) & 24.6 & (3970) & 22.2 & (3220) & 19.4 & (2810)\end{array}$

$\begin{array}{lllllllll}\text { Average } & 31.5 & (4570) & 25.2 & (3660) & 23.3 & (3380) & 19.7 & (2860)\end{array}$

2000 Hours Aging at $505 \mathrm{~K}\left(450^{\circ} \mathrm{F}\right)$

\begin{tabular}{llllllll}
$\mathrm{MPa}$ & Psi & $\mathrm{Mpa}$ & $\mathrm{Psi}$ & $\mathrm{MPa}$ & $\mathrm{Psi}$ & $\mathrm{Mpa}$ & Psi \\
\hline
\end{tabular}

$\begin{array}{llllllll}28.6 & (4140) & 27.1 & (3930) & 16.4 & (2380) & 21.7 & (3150)\end{array}$

$\begin{array}{llllllll}28.7 & (4160) & 26.1 & (3780) & 23.9 & (3470) & 22.6 & (3280)\end{array}$

$\begin{array}{llllllll}28.6 & (4140) & 25.2 & (3660) & 25.9 & (3760) & 19.0 & (2750)\end{array}$

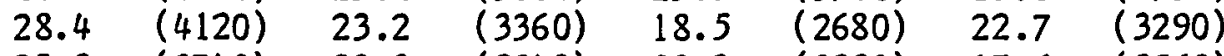

$\begin{array}{llllllll}25.8 & (3740) & 20.3 & (2940) & 22.2 & (3220) & 17.6 & (2560)\end{array}$

$\begin{array}{lllllllll}\text { Average } & 28.0 & (4060) & 24.3 & (3530) & 21.4 & (3100) & 20.8 & (3010)\end{array}$ 
Table 3.2.1-D. Phase II Unstressed Thermal Aging - LARC-TPI Individual Test Values - LAPSHEAR (Cont) 5000 Hours Aging at $505 \mathrm{~K}\left(450^{\circ} \mathrm{F}\right)$

\begin{tabular}{|c|c|c|c|c|c|c|c|}
\hline \multicolumn{2}{|c|}{$219 \mathrm{~K}(-650 \mathrm{~F})$} & \multicolumn{2}{|c|}{ Ambient } & \multicolumn{2}{|c|}{$422 \mathrm{~K}\left(300^{\circ} \mathrm{F}\right)$} & \multicolumn{2}{|c|}{$505 \mathrm{~K}(4500 \mathrm{~F})$} \\
\hline $\mathrm{MPa}$ & Psi & Mpa & Psi & $\mathrm{MPa}$ & Psi & Mpa & Psi \\
\hline $\begin{array}{l}30.8 \\
29.2 \\
32.4 \\
32.6 \\
28.3\end{array}$ & $\begin{array}{l}(4460) \\
(4240) \\
(4700) \\
(4720) \\
(4100)\end{array}$ & $\begin{array}{l}28.3 \\
28.8 \\
27.0 \\
27.6 \\
29.2\end{array}$ & $\begin{array}{l}(4100) \\
(4170) \\
(3910) \\
(4000) \\
(4230)\end{array}$ & $\begin{array}{l}27.6 \\
24.9 \\
28.3 \\
27.0 \\
24.7\end{array}$ & $\begin{array}{l}(4000) \\
(3610) \\
(4100) \\
(3920) \\
(3580)\end{array}$ & $\begin{array}{l}23.6 \\
23.6 \\
17.6 \\
21.1 \\
22.3\end{array}$ & $\begin{array}{l}(3420) \\
(3430) \\
(2560) \\
(3060) \\
(3230)\end{array}$ \\
\hline 30.6 & $(4440)$ & 28.1 & $(4080)$ & 26.5 & $(3840)$ & 21.6 & $(3140)$ \\
\hline
\end{tabular}

$\begin{array}{lllllllll}\text { Average } & 30.6 & (4440) & 28.1 & (4080) & 26.5 & (3840) & 21.6 & (3140)\end{array}$ 
Table 3.2.1-E. Phase II Unstressed Thermal Aging - LARC-TPI Individual Test Values - Peel

Initial Values

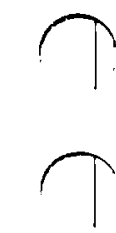

\begin{tabular}{|c|c|c|c|c|c|c|c|c|c|}
\hline$\frac{219 K}{N \cdot M}$ & $\frac{\left(-65^{0} \mathrm{~F}\right)}{\mathrm{lb} / \mathrm{in}}$ & $\mathrm{N} \cdot \frac{\mathrm{Amb}}{\mathrm{M}}$ & $\frac{\text { ient }}{1 \mathrm{~b} / \text { in }}$ & $\frac{422 K}{N \cdot M}$ & $\frac{\left(300^{\circ} \mathrm{F}\right)}{1 \mathrm{~b} / \mathrm{in}}$ & $\frac{505 K}{N \cdot M}$ & $\frac{\left(450^{\circ} \mathrm{F}\right)}{\mathrm{ib} / \mathrm{in}}$ & $\frac{533 K}{N \cdot M}$ & $\frac{\left(500^{\circ} \mathrm{F}\right)}{1 \mathrm{~b} / \mathrm{in}}$ \\
\hline $\begin{array}{l}0.45 \\
0.42 \\
0.36 \\
0.40 \\
\end{array}$ & $\begin{array}{l}(4.0) \\
(3.8) \\
(3.2) \\
(3.6)\end{array}$ & $\begin{array}{l}0.51 \\
\theta .47 \\
0.50 \\
0.50 \\
0.10\end{array}$ & $\begin{array}{l}(4.6) \\
(4.2) \\
(4.5) \\
(4.5) \\
\end{array}$ & $\begin{array}{l}0.42 \\
0.34 \\
0.40 \\
0.42 \\
\end{array}$ & $\begin{array}{l}(3.8) \\
(3.0) \\
(3.6) \\
(3.8) \\
(3.6)\end{array}$ & $\begin{array}{l}1.12 \\
0.87 \\
0.72 \\
0.56 \\
\end{array}$ & $\begin{array}{r}(10.0) \\
(7.8) \\
6.4) \\
(5.0) \\
72\end{array}$ & $\begin{array}{l}0.87 \\
0.90 \\
1.25 \\
1.05 \\
1.01\end{array}$ & $\begin{array}{r}\left(\begin{array}{r}7.8 \\
8.0\end{array}\right) \\
\left(\begin{array}{r}11.2 \\
9.4\end{array}\right) \\
\left(\begin{array}{c}0 \\
0\end{array}\right)\end{array}$ \\
\hline
\end{tabular}

Average

\begin{tabular}{llllllll}
0.45 & $(4.0)$ & 0.45 & $(4.0)$ & 0.31 & $(2.8)$ & 0.54 & $(4.8)$ \\
0.49 & $(4.4)$ & 0.45 & $(4.0)$ & 0.36 & $(3.2)$ & 0.72 & $(6.4)$ \\
0.40 & $(3.6)$ & 0.34 & $(3.0)$ & 0.31 & $(2.8)$ & 0.42 & $(3.8)$ \\
0.42 & $(3.8)$ & 0.28 & $(2.5)$ & 0.25 & $(2.2)$ & 0.38 & $(3.4)$ \\
\hline 0.45 & $(4.0)$ & 0.38 & $(3.4)$ & 0.31 & $(2.8)$ & 0.52 & $(4.6)$
\end{tabular}

Average

\section{Hours Aging at $505 \mathrm{~K}\left(450^{\circ} \mathrm{F}\right)$}

\begin{tabular}{ccccccccc} 
& 0.45 & $(4.0)$ & 0.40 & $(3.6)$ & 0.38 & $(3.4)$ & 0.47 & $(4.2)$ \\
& 0.40 & $(3.6)$ & 0.36 & $(3.2)$ & 0.34 & $(3.0)$ & 0.42 & $(3.8)$ \\
& 0.40 & $(3.6)$ & 0.29 & $(2.6)$ & 0.29 & $(2.6)$ & 0.42 & $(3.8)$ \\
Average & 0.45 & $(4.0)$ & 0.25 & $(2.2)$ & 0.27 & $(2.4)$ & 0.45 & $(4.0)$ \\
\hline & 0.42 & $(3.8)$ & 0.32 & $(2.9)$ & 0.32 & $(2.9)$ & 0.45 & $(4.0)$
\end{tabular}

$T$

5000 Hours Aging at $505 \mathrm{~K}\left(450^{\circ} \mathrm{F}\right)$

$T$

\begin{tabular}{rllllllll} 
& 0.37 & $(3.3)$ & 0.34 & $(3.0)$ & 0.35 & $(3.1)$ & 0.58 & $(5.2)$ \\
0.37 & $(3.3)$ & 0.35 & $(3.1)$ & 0.34 & $(3.0)$ & 0.52 & $(4.7)$ \\
0.37 & $(3.3)$ & 0.30 & $(2.7)$ & 0.37 & $(3.3)$ & 0.45 & $(4.0)$ \\
Average & 0.40 & $(3.6)$ & 0.35 & $(3.1)$ & 0.32 & $(2.9)$ & 0.39 & $(3.5)$ \\
\cline { 2 - 5 } & 0.38 & $(3.4)$ & 0.34 & $(3.0)$ & 0.36 & $(3.2)$ & 0.49 & $(4.4)$
\end{tabular}


Table 3.2.1-F . Phase II Unstressed Thermal Aging - LARC-TPI

Individual Test Values - Crack Extension

Initial Values

\begin{tabular}{|c|c|c|c|c|c|c|c|c|c|}
\hline \multicolumn{2}{|c|}{$219 \mathrm{~K}\left(-65^{\circ} \mathrm{F}\right)$} & \multicolumn{2}{|c|}{ Ambient } & \multicolumn{2}{|c|}{$422 \mathrm{~K}\left(300^{\circ} \mathrm{F}\right)$} & \multicolumn{2}{|c|}{$505 \mathrm{~K}$ (4500F) } & \multicolumn{2}{|c|}{$533 \mathrm{~K}\left(500^{\circ} \mathrm{F}\right)$} \\
\hline $\mathrm{mm}$ & Inch & $\mathrm{mm}$ & $\overline{\text { Inch }}$ & $\mathrm{mm}$ & Inch & $\mathrm{mm}$ & Inch & $\mathrm{mm}$ & Inch \\
\hline $\begin{array}{l}29.7 \\
29.0 \\
26.9 \\
30.5 \\
29.5 \\
29.2\end{array}$ & $\begin{array}{l}(1.17) \\
(1.14) \\
(1.06) \\
(1.20) \\
(1.16) \\
(1.15)\end{array}$ & $\begin{array}{l}29.2 \\
28.4 \\
28.4 \\
27.7 \\
28.2 \\
28.4\end{array}$ & $\begin{array}{l}(1.15) \\
(1.12) \\
(1.12) \\
(1.09) \\
(1.11) \\
(1.12)\end{array}$ & $\begin{array}{l}30.0 \\
30.0 \\
26.9 \\
29.7 \\
29.7 \\
29.2\end{array}$ & $\begin{array}{l}(1.18) \\
(1.18) \\
(1.06) \\
(1.17) \\
(1.17) \\
(1.15)\end{array}$ & $\begin{array}{l}20.4 \\
29.7 \\
28.7 \\
27.7 \\
27.2 \\
28.4\end{array}$ & $\begin{array}{l}(1.12) \\
(1.17) \\
(1.13) \\
(1.09) \\
(1.07) \\
(1.12)\end{array}$ & $\begin{array}{l}29.7 \\
27.9 \\
30.2 \\
27.4 \\
26.4 \\
28.4\end{array}$ & $\begin{array}{l}(1.17) \\
(1.10) \\
(1.19) \\
(1.08) \\
(1.04) \\
(1.12)\end{array}$ \\
\hline
\end{tabular}

100 Hours Aging at $505 \mathrm{~K}\left(450^{\circ} \mathrm{F}\right)$ - Length

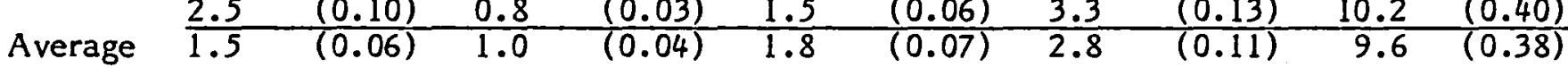

\begin{tabular}{rccccccccc}
1.0 & $(0.04)$ & 1.3 & $(0.05)$ & 2.3 & $(0.09)$ & 1.8 & $(0.07)$ & 10.2 & $(0.40)$ \\
1.3 & $(0.05)$ & 0.8 & $(0.03)$ & 2.0 & $(0.08)$ & 2.3 & $(0.09)$ & 9.9 & $(0.39)$ \\
1.8 & $(0.07)$ & 1.5 & $(0.06)$ & 1.8 & $(0.07)$ & 2.5 & $(0.10)$ & 9.4 & $(0.37)$ \\
1.0 & $(0.04)$ & 1.0 & $(0.04)$ & 1.0 & $(0.04)$ & 3.6 & $(0.14)$ & 9.1 & $(0.36)$ \\
2.5 & $(0.10)$ & 0.8 & $(0.03)$ & 1.5 & $(0.06)$ & 3.3 & $(0.13)$ & 10.2 & $(0.40)$ \\
\hline 1.5 & $(0.06)$ & 1.0 & $(0.04)$ & 1.8 & $(0.07)$ & 2.8 & $(0.11)$ & 9.6 & $(0.38)$
\end{tabular}

500 Hours Aging at $505 \mathrm{~K}\left(450^{\circ} \mathrm{F}\right)$ - Length

\begin{tabular}{|c|c|c|c|c|c|c|c|}
\hline \multirow[b]{2}{*}{$\begin{array}{l}1.8 \\
1.3 \\
1.8 \\
1.5 \\
2.5 \\
1.8\end{array}$} & \multicolumn{5}{|c|}{500 Hours Aging at $505 \mathrm{~K}\left(450^{\circ} \mathrm{F}\right)-$} & \multicolumn{2}{|c|}{ Length } \\
\hline & $\begin{array}{l}(0.07) \\
(0.05) \\
(0.07) \\
(0.06) \\
(0.10) \\
(0.07)\end{array}$ & $\begin{array}{l}1.3 \\
0.8 \\
1.5 \\
1.0 \\
0.8 \\
1.0\end{array}$ & $\begin{array}{l}(0.05) \\
(0.03) \\
(0.06) \\
(0.04) \\
(0.03) \\
(0.04)\end{array}$ & $\begin{array}{l}2.3 \\
2.0 \\
1.8 \\
2.0 \\
2.0 \\
2.0\end{array}$ & $\begin{array}{l}(0.09) \\
(0.08) \\
(0.07) \\
(0.08) \\
(0.08) \\
(0.08)\end{array}$ & $\begin{array}{l}1.8 \\
3.3 \\
3.3 \\
3.6 \\
3.3 \\
3.0\end{array}$ & $\begin{array}{l}(0.07) \\
(0.13) \\
(0.13) \\
(0.14) \\
(0.13) \\
(0.12)\end{array}$ \\
\hline
\end{tabular}

1000 Hours Aging at $505 \mathrm{~K}(450 \circ \mathrm{F})$ - Length

Average

$\begin{array}{llll}2.3 & (0.09) \quad 2.3 & (0.09) \quad 3.3\end{array}$

\begin{tabular}{llllllll}
1.8 & $(0.07)$ & 2.3 & $(0.09)$ & 2.3 & $(0.09)$ & 3.3 & $(0.13)$ \\
1.3 & $(0.05)$ & 1.8 & $(0.07)$ & 3.0 & $(0.12)$ & 3.3 & $(0.13)$ \\
1.8 & $(0.07)$ & 2.8 & $(0.11)$ & 2.8 & $(0.11)$ & 4.1 & $(0.16)$ \\
1.5 & $(0.06)$ & 1.8 & $(0.07)$ & 2.0 & $(0.08)$ & 3.6 & $(0.14)$ \\
2.5 & $(0.10)$ & 0.8 & $(0.03)$ & 3.0 & $(0.12)$ & 3.3 & $(0.13)$ \\
\hline 1.8 & $(0.07)$ & 1.8 & $(0.07)$ & 2.5 & $(0.10)$ & 3.6 & $(0.14)$
\end{tabular}


Table 3.2.1-F . Phase II Unstressed Thermal Aging - LARC-TPI Individual Test Values - Crack Extension (Cont) 2000 Hours Aging at 505K (450\%F) - Length

\begin{tabular}{|c|c|c|c|c|c|c|c|}
\hline \multicolumn{2}{|c|}{$219 \mathrm{~K}\left(-65^{\circ} \mathrm{F}\right)$} & \multicolumn{2}{|c|}{ Ambient } & \multicolumn{2}{|c|}{$422 \mathrm{~K}\left(300^{\circ} \mathrm{F}\right)$} & \multicolumn{2}{|c|}{$505 \mathrm{~K}\left(450^{\circ} \mathrm{F}\right)$} \\
\hline $\mathrm{mm}$ & Inch & $\mathrm{mm}$ & Inch & $\mathrm{mm}$ & Inch & $\mathrm{mm}$ & Inch \\
\hline $\begin{array}{l}2.3 \\
2.0 \\
2.8 \\
1.5 \\
2.5\end{array}$ & $\begin{array}{l}(0.09) \\
(0.08) \\
(0.11) \\
(0.06) \\
(0.10)\end{array}$ & $\begin{array}{l}2.3 \\
2.5 \\
2.8 \\
2.5 \\
0.8\end{array}$ & $\begin{array}{l}(0.09) \\
(0.10) \\
(0.11) \\
(0.10) \\
(0.03)\end{array}$ & $\begin{array}{l}2.3 \\
3.0 \\
2.8 \\
2.8 \\
3.0\end{array}$ & $\begin{array}{l}(0.09) \\
(0.12) \\
(0.11) \\
(0.11) \\
(0.12)\end{array}$ & $\begin{array}{l}3.3 \\
3.3 \\
4.1 \\
3.6 \\
5.1\end{array}$ & $\begin{array}{l}(0.13) \\
(0.13) \\
(0.16) \\
(0.14) \\
(0.20)\end{array}$ \\
\hline 2.3 & $(0.09)$ & 2.3 & $(0.09)$ & 2.8 & $(0.11)$ & 3.8 & $(0.15)$ \\
\hline
\end{tabular}

5000 Hours Aging at $505 \mathrm{~K}$ (4500F) - Length

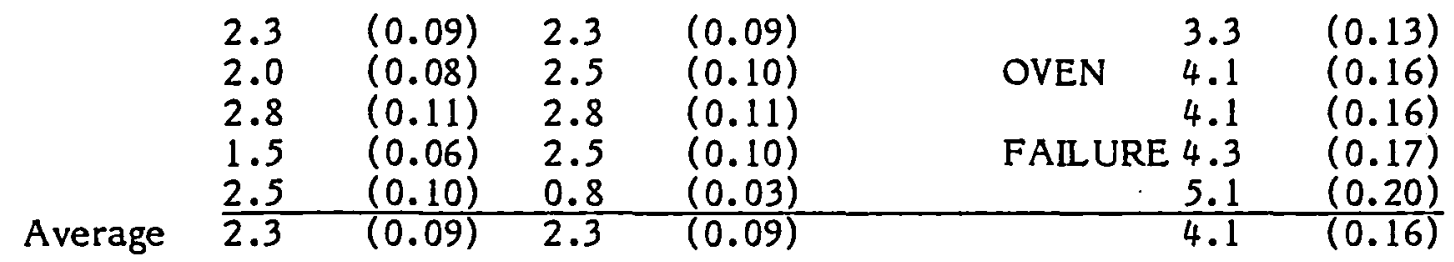




\section{PHASE II STRESSED THERMAL AGING INDIVIDUAL TEST VALUES}




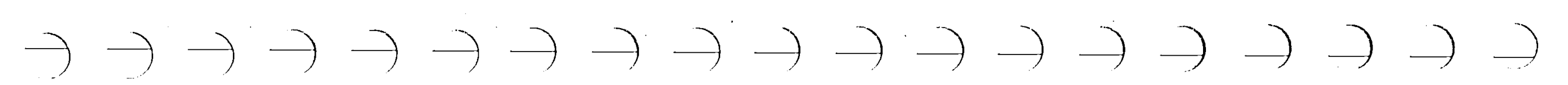

TABLE 3.2.2-A PHASE II STRESSED THERMAL AGING-PPQ INDIVIDUAL TEST VALUES -- LAP SHEAR

Stress

Percent of

Exposure

Exposure Time

Ultimate

Stress Load Temperature

Initial $\quad 100$ Hours

1000 Hours

3000 Hours

5000 Hours

\begin{tabular}{llllllllllllllll}
$\mathrm{MPa}$ & $\mathrm{psi}$ & $\mathrm{K}$ & $(\mathrm{OF})$ & $\mathrm{MPa}$ & psi & $\mathrm{MPa}$ & $\mathrm{psi}$ & $\mathrm{MPa}$ & $\mathrm{psi}$ & $\mathrm{MPa}$ & $\mathrm{psi}$ & $\mathrm{MPa}$ & $\mathrm{psi}$ \\
\hline
\end{tabular}

\section{5}

25

Average

$\begin{array}{llll}8.28 & (1200) & 219 & (-65) \\ 8.28 & (1200) & 219 & (-65) \\ 8.28 & (1200) & 219 & (-65)\end{array}$

50

50

50

Average

$\begin{array}{llll}10.3 & (1500) & 219 & (-65) \\ 10.3 & (1500) & 219 & (-65) \\ 10.3 & (1500) & 219 & (-65)\end{array}$

$10.3(1500) \quad 219 \quad(-65)$

\begin{tabular}{llllllllll}
29.4 & $(4270)$ & 36.2 & $(5250)$ & 36.8 & $(5340)$ & 29.5 & $(4280)$ & 40.4 & $(5860)$ \\
27.8 & $(4030)$ & 33.9 & $(4790)$ & 39.3 & $(5700)$ & 29.9 & $(4340)$ & 32.3 & $(4690)$ \\
32.1 & $(4650)$ & 35.4 & $(5130)$ & 36.8 & $(5340)$ & 31.4 & $(4560)$ & 37.9 & $(5500)$ \\
\hline 28.8 & $(4320)$ & 34.9 & $(5060)$ & 37.7 & $(5460)$ & 30.3 & $(4390)$ & 36.9 & $(5350)$
\end{tabular}

$\begin{array}{lllllllllll}31.5 & (4570) & 33.6 & (4870) & 38.3 & (5560) & 30.8 & (4460) & 37.0 & (5380)\end{array}$

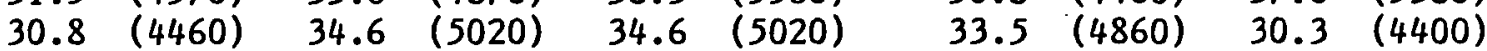

\begin{tabular}{llllllllll}
29.5 & $(4280)$ & 33.9 & $(4910)$ & 36.4 & $(5280)$ & 31.0 & $(4490)$ & 26.2 & $(3800)$ \\
\hline 30.6 & $(4440)$ & 34.0 & $(4930)$ & 36.5 & $(5290)$ & 32.1 & $(4650)$ & 31.2 & $(4530)$
\end{tabular}

25
25
25

Average

$\begin{array}{lll}8.28 & (1200) & \text { Ambient } \\ 8.28 & (1200) & \text { Ambient } \\ 8.28 & (1200) & \text { Ambient }\end{array}$

$\begin{array}{llll}50 & 10.3 & (1500) & \text { Ambient } \\ 50 & 10.3 & (1500) & \text { Ambient } \\ 50 & 10.3 & (1500) & \text { Ambient }\end{array}$

Average

$\begin{array}{lllll}25 & 5.1 & (740) & 505 & (450) \\ 25 & 5.1 & (740) & 505 & (450) \\ 25 & 5.1 & (740) & 505 & (450)\end{array}$

Average

$\begin{array}{lllll}50 & 10.2 & (1480) & 505 & (450) \\ 50 & 10.2 & (1480) & 505 & (450) \\ 50 & 10.2 & (1480) & 505 & (450)\end{array}$

\begin{tabular}{llllllllll}
26.1 & $(3790)$ & 35.0 & $(5070)$ & 32.1 & $(4660)$ & 33.4 & $(4680)$ & 27.9 & $(4040)$ \\
33.9 & $(4920)$ & 35.3 & $(5120)$ & 27.6 & $(4000)$ & 21.0 & $(3040)$ & 31.2 & $(4520)$ \\
33.4 & $(4840)$ & 30.8 & $(4470)$ & 34.2 & $(4960)$ & 32.8 & $(4760)$ & 30.3 & $(4400)$ \\
\hline 31.2 & $(4520)$ & 33.7 & $(4890)$ & 31.3 & $(4540)$ & 28.7 & $(4160)$ & 29.8 & $(4320)$ \\
31.6 & $(4580)$ & 33.2 & $(4810)$ & 36.0 & $(5220)$ & 30.3 & $(4400)$ & 26.6 & $(3860)$ \\
34.1 & $(4940)$ & 35.1 & $(5090)$ & 32.0 & $(4640)$ & 25.7 & $(3720)$ & 30.8 & $(4460)$ \\
34.9 & $(5060)$ & 35.4 & $(5140)$ & 35.6 & $(5160)$ & 30.5 & $(4420)$ & 33.9 & $(4920)$ \\
\hline 33.5 & $(4860)$ & 34.6 & $(5010)$ & 34.6 & $(5010)$ & 28.8 & $(4180)$ & 30.4 & $(4410)$ \\
21.4 & $(3100)$ & 21.0 & $(3050)$ & 23.2 & $(3370)$ & 16.1 & $(2340)$ & 13.0 & $(1890)$ \\
19.9 & $(2880)$ & 18.8 & $(2730)$ & 17.7 & $(2560)$ & 17.9 & $(2590)$ & 10.2 & $(1480)$ \\
19.9 & $(2890)$ & 24.1 & $(3490)$ & 18.6 & $(2690)$ & 14.6 & $(2120)$ & 9.5 & $(1380)$ \\
\hline 20.4 & $(2960)$ & 21.3 & $(3090)$ & 19.8 & $(2870)$ & 16.2 & $(2350)$ & 10.9 & $(1580)$ \\
29.7 & $(3000)$ & 24.2 & $(3510)$ & 19.7 & $(2860)$ & 16.6 & $(2410)$ & 10.8 & $(1570)$ \\
21.6 & $(3130)$ & 24.3 & $(3520)$ & 23.0 & $(3340)$ & 17.0 & $(2460)$ & 14.4 & $(2090)$ \\
16.6 & $(2400)$ & 17.5 & $(2540)$ & 21.2 & $(3070)$ & 16.5 & $(2390)$ & 10.2 & $(1480) *$ \\
\hline 19.6 & $(2840)$ & 22.0 & $(3190)$ & 21.3 & $(3090)$ & 16.7 & $(2420)$ & 11.8 & $(1710)$
\end{tabular}

Average

* Failed During Aging 
TABLE 3.2.2-B PHASE II STRESSED THERMAL AGING-LARC-TPI INDIVIDUAL TEST VALUES - LAP SHEAR

Stress

Percent of

Exposure

\& Test

Exposure Time at $505 \mathrm{~K}\left(450^{\circ} \mathrm{F}\right)$

Ultimate

Stress Load

Temperature

Initial

1000 Hours 3000 Hours 5000 Hours

$\begin{array}{llllllllllllll}\mathrm{MPa} & \mathrm{psi} & \mathrm{K} & (\mathrm{OF}) & \mathrm{MPa} & \mathrm{psi} & \mathrm{MPa} & \mathrm{psi} & \mathrm{MPa} & \mathrm{psi} & \mathrm{MPa} & \mathrm{psi}\end{array}$

25

$8.28 \quad(1200) \quad 219 \quad(-65)$

$8.28 \quad(1200) \quad 219 \quad(-65)$

$8.28 \quad(1200) \quad 219 \quad(-65)$

Average

$\begin{array}{lllll}30 & 10.3 & (1500) & 219 & (-65) \\ 30 & 10.3 & (1500) & 219 & (-65)\end{array}$

Average

$\begin{array}{llll}25 & 8.28 & (1200) & \text { Ambient } \\ 25 & 8.28 & (1200) & \text { Ambient } \\ 25 & 8.28 & (1200) & \text { Ambient }\end{array}$

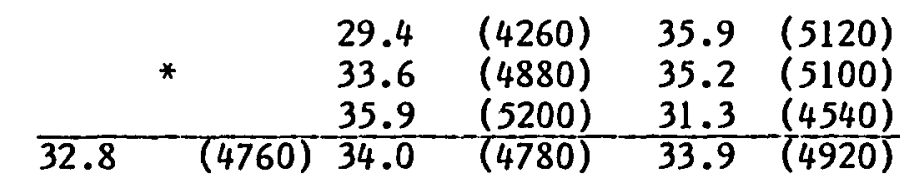

Average Ambient

$\begin{array}{llll}30 & 10.3 & (1500) & \text { Ambient } \\ 30 & 10.3 & (1500) & \text { Ambient } \\ 30 & 10.3 & (1500) & \text { Ambient }\end{array}$

Average

Ambient

$\begin{array}{lllll}25 & 5.1 & (740) & 505 & (450) \\ 25 & 5.1 & (740) & 505 & (450) \\ 25 & 5.1 & (740) & 505 & (450)\end{array}$

Average

$\begin{array}{lllll}50 & 10.2 & (1480) & 505 & (450) \\ 50 & 10.2 & (1480) & 505 & (450) \\ 50 & 10.2 & (1480) & 505 & (450)\end{array}$

Average

$\begin{array}{lllll}35.2 & (5100) & 33.9 \quad(4290)\end{array}$

$\begin{array}{lllll}* & 36.1 & (5240) & 31.6 & (4580)\end{array}$

$\frac{31.0}{32.8(4760)} \frac{(4500)}{34.1}-\frac{30.5}{(4950)}-\frac{(4420)}{32.0}(4640)$

$33.2 \quad(4820) \quad 29.6 \quad(4300)$
$* \quad 29.5$

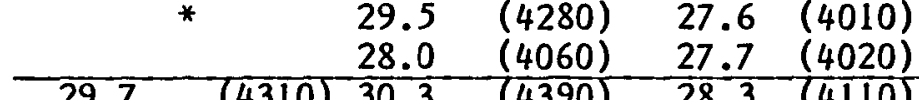

\begin{tabular}{lllll}
$*$ & 27.4 & $(3980)$ & 28.0 & $(4060)$ \\
& 32.6 & $(4720)$ & 30.0 & $(4350)$ \\
& 30.1 & $(4360)$ & 30.6 & $(4430)$ \\
\hline 29.7
\end{tabular}

\begin{tabular}{|c|c|c|c|c|c|}
\hline & * & $\begin{array}{l}21.7 \\
22.3 \\
23.4\end{array}$ & $\begin{array}{l}(3150) \\
(3240) \\
(3390)\end{array}$ & $\begin{array}{l}20.6 \\
22.3 \\
18.1\end{array}$ & $\begin{array}{l}(2980) \\
(3240) \\
(2620)\end{array}$ \\
\hline 4.8 & $(2150)$ & 22.5 & $(3260)$ & 20.3 & $(2950)$ \\
\hline & * & $\begin{array}{l}19.8 \\
24.8 \\
21.5\end{array}$ & $\begin{array}{l}(2870) \\
(3600) \\
(3120)\end{array}$ & $\begin{array}{l}22.2 \\
17.8 \\
24.1\end{array}$ & $\begin{array}{l}(3 \\
(2 \\
(3\end{array}$ \\
\hline 4.8 & $(2150)$ & 22.1 & $\overline{00)}$ & 21.4 & \\
\hline
\end{tabular}

* Average obtained from initial unstressed lap shear data.

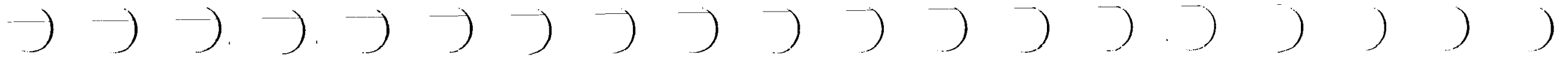




\section{PHASE II HUMIDITY EXPOSURE}

INDIVIDUAL TEST VALUES

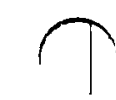

T

$\uparrow$

ণ

T

T

T

T

T

T

T

T

T

T

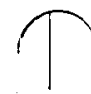


Table 3.2.3 A Phase II Humidity Exposure (1200F/95\% RH

Individual Test Values-PPQ

\begin{tabular}{|c|c|c|c|c|c|c|c|}
\hline \multirow{3}{*}{$\begin{array}{l}\text { Test } \\
\text { Shear, MPa }\end{array}$} & \multirow{2}{*}{$\begin{array}{c}\begin{array}{c}\text { Test } \\
\text { Temperature } \\
\text { (OF) }\end{array} \\
219(-65)\end{array}$} & \multicolumn{4}{|c|}{$\begin{array}{c}\text { Exposure Time, } \\
\text { Hours }\end{array}$} & \multicolumn{2}{|c|}{$\begin{array}{c}\text { Failure Mode } \\
\text { (Percent Cohesive) }\end{array}$} \\
\hline & & \multicolumn{2}{|c|}{1000} & \multicolumn{2}{|c|}{2000} & & \\
\hline & $\begin{array}{c}219(-65) \\
" 1 " \\
" \\
" ~\end{array}$ & $\begin{array}{l}29.6 \\
26.1 \\
26.8 \\
28.1 \\
27.9 \\
27.9\end{array}$ & $\begin{array}{l}(4300) \\
(3790) \\
(3890) \\
(4080) \\
(4050) \\
(4040)\end{array}$ & $\begin{array}{l}24.1 \\
24.1 \\
30.8 \\
32.1 \\
23.0 \\
26.8\end{array}$ & $\begin{array}{l}(3500) \\
(3500) \\
(4460) \\
(4660) \\
(3340) \\
(3890)\end{array}$ & $90-100$ & $80-90$ \\
\hline Average & $\begin{array}{c}\text { Ambient } \\
" \\
" \\
" \\
"\end{array}$ & $\begin{array}{l}27.1 \\
22.7 \\
25.6 \\
21.5 \\
31.9 \\
25.8\end{array}$ & $\begin{array}{l}(3930) \\
(3290) \\
(3720) \\
(3120) \\
(4620) \\
(3740)\end{array}$ & $\begin{array}{l}15.7 \\
22.1 \\
19.4 \\
23.9 \\
21.6 \\
20.6\end{array}$ & $\begin{array}{l}(2280) \\
(3200) \\
(2810) \\
(3460) \\
(3140) \\
(2980)\end{array}$ & $60-70$ & $60-70$ \\
\hline Average & $\begin{array}{c}505(450) \\
n \\
n " \\
n \\
n\end{array}$ & $\begin{array}{r}9.8 \\
18.3 \\
11.9 \\
18.9 \\
15.2 \\
14.8\end{array}$ & $\begin{array}{l}(1420) \\
(2650) \\
(1720) \\
(2740) \\
(2200) \\
(2150)\end{array}$ & $\begin{array}{r}9.8 \\
14.1 \\
13.4 \\
8.8 \\
\frac{14.5}{12.1}\end{array}$ & $\begin{array}{l}(1420) \\
(2050) \\
(1940) \\
(1270) \\
(2100) \\
(1760)\end{array}$ & $85-90$ & $70-80$ \\
\hline Peel, N·M (lb/in) & $\begin{array}{c}219(-65) \\
n \\
n \\
n \\
n\end{array}$ & $\begin{array}{l}0.50 \\
0.50 \\
0.50 \\
0.52 \\
0.47 \\
0.50\end{array}$ & $\begin{array}{l}(4.4) \\
(4.4) \\
(4.4) \\
(4.6) \\
(4.2) \\
(4.4)\end{array}$ & $\begin{array}{l}0.47 \\
0.45) \\
0.54 \\
0.43 \\
\frac{--}{0.47}\end{array}$ & $\begin{array}{l}(4.2) \\
(4.0) \\
(4.8) \\
(3.8) \\
-- \\
\overline{(4.2)}\end{array}$ & $\begin{array}{l}80 \\
80 \\
90 \\
85 \\
70\end{array}$ & $\begin{array}{l}95 \\
70 \\
95 \\
95 \\
--\end{array}$ \\
\hline Average & $\begin{array}{c}\text { Ambient } \\
n \\
n \\
n\end{array}$ & $\begin{array}{l}0.52 \\
0.52 \\
0.54 \\
0.47 \\
0.52\end{array}$ & $\begin{array}{l}(4.6) \\
(4.6) \\
(4.8) \\
(4.2) \\
(4.6)\end{array}$ & $\begin{array}{l}0.45 \\
0.38 \\
0.50 \\
0.20 \\
0.38\end{array}$ & $\begin{array}{l}(4.0) \\
(3.4) \\
(4.4) \\
(1.8) \\
(3.4)\end{array}$ & $\begin{array}{l}70 \\
40 \\
50 \\
50\end{array}$ & $\begin{array}{l}40 \\
40 \\
0 \\
--\end{array}$ \\
\hline Average & $\begin{array}{c}505(450) \\
n \\
" \\
" \\
"\end{array}$ & $\begin{array}{l}0.79 \\
0.86 \\
0.68 \\
0.74 \\
0.77\end{array}$ & $\begin{array}{l}(7.0) \\
(7.6) \\
(6.0) \\
(6.6) \\
(6.8)\end{array}$ & $\begin{array}{l}1.02 \\
0.81 \\
0.79 \\
0.61 \\
0.81\end{array}$ & $\begin{array}{l}(9.0) \\
(7.2) \\
(7.0) \\
(5.4) \\
\frac{(7.2)}{}\end{array}$ & $\begin{array}{l}5 \\
5 \\
10 \\
10\end{array}$ & $\begin{array}{l}50 \\
50 \\
0 \\
0\end{array}$ \\
\hline
\end{tabular}

Crack Extension $\mathrm{mm}$ (inch)

\begin{tabular}{|c|c|c|c|c|c|c|}
\hline $\begin{array}{l}\text { Initial Value, } \\
\mathrm{mm} \text { (inch) }\end{array}$ & 1 Hour & 24 Hours & 100 Hours & 500 Hours & 1000 Hours & 2000 Hours \\
\hline $\begin{array}{l}25.9(1.02) \\
23.6(0.93) \\
24.1(0.95) \\
23.6(0.93) \\
24.1(0.95) \\
24.4(0.96)\end{array}$ & $\begin{array}{l}3.8(0.15) \\
6.9(0.27) \\
3.0(0.12) \\
3.3(0.13) \\
7.1(0.28) \\
4.8(0.19)\end{array}$ & $\begin{array}{l}13.7(0.54) \\
17.0(0.67) \\
12.4(0.49) \\
14.5(0.57) \\
15.0(0.59) \\
14.5(0.57)\end{array}$ & $\begin{array}{l}17.0(0.67) \\
19.8(0.78) \\
18.0(0.71) \\
19.6(0.77) \\
20.1(0.79) \\
18.8(0.74)\end{array}$ & $\begin{array}{l}19.8(0.78) \\
20.8(0.82) \\
24.9(0.98) \\
20.8(0.82) \\
14.5(0.57) \\
20.1(0.79)\end{array}$ & $\begin{array}{l}22.1(0.87) \\
22.4(0.88) \\
24.9(0.98) \\
22.6(0.89) \\
14.5(0.57) \\
21.3(0.84)\end{array}$ & $\begin{array}{l}22.9(0.90) \\
22.4(0.88) \\
25.6(1.01) \\
23.4(0.92) \\
15.7(0.62) \\
22.1(0.87)\end{array}$ \\
\hline
\end{tabular}


Table 3.2.3-B . Phase II Humidity Exposure (322K/95\% RH) Individual Test Values - LARC-TPI

\begin{tabular}{|c|c|c|c|}
\hline \multirow[t]{2}{*}{ Test } & \multirow[t]{2}{*}{$\begin{array}{l}\text { Test } \\
\text { Temperature } \\
\mathrm{K}(\mathrm{OF})\end{array}$} & \multicolumn{2}{|c|}{$\begin{array}{l}\text { Exposure } \\
\text { Time } \\
\text { Hours } \\
\end{array}$} \\
\hline & & $\underline{1000}$ & $\underline{2000}$ \\
\hline $\begin{array}{l}\text { Lap Shear, } \\
\text { MPa (Psi) }\end{array}$ & $\begin{array}{ll}219 & (-65) \\
219 & (-65) \\
219 & (-65) \\
219 & (-65) \\
219 & (-65)\end{array}$ & $\begin{array}{l}27.3(3960) \\
29.7(4310) \\
29.4(4270) \\
20.4(2960) \\
27.5(3990) \\
26.9(3900)\end{array}$ & $\begin{array}{l}25.6(3720) \\
28.3(4100) \\
25.7(3730) \\
27.6(4000) \\
23.2(3360) \\
26.1(3780)\end{array}$ \\
\hline Average & $\begin{array}{l}\text { Abmient } \\
\text { Ambient } \\
\text { Ambient } \\
\text { Ambient } \\
\text { Ambient }\end{array}$ & $\begin{array}{l}18.3(2650) \\
13.9(2010) \\
12.6(1820) \\
17.8(2580) \\
19.5(2830) \\
16.4(2380)\end{array}$ & $\begin{array}{l}13.0(1880) \\
14.8(2150) \\
18.1(2630) \\
18.1(2620) \\
\frac{22.8(3300)}{17.4(2520)}\end{array}$ \\
\hline Average & $\begin{array}{l}505(450) \\
505(450) \\
505(450) \\
505(450) \\
505(450)\end{array}$ & $\begin{array}{l}13.2(1920) \\
13.4(1950) \\
13.8(2000) \\
16.0(2320) \\
15.9(2310) \\
14.5(2100)\end{array}$ & $\begin{array}{r}12.5(1810) \\
9.0(1300) \\
14.4(2090) \\
14.4(2090) \\
13.9(2020) \\
12.8(1860)\end{array}$ \\
\hline $\begin{array}{l}\text { Peel, N.M. } \\
(\mathrm{lb} / \mathrm{in})\end{array}$ & $\begin{array}{ll}219 & (-65) \\
219 & (-65) \\
219 & (-65) \\
219 & (-65) \\
219 & (-65)\end{array}$ & $\begin{array}{l}0.36(3.2) \\
0.34(3.0) \\
0.36(3.2) \\
0.29(2.6) \\
-\quad c \\
0.34(3.0)\end{array}$ & $\begin{array}{l}0.36(3.2) \\
0.43(3.8) \\
0.36(3.2) \\
0.34(3.0) \\
-\frac{-}{0.37}(3.3)\end{array}$ \\
\hline Average & $\begin{array}{l}\text { Abmient } \\
\text { Ambient } \\
\text { Ambient } \\
\text { Ambient } \\
\text { Ambient }\end{array}$ & $\begin{array}{l}0.28(2.5) \\
0.29(2.6) \\
0.32(2.8) \\
0.29(2.6) \\
-\quad-\quad- \\
0.29(2.6)\end{array}$ & $\begin{array}{l}0.29(2.6) \\
0.29(2.6) \\
0.29(2.6) \\
0.25(2.2) \\
-\quad-\quad- \\
0.28(2.5)\end{array}$ \\
\hline & $\begin{array}{l}505(450) \\
505(450) \\
505(450) \\
505(450) \\
505(450)\end{array}$ & $\begin{array}{l}0.45(4.0) \\
0.50(4.4) \\
0.43(3.8) \\
0.47(4.2) \\
-\quad-\quad- \\
\end{array}$ & $\begin{array}{l}0.36(3.2) \\
0.72(6.4) \\
0.45(4.0) \\
0.45(4.0) \\
-\quad- \\
\end{array}$ \\
\hline Average & & $0.47(4.2)$ & $0.50(4.4)$ \\
\hline
\end{tabular}


Table 3.2.3-B . Phase II Humidity Exposure (322K/95\% RH) (Continued) Individual Test Values - LARC-TPI

Test

Crack Extension

MM (Inch)

$\begin{array}{lllllll}\text { RT } & \text { RH } & 100 & 500 & 1000 & 2000 & 5000 \\ \text { Initial } & \text { Initial } & \text { HR } & \text { HR } & \text { HR } & \text { HR } & \text { HR }\end{array}$

$\begin{array}{lllllllllll}27.1 & (1.07) & 1.3(0.05) & 7.6 & (0.30) & 10.4 & (0.41) & 13.7 & (0.54) & 16.0 & (0.63) \\ 27.9(1.10) & 2.5 & (0.10) & 8.4 & (0.33) & 12.7 & (0.50) & 15.0 & (0.59) & 17.0 & (0.67) \\ 28.4(1.12) & 1.5 & (0.06) & 6.1 & (0.24) & 11.6 & (0.46) & 15.7 & (0.62) & 18.3(0.72) \\ 30.0(1.18) & 2.0 & (0.08) & 7.4 & (0.29) & 13.5 & (0.53) & 15.7 & (0.62) & 18.5(0.73) \\ 27.4(1.08) & 1.5(0.06) & 8.6 & (0.34) & 14.2 & (0.56) & 18.0 & (0.71) & 19.3(0.76) \\ 2.82(1.11) & 1.8(0.07) & 7.6(0.30) & 12.4(0.49) & 15.7 & (0.62) & 17.8 & (0.70)\end{array}$




\section{PHASE II FLUID EXPOSURE}

INDIVIDUAL TEST VALUES

$T$

$T$

$T$

$T$

T

$\pi$

T

$T$

$T$

$T$

$T$

$T$

$T$

$T$ 



\section{TABLE 3.2.4-B PHASE II FLUID EXPOSURE - PPQ}

Crack Extension Individual Test Values, MM(Inches)

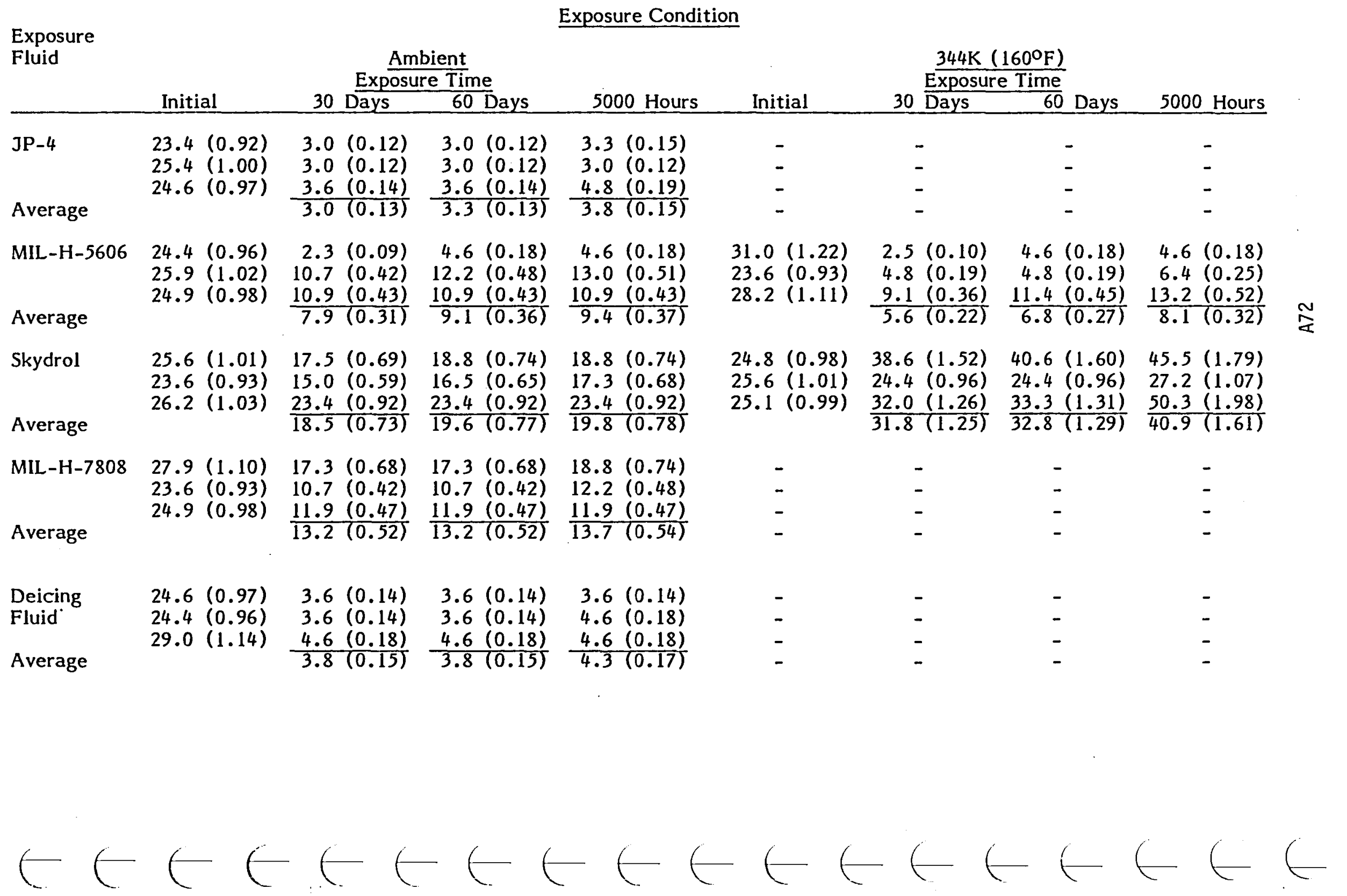



MATERIAL SPECIFICATION
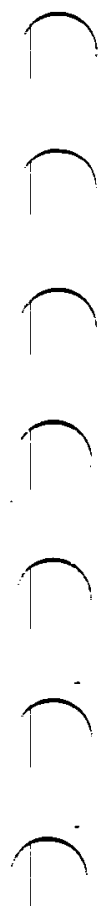


\section{MATERIAL SPECIFICATION}

\subsection{SCOPE}

a. This document establishes the requirements and tests for supplier qualification and purchaser inspection of adhesive suitable for structural bonding sandwich and metalto-metal assemblies suitable for continuous service at elevated temperatures when bonded in accordance with....

b. This specification requires qualified products.

\subsection{CLASSIFICATION}

\subsection{Class}

The adhesive systems shall consist of two classes

Class 1 Polyphenyquinoxaline (PPQ) Resin and Solvent.

Class 2 LARC-13 Resin with aluminum filler and solvent.

\subsection{Types}

Type 1 - will consist of the liquid adhesive with solvent.

Type 2 - will consist of an adhesive film supported with 112 E-glass/A1100 finish.

Type 3 - will consist of an unsupported film of the adhesive.

\subsection{Grades (Type 2 Only)}

Grade $A-0.060 \pm .010 \mathrm{lbs} / \mathrm{ft}^{2}$ adhesive film with separator sheets(s).

Grade $B-0.080 \pm 0.10 \mathrm{lbs} / \mathrm{ft}^{2}$ adhesive film with separator sheet(s).

Grade C - 


\subsection{REFERENCES}

\subsection{DEFINITIONS}

Batch - A batch shall consist of a homogeneous unit of finished adhesive manufactured under controlled conditions at one time or representing a blend of several manufactured units of finished adhesive of the same formulation.

Lot - A lot shall consist of all of the adhesive from one adhesive batch received in one shipment.

Lot - Lot size refers to the total number of units in any one lot irrespective of the Size volume of the container or length of the roll.

Unit - A unit refers to the smallest single portion of adhesive received in any one LOT, i.e., a roll of tape adhesive or a container of liquid adhesive.

\subsection{MATERIAL REQUIREMENTS}

\subsection{Physical Properties}

\subsubsection{Quality Type $1 \& 2$}

Material when visually examined shall be free from foreign materials.

\subsubsection{Consistency Type 1 Adhesive}

Type 1 when agitated must readily form homogenous mixture.

\subsubsection{Storage Life}

Type 1 and 2 adhesive must meet physical requirements af ter 180 days from date of manufacture when packaged according to Section 


\subsubsection{Adhesive Weight Type 2 Only}

Determine adhesive weight of Class I and II, Type 2, Grades A, B and C according to Section 8.8.

\subsubsection{Percent Volatile Type 2 Only}

Determine percent volatile of Class I and II, Type 2, Grades A, B and C according to Section

\subsubsection{Percent Solid of Type 1}

Percent solid of Class I and II, Type 1 shall be the following when tested according to Section 8.9.

$\begin{array}{llr}\text { Class I } & \text { Type } 1 & 9 \pm 1 \% \\ \text { Class II } & \text { Type } 2 & 26 \pm 2 \%\end{array}$

\subsection{QUALIFICATION}

a. Direct all requests for qualification to the Material Department which will request data and samples when desired for qualification purposes.

b. Test data supplied must give test values obtained and not use the word "conforms" showing the adhesive meets requirements of Section 5 and Tables I and II. The required number of standard test specimens for each test specified in Table III shall be fabricated and tested per Section 8. . The data shall state the test facility (supplier or named test laboratory) used in determination of the data.

c. After review of supplier data, the supplier will be advised as to whether adhesive approval has been granted.

d. No changes in raw materials or processing shall be made without notification and prior approval in writing. Any change may require requalification. 


\subsection{QUALITY CONTROL}

\subsection{General}

All materials covered by this specification shall be subjected to both supplier and purchaser inspection to determine compliance with the requirements of this specification.

\subsection{Supplier Inspection}

a. The supplier shall verify that each production shipment has been manufactured from identical materials and by identical methods to those approved for the qualification samples.

b. Supplier shall test each production shipment in accordance with the requirements of Section 6.4 and each shipment shall be accompanied by a test report providing the results of such testing.

c. All areas of Type II film adhesive which are not suitable for structural adhesive bonding shall be legibly marked by the supplier and deducted from the roll yardage.

\subsection{Purchaser Inspection}

a. Each roll or container of adhesive shall be checked for compliance with the identification requirements of Section 8. All packages incorrectly identified shall not be released for storage or production until the correct information has been marked on the package, as required by Section 8 .

b. LOT NUMBERS shall be established at the time of receival and marked on each unit of adhesive received in the lot.

c. The acceptance tests of Table IV are mandatory on each sample of each lot of adhesive.

b. In addition to the tests specifically listed as acceptance tests, any other test described in Section 4 of this specification may be used to assure that production ship- 
ments of adhesive conform to the requirements of this specification and are comparable to the material previously qualified.

\subsection{Sampling, Acceptance, and Rejection Criteria}

a. The sampling unit shall be as follows:

(1) Type I Adhesive - Container (Normally 1-5 gallon capacity)

(2) Type II Film Adhesive - Roll

b. One sample per unit is required for acceptance inspection testing. Each sample shall be taken from different units.

c. Each unit sample shall be of an amount sufficient to conduct all required tests.

d. The number of units of adhesive (sample size) to be tested from each lot under the double variables sampling plan is dependent upon the size of the lot. The sample size shall be as given in Table V. For weight test, randomly select two rolls only from the sample units selected in Table V.

e. Compute the Quality Index $\left(\mathrm{Q}_{\mathrm{L}}\right)$ in accordance with the following equations:

$$
\begin{aligned}
& x=\frac{x}{n} \\
& S=n x^{2}-(x)^{2} \\
& n(n-1) \\
& Q_{L}=\frac{X-L}{S}
\end{aligned}
$$

Where:

$X=$ Individual test value for each specimen

$\bar{x}=$ Average value for each test 
$S=$ Standard deviation for individual specimens

$\mathrm{N}=$ Number of individual specimens tested in accordance with Tables IV and $\mathrm{V}$

$\mathrm{L}=$ Minimum Requirement ( $\mathrm{L}$ Value) per Talbes I and II

f. The lot of adhesive undergoing Acceptance testing shall have the testing continued or shall be accepted or rejected as specified below:

(1) ACCEPT THE LOT when the computed Quality Index for the first sample equals or exceeds the Quality Index Requirement $(k)$ of Column A, Table V for the size of lot undergoing Acceptance testing.

(2) REJECT THE LOT when the computed Quality Index for the first sample equals or is less than the Quality Requirement of Column B, Table $V$ for the size of lot undergoing Acceptance testing or when any individual value is less than the $L$ value of Tables $I$ and II.

(3) CONTINUE TESTING with a second sample from the lot when the computed Quality Index for the first sample falls between the Quality Index Requirements of Column $\mathrm{A}$ and Column $\mathrm{B}$ of Table $\mathrm{V}$.

(a) The second sample shall be of the size specified for the second sample in Table $V$ for the size of lot undergoing testing, and shall be randomly selected from the units not previously tested.

(b) When the number of untested units is less than the number required by Table $\mathrm{V}$, the second sample shall include all untested units and sufficient new samples random selected from the previously tested units to complete the number of samples required by Table IV for the second sample.

(c) Compute the COMBINED QUALITY INDEX from all of the test values for the combined first and second samples. 
(d) ACCEPT THE LOT when the computed combined Quality Index equals or exceeds the Quality Index Requirement $(k)$ of Column C, Table $\mathrm{V}$ for the size of lot undergoing quality assurance testing.

(e) REJECT THE LOT when the combined Quality Index equals or is less than the Quality Index Requirement of Column D, Table V or any individual value is less than the $L$ value of Tables I and II.?

(4) REJECT THE LOT when the film weight does not meet the requirement given in the QPL.

g. Adhesive material of rejectable quality or unsatisfactory manufacturing characteristics may be subjected to chemical analysis in accordance with Section 5.2.e.

\subsection{MATERIAL TEST METHODS}

\subsection{General Bonding Procedure}

a. Adherend Preparation. Titanium $6 \mathrm{Al}-4 \mathrm{~V}$ shall be 10 volt chromic acid anodized or equivalent*.

*Surface must produce cohesive bonds and be thermally and environmentally stable.

b. Priming

(1) Class I Type 1. Apply Class I Type 1 diluted with a 1:1 mixture of xylene and meta-creosol to $9 \pm 1 \%$ solids by brush or spray to $.0005-.001 "$ thickness. Dry in air circulating oven 120 minutes at $425 \pm 10^{\circ} \mathrm{F}$.

(2) Class II Type 1. Apply Class. II Type 1 diluted with DMF to $26 \pm 2 \%$ solids by brush or spray to $.0005-.001$ " thickness. Dry in air circulating oven 30 minutes at $150 \pm 5^{\circ} \mathrm{F}$ followed by 60 minutes at $275 \pm 5^{\circ} \mathrm{F}$.

c. Curing Test Assemblies. Place prepared assemblies in vacuum bag according to Figure 1 or equivalent. Cure and post cure in accordance with process spec. 


\subsection{LAP Bond Shear}

\subsubsection{Fabrication of Lap Bond Test Assemblies}

a. Fabricate test assembly by bonding two $6 \mathrm{~A} 1-4 \mathrm{~V}$ titanium finger panels (see Figure 2) with Type 1 and Type 2 adhesives from the lots being tested.

b. Prime each test panel with Type 1 adhesive within 16 hours of surface preparation.

c. After drying Type 1 adhesive per 8.1.b., apply a strip of Type 2 film adhesive, approximately 0.75 inch wide and 6.5 inches long to the primes surface of one of each pair of test panels.

d. Join the two test panels to make a test assembly having a lap joint with a $0.50 \pm 0.03$ inch overlap as shown in Figure 2.

e. Embed a fine wire thermocouple (No. 30 maximum) in adhesive flash immediately adjacent to one overlap edge, in order to measure the curing temperature.

f. Bag in accordance with Figure 1 .

g. Cure and post cure in accordance with process spec.

\subsubsection{Lap Bond Shear Test Specimens}

a. After cure cut test assemblies into individual test specimens.

(1) All cuts shall be accomplished so as to avoid overheating or mechanical damage to adhesive bond.

(2) Identify each specimen with the test assembly from which cut and with the lot of adhesive being tested.

(3) Trim excess adhesive from the side edges of each specimen. 
b. Any valid individual test value and the arithmetic mean of the test values shall equal or exceed the applicable minimum individual and average requirements in Table I or II. Any identifiable abnormality that cannot be attributed to adhesive performance invalidates a specimen.

\subsubsection{Lap Bond Shear Test Conditions}

a. These tests differ only in the conditioning given the test specimens before and during the time they are being tested. The following requirements are the same for each of the lap bond shear tests:

(1) The testing machine used to determine the lap bond shear strength shall have either vertical or horizontal, self-aligning grips which operate in such a manner, that with the test specimen properly positioned, an imaginary straight line passing through the center of the bonded area and parallel to the metal plates of the specimen would also pass through the center point of each grip mounting. Pin grips fitting the specimen end holes are recommended to prevent slippage.

(2) The testing machine shall have a loading range sufficient to insure a precision and accuracy of \pm 1 percent within a loading range of 240 pounds to 2400 pounds. It shall meet requirements of ASTM Standards Specification E4-67.

(3) At the start of the test, each lap bond shear test specimen shall be positioned so that the inner edge of each grip shall be $2.00 \pm 0.25$ inches from the nearest edge of the lap joint.

(4) Each lap bond shear test specimen shall be loaded in tension at the rate of 1200 to 1400 pounds per minute until the maximum loading is reached and the bond is broken. The maximum stress sustained by the specimen shall be expressed in pounds per square inch of bonded area. The area used for this calculation shall be the actual measured area of the overlap of the test specimen. The area shall be computed to the nearest 0.01 square inch and the tensile shear values obtained shall be rounded to the nearest 10 psi in accordance with the ASTM Standards E29-67. 
b. For Tests No. 1, 4, 6 and 8 of Table I (normal temperature lap bond shear) and Test No. 1 of Table IV, the temperature of the test specimen shall be $75 \pm 5^{\circ} \mathrm{F}$. The specimen shall be maintained within this temperature interval at least 1 hour before the test is made and at all times during the test. Test 4 shall be preceded by heat exposure of 500 hours at $450 \pm 5^{\circ} \mathrm{F}$. Test 6 shall be preceded by heat exposure of 1000 hours at $450 \pm 50 \mathrm{~F}$. Test 8 shall be preceded by heat exposure of 5000 hours at 450 $\pm 50 \mathrm{~F}$.

c. For Test No. 2 of Table I (low temperature lap bond shear) the temperature of the metal at the bond line shall be $-67 \pm 2^{\circ} \mathrm{F}$ for 10 minutes before the specimen is stressed and at all times after the stress is applied until the specimen is broken.

d. For Tests No. 3, 5, 7 and 9 of Table I (elevated temperature lap bond shear) and Test No. 2 of Table IV, the temperature of the metal at the bond line shall be $450 \pm 5$ o F for 10 minutes before the specimen is stressed and at all times after the stress is applied until the specimen is broken. Test 5 shall be preceded by heat exposure of 500 hours at $450 \pm 5^{\circ} \mathrm{F}$. Test 7 shall be preceded by heat exposure of 1000 hours at $450 \pm 50 \mathrm{~F}$. Test 7 shall be preceded by heat exposure of 1000 hours at $450 \pm 50 \mathrm{~F}$. Test 9 shall be preceded by heat exposure of 5000 hours at $450 \pm 5^{\circ} \mathrm{F}$.

e. For Test No. 14 of Table I (salt spray exposure), the salt solution, chamber, accessories, method of suspension, and general procedure shall be in accordance with Federal Test Method Standard No. 151, Method 811.1, "Salt Spary Test." Individually suspend each exposure specimen through one of the holes (see Figure 2).

(1) The specimens shall remain in the salt spray at $95 \pm 5^{\circ} \mathrm{F}$ for 30 days \pm 2 hours.

(2) Within 4 hours after removal from the salt spray, test each of the specimens in lap shear at $75 \pm 5^{\circ} \mathrm{F}$.

(3) In addition to the individual specimen values and the average, report the following information:

(a) Salt solution concentration.

(b) Type of salt and water used in preparation of the solution. 
(c) All readings of temperature within the exposure zone of the chamber.

(d) Method of supporting specimen in the exposure chamber.

(e) Length of exposure.

f. For Test No. 15 of Table I (condensing humidity exposure), the water, humidity cabinet, method of suspension, and general procedure shall be in accordance with Federal Specification MMM-A-132.

(1) The specimens shall remain in the condensing humidity atmosphere at 120 $\pm 50 \mathrm{~F}$ for 30 days \pm 2 hours.

(2) Within 4 hours after removal from the condensing humidity cabinet, test each specimen in lap shear at $75 \pm 5^{\circ} \mathrm{F}$.

(3) In addition to the individual specimen values and grand average, report all temperature readings required by the test method.

g. For Test No. 16 of Table I (jet fuel exposure), completely immerse each specimen in MIL-J-5161 Referee Fuel Grade 2 in such a manner that the test medium has equal access to all sides of the specimen. Faces of specimens immersed in the same container shall not contact each other.

(1) The exposure section shall remain in the test medium at $75 \pm 5^{\circ} \mathrm{F}$ for 30 days \pm 2 hours.

(2) Within 4 hours after removal from the test medium, test each specimen in lap shear at $75 \pm 50 \mathrm{~F}$.

(3) Report all individual specimen values and the average.

h. For Test No. 17, Table I (MIL-H-5606), the test conditions and procedures shall be the same as for Test 16 except the test medium shall be MII-H-5606.

i. For Test No. 18, Table I (MIL-H-7808), the test conditions and procedures shall be the same as for Test 16 except the test medium shall be MIL-H-7808. 
j. For Test No. 19, Table I (aircraft de-ice fluid), the test conditions and procedures shall be the same as for Test 16 except the test medium shall be aircraft de-ice fluid.

\subsection{Lap Bond Fatigue}

\subsubsection{Normal Temperature Lap Bond Fatigue}

a. Perform the normal-temperature Lap Bond Fatigue Test (No. 10) in accordance with the general provisions of Federal Test Method Standard No. 175, Method 1061 and the specific provisions indicated below:

(1) The test machine shall be capable of a cyclic axial load at the rate of $1800 \pm 180$ cycles per minute.

(2) Loads shall be accurate within \pm 1 percent.

(3) During each cycle, the load shall range from a maximum to 10 percent of the maximum.

(4) The test specimens shall conform to the dimensional requirements of Figure 1.

b. The temperature of the metal over the lap bond area shall be $75 \pm 5^{\circ} \mathrm{F}$ at all times during the test.

c. At the start of the test, position each specimen with the overlap area equidistant between the grips of the test machine so that the edge of each grip will be $2.00 \pm$ 0.13 inches from the nearest edge of the bond.

(1) Test each specimen until $10^{6}$ cycles at the particular maximum load have been completed or the specimen fails, whichever is sooner.

(2) Test a total of 10 test specimens, 5 from each of 2 test assemblies, using selected maximum loads such that failures occur with approximately regular spacing over the range of $10^{3}$ to $10^{6}$ cycles. 
(3) Test at least one specimen at a maximum load of approximately $50 \%$ of the $75 \pm 50 \mathrm{~F}$ lap bond shear strength of Test No. 1 .

d. For each test, measure the actual bond area with a precision of $\pm 1 \%$. Calculate the stress in psi corresponding to the maximum load. Plot the number of cycles until bond failure (log scale) and the corresonding maximum bond stress (arithmetic scale) on semi-log graph paper and draw a smooth curve through the plotted points. Extrapolate, if necessary, to the $10^{6}$ cycles ordinate.

e. Record and report all information called for by Federal Test Method Standard No. 175, Method 1061.

Report the fatigue strength as the stress corresponding to the point at which the curve through the plotted points crosses the $10^{6}$ cycles ordinate.

\subsubsection{Elevated Temperature Lap Bond Fatigue}

Perform Fatigue Test No. 11 of Table I in accordance with Section 8.3.1 except for the conditioning prior to testing, the temperature during testing, and the maximum load which shall be $50 \%$ of the $450^{\circ} \mathrm{F}$ strength of Test No. 3 .

A suitable oven shall be provided to maintain the temperature at $350 \pm 10^{\circ} \mathrm{F}$ at all times during the testing.

\subsection{Lap Bond Creep-Rupture-Deformation}

\subsubsection{Normal Temperature Creep Test}

a. Perform the normal temperature creep-rupture-deformation test (No. 9 of Table I) on standard test specimens conforming to the dimensional requirements shown in Figure 1.

(1) Test the lap bond specimens in a "dead-weight" loading test apparatus capable of applying and maintaining a steady load accurate within $1 \%$. 
(2) The temperature of the specimen and the ambient temperature around it shall be $75 \pm 5^{\circ} \mathrm{F}$.

(3) Apply a load of $800 \pm 4$ pounds (1600 psi) to the specimen.

(a) Care must be taken to avoid eccentricity in the loading of the adhesive joint. Prior to testing, check the entire assembly of specimen and loading mechanism for alignment.

(b) Maintain the load for 192 hours or until rupture, whichever occurs first.

(c) Measurements of total deformation, including that due to initial loading, shall be made while the specimen is under stress.

(d) Measurements (to an accuracy of 0.0001 inch) shall be made at such time intervals that a smooth time-deformation curve may be plotted if deformations are large enough to permit.

(4) Measure the actual bond area with a precision of $\pm 1 \%$ and calculate actual stress.

b. Record and report the following for each specimen:

(1) Lap bond area and stress.

(2) Deformation measurements and time for each.

(3) Time to failure, nature and percentage of each type of joint failure.

(4) Time-deformation curve (if deformations permit). 


\subsubsection{Elevated Temperature Creep Test}

a. The elevated temperature creep-rupture-deformation test (No. 11 of Table I) shall conform to the requirements of Section 8.4.1 with the following exceptions and/or additions:

(1) The temperature of the metal at the bond line shall be $450 \pm 10^{\circ} \mathrm{F}$.

(a) The "temperature of the metal and the bond line" and the means for determining it shall be as prescribed in Section 8.1.5, Item c.

(b) A suitable oven, which does not influence the application of the load, shall be provided to maintain the required temperature.

(2) The applied load shall be $400 \pm 2$ pounds ( $800 \mathrm{psi}$ ).

(3) Deformation need not be measured at $450 \pm 10^{\circ} \mathrm{F}$. Measure deformation under the applied load before and after the heated period.

b. Record and report the information required by Section 8.4 .1 , Item b.

\subsection{Metal to Metal "T" Peel}

\subsubsection{Fabrication of T Peel Specimens}

a. Fabricate $T$ peel specimens by bonding two $1 " \pm .003 \times 12 " \times 0.010 " 6 \mathrm{Al}-4 \mathrm{~V}$ titanium strips with Type 1 and Type 2 adhesives from lots being tested. See Section 8.1, General Bonding Procedure.

b. Prime each test strip with Type 1 adhesive within 16 hours of surface preparation.

c. After drying Type 1 adhesive per 8.1.b, apply a strip of Type 2 film adhesive 1 inch wide by 10 inches long. See Figure 4.

d. Bag in accordance with Figure 1. 
e. Cure and post cure per process spec.

f. Identify each specimen with specimen number and lot of adhesive being tested.

g. Trim excess adhesive from edges of specimens.

\subsubsection{T-Peel Test Conditions}

a. These tests differ only in the conditioning given test specimens before and during the time they are being tested. The following requirements are the same for each $T$-peel specimen test:

(1) The testing machine shall be capable of applying a tensile load having the following prescribed conditions.

\subsubsection{1}

a. The machine and loading range shall be so selected that the maximum load on the specimen falls between 15 and 85 percent of the upper limit of the loading range.

b. The rate of movement between heads shall remain essentially constant under fluctuating loads.

NOTE: It is difficult to meet this requirement when loads are measured with a spring-type or pendulum-type weighing device.

c. The machine shall be equiped with suitable grips capable of clamping the specimens firmly and without slippage throughout the tests.

d. The machine shall be autographic, giving a chart that can be read in terms of inches of separation as one coordinate and applied load as the other coordinate.

e. The applied tension as measured and recorded shall be accurate within $\pm 1 \%$. 


\subsubsection{Test Procedure}

Clamp the bent, unbonded ends of the test specimen in test grips of tension testing machine. Apply the load at a constant head speed of $10 \mathrm{in} / \mathrm{min}$. During the peel test, make and autographic recording of load versus head movement or load versus distance peeled. Determine the peel resistance over at least 5 inches length of the bond line after the initial peak.

\subsubsection{Calculation}

Determine from the autographic curve the average peeling load in pounds per inch of specimen width required to separate the adherends. Report value as pounds per 1 inch width.

\subsection{3}

For Tests No. 20 and 22 of Table 1 ( Normal Temperature T-Peel) the temperature of the test specimen shall be $75 \pm 5^{\circ} \mathrm{F}$. The specimen shall be maintained within this temperature range at least one hour before the test is made and at all times during the test. Test 22 shall be preceded by heat exposure of 1000 hours at $450 \pm 10^{\circ} \mathrm{F}$.

\section{5 .4}

For Tests No. 21 and 23 of Table I (Elevated Temperature T-Peel Test), the temperature of the metal at the bond line shall be $450 \pm 10^{\circ} \mathrm{F}$ for 10 minutes before the specimen is stressed and at all times after the stress is applied until the test is complete. Test No. 23 shall be preceded by heat exposure of 1000 hours at $450 \pm 10^{\circ} \mathrm{F}$.

\subsection{Environmental Durability Test}

\subsubsection{Crack Extension Specimen Fabrication}

a. Fabricate crack extension specimens by bonding two $1.0 \pm .003^{\prime \prime} \times 6 "+0.050 " 6 \mathrm{AL}-4 \mathrm{~V}$ titanium parts with Type 1 and Type 2 adhesive from lots being tested. 
b. Prime each test part with Type 1 adhesive within 16 hours of surface preparation.

c. After drying Type 1 adhesive per 8.1.b apply a strip of Type 2 film adhesive 1 inch wide by 5.50 inches long. See Figure 5 .

d. Bag in accordance with Figure 1.

e. Cure and post cure per process spec.

f. Identify each specimen with specimen number and lot of adhesive being tested.

g. Trim excess adhesive from edges of specimens and sand, grind or mill one edge of specimen so crack tip can be easily seen.

\subsubsection{Crack Extension Test Conditions}

a. Precrack the end of the specimen in which the adhesive was omitted by inserting a .125 inch wedge as shown in Figure 5.

b. Locate and mark the tip of the initial crack.

c. Tests 1,2 and 3 of Table III differ only in the conditioning given the specimens after the initial crack tip is marked. Test 1 specimens shall be aged at $75 \pm 5^{\circ} \mathrm{F}$ for 1000 hours. Test 2 specimens shall be aged at $1200 \mathrm{~F}$ in $95-100 \%$ relative humidity for 1000 hours.

d. At the end of the exposure time mark the new crack tip, measure the distance from the initial crack tip to the nearest .05 inch and record that measurement.

\subsubsection{Lap Shear Sustained Stress Loading}

a. Fabricate lap shear specimens per Section 8.2.

b. Put a sustained load of 1200 psi on each specimen and expose to $120 \pm 5^{\circ} \mathrm{F}$ and 95 $100 \%$ relative humidity for 2000 hours. 


\subsection{Honeycomb Specimens}

\subsubsection{Flatwise Tensile Test}

a. Specimen Fabrication

(1) Fabricate specimens by bonding two $6 \mathrm{AL}-4 \mathrm{~V}$ titanium skins 0.020 " thick to $6 \mathrm{~A} 1-4 \mathrm{~V}$ titanium honeycomb core (1/4" cell) (see Figure 5) with Type 1 and Type 2 grade - adhesive.

(2) Clean titanium core and skins and bond according to Section 8.1.

(3) Cut cured assembly into 2" $\times 2$ " specimens. All cuts shall be accomplished so as to avoid overheating or mechanical damage to adhesive bonds.

(4) Identify each specimen with the test assembly from which cut and with the lot of adhesive being tested.

\section{b. Test Conditions}

(1) Environmental exposure shall be performed on 2" $\times 2$ " test specimens before bonding them to attachment blocks.

(2) Tests No. 4 and 5 of Table II shall be exposed $350 \pm 50 \mathrm{~F}$ for 1000 hours before testing.

(3) Bond load block to specimen (Figure 5) by vacuum blasting surfaces and bonding with HR 424 structural adhesive.

(4) Normal temperature test (No. 1 and 4 of Table II) shall be performed at $75 \pm 50 \mathrm{~F}$ with load blocks within this temperature range for at least 30 minutes prior to test.

(5) Low temperature test (No. 2 of Table II) shall be performed at $-65 \pm$ $50 \mathrm{~F}$ with load blocks maintained at this temperature range for at least 30 minutes prior to test. 
(6) Elevated temperature test (No. 3 and 5 of Table II) shall be performed at $450 \pm 100 \mathrm{~F}$ with load blocks maintained at this temperature range for at lease 30 minutes prior to test.

\subsubsection{Honeycomb Peel Test}

a. Honeycomb Peel Specimen Fabrication

(1) Fabricate specimens by bonding two $6 \mathrm{Al}-4 \mathrm{~V}$ titanium skins (one $12 \times 10 \times$ .010 and one $10 \times 10 \times .010$ ) to a $10^{\prime \prime} \times 10^{\prime \prime}$ piece of $6 \mathrm{Al}-4 \mathrm{~V}$ titanium honeycomb core (1/4" cell) with Type 1 and Type 2 grade - adhesive.

(2) Clean skins and core bond according to Section 8.1 .

(3) Cut assemblies into specimens per Figure 6. All cuts shall be accomplished so as to avoid overheating or mechanical damage to the adhesive loads.

(4) Identify each specimen with test assembly from which cut and lot of adhesive being testing.

b. Honeycomb Peel Test Conditions

(1) Normal temperature test (Test No. 6, Table II) shall be performed at $75 \pm 50 \mathrm{~F}$ with specimen held within this temperature range for at least 30 minutes prior to and during test.

(2) Elevated temperature test (Test No. 7 Table II) shall be performed at $450 \pm 5^{\circ} \mathrm{F}$ with specimen held within this range at least 30 minutes prior to and during test.

(3) Place specimen in climbing drum peel apparatus according to Figure 7.

(4) Apply a tensile load at a crosshead speed of $3.00 \pm 0.30$ inches per minute and make an autographic recording of the load. 
(5) Report values as peel strength in pound-inches per 3 inches of specimen width.

\subsection{Weight (Type 2 Adhesive Only)}

a. Adhesive weight measurements are made on a $36 \pm 0.36$ square inch specimen from which the separator sheet has been removed.

(1) At least two specimens shall be cut from each qualification sample.

(2) Specimens shall be taken at random except that no specimen shall include areas closer than 1 inch from the edge of the roll.

b. After the specimen has been weighed to the nearest 0.1 gram, calculate the weight of the adhesive as follows:
(1) $W=0.00882 \mathrm{~S}$

Where:

$W=$ Weight (pounds per square foot)

$\mathrm{S}=$ Sample weight in grams

(2) The calculated weight shall be expressed to the nearest 0.001 pound per square foot in accordance with ASTM Standards E29-

c. Report all test data and the average for each sample.

\subsection{Percent Solids (Type 1 Adhesive Only)}

The percent solids indicated on the Type 1 adhesive containers is $81 \pm 3 \%$. This is the correct percentage for formulation. When this adhesive is heated above $300{ }^{\circ} \mathrm{F}$, the condensation reaction begins and volatile products are released. Therefore, for test purposes the percent solids shall be $76 \pm 3 \%$. 
a. Tare weight two suitable containers for each batch of adhesive in the qualification samples (or lot in the case of Purchaser Inspection).

b. Weigh $15 \pm 2$ grams of well mixed adhesive into each container.

c. All weighing shall be to the nearest 0.1 gram.

d. Heat in a controlled oven at $450 \pm 10^{\circ} \mathrm{F}$ for 1 hour, followed by 1 hour at $500^{\circ} \mathrm{F} \pm$ $100 \mathrm{~F}$.

e. Cool in a desiccator and weigh.

f. Report the percent solids as a weight percentage of the original test sample weight.

g. Report all test data and the average for each qualification (or lot) sample.

\subsection{MATERIAL IDENTIFICATION}

a. Each metal container and roll of adhesive shall be legibly identified and labeled with the items of information listed below. The rolls of adhesive shall have the identification label, or marking, on the inside of the core. Metal containers shall have the identification securely affixed to the container.

(1) Specification Number, Type and Grade of the adhesive.

(2) Supplier's Name and Address.

(3) Supplier's Batch Number.

(4) Date of Manufacture.

(5) Purchase Order Number.

(6) Unit Number of Roll.

b. Both ends of the exterior (shipping) package of all adhesives covered by this specification shall be legibly marked on the outside with the following information.

(1) Specification Number and Type of the Adhesive.

(2) Purchase Order Number.

(3) Supplier's Name and Address. 
(4) Supplier's Batch Number.

(5) Date of Manufacture.

(6) Quantity in this Package.

(7) Date of Shipment.

\subsection{PACKAGING AND MARKING}

a. Type 1 adhesive shall be packaged in clean, air-tight one quart metal containers.

b. Each roll of Type 2 Film Adhesive shall be sealed air-tight in a flexible, vapor barrier bag made of a material qualified to MIL-B-131 for Class 1.

c. The core of each roll of Type 2 Film Adhesive shall contain sufficient desiccant to insure there will be no degradation of the adhesive from water vapor entrapped within the sealed wrapper during the warranty period.

d. The amount of material in each roll of Type 2 Film Adhesive may be adjusted to be compatible with the production cycle of manufacturer, except that the normal roll length shall be at least 20 yards with a minimum width of 36 inches unless otherwise specified on the purchase order.

e. The exterior packaging for all types shall be of such a nature as to prevent physical damage or contamination by foreign substances.

(1) Each package shall be suitably insulated and refrigerated, when necessary, to insure maintenance of the shipping temperature requirements.

(2) The exterior packaging for Type 2 Film Adhesive shall be free of fasteners which could damage or puncture the vapor barrier wrapper.

(3) Support the ends of the core of each roll of Type 2 Film Adhesive, within the exterior packaging, in such a manner as to prevent damage to the vapor barrier wrapper and contact with the sides of the exterior package. 


\subsection{Shipping Temperatures}

The shipping temperatures for Type 1 and Type 2 adhesives shall be as specified in Section 5.1.3. 


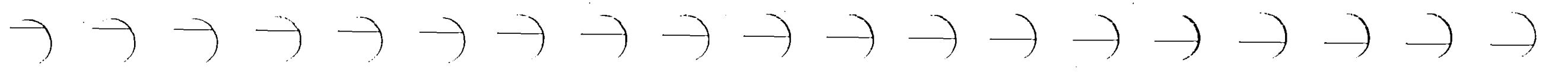

\section{PHYSICAL PROPERTIES OF METAL TO METAL SPECIMENS}

\section{TEST}

1. Lap Shear at $75 \pm 5^{\circ} \mathrm{F}$

2. Lap Shear at $-65 \pm 50 \mathrm{~F}$

3. Lap Shear at $450 \pm 5^{\circ} \mathrm{F}$

4. Lap Shear at $75 \pm 5^{\circ} \mathrm{F}$ After 500 Hours at $450 \pm 5^{\circ} \mathrm{F}$

5. Lap Shear at $450 \pm 5^{\circ} \mathrm{F}$ After 500 Hours at $450 \pm 5^{\circ} \mathrm{F}$

6. Lap Shear at $75 \pm 5^{\circ} \mathrm{F}$ After 1000 Hours at $450 \pm 50 \mathrm{~F}$

7. Lap Shear at $450 \pm 50 \mathrm{~F}$ After 롱

8. Lap Shear at $75+5^{\circ} \mathrm{F}$ After 5000 Hours at $450 \pm 5^{\circ} \mathrm{F}$

9. Lap Shear at $450 \pm 5^{\circ} \mathrm{F}$ After 5000 Hours at $450 \pm 50 \mathrm{~F}$

10. Fatigue Strength at $75 \pm 50 \mathrm{~F}$

11. Fatigue Strength at $450 \pm 5^{\circ} \mathrm{F}$

12. Creep-Rupture-Deformation at $75 \pm 5^{\circ} \mathrm{F}$ Under 1600 PSI for 500 Hours

\section{TEST REFERENCE SECTIONS}

8.2.1 8.2.2 8.2.3.a 8.2.3.b

8.2.1 8.2.2 8.2.3.a 8.2.3.c

8.2.1 8.2.2 8.2.3.a 8.2.3.d

8.2.1 8.2.2 8.2.3.a 8.2.3.b

8.2.1 8.2.2 8.2.3.a 8.2.3.d

8.2.1 8.2.2 8.2.3.a 8.2.3.b

8.2.1 8.2.2 8.2.3.a 8.2.3.d

8.2.1 8.2.2 8.2.3.a 8.2.3.b

8.2.1 8.2.2 8.2.3.a 8.2.3.d

$8.2 .18 .2 .2 \quad 8.3 .1$

$8.2 .1 \quad 8.2 .2 \quad 8.3 .2$

$8.2 .1 \quad 8.2 .2 \quad 8.3 .2$

NUMBER OF SPECIMENS MINIMUM REQUIREMENTS PER BATCH TOTAL AVERAGE INDIVIDUAL

10

10

10

5

5

5

5

5

5

5

5
30

30

30

15

15

15

15

15

15

15

15

12
N/A $10^{6}$ Cycles/Min at 1200 PSI Max

N/A $10^{6}$ Cycles/Min at 750 PSI Max

N/A 0.015 Inches Max 
TABLE I

PHYSICAL PROPERTIES OF METAL TO METAL SPECIMENS

TEST

13. Creep-Rupture-Deformation at $450+5^{\circ} \mathrm{F}$ Under 800 PSI for 500 Hours

14. Shear at $75 \pm 5^{\circ} \mathrm{F}$ After 30 Days Salt Spray Exposure at $95 \pm 5^{\circ} \mathrm{F}$

15. Lap Shear at $75 \pm 50 \mathrm{~F}$ After Exposure to $95-100 \%$ Relative Humidity at $120 \pm 5^{\circ} \mathrm{F}$

8.2.1 8.2.2 8.2.3.a 8.2.3.f 5 15

16. Lap Shear at $75 \pm 5^{\circ} \mathrm{F}$ After 30 Days Immersion in Jet Fuel Grade 2 MIL-J-5161 at $75 \pm 5^{\circ} \mathrm{F}$

8.2.1 8.2.2 8.2.3.a 8.2.3.g

17. Lap Shear at $75 \pm 5^{\circ} \mathrm{F}$ After 30 Days Immersion In MIL-H-5606 at $75 \pm 5^{\circ} \mathrm{F}$

8.2.1 8.2.2 8.2.3.a 8.2.3.h

18. Lap Shear at $75 \pm 5^{\circ} \mathrm{F}$ After Immersion in MIL-H-7807 at $75 \pm 5^{\circ} \mathrm{F}$

8.2.1 8.2.2 8.2.3.a 8.2.3.i

19. Lap Shear at $75 \pm 5^{\circ} \mathrm{F}$ After Immersion in Aircraft De-Ice Fluid at $75 \pm 5^{\circ} \mathrm{F}$

20. T-Peel at $75 \pm 5^{\circ} \mathrm{F}$

8.2.1 8.2.2 8.2.3.a 8.2.3.j

$8.5 .1 \quad 8.5 .2 \quad 8.5 .4$

$8.5 .1 \quad 8.5 .2 \quad 8.5 .4$

21. T-Peel at $450 \pm 50 \mathrm{~F}$
12

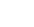
Inches Max Deformation 
$\rightarrow \rightarrow \rightarrow \rightarrow \rightarrow \rightarrow \rightarrow \rightarrow \rightarrow \rightarrow \rightarrow \rightarrow \rightarrow \rightarrow \rightarrow \rightarrow D \rightarrow D$

TABLE I

PHYSICAL PROPERTIES OF METAL TO METAL SPECIMENS

TEST

22. T-Peel at $75 \pm 50 \mathrm{~F}$ After 1000 Hoürs at $450 \pm 50 \mathrm{~F}$

23. T-Peel at $450 \pm 5$ OF After 1000 Hours at $450 \pm 50 \mathrm{~F}$
NUMBER OF SPECIMENS MINIMUM REQUIREMENTS PER BATCH TOTAL AVERAGE INDIVIDUAL

\section{$8.5 .1 \quad 8.5 .2 \quad 8.5 .3$}

$8.5 .1 \quad 8.5 .2 \quad 8.5 .4$
5

5
15

15 
NO. OF SPECIMENS REQUIRED MINIMUM REQUIREMENTS

PER BATCH TOTAL AVERAGE INDIVIDUAL

\section{TESTS}

1. Flatwise Tensile at

$$
75 \pm 50 \mathrm{~F}
$$

2. Flatwise Tensile at

$$
-65 \pm 5^{\circ} \mathrm{F}
$$

3. Flatwise Tensile at

$$
450 \pm 50 \mathrm{~F}
$$

4. Flatwise Tensile at

$$
75+50 \mathrm{~F} \text { After }
$$

$100 \overline{0}$ Hours at $450 \pm 50 \mathrm{~F}$

8.7 .1

8.7 .1

8.7 .2

8.7 .2

5. Flatwise Tensile at

$$
450 \pm 5^{\circ} \mathrm{F}
$$

6. Honeycomb Peel at $75 \pm 50 \mathrm{~F}$

7. Honeycomb Peel at $450 \pm 50 \mathrm{~F}$

8.7 .1

8.7 .1

8.7 .1
疍
15

15

15

5

5

15

15

5 


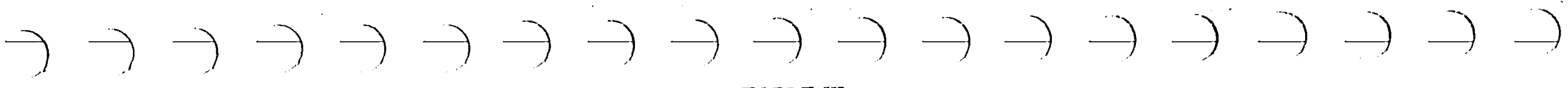
ENVIRONMENTAL DURABILITY TEST

\section{TESTS}

1. Crack Extension After 1000 Hours at $95 \pm 5^{\circ} \mathrm{F}$

2. Crack Extension After 1000 Hours at $450 \pm 50 \mathrm{~F}$

3. Crack Extension After 1000 Hours at 95-100\% Relative Humidity and $120^{\circ} \mathrm{F}$

4. Lab Shear Sustained

Stress Loading at 95-100\% Relative Humidity and $120^{\circ} \mathrm{F}$

\section{6 .18 .6 .2}

\section{6 .18 .6 .2}

8.6 .18 .6 .2

NO. OF SPECIN
PER BATCH

5

5

5

8.6 .3
12
15

15

15

N/A No Failure in

$\begin{array}{ll}\text { N/A } & \text { No Failure in } \\ & 1000 \text { Hour Aging }\end{array}$

居 
TABLE IV

\section{ASSEMBLIES AND SPECIMENS REQUIRED FOR ACCEPTANCE TESTS}

\begin{tabular}{|c|c|c|c|}
\hline & & ASSEMBLIES & SPECIMENS \\
\hline 1. Shear at $75 \pm 5^{\circ} \mathrm{F}$ & 1 & 5 & \\
\hline 2. Shear at $450 \pm 5^{\circ} \mathrm{F}$ & 1 & 5 & \\
\hline 3. Flatwise Tensile at $75 \pm 5^{\circ} \mathrm{F}$ & 1 & 5 & \\
\hline 4. Flatwise Tensile at $450 \pm 5^{\circ} \mathrm{F}$ & 1 & 5 & \\
\hline 5. Percent Volatiles & & 2 & \\
\hline 6. Weight & & 2 & \\
\hline 7. Percent Solids Type 1 Only & & 2 & \\
\hline
\end{tabular}




\section{PROCESS SPECIFICATION}

T

\rceil

$\uparrow$

T

$T$

$T$

$T$

$T$

$T$

$T$

$T$

$T$

$T$

T

$\Gamma$

A106 


\section{PROCESS SPECIFICATION}

HIGH TEMPERATURE STABLE $\left(450^{\circ} \mathrm{F}\right)$ STRUCTURAL ADHESIVES FOR BONDING TITANIUM ASSEMBLIES

1.0

\section{PURPOSE}

This specification establishes the requirements metal-to-metal and sandwich type assemblies designed for high temperature service.

ASTM D-1002

ASTM D-1876 


\section{ADHESIVES}

3.1.1 Class

The adhesive systems shall consist of two classes.

Class 1 Polyphenyquinoxaline (PPQ) Resin and Solvent

Class 2 LARC-13 Resin with aluminum filler and solvent

Class 3 LARC - TPI Resin and Solvent

Types

Type $1 \quad$ - will consist of the liquid adhesive with solvent.

Type 2 - will consist of an adhesive film supported with $112 \mathrm{E}$ glass/A1 100 finish

Type 3 - will consist of an unsupported film of the adhesive

\subsubsection{Grades (Type 2 Only)}

Grade A - $0.060 \pm .010 \mathrm{lbs} / \mathrm{ft}^{2}$ adhesive film with separator sheet(s).

Grade B - $0.080 \pm 0.10 \mathrm{lbs} / \mathrm{ft}^{2}$ adhesive film with separator sheet(s).

Grade C - $0.12 \pm 0.10 \mathrm{lbs} / \mathrm{ft}^{2}$

\subsubsection{Storage}

Before placing the adhesives in refrigerated storage, remove the insulating material used to protect it during shipment.

Store film adhesives in accordance with the supplier's recommendations to protect them from damage and loads other than their own weight. It is recommended that each roll be stored in the original shipping carton. 
Leave each roll of adhesive sealed in its air-tight polyethylene wrapper. After opening for removal of samples, reseal the roll wrapper air-tight.

Storage of adhesives shall be as follows:

\section{CLASS}

1

2

3
STORAGE TEMPERATURE

Below $0^{\circ} \mathrm{F}$

Below $0^{\circ} \mathrm{F}$

Below $0^{\circ} \mathrm{F}$
STORAGE LIFE

12 months

6 months

6 months

a. Scotch-Brite, aluminum oxide

3M Company

cleaning and finishing material,

Type $A$, very fine and Type $F$, super-

fine. OPTIONAL: Tycro, Type 3A, very fine aluminum oxide wheels.

b. Scouring Materials

Pumice

Cascade Pumice Company

Tripoli Powder

E. Reed Burns Sales Company

Wyandotte F1013

a. Frekote 33 Liquid

Frekote, Inc.

b. Frekote 44 Liquid
Frekote, Inc. a. Diglyme

b. M-creosol

c. Acetone

d. Methyl Ethyl Ketone

e. Methyl Isobutyl Ketone
Any source

Any source

Federal Specification QA-261

Federal Specification TT-M-261

Federal Specification TT-M-268 

f. Toluene, Technical
Federal Specification TT-T-548
or Jan-T-171, Grade A
g. Xylene, Technical
Federal Specification TT-X-916, Grade A or B
h. Dimethyl Formanide
Any source
a. No. $6250 \underline{1 /}$
Mystik Adhesive Products
b. No. 6325
c. No. 11
Permacel Division,
d. No. 12
Johnson \& Johnson
e. No. $733 \underline{1 /}$
f. HS-8171PS
Richmond Corporation
g. No. 855
3M Company
h. $\mathrm{P} 412 \mathrm{X}$
Mask Off Company
i. $Y 335$
3M Company
j. PTF-LSI No. 61
3M Company
1/ Only the tapes listed are approved for use on titanium.

\section{MISCELLANEOUS MATERIALS}

a. Thermocouple Wire, Iron Constantan $1268 \mathrm{~T}$ or equivalent, B\&S 20 gage or finer

b. Gloves, rubber latex

Duracraft Corporation,

c. Gloves, cotton, lightweight, or other source white, knitted Cardinal Glove Company, or other source meeting the contamination requirements of

d. Cheese cloth-bleached The Kendall Co. absorbent

Parke-Davis

Betty Day Co.

e. Honeycomb Core

Any source

f. Kapton Film, 2-mil thick

Any source

g. Silicone Rubber Sealant

Any source 
h. Porous Teflon Release Fabric

i. Fiberglass
Any source

Any source 
a. Filter all incoming air. Periodically check, clean or replace filters to ensure proper operation.

b. Maintain a positive air pressure differential, such that unfiltered air does not enter the areas through access doors or other openings.

c. Enclosed areas are required. Keep doors and other openings closed when not in use.

d. Seal and/or cover floors with non-flaking, easily cleaned material, such as plastic, paint, vinyl tile, etc.

e. The following methods only may be used for cleaning within the controlled contamination areas.
(1) Water mopping
- Use mops wet or dampened with water.
(2) Vacuuming
- The exhaust air must either be vented outside the limited contamination area or filtered to at least the same degree as the incoming air for the area.
(3) Chemical mopping - Use mops commercially treated with either propylene glycol or slightly tacky epoxy resin.

f. Cleaning is required when visual inspection shows any accumulated dust, dirt, or other contamination according to the following inspection schedule. 


\section{ITEMS}

1. Equipment, Tables, Floors, etc.

2. All walls, ceiling, beams, overhead fixtures, lights, spray booth, ovens, monorails, etc.
INSPECTION

SCHEDULE

No Inspection

Required

30 days
MAXIMUM CLNG. TIME INTERVAL

24 hours

As required by Quality Control

g. Do not allow internal combustion engines within the areas.

h. Do not permit smoking or eating in the areas.

i. All materials, tools, parts, or equipment taken into the areas shall be free of dirt, grease, oil, or other contaminants detrimental to adhesion.

j. Do not permit processes or operations which produce uncontrolled spray, dust, fumes, or particulate matter in the area.

k. The temperature shall be 65 to $90 \mathrm{~F}$ except the upper temperature limit of $90 \mathrm{~F}$ may be waived for the area adjacent to drying or curing ovens located within a controlled contamination area provided they are separated from the rest of the area.

1. Structural fiberglass, graphite, and aramid epoxy composites may be laid up or assembled concurrently with metal bond assemblies utilizing the same controlled contamination area. The following restrictions must be adhered to throughout the entire controlled contamination area:

(1) All precautions and requirements for cleanliness and contamination control as specified in Section 5 must be enforced. 
(2) Tools must be prepared prior to entering the controlled contamination area. Only parting agents specified in Section 4.3 are allowed.

(3) Within the controlled contamination area metal bond operations will be segregated from composite operations. This segregation will include an identified contiguous floor area, separate work tables, and separate shop aid tools. Personnel should not be intermixed during any given work period.

(4) White cotton gloves, cheese cloth, cleaning solvents and tapes shall conform to the requirements of Section 4 .

(5) The following listed materials or procedures are prohibited in the controlled contamination area.

(a) Application of uncured parting agents

(b) Use of hand cream

(c) Application of conductive coatings

(d) Application of gel coats to molds

(e) All grinding, sanding, or milling operations

(f) Deposition of graphite dust or fibers on bond faying surfaces

m. See Figure 1 for diagram illustrating the facilities and operations that must be kept within the controlled contamination area.

n. Do not use waxes, compounds containing uncured silicone, or any material detrimental to adhesion.

o. The above requirements are considered as minimum and basic; however, it is permissible for a contractor to present its own plan for review and upon written approval by Process Specification Departure (PSD), they may utilize their own plan in lieu of the requirements of this section. 
a. Install filters for airborne dust, traps for moisture and oil, on all air lines or ducts used for spraying and drying of parts in any location, or the operation of air motors within the controlled contamination area; at a point adjacent to the using area, but past the air source. Moisture traps on air lines used for solution agitation are not required.

b. Liquid handling facilities shall preclude contamination by grease, oil, suspended or dissolved solids, or other substances detrimental to adhesion.

c. Design and control lubricated equipment so as to prevent any contamination of adhesives or cleaned details by the lubricant.

d. Since some of the volatile products given off during the drying and curing of adhesives may contain toxic compounds, adequate provision must be made to vent the autoclaves, ovens, and vacuum pump outlets through the roof so as not to endanger personnel. Outlets must be more than 20 feet from air conditioning intakes.

a. To preclude solution cross-contamination during processing, arrange process flow in such a manner that details proceed from a process solution directly into a rinse tank, with cross-over permitted only after rinsing.

b. Processing solutions shall be equipped with suitable temperature control devices designed to maintain solution operating temperatures within the prescribed parameters.

c. Processing solutions shall be equipped with suitable timing devices to ensure proper processing times. 
Spray equipment used for the application of adhesive primers shall be restricted exclusively to that function.

4.5

\section{ADHESIVE/PRIMER STORAGE FACILITIES}

a. Adhesive storage facilities within the limited contamination area shall be used exclusively for adhesives, adhesive primers, and related bonding materials.

b. Low temperature storage facilities shall be equipped with proper temperature indicating devices. 


\section{GENERAL REQUIREMENTS}

a. Maintain a Manufacturing Plan for each assembly or family of assemblies, whichever is applicable. Record all applicable entries of Section 8.

b. Conduct all operations connected with bonding, after the drying of cleaned parts, including the storage of cleaned parts, through their assembly for bonding in a controlled contamination area as described in Section 4.1, except as specified herein.

c. Prohibit the use of talc, waxes, compounds containing uncured silicone, or any material detrimental to adhesion, in the metalbond area, i.e., prefit, clean line, controlled contamination area, and final cure area.

NOTE: $\quad$ Parting agents may be baked onto a tool surface in the same autoclave with bagged assemblies during cure of these assemblies. The parting agent must be applied to the tool outside of the metal bond area.

d. Move all cleaned or anodized parts to the controlled contamination area as soon as possible but not to exceed 2 hours after chemical processing.

a. Handle only when absolutely necessary. Do not twist or distort.

b. Honeycomb core must be handled and stored so as to prevent contamination. 
a. Wear clean, white, knitted cotton gloves at all times when handling cleaned or surface-treated parts. Change gloves frequently to eliminate contamination buildup.

NOTE: Even though clean gloves are worn, handle cleaned, surface-treated or adhesive primed parts as little as possible.

\section{CAUTION: DO NOT TOUCH BOND FAYING SURFACES EXCEPT WHEN ABSOLUTELY NECESSARY}

b. Coat anodized details with liquid adhesive or adhesive primers within 16 hours after cleaning.

c. Anodized titanium parts may be stored for a maximum of 72 hours before they are coated with adhesive provided such parts are carefully covered with oil-free paper during any time in excess of 16 hours, or are stored in a controlled contamination area.

d. Prior to the completion of the bonding operation, do not allow cleaned and surface treated parts or the white gloves to contact any substances (including body skin or hair) capable of contaminating the surfaces to be bonded. Protect bonded subassemblies against contamination until the next bonding operation. Complete the bonding operation within the time limits specified.

e. Protect all parts so as to prevent contamination whenever they are transported outside of their assembly area.

\section{$5.3 \quad$ REQUIREMENTS FOR DETAILS}

5.3.1 Titanium Honeycomb Core Details

a. The core shall be clean with no evidence of corrosion, etching, contamination by oils, grease, or other foreign material (excess 
node bond adhesive on cell walls is not to be considered as "foreign material"). Core shall be removed from its protective wrapping only in a limited contamination area and shall remain in the limited contamination area prior to bonding. Form $\mathrm{B}$ core shall be bonded within 30 days from unwrapping.

b. Actual, rather than apparent, ribbon direction shall be used and it shall not vary from the direction specified on the Engineering drawing by more than 10 degrees. Ribbon direction of individual ribbons or foils shall be determined by a straight line through two node bonds at least 12 inches apart on the same ribbon. The two node points shall be selected in such a manner that the maximum variation from the average ribbon direction will be determined.

NOTE: (1) Actual ribbon direction is as shown in the sketch below.

(2)

Apparent ribbon direction is an optical illusion caused by distorted cell shapes over a large area wherein the actual ribbon direction appears to be approximately 45 degrees to the node bonds. Under close examination the actual ribbon direction can be distinguished from the apparent.

c. Damage to the honeycomb core FACES which will neither be removed by subsequent machining operations nor reinforced subsequently by foam adhesive shall not extend below the plane of the faces over 0.010 inch nor more than one cell in width and one inch in length. 
NOTE: Damage of this nature shall further be limited to one such deformity per square foot of surface or per detail, whichever is smaller.

d. There shall be no evidence of columnar failure (crushing or buckling) except in those areas that will be completely removed by subsequent machining operations, or else reinforced by the complete coating of the cell walls by a dipped, poured or foamed application of adhesive.

NOTE: A normal rippling appearance of the cell walls prevalent in light density cores is acceptable. This rippling is in existence in the as-manufactured core, and may increase slightly after bonding. X-ray techniques cannot be depended upon to determine the extent of rippling short of a condition of full buckling where the core is pleated under crushing load.

A compression test per applicable specification can be used to determine whether the rippling appearance is affecting compressive strength.

e. The cell walls shall be perpendicular to the plane of the core faces unless otherwise specified.

\section{Machining Titanium Honeycomb Core}

a. Machine honeycomb core in the stabilized condition. Wherever possible, stabilize the core by bonding on a false skin.

(1) False skins may be temporarily bonded to the core with any suitable adhesive provided all core and metal surfaces contaminated with the temporary bonding adhesive are removed by subsequent machining.

(2) Honeycomb subassemblies having a permanent core-to-skin bond do not require any further stabilization. 
b. When ice chucking is used, dry the core in an oven at $225-250 \mathrm{~F}$ for a minimum of 90 minutes. Do not dry when vapor degreasing is required.

c. Machine titanium honeycomb core details and subassemblies without the use of lubricants or liquid coolants with the exception of oil-free $\mathrm{CO}_{2}$ gas and water containing less than $150 \mathrm{ppm}$ total (dissolved and suspended) solids.

d. Prohibit any processing or operations which contaminates the honeycomb core.

e. Allow for the difference in final bond line thickness on solid metal components. Machine the core to extend $0.005 \pm 0.003$ inch above the surface of the adjacent metal components.

f. The edges of cell walls at the core face shall not be torn, split, bent over, or otherwise deformed as a result of machining, except as follows:

(1) The edges of the cell walls shall be free of burrs larger than 0.015 inch.

(2) Split or bent cell walls which do not extend below the plane of the core face more than 0.125 inch are acceptable provided such deformities are limited to not more than $10 \%$ of the total face area and are stabilized.

(3) Damage to the core shall not exceed 0.010 inch in depth; one cell in width; and one inch in length. A maximum of one such damaged area will be allowable per square foot or per detail, whichever is smaller. 


\subsubsection{Machining Tolerances}

The following tolerances shall apply unless otherwise specified on the applicable Engineering documents.

a. Core surface variations shall not exceed 0.002 inch in 1 inch or 0.005 inch in 10 inches from true contour.

b. The width of all slots, cut in the core, for flat blades, extrusion fittings, etc., shall be held to the nominal fitting dimension $-0.000$ +0.030 inch

Round holes drilled through the cell walls for foamed-in-place fittings shall be held to the nominal fitting diameter $-0.000$ +0.060 inch

The depth of all step cuts machined in the core for doublers shall be held to the nominal thickness of the doubler plus the nominal thickness of the skin to doubler adhesive bond per applicable specification \pm 0.003 inches.

The width of steps and recesses to accommodate doublers and edge members shall be nominal width of the doubler or edge number $-0.000$ +0.030 inch

The amount of undercut created by disc cutters when machining steps and recesses shall not exceed 0.010 inch. 
a. Check all surfaces to be joined for mating tolerances and prefit in accordance with drawings. Burrs on faying surfaces of metal details must not exceed 0.002 inch. Do not steel-stamp contacting surfaces.

b. Check flexible details, such as skins, to assure that only very light pressure (1-2 psi as calculated on the bond area) is required to give uniform contact over all surfaces to be bonded.

c. Check heavy or rigid details, such as spars, extrusions, etc., and sculptured or contoured core to assure that a maximum pressure of 5 psi on the bond area is required to obtain a maximum gap of 0.005 inch between surfaces to be bonded.

Identification of Details

Prior to cleaning, identify details and the process control assemblies with the assembly being bonded.

\section{CLEANING AND SURFACE TREATMENT OF DETAILS}

a. Clean and surface prepare titanium details per the following procedures.

\subsubsection{General Requirements}

a. Completely immerse parts in the processing solutions.

b. Parts must be moved between surface treatments and rinsing with no delay. Spray nozzles must be incorporated in the frame or hood, positioned so that the surfaces of all detail parts are exposed to spray rinsing simultaneously with their withdrawal from the alkaline cleaning and deoxidizer solutions. Rinsing is then completed in 
separate tanks. Spray rinsing on withdrawal from solutions does not apply to cleaning prior to anodizing.

c. Parts must be racked so that solutions and rinse waters contact all surfaces and drain freely. Parts shall be spaced so that they are visually inspectable to the water break free requirements.

WARNING: Solutions used in this specification are corrosive and toxic. Consult Industrial Hygiene for safety precautions.

Avoid breathing solution mists or vapors.

Do not allow solutions to get in the eyes, on the skin, or on clothing.

d. Observe the following instructions when preparing solutions:

(1) Fill the tank with approximately $1 / 3$ to $3 / 4$ 's of the total water required.

(2) Add solid chemicals slowly by spreading them uniformly over the surface. Agitate the solution to dissolve the chemicals.

(3) Add liquid acids SLOWLY with agitation.

WARNING: $\quad$ Rapid addition of the acid may cause boiling and splattering of the solution.

(4) Fill the tank with water to the operating level, and agitate the solution thoroughly.

(5) Bring the solution to operating temperature.

(6) Analyze and adjust. 
e. Maintain the level of cleaning solutions within two inches of the operating level.

f. Maintain clean solution surfaces.

g. Agitate all cleaning solutions after prolonged standing or after the addition of chemical or water to ensure uniformity of concentration and temperature.

h. Control solutions so as to preclude the accumulation of sludge.

i. Use clean, dry air conforming to the requirements of Section 4.2, Item a. for solution agitation and the drying of parts.

j. Incoming rinse water to be used for rinsing deoxidized parts shall not contain more than $150 \mathrm{ppm}$ of total solids. Where immersion rinsing is used, it shall be double counter current or individual water feed double immersion.

k. A water-break-free surface is required following the rinse after alkaline cleaning and deoxidizing aluminum details.

1. Prohibit immersion cleaning of assemblies containing riveted faying surfaces not fully protected by an organic finish and/or sealant.

m. For plate and sheet titanium, processing is identical for both bare and clad details unless otherwise specified on applicable Engineering documents.

n. Castings, forgings and extrusions must be anodized except as noted on applicable Engineering documents. 
フ

T

7

PROCESS

Alkaline Cleaning

$T$

Anodizing

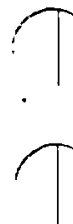

T

5.4.2.1

5.4 .2

RESTRICTIONS ON USE OF PROCESS SOLUTION

bond only.

Preferred for metal

bond only.

bond only.

Composition and Maintenance of Titanium Cleaning Solutions

Alkaline Cleaning Solutions
RESTRICTIONS ON USE OF PROCESS RINSE WATER

Must not be used to

750

MAXIMUM TOTAL SOLIDS

CONTENT IN WATER

ppm

rinse parts from acid

processes.

Preferred for metal $\quad 100$

Use alkaline cleaners listed in the following table:

\section{TABLE I}

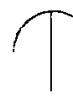

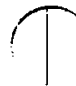
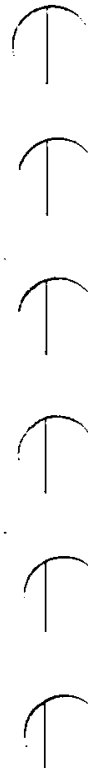

ALKALINE CLEANER RESTRICTIONS

Oakite $61 \mathrm{~A}$

Turco 2623

Wyandotte Altrex B

Cee Bee A-54

Pacific SP-112-LF

Pennsalt 2476

Turco 4090-14

Isoprep 44

Northwest LP3651

Oakite 61B

Oakite $80 \mathrm{~A}$

Pennsalt A-31

Turco 4215 and

4215 Additive

Turco 4215 Special

Wyandotte Aldet

Turco 4215

(Flagnotes in "RESTRICTIONS" column)
CONTROL LIMITS

OZ./GAL.

$$
\begin{aligned}
& 5-8 \\
& 5-8 \\
& 6-8 \\
& 6-8 \\
& 6-8 \\
& 6-8 \\
& 6-8 \\
& 6-8 \\
& 6-8 \\
& 5-8 \\
& 6-8 \\
& 4-8 \\
& 4-8(\text { Turco } 4215) \\
& 4-8 \\
& 4-8 \\
& 0.75-2.25
\end{aligned}
$$

OPERATING TEMPERATURE DEGREES F

$160-190$

$135-175$

$135-190$

$135-145$

$135-145$

$135-145$

$135-190$

$135-145$

$135-145$

$160-190$

$135-145$

$135-185$

$135-185$

$135-185$

$135-185$

$145-190$

These cleaners are not acceptable when rinse water is reprocessed by deionizing, except as noted in 7 . 
These cleaners are acceptable when rinse water is reprocessed by deionizing. Non-silicated soak cleaners

Use Turco 4215 additive with Turco 4215 to improve ink removal. Non-silicated spray cleaner.

Proportions: 1 pint to 1 quart of Turco 4215 additive per 100 gallons of cleaning solution.

These cleaners are acceptable when rinse water is reprocessed by deionizing, provided activated charcoal filters are used and the concentration of wetting agents are maintained below 20 ppm after filtering.

Rinse water temperature of $70 \mathrm{~F}$ minimum is permitted.

\subsubsection{Titanium Anodizing Solution}

a. Make-up and Control Limits

\section{Component}

Chromic Acid

Hydrofluoric Acid

\section{Control Limits}

6.0-7.5 oz/gal $\mathrm{CrO}_{3}$ Control to current density of $1.0-3.0 \mathrm{amps} / \mathrm{ft}^{2}$ at 9 to 10 volts

(1) Add the chemical evenly along the tank and mix thoroughly for at least 15 minutes.

(2) Measure current density on titanium pre-etched in nitrichydrofluoric acid and with continuous agitation of the anodizing solution. Use Ti-6Al-4V panels of $1 / 2$ to $1 \mathrm{ft}^{2}$ and a roughness of RHR 32 or less.

(3) To increase the current density $0.5 \mathrm{amps} / \mathrm{ft}^{2}$, add $140 \mathrm{ml}$ of hydrofluoric acid per 100 gallons of solution.

b. Operating temperature: 60 to $80 \mathrm{~F}$. 
5.4.3 Rinse Requirements

a. Rinsing may be by spray or immersion. Single or double rinse operations may be used. Any combination of rinse operations may be used.

b. Feed water to rinse operations may be direct from source water in accordance with Section 5.4.1, or from any subsequent rinse operation of Section 5.4, except that acid rinse waters shall not be mixed with alkaline rinse waters.

c. Final immersion rinse water after alkaline clean, deoxidizing and anodizing shall not exceed $1000 \mathrm{ppm}$ total dissolved solids. When double independent feed or double counter current rinse is used, the first rinse after anodizing shall not exceed $5000 \mathrm{ppm}$, and the time in first rinse shall not exceed 2 minutes from time of complete immersion to complete withdrawal. Anodize immersion rinse $\operatorname{tank}(s)$ shall be used for anodize rinse only.

d. Immersion rinse tanks shall be agitated to assure adequate rinsing and prevent stratification.

e. Allowable concentration limits may exceed normal control limits for the first 30 seconds of rinsing.

5.4 .4

Process Control

a. Process two crack extension test panels with each load using $6 \times 6 \times 0.050$ inches $\mathrm{Ti}-6 \mathrm{Al}-4 \mathrm{~V}$ panels.

b. Prime panels with Type 1 adhesive and bond with the applicable grade $A$ or $B$ in accordance with this specification.

c. Cut bonded test assemblies into five one-inch wide specimens as shown in Figure 1. Do not overheat when cutting. 
d. Identify all specimens for exposure testing.

e. Precrack ends containing the separator film by inserting a 0.125 inch thick wedge as shown in Figure 1.

f. Locate and mark the tip of the initial crack.

g. Expose the wedged open specimens to 95 to 100 percent relative humidity, for 60 to 75 minutes, in a chamber maintained at $120 \pm$ $5 \mathrm{~F}$.

h. Measure the increase in length of crack resulting from the humidity exposure within two hours after removal.

i. Recycle the corresponding production parts and take corrective action when any one of the ten crack extension specimens tested results in more than 0.25 inch crack growth after exposure.

5.4.5 Quality Control

a. Surfaces shall be free of burned areas and areas which are not anodized, except electrical contact areas which are not anodized are acceptable.

b. Surfaces shall be purple, blue, blue-gold, blue-green or a combination of these colors. Parts with gray or spotty gray areas are not acceptable.

c. Parts which do not conform to the requirements of Section 5.a. and b. may be recycled once in accordance with Section 4.2 and retested. Further recycling requires MRB disposition.

a. Examine each container to assure that the labels are correct, securely affixed, and that the expiration time will not expire prior to the start of curing. 
b. Condition to room temperature prior to opening the container.

c. Do not use contents of any container containing lumps or showing any indication of gellation.

d. Immediately before initial use, thoroughly mix each full container for not less than 5 minutes on a vibrating paint mixer or equivalent.

e. After a container of mixed adhesive primer or liquid adhesive has been standing 4 hours or more, mix it again for at least 2 minutes before further use, unless contained in a tank where it is being constantly stirred.

\section{APPLICATION OF ADHESIVE PRIMERS AND ADHESIVES}

\subsubsection{General Requirements}

a. Exceeding the MANDATORY TIME LIMITS in any step in the application shall be cause for rejection of all affected parts.

b. Do not apply masking tapes to any bond faying surfaces, unless allowed in the applicable Engineering documents.

\subsubsection{Spray Application of Liquid Adhesives and Adhesive Primers}

\subsubsection{General Requirements for Spray Application}

a. Spraying procedures and the selection and operation of equipment shall conform to manufacturer's guidelines.

b. Compressed air used for spraying adhesives shall be free of water, oil and solid particles as tested by blowing air directly on a clean sheet of metal or glass. Test as follows, performing the test as often as necessary. 
(1) Clean the sheet by wiping with a clean cloth or tissue.

(2) Hold the nozzle 8 to 10 inches from the sheet with the air valve fully open for at least 15 seconds.

(3) Look for droplets of oil or water as the air is blowing and after the test.

(4) The air shall not deposit visible oil, water or solid particles on the clean surface.

CAUTION: Periodically check and maintain the filters, oil and moisture traps on the compressed air line system to prevent contamination of the air supply.

c. Apply to the thickness required by .0005"-.001".

d. Spray the details as soon as practicable after cleaning and surface treatment but within the time limits of Section 5.2.2, Items b. and c.

(1) When paint primers are required to be applied during the bonding process, they may be sprayed in the same booth, but not at the same time as the spray application of adhesives and adhesive primers. Apply the paint finish in such a manner that the faying surfaces of parts to be bonded will not be contaminated by these materials.

(2) The top surface of the spray table shall be clean prior to its use.

e. Clean spray equipment with a suitable solvent as required.

WARNING: Avoid breathing vapors or mist. Avoid prolonged or repeated skin contact. 
f. Keep coated details free from all foreign materials, deposits from adjacent spray operations, etc.

g. After spraying, keep all parts in the controlled contamination area until assembled. Contamination of the adhesive or adhesive primer during or after drying shall be cause for rejection of the part.

\subsubsection{2}

\section{Qualification of Spray Coat Operators}

a. Only qualified spray operators shall be allowed to spray production parts.

b. At least once each week, the thickness of the cured film applied by each operator shall be determined by either of the optional methods given in Item e. below.

c. The film thickness requirement is given in the applicable dashnumbered specification.

d. The film thickness determination shall be made with an Isometer Model 2.082 or an instrument with equivalent or greater accuracy and precision.

e. One of the following methods is required.

(1) Method 1 - Examine 16 production parts coated by the operator being qualified. Measure the film thickness in the trim area of the parts after drying as specified by the applicable dash-numbered specification.

(2) Method 2 - Examine a 12-inch square aluminum test panel which has been spray-coated on one side.

(a) Divide the panel into 4 sections, each 6 inches square. 
(b) Determine the average film thickness of 4 readings of approximately equal spacing on each section, after curing as specified by the applicable dash-numbered specification.

f. Fifteen of 16 measurements, made by Method 1 or 2 above, shall be within the required range.

g. In lieu of the thickness measurements described above, an optional weight determination may be made when permitted in the applicable dash-numbered specification.

(1) Weight a 12-inch, square aluminum test panel to the nearest 0.1 gram.

(2) Coat and dry the panel as specified by the applicable dashnumbered specification. Weigh the coated panel to the nearest 0.1 gram.

(3) The weight must be within the range specified in the dashnumbered specification.

h. When the operator fails to meet the requirements of Item e. or g. above, he shall adjust his equipment and/or method of application so that the correct coating is applied. He shall demonstrate his ability to meet the film thickness requirements prior to spraying production details.

\subsubsection{Spray Coating Skins and Details}

a. Apply a continuous wet coating.

b. Reject details when excessive adhesive is applied or large droplets form on bond faying surfaces.

c. Extend the adhesive coverage at least $1 / 8$ inch beyond the actual bond area when possible. 
d. Remove any overspray with a suitable solvent before the adhesive has completely dried. Use care not to dilute the adhesive in the bond area. Some adhesives can be removed with solvent after curing.

e. Position production details and test assemblies on racks in such a manner as to avoid contamination of any surface to be bonded and so as to prevent the details from touching, striking or scratching each other.

f. Store the racked details in a controlled contamination area during the air dry.

g. Oven cure the details when required.

Coating Skins And Details By Other Than Spray Application

a. Any method of application may be used if that method meets requirements.

b. Reject details when large droplets are formed on bond faying surfaces.

c. Mechanical application may induce streaking or mottling of the adhesive that is not apparent when spraying. This condition is not rejectable unless the film thickness requirements are not met.

d. The applicator must be free from contamination when dry as well as when soaked with adhesive. 
e. The use of the mechanical applicator is specifically restricted as follows:

Hard Roller Technique is prohibited on nonconductive materials as fiberglass laminates, plastic parts, plastic films, or paper.

f. Clean the applicators with a suitable solvent.

(1) Dry the appicator by evaporation only, not by rolling or mechanical agitation.

(2) Change the solvent at least once each production shift or when it becomes contaminated with sufficient adhesive to interfere with cleaning.

g. Use a mechanical applicator with one material from one container only. Do not transfer applicators from one pan to another without cleaning.

\subsubsection{Application Of Film Adhesive}

a. Thoroughly solvent clean the table tops, templates, and tools used for laying out, cutting, or handling film adhesives once every 8 hours. Wipe dry, before the solvent evaporates, with clean, dry, lint-free wiping material.

Avoid breathing vapors or mist. Avoid prolonged

WARNING or repeated skin contact. Keep away from sources of ignition.

b. Wear clean gloves conforming to the requirements of Section 3.6 and Section 7 when handling cleaned, coated parts or adhesives.

c. Before opening the wrapper, condition refrigerated adhesives to room temperature until moisture no longer condenses on the 
wrapper, unless otherwise specified in the dash-numbered specification.

\subsubsection{Primer Application}

Type 1 liquid adhesive primer shall be at ambient temperature prior to opening its container.

a. Class I, Type 1

Dilute Class 1 , type 1 adhesive primer with solvent (1:1 mixture of xylene and meta-creosol) to $9 \pm 1 \%$ solids weight. Apply the primer to adherends by brush, spray or roller to a thickness of $.0005^{\prime \prime}-0.001 "$.

b. Class II, Type 1

Dilute Class II, type 1 primer to $26 \pm 2 \%$ solids with DMF and brush, spray, or roller coat the primer onto the adherends to a thickness of $.0005^{\prime \prime}-0.001 "$.

c. Class III, Type 1

Dilute the primer with diglymes to a solids content of $8 \pm 1 \%$ and then apply to the faying surfaces of the adherends to a thickness of .0005 " to .001" with a brush, roller or spray equipment. 
a. Prepare each lap shear test asembly from two standard aluminum or titanium panels to meet the following requirements:

(1) Nominal thickness of aluminum panels is 0.063 in.

(2) Nominal thicknes for titanium panels is $0.050 \mathrm{in.}$

(3) Surface roughness requirements for the lap areas of all panels shall not exceed the equivalent of milled 133 RHR.

(4) Chamfer radius after removal of burrs shall not exceed 0.010 inch.

(5) Panel warpage shall not exceed 0.010 inch over the length or width of the panel.

b. The applicable dash-numbered specification governs the application of the adhesives except as modified herein. After applying and drying of the adhesive primer, apply a strip of film adhesive approximately 0.6 inch wide and 6.5 inches long to the primed faying surface of one panel.

c. Join the two panels to make a lap shear test assembly.

(1) Coat the surface parts of the bonding jig adjacent to the bond areas with an approved parting agent.

d. Before curing, complete identification as applicable.

e. Cure in accordance with the applicable dash numbered specification, in the same cure load as the production assemblies they are to accompany. 
f. Cut test specimens to conform to the dimensional requirements of lap shear as applicable. Do not overheat or damage the bond when cutting. All cuts to be straight and parallel.

1/ Equivalent shall mean any suitable tool or method capable of maintaining the test panel assembly in proper aligned position and capable of applying uniform pressure on the test panel assembly during the cure cycle to provide uniform bond lines.

\section{Titanium Process Control}

a. For each assembly or subassembly, a minimum of one lap-shear assembly must accompany the details through all bonding processes from cleaning through assembly and cure.

b. Prepare the Process Control Test Assemblies from the same lot of adhesive, assemble at the same time, cure in the same load, in the same equipment, and under the same ambient conditions as the production assemblies with the same identification numbers.

c. The Process Control Test Assemblies must accurately reflect the materials and processing conditions of the production assemblies they accompany. When an assembly is bonded in more than one stage, a full set of test assemblies must be initiated with each bonding stage and tested prior to next assembly operation.

d. In order to approximate production part temperatures in the test assemblies, the materials and configurations of the test assembly jigs may be varied to provide a heat transfer rate approximating that of the production tools.

e. When the tooling used has no space for test assemblies, use a separate test assembly platen with one pressure probe and one thermocouple. Connect the diaphragms of the production and the test assembly so that the two diaphragms are at the same pressure. 
f. Alternate: A surface treatement process control method for titanium, similar to that used for aluminum may be used in lieu of that specified in Items a through e above. The surface treatment process control procedure shall require that titanium lap shear assemblies be processed as outlined in Section 5.4.4, concurrently with the production details they represent.

a. Prepare each honeycomb peel test assembly to conform with either. This configuration is recommended where the test apparatus has eccentric, self-tightening clamps. See the applicable dash numbered specification for additional requirements.

b. Identify the test assembly with the appropriate production assembly identification and sequence numbers.

c. Cure in accordance with specification, in the same cure load as the production assembly it is to accompany.

d. Identify each specimen.

e. Cut the test specimens to conform to the dimensional required. All cuts to be straight and parallel. Do not overheat or damage the bond when cutting.

a. Prepare the metal-to-metal peel test assembly and specimens.

Panels may be assembled with no adhesive for 2 to 3 inches back from the end of the panels, leaving the ends free for attachment to the test apparatus.

b. Identify the test assembly with the appropriate production assembly identification and sequence number. 
c. Cure in accordance with the applicable dash numbered specification, in the same cure load as the production assembly they are to accompany.

d. Identify each specimen.

e. Trim approximately one-half inch from one edge of the assembly. Cut three test specimens from the assembly. Discard excess after cutting the specimens. All cuts shall be straight and parallel. Do not damage or overheat the bond when cutting.

\section{CURING OF ADHESIVE BONDS}

5.8.1 General Requirements

a. The cure cycle must be started before the expiration time of the particular lot of adhesive being used.

b. Do not subject the cured bond to stress until the end of the cure cycle.

c. Do not cover assembly vent holes, edge joints, gas escape routes and adhesive escape routes with non-porous materials, such as cellophane, aluminum foil, masking tape, etc., which would restrict venting and the flow of adhesive flash.

d. During each cure of multi-stage bonding operations do not subject bonds of a previous cure to stress other than thermal stress normally encountered in curing operations.

a. Use thermocouples which will aproximate the particular "temperature-electromotive force (emf)" relationship required by the recording instrument in use. 
b. Use thermocouples accurate within $\pm 5 \mathrm{~F}$ at the curing temperature of the adhesive being used. Iron-constantan welded thermocouples are recommended.

c. When welded thermocouples are not used, twists of the wires to form the thermocouple shall not exceed two turns in length.

(1) Mulitple junction boxes around the periphery of the project plate, connected with appropriate leads to a master junction box for connection to the recorder are recommended.

(2) Where long leads are employed, great care must be taken to prevent leaks or breaks in the insulation which would permit the wires to contact the project plate or platen, thereby measuring the temperature of the plate or platen, rather than the bond temperature.

d. Record the cure temperature by means of a thermocouple (20 gauge or finer) embedded in the adhesive bond or in the adhesive flash immediately adjacent to the bond.

e. Unless otherwise specified, thermocouple requirements shall be as listed below:

(1) Platen loads under a single pressure diaphragm - Install a minimum of four thermocouples as to be representative of all bondline temperatures within the load.

(a) One of the above shall be in the flash of a metal-tometal test panel (titanium only).

(b) When honeycomb structures are being bonded, place one thermocouple in the upper and one in the lower bondline flash. 
(2) Individually bagged assemblies - the minimum number of thermocouples shall relate to the number of assemblies in any curing facility (oven, autoclave, etc.) as listed below. Install thermocouples in position on the assemblies which wil register the extremes (fastest and slowest) in rate of rise.

(a) 1 - 3 assemblies require two thermocouples per assembly.

(b) 4-9 assemblies require one thermocouple per assembly.

(c) 10 or more assemblies require one thermocouple for each two assemblies.

(d) For titanium bonding, one additional thermocouple is required in a test panel.

f. Electrically check each thermocouple circuit prior to the bonding operation.

g. Mechanically record the temperature measurement from each thermocouple, during the entire cure cycle.

NOTE: Multipoint recorders are acceptable providing each operating thermocouple is monitored at least once each 6 minutes.

Temperature Sensing Indicators

a. Permanent temperature sensing devices, such as, but not limited to, thermocouples imbedded in tooling, or sensors installed in the curing facility, for example, may be used in lieu of thermocouples imbedded in the bondline of parts. 
b. It is permissible to utilize any combination of thermocouples and/or permanent temperature sensors for controlling and recording the cure cycle of adhesives.

c. Temperature sensors must be mechanically recorded during the entire cure cycle. A maximum time of 6 minutes between printouts is permissible.

d. Prior to any tooling or parts being accepted for cure cycle control by temperature sensors, the tooling or parts must first be qualified by correlating the permanent sensors with thermocouples imbedded strategically in the bondline of parts.

(1) This correlation must be demonstrated on a minimum of 3 production runs. The tooling or parts shall be placed randomly when an oven or autoclave is used.

(2) The correlation must show that all bondlines, as indicated by bondline thermocouples, can be controlled for rate-of-rise and cure temperature by the permanent thermal sensors, and are within specification requirements.

(3) Any major tool rework or redesign requires a new thermal sensor profile and correlation be established prior to eliminating bondline thermocouples for production.

(4) Any replacement or relocation of thermal sensors shall require re-correlation of the new thermal device with the original device or with other calibration devices.

e. The recording chart printout points must be traceable as being from bondline thermocouples or thermal sensing devices on all production runs whenever the two are mixed in the same autoclave or oven load. 
f. When a correlation is established, Quality Control shall require permanent identification of the tool or thermal sensing device placement as being acceptable for bonding without thermocouples in the bondline. Whenever a correlation cannot be established, Quality Control shall reject the option and require thermocouples in the bondline.

All tools or parts not requiring part thermocouples must be identified.

(1) A permanent record of the correlation data shall be kept on file for MRB reference or other purposes.

(2) Quality Control may require periodic requalification per Item d. of the thermal sensor profile to ensure that the thermal sensors agree with part temperature.

(3) All details and assemblies not requiring part thermocouples shall be so identified on the process control records.

5.8.3 Cure Temperature Requirements

a. Cure as specified below:

b. The heating rate from $120 \mathrm{~F}$ to the minimum cure temperature shall be as uniform as practicable, but shall not be greater than $9 \mathrm{~F} /$ minute.

c. At the end of the cure period, cool the assembly a $5^{\circ} \mathrm{F} /$ minute maximum.

Class $1 \quad 625^{\circ} \mathrm{F}$ for $1 \mathrm{hr}$

Class $2 \quad 600^{\circ} \mathrm{F}$ for

Class $3 \quad 625^{\circ} \mathrm{F}$ for $1 \mathrm{hr}$ 
a. The cure pressure shall be as follows or as specified in the applicable dash-numbered specification, or applicable Engineering document:

(1) The pressure on assemblies containing honeycomb core shall not exceed the maximums given in Table II, unless specifically superseded by an appropriate Engineering Document.

(2) The pressure shall be within \pm 5 psi of the current bonding pressure established by Manufacturing. This pressure is stamped on the bonding tool (when used), after part qualification or requalification.

NOTE: This information may be recorded on the part qualification record rather than on the tool.

b. Apply pressure in such a manner as to minimize movement of the details.

c. Apply the required pressure before the bond temperature reaches $120 \mathrm{~F}$, unless otherwise specified in the dash-numbered specifications.

d. Curing under vacuum is prohibited unless permitted by the applicable dash-numbered specification.

(1) If a vacuum is permitted, a minimum of 20 inches of mercury shall be applied before the cure begins and maintained during the entire cure.

(2) Large area doublers containing a vent hole pattern as specified below may have non-vented areas up to 3 inches in width. 
Finish And Corrosion Protection Of Bonded Assemblies

a. Leave the adhesive flash to seal the joints of the completed assembly whenever possible. When the flash must be removed, perform the removal in such a manner as to prevent damage to the skin or delamination of the bond.

b. Corrosion protect and finish the completed assembly, including edges, as specified by the Engineering drawings. Chemical surface preparation (e.g., Alodine) may be omitted prior to priming for touch-up of trimmed edges only.

Packaging And Storage

Suitably package the completed assembly so as to prevent damage during storage, transportation, and shipment. 
a. Quality Control shall enforce all requirements of this specification.

b. All tests of this specification are classified as acceptance tests. The necessary techniques, inspection procedures, and methods of testing common to all the dash numbered specifications are specified herein. Perform these tests during the fabrication of adhesive bonded airframe parts.

c. Quality Control shall inspect in accordance with Section 5.1, Item $f$, and verify that corrective action has taken place when required. USE

6.1.1 Storage

a. Verify that adhesive primers and adhesives are stored at the temperature specified and that the storage life is not exceeded.

b. Maintain a Validation Record containing the following information for each lot of adhesive:

(1) Lot number (assigned by purchaser).

(2) Batch number (assigned by manufacturer).

(3) Date of manufacture.

(4) Date shipped from vendor.

(5) Receiving inspection date and test values.

(6) Reinspection dates and test values during storage. 
(7) Storage temperature.

(8) Date of initial evaluation for release for production use and test values.

(9) Date of issue for production use.

(10) Expiration date and hour.

(11) Requalification dates, test values, and new expiration date and hour.

6.1.2 Adhesive Evaluation For Release For Production Use

6.1.2.1 General Requirements

a. Do not release any container or roll, or portion thereof, of adhesive which appears to be contaminated or of inferior quality.

b. Perform the following evaluation tests on two samples from each lot of adhesive. Take the two samples from different rolls or containers of adhesive.

(1) From each sample of adhesive, prepare one Lap Shear Test Assembly in the same manner as for Process Control test assemblies and test as specified.

(2) From each sample of adhesive, prepare one Honeycomb Peel Test Assembly in the same manner as for Process Control Test Assemblies except use the materials listed below, and test as specified.

(a) Core Material - T. Honeycomb or Polyimide Honeycomb, whichever is applicable.

(b) Skin Material - 0.020 inch thick, 6A1-4VT. 
NOTE: This test is not required for adhesive systems used only for metal-to-metal bonding.

(3) From each sample of adhesive, prepare one Metal-to-Metal Peel Test Assembly in the same manner as for the Process Control Test Assemblies.

c. The following test requirements must be complied with:

(1) Adhesive primers and film adhesives may be evaluated simultaneously.

(a) When a test failure occurs on a simultaneous evaluation, then test and evaluate each type separately.

(b) To test either type separately, it is mandatory that a validated adhesive of the other type be used to complete the bond.

(2) Test and evaluate liquid adhesive or pour coat with a validated film adhesive.

d. Upon completion of the evaluation testing, record an expiration time, by date and hour, for each lot of adhesive released for production use as follows;

(1) The expiration time shall be 168 hours from the date and hour of sampling (application of the adhesive primer to the test assembly) or as modified by the dash numbered specification.

(2) Securely affix a tag or label, showing the expiration time, by date and hour, and the stamp of the Quality Control representative making the test, to each roll or container in the adhesive lot. 
e. Prior to release for production use, label each container of liquid adhesive, or primer and each roll of film adhesive on the inside of the core and transfer the DATE OF SHIPMENT, as it appears on the wrapper, and/or lot number to this label, plus such other outside information as does not already appear on the inside label.

f. When an adhesive fails to meet the evaluation requirements, affix a tag or label of distinctive color, bearing the word "REJECTED" in large letters together with the date to each roll or container in the rejected lot.

\subsubsection{Evaluation Requirements for Release to Production Use}

\subsection{Lap Shear Evaluation}

a. Accept the lot of adhesives when either of the two criteria below are met:

(1) Each of the 10 individual test specimens has a shear strength, as calculated from the actual bond area, equal to, or greater than, the acceptable minimum average value for the adhesive system under test.

(2) The grand average for the 10 test specimens exceeds the acceptable minimum average value, and no individual test specimen value is below the acceptable minimum individual value.

\section{Honeycomb Peel Evaluation 1}

a. Accept the lot of adhesive when either of the two criteria below are met:

(1) Each of the 6 individual test specimens has a peel strength equal to, or greater than the acceptable minimum average value for the adhesive system under test. 
(2) The grand average for the 6 test specimens exceeds the acceptable minimum average value, and no individual test specimen value is below the acceptable minimum individual value.

\subsection{Metal-to-Metal Peel Evaluation}

a. Accept the lot of adhesive when either of the two criteria below are met:

(1) Each of the 6 individual test specimens has a metal-to-metal peel strength equal to, or greater than, the acceptable minimum average value for the adhesive system under test.

(2) The grand average for the 6 test specimens exceeds the acceptable minimum average value, and no individual test specimen value is below the acceptable minimum individual value.

\subsubsection{Release for Production Use Deleted}

a. No adhesives shall be used in production after the expiration time for the lot.

b. After a particular lot of adhesives has been validated and put into production use, it may be revalidated for subsequent production use by the procedures of Section 6.1.2.

c. OPTION FOR TITANIUM: The PROCESS CONTROL test specimens required by the dash numbered specification may be used for the dual purpose of Process Control and adhesive revalidation. The particular lot of adhesive may be considered revalidated for a period of 168 hours (See Section 6.1.2, Item d) after the hour or application of the adhesive to the most recently assembled lap 
shear test assembly assembled during the 24 hour period selected for the optional method of qualification, provided the following conditions are met:

(1) A minimum of 5 lap shear, 5 metal-to-metal, and 5 honeycomb peel test assemblies is required to maintain the validation of any particular lot of adhesive under the optional provisions.

(2) The grand average of all test specimens tested as required by Item c.(1) above exceeds the qualification requirements for the lap shear, metal-to-metal peel, and honeycomb peel strengths for the adhesive system being used.

(3) Record the lot number and grand average for the lap shear, metal-to-metal peel, and honeycomb peel in the Validation Record required by Section 6.1.1.

Honeycomb peel is not applicable when the adhesive is to be used for metal-to-metal bonding only.

d. (1) When any of the requirements of Item c. above are not met or complied with, the particular lot of adhesive shall not be used, but shall be sampled, tested, and re-evaluated in accordance with Section 6.1.2.

(2) When the failure can be attributed to causes other than defective adhesive (such as Cleaning solutions out-of-process limits), random select a series of test results from the previous 24 hour period and evaluate these for revalidation. When the results of this evaluation fail to meet the requirements of Item c.(2) above, the particular lot of adhesive shall not be used, but shall be sampled, tested, and re-evaluated in accordance with Section 6.1.2. 
e. (1) When adhesive is returned to refrigerated storage during the shop use period, the expiration time under which it was being used shall continue to apply.

(2) Seal the adhesive container air-tight before returning it to refrigeration.

f. Verify that contaminated or damaged film adhesive or containers of liquid adhesive or primers are not released for production use until tested and evaluated in accordance with Section 6.1.2.

g. After release for production use, verify that all liquid adhesives or primers are sealed in metal containers at all times except when in actual use, and that film adhesives are wrapped in clean polythylene film except when suspended on horizontal racks in the controlled contamination room.

6.3

6.3 .1

6.3 .2

6.3 .3

6.4

\section{TEST METHODS}

Lap Shear Test Method

Determine the lapshear strength at $70-90 \mathrm{~F}$.

Honeycomb Peel Test Method

Determine the honeycomb peel strength at $70^{\circ}-90 \mathrm{~F}$.

Metal-To-Metal Peel Test Method

Determine the metal-to-metal peel strength at $70-90 \mathrm{~F}$.

\section{PROCESS CONTROL}

The primary and continuing purpose of Process Control is to ensure that all processing requirements of this specification are continuously complied with during all phases of producing adhesive bonded assemblies and 
to detect at the earliest possible moment any trouble areas that would interfere with the production of acceptable parts.

\subsubsection{Records}

Maintain permanent records showing the following information:

\section{Solution Control Record}

a. Results of the analytical tests conducted on each solution, including contaminants and ion build-up which could alter the effect of the solution.

b. The required strength of each solution.

c. The amount of chemicals added to replenish the solutions and the cumulative total of such additions.

Contamination refers only to the presence of foreign material detrimental to bonding, i.e., grease, oil, suspended solids, dissolved solids, etc., in sufficient amount to leave a deposit or film on cleaned surfaces.

\subsubsection{2}

Primer Base and Adhesive Cure Cycle Temperature and Pressure Charts

Identify the temperature and pressure charts for each bake or cure cycle with the assemblies, subassemblies, and process control assemblies cured in that cycle. Inspection shall verify the acceptability of the bake or cure cycle on the manufacturing plan. Charts may be destroyed after the lap shear and/or peel tests have been evaluated and all test data recorded on the manufacturing plan and verified.

\subsubsection{Processing Data}

The following specific items are required to be recorded and identified with the Manufacturing Plan. It is permissible to collect the specific 
data, except Items a., b., and c. below, on forms separate from the Manufacturing Plan to which the data is applicable. The complete data forms may also be separated from the plan upon final "buy off" provided they are traceable to the plan and retained as a permanent record.

a. Sequence number. (Titanium Only)

b. Assembly or subassembly part number.

c. Unit serial number.

d. Cleaning of details.

(1) Chemical Cleaning - Completion date and hour; Number of cycles.

(2) Anodize - Completion date and hour; Number of cycles.

e. Adhesives

BMS Liquid Adhesive
or Primer

Lot Number

Container Number

Expiration Time

Removed from

Refrigeration

Application

Oven Bake
Date \& Hour

Date \& Hour if applicable

Date \& Hour

Start of Cure

Date \& Hour
Film

Adhesive

Lot Number

Lot Number

Roll Number

Date \& Hour

Date \& Hour

Date \& Hour Date \& Hour

Date \& Hour

Date $\&$ Hour

Foam

Adhesives 
f. Assembly of Details

g. Start of Cure Period

h. Cure Load Numbers

i. Lap Shear Values, Specimens 1-5

(Titanium Only)

j. Honeycomb Peel Strength

(lb-ins/3 in. width) (Titanium Only)

k. Metal-to-Metal Peel Strength

(lb-ins./specify specimen width)

(Titanium Only)
Completion Date \& Hour

Date \& Hour
PSI Average

PSI Range

Average

Minimum

Average

Minimum

1. In case of rejection, record all pertinent information (i.e., damage, cause, extent, rejection tag number, MRB authorization, Engineer ing change in part or adjacent parts, etc.) on the Manufacturing Plan and Date Page.

m. In-Process Correction

State deficiency and action authorized by Quality Control Supervisor (name).

\subsubsection{Sequence Numbers (Titanium Only)}

a. After assembly of a part, assign the sequence number and enter it on the Manufacturing Plan.

(1) Sequence numbers indicate the order of release from the assembly room, for crushing or curing, without regard to the adhesive system. The sequence numbers start with number 1 at the beginning of each work day and cover only one 
calendar day. The sequence numbers indicate the month, day, year, and the order of release from the tape assembly room.

Example: 9-25-8-10 designates the tenth assembly leaving the tape assembly room on September 25, 1968.

(2) There may be gaps in the sequence numbers for a specific adhesive system. Where such gaps occur, the intervening numbers will be found on the Process Control Charts of the other adhesive systems.

b. At the time of assigning the sequence number, the Quality Control Inspector may review the Manufacturing Plan and conduct any inspections he deems necessary.

(1) The frequency of such inspections shall conform to good Quality Control practice and be of sufficient number to ensure conformity to the requirements of Section 8.

(2) The review of the Manufacturing Plan and Data Page shall be such as to ensure that the processing data and time limits as recorded are in accordance with the processing requirements.

c. The final assembly inspection (see Section 6.5) must include a review of the Manufacturing Plan and Data Page and Cure Cycle Charts for the assembly being inspected.

d. The Data Page may be separated from the Manufacturing Plan for data collection and analysis. They will then be filed and retained in an approved location. 


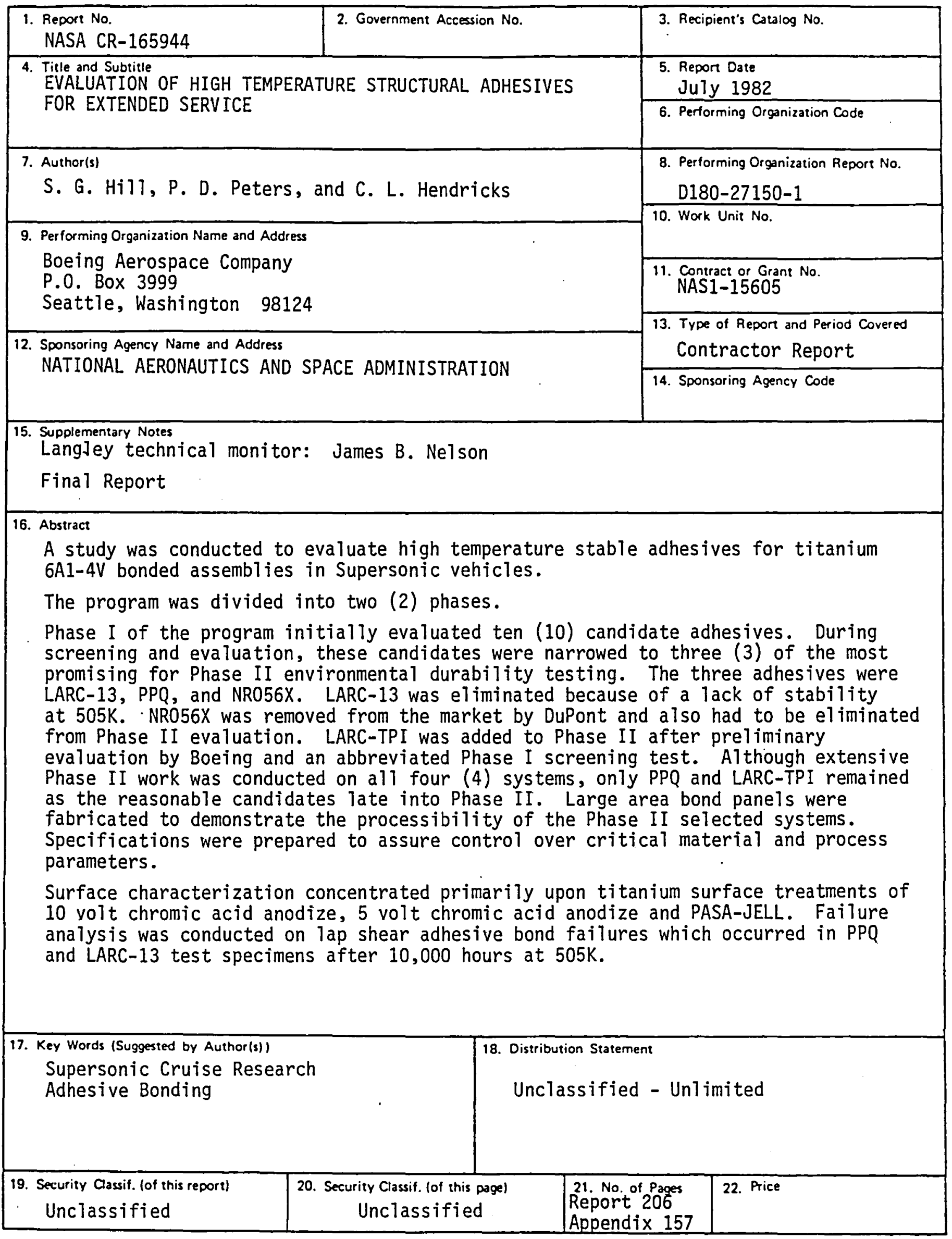


End of Document 